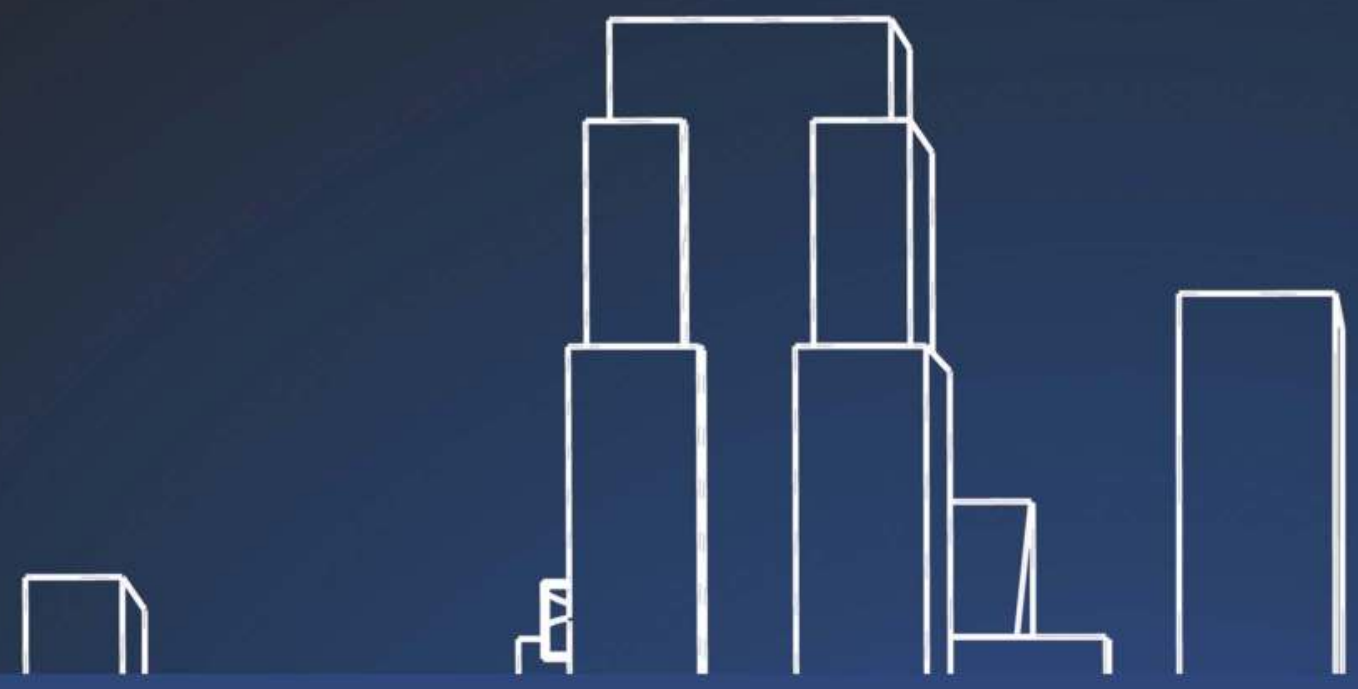

Routledge Studies in Crime and Society

\title{
CRIME AND FEAR IN PUBLIC PLACES
}

TOWARDS SAFE, INCLUSIVE AND SUSTAINABLE CITIES

Edited by

Vania Ceccato and Mahesh K. Nalla

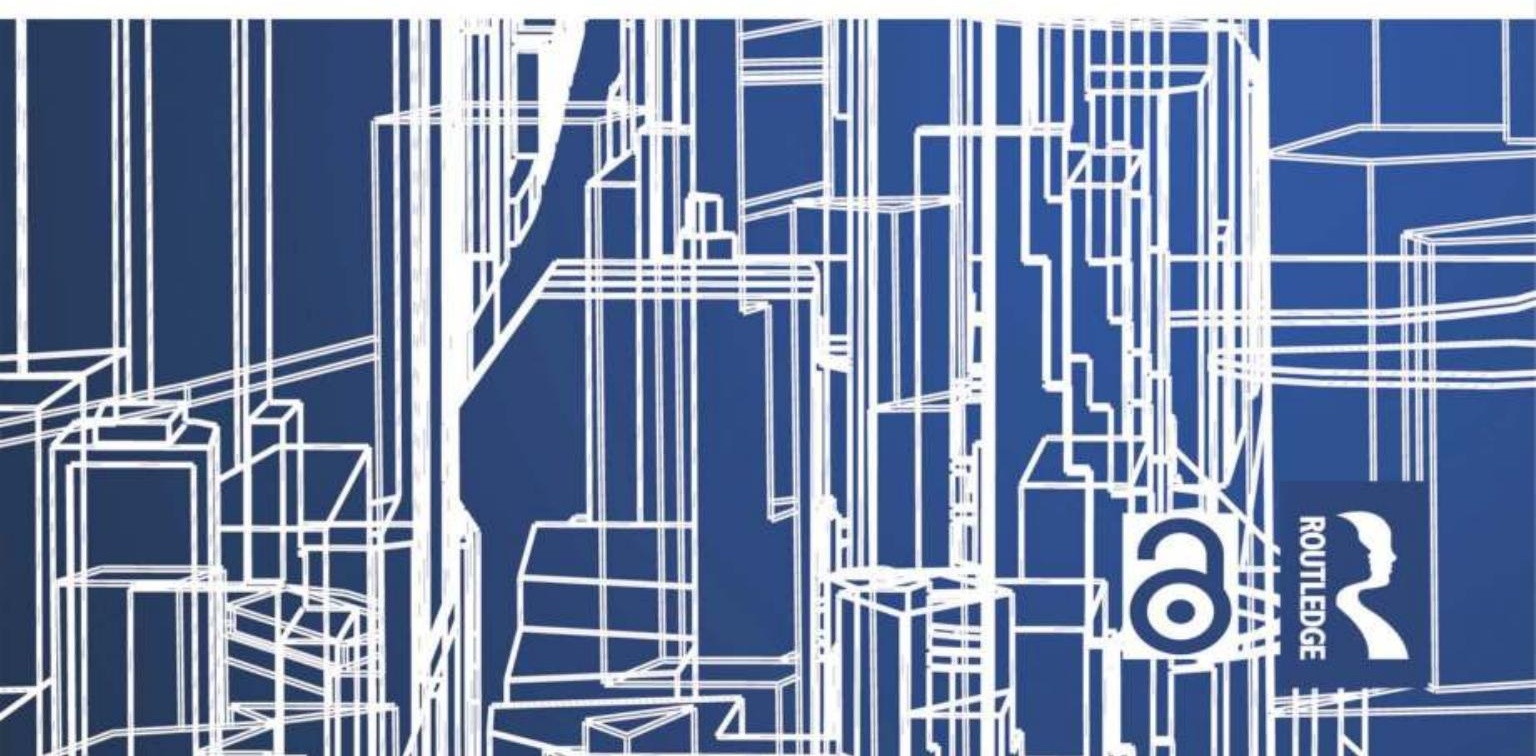




\title{
Crime and Fear in Public Places
}

\begin{abstract}
Crime and Fear in Public Places consists of an important tool to advance the international urban safety agenda as it provides readers with a view on the debate over safety and public places, taking a multi-disciplinary approach that takes into consideration several fields of knowledge. The cutting-edge research contained in this book incorporates different perspectives on the phenomenon of crime and fear in public places and fosters the co-production of safety, which is a basic principle contained in the Guidelines, thus contributing towards more cohesive societies and safer cities for all.
\end{abstract}

Juma Assiago, Head, Safer Cities Programme, UN-HABITAT

With expertise from a diverse range of disciplines, this compilation achieves a thorough investigation of how individual mobility, social and built landscapes, and policies interact and relate to crime and fear in public places. Insightful and creative, with implications to make communities safer and improve public health.

Professor Douglas Wiebe, University of Pennsylvania, Philadelphia, USA

Numerous organizations call for resilient and safe spaces. Many people dream of enjoying vibrant places. Yet, crime and fear in public space threatens these ideals. This book offers timeous information and practical suggestions towards safe places-indeed, a valuable toolkit for everyone working towards inclusive change in public space.

Professor Karina Landman, University of Pretoria, South Africa

No city environment reflects the meaning of urban life better than a public place. A public place, whatever its nature - a park, a mall, a train platform or a street corner-is where people pass by, meet each other and at times become a victim of crime. With this book, we submit that crime and safety in public places are not issues that can be easily dealt with within the boundaries of a single discipline. The book aims to illustrate the complexity of patterns of crime and fear in public places with examples of studies on these topics contextualized in different cities and countries around the world. This is achieved by tackling five cross-cutting themes: the nature of the city's environment as a backdrop for crime and fear; the dynamics of individuals' daily routines and their transit safety; the safety perceptions experienced by those who are most in fear in public places; the metrics of crime and fear; and, finally, examples of current practices in promoting safety. All these original chapters contribute to our quest for safer, more inclusive, resilient, equitable and sustainable cities and human settlements aligned to the Global 2030 Agenda for Sustainable Development.

Vania Ceccato is a Professor at Department of Urban Planning and Environment, KTH Royal Institute of Technology, Stockholm, Sweden. Her research covers the situational conditions of crime and fear in urban and rural environments. Gendered safety and the intersectionality of victimization are essential components in her research. She is the author of several books, including Rural Crime and Community Safety and is co-editor of Transit Crime and Sexual Violence in Cities. She is the national coordinator of Safeplaces, which is a network for knowledge sharing between academia and practice devoted to the situational conditions of crime and best practices in situational crime prevention.

Mahesh K. Nalla is a Professor in the School of Criminal Justice at Michigan State University. His research interest centers on crime governance with a focus on public and private policing. His research has appeared in the Journal of Research and Crime and Delinquency, Justice Quarterly, and Annals of the American Political and Social Science, among others. He has coordinated and led a global project into firearm-related violence prevention programs for the United Nations and crafted the International Protocol Against the Illicit Manufacturing of and Trafficking in Firearms, Ammunition and Other Related Materials, as a supplement to the United Nations Convention Against Transnational Organized Crime. 


\section{Routledge Studies in Crime and Society}

The Risks and Benefits of Private Security Companies Working with Victims of Domestic Violence Diarmaid Harkin

The Human Factor of Cybercrime

Edited by Rutger Leukfeldt and Thomas J. Holt

Medical Misinformation and Social Harm in Non-Science

Based Health Practices

A Multidisciplinary Perspective

Edited by Anita Lavorgna and Anna Di Ronco

Crime, Harm and Consumer Culture

Edited by Steve Hall, Tereza Kuldova and Mark Horsley

Legalizing Cannabis

Experiences, Lessons and Scenarios

Edited by Tom Decorte, Simon Lenton and Chris Wilkins

Female Capital Punishment

From the Gallows to Unofficial Abolition in Connecticut

Lawrence B. Goodheart

Risk and Harm in Youth Sexting

Young People's Perspectives

Emily Setty

Gendered Responses to Male Offending in Barbados

Patriarchal Perceptions and their Effect on Offender Treatment

Corin Bailey

Crime and Fear in Public Places

Towards Safe, Inclusive and Sustainable Cities

Edited by Vania Ceccato and Mahesh K. Nalla

For more information about this series, please visit: www.routledge.com/ Routledge-Studies-in-Crime-and-Society/book-series/RSCS 


\section{Crime and Fear in Public Places}

Towards Safe, Inclusive and Sustainable Cities

\section{Edited by Vania Ceccato and Mahesh K. Nalla}


First published 2020

by Routledge

2 Park Square, Milton Park, Abingdon, Oxon OXI4 4RN

and by Routledge

52 Vanderbilt Avenue, New York, NY 10017

Routledge is an imprint of the Taylor \& Francis Group, an informa business

(C) 2020 selection and editorial matter, Vania Ceccato and Mahesh K. Nalla; individual chapters, the contributors

The right of Vania Ceccato and Mahesh K. Nalla to be identified as the authors of the editorial material, and of the authors for their individual chapters, has been asserted in accordance with sections 77 and 78 of the Copyright, Designs and Patents Act 1988.

The Open Access version of this book, available at www.taylorfrancis.com, has been made available under a Creative Commons Attribution-Non Commercial-No Derivatives 4.0 license

Trademark notice: Product or corporate names may be trademarks or registered trademarks, and are used only for identification and explanation without intent to infringe.

British Library Cataloguing-in-Publication Data

A catalogue record for this book is available from the British Library

Library of Congress Cataloging-in-Publication Data

A catalog record has been requested for this book

ISBN: 978-0-367-37128-9 (hbk)

ISBN: 978-0-367-51769-4 (pbk)

ISBN: 978-0-429-35277-5 (ebk)

Typeset in Galliard

by Wearset Ltd, Boldon, Tyne and Wear 
This book is dedicated to all those professionals working to reduce crime and fear in public places around the world, and aiming at making urban and rural environments safer and more social sustainable for all. 


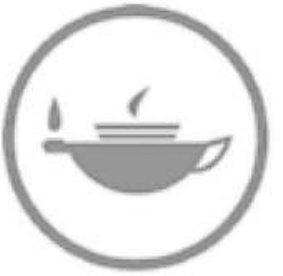

Taylor \& Francis Taylor \& Francis Group http://taylorandfrancis.com 


\section{Contents}

List of figures $\quad$ xi

List of tables xiv

List of appendices xvi

Notes on contributors xvii

Preface xxii

Acknowledgments xxiv

PART I

Crime and fear in public places: an introduction $\quad 1$

1 Crime and fear in public places: aim, scope and context 3 VANIA CECCATO, JUMA ASSIAGO AND

MAHESH K. NALLA

2 The circumstances of crime and fear in public places:

a review of theories

VANIA CECCATO

3 The architecture of crime and fear of crime:

research evidence on lighting, CCTV and CPTED features

VANIA CECCATO

\section{PART II}

The environment

4 Do green areas affect crime and safety?

VANIA CECCATO, ANA CANABARRO AND

LISANDRA VAZQUEZ

5 Safety of urban park users: the case of Poznan, Poland 
viii Contents

6 The role of public places in Disability Hate Crimes (DHCs)

\section{PART III}

The movement

7 Youth safety in public transportation: the case of eastern Mexico City, Mexico

JAVIER ROMERO-TORRES AND VANIA CECCATO

8 Transit safety among college students in Tokyo-

Kanagawa, Japan: victimization, safety perceptions and preventive measures

SEIJI SHIBATA

9 Women and LGBTI youth as targets: assessing transit safety in Rio Claro, Brazil

FARID NOURANI, SÉRGIO LUIS ANTONELLO,

JOSÉ SILVIO GOVONE AND VANIA CECCATO

10 An analysis of transit safety among college students in Lagos, Nigeria

SMART E. OTU AND AUGUSTINE AGUGUA

\section{PART IV}

The users' perspective

11 Contested gendered space: public sexual harassment and women's safety work

FIONA VERA-GRAY AND LIZ KELLY

12 Sexual harassment in public spaces in India: victimization and offending patterns

13 Does context matter? Older adults' safety perceptions of neighborhood environments in Sweden

VANESSA STJERNBORG AND ROYA BAMZAR

14 Individual and spatial dimensions of women's fear of crime: a Scandinavian study case 
PART V

The metrics

15 Contextual determinants of fear of crime in public transit: an Ecological Momentary Assessment (EMA) pilot study

YASEMIN IRVIN-ERICKSON, AMMAR A. MALIK

AND FAISAL KAMIRAN

16 Mapping Open Drug Scenes (ODS)

MIA-MARIA MAGNUSSON

17 "Fear in 280 characters": a new approach for evaluation of fear over time in cyberspace

FRANCISCO J. CASTRO-TOLEDO, TOBIAS

GRETENKORT, MIRIAM ESTEVE AND

FERNANDO MIRÓ-LLINARES

\section{PART VI}

The intervention

18 Fear of the dark: the potential impact of reduced street lighting on crime and fear of crime

PIA STRUYF

19 Evaluating harm-reduction initiatives in a night-time economy and music festival context

LAURA GARIUS, BETHANY WARD, KIRSTY

TEAGUE AND ANDROMACHI TSELONI

20 Crime and fear in Hollygrove-building neighborhood resilience

MATEJA MIHINJAC AND GREGORY SAVILLE

21 Safety in the making: an assessment of urban planners' practices in municipalities in Sweden

VANIA CECCATO

\section{PART VII}

Crime and fear in public places: conclusions and recommendations

22 Crime and fear in public places: a global look 
$\mathrm{x}$ Contents

23 Responding to crime and fear in public places: towards an agenda for research and practice

VANIA CECCATO AND JUMA ASSIAGO

Index 


\section{Figures}

1.1 Crime and fear in public places: the five themes of the book

2.1 Safety interventions steps

3.1 Network visualization map with focus on (a) "crime" and (b) "fear of crime"

3.2 Effect of lighting, CCTV and CPTED features on crime and fear of crime according to the international literature $1968-2018$

4.1 Data collection and selection in Scopus and Google Scholar, 1968-2018

4.2 The categorization of green areas adapted from Goode and Collins (2014)

4.3 Literature search for keyword: "greenspace" in publications that relate to crime and fear of crime, 1968-2018.

(a) Network visualization map with focus on "greenspace" as an example in Scopus, 1968-2018. (b) Density visualization of author keywords, 1968-2018, in Scopus based on total occurrences, association strength

4.4 Analysis of the relationship of green areas and crime and fear/perceived safety

5.1 Cytadela Park

5.2 Rosarium in Cytadela Park

5.3 Survey results: (a) park users' safety perceptions—day and evening hours; (b) safety and physical and social environmental features of the park; (c) occurrence of selected negative safety phenomena in the park

5.4 (a) Fortification ruins and mixed types of path surfaces;

(b) lit paths by night; (c) amphitheater

7.1 (a) Sexual victimization by duration of the trip and

(b) frequency of use of PT

7.2 Types of sexual harassments in transit and by transportation mode. Access means on the way to/from bus stops and or Metro station 


\section{xii Figures}

7.3 Perceived safety by gender, transportation mode, settings and time of day

8.1 Results of participants' safety perceptions (\%) concerning their railway usage during daytime and night-time.

The numbers on the low proportion groups

("never" and "do not use") are omitted

9.1 Profile of survey participants

9.2 Students' perception of public transportation safety during daytime

9.3 Students' perception of public transportation safety after dark

9.4 Main impediments for students to use bus service more frequently

9.5 Percentages of students in each group who take some precautions in public transportation

10.1 (a) A typical modern LAMA and LAMTA bus station.

(b) Molue bus station in Lagos, Nigeria

10.2 Safety perceptions by gender in transit environments in Lagos, Nigeria

10.3 Safety perceptions by age groups in transit environments in Lagos, Nigeria

12.1 Percentage comparisons of the imagery of $\mathrm{SH}$ for females $(N=766)$ and males $(N=621)$

12.2 Frequency and age distribution of victims and offenders

12.3 Percentage of victims $(N=467)$ and offenders $(N=317)$ awareness of $\mathrm{SH}$ laws and their effectiveness

14.1 Stockholm by respondents who declare feeling fearful in the neighborhood (percent)

16.1 Open drug scenes in Stockholm county, 2017

16.2 ODS and train lines in the northern part of Stockholm, 2017

16.3 ODS and shootings in Stockholm county, 2017

16.4 Open drug scenes, shootings and perceived safety measures in the northern part of Stockholm municipality

17.1 Development of tweets' emotional profiles during the first 24 hours after each attack and grouped by hashtags

17.2 Emotive values of tweets across different classes of hashtags (descriptive, solidary, opposed)

17.3 Distribution of emotive values (valence and arousal) across different hashtags. Hashtags are ordered by mean valence per tweet in descending order

19.1 Violent and sexual offences occurring in City A

19.2 Violent and sexual offences occurring in City B

20.1 (a) Hollygrove neighborhood in relation to New Orleans CBD. (b) The Hollygrove neighborhood boundaries

20.2 The basic action research cycle 
20.3 Data and methods used in Hollygrove 387

20.4 Map showing locations of high fear levels 388

20.5 A map showing bus stop-homicide correlates $\quad 390$

21.1 CPTED core principles 404

21.2 (a) Do you use any policies, governance documents or the like that deal with forms of crime prevention and security-creating physical measures, $N=137$ (55 percent).

(b) Will you in your municipality work more with the physical environment and safety in planning? $N=137$ (55 percent).

(c) What would planners want in the municipality to better work preventively with the incorporation of physical environment principles and situational crime prevention? $N=138$ (56 percent) 


\section{Tables}

4.1 Sets of keywords, number of results and documents selected from Google Scholar and Scopus

$\begin{array}{lll}4.2 & \text { Inclusion and exclusion criteria } & 81\end{array}$

$\begin{array}{lll}5.1 & \text { CPTED principles and used methods } & 113\end{array}$

7.1 Sexual victimization by individual characteristics and transportation mode

7.2 Aggressions in relation to gender and transportation mode (\%)

7.3 Mexico City student precautions while travelling on public transit (\%)

8.1 Summary of the participants' frequency of railway use and commuting time

8.2 Cross-tables between the experiences and perceptions of groping on trains among female participants

8.3 Respondents who identified measures that would make railway travel safer

8.4 Cross-tables between the experiences of groping and the perceptions of survey cameras and women-only cars among female participants

9.1 Intersectionality of students' concerns about public transportation

9.2 Intersectionality of victims regarding three types of crime analyzed

9.3 Intersectionality of victims regarding sexual assault or harassment crime

10.1 Respondents' concerns about using buses, tricycle or motorcycles in Lagos, Nigeria

10.2 Problems of sexual harassment respondents encountered at the bus/tricycle/motorcycle stops within the past

3 years in Lagos, Nigeria

10.3 Precautionary measures taken by users of bus/tricycle/ motorcycle stops 
12.1 Descriptive statistics of victims ( $N=467,60.7 \%)$

and offenders $(N=317)$

238

12.2 Comparison of percentage of victimization $(N=467)$ and self-reported offending $(N=317)$ of SH behaviors

12.3 Comparison of percentage of self-reported offending and offending by their male friends

$\begin{array}{lll}\text { 13.1 Characteristics of the two neighborhoods } & 254 \\ \text { 13.2 Characteristics of the participants in the two case studies } & 256\end{array}$

13.3 Summary of the results of the two cases

258

14.1 Results of binary logistic regression, $\Upsilon=($ a) women who declared they felt most fearful (very unsafe, often unsafe, do not go out fear of being a crime victim);

(b) all unsafe women

14.2 Results of binary logistic regression, $\Upsilon=($ a) avoidance behavior-keep away from certain places/streets (always, often, do not go out fear of being a crime victim) — among most fearful women and among (b) all unsafe women

14.3 Results of binary logistic regression, $\Upsilon=($ a) we ask neighbors to look out for the residence when we are absent, among
(a) most fearful women and (b) all unsafe women

15.1 Descriptive statistics for the observations included in the

OLS model

15.2 Ordinal logistic regression results of fear of crime $(n=216)$

15.3 Ordinal Logistic regression results of perceived risk of victimization $(n=216)$

16.1 Disruption in the area associated with ODS 313

$\begin{array}{ll}\text { 16.2 Crime concentration in ODS } & 315\end{array}$

$\begin{array}{ll}16.3 \text { ODS and vulnerable neighborhoods } & 316\end{array}$

$\begin{array}{ll}\text { 16.4 The typology of ODS in Stockholm, } 2017 & 317\end{array}$

19.1 Standard mean difference tests 370

20.1 Reported homicides for New Orleans and Hollygrove neighborhood 2002-2004

20.2 Reported homicides for New Orleans and Hollygrove neighborhood 2015-2017 


\section{Appendices}

Chapter 3-Appendix

Table A3.1 The effect of lighting on crime and/or fear

Table A3.2 The effect of CCTV on crime and/or fear (publications mentioning CCTV in the title, keywords, abstracts)

Table A3.3 The effect of CPTED on crime and/or fear (publications mentioning CPTED in the title, keywords, abstracts)

Chapter 4-Appendix

Table A4.1 Green areas (parks, forests, neighborhood parks, green vacant land, interstitial spaces) and crime $\quad 90$

Table A4.2 Green areas and safety perceptions/fear of crime 95

Table A4.3 Green areas and crime and safety perceptions/ fear of crime

Chapter 10-Appendix

Table A10.1 The profile of respondents 


\section{Contributors}

Sergio Luis Antonello is a lecturer in computer science at Fundação Hermínio Ometto (FHO) at Araras, SP, Brazil. His main research areas include programming languages, algorithms data structures and geoprocessing. He is also a computer analyst at the Environmental Analysis and Planning Centre (CEAPLA) of UNESP.

Augustine Agugua lectures in the Department of Sociology, University of Lagos, Akoka, where he obtained his MSc and PhD certificates in Sociology. He has contributed chapters to many books and journals, both within and outside Nigeria. Dr. Agugua has also presented several papers on burning issues of policy and research interest in various conferences and workshops, locally and internationally.

Juma Assiago is an Urbanist and Social Scientist, is the Global Coordinator of the Safer Cities Programme at UN-Habitat. He holds a Master of Science degree in Sustainable Urban Development (Oxford University, UK). He has accumulated 18 years of international working experience providing technical support to both national and local governments on the development and implementation of city crime prevention and urban safety strategies.

Roya Bamzar is a doctor in Planning and Decision Analysis, KTH Royal Institute of Technology, Stockholm, Sweden. Her research covers the issues related to the interplay between physical/social environments and older individuals with regards to safety, and how these interactions change and shape the lives of the seniors.

Emilia Bogacka is an assistant professor at the Department of Social Geography at Adam Mickiewicz University, Poznań, Poland. Her current research focuses on crime and fear in various spatial scales of the city, especially public places such as parks and public transportation stops.

Francisco J. Castro-Toledo is an assistant professor of Criminal Law and Criminology at Miguel Hernández University, a researcher at CRIMINA Research Centre for the Study and Prevention of Crime and CEO of Plus Ethics. His research interests are currently focused on experimental research designs in crime sciences, epistemology in social sciences and ethical analysis applied to ICT and artificial intelligence. 
Ana Canabarro is a Brazilian biomedical scientist and a current Master's student of Public Health-Epidemiology at Karolinska Institutet. She has diverse experiences in research, including topics in space physiology, telemedicine, and clinical research. Her new research subject is the causes and effects of violence on public health.

Vania Ceccato is a Professor in the Department of Urban Planning and Environment, KTH Royal Institute of Technology, Stockholm, Sweden. Her research is on the situational conditions of crime and fear in urban and rural environments. Gendered safety and the intersectionality of victimization are essential components in her research. She is the author of several books, including Rural Crime and Community Safety and co-editor of Transit Crime and Sexual Violence in Cities. She is the national coordinator of Safeplaces, which is a network for knowledge sharing between academia and practice devoted to the situational conditions of crime and best practices in situational crime prevention.

Miriam Esteve is a Computer Engineer and expert in Big Data, Decision Support Systems and Crime Analysis and Prevention at the Miguel Hernández University in Elche. She is a PhD Student at the University Institute of Operative Research. His areas of research focus on the application of Machine Learning techniques based on crime data, such as violent and hate speech and fear of crime.

Laura Garius is a Lecturer in Criminology and member of the Quantitative and Spatial Criminology group at Nottingham Trent University. Her doctorate examined trends in night-time economy violence and modelled the risk of violent victimization/assault severity. Laura conducted research as part of the ESRCfunded 'Violence Trends Project' and 'Nottingham Shop Theft Project': examining local and national trends in violence and shop theft, as well as conducting interviews with prolific offenders.

Riccardo Girolimetto is a Psychologist dealing with social inclusion, hate crimes, disability, prevention violence practices and criminal justice. He has a qualification in legal-forensic psychology. As researcher he is working on western history of deviance in collaboration with the University of Padova, Department of Philosophy, Sociology, Education and Applied Psychology.

José Silvio Govone is an Associate Professor at the Department of Statistics, Applied Mathematics and Computer Science of the São Paulo State University (UNESP) at Rio Claro. His main research areas include biostatistics, spatial statistics and public policies. He is also member of the Environmental Studies Center (CEA) of UNESP.

Tobias Gretenkort is a $\mathrm{PhD}$ Candidate at RWTH Aachen University, with his thesis and other research concerning the relationship between language and technology. He has authored and co-authored various articles in Romance sociolinguistics, pragmatics and dialectology, with a strong focus on data-driven, quantitative methods. His most recent research includes the use of data-driven methods at the intersection of linguistic and criminological research. 
Yasemin Irvin-Erickson is an Assistant Professor of Criminology, Law and Society at George Mason University and a Fellow at the Urban Institute's Justice Policy Center. She researches primarily in the area of urban security, victimization, technology, and the economic empowerment of vulnerable populations.

Antonio Iudici is Adjunct Professor at the University of Padova, Tutor Adjunct Professor at the Catholic University of the Sacred Heart, Milan, and Lecturer for the Institute of Psychology and Psychotherapy of Padova. He is in charge of health promotion and the most in-depth issues concern the inclusion of people with disabilities, children, students and victims of violence. He has published two monographs and some articles in national and international journals.

Faisal Kamiran is the Dean of Sciences and Chairperson at the Department of Computer Science at Information Technology University in Pakistan. His research interests include fairness-aware data analytics and machine learning to safeguard the rights of deprived communities and individuals, ICTD, social media analytics, and text mining.

Liz Kelly is a Professor of Sexualized Violence at London Metropolitan University, where she is also Director of the Child and Woman Abuse Studies Unit (CWASU). She has been active in the field of violence against women and children for almost 30 years. As special advisors to the British Council, CWASU undertakes considerable international work (in Africa, Asia, Europe and South America), providing consultancy and training on research and policy.

Mia-Maria Magnusson is a PhD Student at the Department of Criminology at Malmö University and a Police detective at the Stockholm Police, Sweden. Her experience as a drug detective is combined with recent research on the topic of drug crimes and the police. Her research focuses on open drug scenes where drug use and the selling of drugs takes place in the public.

Ammar A. Malik is the Director of Evidence for Policy Design Research at Harvard Kennedy School. His research focuses on spatial urban forms and their economic implications, the political economy of public service delivery, and the distributional effects of urban public transport.

Mateja Mihinjac is a criminologist currently completing her Doctorate from Griffith University, Australia. She specializes in implementation of CPTED and a safety planning method called SafeGrowth. Mateja currently serves as Executive Director at the International CPTED Association.

Fernando Miró-Llinares is Professor of Criminal Law and Criminology at the Miguel Hernández University in Elche, and Director of a Research Center for the Study and Prevention of Crime of the same university. He specializes in philosophy of law, cybercrime, situational crime prevention, criminal economic and business law, and the law in new technologies. He is the author of multiple high impact publications and papers on these matters. 
Mahesh K. Nalla is a Professor in the School of Criminal Justice at Michigan State University. His research centers on crime governance with a focus on public and private policing. His research has appeared in the Journal of Research and Crime and Delinquency, Justice Quarterly, and Annals of the American Academy of Political and Social Science, among others. He had coordinated and led a global project into firearm-related violence prevention programs for the United Nations and crafted the International Protocol Against the Illicit Manufacturing of and Trafficking in Firearms, Ammunition and Other Related Materials, as a supplement to the United Nations Convention Against Transnational Organized Crime.

Farid Nourani is a Professor at the Department of Statistics, Applied Mathematics and Computer Science of the São Paulo State University (UNESP), Rio Claro Campus, Brazil. His main research areas include crime mapping and development of information systems to support the decision-making process in public policies. Currently he coordinates the Center for Environmental Analysis and Planning (CEAPLA).

Smart E. Otu is a Professor of Criminology \& Security Studies and Dean, Faculty of Law at Alex Ekwueme Federal University. He has published in reputable journals and is currently working on a book on security and public affairs to be edited by him and two other colleagues.

Gregory Saville is an urban planner and practicing criminologist specializing in CPTED, 2nd Generation CPTED, and the SafeGrowth urban planning method. $\mathrm{He}$ is a former police officer and faculty member in university criminology programs. He is also a co-founder of the International CPTED Association. He has published SafeGrowth: Building Neighborhoods of Safety and Livability, documenting the success and spread of the method in neighborhoods across North America.

Seiji Shibata is a professor at the Department of Human Psychology at Sagami Women's University. He is an environmental psychologist. His research interests include perceptions about safety and security in public spaces. He is a former chief editor of the Japanese Journal of Environmental Psychology.

Vanessa Stjernborg is a researcher at the Department of Urban Studies at Malmo University and at K2-the Swedish Knowledge Centre for Public Transport, Sweden. Her research focuses mainly on everyday mobilities and its relationship to individual, social and environmental factors. Her main current research areas are everyday mobilities and fear of crime, the traveler's perspective in public transport and disabilities and public transport.

Pia Struyf is a teaching assistant and researcher at the Crime \& Society Research Group (CRiS) of the Vrije Universiteit Brussel, Belgium. She holds a master's degree in Criminology and is mainly interested in sex work. Since June 2019, she has worked on her $\mathrm{PhD}$ research project, investigating Belgian practices of policing sex work. 
Kirsty Teague is a Lecturer in Criminology at NTU. Her doctoral research focuses on the rehabilitation and reintegration of individuals with sexual convictions post-release from prison. Kirsty's research is conducted in conjunction with the Sexual Offences, Crime and Misconduct Research Unit at NTU.

Javier Romero-Torres is a Professor at the Department of Transport, Centro Universitario UAEM Nezahualcóyotl, Autonomous University of Mexico State, Nezahualcóyotl, Mexico. Research areas: public transportation, quality service, and discrete choice models. He is the co-author of Perception of Satisfaction from Women-Only Public Transportation and co-editor of Transport Topics (2017).

Andromachi Tseloni is Professor of Quantitative Criminology and leads the QSC group at NTU. Andromachi led the ESRC-funded projects 'Violence Trends' and 'Burglary and Security'. The latter received the Office for National Statistics Research Excellence Award 2019 and its findings are presented in the Springer book: Reducing Burglary.

Fiona Vera-Gray is a Research Fellow based at Durham Law School. She researches violence against women and acted as a special advisor to Westminster during a recent inquiry, and has published widely in the area. Her book The Right Amount of Panic: How Women Trade Freedom for Safety draws on original research from the UK to explore the habitual strategies women and girls employ to maintain a sense of safety in public spaces.

Lisandra Vazquez is an Architect and Urbanist from São Paulo, Brazil, experienced in land regularization and social housing. Recently, she obtained the title of MSc in Urbanism Studies from the Royal Institute of Technology (KTH) in Sweden.

Bethany Ward is a PhD researcher and sessional Lecturer in Criminology at NTU and a member of the QSC research group. Bethany's doctoral research models the relationship between the risk of experiencing victimization and the fear of crime.

Anna Yates is a Geography PhD student at the University of Newcastle, UK. She completed her undergraduate degree in Geography at the University of Cambridge and is currently investigating women's fear of crime in Stockholm as part of her $\mathrm{PhD}$. 


\section{Preface}

Cities are sites of safety, resilience and opportunity, where an estimated threequarters of all global economic production occurs and yet they are also frequently home to extreme and chronic forms of poverty, inequality, and insecurity. Traditional urban cleavages have grown wider and more intense. Poverty is an urban reality, with the speed of urbanization outpacing the ability of local governments to build essential infrastructure, deliver basic services, and ensure social cohesion. Personal and community insecurities are facts of everyday life, some 60 percent of all urban residents in developing countries have been victims of crime (UN-Habitat, 2007). The intensification of risks has put the "urban advantage" in jeopardy for hundreds of millions of people.

Poorly planned urbanization, in conjunction with growing inequality and distrust, has fabricated "urban segregation patterns that enlarge physical and symbolical distances between citizens which in some cases have led to progressive privatization of security, gated communities and ghettos" (UN-Habitat, 2015). Economic, racial, class, and cultural discrimination, lack of economic opportunities, weak governance, and unequal access to urban resources, create varied forms of exclusion and vulnerabilities for women, girls, boys and men.

The 2030 Agenda for Sustainable Development and the New Urban Agenda has recognized the importance of urban safety as a prerequisite to sustainable urban development, there can be no sustainable urban development without safety and likewise no safety without sustainable urban development. Specifically, the 2030 Agenda has set a Goal 11 to make cities and human settlements safe, inclusive, resilient and sustainable. The New Urban Agenda also highlights the need to promote safe, healthy, inclusive and secure environments in cities and human settlements enabling all to live, work and participate in urban life without fear of violence and intimidation, taking into consideration that women and girls, children and youth, and persons in vulnerable situations are often particularly affected (UN-Habitat, 2017, paragraph 39). In this aspect, inclusive, accessible, green and quality public spaces should be prioritized and encouraged, as enhancing social and intergenerational interactions, cultural expressions and political participation, foster social cohesion, inclusion and safety.

In the implementation of the 2030 Agenda and the New Urban Agenda, member states have adopted UN system-wide Guidelines on Safer Cities and 
Human Settlements building on the 25 years of practice undertaken by the UN-Habitat Safer Cities Programme and its implementing partners in the Global Network on Safer Cities (GNSC). The Guidelines provide municipalities, as well as other levels of government and civil society with basic principles, process and content towards integrating crime prevention into urban strategies and places the design and management of public spaces as crucial to achieving the goal of making cities safer. This will enhance the link between research and practice, towards the systematization of city safety experiences that have embraced the co-production principle. In this endeavor, cities and other human settlements will be approached as laboratories of knowledge consolidation, learning, innovation to inform the integrated solutions in the 2030 aspiration. The work of KTH and the Safe Places Network will form a key global hub in contributing to this systematization of experiences.

I am pleased therefore to present Crime and Fear in Public Places, which consists of an important tool to advance the international urban safety agenda as it provides readers with a view on the debate over safety and public places, taking a multidisciplinary approach that takes into consideration several fields of knowledge. The cutting-edge research contained in this book incorporates different perspectives on the phenomenon of crime and fear in public places and fosters the co-production of safety, which is a basic principle contained in the Guidelines, thus contributing towards more cohesive societies and safer cities for all.

Juma Assiago, Head, Safer Cities Programme, UN-HABITAT

\section{References}

UN-Habitat (2007). Global Report on Human Settlements 2007: Enhancing Urban Safety and Security. Nairobi: UNON.

UN-Habitat (2015). Issue Paper: Habitat III: 3.

UN-Habitat (2017). New Urban Agenda. https://unhabitat.org/sites/default/files/ 2019/05/nua-english.pdf (accessed 5 May 2020). 


\section{Acknowledgments}

We are grateful for the great work, patience and commitment of all contributors of this book, distributed in 13 countries around the world, who managed to deliver high quality research with clear relevance for practice. This book would not have been possible without the 2018 \#SafetyForUs conference on 'Crime and Fear in Public Places: Patterns, Challenges and Actions', an international arena about individual's right to safe public places, 17-18 October, that took place in Stockholm, Sweden, at the School of Architecture and the Built Environment, KTH Royal Institute of Technology. This conference was organized and funded by the Safeplaces network (Säkraplatser nätverket, which is supported by KTH and The Swedish National Council for Crime Prevention-Brottsförebyggande rådet-Brå) that creates a number of initiatives devoted to information sharing about the situational conditions in which crime occurs and the best ways to prevent them. Big thanks go to all involved in this event: speakers, discussants and all participants who directly and indirectly contributed to the chapters that are an integral part of this book.

We are particularly grateful for the time and trouble many researchers took to read the chapters and provide comments to the chapters published in this book. They are listed here in alphabetical order: Alexander Engström, Asifa Iqbal, Ben Stickle, Bonnie Mak, Bo Grönlund, Carlos Carcach, Catherine Sundling, Charlotta Thodelius, Christopher Sedelmaier, Edward Hall, Eric Piza, Ines Guedes, Lisa Tompson, Lisbeth Lindahl, Luzi Shi, Manne Gerell, Martha Smith, Martin Andresen, Mary Chadee, Mariko Uda, Matthew Davies, Natasha Mulvihill, Stefan Lundberg, Tim Hart, Victoria Sytsma.

On behalf of all authors, we would like to thank UN-HABITAT-Safer Cities Programme, KTH Royal Institute of Technology and Michigan State University for covering the Open Access fee involved in the production of this book; without the generous contribution from these institutions, this edited volume would not be available free of charge. They deserve our thanks!

We would also like to thank our publisher, Routledge, for believing in this effort. We particularly wish to acknowledge Charlotte Endersby, Arunima Aditya and Pip Clubbs for their stewardship of the project.

Finally, we would also like to thank colleagues at our respective universities for supporting our work during the process of editing this book. In Stockholm 
in particular, a big thanks goes to students, colleagues in the School of Architecture and Built Environment (far too many to be named here!) and KTH administration for supporting the conference 'Crime and Fear in Public Places,' and especially to Stefan Attig-thank you. Thanks Rebecca Foreman for proofreading my chapters. Any remaining shortcomings are, of course, entirely the editors' responsibility.

Lastly but importantly, a big "thank you" goes to our families for all their love, support, and patience with us as we were putting together this edited volume. 


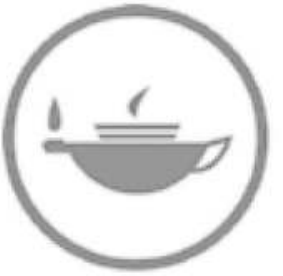

Taylor \& Francis Taylor \& Francis Group http://taylorandfrancis.com 


\section{Part I}

\section{Crime and fear in public places}

An introduction

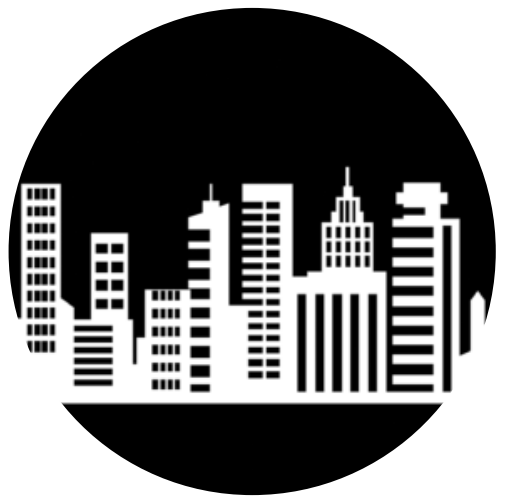




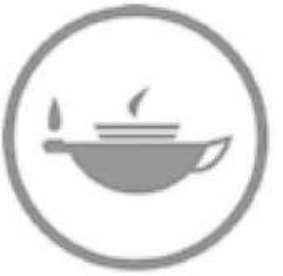

Taylor \& Francis Taylor \& Francis Group http://taylorandfrancis.com 


\title{
1 Crime and fear in public places
}

\section{Aim, scope and context}

\author{
Vania Ceccato, Juma Assiago \\ and Mabesh K. Nalla
}

\subsection{Introduction}

Safety is an essential dimension of urban sustainability. In a sustainable city, safety ensures each person a place to live free from danger but also has the possibility of movement that is essential to place attachment and one's quality of life (UN-Habitat, 2013, 2017, 2019). The adoption by member states of the 2030 Agenda for Sustainable Development (UN, 2019) and the New Urban Agenda have provided a global blueprint towards better connected, mixed use and compact cities and human settlements. Additionally, the adoption of UN system-wide Guidelines on Safer Cities and Human Settlements provides further guidance to national and local governments to plan and make cities and human settlements safer. The UN-Habitat's approach is premised on 'prevention' rather than reaction, to effectively address the complex challenges of urban insecurity, crime and violence. Placing public places and public transit availability, use and access at the center of the urban safety debate is a new way of understanding the role of cities and local governments in the prevention of crime and violence. Challenging traditional assumptions about urban crime and violence to make cities places of hope should influence global understanding of how individuals use and access the city in differentiated experiences.

No city environment reflects the meaning of urban life better than a public place. A public place, whatever its nature-a park, a mall, a train platform or a street corner-is where people pass by, meet each other, socialize and occasionally (only occasionally) become a victim of crime (Ceccato, 2016). The international research on environmental criminology and place-based crime prevention has long demonstrated how important the particular situational conditions of public places are to crime and citizens' perceived safety. Yet, what makes a public place safe remains open to debate.

With this book, we engage in this debate by submitting that crime and safety in public places are not issues that can be easily dealt with within the boundaries of a single discipline, such as criminology or urban planning. Rather, they require knowledge and practical examples from other disciplines. This edited volume also assembles a unique set of original research as chapters that deal with public place and the situational conditions of crime (Clarke, 1997) and 


\section{Vania Ceccato et al.}

fear, from the perspective of sociology, criminology, geography, architecture, urban planning, engineering, computer science, gender studies, transportation, and law enforcement. These studies cross traditional boundaries between disciplines yet share a number of important commonalities.

Overall, this discussion about safety in public places is not only an important issue for research but also for the vision and practices of long-term sustainability of cities (UN-Habitat, 2019). Promoting accessibility for all social groups in the city regardless of people's background is a key factor towards the realization of safe and sustainable cities and human settlements, using holistic, evidence-based and multidisciplinary approaches to urban safety and security.

This chapter provides an introduction to the theme of crime and fear in public places, the book's scope, steps taken in the making of the book, key definitions, and the synopsis of the chapters.

\subsection{Aim, scope and context}

The aim of the book is to illustrate the complexity of patterns of crime and fear in public places by providing examples of studies on these topics contextualized in different cities and countries around the world. All contributions add to our quest for safer, inclusive, resilient, equitable and sustainable cities and human settlements aligned to the Global 2030 Agenda for Sustainable Development (UN, 2019).

This is achieved by tackling five themes (Figure 1.1):

1 the nature of the city's structure as a backdrop for crime and fear (The environment),

2 the dynamics of people's daily routines and their transit safety (The movement),

3 the safety experienced by those who are most targeted by these offences in public places (The users' perspective),

4 the methodological challenges and advancements in the analysis of crime and fear (The Metrics), and,

5 the examples of current practices in promoting safety for different groups of society, both by academics and practitioners (The intervention).

Safety is one of the main concerns regarding public spaces. In fact, safety highly affects the use of a public place and its accessibility. Several environmental characteristics affect the safety of public places, yet it is safety perception that plays a significant role in making places appear safe or unsafe to people (Costamagna, Lind, \& Stjernström, 2019). Therefore, how cities are planned and designed has a major impact on an individual's safety (Ceccato, 2016). In this book, we provide examples, on the one hand, of public places that concentrate people and therefore offer crime opportunities. This is discussed in the cross-cutting theme The environment, which is focused on the city environment as the backdrop of crime and fear. Transportation nodes, parks, sports 

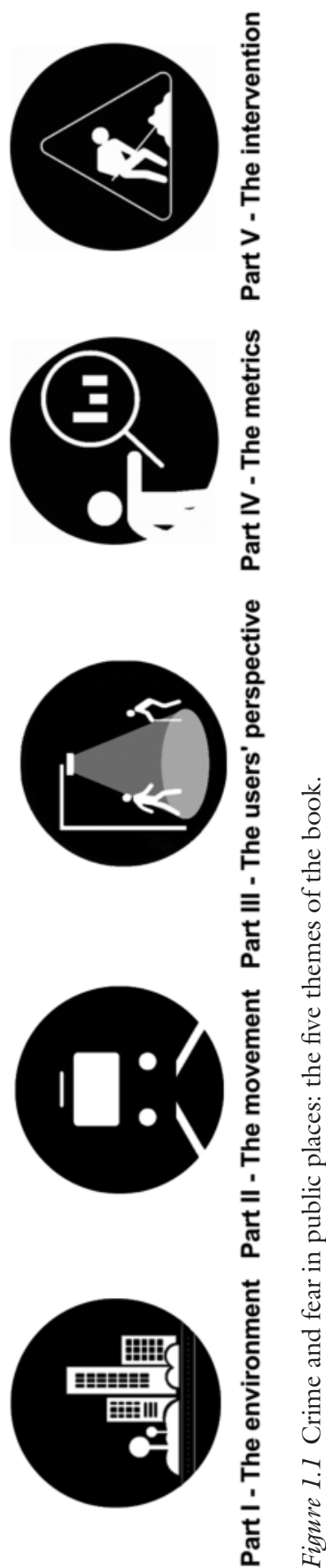


\section{Vania Ceccato et al.}

arenas, and university campuses illustrate the types of criminogenic conditions that might be at play in these environments. The environments where crime concentrates are different from other places in the city (Sherman, Gartin, \& Buerger, 1989), because they are crime hot spots, that is, they have the capacity to attract and/or generate crime (Brantingham \& Brantingham, 1995). Crime generators pull "masses of people who without any predetermined criminal motivation stumble upon an opportunity too good to pass up". Motivated offenders are drawn to crime by known criminal opportunities in particular places-these places are crime attractors (Franka et al., 2011, p. 1). We also provide examples of public places that are criminogenic because they offer the right conditions for anonymity, which is essential for certain types of crime. Robbery, rape, and even violations such as the dumping of garbage and chemicals, for instance, only happen in places with poor surveillance and reduced opportunities for intervention (Ceccato \& Uittenbogaard, 2014; Pettiway, 1982). These are characteristics of forests, desolated places, and roadsides that can make certain types of targets more vulnerable to victimization than others can (see the chapter about the role of public places in Disability Hate Crimes, for example). Desolate places in a park can also be pointed out as places that trigger fear and anxiety among park users.

Even when crime does not happen in a particular public place, if an individual feels unsafe in that place, that person may avoid it at particular times of the day or altogether (Ceccato, 2012, 2013). We show in this book that this is problematic because, in some cities, especially those in the Global South, a large percentage of the population, often women, spend much of their time in public places. They are "transit captives": they have relatively less access to non-public forms of transportation and are, therefore, overly reliant on public transport and spend much of their time in public places. The cross-cutting theme The movement will focus on "the dynamics of crime and fear in the transit city" and it constitutes a fundamental part of the book. A particular concern of women is the fear of sexual harassment while travelling, a concern that seems universal, as incidents of sexual harassment are reported on buses and trains in cities around the world (Ceccato \& Loukaitou-Sideris, 2020). If public transportation is not reliable or safe, women's mobility is impaired. Although women are most often the target of these types of behavior, they are not the only victims. There is evidence that gay men and transgendered persons are often victims of sexual harassment and violence in the São Paulo metro (Ceccato \& Paz, 2017) and other cities in the world (Gekoski et al., 2015).

An individual's right to safe public places is also highly dependent on society's norms and structures, whether they promote or limit one's freedom to move around without hindrance or fear. The risk of being a victim of crime and individual perceptions of personal safety are not only issues related to one's age or gender but result from the intersection of a set of individual characteristics. In this book, we examine victimization and fear through an intersectional lens, considering issues of gender and age in particular in the cross-cutting theme The users' perspective. Being an older and poor person creates "synergic layers 
of disadvantage" that affect whether one is at risk of being a victim of crime and how one experiences the world and expresses fear. This part also includes the perspective of victims of crimes as well as the offenders.

The book's contributions illustrate new ways of measuring crime and/or perceived safety in public places. In Part V, The metrics, data about public places have been an important element in the discovery of patterns of regularities of both crime and fear in city environments. Equally important has been the use of spatial analysis for planning purposes, particularly when the goal has been to focus resources-more precisely, to tackle unsafe places and formulate preventive actions. The potential of these analyses is directly linked to the technological development of place-based techniques as well as use of "big data" both in academia and among planners and other professionals.

In particular, this book examines the evidence of victimization of crime in public places, feelings of perceived safety or lack thereof, and the necessary improvements that can make these places safer. The cross-cutting theme The intervention provides concrete examples of practices to guide public policy and local practices. Examples of collaborative safety planning strategies that aim at improvements of safety through local governance around the world make up this part. These chapters provide better grounds to assess the risk of crime and perceived fear that can help urban planners to better plan public places.

\subsection{Steps taken in the making of the book}

In order to create a cohesive edited volume, the authors met in Stockholm, Sweden, on 19 October 2018, to discuss the scope and structure of the book, as well as the particularities of the cities and countries. This meeting followed the conference "Crime and Fear in Public Places: Patterns, Challenges and Actions" that took place in Stockholm, Sweden, 17-18 October 2018, where researchers presented their results in seven parallel sessions.

All chapters went through a blind peer review process with, on average, two reviewers per chapter (see the Acknowledgements for a list of reviewers) and were guided by a template of evaluation criteria from editors. With the sets of suggestions in hand, the authors had a chance to incorporate suggestions to the chapters and re-submit to editors-a process that took about six months to complete. From the original submissions, four contributions were eliminated during this process. This evaluation process ensured that book followed a basic structure in terms of size, geographical coverage and degree of multidisciplinarity. The book is perhaps the first publication devoted entirely to crime and fear of crime in public places from a truly international perspective. Since the majority of the current literature to date is dominated by North American and Western European study cases, this book opens up this field of research to other contexts and includes countries from Africa, Asia and Latin America, drawing from the experiences of cities in the Global North and the Global South. Specifically, the book contains contributions from Poland, Sweden, the United Kingdom, 
Mexico, India, Japan, Spain, Belgium, Australia, Italy, Brazil and the United States.

\subsection{Definitions and terms}

In this section, we define the most common terms used in this edited volume. This set of definitions and terms is expected to support the reading of the chapters that follow. What we mean by a particular term is not absolute and may slightly change from chapter to chapter. What we need to be aware of is that a definition bears a morality, which we argue, should better be spelled out, because whatever definition we assume has implications for how we, as researchers, approach a particular issue.

Let's take the case of public places. Why is it so important to think about the concept of public places? First, because our focus in this special book is on the circumstances of crimes in these public arenas, namely, common, shared environments (often non-virtual) that can be accessed by individuals often at all times, such as parks, pedestrian paths, tunnels, streets, interstitial spaces between buildings, transport nodes such as bus stops, surrounding areas, public places in neighborhoods. Second, crime-and the nature of each crime-depends on where the offense takes place. Open public spaces by their nature are perfect for pickpocketing but not for robbery; the former demands a crowd, the latter requires anonymity, sometimes characteristics of some desolated public places. Third, it is important to reflect upon the concept of public place because offense definitions (and offense seriousness) are determined by the situational conditions of crime. Whether a crime happens in a domestic, private environment or in the public realm is information that serves to support the work of the police. For instance, 'indoors' are considered places where order and crime cannot be affected by police surveillance or where any other type of intervention of the police is limited; for example, in premises of various kinds, dwellings, workplaces, shops and entertainment. Regardless of the differences in legal definition of what a public place is in different contexts, if a crime happens in a public space, its seriousness is determined not only by the rules of publicness of that setting but also the extent these rules are put in practice by those who manage and consume this particular public space.

Public place is a general term used in this book to describe any place where individuals are victims of a crime, or a place that, by the physical and social characteristics of its environment, triggers fear of crime, anxieties and other safety concerns. Individuals have partial or full access in a public place, either under free conditions or payment, such as a shopping mall, a sports stadium, a park or a train platform. In this volume, a wide range of public places with varying degrees of access for the public are used as a reference for analysis, namely parks, streets, open drug scenes, interstitial places in neighborhoods, and bus stops as well as places on the way to them. Sometimes public places are used as a synonym for publically accessed spaces and places as 'neighborhoods' or 
'neighborhood contexts' (see Chapters 6, 13 and 20). In addition, how virtual social networks can mirror real public places is discussed.

Thus, in this book, the term public place is distinct from the general concept of public space, which is often used in architecture and urban planning to indicate open areas, green areas, town squares, large interstitial spaces in which individuals may move freely, where entry is in some way unrestricted. Some authors define public space as, for instance, the 'space that is not controlled by private individuals or organizations, and therefore is open to the general public' (Madanipour, 1996, p. 144). Costamagna et al. (2019, p. 133) suggest

a public space is a place that is characterized by a collective social use and is freely accessible and usable by everyone. Such spaces can be either indoors or outdoors, and may include walkways, parks and other open areas like public squares, public building lobbies and various other areas where people can sit, gather or pass through.

Overall, almost all definitions of and views about public space include the primary indicators of accessibility and activity, stating that urban public space is an area that is accessible to all people and is the setting for their activities (Costamagna et al., 2019, p. 135). In reality, the two terms public place and public space have been used interchangeably in the literature (Ceccato, 2016, 2017; Hadavi, Kaplan, \& Hunter, 2018; Németh, 2012) and their definitional boundaries are often blurred, as also in this edited volume. For more details, see Ceccato (2015). On a more practical note, what is important to remember is that what constitutes a public place is highly context dependent. The conditions in a winter day in the streets of Lagos, Manilla or Sao Paulo are not the same as those found in cities of the Nordic countries, with long, cold, dark days. Gehl (2013) reminds us that cities must be lively, safe, sustainable and healthy, but these are hard conditions to achieve in northern cities in the winter. Public spaces are the places where most human social relations take place and are indeed particularly important for individual's health. In addition, "the presence of inclusive public spaces that accommodate the needs of a multitude of people, who may not otherwise cross paths in their daily lives, is therefore essential to a rich public life and an integrative society" (Costamagna et al., 2019, p. 134).

Social sustainability is one of the three dimensions of sustainability, the others being economic and environmental, and is the least defined and least understood. Richard, Johansson, and Salonen (2015) define it as the capacity of a society to tackle complex societal issues and its resilient ability to continuously function as a social system. A socially sustainable city, they suggest, can only be achieved if it builds mutual trust through public places that allow for people to feel self-confident without fear and discrimination.

Governance refers to all processes of governing, whether by a government, market, or network, whether over a formal or informal organization, or territory, and whether laws, norms, power or language (Bevir, 2012). 


\section{Vania Ceccato et al.}

Victimization and safety perceptions. In this book we adopted the two UNHabitat dimensions of safety and security: actual and perceived. Actual safety/ security refers to the risk of becoming a crime victim, measured by a variety of metrics and crime statistics, while perceived safety/security refers to people's safety perception through the lens of fear and anxiety. In many cases, urban dynamics and socio-spatial characteristics have an influence on whether a city has high levels of crime and violence. Spatial, social and economic fragmentation and exclusion feed insecurity and vice versa (UN-Habitat, 2019). Safety also depends on what happens in these places, and in turn what happens in them depends on how safe these places are perceived to be (Ceccato, 2016). Poor perceived safety has also been linked to public perceptions of disorder, which in turn have also been associated with serious crimes, implicit stereotypes about ethnic background and social efficacy (Sampson \& Raudenbush, 2004). Acts of disorder function as symbols of the extent to which an area is in decline or that nobody is in control (Lewis \& Maxfield, 1980). If people feel a lack of social control, this may decrease the walkability of streets and indirectly affects their health conditions (Branas et al., 2011).

Public transport or public transportation is the term used here to capture what North American readers often call "public transit", "mass transit" or "rapid transit" systems (Newton, 2014, p. 709). These systems, such as trains, buses, trams, comprise forms of transport that are available to the public, charge set fares, and run on fixed routes. In this book, the type of transit systems may vary from city to city.

Sexual offenses and crimes can be a vast array of sexual behaviors that range from sexual harassment to sexual assault. The boundaries between these types of acts are blurred. As early as in the 1990s, Cohan and Shakeshaft (1995) distinguished between what they called "noncontact" and "contact" sexual violence. In the noncontact category, they included nonverbal sexual abuse and verbal sexual abuse, while in the contact category, they included sexual abuse such as touching, kissing and rape. For more details see Ceccato and Loukaitou-Sideris (2020).

Whole journey approach (Natarajan, Schmuhl, Sudula, \& Mandala, 2017) includes walking to and from the public transportation (bus stops, train stations) as well as waiting for and riding on the bus or subway, it is the trip from door-to-door.

Intersectionality is an approach that considers the multiple identities of the population in order to tie them through categories that allow the identification of interactions between such identities and the activities or experiences of individuals (Levin, 2015). More specifically, however, the intersectionality approach is often in response to certain conditions that represent oppression: power relations, inequalities, justice in different social contexts (Hopkins, 2017).

\subsection{Chapter synopses}

The book that follows is composed of seven parts and 23 chapters. Part I consists of three chapters: following this introductory chapter, which presents the 
subject area, definitions, and scope, Chapter 2 discusses a number of criminological theories that provide the theoretical background for the chapters of the book. Chapter 3 presents the research evidence on crime and fear in public places, focusing on three main aspects of design and security technology (lighting, CCTV and CPTED). This initial part motivates why crime and fear in public places are worthy topics and presents the aim of the book, the scope, the five cross-cutting themes (Parts II to VI), the theory and the delimitations.

Part II portrays the city environments as the backdrop for crime and fear in different types of public places, such as parks. The first chapter of this Part, Chapter 4 , is devoted to general evidence of the importance of the physical environment for crime and perceived safety in parks using CPTED as a theoretical framework while Chapter 6 is a literature overview about the role of public places for hate crimes towards individuals with disabilities.

Part III offers examples of transit safety with a focus on sexual crime against young people (university students) deriving from four case studies: Mexico City, Mexico; Tokyo/Kanagawa, Japan; Rio Claro, Brazil; and Lagos, Nigeria. We report the results from a recent survey focusing on the experiences of victimization, in particular sexual crimes and perceived safety among university students, which was part of a global investigation conducted in conjunction with other cities by researchers from six continents (Ceccato \& Loukaitou-Sideris, 2019). We focus on university students because the majority of the victims of sexual harassment in transit are young people (Beller, Garelik, \& Cooper, 1980), they are more similar to each other in age than the general population, and, since they have lower car ownership rates than the rest of the population, they have to rely on public transportation more extensively than do other urban residents. Lastly, we also had a practical motivation to focus on college students, as we could reach them more easily than other groups through their universities. Focus is placed on the relationship between safety and the types of environments that individuals are exposed to when they travel, which means that the book adopts a whole journey approach to safety.

One of the novelties of this book is that a few contributions deal with users, the people who "consume" public places. They may sometimes become a victim of crime, sometimes are the offenders or, just by their presence, may prevent crime from happening. Part IV is devoted to patterns of victimization and perceived safety by specific groups of city users. The chapters highlight the differing needs of these groups but also the role of public spaces on offending. This Part starts with a theoretical piece about sexual harassment in public places and women's safety work followed by an analysis of sexual victimization and offending patterns in India. More specifically, the concordance rates between victims and offenders of sexual harassment as well as offenders and their male friends' sexual harassment offending patterns is examined. Chapters 13 and 14 deal with the importance of neighborhood context to individual's perceived safety: one is focused on older adults' patterns of perceived safety and the other on women's fear, in particular the interplay between individual and environmental factors in impacting fear. 


\section{Vania Ceccato et al.}

Part V, the metrics, focuses on methods and new data sources for assessing patterns of crime and fear in public places. The first chapter describes a pilot of Ecological Momentary Assessment to assess contextual determinants of fear of crime followed by, Chapter 16, which looks at a combination of quantitative and qualitative techniques to map and evaluate the nature of Open Drug Scenes (ODS). The final contribution makes use of data coming from social media to describe fear in cyberspace. In the digital age, "eyes" are complemented by technologies such as smartphones, "apps," or body-worn cameras, giving expression to new ways of depicting what happens in public space (Ceccato, 2019; Gibson, 2014). In this book, this chapter goes beyond the concrete, tangible arenas such as parks and streets and is devoted instead to virtual public places. The contribution focuses on the phenomenon of fear in cyberspace, through the analysis of emotional linguistic responses of online social media using "big data": a sample of more than two million tweets collected on three occasions: after the attacks on Charlie Hebdo, at Nice, and at Barcelona between 2015 and 2017.

Part VI offers four examples of current practices in promoting safety for different groups of society, both by academics and practitioners. The first chapter in this Part focuses on a particular feature of the urban environment that is traditionally associated with declared levels of fear: street lighting. This contribution critically reflects upon the impact of street lighting on crime and the fear of crime, with a particular emphasis on the effect of reduced street lighting, using as a reference studies published since the 1960s on this subject. The second chapter turns our attention to the night-time economy and, in particular, the music festival context to evaluate harm-reduction initiatives in the UK. Part VI also illustrates a case study in social capacity building from the New Orleans neighborhood following Hurricane Katrina, in the US. Using an action research case study approach, the journey of residents in rebuilding their neighborhood is described, focusing on a ten-year period beginning with initial community initiatives in 2008 and subsequent programs in the following years. Finally, Chapter 21 looks at urban planners' practices with regards to safety issues in municipalities in Sweden, based on answers from surveys collected from 85 percent of municipalities in Sweden in 2019.

Part VII brings together this edited volume, and highlights and summarizes the main findings presented in the book, based on each of the preceding sections. Based on the literature and the empirical findings, Part VII answers two important questions: assessing the nature of fear of crime in public places globally, and what can cities do to reduce crime and fear through research, design and policy? These final chapters discuss the findings comparatively and their implications for theory and practice, then suggests a future research agenda. How do we make public places safer for various types of city users? In different city and country contexts following an agenda aligned to the 2030 Agenda for Sustainable Development?

The book concludes by stating the need for urban policy integration taking into account the relationship between the urban environment and safety and 
social sustainability of cities; individual's safety from an intersectional lens; and individual's mobility from the perspective of a whole journey approach in Global North-South contexts, in urban areas and smaller settlements, often in tangible spaces but also, and more often than even before, interconnected to virtual public spaces. Interventions ought to be inclusive, engaging and backed up by long-term democratic processes that lead to change, and aimed at creating safe and sustainable environments for all. In the end, urban development emerges from prosperity, through adequate and sound evidence-based planning, management and governance; it comes to be fully enjoyed once urban safety is guaranteed.

\subsection{Concluding remarks}

The aim of the book is to characterize with examples from all around the world the dynamics of crime and fear in public places depicted by five crosscutting themes: environment, movement, city users' perspective, metrics and interventions. Emphasis is given to the relationship between safety and the types of environments that individuals are exposed to, but also the impact of a lack of perceived safety and its potential determinants. In addition, this book examines the evidence of victimization and fear in public places from an interdisciplinary perspective, with examples from the Global North-South contexts, considering theories at the crossroads of several disciplines, such as environmental criminology, architecture and design, urban planning, geography, psychology, gender and LGBTQI studies, transportation, data science, engineering, linguistics, and law enforcement. The book can, therefore, be a resource for academics and students in urban planning, criminology, geography, and sociology, by professionals in police and law enforcement and transportation, and for policymakers and city planners interested in ensuring safe travel in their cities. Thus, this book is targeted at both researchers and practitioners with a hope to invite and encourage greater inter- and multi-disciplinary dialogue.

\section{References}

Beller, A., Garelik, S., \& Cooper, S. (1980). Sex crimes in the subway. Criminology, $18,35-52$.

Bevir, M. (2012). Governance: A Very Short Introduction. Oxford: Oxford University Press.

Branas, C. C., Cheney, R. A., MacDonald, J. M., Tam, V. W., Jackson, T. D., \& Ten Havey, T. R. (2011). A difference-in-differences analysis of health, safety, and greening vacant urban space. American Journal of Epidemiology, 174, 1296-1306.

Brantingham, P. L., \& Brantingham, P. J. (1995). Criminality of place: Crime generators and crime attractors. European Journal on Criminal Policy and Research, 3, 1-26.

Ceccato, V. (2012). The urban fabric of crime and fear. In V. Ceccato (Ed.), The Urban Fabric of Crime and Fear (pp. 1-33). Dordrecht, Heidelberg, New York, London: Springer Netherlands.

Ceccato, V. (2013). Moving Safely: Crime and Perceived Safety in Stockholm's Subway Stations. Plymouth: Lexington. 


\section{Vania Ceccato et al.}

Ceccato, V. (2015). Public space and the situational conditions of crime and fear. International Criminal Justice Review, 26, 69-79.

Ceccato, V. (2016). Public space and the situational conditions of crime and fear. International Criminal Justice Review, 26, 69-79.

Ceccato, V. (2017). Women's transit safety: Making connections and defining future directions in research and practice. Crime Prevention and Community Safety, 19, 276-287.

Ceccato, V. (2019). Special issue: Crime and control in the digital era. Criminal Justice Review, 44, 5-10.

Ceccato, V., \& Loukaitou-Sideris, A. (2019). Transit Safety among College Students: An International Study. www.kth.se/abe/om-skolan/inst/som/avdelningar/urbana-studier/ forskning/urban-community-sa/trygghet-i-kollektiv (accessed 14 February 2020).

Ceccato, V., \& Loukaitou-Sideris, A. (2020). Transit Crime and Sexual Violence in Cities: International Evidence and Prevention. London: Routledge.

Ceccato, V., \& Paz, Y. (2017). Crime in São Paulo's metro system: sexual crimes against women. Crime Prevention and Community Safety, 19(3), 211-226.

Ceccato, V., \& Uittenbogaard, A. C. (2014). Space-time dynamics of crime in transport nodes. Annals of the Association of American Geographers, 104, 131-150.

Clarke, R. V. (1997). Situational Crime Prevention: Successful Case Studies. New York: Harrow and Heston.

Cohan, A., \& Shakeshaft, C. (1995). Sexual Abuse of Students by School Personnel. https://digitalcommons.molloy.edu/edu_fac/10 (accessed 13 February 2020).

Costamagna, F., Lind, R., \& Stjernström, O. (2019). Livability of urban public spaces in northern Swedish cities: The case of Umeå. Planning Practice \& Research, $34,131-148$.

Franka, R., Vahid, D., Reida, A., Singhb, S., Cinnamona, J., \& Brantingham, P. (2011). Power of criminal attractors: Modeling the pull of activity nodes. Journal of Artificial Societies and Social Simulation, 14.

Gehl, J. (2013). Cities for People. Washington, DC: Island Press.

Gekoski, A., Jacqueline, M., Gray, M. H., Horvath, S. E., Aliye, E., \& Adler, J. (2015). 'What Works' in Reducing Sexual Harassment and Sexual Offences on Public Transport Nationally and Internationally: A Rapid Evidence Assessment. www.mdx.ac.uk/ data/assets/pdf_file/0019/155800/What-Works-in-Reducing-Sexual-Harassmentand-Sexual-Offences-on-Public-Transport-Nationally-and-Internationally.pdf (accessed 20 February 2020).

Gibson, T. A. (2014). In defense of law and order: Urban space, fear of crime, and the virtues of social control. Journal of Communication Inquiry, 38, 223-242.

Hadavi, S., Kaplan, R., \& Hunter, M. R. (2018). How does perception of nearby nature affect multiple aspects of neighbourhood satisfaction and use patterns? Landscape Research, 43, 360-379.

Hopkins, P. (2017). Social geography I: Intersectionality. Progress in Human Geography, 43(5), 937-947.

Levin, L. (2015). Gender equality and safety, a challenge for transport planning: Moving away from stereotypes and stereotypical attitudes and habits. In Newton, A. and Ceccato, V. (Ed.), Safety and Security in Transit Environments. Crime Prevention and Security Management (pp. 309-327). London: Palgrave Macmillan.

Lewis, D. A., \& Maxfield, M. G. (1980). Fear in the Neighborhoods: An investigation of the impact of crime. Journal of Research in Crime and Delinquency, 17, 160-189.

Madanipour, A. (1996). Design of Urban Space. New York: Wiley.

Natarajan, M., Schmuhl, M., Sudula, S., \& Mandala, M. (2017). Sexual victimization of college students in public transport environments: A whole journey approach. Crime Prevention and Community Safety, 19, 168-182. 
Németh, J. (2012). Controlling the commons: How public is public space? Urban Affairs Review, 48, 811-835.

Newton, A. (2014). Crime on public transport. Encyclopedia of Criminology and Criminal Justice (pp. 709-720). London: Springer.

Pettiway, L. E. (1982). Mobility of robbery and burglary offenders: Ghetto and nonghetto spaces. Urban Affairs Review, 18, 255-270.

Richard, E., Johansson, M., \& Salonen, T. (2015). Reflections on the right to health. In M. J. E. Richard, \& T. Salonen (Eds.), Social Transformations in Scandinavian Cities: Nordic Perspectives on Urban Marginalization and Social Sustainability (pp. 251-264). Lund, Sweden: Nordic Academic Press.

Sampson, R. J., \& Raudenbush, S. W. (2004). Seeing disorder: Neighborhood stigma and the social construction of "broken windows". Social Psychology Quarterly, 67, 319-342.

Sherman, L. W., Gartin, P. R., \& Buerger, M. E. (1989). Hot spots of predatory crime: Routine activities and the criminology of place. Criminology, 27, 27-56.

UN-Habitat (2013). Creating Safe Public Spaces. www.unwomen.org/en/what-we-do/ ending-violence-against-women/creating-safe-public-spaces (accessed 14 February 2020).

UN-Habitat (2017). Safe Cities Global Initiatives. UN, 2. www.unwomen.org (accessed 14 February 2020).

UN-Habitat (2019). Safer Cities Programme. https://fukuoka.unhabitat.org/programmes/ detail04_01_en.html (accessed 14 February 2020).

United Nations (2019). The Sustainable Development Goals. www.un.org/sustainable development/sustainable-development-goals/ (accessed 14 February 2020). 


\title{
2 The circumstances of crime and fear in public places
}

\section{A review of theories}

\author{
Vania Ceccato
}

\subsection{Introduction}

This chapter discusses the extant theories used to interpret the occurrence of crime and fear in public places, which are set out within the framework suggested in the previous chapter. The aim is to translate these theories into an integrated conceptual framework within which safety (crime and fear) in public environments can be examined. None of these theoretical perspectives is without criticism, and none has been explicitly developed for application to public places. This theoretical review is intended to support the analysis of the empirical research illustrated in the five cross-cutting themes of the book derived from a wide range of perspectives and disciplines. We begin by discussing the concept of public places in relation to the dynamics of urban crime and fear. Then, due to the range of theoretical approaches in the international literature, the chapter concentrates on those aspects considered salient to the major components of the book: the city environment, people's mobility, users' perspective, metrics of crime and fear and intervention.

\subsection{Public places and safety}

To be fully public, a public place must be safe. Public places are entities that are collectively shared. They can be an indoor or an outdoor area, more often publicly owned, to which anyone has access. ${ }^{1}$ They can take different shapes: from parks, streets and transit environments, to shopping malls or interstitial spaces, each one with its own design features. Public places may gather thousands of people (e.g., stadiums, airports, major central stations) or be desolate paths or empty stations. In either case, poor design can maximize crime opportunities or give users the notion that nobody is in control and, therefore, they are unsafe. Although it is difficult to make generalizations about safety in public places, the international literature on environmental criminology discussed in this chapter (e.g., Brantingham \& Brantingham, 1984; Eck, 1998; Sherman, Gartin, \& Buerger, 1989; Weisburd, 2015) demonstrates how to detect situational conditions that generate crime in several types of public places and ways to promote safety perceptions. In the next section we review 
environmental criminology theories that focus on the role of urban environment in crime and perceived safety.

\subsection{The urban environment}

Crime opportunities are influenced by the design of urban spaces and the way such spaces are arranged in the urban fabric. Thus, architects, planners and safety experts have an important role to play when a new public place is planned and safety guidelines are implemented. These experts decide details that affect types of facades, the height of walls, orientation of windows, garages, storage spaces and more, which, alone or together, impact the safety of the area. Brantingham and Brantingham (1995, p. 3) suggest that:

the urban settings that create crime and fear are human constructions ... homes, parks, factories, transport systems ... the ways in which we assemble these large building blocks of routine activity into the urban cloth can have an enormous impact on our fear levels and on the quantities, types and timing of crimes we suffer.

Indeed, crime opportunities are also a function of the density of buildings, layout of streets and entrances, the connection of backyards with the main streets, alleys, parking spaces, physical barriers between buildings and public places as well as modern security features (e.g., CCTV) that individually or together affect surveillance opportunities and allow guardianship. Guardianship is the process by which individuals function as effective informal crime prevention and control agents (Reynald, 2014) and is therefore key to the safety of an area. Yet, the risk of being victimized by a crime is also dependent on the overall context at work in a particular setting, at a particular time. Public places in inner city areas are peculiar places because they often concentrate risky facilities (Clarke \& Eck, 2007) at much higher ratios than anywhere else in the city. How these design features relate to the whole city, support accessibility and create feelings of territoriality while allowing surveillance and guardianship is largely illustrated in the literature (Armitage, 2018; Armitage \& Monchuk, 2011; Ceccato, 2012a, 2012b; Cozens \& Hillier, 2008; Cozens, 2011; Grönlund, 2012; Loukaitou-Sideris, 2012; Poyner, 1986, 1991, 2005).

\section{Urban design and safety: key concepts in a bistorical perspective}

Theories developed since the 1950s indicate the importance of the design of microspaces to the whole urban structure in creating opportunities/barriers for human activities, including crime. Some theories are particularly devoted to the understanding of how individuals shape different environments, how they are affected by them and are engaged in the (use and maintenance of) spaces as indicators of the quality of the area (Barker, 1968; Sommer, 1972; Thomlinson, 1969). 
It was not until the early 1970s that a more explicit set of design rules was developed to encourage monitoring of public spaces with the intention to reduce crime opportunities. One example was Crime Prevention Through Environmental Design (CPTED), introduced by criminologist C. Ray Jeffery in 1971. CPTED is defined as "the corrected design and the efficient use of the built environment that can lead to a reduction in fear of crime and crime incidents and to an improvement in quality of life" (Crowe, 2000). Jeffery's ideas-that the environment has an impact on crime-encountered great resistance, especially among criminologists who claimed he advocated for simplified extrapolations between the physical environment and human behavior (Jeffery, 1977).

Nearly at the same time, the architect Oscar Newman put forward the theory of "defensible space" (Newman, 1972) having clear similarities with Jeffery's CPTED. Defensible space is defined as an environment whose physical characteristics function to allow individuals to become key agents in ensuring their safety. Natural surveillance - a key concept in this model - involves ensuring clear sightlines by designing the "right" placement of physical features, such as windows. CPTED ideas started to attract more notice outside academia with the publication of the Design Guidelines for Creating Defensible Space by the National Institute of Law Enforcement and Criminal Justice (now the National Institute of Justice). What most people are unaware of is that, as early as the 1950s, similar ideas were developed in the United States linking the importance of the urban design to neighborhood quality. Elizabeth Wood, a housing advocate and planner in Chicago, urged planners to build small projects (instead of the tall structures considered modern at the time) and to incorporate shops, parks and even pubs to transform housing complexes into real neighborhoods. Wood's principles were never implemented according to the original intentions. Another pioneer was the journalist Jane Jacobs, who, in the 1960s and in the same vein as Woods, criticized the failure of design of public housing in the United States. Jacobs coined the iconic concept of "eyes on the street" (Jacobs, 1961), highlighting how urban design plays a crucial role in providing opportunities for surveillance, guardianship and crime prevention. For a street to be safe, Jacobs (1961, p. 35) wrote:

... there must be eyes on the street, eyes that belong to those we can call the natural owners of the street.

Promoting opportunities for surveillance is, of course, not automatically effective. Effectiveness here depends largely on the willingness and the ability of the individual in exercising guardianship. For example, according to Eck (2019), place managers are important because they can exercise control over users and in doing so contribute to the safety of the public space. Nowadays, "eyes" can be complemented by technologies that give expression to new ways of depicting what happens in public places, from surveillance to sousveillance (see Ceccato, 2019 and in this book, part "The metrics").

The interrelations between urban design and an individual's willingness and ability to exercise control over an area were also indicated by research in the 
United Kingdom by the geographer Alice Coleman (Coleman, 1985). Coleman carried out an extensive study showing the impact of modernistic large-scale social housing projects on safety. The author showed how the scale and size of the built environment were essential parts of the problem: the size of the building lot, the number of blocks, the number of dwellings per block, the number of floors and the number of households around the same stairwell. Her study was controversial and, among other things, was criticized for lack of attention to social factors interacting with the physical (Mikellides, 2007) as well as for its methodology (Hillier, 1986).

In the late 1980s, safety and security guidelines were created in the UK for the certification of new residential areas. A similar model of certification was also developed in the Netherlands. The ideas of the Dutch model derived in part from the principles of living structure as a "pattern language", created by Christopher Alexander and others (Alexander, Ishikawa, \& Silverstein, 1977). This model describes methods for constructing "practical, safe, and attractive designs at every scale" and later inspired the "secured by design" model implemented in the Netherlands in the 1990s (Jongejan \& Woldendorp, 2013).

In the decades that followed, both research and practice have moved away from the strict link between an area's physical environment and safety and focused more on its social dimension. In the United States, this approach was called the "second generation of CPTED" and has evolved in different ways. On one hand, this development has led to the engagement of individuals in participatory plans, in particular those incorporating different users' perspectives on urban spaces, such as women and children. Safety walks, especially women's safety walks, are an example of these methods (Whitzman, 2007; Whitzman, Shaw, Andrew, \& Travers, 2009). Similarly, another practical example of second generation CPTED was reported by Gregory Saville and team (2009), who implemented planning safety models combining community development strategies and crime prevention programs in neighborhoods (see also Saville, 2018). According to Armitage and Ekblom (2019), Saville is a pioneer of second generation CPTED that stresses the importance of public participation in the processes of evolving safer, more sociable urban places. His concept builds on crime prevention through urban design principles, but emphasizing the role that communities can play to create safe and sustainable communities. A step forward is proposed by Mihinjac and Saville (2019) with the "CPTED third generation", a framework that integrates issues of safety, public health and sustainability.

On the other hand, around the world, current ways of implementing CPTED ideas in municipal planning have often involved consulting firms delivering proposals for urban design as well as integrated planning strategies that combine evaluations of the physical and social environments with participatory schemes, involving residents and stakeholders (see for example Gray \& Novacevski, 2015; Jongejan \& Woldendorp, 2013). This development has also witnessed an increasing commodification of security (Goold, Loader, \& Thumala, 2010) that can take different forms, from an industry that survives by delivering a range of (often untested) products and security gadgets (e.g., CCTV cameras, drones, 
security windows), to organizations that provide security standards and certifications, not infrequently recycled models from the original first generation of CPTED principles. This commodification has been extreme, and gated communities have turned into permanent housing and safety solutions in crime-ridden countries (Asiedu \& Arku, 2009; Branic \& Kubrin, 2018; Breetzke, Landman, \& Cohn, 2014; Chase, 2008; Grundström, 2018; Lemanski, 2006; Wilson, 1999) and have found their way into Europe (Grundström, 2018) and elsewhere (Tedong, Grant, \& Abd Aziz, 2014).

Partnership initiatives between the public and private sectors (e.g., Building Improvement Districts (BIDs)) have become an integral part of the model of delivering safety guidelines and strategies in planning schemes around the world (Clutter, Henderson, \& Haberman, 2019; McCarthy \& Doyle, 2011; Symes \& Steel, 2003). In smaller communities, policing and crime prevention initiatives, in the absence of the police forces, have involved NGOs, security companies and the voluntary sector to tackle safety problems (Kang, 2011; Uhnoo \& Hansen Löfstrand, 2018; Yarwood \& Edwards, 1995). It is unclear, however, whether this development can continue to ensure safety as a human right and not only for those who can afford it.

In summary, the planning models that have flourished in the past 20 years are filling up the void in knowledge (and action) of researchers and in particular of public actors (namely, between planners, police officers, policymakers, engineers and the like) in recognizing the importance of links between safety and the physical and social environments.

\section{Safety and neigbborbood context}

The causes of crime have traditionally been attributed much more to the characteristics of the individual than to the situational conditions where crime occurs. The first school of knowledge that pointed to the role of society in crimemore explicitly neighborhoods-were researchers Shaw and McKay (Shaw \& McKay, 1942) in the United States. In the early 1930s, they suggested a link between poverty, housing mobility, weak social control and crime in some areas of Chicago. It was believed that social control in some areas was the key to making a residential area safe. (Social control can be interpreted as the process of a group regulating itself according to its beliefs, principles and values.) Socially disorganized neighborhoods (neighborhoods with high housing and business turnover, lack of community agency and participation) typically have more crime and less social control. Social disorganization theory and its modern developments (Kornhauser, 1978; Sampson, Raudenbush, \& Earls, 1997; Shaw \& McKay, 1942) have provided the theoretical underpinning for many studies that focus on the impact of neighborhood characteristics on crime as well as key indications on how to prevent crime.

When residents and stakeholders are not willing to join forces to prevent petty crimes, a sense of disorder in society develops. In particular disadvantaged areas, this process reproduces itself-disorder causes crime, crime in turn creates 
fear-leading to a spiral of decay. These ideas formed the basis for Wilson and Kelling's broken windows theory (Wilson \& Kelling, 1982), namely that disorder in one area attracts more crime. The simplistic link between economic vulnerability, disorder and crime was later contested. In the 1990s, Sampson and colleagues showed that people's ability to work for a common good, despite levels of cohesion, was also important for preventing crime. These ideas formed the basis of the collective efficacy theory (Sampson et al., 1997).

Both theories (social disorganization theory and collective efficacy) have been applied to explain why some residential areas differ in their amount of crime, but the theories failed to explain why specific places in a particular area become crime places. They also failed in considering individuals' modern lifestyles and patterns of daily mobility and communication. Individuals allow themselves to be affected by the environment as they spend different amounts of time in different places (where they reside, work or are in transit) with varying criminogenic properties. The decisions that individuals take to be on the move may result in a reduction of their safety, depending on where and how they travel. The importance of the quality of the environment while one is in transit will be further discussed in the next section.

\subsection{The movement}

Individuals' activities and daily habits are rhythmic (comprised of repetitive patterns in different parts of the city), which in turn affects patterns of crime. Crimes occur when individuals are waiting for a bus, traveling on some means of transportation or walking to a station. They may be unfamiliar with the risks of becoming a crime victim as they may be navigating an unknown environment or during risky hours. But when and where does most crime happen?

The criminologists Lawrence Cohen and Marcus Felson suggest that crime takes place when a motivated offender and a suitable target (victim or property) meet in time and space, without the presence of a capable guardian (Cohen \& Felson, 1979). By adopting principles of rational choice theory (Becker, 1968) and assuming that criminals act rationally (which is not always the case), one can state that a crime occurs when the conditions are such that the benefits to them of a crime outweigh the costs, suggesting that a lack of guardianship is a crucial element influencing where/when certain offences occur. A capable guardian, for instance, acts through his presence to prevent crime and through his absence to make crime more likely to occur, while motivated criminals do not search through a whole city for targets; they look for targets within their more restricted awareness space (Brantingham \& Brantingham, 1984).

Following crime pattern theory, the awareness space of an individual is composed of his or her "anchor points" in the urban landscape, such as place of residence, school and frequently used subway stations and transit lines connecting these anchor points. It is the interaction of the location of potential targets and the criminal's awareness or activity space that culminate in particular patterns of crime occurrence. Yet, the urban environment does not affect 


\section{Vania Ceccato}

individuals equally. First, individuals differ from one another. Second, the environment differs from place to place, and individuals are bound to react differently to different environments. As Wikström, Mann, and Hardie (2018) suggest, crime can be viewed not simply as the product of deep social, economic and psychological causes but also as the result of deliberate choices by individuals reacting to particular environmental circumstances.

A public place can generate thousands of crime opportunities, some more obvious to potential offenders or crime-prone individuals (those individuals that would consider crime as an alternative, based on their morality and self-control) than to anybody else. Yet, crime opportunities are neither uniformly nor randomly distributed in space and time (Ratcliffe, 2010). Temporal variations of crime are related to people's routine activity. They do follow rhythmic patterns of human activity, some varying daily, others weekly or seasonally. A target, a motivated offender and a capable guardian must converge in (public) place and time for crime to occur (Cohen \& Felson, 1979) as previously suggested, but such interaction is not enough to explain why a public place becomes a crime place.

A crime is an outcome of a perception choice process initiated by the interaction between the individual's crime propensity and his or her exposure to a criminogenic place (Wikström, Ceccato, Hardie, \& Treiber, 2010). According to situational action theory, a place "may become criminogenic when activities and users encourage behavioral norms that conflict with the law, and/or they are ineffective at enforcing the law" (Wikström \& Treiber, 2017, p. 82). Crime depends on the moral norms of a particular place, which in turn "depend on what kinds of activities take place within them and what kinds of people tend to be present, both of which are likely to vary by time of day, week and/or year" (Wikström \& Treiber, 2017, p. 82).

Therefore, the environment has a role to play in affecting a place's behavioral norms through the way it is designed and maintained, how it is used through the day by residents and visitors and how well it is interlinked to the rest of the neighborhood and city. Yet, according to Wikström et al. (2018), only when a crime-prone individual spends enough time in a criminogenic setting may a crime occur. To better prevent crime, one must better understand why a particular environment becomes criminogenic in the first place. A first step is to change public places that concentrate the most crimes; as described below, they are not criminogenically homogeneous: some attract crime, others absorb or radiate crime.

\section{Criminogenic public places}

We know that crime is six times more concentrated in places than among people (Weisburd \& Telep, 2011) and that most places have no crime (Eck, 1998; Sherman et al., 1989; Weisburd, Bushway, Lum, \& Yang, 2004). If an area offers shopping, recreation and restaurants, this area is bound to have a higher crime rate than residential areas just because it contains multiple "risky 
facilities" (Clarke \& Eck, 2007). For instance, about 60 percent of all crimes reported to the police in Stockholm occur within 500 meters of a metro station (Ceccato, 2012b; Ceccato, Uittenbogaard, \& Bamzar, 2011), and 10 percent of crimes that have happened in a shopping mall are concentrated in a particular part of the facility (Ceccato, Falk, Parsanezhad, \& Tarandi, 2018).

A public place is often a risky place, a place that concentrates a disproportionately high amount of crimes in relation to its surroundings (Clarke \& Eck, 2007). Some places will attract crime from the surrounding areas, others will generate crime. The types of interaction such a public place has with its surroundings and city contexts will determine its nature as a criminogenic place.

According to Brantingham and Brantingham (1995), a public place can be a crime generator, a place with many criminal opportunities that are well known to criminals; for example, a hidden spot outside a transit station can provide the perfect place for selling drugs.

A public place can also be a crime attractor; for example, a shopping mall or a bus stop may attract large numbers of people for reasons unrelated to criminal motivation, creating many opportunities for crime (Groff \& McCord, 2012; Hilborn, 2009; Iqbal \& Ceccato, 2015).

A busy public toilet may concentrate disorder and damage to public property and become a crime enabler (Clarke \& Eck, 2005), when rules of conduct are absent or are not enforced by users or place managers.

Bowers (2014, p. 389) explored the nature of the relationship between crimes occurring within a particular public place and those occurring outside but near the place and found that such a public place can become a crime radiator or crime absorber (Bowers, 2014). Crime radiators "cause crime in the immediate environment as well as internally", while crime absorbers absorb risk from the external locale.

As discussed in Section 2.3, place managers are important because they can contribute to the safety of the public spaces by exercising control over users (Eck, 2019), but these key actors are not alone. Felson (2006) suggests that multiple actors exercise social control: the "place manager" is the person responsible for controlling the behavior in a particular place, such as a teacher in a school or a security guard in a shopping center or a station. Then there is the "handler", who controls the individual (parent, sibling) who may be considering crime as an alternative, and finally the "capable guardian", who can protect the target, either a property or a person. As for targets, there are two types of guardians: formal guardians whose responsibility is to protect people and property from crime, such as police officers and security guards, and informal guardians, including friends and others who are at the same place as the target. A thief may give up stealing a purse if (s)he notices that (s)he is being watched by people on the bench or by the restaurant owner.

A limitation of this approach of focusing on where most crimes occur is that it often takes only the crime scene into account. Research by police officer Tamara Herold and her colleagues in the United States shows that the crime dynamics can be better understood through information about "where" and 


\section{Vania Ceccato}

"when" criminal networks socialize before a crime takes place (Madensen, Herold, Hammer, \& Christenson, 2017). They suggest that "comfort places" (e.g., a corner of a street where criminals hang out) play an important role in criminal proceedings although they are not crime scenes. Another limitation is that the detection of crime concentrations is scale dependent and works best in larger urban centers. In other words, this approach is less informative of the dynamics of crime of public places in rural contexts or smaller municipalities, simply because rural communities do not have enough risky facilities to generate or spread crime as larger urban areas have.

\subsection{The users' perspective}

An individual's risk perception often reflects something other than the likelihood of being a victim of crime. Koskela and Pain (2000) suggest that we create mental maps of feared environments and unsafe places based on our prior experiences as well as on media stories and the accounts of others. Sandercock (2005) argues that expressions of fear of crime are actually fear of others.

Fear, according to Warr (2000, p. 453), is "an emotion, a feeling of alarm or dread caused by awareness of expectation of danger". Jackson and Gray (2010) distinguish between "functional" and "dysfunctional" fear. Functional fear leads to precautionary actions that reduce both fear and risk of victimization, while dysfunctional fear leads to negative impacts on individuals, such as constrained mobility and avoidance of public spaces, as discussed in Parts III and IV of this book, affecting individuals' health and the overall sustainability of a place. A safe city is a sustainable city, one that allows living without the risk of being a victim of crime or fear of victimization.

By tradition, women describe themselves as feeling more fear in urban environments than men (Pain, 2000), partly because men and women use and experience such environments in different ways (Dymén \& Ceccato, 2012). However, we must not believe that an individual's safety is based solely on gender. Several individual factors determine the risk of victimization as well as safety perceptions. Women, the elderly, members of ethnic minority groups, those who belong to the LBTQTI community, those with disabilities and those who are disadvantaged report higher levels of fear of crime (Box, Hale, \& Andrews, 1988; Garofalo \& Laub, 1979; Pain \& Smith, 2008).

Disability affects vulnerability to crime (Iudici, 2015; Iudici, Bertoli, \& Faccio, 2017). In Stockholm city, for example, those who feel that they have one or more disabilities state twice as much fear of being victims of assault and robbery than the general population. Three times as many say they were worried or do not go out after dark where they live because they are afraid of being exposed to crime (Ceccato, 2013b). However, although men are victims of reported crime while in transit more often than women are (Morgan \& Smith, 2006), women declare being more fearful than men (Ceccato, 2013b; Dymén \& Ceccato, 2012). Similarly, while young people are statistically more 
at risk of being victimized, older and/or disabled individuals tend to be more fearful (Furstenberg, 1971; Lagrange \& Ferraro, 1989). In sum, it is fundamental to consider the intersection of multiple individual factors (e.g. age, gender, disability) when assessing differences in individual's risk of victimization and safety perceptions.

Environmental factors in public places contributing to fear include dark environments, poor guardianship, lack of maintenance, physical and social disorder, and unkempt and abandoned buildings (Loukaitou-Sideris 2009, see also Chapter 3 in this book). This is problematic not only because signs of physical deterioration are often visible in public places but also because these nuisances are able to capture a much broader range of problems (Skogan, 1996). Paradoxically, the presence of police may generate uneasy feelings (Gray, 2015). In addition, some potential local and global dangers may mediate fear and vulnerability in modern societies (Beck, 1992). All these interlayers of factors lead to more fear and limit individuals' mobility, often creating borders and more control of public places, with more negative consequences to those who use them.

\subsection{The metrics}

Almost everything that happens, happens somewhere (Longley et al., 2005), so knowing where a phenomenon takes place can be critically important to understanding its nature and acting upon it. This is particularly important to those whose responsibility is to assess or ensure safety conditions in cities (Ceccato, 2013a; Weisburd, Bruinsma, \& Bernasco, 2009). Research shows a vast number of techniques and methods that can be used to detect safety problems, either for finding crime concentration or areas perceived as unsafe. Some methods are more appropriate for intervention and assessment, while others require the long-term involvement of relevant stakeholders, such as safety walks and neighborhood watch initiatives. See Section 2.7 for a detailed discussion of these methods.

New technologies can provide a nuanced understanding of use of public places in relation to crime and perceived safety (Ceccato, 2019). Ecological momentary assessments (EMAs) are a data collection method in which information about individuals' experiences, emotions and behaviors is collected in real time via smart devices as individuals go about their lives (Raento, Oulasvirta, \& Eagle, 2009).

In the era of smartphones, "eyes" are complemented by "apps" or body cameras, giving expression to new ways of depicting what happens in public space. This development is bound to redefine what social control is, in particular the role of guardians and place managers, but also how we detect and assess a safety problem. In Chapter 15 of this book, this digital methodology is exemplified to assess fear while in transit. Commonly used are apps, virtual reality (VR) and building information modeling (BIM). An app is a mobile application, for mobile devices such as smart phones and tablets, while VR is computer technology that simulates real or fictional environments and our presence and interaction in them. There are also other digital solutions that can be implemented when an area is being built. For instance, BIM is a process that 
creates and uses an intelligent 3D model to inform and communicate project decisions and to project, visualize, simulate and collaborate, which gives greater clarity to all stakeholders throughout the project lifecycle. BIM makes it easier to show at a micro scale where safety problems are (see, for instance, BIM in a shopping mall in Ceccato et al. 2018).

The introduction of computerized mapping systems as part of police command and control since the 1980s and 1990s has led to the creation of software for visualizing the growing amounts of geocoded crime data. In addition, geographic information systems (GIS) have made geographical analyses of crime data possible for a wide number of users, facilitating the integration of many types of data into a common spatial framework (Ceccato, 2013a). The use of spatial tools such as GIS has been incorporated into research and planning in public participation initiatives (see Part VI in this book) and, more recently, into new methodologies aiming at predicting human reactions about terrorism events using real-time data (see Chapter 17 for use of data from Twitter). In such cases, the digital arena is the new public place where crime may occur.

\subsection{The intervention}

Promoting safe and sustainable urban environments demands well-coordinated actions from multidisciplinary teams of experts (involving architects, planners, safety experts, police and policymakers, to name a few) and efforts from civil society. There are two distinct "time windows of action" for these groups of experts.

The first one is when a public place is at the planning stage. Architects, planners and safety experts, in particular, play important roles ensuring safe environments at this stage.

The second one is when the "city is already out there" and actions remediate "faulty" environments, namely those places that are contributing to crime and/ or poor perceived safety. The role of safety experts in teamwork-with police officers and local teams engaging different groups of the community-becomes perhaps more important than those of planners or architects at this stage. These time windows of intervention are discussed below in detail.

\section{Safety at the design and planning stage}

The first time window of action is when a (public) place is at the planning stage. This is a unique opportunity, since architects and planners in particular have the opportunity to idealize how buildings and the spaces between them should be designed. It is at this time they can make choices that can affect the future of the area to prevent crime and promote safety. The planning and design of public places (streets, tunnels, bridges, stations, parks and other spaces) are crucial, as are their location and spatial arrangement. At this stage, experts can apply their knowledge by creatively assembling "the building blocks of routine activity into the urban cloth" (Brantingham \& Brantingham 1995, p. 3) to 
maximize safety. This may include planning for details of the physical environment such as smooth boundaries between public, semi-private and private places; strengthening the experience of social control in particular spots, such as transportation nodes and shopping malls; designing buildings so that windows provide an opportunity for natural surveillance. Other features are also possible, such as promoting activities that generate the right amount of people on the street or finding the right balance between the benefits of double illumination in a square and energy savings. In reality, these experts work under the pressure of limited resources, strict building and planning regulations and demands from diverse special interests that wish to prioritize other aspects of the construction, such as energy savings or economic efficiency.

Proven methods and principles under the CPTED umbrella can support design and planning of buildings and public spaces to promote safety (Armitage, 2013; Grönlund, 2012; Jeffery, 1977; Newman, 1972; Saville, 2009). International evidence shows that these principles impact positively on safety. In England, research has shown that houses that are guarded by three or more other properties experienced 38 percent less crime (Armitage, 2013). This effect has been confirmed both in new production and in existing buildings, for crime and fear of crime, in the Netherlands (CVP 2015) and also in Korea (Seo \& Lee, 2017).

There is a growing body of research that supports the assertion that crime prevention through environmental design is effective in reducing both crime and fear of crime in the community (Ceccato \& Tcacencu, 2018; Cozens, Saville, \& Hillier, 2005; Cozens, Neale, Whitaker, Hillier, \& Graham, 2003; Kajalo \& Lindblom, 2010).

However, there are many barriers for the implementation of these safety guidelines in practice. In most countries, safety principles are not an integral part of new building projects. Construction companies often skip extra demands unless they are based on the requirements in a project for economic reasons. In Sweden, for instance, if safety issues are considered in the planning process of a new residential area, they often relate to traffic safety or fire hazards (see Chapter 21 of this book or Ceccato, Vasquez, Langefors, Canabarro, \& Petersson, 2019). Second, there is a concern and a risk about who is responsible for the process, which can produce variations in the delivery process-not only who delivers (police or civilians based in municipalities and/or consultants), but also how safety guidelines are implemented, thus resulting in a different impact on social groups using public places, for instance.

The need to find new ways of working and of improving knowledge among stakeholders concerning the impact of the urban environment on safety constitutes another barrier. While planners and architects see that crime and safety perceptions do not belong in their subject area, safety experts often focus too much on offenders and too little on the situational conditions of crime and safety, making this issue a neglected area in urban planning. 
Finally, as suggested by Wikström and Treiber (2017), interventions that specifically target environmental characteristics can only be effective in preventing crime if they promote changes in how people perceive crime as an alternative in the specific environment. This means that "building right" from the beginning is not enough. It also requires good and continuous maintenance after an area is built (see for example Branas et al., 2011), through dialogue with relevant stakeholders that takes into account different users' needs and demands on that particular place.

\section{Safety in pre-existing urban environments}

There are plenty of opportunities to improve safety when the city is already there. But how do we get there, how do we go from words to action? Planners, architects and safety experts often make use of principles of routine activity and situational crime prevention (Clarke, 1995; Cohen \& Felson, 1979) as theoretical references to tackle particular places (and times) that suffer disproportionately high crime levels.

Working in a team will make it easier to place a particular safety problem into local contexts, especially the needs of those who make use of that particular environment. Some of these problems are not visible to experts, and engaging with users and locals who know well the area is a good starting point. It is also important to calibrate the use of resources, knowledge and experience within the group for best results. For instance, check what collective experiences there are in the working group, if there is lack of knowledge that may be needed in the solution process and which actors are responsible for which areas of the process (Forsemalm, Johansson, \& Göransson, 2019).

A deep understanding of the nature of the safety problem (Figure 2.1) is fundamental. It is less obvious how current serious urban problems, such as violence and organized crime can be solved and how they create fear. Solutions demand more than "fixing the lighting or cutting bushes". Detecting the problem and analyzing it in detail is important (crime-specific, context-specific),

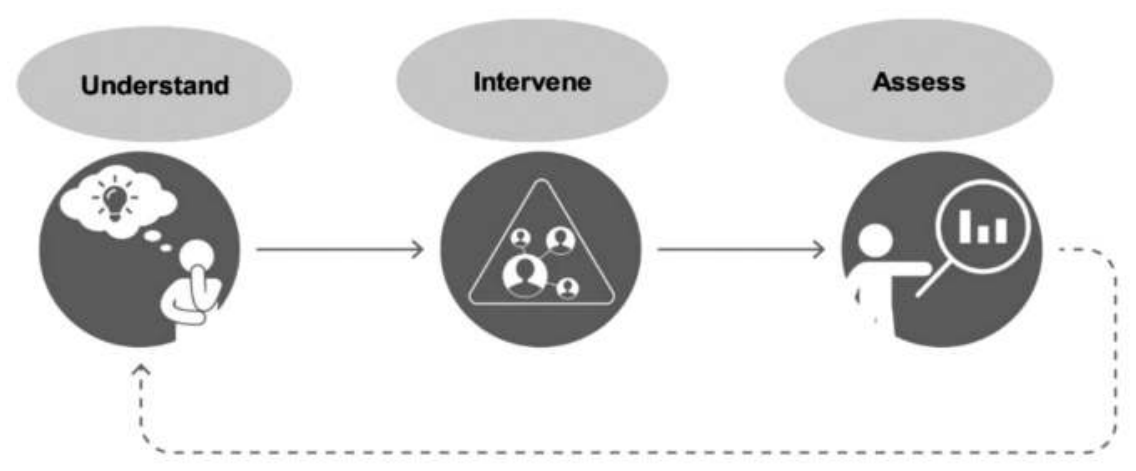

Figure 2.1 Safety interventions steps. 
both to obtain an accurate picture of the phenomenon and to be able to measure the outcome of future interventions using a "before and after" scenario. What is it in the environment that leads a person to commit crimes in that particular spot? What is it that generates feelings of worry and fear? Using recommendations from Clarke and Eck (2005), it is possible to further develop a number of questions to be answered at the beginning of the process before defining safety interventions.

What? Does the problem concern crime or perceived security? Is it a new area to be planned, or will an existing area be improved?

Where? Is the problem happening in a city or in the countryside? Is it in a residential area, in a square or in a building?

When? During which times of the day/days of the week/months of the year does the problem occur? Is it constant over time or does it vary?

Who? Who is badly affected by the problem, does it affect the entire population equally or are there specific groups - such as women, the elderly, children, the financially vulnerable-who are affected? Is there information about those who commit crimes and their modus operandi?

The answers to these questions will have a major impact on the choice of the solutions and are important to bring to light through the solution process. At this stage, major changes in the physical environment to improve safety may be costly and may not even be desirable because of negative impacts on the aesthetics of the place (grates in the windows and facades, fences around parks and squares, barriers that limit movement in street sections, in some cases, CCTVs for control and surveillance). Below is a list of a number of techniques and methods popularly used to detect safety problems and work with them.

Security certification: Quality control designed to reduce exposure to crime in residential properties. The verification is carried out using a checklist, which is primarily adapted to existing buildings and can be used in apartment buildings. The checklist may look different depending on whether it is applied in housing that already exists and has problems with crime and insecurity, or used to build a knowledge base when planning new housing and/or public environments.

Neighborhood watch: Various activities in an area aimed at improving residents' involvement, sense of participation and social affiliation and thus the social control that is fundamental to crime prevention and security. These activities (for example, informing neighbors to pay extra attention at times to who is moving around the area) are also expected to change the behavior of potential victims and thus reduce opportunities for crime.

Night patrol: Also called parental walking, adult walking, dads and moms in town or adults in town. Groups of adults move out on the streets and squares 
and into environments where young people stay in the evening and night time, in order to create a safer environment.

Social impact assessment: Packages for analyzing, monitoring and managing the intended and unintended social consequences, both positive and negative, of planned actions and any social change processes that result from these efforts (Vanclay, 2003). For example, a change in a city can have different consequences at different times of the day or have different consequences for different groups of people, which need to be made visible and taken into account in planning processes.

Safety walk: A group of people going through an area and systematically inventorying or inspecting it from a security standpoint, often with a fieldwork protocol in hand, in paper form or digitally using an app (Creswell, 2013, p. 168), although the "walk" can be virtual. During the inventory, locations and spaces that are perceived as unsafe or at risk of becoming crime sites are noted, as well as the specific physical circumstances that contribute to the problems. The process includes developing proposals for solutions, and the safety inventory can then form the basis for safety interventions.

Building improvement district: BID represents a collaboration scheme of local property owners in conjunction with local agencies (e.g., city offices, the police, the fire and rescue services, et al.).

Placemaking: This is a set of participatory approaches to planning, design and management of public places that engage individuals and communities into a process for transformation (Schneekloth \& Shibley, 1995). One example is creative placemaking, which is thought to contribute to livability of an area by addressing users' safety, aesthetic and expressive needs by using expressions of art and culture.

Once the working team understand a problem, it is time to intervene (Figure 2.1). One challenge with safety problems is to make sure that the measures being implementing also work as expected and do not have unwanted side effects. Relatively easy solutions, such as creating physical barriers may increase safety for some, but may be at the expense of other groups or the entire population. There are sometimes contradictions between sustainability goals; for example, good lighting in an area can make people safe but at the same time increase energy consumption, which contributes to global warming. There are expectations that safety interventions in the physical environment can be proportionate and weighed against the long-term vision for an area as well as other sustainability goals (Ceccato \& Pettersson, 2019).

Even at this stage, it is important to work systematically and with regard to detail; that is, each crime has its dynamics and requires specific measures. A prerequisite for this is to have a good understanding of the problem, to analyze and document what the situation was like before the intervention and the outcomes after changes were put into operation. This means, more specifically, that one must consider scale (a place or a residential area) and context (metropolitan context vs. smaller municipality). It is also important to prioritise and calibrate the use of resources, knowledge and experience of your team for best results during the intervention. 
It is fundamental to follow the same methods when evaluating the effects of the intervention. Also important is to keep in mind that the measures that have been implemented are probably not the only changes that have taken place during the period measured. Therefore, assessing the same measure in several places is desirable (Figure 2.1). Using control areas-where no action has been implemented-makes the results of the evaluation more reliable. A control area should have the same problem make-up as the areas where the measure is being tested. In this way, it shows what one would expect to have happened in the implementation area if no action was taken. Another reason to use a control area is that the effect of interventions can spread to a larger area than the one initially planned. This applies to both good and bad effects. For example, better lighting and maintenance in a public place can make the surrounding area also feel safer, but it can also mean, despite the fact that it does not happen so often, that the original feeling of poor safety is moved to another place. Keep in mind that it can take a long time for the results of actions to become clear, so if actions are evaluated too soon their effects may not be visible at the current time. It may also happen that the problems recur after the evaluation. Therefore, it is good to keep track of the area or place where measures have been implemented for a long time and to continuously assess the occurrence of crime and insecurity.

Moreover, the impact of an intervention is often not homogeneous in the study area. Of course, there are also examples of measures that have not worked at all, but if these have been evaluated, they need not be seen as total failures. Unexpected results are not necessarily "bad results" because they indicate that those interventions are not worth investing in the future, and resources can be spent on other measures.

By the same token, the fact that an action has a positive effect on a place for a certain period of time does not mean that the intervention will generate the same results elsewhere and should be used anywhere or at any time (with the same outcome). The context, as already mentioned, is of great importance: what works for a problem in a metropolitan context may not have the same effect on the same problem in sparsely populated areas. In real life, evaluation with control areas is not always possible, so triangulations of several qualitative assessments are good alternatives, for example through interviews, focus groups, photographs or safety walks before, during and after measures have been implemented. In the next chapters, and in particular in Chapters 18 to 21 , examples of innovative methods (e.g., mapping, apps and Twitter data) are introduced to report safety interventions in a more nuanced way.

\subsection{Concluding remarks}

Crime happens in all sorts of public places: from crowded streets to desolate interstitial spaces between buildings; in large cities or small towns, some more in rush hours, others during the dark, quiet hours of the day. Some of these public places are dangerous but may be perceived as safe; others do not offer any kind of risk but may still be viewed as unsafe. In this chapter, the concept of 


\section{Vania Ceccato}

public places in relation to the dynamics of urban crime and fear was discussed. Then, theories describing the mechanisms linking crime and fear with the built environment were analyzed in relation to the role of architects, planners and safety experts. This was followed by theories describing the nature of fear, with particular focus on the fear of crime and those who are most victimized or most in fear. The chapter ends by presenting methods of analysis regarding safety problems and how safety interventions are put into practice. This review also shows that a large number of models of safety interventions have been suggested in the last decades in an attempt to fill the void in knowledge (and action) of researchers and practitioners in recognizing the importance of the physical and social environment to safety. Who delivers safety interventions is also relevant to ensuring all needs are considered. "Building right" from the beginning is not enough. In areas that already exist, focusing on specific problems is fundamental, as is making sure that assessments of safety interventions are systematically performed. Finally, it is important to have a long-term perspective of the safety of an area-one that accepts that the area is in continuous transformation and that safety needs may be changing.

\section{Note}

1 Instead of weighing the multiple ways we can conceptualize public place and public space, we chose to use these terms interchangeably in this book, extending the concept to public places that are digital, as illustrated in Chapters 1 and 17. For a brief definitional discussion of public places and crime, see Ceccato (2016).

\section{References}

Alexander, D., Ishikawa, S., \& Silverstein, M. (1977). A Pattern Language: Towns, Buildings, Construction. USA: Oxford University Press.

Armitage, C. J., \& Ekblom, P. (2019). Rebuilding Crime Prevention Through Environmental Design: Strengthening the Links with Crime Science. Abingdon: Routledge.

Armitage, R. (2013). Crime Prevention through Housing Design: Policy and Practice. Basingstoke, UK: Palgrave Macmillan.

Armitage, R. (2018). Burglars' take on crime prevention through environmental design (CPTED): reconsidering the relevance from an offender perspective. Security Journal, 31, 285-304.

Armitage, R., \& Monchuk, L. (2011). Sustaining the crime reduction impact of designing out crime: re-evaluating the Secured by Design scheme 10 years on. Security Journal, 24, 320-343.

Asiedu, A. B., \& Arku, G. (2009). The rise of gated housing estates in Ghana: empirical insights from three communities in metropolitan Accra. Journal of Housing and the Built Environment, 24, 227-247.

Barker, R. (1968). Ecological Psychology Concepts and Methods for Studying the Environment of Human Behaviour. Stanford: Stanford University Press.

Beck, U. (1992). Risk Society: Towards a New Modernity. London: Sage.

Becker, G.S. (1968). Crime and punishment: an economic approach. The Journal of Political Economy, 76(2), 169-217.

Bowers, K. (2014). Risky facilities: Crime radiators or crime absorbers? A comparison of internal and external levels of theft. Journal of Quantitative Criminology, 30, 389-414. 
Box, S., Hale, C., \& Andrews, G. (1988). Explaining fear of crime. British Journal of Criminology, 28, 340-356.

Branas, C. C., Cheney, R. A., MacDonald, J. M., Tam, V. W., Jackson, T. D., \& Ten Havey, T. R. (2011). A difference-in-differences analysis of health, safety, and greening vacant urban space. American Journal of Epidemiology, 174, 1296-1306.

Branic, N., \& Kubrin, C. E. (2018). Gated communities and crime in the United States. In G. Bruinsma \& S. D. Johnson (Eds.), The Oxford Handbook of Environmental Criminology (Vol. 1). New York: Oxford University Press.

Brantingham, P. J., \& Brantingham, P. L. (1984). Patterns in Crime. New York: Macmillan.

Brantingham, P. L., \& Brantingham, P. J. (1995). Criminality of place: crime generators and crime attractors. European Journal on Criminal Policy and Research, 3, 1-26.

Breetzke, G. D., Landman, K., \& Cohn, E. G. (2014). Is it safer behind the gates? Crime and gated communities in South Africa. Journal of Housing and the Built Environment, $29,123-139$.

Ceccato, V. (2012a). The Urban Fabric of Crime and Fear. Dordrecht Netherlands; New York; London: Springer.

Ceccato, V. (2012b). Vilken betydelse har miljön för trygghet och säkerhet på Stockholms tunnelbana? PLAN, 1, 39-43.

Ceccato, V. (2013a). Integrating geographical information into urban safety research and planning. Proceedings of the Institution of Civil Engineers: Urban Design and Planning, 166, 15-23.

Ceccato, V. (2013b). Moving Safely: Crime and Perceived Safety in Stockholm's Subway Stations. Plymouth: Lexington.

Ceccato, V. (2016). Public space and the situational conditions of crime and fear. International Criminal Justice Review, 26, 69-79.

Ceccato, V. (2019). Eyes and apps on the streets: from surveillance to sousveillance using smartphones. Criminal Justice Review, 44, 25-41.

Ceccato, V., Falk, Ö., Parsanezhad, P., \& Tarandi, V. (2018). Crime in a Scandinavian shopping centre. In A. R. Ceccato V. (Ed.), Retail Crime: International Evidence and Prevention: Cham: Palgrave Macmillan.

Ceccato, V., \& Pettersson, R. (2019). Tryggstadsmiljön i praktiken: Visioner, exempel och tips. www.kth.se/files/view/vace/5dc3a43c38cal004b7abb8el/trygg-stadsmiljoe-i-praktiken_ v.pdf (accessed 20 January 2020).

Ceccato, V., \& Tcacencu, S. (2018). Perceived safety in a shopping centre: a Swedish case study. In V. Ceccato \& R. Armitage (Eds.), Retail Crime: International Evidence and Prevention (pp. 215-242). Cham: Springer International Publishing.

Ceccato, V., Uittenbogaard, A., \& Bamzar, R. (2011). Safety in Stockholm's underground stations: the importance of environmental attributes and context. Security Journal, 26, 33-59.

Ceccato, V., Vasquez, L., Langefors, L., Canabarro, A., \& Petersson, R. (2019). En trygg stadsmiljö: Teori och praktik för brottsförebyggande \& trygghetsskapande åtgärder. Retrieved from Stockholm: http://kth.diva-portal.org/smash/get/diva2:13 58155/FULLTEXT01.pdf (accessed 20 January 2020).

Chase, J. (2008). Their space: security and service workers in a Brazilian gated community. Geographical Review, 98, 476-495.

Clarke, R. C., \& Eck, J. E. (2005). Crime analysis for problem solvers in 60 small steps. Retrieved from www.semanticscholar.org/paper/Crime-Analysis-for-Problem-Solversin-60-Small-Clarke-Eck/be59dec7e23070bf8857745e737d9f4c90aeff5e (accessed 18 April 2020)

Clarke, R., \& Eck, J. (2007). Understanding Risky Facilities. Tool Guide No. 6. Retrieved from https://popcenter.asu.edu/content/understanding-risky-facilities (accessed 20 January 2020). 


\section{Vania Ceccato}

Clarke, R. V. (1995). Situational crime prevention. Crime and Justice, 19, 91-150.

Clutter, J. E., Henderson, S., \& Haberman, C. P. (2019). The impact of business improvement district proximity on street block robbery counts. Crime \& Delinquency, doi:10.1177/0011128719834559.

Cohen, L. E., \& Felson, M. (1979). Social change and crime rate trends: a routine activity approach. American Sociological Review, 44, 588-608.

Coleman, A. (1985). Utopia on Trial. Vision and Reality in Planned Housing. London: Hillary Shipman.

Cozens, P., \& Hillier, D. (2008). The shape of things to come: New urbanism, the grid and the Cul-De-Sac. International Planning Studies, 13, 51-73.

Cozens, P. M. (2011). Urban planning and environmental criminology: towards a new perspective for safer cities. Planning Practice and Research, 26, 481-508.

Cozens, P. M., Neale, R. H., Whitaker, J., Hillier, D., \& Graham, M. (2003). A critical review of street lighting, crime and fear of crime in the British city. Crime Prevention and Community Safety, 5, 7-24.

Cozens, P. M., Saville, G., \& Hillier, D. (2005). Crime prevention through environmental design (CPTED): a review and modern bibliography. Property management, $23(5), 328-356$.

Creswell, J. W. (2013). Qualitative Inquiry o Research Design: Choosing among Five Approaches. Thousand Oaks, CA: Sage.

Crowe, T. (2000). Crime Prevention Through Environmental Design: Applications of Architectural Design and Space Management Concepts. Oxford: ButterworthHeinemann.

CVP, Centrum voor Criminaliteitspreventie en Veiligheid (2015). Bestaande bouw Handboek Politiekeurmerk Veilig Wonen. Retrieved from www.kiwa.com/contentassets/a5e877747a6c4dbea77ff0698c220536/pkvw-handboek-bestaande-bouw-2015. pdf (accessed 11 December 2019).

Dymén, C., \& Ceccato, V. (2012). An international perspective of the gender dimension in planning for urban safety. In V. Ceccato (Ed.), The Urban Fabric of Crime and Fear (pp. 311-341). Dordrecht, Heidelberg, New York, London: Springer.

Eck, J. (1998). Preventing crime at places. In: Preventing Crime: What Works, What Does Not, What's Promising. Retrieved from www.ncjrs.gov/works/index.htm.

Eck, J. E. (2019). Place Managers and Crime Places. Oxford: Oxford University Press, doi: 10.1093 /acrefore/9780190264079.013.30

Felson, M. (2006). Crime and Nature. Thousand Oaks: Sage.

Forsemalm, J., Johansson, M., \& Göransson, P. (2019). Evidensbaserad stadsutvecklingbortom urbana anedokter. Årsta: Dokument Press.

Furstenberg, J. F. F. (1971). Public reaction to crime in the streets. The American Scholar, 40, 601-610.

Garofalo, J., \& Laub, J. (1979). Fear of crime-broadening our perspective. Victomology, $3,242-253$.

Goold, B., Loader, I., \& Thumala, A. (2010). Consuming security?: Tools for a sociology of security consumption. Theoretical Criminology, 14, 3-30.

Gray, F. (2015). The misanthropes, larrikins and mallrats of Market Square: an enduring public space dilemma in Central Geelong. In SAHANZ 2015: Architecture Institutes and Change. Proceedings of the 32nd Annual Conference of Society of Architectural Historians Australia and New Zealand. (pp. 218-230). Society of Architectural Historians Australia and New Zealand.

Gray, F., \& Novacevski, M. (2015). Unlawful acts, unkind architecture and unhelpful perceptions: A case study of Market Square Mall, Geelong. In Proceedings of the Safe Cities Conference 2015 (pp. 4-18). Association for Sustainability in Business. 
Groff, E., \& McCord, E. S. (2012). The role of neighborhood parks as crime generators. Security Journal, 25, 1-24.

Grundström, K. (2018). Grindsamhälle: the rise of urban gating and gated housing in Sweden. Housing Studies, 33, 18-39.

Grönlund, B. (2012). Is hammarby sjöstad a model case? Crime prevention through environmental design in Stockholm, Sweden. In V. Ceccato (Ed.), The Urban Fabric of Crime and Fear (pp. 283-310). Dordrecht: Springer Netherlands.

Hilborn, J. (2009). Dealing with crime and disorder in urban parks. Retrieved from www.cops.usdoj.gov (accessed 14 April 2012).

Hillier, B. (1986). City of Alice's dreams. Architects' Journal, 9, 39-41.

Iqbal, A., \& Ceccato, V. (2015). Does crime in parks affect apartment prices? Journal of Scandinavian Studies in Criminology and Crime Prevention, 16, 97-121.

Iudici, A. (2015). Sexual harassment against people with mental disabilities in transit environments: implications for services and clinics. In V. Ceccato \& A. Newton (Eds.), Safety and Security in Transit Environments: An Interdisciplinary Approach (pp. 328-343). London: Palgrave Macmillan UK.

Iudici, A., Bertoli, L., \& Faccio, E. (2017). The 'invisible' needs of women with disabilities in transportation systems. Crime Prevention and Community Safety, $19,264-275$.

Jackson, J., \& Gray, E. (2010). Functional fear and public insecurities about crime. British Journal of Criminology, 50, 1-22.

Jacobs, J. (1961). The Death and Life of Great American Cities. New York: Vintage Books.

Jeffery, C. R. (1977). Crime Prevention through Environmental Design. (2nd ed.). Beverly Hills: Sage.

Jongejan, A., \& Woldendorp, T. (2013). A successful CPTED approach: the Dutch 'Police Label Secure Housing'. Built Environment (1978-), 39, 31-48.

Kajalo, S., \& Lindblom, A. (2010). The perceived effectiveness of surveillance in reducing crime at shopping centers in Finland. Property Management, 28(1), 47-59.

Kang, J. H. (2011). Participation in the community social control, the Neighborhood Watch groups: individual and neighborhood-related factors. Crime \& Delinquency, 61, 188-212.

Kornhauser, R. (1978). Social sources of Delinquency. Chicago: University of Chicago Press.

Koskela, H., \& Pain, R. (2000). Revisiting fear and place: women's fear of attack and the built environment. Geoforum, 31, 269-280.

Lagrange, R. L., \& Ferraro, K. F. (1989). Assessing age and gender differences in perceived risk and fear of crime. Criminology, 27, 697-720.

Lemanski, C. (2006). Residential responses to fear (of crime plus) in two Cape Town suburbs: implications for the post-apartheid city. Journal of International Development, $18,787-802$.

Longley, P. A., Goodchild, M. F., Maguire, D. J., \& Rhind, D. W. (2005). Geographic Information Systems and Science. Chichester, UK: John Wiley.

Loukaitou-Sideris, A. (2009). What brings children to the park? Analysis and measurement of the variables affecting children's use of parks. Journal of the American Planning Association, 76, 89-107.

Loukaitou-Sideris, A. (2012). Safe on the move: the importance of the built environment. In V. Ceccato (Ed.), The Urban Fabric of Crime and Fear (pp. 85-110). Dordrecht: Springer Netherlands.

Madensen, T. D., Herold, M., Hammer, M. G., \& Christenson, B. R. (2017). Place-based investigations to disrupt crime place networks. Police Chief Magazine, Washington, DC. 


\section{Vania Ceccato}

McCarthy, J., \& Doyle, M. (2011). Business improvement districts and conservation-led regeneration. Urban Research and Practice, 4, 175-192.

Mihinjac, M., \& Saville, G. (2019). Third-generation Crime Prevention Through Environmental Design (CPTED). Social Sciences, 8, doi:10.3390/socsci8060182.

Mikellides, B. (2007). Theory, practice and education: architectural psychology 1969-2007. Journal of Learning and Teaching, 2(2).

Morgan, R., \& Smith, M. J. (2006). Crimes against passengers: theft, robbery, assault and indecent assault. In D. B. C. M. J. Smith (Ed.), Secure and Tranquil Travel: Preventing Crime and Disorder on Public Transport (pp. 77-102). London: Jill Dando Institute of Crime Science.

Newman, O. (1972). Defensible Space-Crime Prevention through Urban Design. New York: Collier Books.

Pain, R. (2000). Place, social relations and the fear of crime: a review. Progress in Human Geography, 24(3), 365-387.

Pain, R., \& Smith, S. J. (2008). Fear: critical geopolitics and everyday life. In R. Pain \& S. J. Smith (Eds.), Fear: Critical Geopolitics and Everyday Life (pp. 1-24). Aldershot: Ashgate.

Poyner, B. (1986). A Model for Action: Situational Crime Prevention. London: Her Majesty's Stationery Office.

Poyner, B. (1991). Situational crime prevention in two parking facilities. In R. V. Clarke (Ed.), Situational Crime Prevention-Successful Case Studies (pp. 157-166). USA: Lynne Rienner Publishers.

Poyner, B. (2005). Crime-free Housing in the 21st Century. London, UK: Jill Dando Institute of Crime Science.

Raento, M., Oulasvirta, A., \& Eagle, N. (2009). Smartphones: an emerging tool for social scientists. Sociological Methods \& Research, 37, 426-454.

Ratcliffe, J. (2010). Crime mapping: spatial and temporal challenges. In A. R. Piquero \& D. Weisburd (Eds.), Handbook of Quantitative Criminology (pp. 5-24). New York: Springer.

Reynald, D. M. (2014). Informal guardianship. In G. Bruinsma \& D. Weisburd (Eds.), Encyclopedia of Criminology and Criminal Justice (pp. 2480-2489). New York: Springer New York.

Sampson, R. J., Raudenbush, S. W., \& Earls, F. (1997). Neighborhoods and violent crime: a multilevel study of collective efficacy. Science, 277(5328), 918-924.

Sandercock, R. J. (Ed.) (2005). Difference, Fear and Habitus, a Political Economy of Urban Fear. Aldershot: Ashgate.

Saville, G. (2009). SafeGrowth: moving forward in neighbourhood development. Built Environment (1978-), 35, 386-402.

Saville, G. (2018). Safegrowth: Building Neighbourhoods of Safety and Livability. Charleston: CreateSpace.

Schneekloth, L. H., \& Shibley, R. G. (1995). Placemaking: The Art and Practice of Building Communities. New York: Wiley.

Seo, S. Y., \& Lee, K. H. (2017). Effects of changes in neighbourhood environment due to the CPTED project on residents' social activities and sense of community: a case study on the Cheonan Safe Village Project in Korea. International Journal of Urban Sciences, 21, 326-343.

Shaw, C. R., \& McKay, H. D. (1942). Juvenile Delinquency and Urban Areas. Chicago: University of Chicago Press.

Sherman, L. W., Gartin, P. R., \& Buerger, M. E. (1989). Hot spots of predatory crime: Routine activities and the criminology of place. Criminology, 27(1), 27-56.

Skogan, W. G. (1996). The police and public opinion in Britain. American Behavioral Scientist, 39, 421-432. 
Sommer, R. (1972). Design Awareness. Corte Madera: Reinhart Press.

Symes, M., \& Steel, M. (2003). Lessons from America: the role of business improvement districts as an agent of urban regeneration. The Town Planning Review, 74, 301-313.

Tedong, P. A., Grant, J. L., \& Abd Aziz, W. N. A. W. (2014). The social and spatial implications of community action to enclose space: guarded neighbourhoods in Selangor, Malaysia. Cities, 4l(PA), 30-37.

Thomlinson, R. (1969). Urban Structure the Social and Spatial Character of Cities. Toronto: Random House Publishing.

Uhnoo, S., \& Hansen Löfstrand, C. (2018). Voluntary policing in Sweden: media reports of contemporary forms of police-citizen partnerships. Journal of Scandinavian Studies in Criminology and Crime Prevention, 19, 41-60.

Vanclay, F. (2003). International principles for social impact assessment. Impact Assessment \& Project Appraisal, 21, 5-11.

Warr, M. (2000). Fear of crime in the United States: avenues for research and policy. Criminal Justice and Behavior, 4, 451-489.

Weisburd, D. (2015). The law of crime concentration and the criminology of place. Criminology, 53, 133-157.

Weisburd, D., Bruinsma, G. J. N., \& Bernasco, W. (2009). Units of analysis in geographic criminology: Historical development, critical issues, and open questions. In D Weisburd, G. J. N. Bruinsma, W. Bernasco (Eds.), Putting Crime in its Place: Units of Analysis in Geographic Criminology (pp. 3-31). New York: Springer New York.

Weisburd, D., Bushway, S., Lum, C., \& Yang, S. M. (2004). Trajectories of crime at places: a longitudinal study of street segments in the city of Seattle. Criminology, $42,283-321$.

Weisburd, D., \& Telep, C. (2011). The efficiency of place based policing. In E. D. E. De Vree, W. Broer, P. Van der Laan (Eds.), Evidence Based Policing (pp. 247-262). Antwerpen, Apeldoorn, Portland: Maklu.

Whitzman, C. (2007). Stuck at the front door: gender, fear of crime and the challenge of creating safer space. Environment and Planning A, 39, 2715-2732.

Whitzman, C., Shaw, M., Andrew, C., \& Travers, K. (2009). The effectiveness of women's safety audits. Security Journal, 22, 205-218.

Wikström, P.-O., Ceccato, V., Hardie, B., \& Treiber, K. (2010). Activity fields and the dynamics of crime. Journal of Quantitative Criminology, 26, 55-87.

Wikström, P.-O. H., Mann, R. P., \& Hardie, B. (2018). Young people's differential vulnerability to criminogenic exposure: bridging the gap between people- and place-oriented approaches in the study of crime causation. European Journal of Criminology, 15, 10-31.

Wikström, P.-O. H., \& Treiber, K. (2017). Beyond risk factors: an analytical approach to crime prevention. In B. Teasdale \& M. S. Bradley (Eds.), Preventing Crime and Violence (pp. 73-87). Cham: Springer International Publishing.

Wilson, F. H. (1999). Fortress America: gated communities in the United States. [Fortress America: Gated Communities in the United States, Edward J. Blakely, Mary Gail Snyder]. Contemporary Sociology, 28, 83-84.

Wilson, J. Q., \& Kelling, G. L. (1982). Broken windows. Atlantic Monthly, 249, 29-38.

Yarwood, R., \& Edwards, B. (1995). Voluntary action in rural areas: the case of neighbourhood watch. Journal of Rural Studies, 11, 447-459. 


\title{
3 The architecture of crime and fear of crime
}

\author{
Research evidence on lighting, \\ CCTV and CPTED features ${ }^{1}$
}

\section{Vania Ceccato}

\subsection{Introduction}

Urban design shapes the built environment and the types of human activities that take place in it. A safe environment is one that maximizes the use of public places with a mix of users carrying out a variety of routine activities; it is a place that encourages social interaction. A safe environment depends on what happens in this place, and what happens in it depends on how safe it is perceived to be. Lighting is essential for feeling safe in a place (Green, Perkins, Steinbach, \& Edwards, 2015; Johansson, Rosen, \& Kuller, 2011), but the impact on safety of other environmental features, such as security technologies, is less obvious (Lorenc et al., 2013; Lum, Stoltz, Koper, \& Scherer, 2019). For some people the presence of a closed-circuit television camera (CCTV) reduces their confidence, while others feel empowered and safe (Koskela, 2002; Yavuz \& Welch, 2010). So what makes a public place safe?

The aim of this chapter is to discuss the evidence in the international literature of the effects of urban design on safety-in particular, the relationship between features such as lighting and CCTV to the occurrence of crime and/or individuals' safety perceptions. Potential unexpected side effects of these features on a city's overall quality are also discussed.

To achieve these goals, the literature from 1968 to 2018 was searched, using as references the Scopus, Web of Science and JSTOR databases. Bibliometric visualization software was used to manage and map the vast material, spanning more than five decades of research, on crime and fear of crime and to answer the following questions.

- Does urban design, indicated by crime prevention through environmental design (CPTED) features, have any impact on crime and/or safety perceptions, and if so, how?

- Does lighting and/or CCTV have any effect on crime, and if so, what are the mechanisms? Are safety perceptions affected by lighting and/or CCTV, and if so, what are the mechanisms?

- Is there any risk (or "side effect") when prioritizing safety over other sustainability goals? 
The literature overview focuses on particular features of accessible public places (streets, parks, etc.) and neighborhood structure, because it is at this scale that crime and fear take shape. In addition, it is at this scale that the impact of planning decisions is experienced and planning solutions can be implemented. Finally, it is also at this scale that many safety problems can be addressed through inclusive policies by direct involvement of local stakeholders (police, safety experts, community groups) and those voices normally excluded from planning decisions.

The decision to focus this literature overview on lighting and CCTV was taken because the international literature has been strongly dominated by these features in recent decades (Painter \& Farrington, 1994; Piza, Welsh, Farrington, \& Thomas, 2019; Quinet \& Nunn, 1998; Ratcliffe, Taniguchi, \& Taylor, 2009; Sutton \& Wilson, 2004; van Rijswijk \& Haans, 2018; Welsh \& Farrington, 2009; Williams \& Johnstone, 2000).

This chapter is structured as follows. First, the importance of assessing the stateof-the-art research is introduced with a focus on urban design, crime and safety. Then methods are reported, followed by the results. In the final section, gaps in the literature and suggestions for a research agenda close the chapter. Note that in this study "public places" and "public spaces" will be used interchangeably.

\subsection{Public places, urban design and safety}

"Public space" (or here "public place") means a space legally open and accessible without the permission of anyone else, such as a common (Németh, 2012). In reality, most public spaces are conditionally "free", because action allowed in these spaces falls within the law of the locality in which the space is located. Accessibility is thought to be a basic characteristic of these places. Yet, although public spaces/places might be accessible to everyone, why is it that safety in these places may not be attainable by all?

First, safety is a function of the way one perceives these places, so an individual's fears depend on her/his individual characteristics: physical and psychological abilities, age, gender, ethnic background, sexual and socioeconomic statuses (Box, Hale, \& Andrews, 1988; Garofalo \& Laub, 1979; Pain \& Smith, 2008). It is also these characteristics (individually or intersectionally) that determine an individual's risk of victimization of crime. Although men are more victimized by crime in public places, it is women who fear public places the most (Ferraro, 1996; Pain, 1997).

Second, as previously suggested, safety also depends on what happens in these public places, and what happens in them depends on how safe these places are perceived to be. Loukaitou-Sideris and Eck (2007) indicated that walking and cycling are greatly influenced by what happens in streets and other public spaces. Safe public places invite outdoor activities, including daily walks. Poor maintenance or signs of physical deterioration of an area are thought to be more important determinants of fear of crime than the actual incidence of crime. Either way, fear may inhibit people from using a public place or lead them to avoid certain times of the day (Gray, Jackson, \& Farrall, 2011; Jackson \& Gray, 2010). Wilson and Kelling (1982) suggested that acts of vandalism and public disorder 
function as symbols of the extent to which an area is in decline, which might affect subsequent levels of crime and safety perceptions.

Third, public places are often contested places where individuals relate to rules conduct and publicness (Smith \& Low, 2013). The right to feel safe rests on a thin equilibrium between place users of all types and what Eck (2019) called "place managers", they are those people and organizations that are physically and legally able to prevent crime in a place. Each public place bears a certain morality that defines what can be done in it (under or beyond the rule of law). This morality also determines those who are the "legitimate users" (Knutsson, 1997) and those who are not.

Finally, public places vary in their levels of crime and/or in the way they are perceived. Crime and fear of crime are different phenomena. What makes a place criminogenic does not necessarily make it unsafe, and vice versa (e.g., Ceccato \& Lukyte, 2011; Ferraro, 1995; Gray, Jackson, \& Farrall, 2008; LaGrange, Ferraro, \& Supancic, 1992; Pain, MacFarlane, \& Turner, 2006). This fact has implications for both research and practice, because the root causes of crime are often not those that affect people's poor safety perceptions of a place, although they may share similar triggers. Because the environment plays an important role in affecting victimization and/or shaping fears, we focus in this chapter on environmental factors that have a direct impact on crime occurrence and fear.

As suggested in Chapter 2, poorly designed and managed built environments can create opportunities for crime and make people feel unsafe (Clarke, 2012; Crowe, 2000; Jongejan \& Woldendorp, 2013; Monchuk, 2011; Reynald, 2011). A safe environment is the one that maximizes the use of public places by a mix of users with different routine activities; it is a place that encourages social interaction, increases visibility and surveillance by passers-by and, as a result, reduces the risk of crime. Crime is less likely to occur in places where there are clear, welldefined routes and people can easily enter and leave, a place that avoids barriers and obstacles. In addition, public places that are well managed and maintained generally feel safer and encourage people to use them; they exhibit "ownership". This in turn encourages activity and natural surveillance. As indicated in Chapter 2, these principles are well encapsulated by CPTED (Crowe, 2000) and in principles of routine activity (Cohen \& Felson, 1979; Felson, 2002) and Situational Action Theory (e.g. Wikström \& Treiber, 2017).

Although the international literature shows much evidence for the effect of CPTED features on safety, the evidence is mixed; for a review, see Cozens, Saville, and Hillier (2005), Cozens and Love (2015) and Farrington and Welsh (2002). Building on these previous reviews of the literature, this chapter aims to contribute to the evidence in this area by collecting and systematizing scholarly knowledge on the effect of urban design on urban safety-in particular, the impact of features such as lighting and CCTV on crime and/or perceived safety.

\subsection{Data and methods}

The literature search covered 50 years, from 1968 to 2018 , of publications in the databases Scopus, Web of Science and JSTOR. The bibliographic selection 
was conducted in two steps: first, we focused on the bibliometric analysis and then on in-depth analysis of the material as described in sections. This is a review of literature inspired by the principles of the Cochrane Handbook for Systematic Reviews (Higgins \& Green, 2011) as well as the PRISMA checklist (Moher, Liberati, Tetzlaff, \& Altman, 2009). One of the features that distinguish this type of review from others is the pre-specification of studies following a set of eligibility criteria (Higgins \& Green, 2011). In this case, we considered both quantitative and qualitative analysis. This means that some studies did not focus on causal links between urban design and crime only but included studies of a more qualitative character typical in the planning literature. We also extended our search of articles to fear of crime and to reports. This opened up for evidence beyond the European and North American literature.

The bibliometric analysis included 4,730 articles obtained and selected from the databases (in * ${ }^{*}$.ris) in different stages. VOSviewer version 1.6.12 (www. vosviewer.com) is a free-access software tool that was used to create bibliometric maps based on the keywords cited in each selected article and to group the terms in clusters according to their linkages (van Eck \& Waltman, 2019). The criterion of a minimum of two repetitions criterion aimed at avoiding terms without links or with weak links to the theme and, secondly, ensuring terms were covered and articles were representative. Output files from the database were used to produce informative network maps by theme. A number of themes were selected based on the clusters that emerged from the literature and are discussed in Section 3.4, Figure 3.1.

These themes supported the selection of topics that were thought to be relevant for further investigation in an in-depth analysis of the 106 articles (Figure 3.2). The effect of, for instance, lighting on crime and/or safety was assessed in four ways: lighting has a positive effect, namely, reducing crime and/or increasing perceived safety; lighting has a negative effect on crime and or perceived safety, namely, increasing crime and reducing safety perceptions. Inconclusive/conflicting effect was when the different, contradictory effects were observed and finally, no effect/difference, when no statistically significant impact was found on crime and/or fear of crime. The analysis also checked whether there was any relationship between lighting and crime and/or fear of crime and the location of the study area by continent.

Note that the types of methods and datasets used in the analysis covering 106 publications (35 on lighting, 22 on CCTV and 49 on CPTED) varied greatly, even among the quantitative pieces, which makes it difficult to strictly compare effects. Various studies showed that the effect of lighting, for example, on safety was dependent on crime types, levels and contexts. In addition, the search of the literature focused on public places in general and encompassed a variety of environments, from open streets to shopping malls. The analysis was based instead on a comparative assessment of the author's declared findings and conclusions in each publication. Caution is therefore necessary when drawing conclusions. 

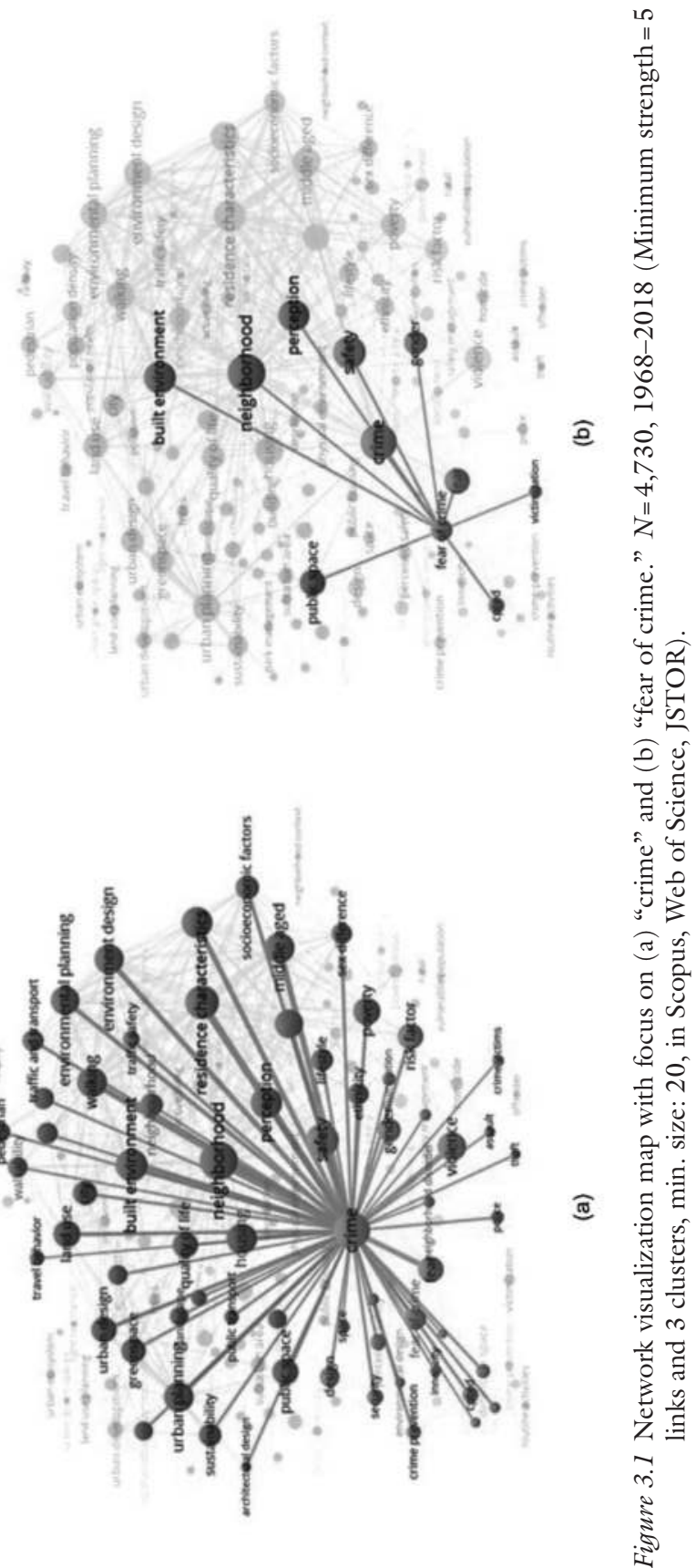


\subsection{Results and discussion}

\section{Overall bibliometric trends}

Internationally, research in this area has significantly increased in the past three decades. The bibliometric analysis for both crime and fear of crime resulted in three clusters as an outcome of the literature search based on 4,730 articles. Figure 3.1(a) shows a cluster associated with crime and victimization; another cluster with neighborhood and socio-economic conditions; and another one, which refers to studies on urban planning and landscape of the city. The greater the weight of an item by level of importance, the larger the circle. The distance between two keywords indicates the relatedness of the keywords, in terms of co-citation links. Note that there are many more articles on crime linking these three clusters than for the articles on fear of crime (Figure 3.1(b)). This complexity is not found when "fear of crime" is visualized as the focus, and articles on "built environment" are relatively "far" from "fear of crime" when compared with articles dealing with "crime".

The in-depth analysis revealed that there were 37 studies showing the effect of lighting (69 percent) out of 53 archived articles from the international literature: 72 percent of them found a positive impact of lighting on crime and/or fear (Appendix, Table A3.1). These articles were mostly published between 1998 and 2018, with a peak in 2008 (from 1968-2019), from Western Europe and the United States, but also from Asia and South America (Figure 3.2). In terms of methodology, 23 were classified as quantitative pieces, eight qualitative articles and four mixed methods. In the next section, some of the most important studies, starting from those dating back to the late 1980s and early 1990s (Griswold, 1984; Painter \& Farrington, 1994; Poyner \& Webb, 1987), will be discussed in detail.

As for CCTV, 67 percent of 22 articles (out of 63 that were selected, Appendix, Table A3.2) show that this technology had a reductive effect either on crime or perceived safety, the great majority of them in Europe and the United States. Of these, half were quantitative studies, about a quarter used mixed methods and the remainder used qualitative analysis, most revealing some effect on safety perceptions. Similar to the findings of Welsh and Farrington (2004) that CCTV had an effect only for car parks (in a data metaanalysis of 41 studies), this review showed that one quarter of the articles either showed no effect of CCTV or were inconclusive, with mixed results.

Some studies used one or various CPTED principles together to assess safety (Appendix, Table A3.3, these were selected using CPTED in the keyword, in the title or abstract). Although 65 percent of them indicated some positive impact on either crime or safety perceptions, they evaluated different aspects of CPTED and varied greatly in method and how rigorous they were performed, so caution is necessary when drawing conclusions. A bit more than half of them (27 articles) were composed of studies devoted to the importance of the physical environment and spatial arrangement as the core of the analysis. Only four included aspects of city livability, health and sustainability issues, and the remainder included aspects of community engagement and social cohesion or 


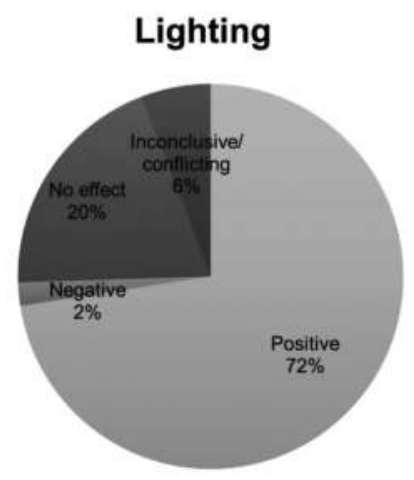

$N=35$ articles out of 51 selected $(69 \%)$

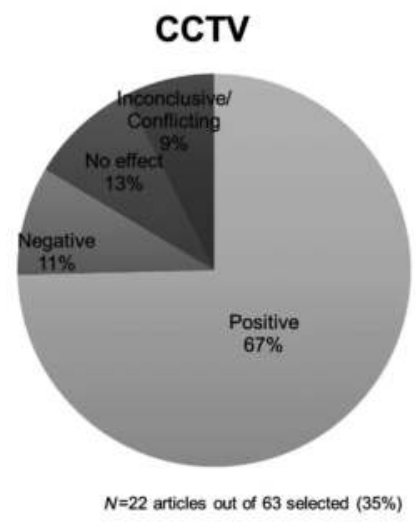

\section{CPTED features}

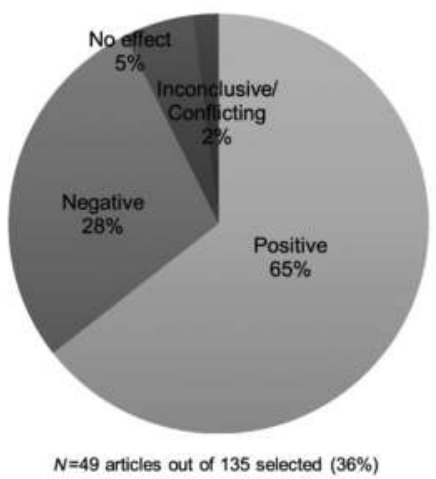

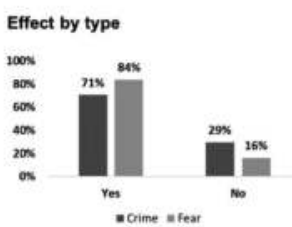

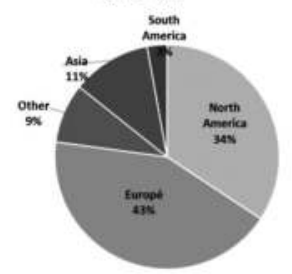

Effect by type
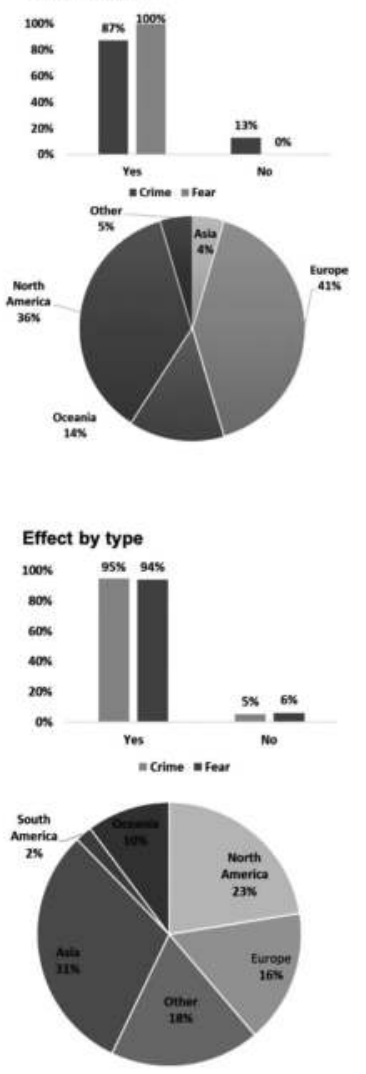

Figure 3.2 Effect of lighting, CCTV and CPTED features on crime and fear of crime according to the international literature 1968-2018. $N=106$ articles. 
user's perspective. Figure 3.2 summarizes the characteristics of publications that link crime and fear to CPTED principles, CCTV and lighting.

\section{The effect of lighting on crime and fear}

There is no other feature of urban space that is more controversial with regards to its effect on safety than lighting. Lighting is thought to improve safety perceptions, but previous research shows that its effect on crime is conflicting (Cozens, Neale, Whitaker, Hillier, \& Graham, 2003; Green et al., 2015; Lawson, Rogerson, \& Barnacle, 2018; Painter \& Farrington, 1994). Although there has been evidence that introducing street lighting reduces road traffic collisions and crimes, there was no evidence of any increase in crime or accidents where street lighting was reduced at night (Perkins, Steinbach, \& Tompson, 2015). Traditionally, it is believed that modifying nighttime visibility in urban areas should affect opportunities for crime by increasing the perceived risk of offender detection, or, alternatively, lighting increases the chances for certain types of crimes by making victims more visible: the "fishbowl effect". At the same time, an improvement of street lighting may have an extra indirect effect. Residents are believed to invest more in their community and show that people in that area are in control, encouraging potential offenders to find other areas that are "less risky" in terms of detection. What does this literature overview indicate?

Out of 35 articles, the overall effect of illumination on crime is positive: 72 percent of studies show that (good) lighting has a positive effect on safety, in other words reduces crime and/or fear of crime. Such an effect is slightly more prominent on perceived safety than on crime occurrence (Figure 3.2, see effect by type: crime and fear). These results reflect a diverse flora of studies, with different methods, types of crime, safety perception indicators and geographical contexts. For example, crimes vary greatly by type, from theft and robbery as well as less frequent offenses with very different mechanisms and records, such as violent crimes, homicides, police calls for service and total crime. The spectrum of urban environments varies widely, too, from large cities to rural communities as well as computer-generated landscapes, but the reductive effect is consistent.

After several small-sample analyses in the United Kingdom, the seminal study by Atkins, Husain, and Storey (1991) broke fresh ground by showing that better street lighting had little or no effect on crime. However, they also found that the improved street lighting was warmly welcomed by the public and that it provided a measure of reassurance to some people, particularly women, who were fearful in their use of public space. The study by Herbert and Davidson (1994) examining the impact of improved street lighting upon crime and community safety in two British cities also concluded that perceived safety was increased by improved street lighting, although similar effects on crime rates were difficult to assess. Mixed effects were also found in Japan for property crimes, by Takizawa, Koo, and Katoh (2010), in the United States, by Groff and McCord (2012), and by Cozens, Neale, Whitaker, Hillier and 
Graham (2003) and all these three studies suggest further research on the effect of street lighting on crime.

Among studies that found crime reduction in association with lighting, Quinet and Nunn (1998) reported on an evaluation of the effects of streetlights on crime in several neighborhoods in Indianapolis. Also in the United States, Loomis, Marshall, Wolf, Runyan, and Butts (2002) found that bright exterior light was associated with reduction of homicides in workplaces. Byun and $\mathrm{Ha}$ (2016) found that lighting was associated with the reduction of burglaries in Seoul, South Korea. Peek-Asa and Casteel (2010) indicated that good lighting presents a reduction of total robbery, controlling for a number of factors in the retail setting. In a rural context in the Global South, the study by Arvate, Falsete, Ribeiro, and Souza (2018) showed that better lighting is associated with a decrease in homicides. Farrington and Welsh (2002) reported a systematic review incorporating meta-analytic techniques of the effects of improved street lighting on crime to indicate that good lighting has a positive effect on crime reduction. More intriguing was the study by Stolzenberg, D'Alessio, and Flexon (2017) who investigated the effect of moon illumination on reported crime occurring outdoors between the hours of $10 \mathrm{pm}$ and $2 \mathrm{am}$ in 13 US states, as well as the District of Columbia. Findings showed that moonlight had a reductive effect on outdoor crime, though no significant influence on indoor crimes and total crime. In addition, in England and Wales, Skudder et al. (2018) showed that external and internal lighting were effective and also had a small carbon footprint.

In terms of safety perceptions, there is positive evidence of the effect of lighting, but some of the studies are also inconclusive. It is important to keep in mind that these articles are based on different methods with varied statistical rigor and large differences in sample sizes. In Ohio, in the United States, Tseng, Duane, and Hadipriono (2004) showed that lighting was the most significant factor in determining the quality of users' perceptions of parking garages. In Sweden, where the winters are dark and long, Tjoa and Devon (2010) showed how illumination in a Swedish city positively affected perceived safety and influenced accessibility, walking and cycling. Also in Sweden, Johansson, Pedersen, Maleetipwan-Mattsson, Kuhn, and Laike (2014) found a positive effect of lighting on accessibility and perceived safety. Yet another study in Sweden, by Lindgren and Nilsen (2012), confirmed the importance of good illumination in relation to greenery in residential areas. In a qualitative study by Pain et al. (2006) in the United Kingdom, findings showed that individual's reports are complex and reflective about the influence of lighting on crime and fear.

There were a number of experimental studies to test the effect of lighting on safety. Using artificial urban scenes, Stamps (2005) found that the perception of safety was strongly correlated with the lightness of the scene. Using computer-generated urban scenes, Nikunen and Korpela (2012) found that lighting had a positive effect on overall fear, while Haans and de Kort (2012) demonstrated that people prefer having light in their own immediate surroundings rather than on the road that lies ahead. Also using computer-generated 
landscapes, Nasar and Bokharaei (2017) found that uniform lighting would be judged more appealing or safer than would non-uniform lighting, but its effects are uncertain. Using a simulation analysis in South Korea, Kim and Park (2017) found that increased illuminance could not be linked to an improvement in pedestrians' visibility or perceptions of safety because many factors were thought to be important to be considered for a real improvement in visibility. An interesting study was performed by van Rijswijk and Haans (2018) in which participants reported increased perception of safety in improved lighting environments after an evaluation of 100 pictures of different streets at night in the Netherlands. Using real-time data, Castro-Toledo, Perea-Garcia, BautistaOrtuno, and Mitkidis (2017) assessed fear in urban public space in Spain, Denmark and the United States and found that lack of good lighting was associated with psychological reactions of arousal related to fear, and heart rates collected seemed to sustain that finding.

The type of lighting and its impact on safety perceptions was the focus of a number of studies in particular settings, with mixed results, such as university campuses, bridges and roads (De Boer, Heylen, \& Teeuw, 2014; Fotios, 2016; Fotios, Unwin, \& Farrall, 2015; Haans \& de Kort, 2012; Kim \& Noh, 2018). Others focused on the effect of lighting in transit environments (Chandra, Jimenez, \& Radhakrishnan, 2017; Ferrer, Ruiz, \& Mars, 2015; Green et al., 2015; Rankavat \& Tiwari, 2016; Srisuwan, 2011).

\section{The effect of CCTV on crime and fear}

One of the most seminal works was published by Brown (1996), who found mixed evidence of the effective use of CCTV on crime in three British cities. A well-known meta-analysis in this field was done by Welsh and Farrington (2009), who concluded that cameras are effective if systems are designed with close attention to the setting and its specific crime problems. They performed a meta-analysis of 41 studies to show that for car parks, CCTV has a reductive effect, but results are inconclusive for total crimes (Welsh \& Farrington, 2009). The reductive effect of CCTV was also confirmed by other studies elsewhere (Caplan, Kennedy, \& Petrossian, 2011; Ratcliffe et al., 2009; Tjoa \& Devon, 2010), while others show mixed results, such as those by Lett, Hier, and Walby (2010), Tjernberg and Granhag (2019), La Vigne et al. (2011), Ceccato (2013), Taylor, Koper, and Woods (2012), and no effect by Gerell (2016).

The most recent evidence is reported by Piza et al. (2019), which is a systematic review and meta-analysis of the effects of CCTV surveillance cameras on crime. The findings show that CCTV is associated with a significant and modest decrease in crime. The largest and most consistent effects of CCTV were observed in car parks. The results of the analysis also demonstrated evidence of significant crime reduction in other settings, particularly residential areas. CCTV schemes incorporating active monitoring generated larger effect sizes than did passive systems. Schemes deploying multiple interventions alongside CCTV generated larger effect sizes than did schemes deploying single or no 
other interventions alongside CCTV. As for the effect on safety perceptions, several studies show inconclusive findings of the effect of CCTV or that its effect was dependent on other security measures such as lighting (Cozens \& Davies, 2013; Fussey, 2013; Peek-Asa \& Casteel, 2010; Sanders \& Hannem, 2012; Skudder et al., 2018; Yavuz \& Welch, 2010).

Crime prevention based on modern technologies, such as cameras, alarms and lighting sensors, is often associated with large cities and rarely linked to rural areas (Weisheit and Donnermeyer, 2000). However, recent literature has shown signs of the expansion of technology as a preventive measure against property and wildlife crimes in rural areas (Aransiola \& Ceccato, 2020; Ceccato, 2016). This expansion trend was noticed early on by Sutton and Wilson (2004), who executed a descriptive analysis of data obtained through in-depth interviews on all 33 Australian CCTV schemes. The authors noted significant expansion of CCTV surveillance in smaller regional and rural centers and in suburban locations but were unclear about the effect in these environments. In a rural context, Mears, Scott, and Bhati (2007) made use of data from agricultural censuses, victimization surveys and interviews to test the effect of CCTV. They found CCTV to be associated with higher levels of victimization in rural areas in the United States. The direction of causality was a problem also mentioned in the study in rural Australia by Anderson and McCall (2005), that found that if perception of crime increases, CCTV usage also increases.

\section{CPTED, crime and fear}

The international literature is richly populated by examples of how one or a combination of multiple characteristics of houses, neighborhoods and street features come together to affect the geography of crime and perceived safety. Such studies accounted for more than half of the studies reviewed and belong to what is normally called "first generation CPTED" (Saville, 2013). Although most studies make use of CPTED principles to tackle crime and reduce fear, a share of them are of a different type. They are "before-after analyses" of a safety intervention. The maintenance and perception of an area are important for safety, but equally important is people's involvement in voluntary activities, from neighborhood cooperation to safety walking. The effectiveness of these activities is difficult to assess and varies; short-term evaluations dominate these studies.

Several examples of the literature show how specific and crime-tailored crime prevention interventions need to be in order to be effective. Positive results were found by Poyner (1991) after security improvements were made to parking lots, as well as by Tseng et al. (2004) in relation to the layout and management of garages; retail environments by Hunter and Jeffery (1997); parks by Knutsson (1997) and Iqbal and Ceccato (2015); streets by Armitage (2011); and schools by Bradshaw, Milam, Furr-Holden, and Lindstrom Johnson (2015) and Vagi et al. (2018).

Maintenance is a fundamental aspect of the safety of public places and an essential CPTED component assessed in many studies. Poorly maintained urban 
land affects people's perceptions of safety and also victimization (Branas et al., 2018). Poyner (1994) illustrated the effect of demolition in the United Kingdom showing that property crime decreased. In the United States, Freedman and Owens (2011) found that new construction and rehabilitation of existing housing led to reductions in violent crime but not in property offenses. In Chicago, Aliprantis and Hartley (2015) found significant reductions in homicide rates around demolition sites. Similar findings were reported by Kondo, Andreyeva, South, MacDonald, and Branas (2018) for violent crimes and alcohol availability, and by Branas et al. (2018) for overall crime and nuisances in neighborhoods below the poverty line.

Research also shows examples of urban design producing safer environments. Gray and Novacevski (2015) stated that architecture can encourage a more equitable use of the space and may diminish the sense of fear. Gray (2015) also showed how the built environment has an important role to play in addressing safety problems by presenting opportunities for local stakeholders. In addition, Vagi et al. (2018) assessed CPTED in school environments and showed that students' performance was generally associated with higher perceptions of safety and lower levels of violence perpetration and perceived risk.

\section{CPTED, crime and fear in transit environments}

Bus stops and transit stations are criminogenic places (Bowers, 2014; Cozens, Neale, Whitaker, \& Hillier, 2002, 2003; Cozens \& van der Linde, 2015; Loukaitou-Sideris, 1999, 2012, 2014; Loukaitou-Sideris \& Stieglitz, 2002; Newton, Johnson, \& Bowers, 2004; Uittenbogaard \& Ceccato, 2014). Previous research in transit environments has shown that design that promotes visibility and clear lines of sight, through the absence of nooks and corners, visible ticket booths, overpass (rather than underpass) walkways and separation of passenger flows promotes safety (Ceccato, Uittenbogaard, \&. Bamzar, 2013b; Gaylord \& Galliher, 1991; Loukaitou-Sideris, Liggett, \& Iseki, 2002; Myhre \& Rosso 1996). Similarly, Smith and Clarke (2000) pointed out that high crime rates in transit environments are due to overcrowding (high density, more potential offenders) and lack of supervision (low density, low levels of natural surveillance).

The weight of empirical evidence indicates that environmental factors include good lighting, good visibility, maintenance/cleanliness and presence of people. Surveillance through CCTV cameras has also been found to have some effect on crime reduction, but its effectiveness may differ by the type of offense, and the evidence is not always conclusive for transit environments (Armitage, 2006; Ceccato, Cats, \& Wang, 2015; Ceccato \& Newton, 2015; Newton, 2008; Squires, 1992; Uittenbogaard \& Ceccato, 2015; Welsh \& Farrington, 2009; Winge \& Knutsson, 2003).

Opportunities for crime are also dependent on stations' environmental attributes and type of neighborhood in which they are located (Ceccato et al., 2013b). This applies to city and country contexts (Ceccato, 2018). Venez 
Moudon et al. (2018) found that crime rates at transit stops are higher in densely populated neighborhoods because there are more potential offenders, whereas crime rates are lower when there are more people at transit stops because they offer higher levels of natural surveillance. In Brazil, Ceccato and Paz (2017) found that sexual violence was concentrated at the busiest central stations and at stations that also attract other types of violence and events of public disorder. These results lend general empirical support to situational mechanisms at work in transit environments and surrounding areas. Also in Brazil, De Souza and Miller (2012) indicated how situational factors help explain homicide within the favela.

Perceived safety in stations and bus stops also highlights the importance of CPTED. Cozens et al. (2003) utilized interactive virtual reality scenes as the environmental stimuli to elucidate where passengers' fears were located in and around the station and how service providers can make stations safer, in a representative sample of railway stations on a network in South Wales using CPTED. CCTV, more staff and maintenance are a few suggestions to improve perceived safety among passengers. The importance of CPTED is also highlighted elsewhere in the literature for both subway stations and for bus stops by Abenoza, Ceccato, Susilo, and Cats (2018); Ceccato, Uittenbogaard, and Bamzar (2013a). Other studies focused on smaller municipalities. Cozens and van der Linde (2015) assessed two different railway stations in Perth, Australia, to find that rail users perceived the station that was not designed using CPTED to be marginally safer than the one that exhibited CPTED qualities, partly because of the contexts of the stations.

\section{Unexpected outcomes and 'side effects' when planning for safe environments}

The international literature shows examples of interventions that are planned to deliberately make public places safe. Most of them succeed to different extents. Others fail-for various reasons and despite all "good intentions"-so producing unexpected outcomes (e.g., Jeong, Kang, \& Lee, 2017; Saleh, Saif, \& Sartawi, 2015; Shamsuddin \& Hussin, 2013). Although there might be many reasons why these interventions did not work as planned (e.g. lack of proper data, choice of study area, inadequate methods, organizational barriers), all these cases touched upon the importance of personnel training to obtain expected results (for further discussion, see for example Zahm, 2005).

This happens when, instead of improving safety, after intervention:

(a) more crime and/or fear are observed,

(b) crime decreased, but not for all types of crime,

(c) crime goes up and fear goes down,

(d) displacement of crime/fear in time or space were observed,

(e) safety is improved, but not for everybody, 
(f) unexpected consequences to the sustainability of the whole city occur, such as exclusion of users or geographical segregation of areas (e.g., gated communities).

(g) safety is improved but such an outcome is an unintended result of other factors or mechanisms not controlled for.

These types of unexpected results can be illustrated by the study by Cozens and van der Linde (2015) for rail stations and CPTED effectiveness, those discussed in White (1993) for commercial areas, or by England (2008) in selected neighborhoods in the United States. Similarly, promoting surveillance in an environment has been intended to create a safe place for customers, but it may also be perceived as an exclusionary practice to others who are non-customers (Akinci, 2015). These studies suggested that safety interventions have led unintentionally to social exclusion of certain groups of individuals.

Is there any risk (or "side effect") when prioritizing safety (using barriers) over other sustainability goals? One of the side effects of creating barriers is intensification of geographical segregation. There are studies that illustrate when safety (of some) has been prioritized to the detriment to other aspects of urban life, such as public transportation (for all). Gated communities are an example of a "desired safety solution" that in many countries has been legitimized by high crime rates and socioeconomic inequality (Branic \& Kubrin, 2018; Breetzke, Landman, \& Cohn, 2014; Carvalho, George, \& Anthony, 1997; Gliori, 2018; Grundström, 2018; Landman, 2004; Luymes, 1997). Inevitably, the outcome is that safety becomes a function of those who can afford it, a commodity objectified by the physical environment. In the South African context, Landman (2004) showed that gated communities have proliferated since 1994. Using as reference Johannesburg and Tshwane, Gauteng, the author suggested that these facilities cause a number of problems and raise serious concerns regarding social exclusion, citizenship and democracy. Her study calls for different planning approaches to different types of gated communities in order to begin to address some of the contemporary challenges that this type of housing/safety solution imposes to society as a whole.

Another side effect of gated communities is spatial fragmentation, namely "the break of continuity, contiguity and morphological coherence of urban" (Santos, 2020, p. 1). An example is illustrated by Gray (2015) who examined the fragmentation's impact caused by the insertion of two shopping malls in the neighboring area. The author suggested that the fragmentation of the urban fabric has led to serious implications in the social and spatial dynamics of the area, for social cohesion and sense of place.

A third side effect is mobility restrictions. Gated communities and barriers affect human mobility and ultimately human health and life chances (Bornioli, Parkhurst, \& Morgan, 2018; Branic \& Kubrin, 2018; Duncan et al., 2012; Tanulku, 2018). Research in a South African context by Landman (2012) shows examples of how these facilities mean longer distances to public transportation and limit access to public facilities for the rest of the population. The 


\section{Vania Ceccato}

so-called 'transit captives', particularly women, elderly and children might be the groups most affected by these disruptions (Ceccato, 2017).

Note that in the 12 articles about gated communities that were reviewed in this literature overview, 68 percent of studies showed that this housing form was associated with lower crime rates or fear (often inside the compounds/facilities), 8 percent showed a negative effect (crime increase or fear increase), 15 percent showed no effect, and 9 percent were inconclusive. The effect of securitization of the urban environment seems to be more evident in studies of perceived safety than for victimization, especially because it is not easy to compare total crimes inside and/or outside these facilities (Rogers, 2005, 2007). Yet, in a recent study by Hedayati-Marzbali, Tilaki, and Abdullah (2017) residents in gated communities, despite experiencing relatively high levels of social cohesion, showed moderate safety levels when compared with those living outside.

\subsection{Concluding remarks}

The expected positive effect of lighting, CCTV and other CPTED features on reducing crime and maximizing safety perceptions is confirmed by the literature reported in this chapter, despite great variations in methods used in these studies. This conclusion derives from the overall assumption that there is a great deal of international research that shows significant links between the urban environment and safety, mainly from North America and Western Europe. Turning back to the initial question, what makes a public place safe?

Lighting and maintenance are for sure important components of a safe public place but these characteristics often do not come alone. In the studies reported in this review, lighting is often a "surrogate" (or interacts) with other aspects of the environment that lead to reduced crime risk, such as good visibility. Studies show that lighting has a reductive effect on a variety of types of crime, from public disorder to homicides, and on fear of crime. However, the "fishbowl effect" is also mentioned in a number of studies dealing with fear of crime.

Security cameras have an overarching effect of reducing crime but for safety perceptions; such an effect depends on the type of user. In addition, its effectiveness seems to be related to other investments, such as in lighting and other security measures. In recent decades, CCTV together with other modern technologies have become more widespread in rural areas as crime prevention tools. Research indicates that CCTV can become more effective if security systems are designed with great responsiveness to the urban design and its specific crime problems.

Among those classified as CPTED studies, maintenance is a fundamental aspect of the safety of public places, for a variety of environments, from school grounds and parking lots, to transit stations. Findings also show that, together with other interventions, people's involvement in voluntary activities (e.g., safety walks, neighborhood watch) may reduce crime and/or improve safety perceptions. 
Studies show that there are risks of "side effects" when safety interventions do not take into account the city's overall sustainability-more research is therefore needed in this topic. Better processes and methods are needed to tackle safety problems other than reducing permeability and maximizing control by creating barriers (gates, fences, walls). Planning decisions must be made with regard to questions beyond the technical debate of whether or not a particular solution 'works' against crime or fear. Gated communities may be an effective technical solution but it is not, we state, a sustainable one. If a city has to be called sustainable, safety and mobility have to be rights attained by all. Therefore, future research should assess potential areas of conflict between these sustainability goals.

A note of caution is necessary, because this literature overview is based on studies with different types of methods and a variety of approaches. In addition, although our sample of articles covers more than 4,000 articles, it is biased towards expected positive results (it is impossible to know how many studies that have produced negative or "unexpected" results were never published). The impact of this positive biases towards evidence-based planning should be further investigated in future studies.

In addition, "good outcomes" (e.g., illumination reduces fear of crime) are more likely to get published. However, it is argued here that "bad outcomes" (e.g., illumination increases fear of crime) are just as valuable as those that show that the intervention has "succeeded". Although there might be many reasons why interventions did not work as planned, lack of proper training has been highlighted as a common cause in many studies. Sometimes the intervention is evaluated too early in the process; in others, too late. Or it can be that the method used in evaluation is not appropriate. Sometimes the context and scale of a particular problem/case play a role in affecting outcomes. It is no surprise when an intervention that worked in big cities does not produce the same results in a rural community. There are lessons to be learned for future actions about "faulty processes" and "bad outcomes": What can be done differently to avoid these pitfalls in the future?

\section{Note}

1 The chapter summarizes and builds on parts of the report written in Swedish by Ceccato et al. (2019), commissioned by the Swedish National Board of Housing, Building and Planning (Boverket), that had as its main aim to inspect current national and international theories and practices in situational crime prevention and safety ensuring measures. The author would like to thank Lisandra Vasquez and Ana Canabarro for executing the data collection reported in Ceccato et al. (2019). 


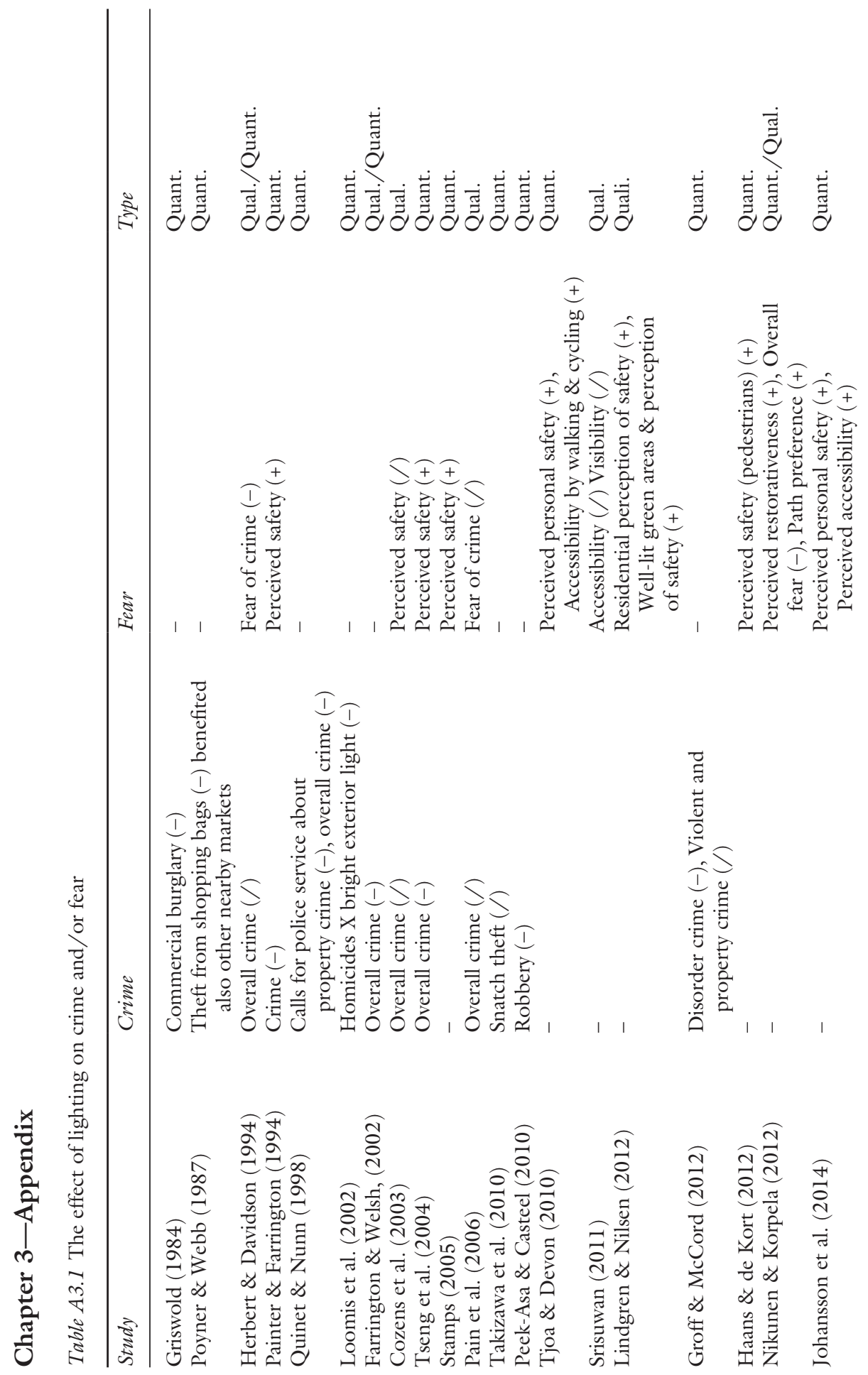



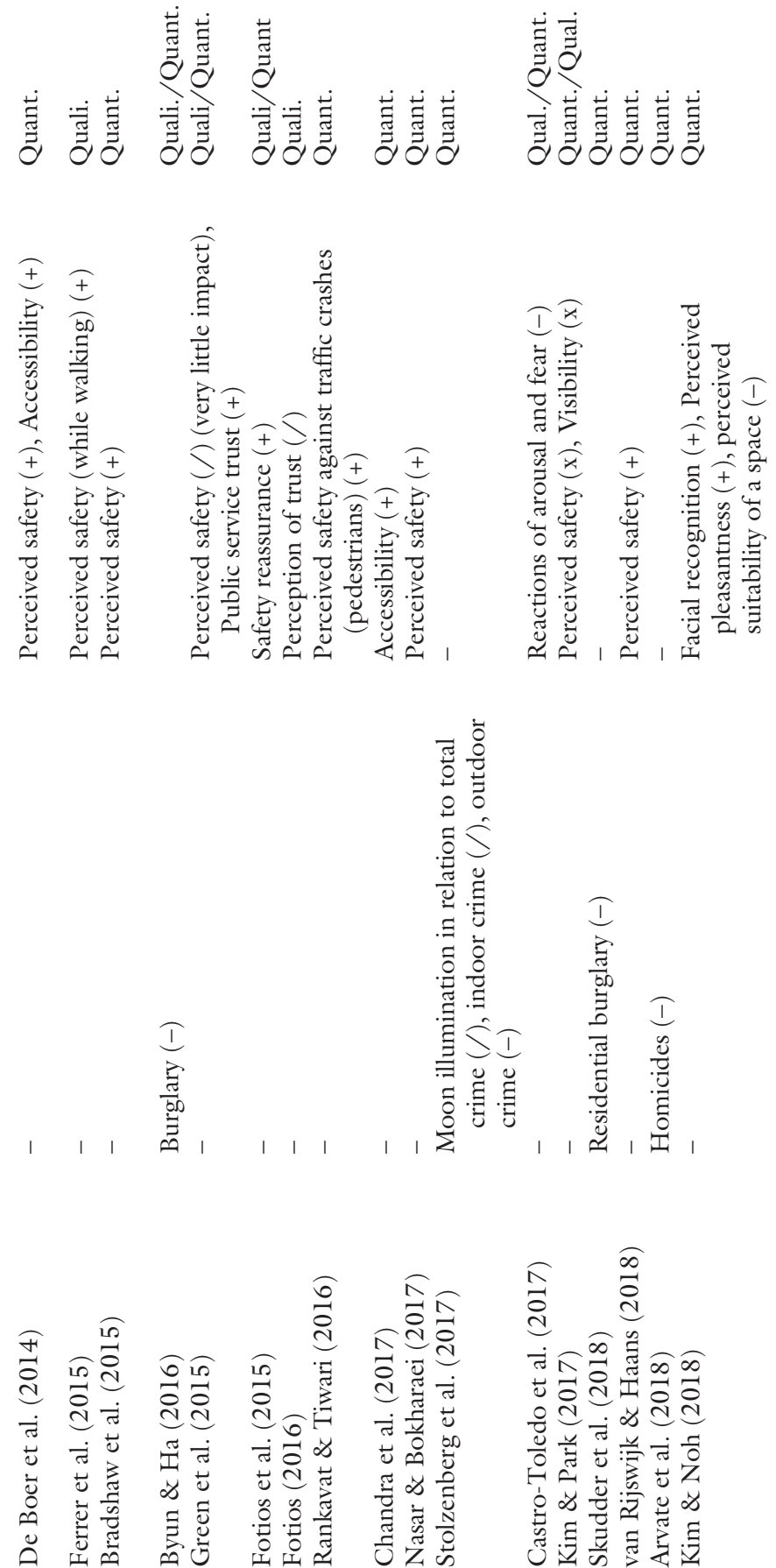


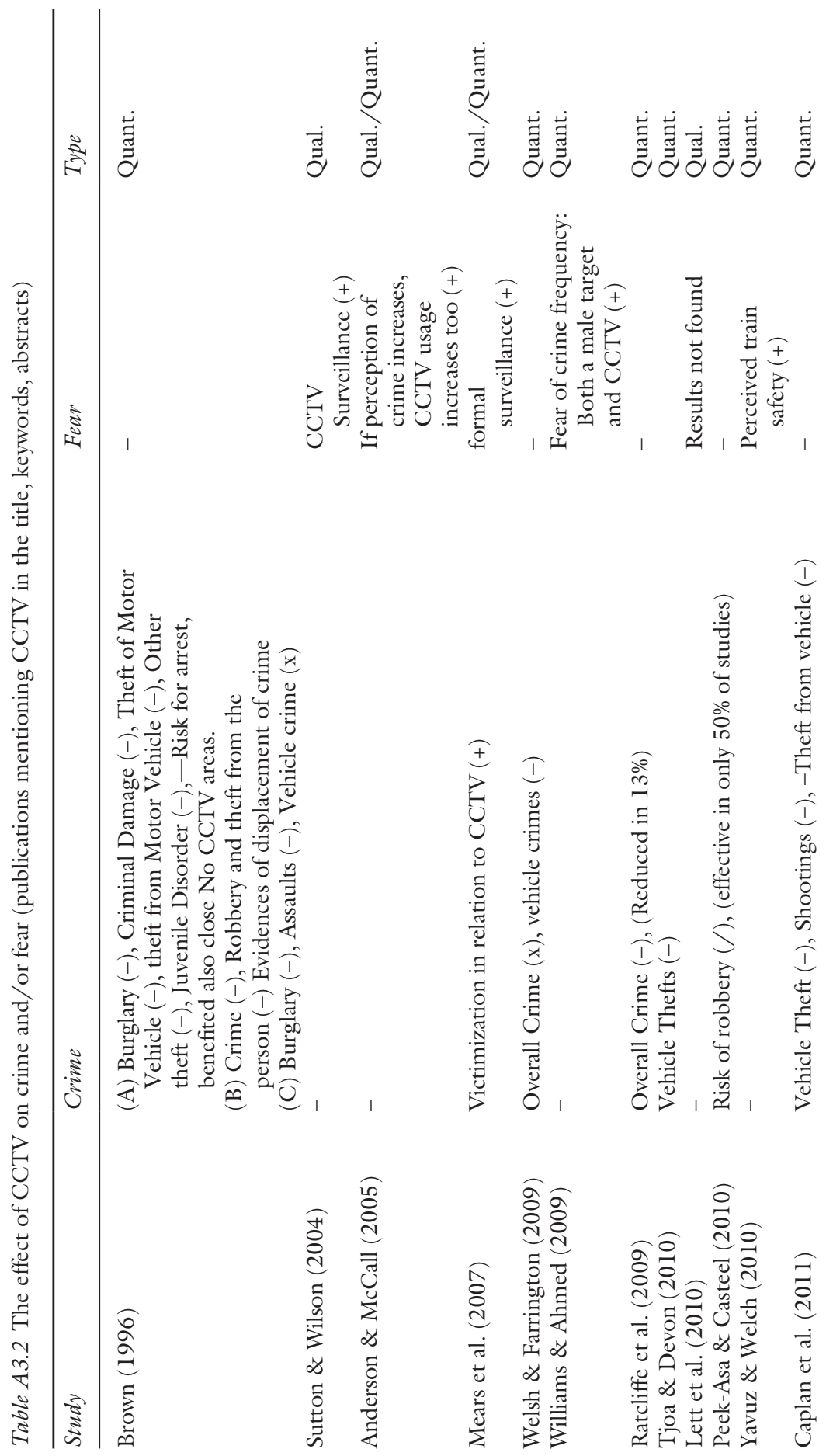


$\frac{\dot{\Xi}}{\stackrel{\Xi}{\Xi}}$

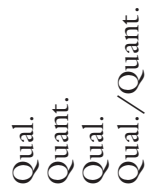

离

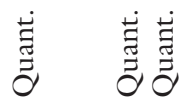

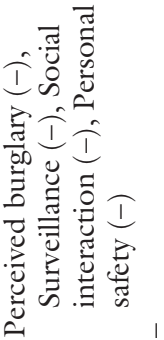

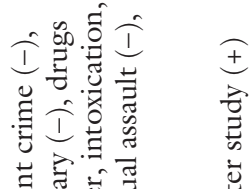

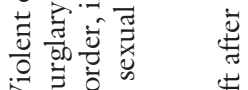

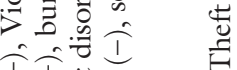

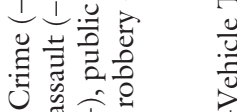

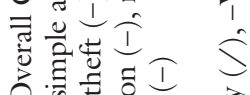

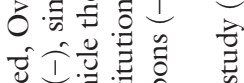

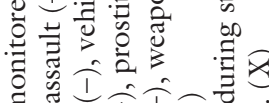

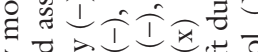
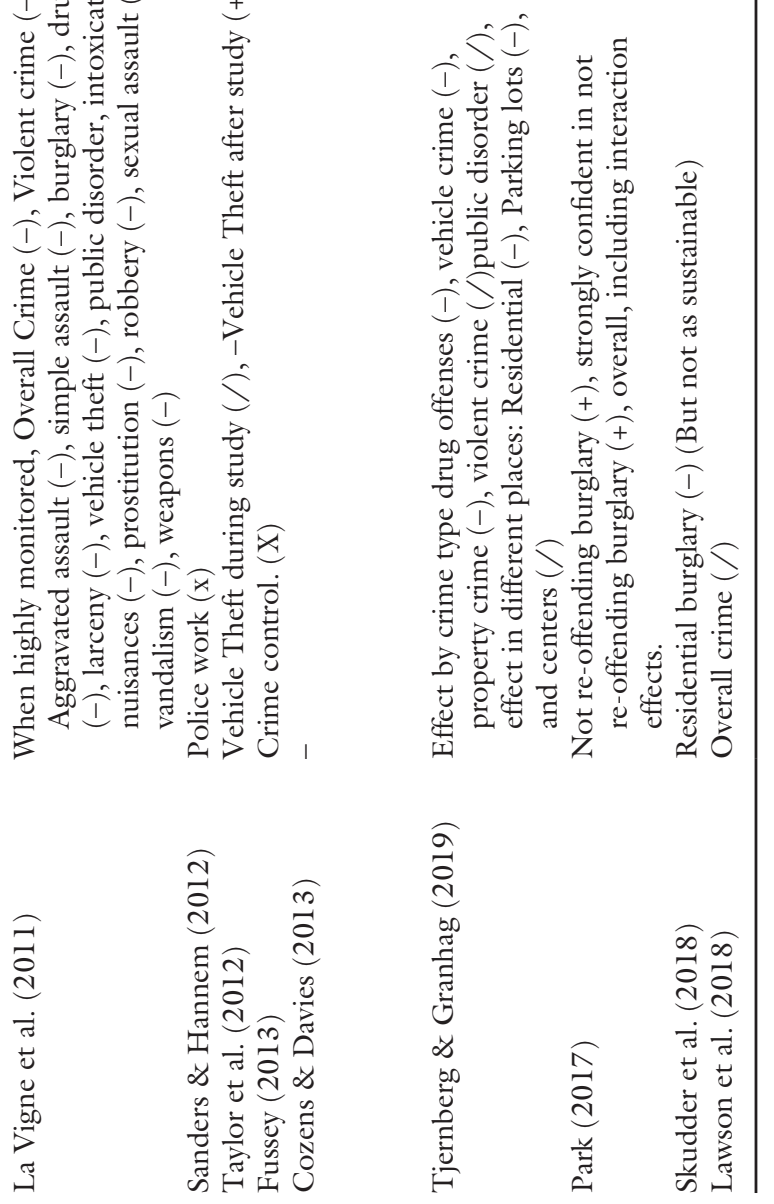


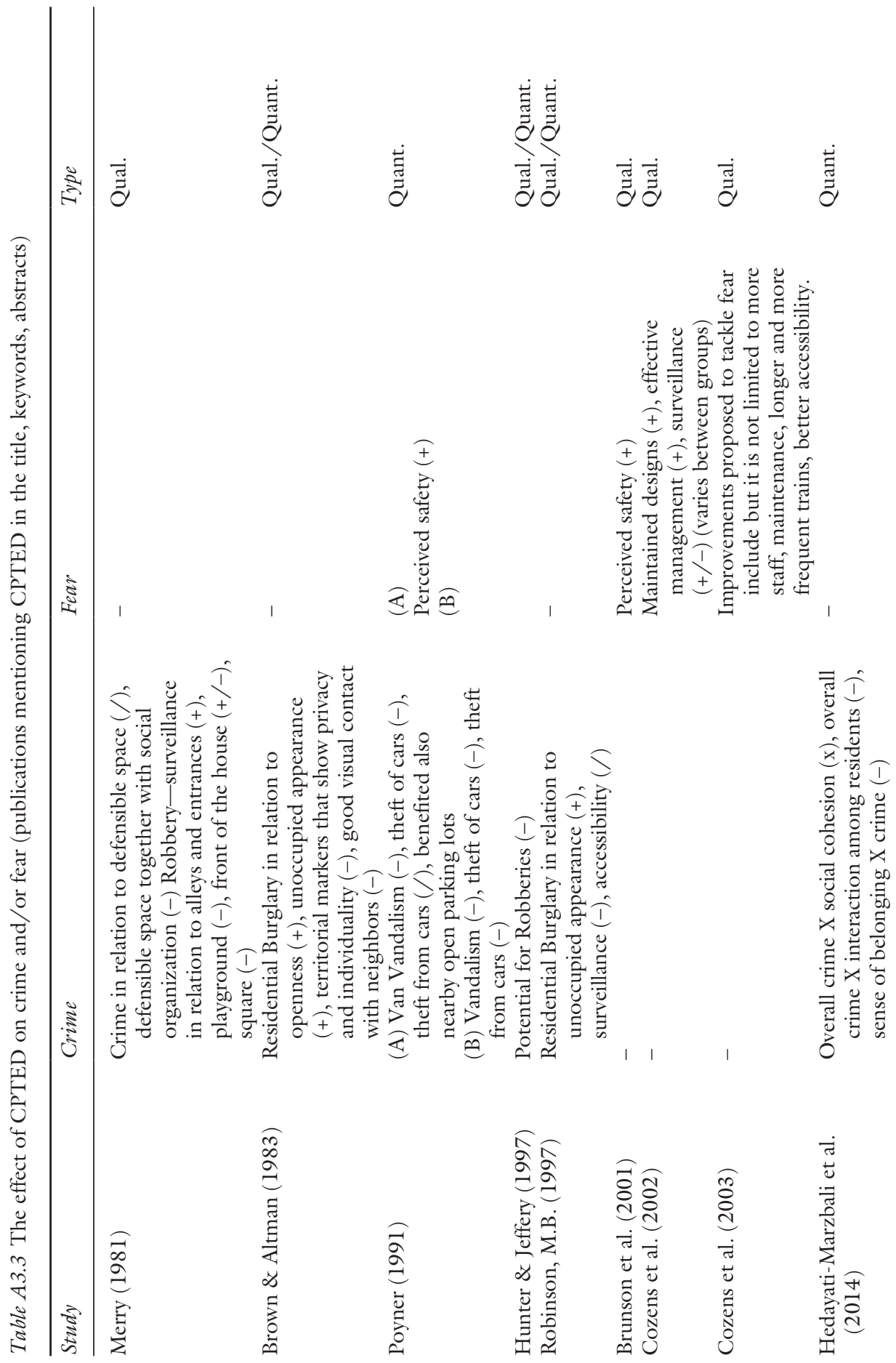


言言言

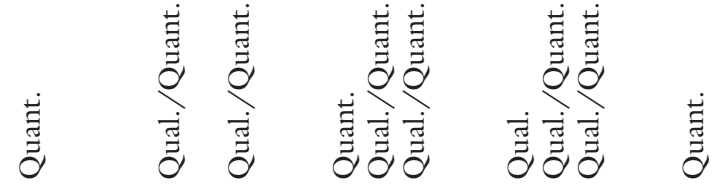

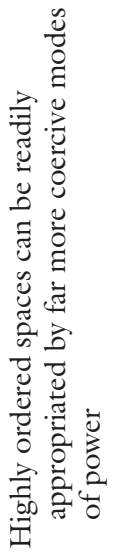
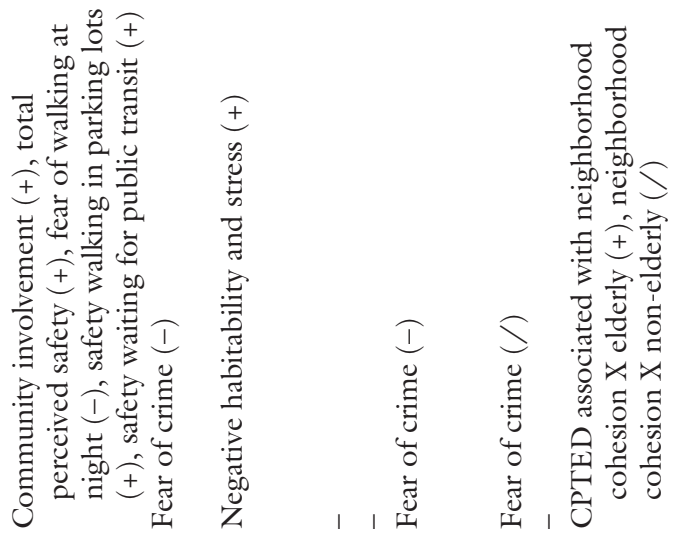

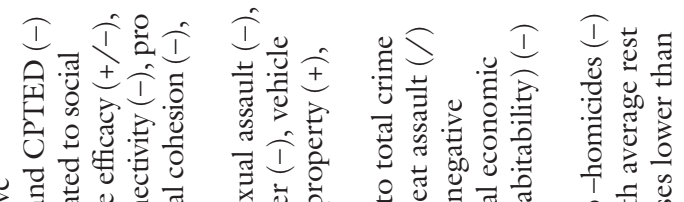

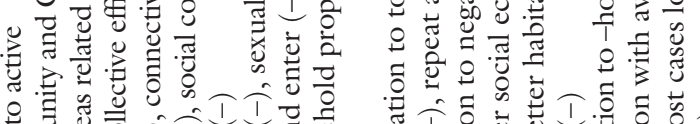

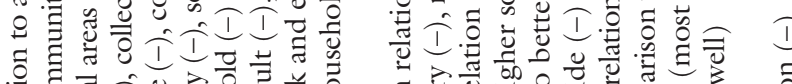

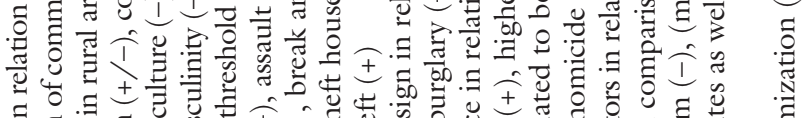

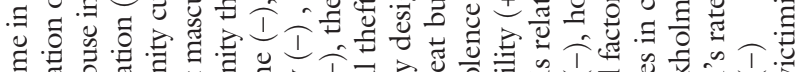

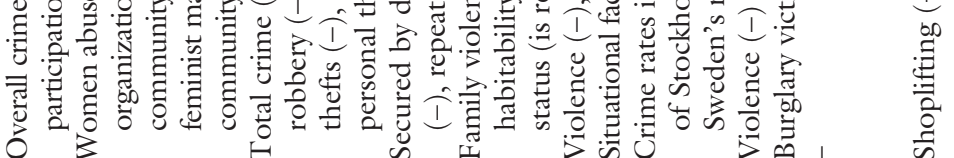
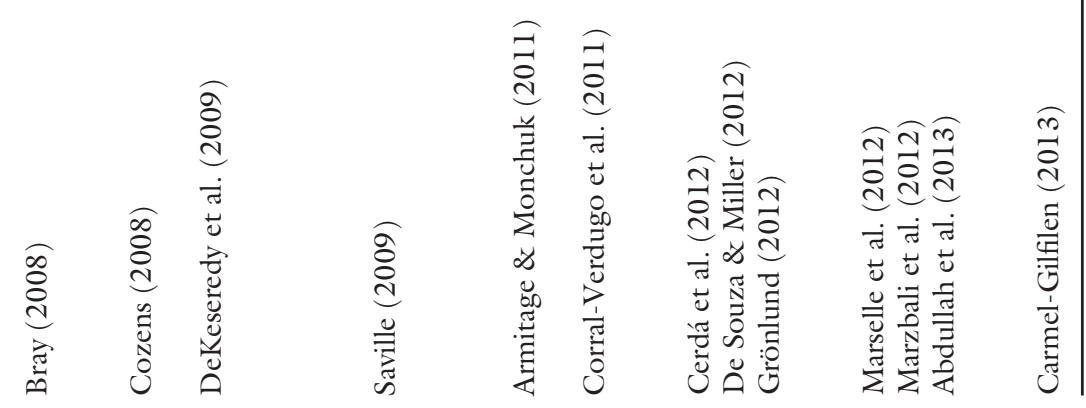


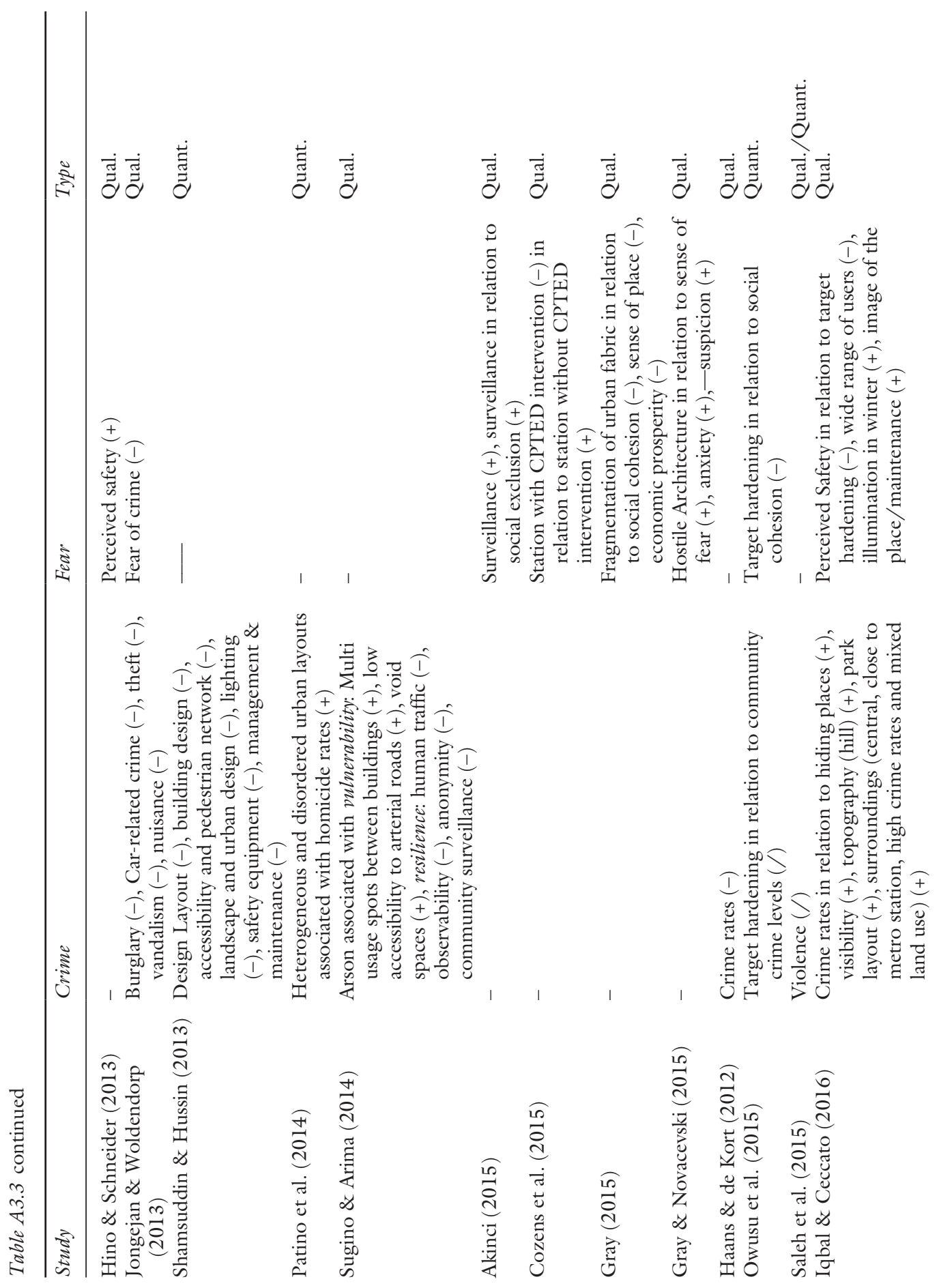


离

茪 节

节

๘̊
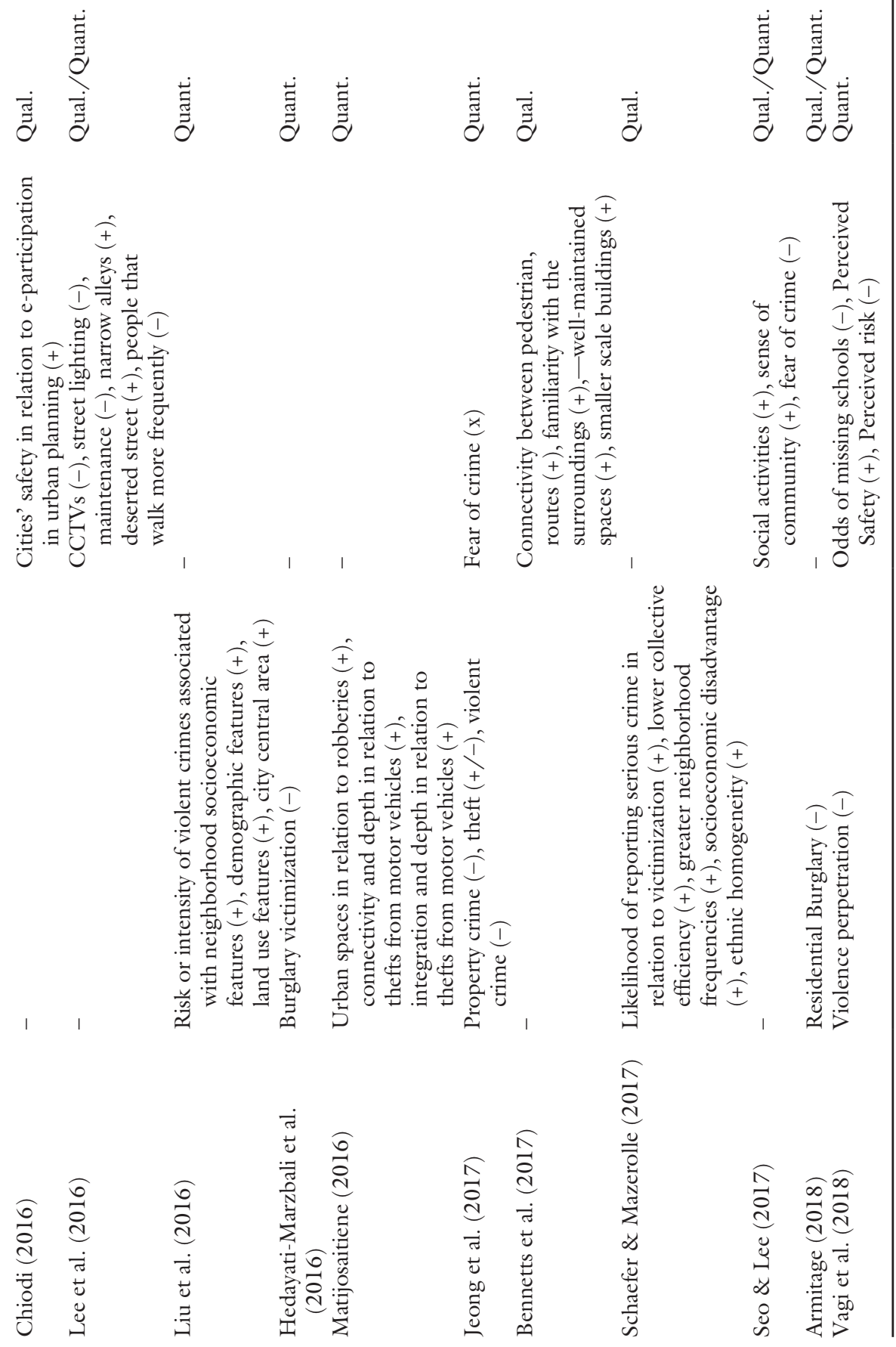


\section{Vania Ceccato}

\section{References}

Abenoza, R. F., Ceccato, V., Susilo, Y. O., \& Cats, O. (2018). Individual, travel, and bus stop characteristics influencing travelers' safety perceptions. Transportation Research Record, 2672, 19-28.

Abdullah, A., Marzbali, M. H., \& Tilaki, M. J. M. (2013). Predicting the influence of CPTED on perceived neighbourhood cohesion: Considering differences across age. Journal of Environmental Psychology, 36, 54-64.

Akinci, G. M. (2015). The purposes and meanings of surveillance: A case study in a shopping mall in Ankara, Turkey. Security Journal, 28, 39-53.

Aliprantis, D., \& Hartley, D. (2015). Blowing it up and knocking it down: The local and city-wide effects of demolishing high concentration public housing on crime. Journal of Urban Economics, 88, 67-81.

Anderson, K. M., \& McCall, M. (2005). Farm Crime in Australia. Canberra: Australian Institute of Criminology.

Aransiola, T. J. and Ceccato, V. (2020). The role of modern technology in rural situational crime prevention: a review of the literature. In A. Harkness (Ed.), Rural Crime Prevention - Theory, Tactics and Techniques (pp. 58-72). Oxford: Routledge.

Armitage, R. (2006). Predicting and preventing: Developing a risk assessment mechanism for residential housing. Crime Prevention and Community Safety, 8, 137-149.

Armitage, R. (2011). The Impact of Connectivity and Through-Movement within Residential Developments on Levels of Crime and Anti-Social Behaviour. (Unpublished Dissertation), University of Huddersfield, UK.

Armitage, R. (2018). Burglars' take on Crime Prevention Through Environmental Design (CPTED): Reconsidering the relevance from an offender perspective. Security Journal, 31, 285-304.

Armitage, R., \& Monchuk, L. (2011). Sustaining the crime reduction impact of designing out crime: re-evaluating the Secured by Design scheme 10 years on. Security Journal, 24(4), 320-343.

Arvate, P., Falsete, F. O., Ribeiro, F. G., \& Souza, A. P. (2018). Lighting and homicides: Evaluating the effect of an electrification policy in rural Brazil on violent crime reduction. Journal of Quantitative Criminology, 34, 1047-1078.

Atkins, S., Husain, S., \& Storey, A. (1991). The influence of street lighting on crime and fear of crime. Retrieved from London: www.celfosc.org/biblio/seguridad/atkins.pdf (accessed 15 January 2020).

Bennetts, H., Soebarto, V., Oakley, S., \& Babie, P. (2017). Feeling safe and comfortable in the urban environment. Journal of Urbanism, 10, 401-421.

Bornioli, A., Parkhurst, G., \& Morgan, P. L. (2018). The psychological wellbeing benefits of place engagement during walking in urban environments: A qualitative photoelicitation study. Health o Place, 53, 228-236.

Bowers, K. (2014). Risky facilities: Crime radiators or crime absorbers? A comparison of internal and external levels of theft. Journal of Quantitative Criminology, 30, 389-414.

Box, S., Hale, C., \& Andrews, G. (1988). Explaining fear of crime. The British Journal of Criminology, 28(3), 340-356.

Bradshaw, C. P., Milam, A. J., Furr-Holden, C. D. M., \& Lindstrom Johnson, S. (2015). The School Assessment for Environmental Typology (SAfETy): An observational measure of the school environment. American Journal of Community Psychology, 56, 280-292.

Branas, C. C., South, E., Kondo, M. C., Hohl, B. C., Bourgois, P., Wiebe, D. J., \& MacDonald, J. M. (2018). Citywide cluster randomized trial to restore blighted vacant land and its effects on violence, crime, and fear. Proceedings of the National Academy of Sciences, 115, 2946. 
Branic, N., \& Kubrin, C. E. (2018). Gated communities and crime in the United States. In G. Bruinsma \& S. D. Johnson (Eds.), The Oxford Handbook of Environmental Criminology (Vol. 1). New York: Oxford University Press.

Bray, D. (2008). Designing to govern: Space and power in two Wuhan communities. Built Environment (1978-), 34, 392-407.

Breetzke, G. D., Landman, K., \& Cohn, E. G. (2014). Is it safer behind the gates? Crime and gated communities in South Africa. Journal of Housing and the Built Environment, $29,123-139$.

Brown, B. B., \& Altman, I. (1983). Territoriality, defensible space and residential burglary: An environmental analysis. Journal of Environmental Psychology, 3, 203-220.

Brown, B. (1996). CCTV in three town centers in England. In R. V. Clarke (Ed.), Situational Crime Prevention—Successful Case Studies (pp. 167-182). USA: Lynne Rienner Publishers.

Brunson, L., Kuo, F. E., \& Sullivan, W. C. (2001). Resident appropriation of defensible space in public housing: Implications for safety and community. Environment and Behavior, 33, 626-652.

Byun, G., \& Ha, M. (2016). Factors of a surveillance environment that affect burglaries in commercial districts. Journal of Asian Architecture and Building Engineering, 15, 73-80.

Caplan, J. M., Kennedy, L. W., \& Petrossian, G. (2011). Police-monitored CCTV cameras in Newark, NJ: A quasi-experimental test of crime deterrence. Journal of Experimental Criminology, 7, 255-274.

Carmel-Gilfilen, C. (2013). Bridging security and good design: Understanding perceptions of expert and novice shoplifters. Security Journal, 26, 80-105.

Carvalho, M., George, R. V., \& Anthony, K. H. (1997). Residential satisfaction in Condomínios exclusivos (gate-guarded neighborhoods) in Brazil. Environment and Behavior, 29, 734-768.

Castro-Toledo, F., Perea-Garcia, J., Bautista-Ortuno, R., \& Mitkidis, P. (2017). Influence of environmental variables on fear of crime: Comparing self-report data with physiological measures in an experimental design. Journal of Experimental Criminology, 13, 537-545.

Ceccato, V. (2013). Moving Safely: Crime and Perceived Safety in Stockholm's Subway Stations. Plymouth: Lexington.

Ceccato, V. (2016). Rural Crime and Community Safety. New York: Routledge.

Ceccato, V. (2017). Women's victimisation and safety in transit environments. Crime Prevention and Community Safety, 19, 163-167.

Ceccato, V. (2018). Crime in transit environments: Lessons from Stockholm (Sweden) and São Paulo (Brazil) metro systems: 交通环境犯罪: 从瑞典斯德哥尔摩和巴西圣保罗 地铁系统的经验总结. Landscape Architecture, 7 .

Ceccato, V., Cats, O., \& Wang, Q. (2015). The geography of pickpocketing at bus stops: An analysis of grid cells. In V. Ceccato \& A. Newton (Eds.), Safety and Security in Transit Environments: An Interdisciplinary Approach (pp. 76-98). London: Palgrave Macmillan UK.

Ceccato, V., \& Lukyte, N. (2011). Safety and sustainability in a city in transition: The case of Vilnius, Lithuania. Cities, 28, 83-94.

Ceccato, V., \& Newton, A. (Eds.). (2015). Safety and Security in Transit Environments: An Interdisciplinary Approach. London: Palgrave.

Ceccato, V., \& Paz, Y. (2017). Crime in São Paulo's metro system: Sexual crimes against women. Crime Prevention and Community Safety, 19, 211-226.

Ceccato, V., Uittenbogaard, A., \& Bamzar, R. (2013a). Security in Stockholm's underground stations: The importance of environmental attributes and context. Security Journal, 26, 33-59. 


\section{Vania Ceccato}

Ceccato, V., Uittenbogaard, A. C., \& Bamzar, R. (2013b). Safety in Stockholm's underground stations: The importance of environmental attributes and context. Security Journal, 26, 33-59.

Ceccato, V., Vasquez, L., Langefors, L., Canabarro, A., \& Petersson, R. (2019). En trygg stadsmiljö: Teori och praktik för brottsförebyggande \& trygghetsskapande åtgärder. Retrieved from Stockholm: http://kth.diva-portal.org/smash/get/diva2:1358155/ FULLTEXT01.pdf (accessed 12 November 2019).

Cerdá, M., Morenoff, J. D., Hansen, B. B., Tessari Hicks, K. J., Duque, L. F., Restrepo, A., \& Diez-Roux, A. V. (2012). Reducing violence by transforming neighborhoods: A natural experiment in Medellín, Colombia. American Journal of Epidemiology, 175, 1045-1053.

Chandra, S., Jimenez, J., \& Radhakrishnan, R. (2017). Accessibility evaluations for nighttime walking and bicycling for low-income shift workers. Journal of Transport Geography, 64, 97-108.

Chiodi, S. I. (2016). Crime prevention through urban design and planning in the smart city era: The challenge of disseminating CP-UDP in Italy: learning from Europe. Journal of Place Management and Development, 9, 137-152.

Clarke, R. V. (2012). The Theory of Crime Prevention through Environmental DesignCPTED. https://pdfs.semanticscholar.org/4a94/e72074e829aba49ff001el77870d37bel3d5.pdf (accessed 20 February 2020).

Cohen, L. E., \& Felson, M. (1979). Social change and crime rate trends: A routine activity approach. American Sociological Review, 44, 588-608.

Corral-Verdugo, V., M. Frías-Armenta, \& González-Lomelí, D. (2011). Environmental factors in housing habitability as determinants of family violence. In Bio-Psycho-Social Perspectives on Interpersonal Violence (pp. 125-142). New York: Nova Science Publishers, Inc

Cozens, P. (2008) Crime prevention through environmental design in Western Australia: planning for sustainable urban futures. International Journal of Sustainable Development and Planning, 3, 272-292.

Cozens, P., \& Davies, T. (2013). Crime and residential security shutters in an Australian suburb: Exploring perceptions of 'Eyes on the Street', social interaction and personal safety. Crime Prevention and Community Safety, 15, 175-191.

Cozens, P., \& Love, T. (2015). A review and current status of Crime Prevention through Environmental Design (CPTED). Journal of Planning Literature, 30, 393-412.

Cozens, P., Neale, R., Whitaker, J., \& Hillier, D. (2002). Managing crime and the fear of crime at railway stations-A case study in South Wales (UK). International Journal of Transport Management, 1, 121-132.

Cozens, P., Neale, R., Whitaker, J., \& Hillier, D. (2003). Investigating personal safety at railway stations using "virtual reality" technology. Facilities, 21, 188-194.

Cozens, P. M., Neale, R. H., Whitaker, J., Hillier, D., \& Graham, M. (2003). A critical review of street lighting, crime and fear of crime in the British city. Crime Prevention and Community Safety, 5, 7-24.

Cozens, P. M., Saville, G., \& Hillier, D. (2005). Crime prevention through environmental design (CPTED): A review and modern bibliography. Property Management, $23,328-356$.

Cozens, P., \& van der Linde, T. (2015). Perceptions of Crime Prevention Through Environmental Design (CPTED) at Australian railway stations. Journal of Public Transportation, 18, 73-92.

Crowe, T. (2000). Crime Prevention Through Environmental Design: Applications of Architectural Design and Space Management Concepts. Oxford: Butterworth-Heinemann. 
De Boer, J., Heylen, D. K. J., \& Teeuw, W. B. (2014). Persuasive ways to change entrance use of buildings. Psychology Journal, 12, 71-86.

De Souza, E., \& Miller, J. (2012). Homicide in the Brazilian favela: Does opportunity make the killer? British Journal of Criminology, 52, 786-807.

DeKeseredy, W. S., Donnermeyer, J. F., \& Schwartz, M. D. (2009). Toward a gendered Second Generation CPTED for preventing woman abuse in rural communities. Security Journal, 22, 178-189.

Duncan, D. T., Castro, M. C., Gortmaker, S. L., Aldstadt, J., Melly, S. J., \& Bennett, G. G. (2012). Racial differences in the built environment-body mass index relationship? A geospatial analysis of adolescents in urban neighborhoods. International Journal of Health Geographics, 11.

Eck, J. E. (2019). Place Managers and Crime Places. Oxford: Oxford University Press.

England, M. (2008). When 'good neighbors' go bad: Territorial geographies of neighborhood associations. Environment and Planning A, 40, 2879-2894.

Farrington, D. P., \& Welsh, B. C. (2002). Improved street lighting and crime prevention. Justice Quarterly, 19, 313-342.

Felson, M. (2002). Crime and Everyday Life. Thousand Oaks: Sage.

Ferraro, K. F. (1995). Fear of Crime: Interpreting Victimization Risk. Albany, NY: State University of New York Press.

Ferraro, K. F. (1996). Women's fear of victimization: Shadow of sexual assault? Social Forces, 75, 667-690.

Ferrer, S., Ruiz, T., \& Mars, L. (2015). A qualitative study on the role of the built environment for short walking trips. Transportation Research Part F-Traffic Psychology and Behaviour, 33, 141-160.

Fotios, S. (2016). Comment on empirical evidence for the design of public lighting. Safety Science, 86, 88-91.

Fotios, S., Unwin, J., \& Farrall, S. (2015). Road lighting and pedestrian reassurance after dark: A review. Lighting Research \& Technology, 47, 449-469.

Freedman, M., \& Owens, E. G. (2011). Low-income housing development and crime. Journal of Urban Economics, 70, 115-131.

Fussey, P. (2013). Contested topologies of UK counterterrorist surveillance: The rise and fall of Project Champion. Critical Studies on Terrorism, 6, 351-370.

Garofalo, J., \& Laub, J. (1978). The fear of crime: broadening our perspective. Victimology, 3(3-4), 242-253.

Gaylord, M. S., \& Galliher, J. F. (1991). Riding the underground dragon: Crime control and public order on Hong Kong's mass transit railway. British Journal of Criminology, $31,15-26$.

Gerell, M. (2016). Hot spot policing with actively monitored CCTV cameras: Does it reduce assaults in public places? International Criminal Justice Review, 26, 187-201.

Gliori, G. (2018). Grindsamhällen: Är det något att utveckla inom den svenska stadsplaneringen? (Independent thesis Basic level (degree of Bachelor) Student thesis).

Gray, E., Jackson, J., \& Farrall, S. (2008). Reassessing the fear of crime. European Journal of Criminology, 5, 363-380.

Gray, E., Jackson, J., \& Farrall, S. (2011). Feelings and functions in the fear of crime: Applying a new approach to victimisation insecurity. British Journal of Criminology, $51,75-94$.

Gray, F. (2015). The misanthropes, larrikins and mallrats of Market Square: An enduring public space dilemma in Central Geelong. In SAHANZ 2015: Architecture Institutes and Change. Proceedings of the 32nd Annual Conference of Society of Architectural Historians Australia and New Zealand, Society of Architectural Historians Australia and New Zealand, Sydney, NSW, pp. 218-230. 
Gray, F., \& Novacevski, M. (2015). Unlawful acts, unkind architecture and unhelpful perceptions: A case study of Market Square Mall, Geelong. In Proceedings of the Safe Cities Conference 2015, Association for Sustainability in Business, Nerang, Qld., pp. 4-18.

Green, J., Perkins, C., Steinbach, R., \& Edwards, P. (2015). Reduced street lighting at night and health: A rapid appraisal of public views in England and Wales. Health and Place, 34, 171-180.

Griswold, D. B. (1984). Crime prevention and commercial Burglary: A time series analysis. Journal of Criminal Justice, 12, 493-501.

Groff, E., \& McCord, E. S. (2012). The role of neighborhood parks as crime generators. Security Journal, 25, 1-24.

Grundström, K. (2018). Grindsamhälle: the rise of urban gating and gated housing in Sweden. Housing Studies, 33, 18-39.

Grönlund, B. (2012). Is hammarby sjöstad a model case? Crime prevention through environmental design in Stockholm, Sweden. In The Urban Fabric of Crime and Fear (pp. 283-310). Dordrecht: Springer Netherlands.

Haans, A., \& de Kort, Y. A. W. (2012). Light distribution in dynamic street lighting: Two experimental studies on its effects on perceived safety, prospect, concealment, and escape. Journal of Environmental Psychology, 32, 342-352.

Hedayati-Marzbali, M., A. Abdullah, N. A. Razak \& Maghsoodi Tilaki, M. J. (2014). Examining social cohesion and victimization in a Malaysian multiethnic neighborhood. International Journal of Law, Crime and Justice, 42, 384-405.

Hedayati-Marzbali, M. H., Esmaieli, M., Abolghasemi, H., \& Marzbali, M. H. (2016). Tetracycline adsorption by $\mathrm{H} 3 \mathrm{PO} 4$-activated carbon produced from apricot nut shells: A batch study. Process Safety and Environmental Protection, 102, 700-709.

Hedayati-Marzbali, M., Tilaki, M. J. M., \& Abdullah, A. (2017). Assessing the effect of neighbourhood structure on residents' perceptions of safety in gated communities: A case study of Iran. Safer Communities, 16, 3-19.

Herbert, D., \& Davidson, N. (1994). Modifying the built environment, the impact of improved lighting. Geoforum, 25, 339-350.

Higgins, J. P., \& Green, S. (Eds.). (2011). Cochrane Handbook for Systematic Reviews of Interventions (Vol. 4). Chichester, UK: John Wiley \& Sons.

Hino, K., \& Schneider R. H. (2013). Planning for crime prevention in Japan. Built Environment, 39(1), 114-139.

Hunter, R. D., \& Jeffery, R. (1997). Preventing convenience store robbery through environmental design. In R. V. Clarke (Ed.), Situational Crime Prevention-Successful Case Studies (pp. 191-199). USA: Lynne Rienner Publishers.

Iqbal, A., \& Ceccato, V. (2015). Is CPTED useful to guide the inventory of safety in parks? A study case in Stockholm, Sweden. International Criminal Justice Review, 26, 150-168.

Jackson, J., \& Gray, E. (2010). Functional fear and public insecurities about crime. British Journal of Criminology, 50, 1-22.

Jeong, Y., Kang, Y., \& Lee, M. (2017). Effectiveness of a project applying crime prevention through environmental design in an urban area in South Korea. Journal of Asian Architecture and Building Engineering, 16, 543-549.

Johansson, M., Pedersen, E., Maleetipwan-Mattsson, P., Kuhn, L., \& Laike, T. (2014). Perceived outdoor lighting quality (POLQ): A lighting assessment tool. Journal of Environmental Psychology, 39, 14-21.

Johansson, M., Rosen, M., \& Kuller, R. (2011). Individual factors influencing the assessment of the outdoor lighting of an urban footpath. Lighting Research \& Technology, $43,31-43$.

Jongejan, A., \& Woldendorp, T. (2013). A successful CPTED approach: The Dutch 'police label secure housing'. Built Environment (1978-), 39, 31-48. 
Kim, D., \& Park, S. (2017). Improving community street lighting using CPTED: A case study of three communities in Korea. Sustainable Cities and Society, 28, 233-241.

Kim, D. H., \& Noh, K. B. (2018). Perceived adequacy of illumination and pedestrians' night-time experiences in urban obscured spaces: A case of London. Indoor and Built Environment, 27, 1134-148.

Knutsson, J. (1997). Restoring public order in a city park. Policing for prevention: Reducing crime. National Council for Crime Prevention. Stockholm: BRÅ.

Kondo, M. C., Andreyeva, E., South, E. C., MacDonald, J. M., \& Branas, C. C. (2018). Neighborhood interventions to reduce violence. Annual Review of Public Health, $39,253-271$.

Koskela, H. (2002). Video surveillance, gender, and the safety of public urban space: "Peeping tom" goes high tech? Urban Geography, 23, 257-278.

LaGrange, R. L., Ferraro, K. F., \& Supancic, M. (1992). Perceived risk and fear of crime: Role of social and physical incivilities. Journal of Research in Crime and Delinquency, 29, 311-334.

Landman, K. (2004). Gated communities in South Africa: The challenge for spatial planning and land use management. The Town Planning Review, 75, 151-172.

Landman, K. (2012). Reconsidering crime and urban fortification in South Africa. In V. Ceccato (Ed.), The Urban Fabric of Crime and Fear (pp. 239-264). Dordrecht: Springer Netherlands.

La Vigne, N. G. L., Lowry, S. S., Markman, J. A., \& Dwyer, A. M. (2011). Evaluating the Use of Public Surveillance Cameras for Crime Control and Prevention. Washington, DC: Urban studies Institute.

Lawson, T., Rogerson, R., \& Barnacle, M. (2018). A comparison between the cost effectiveness of CCTV and improved street lighting as a means of crime reduction. Computers, Environment and Urban Systems, 68, 17-25.

Lee, J. S., Park, S., \& Jung, S. (2016). Effect of Crime Prevention through Environmental Design (CPTED) measures on active living and fear of crime. Sustainability, 8, 16.

Lett, D., Hier, S. P., \& Walby, K. (2010). CCTV surveillance and the civic conversation: A study in public sociology. The Canadian Journal of Sociology/Cahiers canadiens de sociologie, $35,437-462$.

Lindgren, T., \& Nilsen, M. R. (2012). Safety in residential areas. Tijdschrift voor Economische en Sociale Geografie, 103, 196-208.

Liu, D., Song, W., \& Xiu, C. (2016). Spatial patterns of violent crimes and neighborhood characteristics in Changchun, China. Australian and New Zealand Journal of Criminology, 49, 53-72.

Loomis, D., Marshall, S. W., Wolf, S. H., Runyan, C. W., \& Butts, J. D. (2002). Effectiveness of safety measures recommended for prevention of workplace homicide. Journal of the American Medical Association, 287, 1011-1017.

Lorenc, T., Petticrew, M., Whitehead, M., Neary, D., Clayton, S., Wright, K. Renton, A. (2013). Environmental interventions to reduce fear of crime: systematic review of effectiveness. Systemic Reviews, 2, 30.

Loukaitou-sideris, A. (1999). Hot spots of bus stop crime: The importance of environmental attributes. Journal of the American Planning Association, 65(4), 395-411.

Loukaitou-Sideris, A. (2012). Safe on the move: The importance of the built environment. In V. Ceccato (Ed.), The Urban Fabric of Crime and Fear (pp. 85-110). Dordrecht: Springer Netherlands.

Loukaitou-Sideris, A. (2014). Fear and safety in transit environments from the women's perspective. Security Journal, 27, 242-256.

Loukaitou-Sideris, A., \& Eck, J. E. (2007). Crime prevention and active living. American Journal of Health Promotion, 21 (4 suppl), 380-389. 
Loukaitou-Sideris, A., Liggett, R., \& Iseki, H. (2002). The geography of transit crime: Documentation and evaluation of crime incidence on and around the Green Line stations in Los Angeles. Journal of Planning Education and Research, 22, 135-151.

Loukaitou-Sideris, A., \& Stieglitz, O. (2002). Children in Los Angeles Parks: A study of equity, quality and children's satisfaction with neighbourhood parks. The Town Planning Review, 73, 467-488.

Lum, C., Stoltz, M., Koper, C., \& Scherer, J. A. (2019). Research on body-worn cameras. Criminology \& Public Policy, 18, 93-118.

Luymes, D. (1997). The fortification of suburbia: Investigating the rise of enclave communities. Landscape and Urban Planning, 39, 187-203.

Marselle, M., Wootton, A. B., \& Hamilton, M. G. (2012). A design against crime intervention to reduce violence in the night-time economy. Security Journal, 25, 116-133.

Marzbali, M. H., Abdullah, A., Abd Razak, N., \& Tilaki, M. J. M. (2012). The relationship between socio-economic characteristics, victimization and CPTED principles: Evidence from the MIMIC model. Crime Law and Social Change, 58, 351-371.

Matijosaitiene, I. (2016). Combination of CPTED and space syntax for the analysis of crime. Safer Communities, 15, 49-62.

Mears, D. P., Scott, M. L., \& Bhati, A. S. (2007). A process and outcome evaluation of an agricultural crime prevention initiative. Criminal Justice Policy Review, 18, 51-80.

Merry, S. E. (1981). Defensible space undefended: Social factors in crime control through environmental design. Urban Affairs Review, 16, 397-422.

Monchuk, L. (2011). The way forward in designing out crime? Greater Manchester police design for security consultancy. Safer Communities, 10, 31-40.

Moher, D., Liberati, A., Tetzlaff, J., \& Altman, D. (2009). Preferred reporting items for systematic reviews and meta-analyses: the PRISMA statement. PLoS Med, 6(7), e1000097. doi:doi:10.1371/journal.pmed1000097.

Myhre, M., \& Rosso, F. (Eds.). (1996). Designing for Security in Meteor: A Projected New Metro Line in Paris (Vol. 6). Monsey, NY: Willow Tree.

Nasar, J. L., \& Bokharaei, S. (2017). Impressions of lighting in public squares after dark. Environment and Behavior, 49, 227-254.

Németh, J. (2012). Controlling the commons: How public is public space? Urban Affairs Review. 48, 811-835.

Newton, A. (2008). A study of bus route crime risk in urban areas: The changing environs of a bus journey. Built Environment (1978-), 34(1), 88-103.

Newton, A. D., Johnson, S. D., \& Bowers, K. J. (2004). Crime on bus routes: An evaluation of a safer travel initiative. Policing: An International Journal of Police Strategies o Management, 27, 302-319.

Nikunen, H., \& Korpela, K. M. (2012). The effects of scene contents and focus of light on perceived restorativeness, fear and preference in nightscapes. Journal of Environmental Planning and Management, 55, 453-468.

Owusu, G., Wrigley-Asante, C., Oteng-Ababio, M., \& Yaa Owusu, A. (2015). Crime Prevention Through Environmental Design (CPTED) and built-environmental manifestations in Accra and Kumasi, Ghana. Crime Prevention and Community Safety, 17, 249-269.

Pain, R., MacFarlane, R., \& Turner, K. (2006). 'When, where, if, and but': Qualifying GIS and the effect of streetlighting on crime and fear. Environment and Planning AEconomy and Space, 38, 2055-2074.

Pain, R. H. (1997). Social geographies of women's fear of crime. Transactions of the Institute of British Geographers, 22, 231-244. 
Pain, R. and Smith, S. J. (2008). Fear, critical geopolitics and everyday life. In Pain. R \& Smith, S.J. (Eds), Fear: Critical Geopolitics And Everyday Life (pp. 1-24). Aldershot: Ashgate.

Painter, K., \& Farrington, D. P. (1994). The crime reducing effect of improved street lighting: The Dudley Project. In R. V. Clarke (Ed.), Situational Crime PreventionSuccessful Case Studies (pp. 209-226). USA: Lynne Rienner Publishers.

Park, M., Perez, N., Jennings, W. G., \& Gover, A. R. (2017). A preliminary examination of the role of deterrence and target hardening on future recidivism risk among burglars in South Korea. Security Journal, 30, 903-921.

Patino, J. E., Duque, J. C., Pardo-Pascual, J. E., \& Ruiz, L. A. (2014). Using remote sensing to assess the relationship between crime and the urban layout. Applied Geography, 55, 48-60.

Peek-Asa, C., \& Casteel, C. H. (2010). Documenting the need for translational research: An example from workplace violence prevention. Injury Prevention, 16, 50-52.

Perkins, C., Steinbach, R., \& Tompson, L. (2015). What is the effect of reduced street lighting on crime and road traffic injuries at night? A mixed-methods study. Southampton (UK). Public Health Research, 3(11).

Piza, E. L., Welsh, B. C., Farrington, D. P., \& Thomas, A. L. (2019). CCTV surveillance for crime prevention. Criminology \& Public Policy, 18, 135-159.

Poyner, B. (1991). Situational crime prevention in two parking facilities. In R. V. Clarke (Ed.), Situational Crime Prevention-Successful Case Studies (pp. 157-166). USA: Lynne Rienner Publishers.

Poyner, B. (1994). An evaluation of walkway demolition on a British housing estate. In R. V. Clarke (Ed.), Situational Crime Prevention-Successful Case Studies (pp. 59-73). USA: Lynne Rienner Publishers.

Poyner, B., \& Webb, B. (1987). Reducing theft from shopping bags in city center markets. In R. V. Clarke (Ed.), Situational Crime Prevention-Successful Case Studies (pp. 83-89). USA: Lynne Rienner Publishers.

Quinet, K. D., \& Nunn, S. (1998). Illuminating crime: The impact of street lighting on calls for police service. Evaluation Review, 22, 751-779.

Rankavat, S., \& Tiwari, G. (2016). Pedestrians risk perception of traffic crash and built environment features-Delhi, India. Safety Science, 87, 1-7.

Ratcliffe, J. H., Taniguchi, T., \& Taylor, R. B. (2009). The crime reduction effects of public CCTV cameras: A multi-method spatial approach. Justice Quarterly, 26, 746-770.

Reynald, D. M. (2011). Translating CPTED into crime preventive action: A critical examination of CPTED as a tool for active guardianship. European Journal on Criminal Policy and Research, 17, 69-81.

Robinson, M. B., \& Robinson, C. E. (1997). Environmental characteristics associated with residential burglaries of student apartment complexes. Environment and Behavior, 29, 657-675.

Rogers, C. (2005). Gate expectations: Initial findings from a crime and disorder prevention initiative. Safer Communities, 4, 19-22.

Rogers, C. (2007). Alley-gates: Theory and practice-A perspective from urban south wales. Crime Prevention and Community Safety, 9, 179-200.

Saleh, A. S., Saif, N. I., \& Sartawi, K. S. (2015). CPTED and workplace violence in Jordanian public hospitals. Asian Social Science, 11, 336-347.

Sanders, C. B., \& Hannem, S. (2012). Policing "the risky": Technology and surveillance in everyday patrol work. Canadian Review of Sociology, 49, 389-410.

Santos, J. R. (2020). Decoding (sub)urban-rural fragmentation processes: A morphogenetic approach in Lisbon metropolis In A. K.-F. a. A. Djukić (Ed.), Handbook of 
Research on Urban-Rural Synergy Development Through Housing, Landscape, and Tourism (p. 434). Hershey, PA: IGI Global.

Saville, G. (2009). SafeGrowth: Moving forward in neighbourhood development. Built Environment (1978-), 35, 386-402.

Saville, G. (2013). Third Generation of CPTED. www.alternation.ca (accessed 18 October 2019).

Schaefer, L., \& Mazerolle L. (2017). Predicting perceptions of crime: Community residents' recognition and classification of local crime problems. Australian \& New Zealand Journal of Criminology, 51, 183-203.

Schaefer, L., \& Mazerolle, L. (2018). Predicting perceptions of crime: Community residents' recognition and classification of local crime problems. Australian and New Zealand Journal of Criminology, 51, 183-203.

Seo, S. Y., \& Lee, K. H. (2017). Effects of changes in neighbourhood environment due to the CPTED project on residents' social activities and sense of community: A case study on the Cheonan Safe Village Project in Korea. International Journal of Urban Sciences, 21, 326-343.

Shamsuddin, S., \& Hussin, N. A. (2013). Implementation of crime prevention through environmental design by Kuala Lumpur city hall. In N. Xu, L. Tian, \& F. Dai (Eds.), Sustainable Cities Development and Environment Protection, Pts 1-3 (Vol. 361-363, pp. 193+). Durnten-Zurich: Trans Tech Publications Ltd.

Skudder, H., Brunton-Smith, I., Tseloni, A., McInnes, A., Cole, J., Thompson, R., \& Druckman, A. (2018). Can burglary prevention be low-carbon and effective? Investigating the environmental performance of burglary prevention measures. Security Journal, 31, 111-138.

Smith, M. J., \& Clarke, R. V. (2000). Crime and public transport. Crime and Justice, 27, $169-233$.

Smith, N., \& Low, S. (Eds.) (2013). The Politics of Public Place. London, New York: Routledge.

Squires, G. D. (1992). From Redlining to Reinvestment: Community Response to Urban Disinvestment. Philadelphia: Temple University Press.

Srisuwan, A. (2011). Street lighting design for a traditional city: A case study of Jesi, Italy. Proceedings of the Conference Light 2011, 121. www.witpress.com/elibrary/ wit-transactions-on-the-built-environment/121/22051 (accessed 20 February 2020).

Stamps III, A. E. (2005). Enclosure and safety in urbanscapes. Environment and Behavior, 37, 102-133.

Stolzenberg, L., D'Alessio, S. J., \& Flexon, J. L. (2017). A hunter's moon: The effect of moon illumination on outdoor crime. American Journal of Criminal Justice, 42, 188-197.

Sugino, H., \& Arima, T. (2014). Spatial vulnerability and district resilience for the next generation of CPTED: A case study of crime preventive spatial design targeting arson. International Review for Spatial Planning and Sustainable Development, 2, 23-41.

Sutton, A., \& Wilson, D. (2004). Open-street CCTV in Australia: The politics of resistance and expansion. Surveillance \& Society, 2, 310-322.

Takizawa, A., Koo, W., \& Katoh, N. (2010). Discovering distinctive spatial patterns of snatch theft in Kyoto City with CAEP. Journal of Asian Architecture and Building Engineering, 9, 103-110.

Tanulku, B. (2018). The formation and perception of safety, danger and insecurity inside gated communities: Two cases from Istanbul, Turkey. Journal of Housing and the Built Environment, 33, 151-173.

Taylor, B., Koper, C., \& Woods, D. (2012). Combating vehicle theft in Arizona: A randomized experiment with license plate recognition technology. Criminal Justice Review, 37, 24-50. 
Tjernberg, C., \& Granhag, F. (2019). Kamerabevakning som brottsförebyggande åtgärd: Ett evidensbaserat beslutsstöd samt vägledning. Västra Götalands länsstyrelsen, www. lansstyrelsen.se/download/18.26f506e0167c605d56942223/1551356889287/ brottsforebyggande-arbete-kameraovervakning.pdf (accessed 16 February 2020).

Tjoa, P. F., \& Devon, R. (2010). Safety by design: A review on planning and design strategies for a safer living environment in higher education communities. World Transactions on Engineering and Technology Education, 8, 301-309.

Tseng, C. H., Duane, J., \& Hadipriono, F. (2004). Performance of campus, parking garages in preventing crime. Journal of Performance of Constructed Facilities, 18, $21-28$.

Uittenbogaard, A., \& Ceccato, V. (2014). Safety in Stockholm's underground stations: An agenda for action. European Journal on Criminal Policy and Research, 20, 73-100.

Uittenbogaard, A., \& Ceccato, V. (2015). Temporal and spatial patterns of suicides in Stockholm's subway stations. Accident Analysis \& Prevention, 81, 96-106.

Vagi, K. J., Stevens, M. R., Simon, T. R., Basile, K. C., Carter, S. P., \& Carter, S. L. (2018). Crime Prevention Through Environmental Design (CPTED) characteristics associated with violence and safety in middle schools. Journal of School Health, $88,296-305$.

van Eck, N. J., \& Waltman, L. (2019). VOSviewer version 1.6.12. Leiden: Leiden University. Retrieved from www.vosviewer.com (accessed 20 February 2020).

van Rijswijk, L., \& Haans, A. (2018). Illuminating for safety: Investigating the role of lighting appraisals on the perception of safety in the urban environment. Environment and Behavior, 50, 889-912.

Vernez Moudon, A., Bassok, A., \& Kang, M. (2018). Safe from Crime at LocationSpecific Transit Facilities (No. WA-RD 882.1). Washington (State). Department of Transportation. Research Office.

Weisheit, R. A., \& Donnermeyer, J. F. (2000). Change and continuity in crime. Criminal Justice, 1, 309-357.

Welsh, B. C., \& Farrington, D. P. (2004). Evidence-based crime prevention: The effectiveness of CCTV. Crime Prevention and Community Safety, 6, 21-33.

Welsh, B. C., \& Farrington, D. P. (2009). Public area CCTV and crime prevention: An updated systematic review and meta-analysis. Justice Quarterly, 26, 716-745.

White, R. (1993). Youth and the conflict over urban space. Children's Environments, $10(1), 85-93$.

Wikström, P. O., \& Treiber, K. (2017). Beyond risk factors: an analytical approach to crime prevention. In B. M. E. Teasdale (Ed.), Preventing Crime and Violence. Advances in Prevention Science. Cham: Springer.

Williams, D., \& Ahmed, J. (2009). The relationship between antisocial stereotypes and public CCTV systems: Exploring fear of crime in the modern surveillance society. Psychology, Crime and Law, 15, 743-758.

Williams, K. S., \& Johnstone, C. (2000). The politics of the selective gaze: Closed circuit television and the policing of public space. Crime, Law and Social Change, 34, $183-210$.

Wilson, J. Q., \& Kelling, G. L. (1982). Broken windows. Atlantic Monthly, 249, 29-38.

Winge, S., \& Knutsson, J. (2003). An evaluation of the CCTV scheme at Oslo central railway station. Crime Prevention and Community Safety, 5, 49-59.

Yavuz, N., \& Welch, E. W. (2010). Addressing fear of crime in public space: Gender differences in reaction to safety measures in train transit. Urban Studies, 47, 2491-2515.

Zahm, D. (2005). Learning, translating and implementing CPTED. Journal of Architectural and Planning Research, 22, 284-293. 


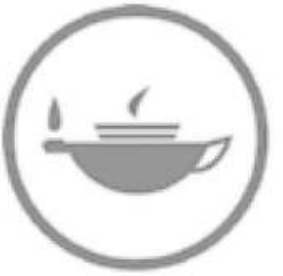

Taylor \& Francis Taylor \& Francis Group http://taylorandfrancis.com 


\section{Part II}

The environment

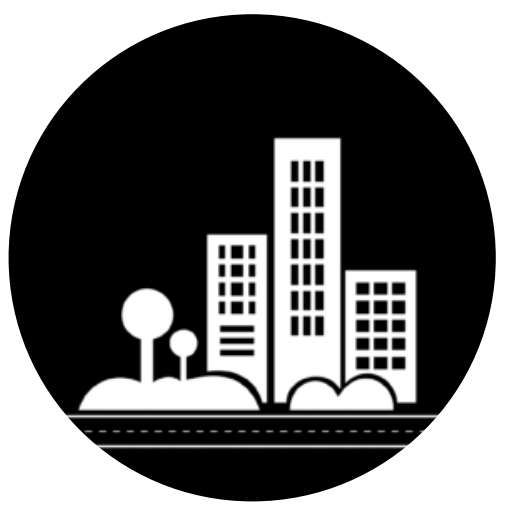




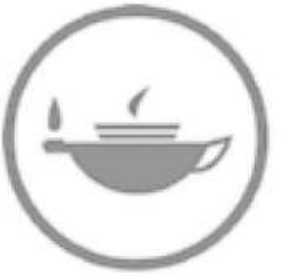

Taylor \& Francis Taylor \& Francis Group http://taylorandfrancis.com 


\title{
4 Do green areas affect crime and safety?
}

\author{
Vania Ceccato, Ana Canabarro \\ and Lisandra Vazquez
}

\subsection{Introduction}

People's satisfaction with and perceptions of the quality of green areas are thought to be important in the creation of sustainable cities (Chiesura, 2004; Iqbal \& Ceccato, 2015; Mulliner \& Maliene, 2011). A green area (or space)be it a park, a forest, a meadow, a green belt-is often associated with environmental amenities in cities, place attachment, citizens' health and sustainability (Babey, Tan, Wolstein, \& Diamant, 2015; Bogar \& Beyer, 2015; Cohen et al., 2016; Gómez, Baur, Hill, \& Georgiev, 2015; Troy \& Grove, 2008). However, green areas are far from homogeneous in nature, function and other inherent qualities. Safety is one of the basic qualities that make a green area attractive and is an important component of sustainable environments (UN-Habitat, 2019; UNHSP, 2007). If a green area is unsafe, or at least felt so by its users, its quality most likely is compromised.

In this chapter we investigate the nature of green areas in relation to safety. This study builds on previous literature overviews (Bogar \& Beyer, 2015; Kondo, Fluehr, McKeon, \& Branas, 2018a) that assessed the state of evidence on relationships among green space, violence and crime. Bogar and Beyer (2015) focused on studies from the United States from 2001 and 2013. Overall, they found significant evidence to support the positive impacts of green space on safety, despite incompatible research designs and conflicting results. Kondo, Fluehr et al. (2018) found consistent negative associations between green space exposure and violence and health outcomes. They called for additional research and standardization among studies for a better understanding of the relationship between green areas and safety. This study responds to those calls by extending the review to literature from other parts of the world and looking into the relationship between green space and safety perceptions/fear of crime, which have been lacking.

The aim of this chapter is to identify and assess the nature of published, peerreviewed literature in English on the relationship between green areas (parks, forests, neighborhood parks, green vacant land, interstitial spaces) and crime and perceived safety. This is achieved by performing a systematic literature overview from 1968 to 2018 from the major databases and assessing thematic 
trends. We used the software VOSviewer (www.vosviewer.com) to manage and organize the vast material spanning five decades into two overarching themes: the relationship between green areas and crime, and the relationship between green areas and fear or poor perceived safety. This literature review aims to collect and systematize scholarly knowledge on the topic to respond to the following questions.

1. Which are the most common types of green areas associated with crime and/or poor perceived safety in the international literature?

2. Do green areas affect the occurrence of crime and disorder and, if so, how?

3. Do green areas impact on perceived safety and, if so, what are the mechanisms?

This chapter is structured as follows. First, we discuss the basic definitions and theoretical necessary principles, then report the methods, followed by the results. In the final section we identify gaps in the literature and suggest a research agenda on green areas and safety as well as policy implications of the current knowledge.

Note that in this study "green areas" and "green spaces" will be used interchangeably.

\subsection{Theory and definitions of green areas and safety}

\section{Types of green areas and crime}

Goode and Collins (2014) categorized green spaces in six groups according to their origin, development and walkability. Although the categories were created for green areas in the British context, they can be helpful to illustrate the spectrum of green areas found in other parts of the world. The first category is "tended" green spaces for pleasure and is composed of squares, parks and campuses, botanical gardens, gardens, tree-lined streets, flowerbeds, verges and pockets of space. The second category is called "tended" green spaces for use, and is composed of allotments, playing fields, greens and playgrounds, graveyards and cemeteries. Then, they suggest "un-tended" green spaces, such as disused railway lines and wasteland, and water features, such as those green areas close by rivers, streams, lakes and ponds, canals, conduits and millstreams, dockyards and waterfronts. In addition, there are "natural" green spaces, for example, meadows, heaths and woodland, and finally "controlled" green spaces, which include green belts and nature reserves.

Green areas (or spaces) tend to be associated with amenities and safety but not everywhere (Ceccato \& Hanson, 2013; Groff \& McCord, 2011; Iqbal \& Ceccato, 2015). Vacant lands and/or interstitial spaces with greenery may be considered an indication not of environmental quality but quite the opposite, as they may attract problems, such as littering, and more serious crimes, such as drugs, robbery and rape, that seriously affect urban quality (Iqbal \& Ceccato, 2015; Troyer \& Wright, 1985). 
The international literature on green spaces and safety covers a wide spectrum of environments, from parks to interstitial spaces, of varied sizes and functions. What are the most common types of green areas linked to issues of crime and poor perceived safety? Size, location and function are important determinants of safety in a green area (Iqbal \& Ceccato, 2016), as are temporal factors that interact with the city structure and people's routine activity (Cohen \& Felson, 1979). Brantingham and Brantingham (1984) suggested that offenders become familiar with the places that are relevant to them ("nodes") and the corridors that link them ("paths"). These nodes and paths constitute offenders' awareness space, and it is within or on the fringes of this space that they are most likely to commit an offense. Green areas can be nodes or areas in those paths located within many offenders' awareness space and can become a risky place.

\section{Green areas as risky places}

A green area can become a risky place, namely a place that concentrates a disproportionately high number of crimes in relation to its surroundings (Clarke \& Eck, 2007). As a risky place, a green area can be a crime generator (Brantingham \& Brantingham, 1995); in other words, people with criminal motivation can be drawn to, for example, a desolated park that provides the basic conditions for crime to happen. Crime generators are risky places with many criminal opportunities that are well known to offenders, such as an open drug market in a park. A park can also be a crime attractor; for example, a green area attracts large numbers of people for reasons unrelated to criminal motivation, creating many opportunities for crime (Groff \& McCord, 2011; Hilborn, 2009; Iqbal \& Ceccato, 2015). A green area can also become a crime enabler when there is little regulation of behavior at that place: rules of conduct are absent or not enforced (Clarke \& Eck, 2005). The physical and social environment, the maintenance of the place (e.g., illumination) and the mechanisms that reinforce guardianship (e.g., "eyes on the park") are fundamental to keeping it safe. Green areas can also become crime radiators or crime absorbers (Bowers, 2014). Bowers (2014, p. 389) explored the nature of the relationship between a particular place and what occurs outside but near the place. Crime radiators "cause crime in the immediate environment as well as internally", while crime absorbers absorb risk from the external locale.

Whether a green area is a risky place depends on the context, not only spatially (by type of land use, inner city-outskirts, rural-urban) but also temporally (by hour of the day, day of the week, seasonally). The type of green area, its function and design influence what occurs in it as well as in places surrounding it. This implies that environments can be planned, built and modified following design principles that reduce the opportunities for crime. This can be done by stimulating surveillance at particular times, fostering territoriality and reducing areas of conflict by controlling access and improving overall perceived safety (Armitage, 2013; Cozens, Saville, \& Hillier, 2005; Ekblom, 2011, 
2019; Iqbal \& Ceccato, 2016; Jeffery, 1971, 1977; Newman, 1972; Saville, 2019).

\section{Green areas and safety perceptions}

A desolate, unsafe park can reduce the walkability of the whole area where it is located. The mechanisms linking individuals and safety vary, but they are often associated with the inherent qualities of environments (streets and places) that encourage individuals to use them. People in the streets create "eyes on the streets" (Jacobs, 1961), which can affect the risk of crime and safety perceptions (Cohen \& Felson, 1979; Reynald, 2010). Indeed, Talen and Koschinsky (2014) indicated that the quality of the urban environment, social interaction, safety and health are interrelated. Fear of crime can change and limit an individual's activities (Giurgescu et al., 2017; Jackson \& Gouseti, 2012; Lorenc et al., 2013), restricting her/his own mobility and ultimately her/his health.

Yet, the way we perceive the environment is also a function of what we are. Individual factors play a role in defining perceptions of risk and safety. Previous research confirms that an individual's fears depend on individual physical abilities as well as on age, gender, sexual status, ethnicity and socioeconomic background (Box, Hale, \& Andrews, 1988; Garofalo \& Laub, 1979; Pain \& Smith, 2008). Therefore, the nature of perceived safety (or the lack thereof, i.e., fear) is a multi-faceted and multi-scale phenomenon (Day, 2009; Los, 2002; Wyant, 2008), a result of the intersection of an individual's characteristics and the environments to which he/she is exposed.

\subsection{Methodology}

The literature search covered 50 years, from 1968 to 2018, of publications in the following databases: Scopus and Google Scholar. Although our search extended back 50 years, articles in this particular topic only started to appear in journals in the 1980s and 1990s. The bibliographic selection was conducted in two steps: first, we focused on the bibliometric analysis and then on in-depth analysis of the material.

Three combinations of keywords were used to search in each database, as shown in Table 4.1. The searches were conducted in July 2019 and aimed to combine terms related to crime, fear or different kinds of violence with the ones linked to green areas. This is a review of literature inspired by the principles of the Cochrane Handbook for Systematic Reviews (Higgins \& Green, 2011) as well as the PRISMA checklist (Moher, Liberati, Tetzlaff, \& Altman, 2009 ). One of the features that distinguish this type of review from others is the pre-specification of studies following a set of eligibility criteria (Higgins \& Green, 2011). The flowchart in Figure 4.1 illustrates an approximate estimation of the articles during the process of collection and selection of the publications. 
Table 4.1 Sets of keywords, number of results and documents selected from Google Scholar and Scopus

\begin{tabular}{|c|c|c|c|}
\hline Database & Keywords & Results & Selected \\
\hline \multirow[t]{3}{*}{ Scopus } & 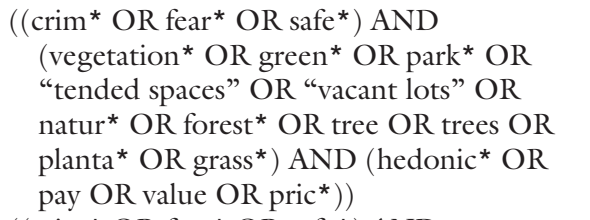 & 16 & 4 \\
\hline & 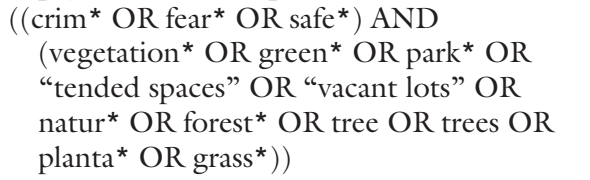 & 1,045 & 68 \\
\hline & $\begin{array}{l}\text { ((burglar* OR larcen* OR theft* OR } \\
\text { murder* OR assault* OR robber* OR } \\
\text { felon* OR aggressi* OR violenc* OR } \\
\text { disorder OR offence) AND (vegetation* } \\
\text { OR green* OR park* OR “tended spaces" } \\
\text { OR "vacant lots" OR forest* OR tree OR } \\
\text { trees OR planta* OR grass*)) }\end{array}$ & 640 & 23 \\
\hline \multirow[t]{3}{*}{$\begin{array}{l}\text { Google } \\
\text { Scholar }\end{array}$} & $\begin{array}{l}\text { (crime OR fear OR safe OR safety)+ } \\
\text { ("tended spaces" OR "vacant lots" OR } \\
\text { nature OR forest OR tree OR trees OR } \\
\text { plantation OR grass OR green OR parks } \\
\text { OR park OR vegetation) + (prices OR } \\
\text { price OR value OR values OR pay OR } \\
\text { hedonic) }\end{array}$ & 20 & 3 \\
\hline & $\begin{array}{l}\text { (crime OR fear OR safe OR safety) + } \\
\text { ("tended spaces" OR “vacant lots" OR } \\
\text { nature OR forest OR tree OR trees OR } \\
\text { plantation OR grass OR green OR parks } \\
\text { OR park OR vegetation) }\end{array}$ & 2,940 & 6 \\
\hline & $\begin{array}{l}\text { (burglary OR larceny OR theft OR murder } \\
\text { OR assault OR robbery OR felony OR } \\
\text { aggression OR violence OR offence) + } \\
\text { ("tended spaces" OR “vacant lots" OR } \\
\text { forest OR tree OR trees OR plantation } \\
\text { OR grass OR green OR vegetation } \\
\text { OR park) }\end{array}$ & 328 & 4 \\
\hline Total & & 4,989 & 108 \\
\hline
\end{tabular}

\section{Bibliometric analysis}

The bibliometric analysis included only 95 articles obtained and selected from Scopus (in * ${ }^{*}$.ris) in the data collection process. VOSviewer version 1.6.12 (www.vosviewer.com) is a free-access software tool that was used to create bibliometric maps based on the keywords cited in each selected article and to group terms in clusters according to their linkages. The map in VOSviewer was 


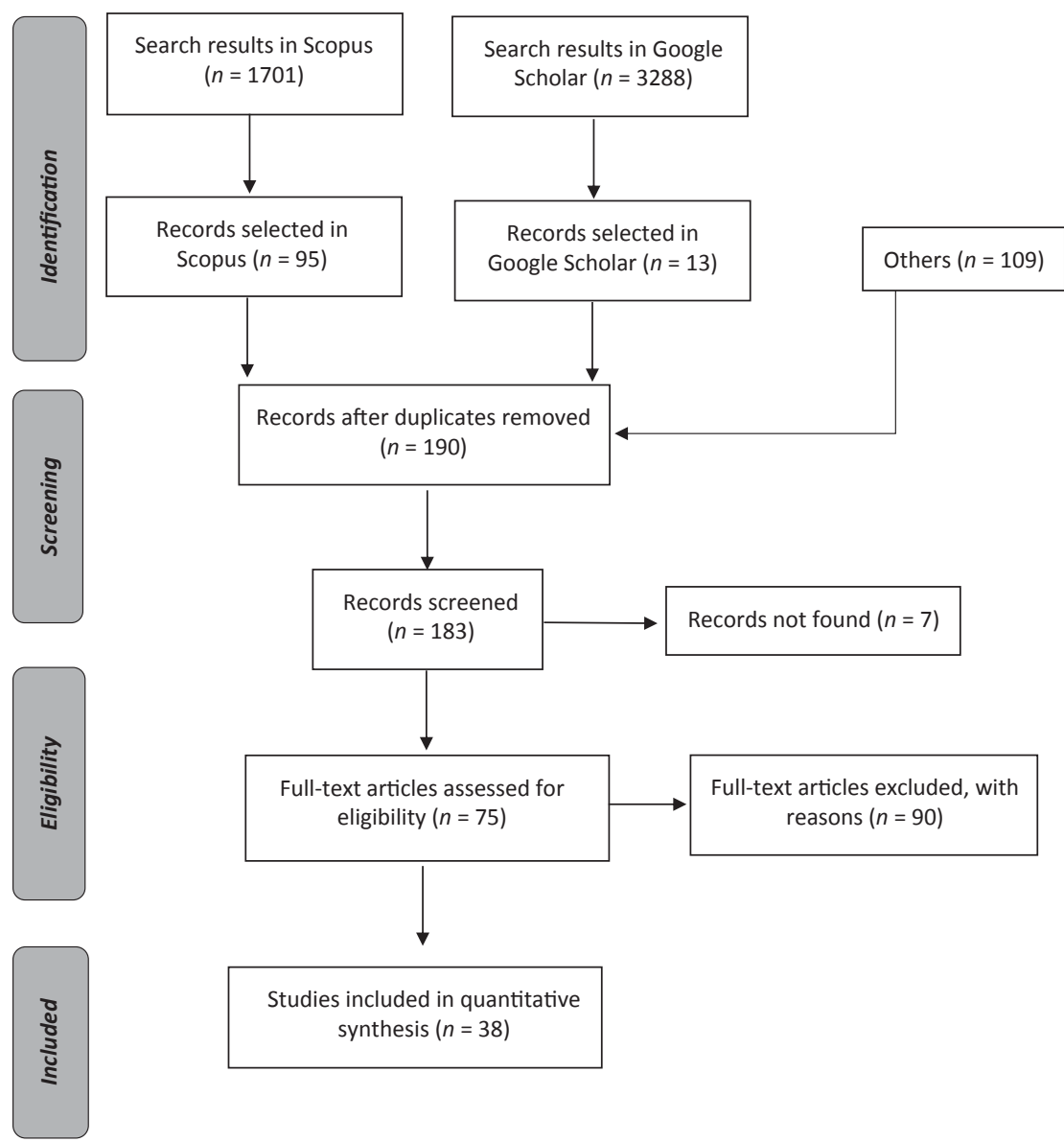

Figure 4.1 Data collection and selection in Scopus and Google Scholar, 1968-2018.

created based on the bibliometric data, and the 95 articles mentioned above were used as input data. The co-occurrence analysis was performed using the keywords adopting the counting method. It resulted in a total of 800 terms, of which only 244 met the threshold of the minimum number of two occurrences/repetitions. This criterion of a minimum of two repetitions was selected to avoid terms without links or with weak links to the theme and at the same time to ensure the coverage of the terms and representativeness of the articles. The final selection resulted in 95 items out of the 244 keywords, and the map was created using the default settings. We performed thematic content analysis. Output files from the database were used to produce informative network maps by theme. A number of themes were selected based on the clusters that emerged from the literature and are discussed in Section 4.4. 


\section{In-depth analysis}

In addition to the search on Scopus, we also searched Google Scholar. In some cases, one of the keywords was excluded from one of the searches to make the results more specific to the target subject. Our inclusion and exclusion criteria for both databases are presented in Table 4.2. The total was 4,989 publications, of which 66 percent were from Google Scholar (Table 4.1). Unfortunately, the results were too general, so only the first 10 pages were considered for evaluation. The advantage of using Google Scholar is that this platform includes papers published before 1970, which were lacking in the Scopus search. Only 38 were eligible (articles that contained links between green areas, crime and/ or fear) and constitute the base for the analysis (Tables A4.1-A4.3 in the Appendix). In a few cases, articles appear in two different tables because they evaluate both crime and fear. These themes support the selection of topics that are relevant to be investigated in detail and that are discussed in the literature overview, more specifically the correlation or effect of green areas on crime and/or safety:

- Positive: decline of crime and increase of safety perceptions, an expected effect

- Negative: green areas have unexpected effect on crime and/or safety/fear

- Inconclusive: different effects were observed in different variables

- No difference: no statistically significant impact or crime and/or fear of crime remained the same (before and after interventions, for example)

Table 4.2 Inclusion and exclusion criteria

\begin{tabular}{|c|c|c|c|}
\hline Criteria & Inclusion & Exclusion & Database \\
\hline 1. Year & 1968-2018 & Others & $\begin{array}{l}\text { Scopus and } \\
\text { Google Scholar }\end{array}$ \\
\hline 2. Language & English & Others & $\begin{array}{l}\text { Scopus and } \\
\text { Google Scholar }\end{array}$ \\
\hline 3. Document & $\begin{array}{l}\text { Article, Book, Chapter, } \\
\text { Review }\end{array}$ & Others & Scopus \\
\hline 4. Subject Area & $\begin{array}{l}\text { Engineering; Medicine; } \\
\text { Social Sciences; } \\
\text { Environmental Science; } \\
\text { Psychology; Economics, } \\
\text { Econometrics and } \\
\text { Finance; Multidisciplinary; } \\
\text { Undefined }\end{array}$ & Others & Scopus \\
\hline 5. Field & Title & Others & Google Scholar \\
\hline 6. & Null & $\begin{array}{l}\text { Include } \\
\text { Patents, } \\
\text { Include } \\
\text { citations }\end{array}$ & Google Scholar \\
\hline 7. & Sort by relevance & Null & Google Scholar \\
\hline
\end{tabular}




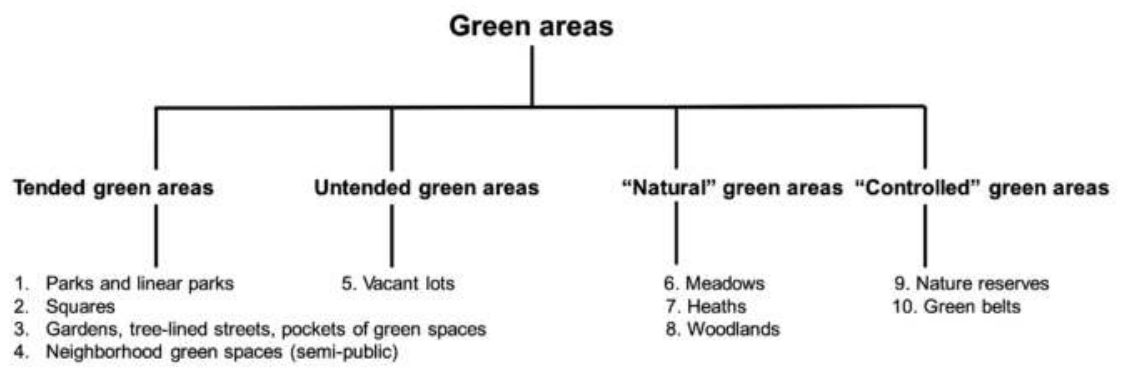

Figure 4.2 The categorization of green areas adapted from Goode and Collins (2014).

The cities in the studies are classified into the following five types: (1) global cities and/or capitals; (2) regional capitals; (3) local city centers; (4) small towns and/or communities; and (5) other. Green areas were also classified into the categories suggested by Goode and Collins (2014) and are numbered as suggested in Figure 4.2.

\subsection{Results and discussion}

This study builds on two current systematic literatures (Bogar \& Beyer, 2015; Kondo et al., 2018a) that assessed the evidence on relationships among green space, violence and crime. These authors call for additional research and standardization among research studies to better understand the relationship between urban green space, violence and crime. Below we discuss the results, also including publications that deal with green areas and fear, in articles from around the world written in English.

\section{Green areas and safety: overall patterns}

The bibliometric analysis resulted in seven themes as an outcome of the literature search (Figure 4.3(a)). The themes vary from crime and safety, to design of the urban environment and neighborhood, residence characteristics and urban health, taken from Scopus and Google Scholar, 1968-2018. The greater the weight of an item, the larger the circle. Most of the articles link greenspace/ areas, crime and safety, urban area, perception and neighborhood issues. The distance between two keywords indicates the relatedness of the keywords, in terms of co-citation links. Figure 4.3(b) corresponds to the density visualization of authors' keywords based on total occurrences, association strength. The analysis of the overall pattern has been complemented with an in-depth analysis of 38 articles, which is discussed below.

The vast majority of the studies focused on "type 1 green areas," namely those categorized as "tended green spaces for pleasure," as suggested by Goode and 

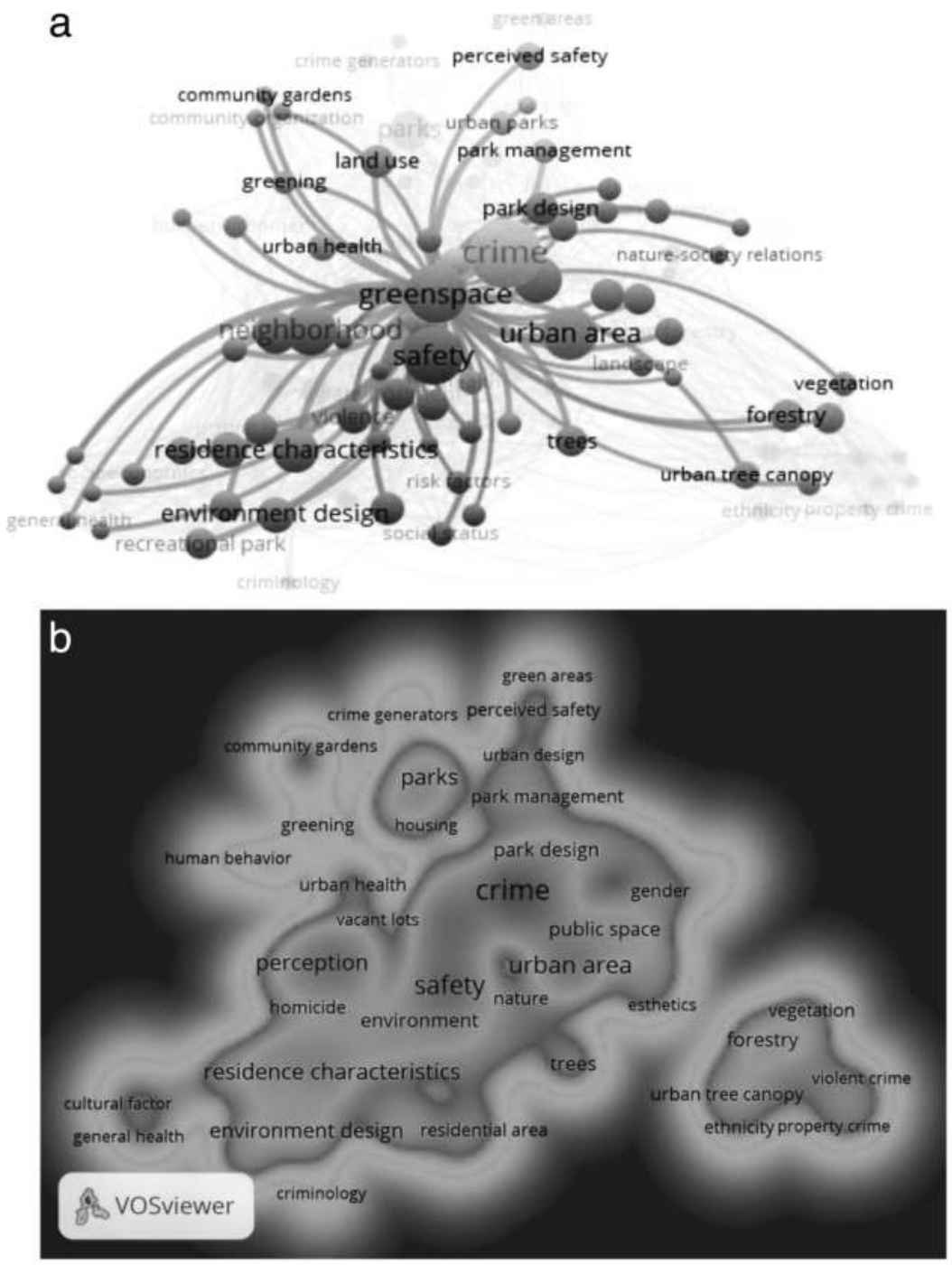

Figure 4.3 Literature search for keyword: "greenspace" in publications that relate to crime and fear of crime, 1968-2018. (a) Network visualization map with focus on "greenspace" as an example in Scopus, 1968-2018. (b) Density visualization of author keywords, 1968-2018, in Scopus based on total occurrences, association strength.

Collins (2014), including squares, parks and campuses (Figure 4.2). This finding is based on the in-depth analysis collected from 38 articles. Around 70 percent of these studies are from North America, 15 percent from European countries, and 15 percent from Asia, Australia and other countries. In North America, the sites 


\section{Vania Ceccato et al.}

might vary between global/capital cities and regional capitals (Cleveland, Denver, Philadelphia, New Haven, Cincinnati, Portland). Only two were in the local urban centers of Youngstown, Ohio, and Flint, Michigan (Appendix).

Out of 38 articles, 43 percent deal with the relationship between crime and green spaces and 47 percent green spaces and safety perception/fear, while 10 percent dealt with both crime and fear in relation to a variety of types of green area (Figure 4.4(a)). As much as 41 percent of the articles show that green areas affect safety positively (for example: vegetation in abundance is associated with lower rates of assault, robbery and burglary; in low-income neighborhoods residents perceived nearby parks as being safe; and interventions in a park decreased

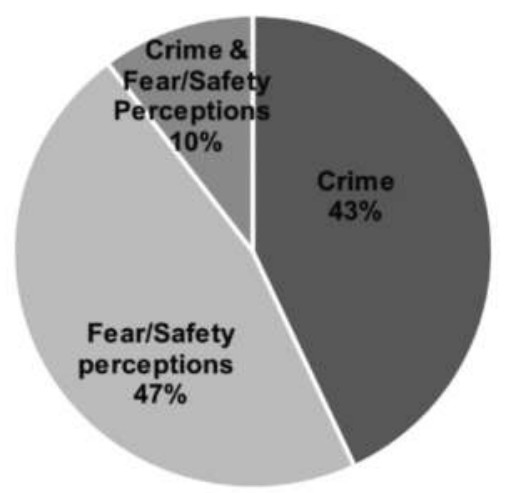

(a) Studies by safety measure

$N=38(16+18+4=38)$

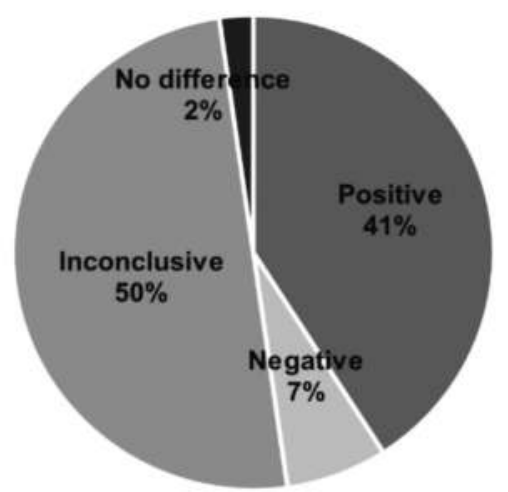

(b) Studies by relationship with green areas

Figure 4.4 Analysis of the relationship of green areas and crime and fear/perceived safety. 
overall crime compared with those areas that did not receive an intervention), while 7 percent of the articles indicate that green areas have a negative impact (for example, increased crime), 50 percent of the articles show inconclusive/ conflicting results (different effects were observed in different variables) and 2 percent showed no effect, or not statistically significant (Figure 4.4(b)).

\section{Green areas and crime}

Although the studies show conflicting results, the overall pattern is that green areas do not seem to be related to an increase in crime. On the contrary, there were certain studies that revealed that green areas had a decreasing effect on crime, or that safety interventions decreased crime in green areas and/or neighborhoods. Eight articles suggested that green areas are not associated with crime occurrence or increase (Gilstad-Hayden et al., 2015; Heinze et al., 2018; Kondo, Andreyeva et al., 2018; Kondo, Fluehr et al., 2018; Kondo, Han et al., 2017; Kondo, South et al., 2017; Kuo \& Sullivan, 2001a; Wolfe \& Mennis, 2012; Ye et al., 2018), and two did not show any evidence either way (Garvin et al., 2013; Kimpton et al., 2017). Among those studies that did not show the negative effect of green areas, two studies focused on vacant lots in urban areas, four investigated trees and vegetation coverage in cities, and two analyzed the neighborhood-scale green areas around big cities. Outcomes for crime were categorized by type of crime according to the articles as shown in Appendix, Table A4.1.

Nearly all studies are cross-sectional analyses. One exception was the study by Branas et al. (2018) that analyzed a total of 541 randomly sampled vacant lots that were assigned into treatment and control study arms; outcomes from police and 445 randomly sampled participants were analyzed over a 38-month study period. Participants living near "treated" vacant lots reported significantly reduced perceptions of crime, vandalism and safety concerns when going outside their homes as well as increased use of outside spaces for relaxing and socializing. Significant reductions in crime overall and nuisances were also found after the treatment of vacant lots in neighborhoods below the poverty line.

In our sample that covered studies on all continents, we found that regression models were used six times with varying research designs. Quasi-experimental, difference-in-difference analysis, autocorrelations, circular statistics and geocoded mappings were also applied. Mixed methods were also common. For example, Groff and McCord (2011) performed a field survey and combined it with statistical analysis (location quotients and comparison) to examine the relationship between parks and crime and disorder in Philadelphia.

Maintenance of green areas and parks plays an important role when it comes to the relationship between green areas and crime. Vacant lots that are well managed and maintained, for instance, have less crime (Branas et al., 2011; Heinze et al., 2018) and better perceived safety (Branas et al., 2011; Garvin et al., 2013; Heinze et al., 2018). Better maintained vacant lots have fewer assaults, gun assaults, vandalism and violent crimes than street segments with vacant, abandoned and untreated lots (Branas et al., 2011; Heinze et al., 2018). 
In addition, being under and around tree coverage is associated with violence, property crimes, gun assault and total crime (Branas et al., 2011; GilstadHayden et al., 2015; Kondo, Han, et al., 2017; Ye et al., 2018). This appears to support former findings from research conducted in big cities where trees and other vegetation were associated with total crime and disorder. In addition, the effect of good maintenance was noted in previous studies from the 1990s. Poyner (1994), for example, illustrated the effect of demolition in the UK, showing that robberies and snatches decreased. In the United States, Freedman and Owens (2011) showed that new construction and rehabilitation have led to significant reductions in violent crime that is measurable at the county level, although there are no detectable effects on property crime. Similarly, Aliprantis and Hartley (2015) estimated the effects of closures and demolition in Chicago; findings showed a significant decrease in homicides around demolitions. Note that these studies (Poyner, 1994, Freedman \& Owens, 2011; Aliprantis \& Hartley, 2015) were not included in our review because their primary focus was on demolitions, so they did not satisfy the selection criteria.

However, crime seems to have been associated with green areas in three studies. For example, the study of Kondo, Han et al. (2017) showed that tree damage caused by an invasive tree pest was associated with an increase in total crime (except damage/endangerment, burglary, robbery and rape). Further investigation revealed that certain types of green area are more crime-prone than others, meaning that when greenspaces are heterogeneous they can influence both the timing and the frequency of crime (Kimpton et al., 2017). Parks in an urban area, for instance, can be crime generators (Groff \& McCord, 2011).

\section{Green areas and safety perceptions}

Appendix Table A4.2 summarizes 18 articles that deal with fear of crime and perceived safety in green areas. Almost 41 percent of them showed positive effects on safety of the presence of green areas (Branas et al., 2011; Coley et al., 1997; Farbod et al., 2017; Garvin et al., 2013; Kuo et al., 1998; Lindgren \& Nilsen, 2012; Ward Thompson et al., 2013; Vaughan et al., 2018). These findings include the impact of green areas on health status (e.g., Branas et al., 2011). Among the types of green area reported in these articles, parks comprise 48 percent of studies, green areas in neighborhoods 30 percent and woodlands 13 percent. The remaining articles focused on the influence of woodlands and trees on perceived safety. In only six studies did fear of crime increase with green areas, but these findings mainly focused on specific groups and situations (Cohen et al., 2010; Loukaitou-Sideris \& Sideris, 2010; Madge, 1997; Parra et al., 2010; Shackleton et al., 2015; Stodolska \& Shinew, 2010). As many as 60 percent of articles were based in the United States, 23 percent Europe, 14 percent Asia and the remainder elsewhere.

Safety perceptions vary according to users' profiles in these green areas. Gender plays an important role in perceived safety in green areas, and women tend to report more fear of crime than men in these environments (Jorgensen et al., 2013; 
Kuo \& Sullivan, 2001b; Loukaitou-Sideris \& Sideris, 2010; Madge, 1997; Shackleton et al., 2015). The fear of crime in green areas is also influenced by other factors. Particular uses of the park may affect safety negatively, especially among women (Jorgensen et al., 2013). Interestingly, park use leads to more park use (performing sports competitions and recreational activities) but not safety alone (Cohen et al., 2010; Loukaitou-Sideris \& Sideris, 2010).

Four articles that relate fear of crime in green areas also link to the occurrence of crimes, such as vandalism and graffiti (Jansson et al., 2013; Maruthaveeran \& Van den Bosh, 2015; Parra et al., 2010; Stodolska \& Shinew, 2010). While Appendix, Table A4.3, demonstrates some overlap in outcome directions related to urban green areas, crime and fear (e.g., wellmaintained neighborhood parks demonstrate consistent decreases in crime and fear), the table also shows evidence of specific crimes and fear with opposite relationships with urban green space, or at least varying by type of crime, resident or time of day (e.g., perceived safety was dependent on the number of people present in the park). As these results tend to be inconclusive, we will not discuss them further.

\subsection{Final considerations}

This chapter set out to assess the nature of published peer-reviewed literature in English on the relationship between green areas and safety from 1968 to 2018. We first defined what we meant by green areas in the urban context, then we associated green areas with both actual risk of being victimized by crime and in relation to fear of crime and/or safety perceptions by users. The literature shows a predominately positive trend in the effect of green areas on safety (both crime and fear/safety perceptions), but about half of the studies show inconclusive or conflicting findings. Despite the fact that these findings are similar to what was suggested by previous literature overviews (Bogar \& Beyer, 2015; Kondo et al., 2018b), caution is necessary when drawing this conclusion.

First, the current body of literature is not extensive enough to determine the effects of all types of green area and all types of crime. As for the types of green area, our results were dominated by what Goode and Collins (2014) call "tended green spaces for pleasure", such as parks, botanical gardens and squares. In addition, the studies used different methods, which makes it difficult to compare conflicting findings. Various studies showed that the effect of green areas on safety was dependent on crime types, levels and contexts, but to what extent might these differences just be an artefact of the methods?

Second, although we report results and draw conclusions based on hundreds of publications, it is important to remember that publications in peer-reviewed journals are more likely to show positive "expected" results than results that are uncertain, negative or "unexpected". At the same time, it is impossible to estimate the "dark figure" of unpublished materials, in other words, to estimate how many studies had negative or unexpected results and were not published. 
Third, what works internationally in terms of the impact on green areas may not work locally. The literature reported in this overview is dominated by studies in North America and the UK. Caution should be exercised when conclusions drawn from findings that are country- or city-specific are applied to the context of cities in the Nordic countries, which have different city structures, climate, political and cultural contexts, and distinct urban planning traditions.

Despite these limitations, the contribution of this chapter is to extend the results to publications in English for other parts of the world beyond the United States. We went beyond the "park-crime link" and looked for evidence of potential relationships between green areas and perceived safety and fear of crime. Finally, despite the fact that most articles were quantitative pieces, we also considered studies that adopted mixed methods, allowing for examples of interventions on parks and consequently on safety.

\section{Research recommendations}

The results of this literature overview show opportunities for improving our understanding through future research. One of these future research areas is the need to better understand why certain types of green area become a crime magnet and others do not; namely, why they become risky places that generate (and/or attract, absorb or radiate) crime. The temporal and spatial contexts of green areas are important aspects to be considered. Another area that remains open for further research is the relationship between the use of spaces and the well-known mismatches between the design of crime-ridden micro-places and safety perceptions in multi-functional parks (Ceccato \& Hanson, 2013) (see also Chapter 5). Finally, one important area for future research is the testing of rigorous longitudinal methodologies that can provide assessments over time and be applied in contexts other than those that are tested here.

\section{Policy implications}

More than just risky places, green areas play an important role in the sustainability of cities, so it is essential to know about their safety qualities, as was the intention of this study. We have shown a predominately positive relationship between green areas and safety in the 38 studies. This impact must be contextualized both spatially and temporally to properly inform practices of maintenance of these public places.

Planning for a safe green area is part of creating a public place that is safe and inclusive for all. Park visitors, for instance, constitute only one group of users. There might be those who have the park as a working place (vendors), others who "just" pass by (transients and people waiting for a bus) or those who temporarily reside in them (homeless). Groff and McCord (2011) stated that parks and other green areas are contested spaces in cities. Since they are often publicly owned, they are at the same time everyone's and no one's. They may offer poor 
guardianship and therefore are susceptible to be taken over by illegal activities or activities that trigger fear among visitors.

Like many other public places, parks and squares accommodate groups that are often viewed as a security problem rather than as individuals who have a right to be there and feel safe. In these circumstances, getting the right person or organization to be responsible for these environments is important (knowing who is in charge of delivering security services for whom, where and when). In most cases in public places - and in particular parks - there are no quick fixes for safety problems. They demand a multi-pronged approach, with long-term engagement of multiple authors in collaborative frameworks. Inspired by theoretical principles of environmental criminology and situational crime prevention, fieldwork protocols (Ceccato, 2019) can be used to detect particular safety problems in parks and help practitioners to think systematically about solutions that can be effective, inclusive and sustainable. 


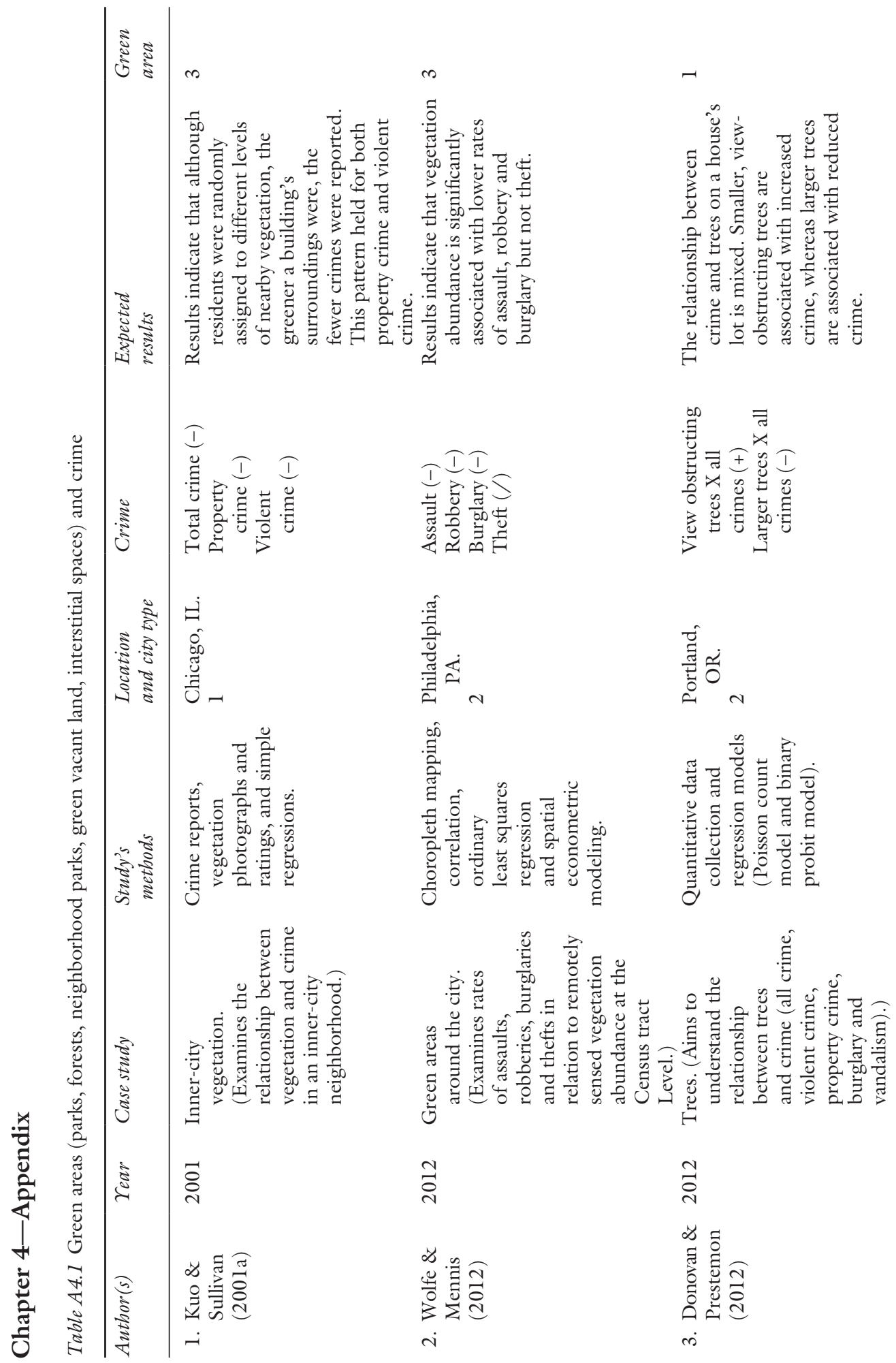




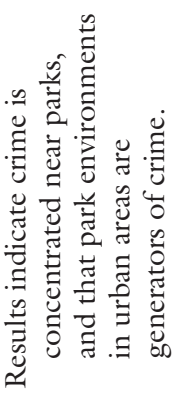

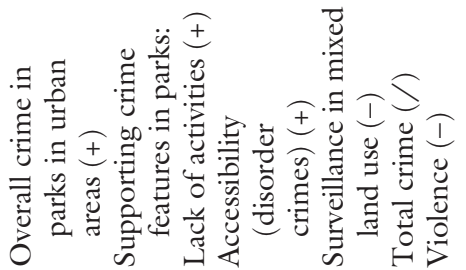
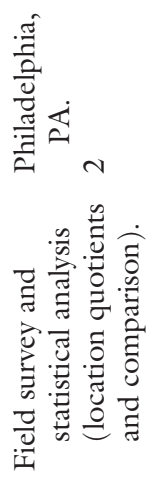

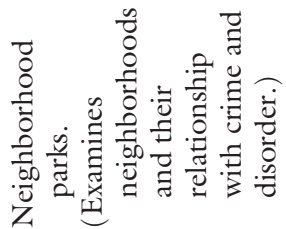

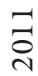

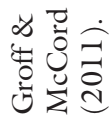

$+$

$\stackrel{10}{2}$
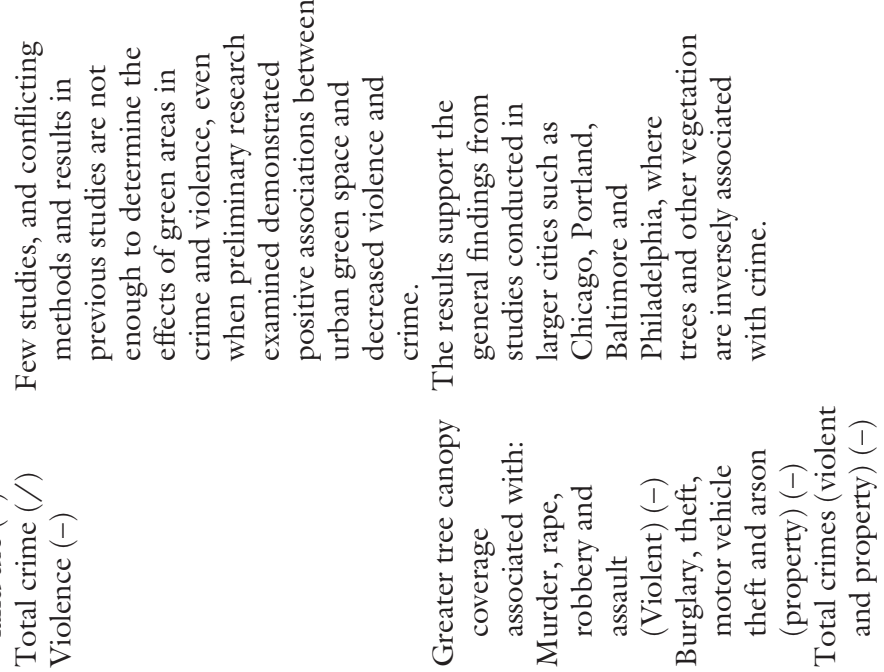

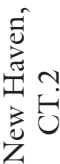
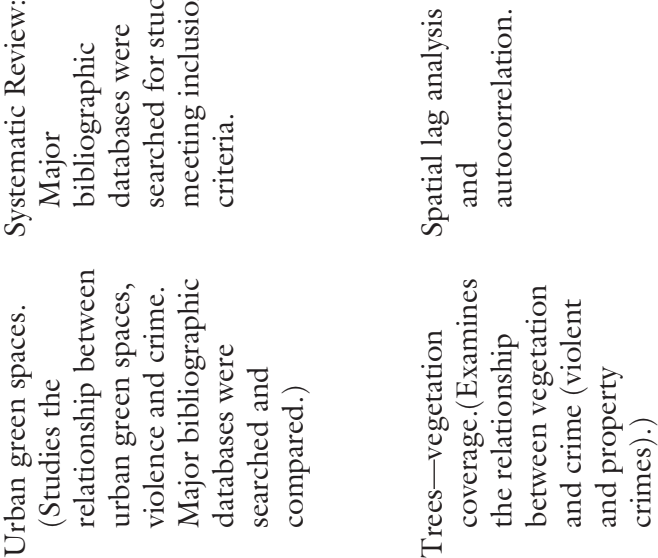

웅

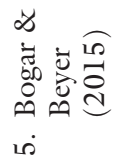




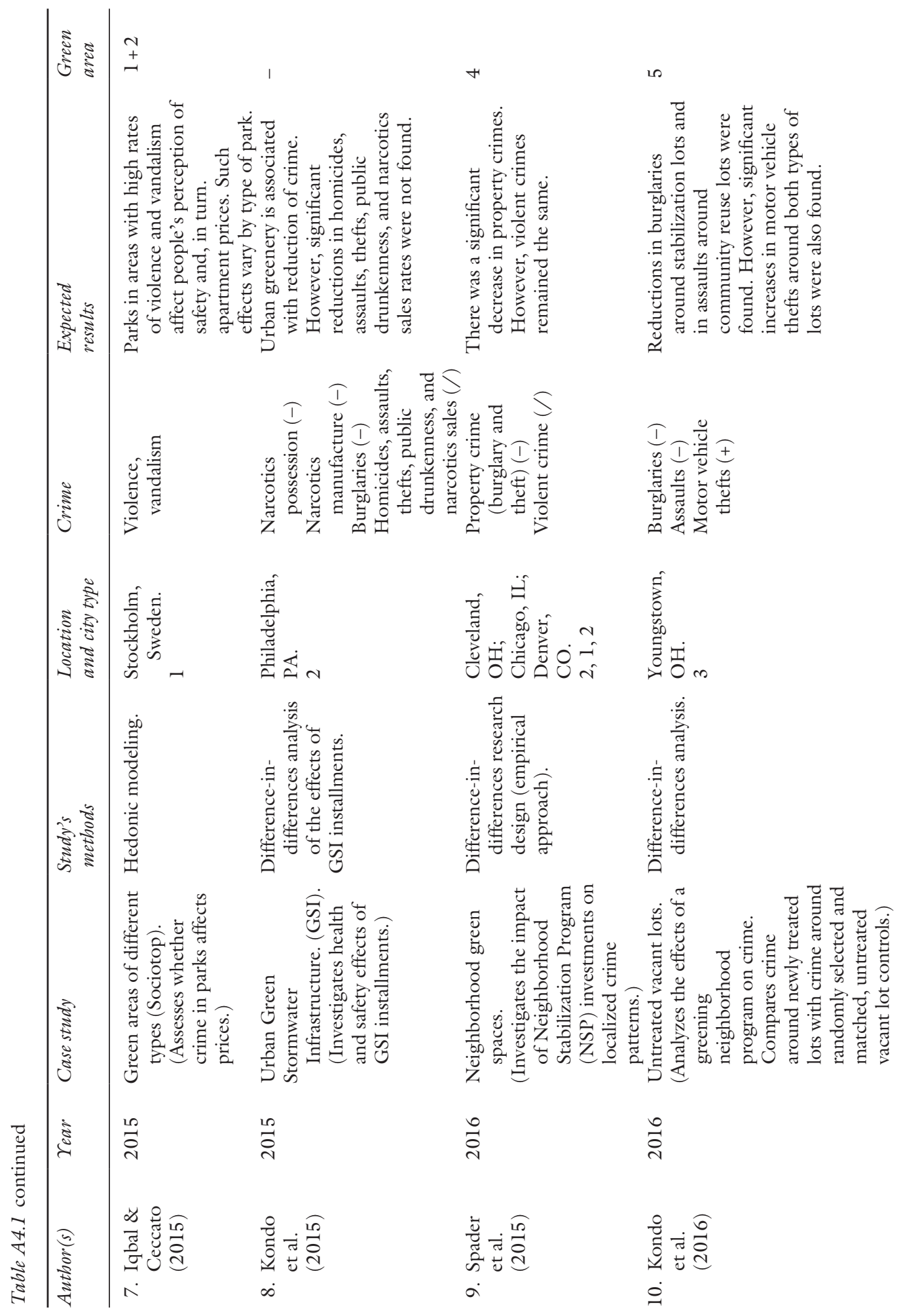



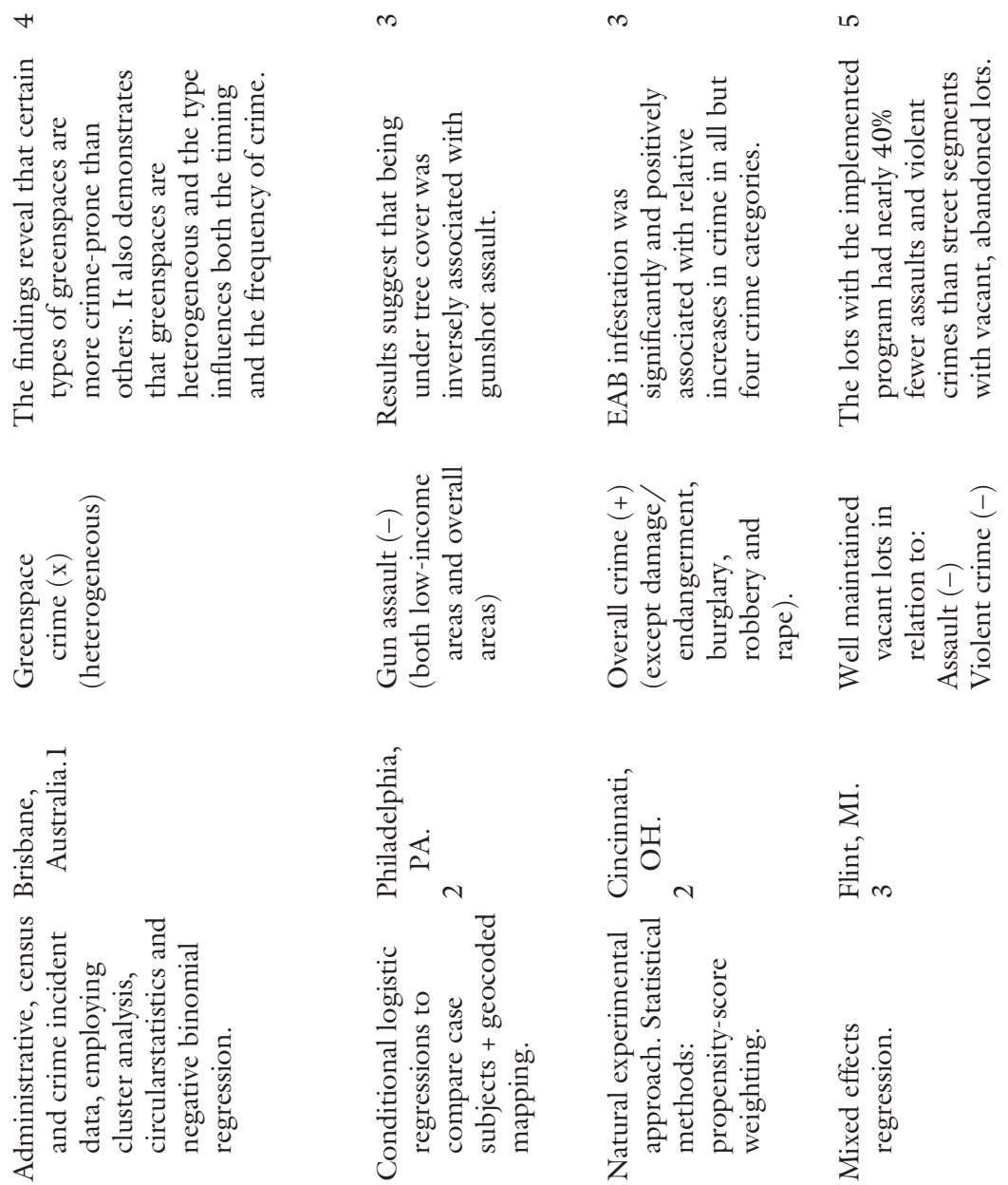

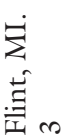

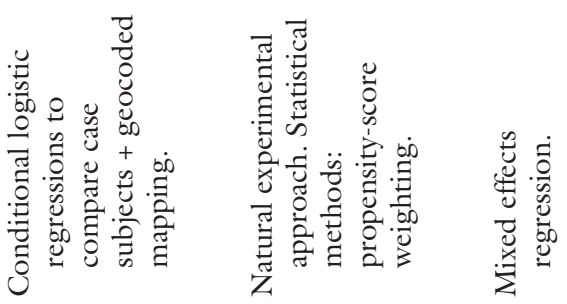

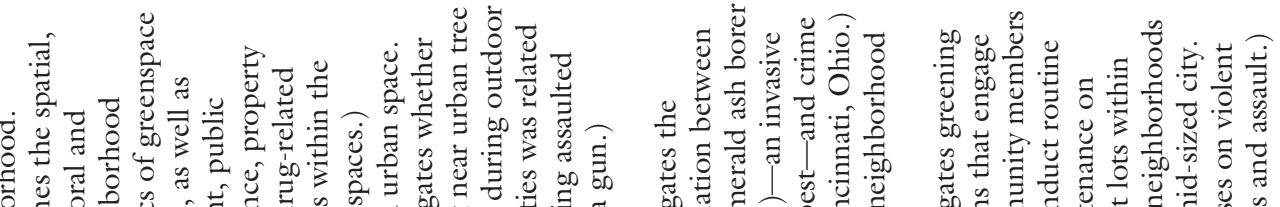

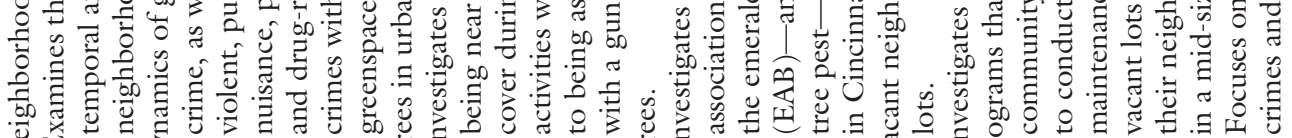

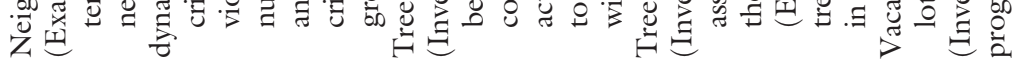

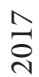

공

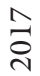

$\stackrel{\infty}{\stackrel{\infty}{\sim}}$

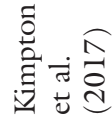

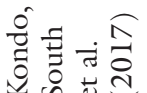

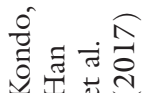

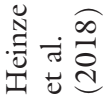

ㄱ.

$\ddot{2}$

サ 


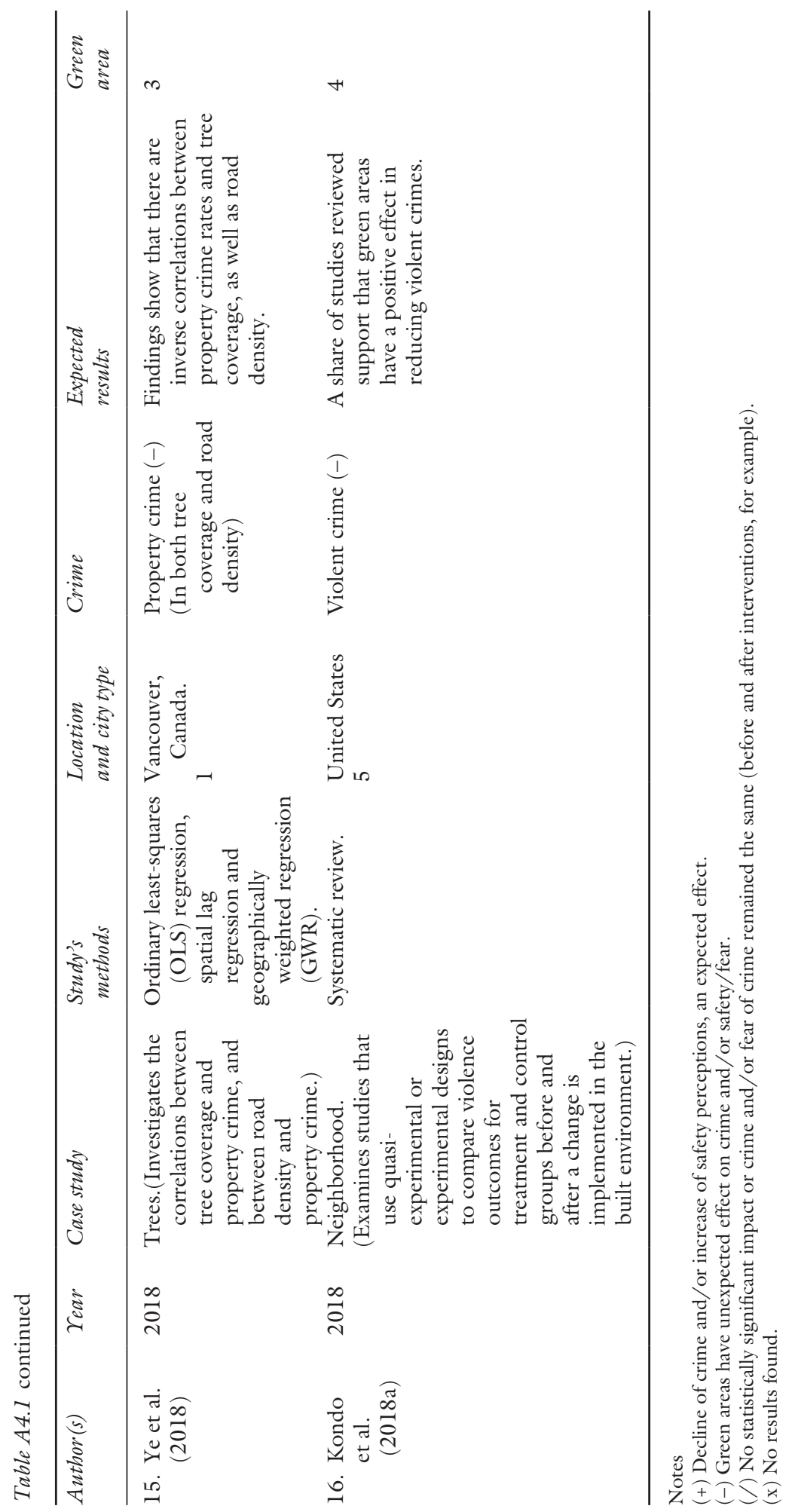


Do green areas affect crime and safety? 95

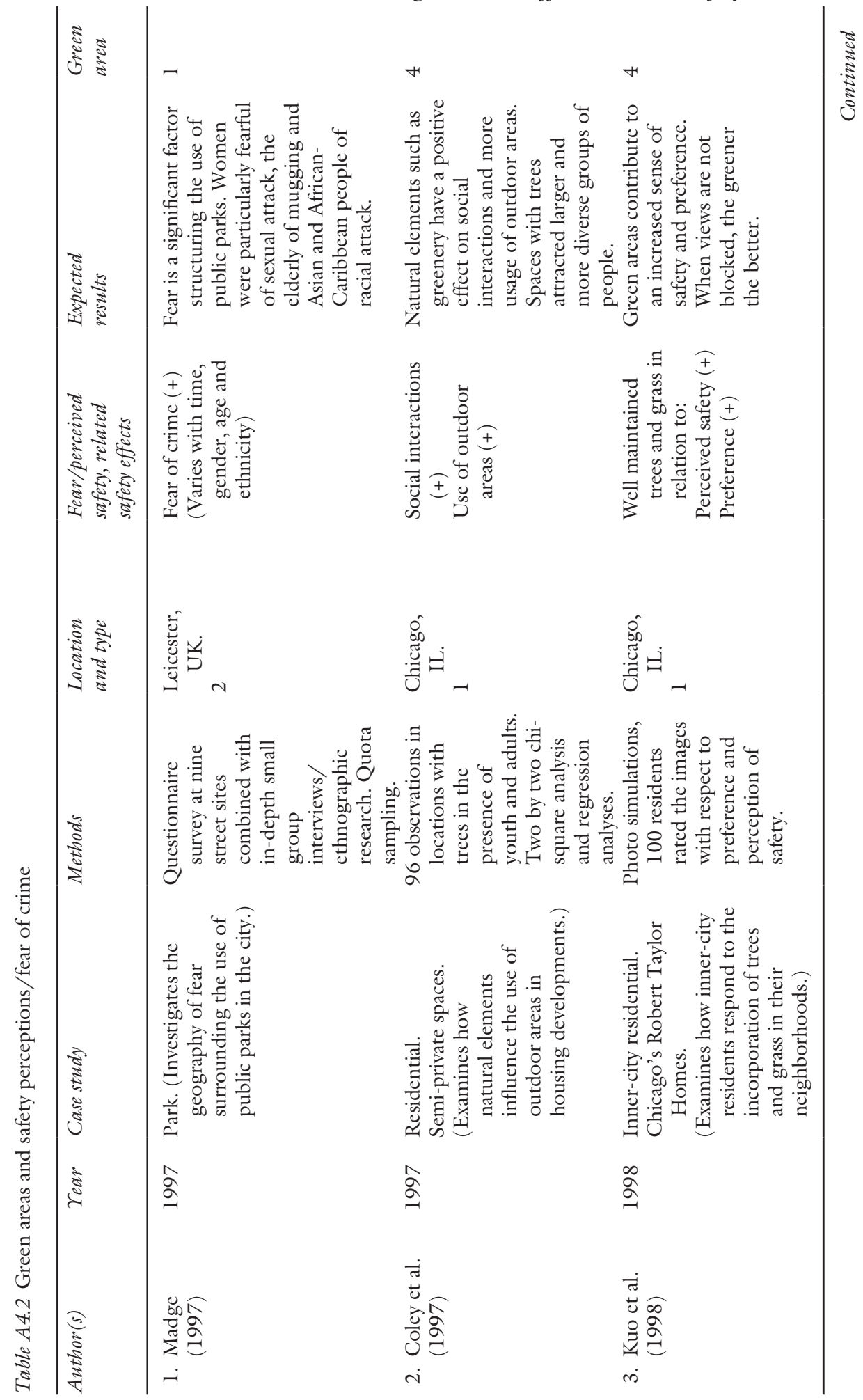




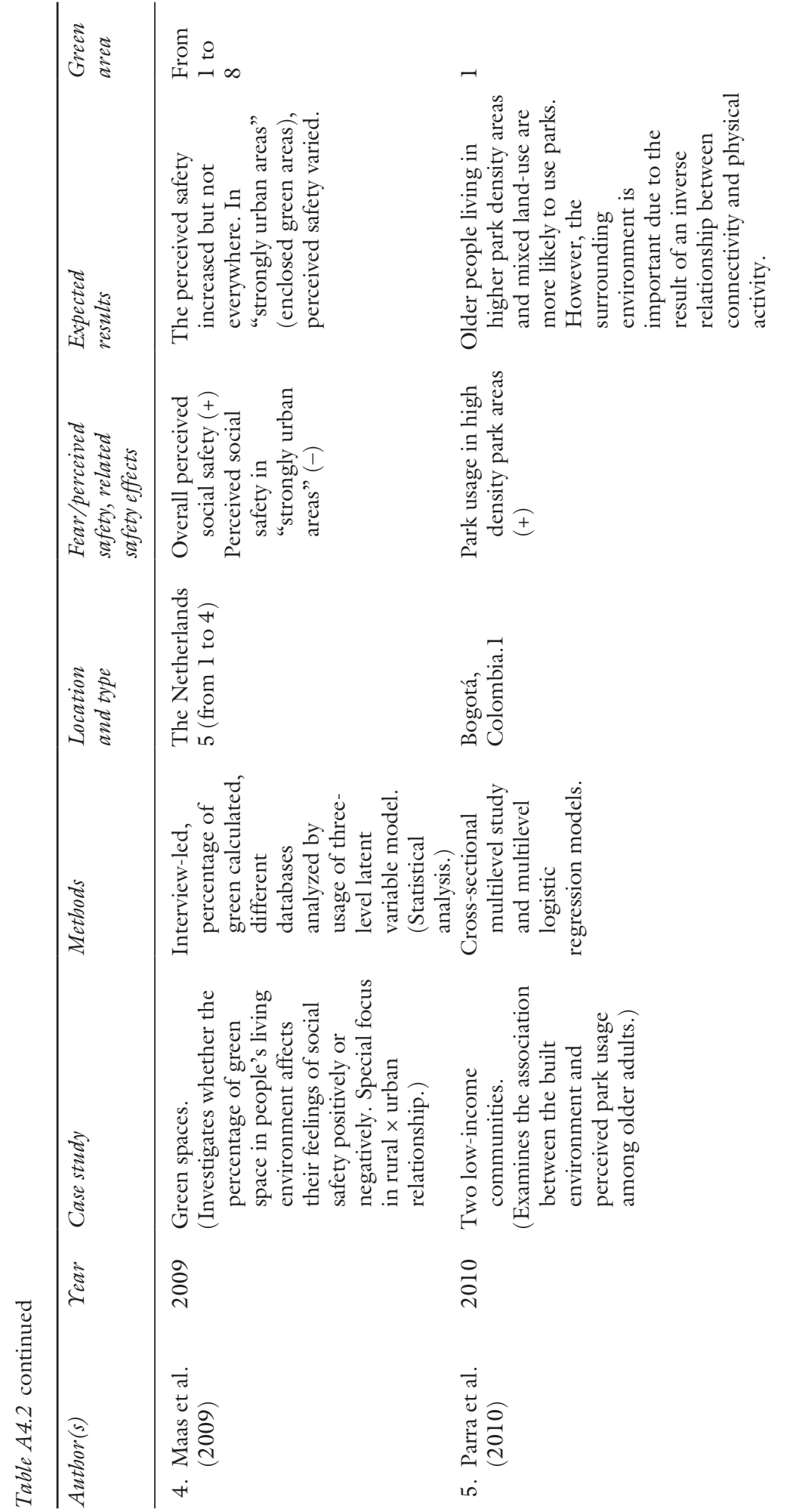



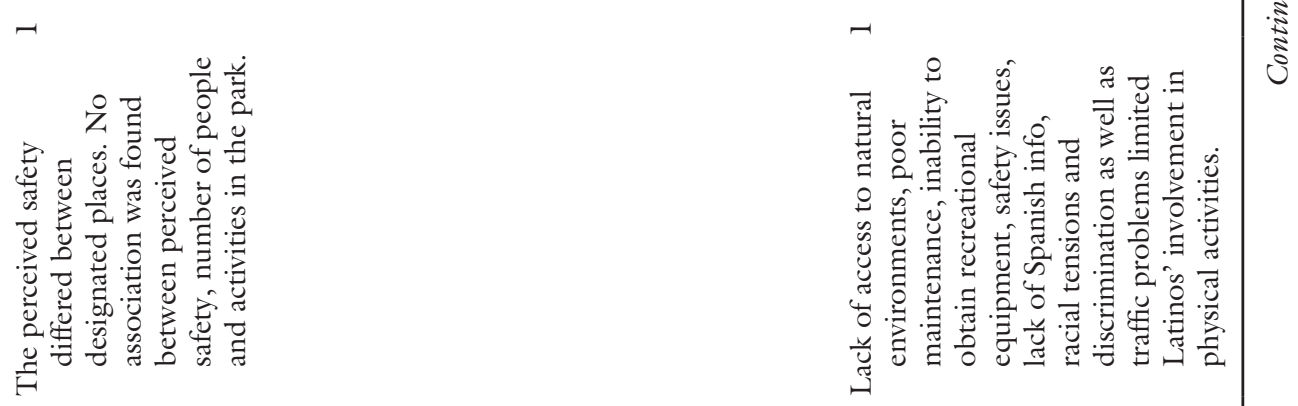

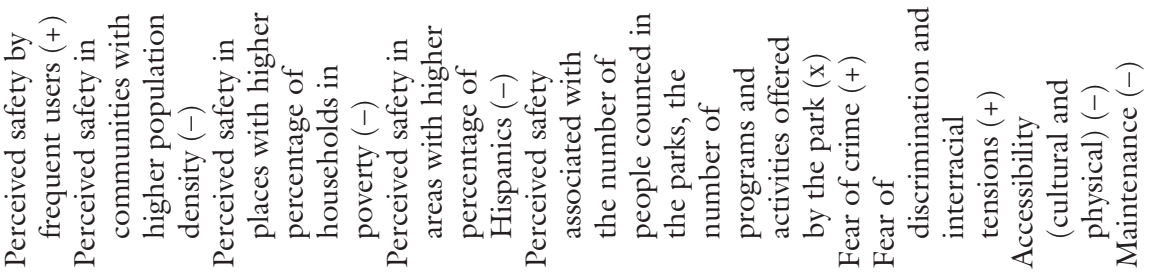
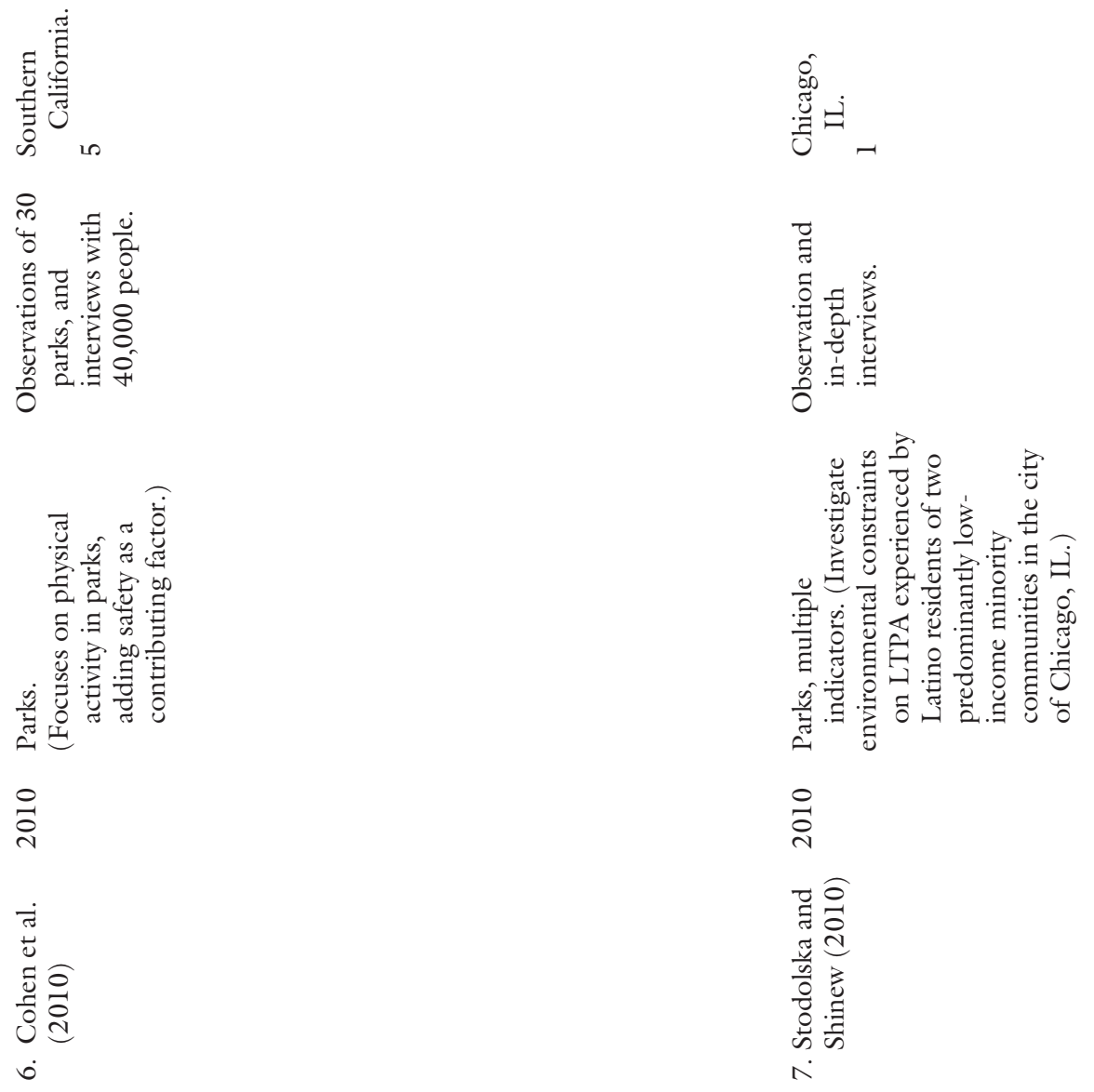
98 Vania Ceccato et al.

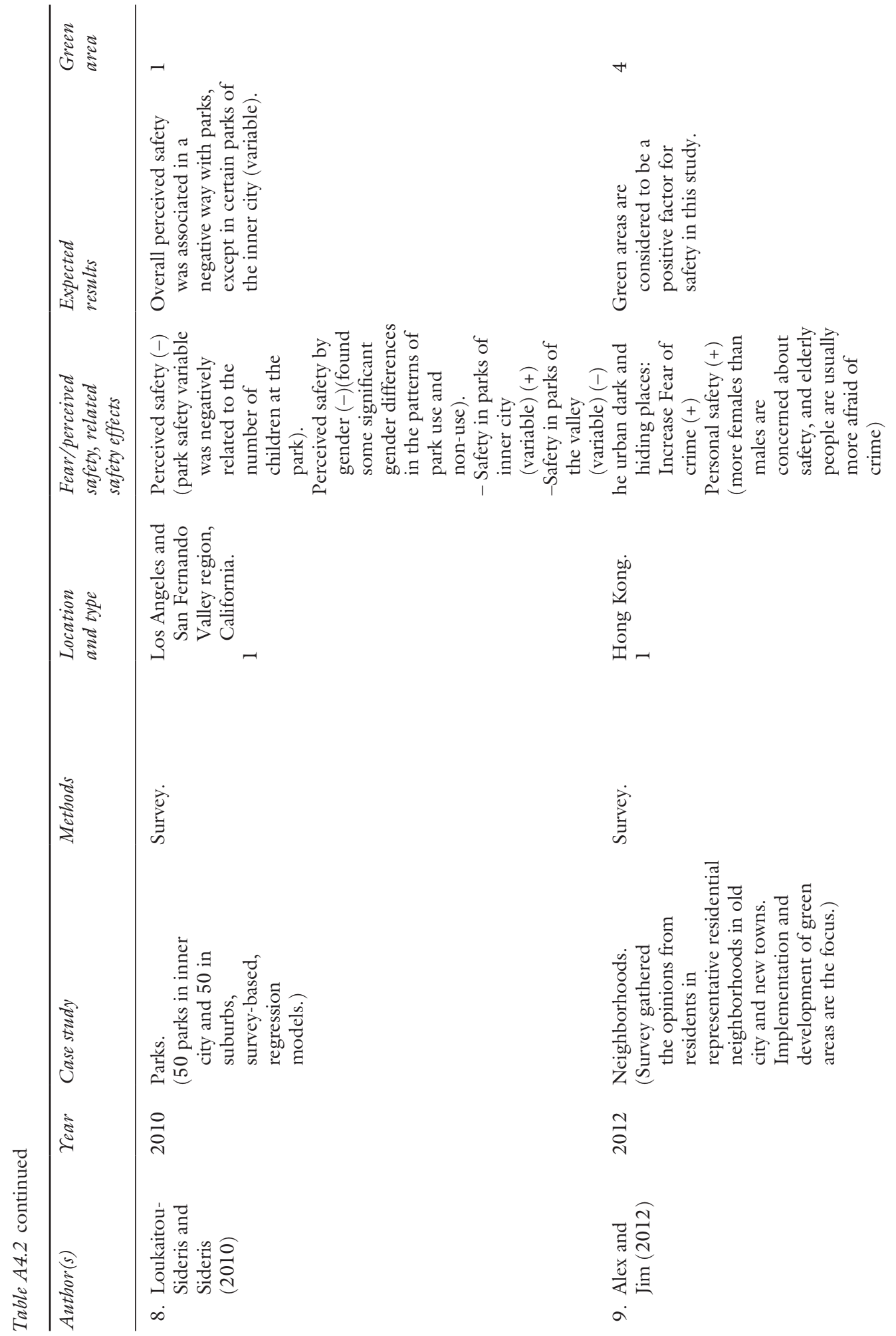




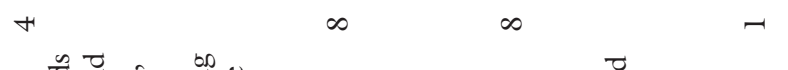

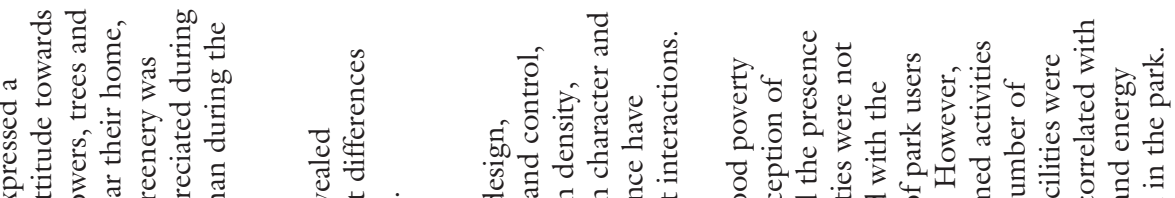

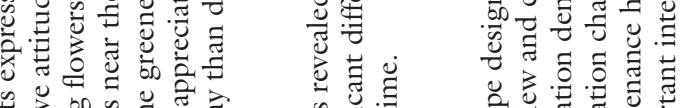

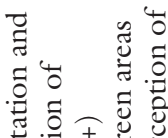

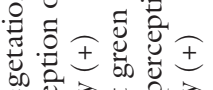

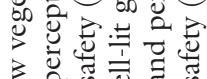

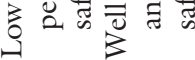
z

$\frac{\pi}{\tilde{n}}$

离离离

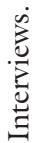

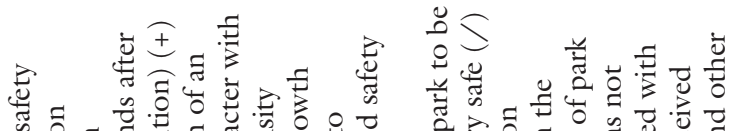

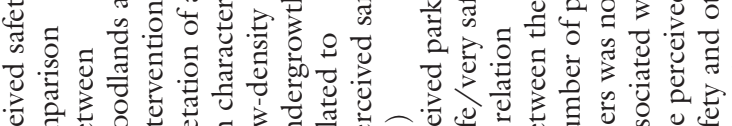

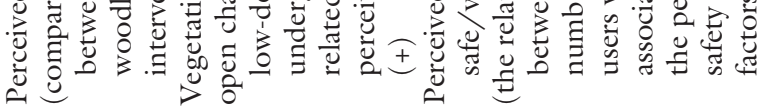
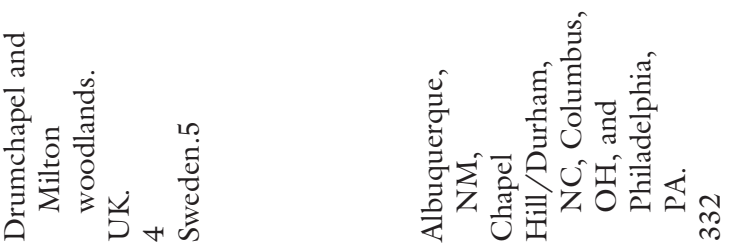

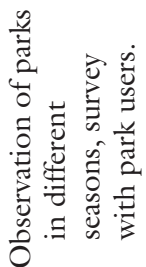

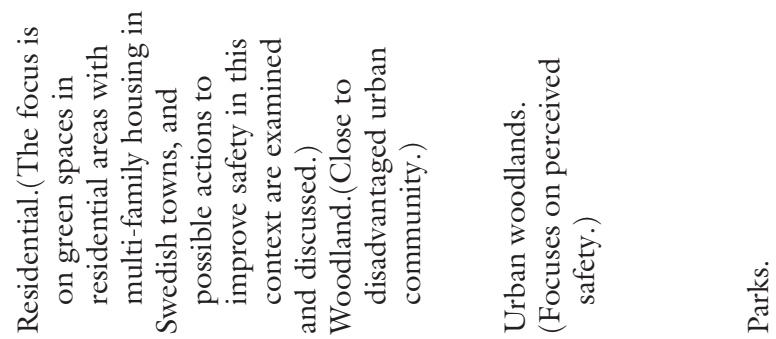

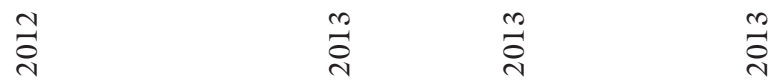

\begin{tabular}{|c|c|c|c|}
\hline 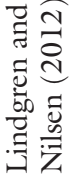 & 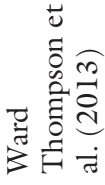 & 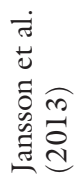 & 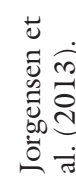 \\
\hline$c$ & $\beth$ & $\stackrel{\sim}{\sim}$ & 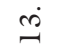 \\
\hline
\end{tabular}


Vania Ceccato et al.

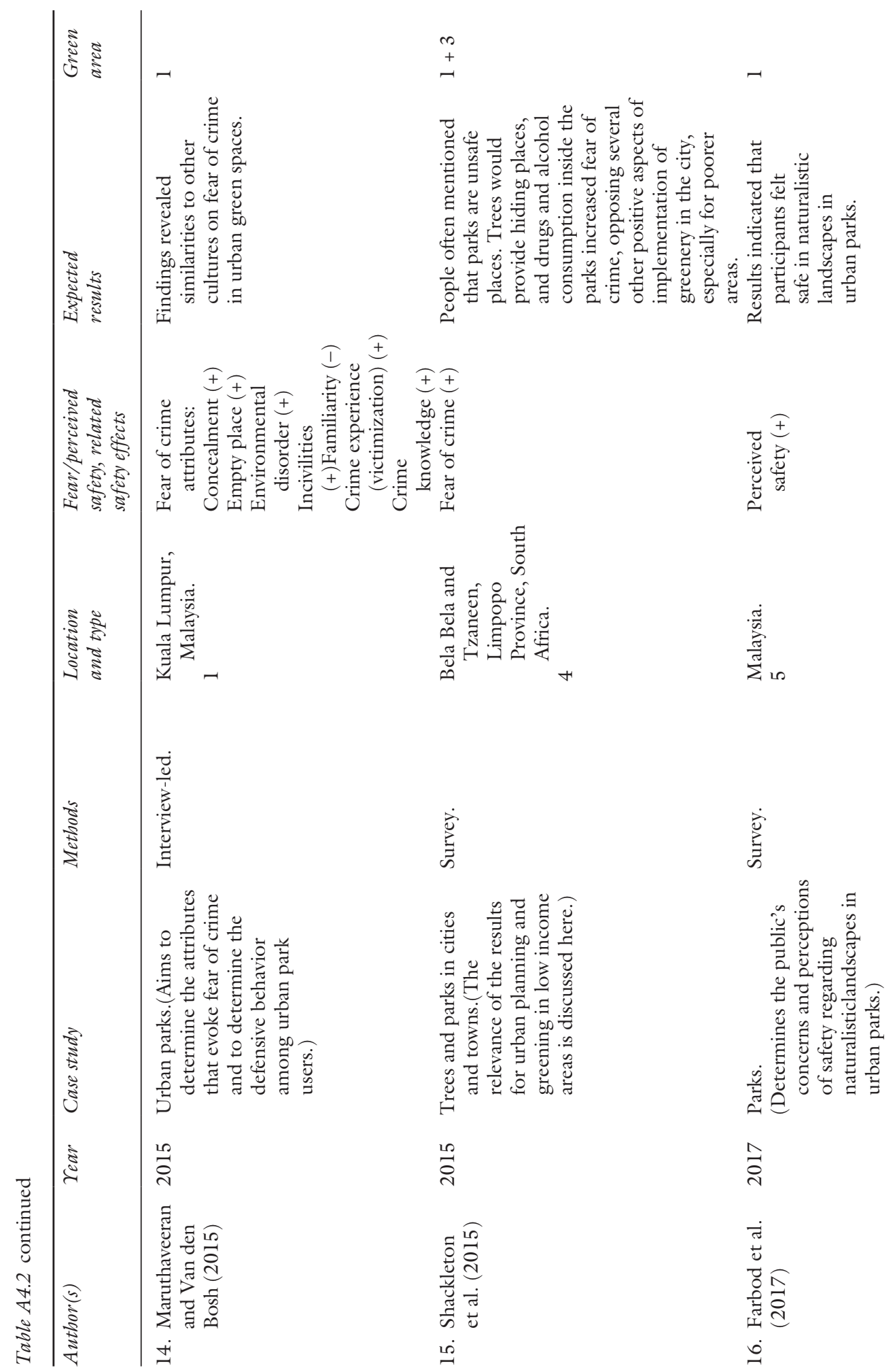



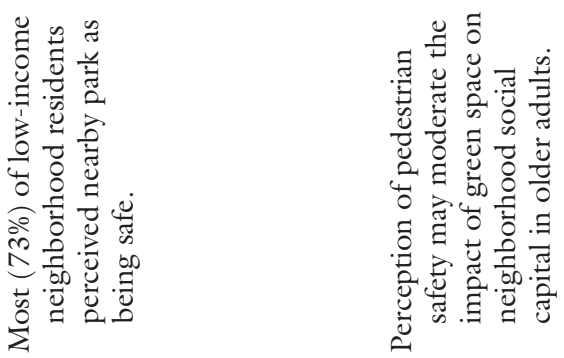

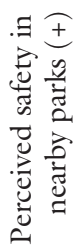

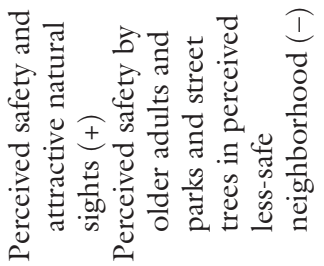

感

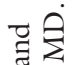

से

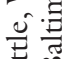

苞 $-N$

㐫

㐫

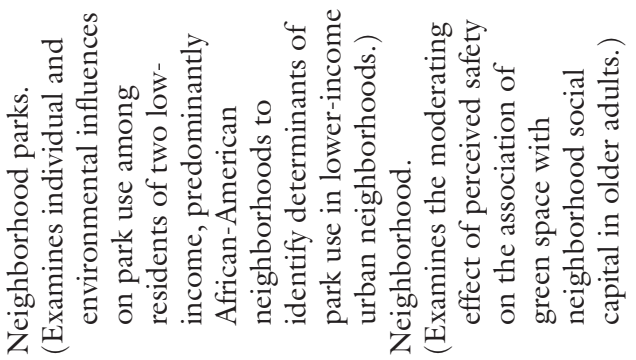

$\stackrel{\infty}{\circ}$

$\stackrel{\infty}{\stackrel{2}{*}}$

तं

苟市

สं

可

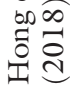

I

$\infty$

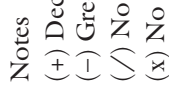



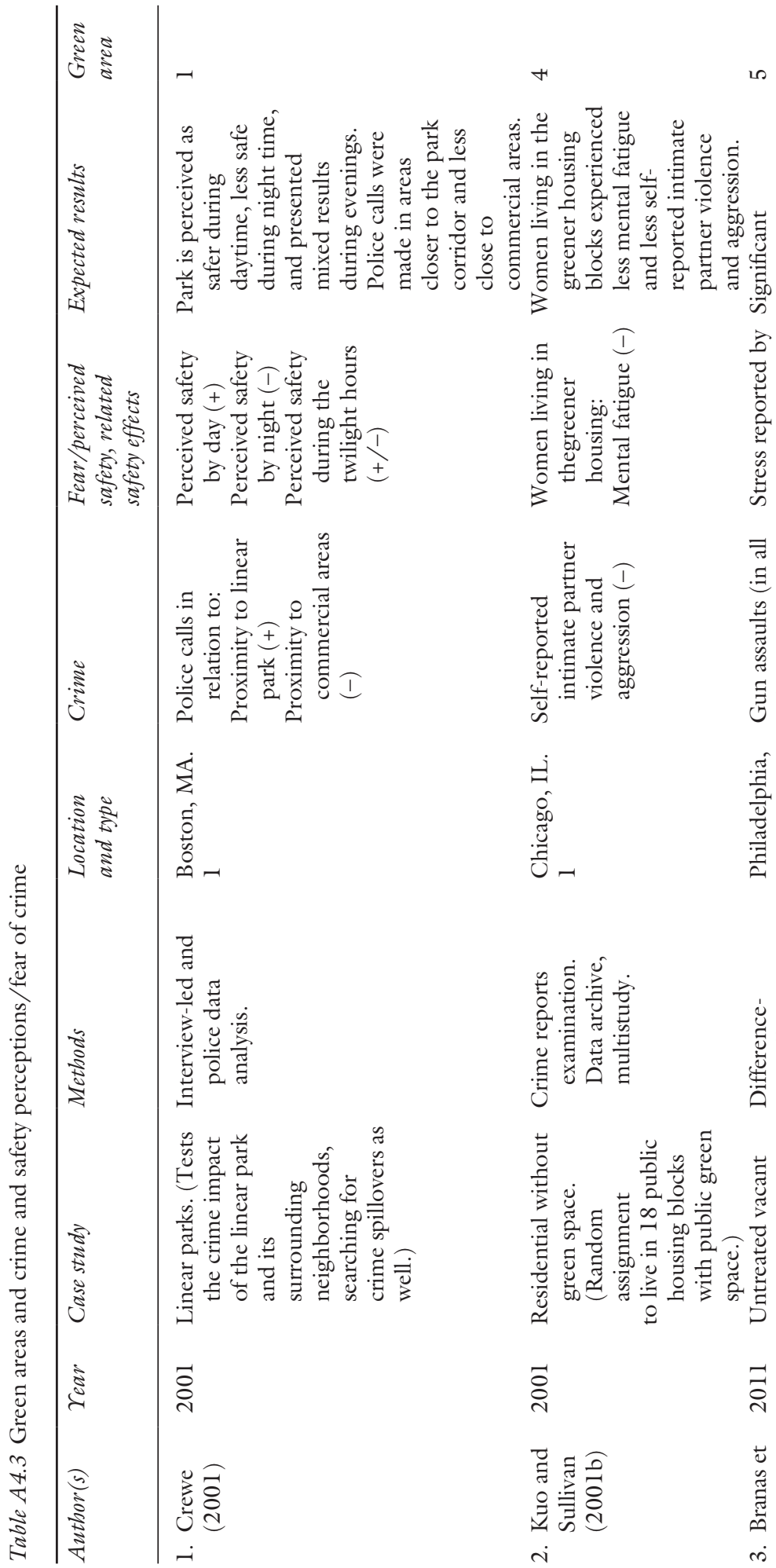

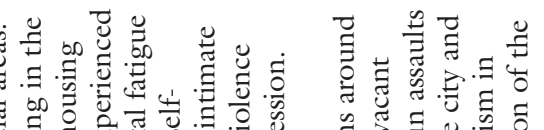

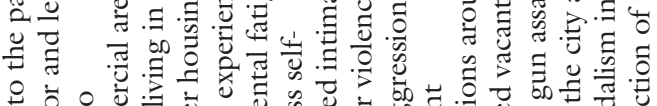



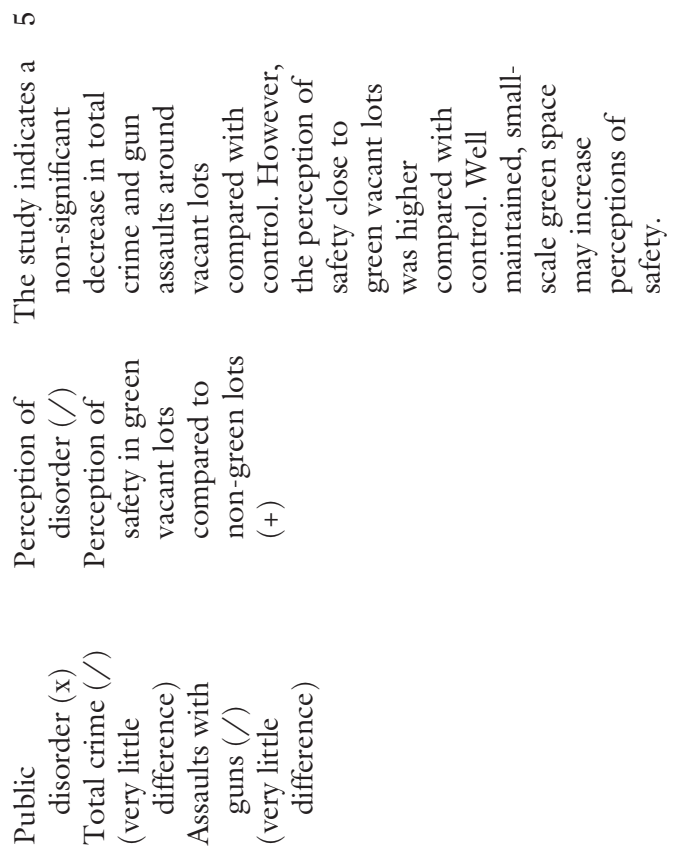

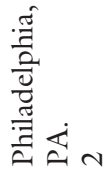

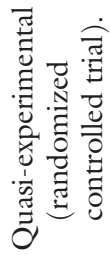

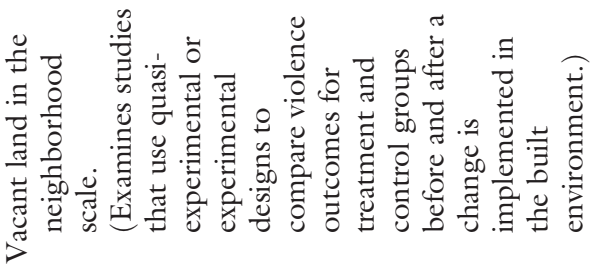

$$
\begin{aligned}
& \text { 웅 }
\end{aligned}
$$

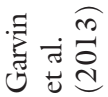

$$
\begin{aligned}
& \text { +ن }
\end{aligned}
$$

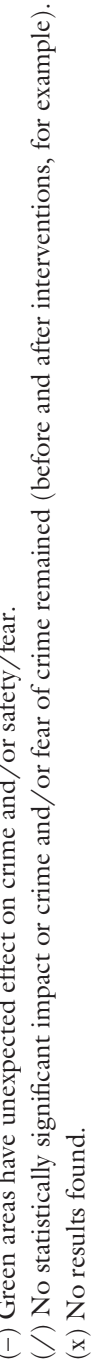




\section{Vania Ceccato et al.}

\section{References}

Alex, Y. H. Lo \& C. Y. Jim. (2012). Citizen attitude and expectation towards greenspace provision in compact urban milieu. Land Use Policy, 29, 577-586.

Aliprantis, D., \& Hartley, D. (2015). Blowing it up and knocking it down: The local and city-wide effects of demolishing high concentration public housing on crime. Journal of Urban Economics, 88, 67-81.

Armitage, R. (2013). Crime Prevention through Housing Design: Policy and Practice. Basingstoke: Palgrave Macmillan.

Babey, S. H., Tan, D., Wolstein, J., \& Diamant, A. L. (2015). Neighborhood, family and individual characteristics related to adolescent park-based physical activity. Preventive Medicine, 76, 31-36.

Bogar, S., \& Beyer, K. M. (2015). Green space, violence, and crime: A systematic review. Trauma, Violence, and Abuse, 17, 160-171.

Bowers, K. (2014). Risky facilities: Crime radiators or crime absorbers? A comparison of internal and external levels of theft. Journal of Quantitative Criminology, 30, 389-414.

Box, S., Hale, C., \& Andrews, G. (1988). Explaining fear of crime. British Journal of Criminology, 28, 340-356.

Branas, C. C., Cheney, R. A., MacDonald, J. M., Tam, V. W., Jackson, T. D., \& Ten Have, T. R. (2011). A difference-in-differences analysis of health, safety, and greening vacant urban space. American Journal of Epidemiology, 174, 1296-1306.

Branas, C. C., South, E., Kondo, M. C., Hohl, B. C., Bourgois, P., Wiebe, D. J., \& MacDonald, J. M. (2018). Citywide cluster randomized trial to restore blighted vacant land and its effects on violence, crime, and fear. Proceedings of the National Academy of Sciences, 115, 2946.

Brantingham, P. J., \& Brantingham, P. L. (1984). Patterns in Crime. New York: Macmillan.

Brantingham, P. L., \& Brantingham, P. J. (1995). Criminality of place: Crime generators and crime attractors. European Journal on Criminal Policy and Research, 3, 1-26.

Ceccato, V. (2019). Fieldwork protocol as a safety inventory tool in public places. Criminal Justice Studies, 32, 165-188.

Ceccato, V., \& Hanson, M. (2013). Experiences from Assessing Safety in Vingis Park, Vilnius, Lithuania. Review of European Studies, 5, 1-16.

Chiesura, A. (2004). The role of urban parks for the sustainable city. Landscape and Urban Planning, 68, 129-138.

Clarke, R., \& Eck, J. (2007). Understanding risky facilities. Tool Guide No. 6. Retrieved from https://popcenter.asu.edu/content/understanding-risky-facilities (accessed 20 February 2020).

Clarke, R. C., \& Eck, J. E. (2005). Crime analysis for problem solvers in 60 small steps. https://popcenter.asu.edu/content/crime-analysis-problem-solvers-60-small-steps (accessed 20 February 2020).

Cohen, D. A., Han, B., Derose, K. P., Williamson, S., Marsh, T., Raaen, L., \& McKenzie, T. L. (2016). The paradox of parks in low-income areas: park use and perceived threats. Environment and Behavior, 48, 230-245.

Cohen, D. A., Marsh, T., Williamson, S., Derose, K. P., Martinez, H., Setodji, C., \& McKenzie, T. L. (2010). Parks and physical activity: Why are some parks used more than others? Preventive Medicine, 50(SUPPL.), S9-S12.

Cohen, L. E., \& Felson, M. (1979). Social change and crime rate trends: A routine activity approach. American Sociological Review, 44, 588-608.

Coley, R. L., Kuo, F. E., \& Sullivan, W. C. (1997). Where does community grow? The social context created by nature in urban public housing. Environment and Behavior, 29, 468-494.

Cozens, P. M., Saville, G., \& Hillier, D. (2005). Crime prevention through environmental design (CPTED): A review and modern bibliography. Property Management, 23, 328-356. 
Crewe, K. (2001). Linear parks and urban neighbourhoods: A study of the crime impact of the Boston South-west Corridor. Journal of Urban Design, 6, 245-264.

Day, K. (2009). Being feared: Masculinity and race in public space. In M. L. S. Farrall (Ed.), Fear of Crime: Critical Voices in an Age of Anxiety (pp. 82-107). New York: Routledge-Cavendish.

Donovan, G. H., \& Prestemon, J. P. (2012). The effects of trees on crime in Portland, Oregon. Environment and Behavior, 44, 3-30.

Ekblom, P. (2011). Deconstructing CPTED ... and reconstructing it for practice, knowledge management and research. European Journal on Criminal Policy and Research, 17, 7-28.

Ekblom, P. (2019). Sharpening up CPTED-towards an ontology based on crime science and ecology. In P. Ekblom \& R. Armitage (Eds.), Rebuilding Crime Prevention Through Environmental Design: Strengthening the Links with Crime Science. Abingdon, Oxon: Routledge.

Farbod, S., Kamal, M., \& Maulan, S. (2017). Safety perception and concerns in naturalistic landscapes of urban parks in Malaysia. Security Journal, 30, 106-122.

Freedman, M., \& Owens, E. G. (2011). Low-income housing development and crime. Journal of Urban Economics, 70, 115-131.

Garofalo, J., \& Laub, J. (1979). Fear of crime-broadening our perspective. Victomology, $3,242-253$.

Garvin, E. C., Cannuscio, C. C., \& Branas, C. C. (2013). Greening vacant lots to reduce violent crime: A randomised controlled trial. Injury Prevention, 19, 198-203.

Gilstad-Hayden, K., Wallace, L. R., Carroll-Scott, A., Meyer, S. R., Barbo, S., MurphyDunning, C., \& Ickovics, J. R. (2015). Research note: Greater tree canopy cover is associated with lower rates of both violent and property crime in New Haven, CT. Landscape and Urban Planning, 143, 248-253.

Giurgescu, C., Zenk, S. N., Templin, T. N., Engeland, C. G., Kavanaugh, K., \& Misra, D. P. (2017). The impact of neighborhood conditions and psychological distress on preterm birth in African-American women. Public Health Nursing, 34, 256-266.

Gómez, E., Baur, J. W. R., Hill, E., \& Georgiev, S. (2015). Urban parks and psychological sense of community. Journal of Leisure Research, 47, 388-398.

Goode, D., \& Collins, W. (2014). The different types of urban green spaces. Urban Rambles. http://urbanrambles.org/contact-urban-rambles (accessed 20 February 2020).

Groff, E., \& McCord, E. (2011). The role of neighborhood parks as crime generators. Security Journal, 25, 1-24.

Heinze, J. E., Krusky-Morey, A., Vagi, K. J., Reischl, T. M., Franzen, S., Pruett, N. K., .., Zimmerman, M. A. (2018). Busy streets theory: The effects of community-engaged greening on violence. American Journal of Community Psychology, 62, 101-109.

Higgins, J. P. T., \& Green, S. (2011). Cochrane Handbook for Systematic Reviews of Interventions. G. S. Higgins JPT (Ed.) https://training.cochrane.org/handbook (accessed 29 June 2019).

Hilborn, J. (2009). Dealing with Crime and Disorder in Urban Parks. Retrieved from www.cops.usdoj.gov (accessed 18 October 2019).

Hong, A., Sallis, J. F., King, A. C., Conway, T. L., Saelens, B., Cain, K. L., ..., Frank, L. D. (2018). Linking green space to neighborhood social capital in older adults: The role of perceived safety. Social Science \& Medicine, 207, 38-45.

Iqbal, A., \& Ceccato, V. (2015). Does crime in parks affect apartment prices? Journal of Scandinavian Studies in Criminology and Crime Prevention, 16, 97-121.

Iqbal, A., \& Ceccato, V. (2016). Is CPTED useful to guide the inventory of safety in parks? A study case in Stockholm, Sweden. International Criminal Justice Review, 26, 150-168.

Jackson, J., \& Gouseti, I. (Eds.). (2012). Fear of Crime: An Entry to the Encyclopedia of Theoretical Criminology. Chichester: Wiley-Blackwell.

Jacobs, J. (1961). The Death and Life of Great American Cities. New York: Vintage Books. 
Jansson, M., Fors, H., Lindgren, T., \& Wistrom, B. (2013). Perceived personal safety in relation to urban woodland vegetation-A review. Urban Forestry \& Urban Greening, $12,127-133$.

Jeffery, C. R. (1971). Crime prevention through environmental design. American Behavioral Scientist, 14, 598 .

Jeffery, C. R. (1977). Crime Prevention through Environmental Design. (2nd ed.). Beverly Hills: Sage.

Jorgensen, L. J., Ellis, G. D., \& Ruddell, E. (2013). Fear perceptions in public parks: Interactions of environmental concealment, the presence of people recreating, and gender. Environment and Behavior, 45, 803-820.

Kimpton, A., Corcoran, J., \& Wickes, R. (2017). Greenspace and crime: An analysis of greenspace types, neighboring composition, and the temporal dimensions of crime. Journal of Research in Crime and Delinquency, 54, 303-337.

Kondo, M. C., Andreyeva, E., South, E. C., MacDonald, J. M., \& Branas, C. C. (2018a). Neighborhood interventions to reduce violence. Annual Review of Public Health, 39, 253-271.

Kondo, M. C., Fluehr, J. M., McKeon, T., \& Branas, C. C. (2018b). Urban green space and its impact on human health. International Journal of Environmental Research and Public Health, 15(3).

Kondo, M. C., Han, S., Donovan, G. H., \& MacDonald, J. M. (2017). The association between urban trees and crime: Evidence from the spread of the emerald ash borer in Cincinnati. Landscape and Urban Planning, 157, 193-199.

Kondo, M. C., South, E. C., Branas, C. C., Richmond, T. S., \& Wiebe, D. J. (2017). The Association between urban tree cover and gun assault: A case-control and casecrossover study. American Journal of Epidemiology, 186, 289-296.

Kondo, M., Hohl, B., Han, S., \& Branas, C. (2016). Effects of greening and community reuse of vacant lots on crime. Urban Studies, 53, 3279-3295.

Kondo, M. C., Low, S. C., Henning, J., \& Branas, C. C. (2015). The impact of green stormwater infrastructure installation on surrounding health and safety. American Journal of Public Health, 105, el14-e121.

Kuo, F. E., Bacaicoa, M., \& Sullivan, W. C. (1998). Transforming inner-city landscapes: Trees, sense of safety, and preference. Environment and Behavior, 30, 28-59.

Kuo, F. E., \& Sullivan, W. C. (2001a). Environment and crime in the inner city does vegetation reduce crime? Environment and Behavior, 33, 343-367.

Kuo, F. E., \& Sullivan, W. C. (2001b). Aggression and violence in the inner city: Effects of environment via mental fatigue. Environment and Behavior, 33, 543-571.

Lindgren, T., \& Nilsen, M. R. (2012). Safety in residential areas. Tijdschrift voor Economische en Sociale Geografie, 103, 196-208.

Lorenc, T., Petticrew, M., Whitehead, M., Neary, D., Clayton, S., Wright, K., ..., Renton, A. (2013). Environmental interventions to reduce fear of crime: Systematic review of effectiveness. Systematic Reviews, 2, 1-10.

Los, M. (2002). Post-communist fear of crime and the commercialization of security. Theoretical Criminology, 6, 165-188.

Loukaitou-Sideris, A., \& Sideris, A. (2010). What brings children to the park? Analysis and measurement of the variables affecting children's use of parks. Journal of the American Planning Association, 76, 89-107.

Maas, J., Spreeuwenberg, P., van Winsum-Westra, M., Verheij, R. A., Vries, S., \& Groenewegen, P. P. (2009). Is green space in the living environment associated with people's feelings of social safety? Environment and Planning A, 41, 1763-1777.

Madge, C. (1997). Public parks and the geography of fear. Tijdschrift voor Economische en Sociale Geografie, 88, 237-250.

Maruthaveeran, S., \& Van den Bosh, C. K. (2015). Fear of crime in urban parks-What the residents of Kuala Lumpur have to say? Urban Forestry and Urban Greening, 14, 702-713. 
Moher, D., Liberati, A., Tetzlaff, J., \& Altman, D. (2009). Preferred reporting items for systematic reviews and meta-analyses: The PRISMA statement. PLoS Med, 6, el000097.

Mulliner, E., \& Maliene, V. (2011). An introductory review to the special issue: Attractive places to live. Urban Design International, 16, 147-152.

Newman, O. (1972). Defensible Space-Crime Prevention through Urban Design. New York: Collier Books.

Pain, R., \& Smith, S. J. (2008). Fear: Critical geopolitics and everyday life. In R. Pain \& S. J. Smith (Eds.), Fear: Critical Geopolitics and Everyday Life (pp. 1-24). Aldershot: Ashgate.

Parra, D. C., Gomez, L. F., Fleischer, N. L., \& David Pinzon, J. (2010). Built environment characteristics and perceived active park use among older adults: Results from a multilevel study in Bogotá. Health and Place, 16, 1174-1181.

Poyner, B. (1994). An evaluation of walkway demolition on a British housing estate. In R. V. Clarke (Ed.), Situational Crime Prevention-Successful Case Studies (pp. 59-73). USA: Lynne Rienner Publishers.

Reynald, D. M. (2010). Guardians on guardianship: Factors affecting the willingness to supervise, the ability to detect potential offenders, and the willingness to intervene. Journal of Research in Crime and Delinquency, 47, 358-390.

Saville, G. (2019). Third Generation of CPTED. www.alternation.ca (accessed 12 January 2020).

Shackleton, S., Chinyimba, A., Hebinck, P., Shackleton, C., \& Kaoma, H. (2015). Multiple benefits and values of trees in urban landscapes in two towns in northern South Africa. Landscape and Urban Planning, 136, 76-86.

Spader, J., Schuetz, J., \& Cortes, A. (2015). Fewer vacants, fewer crimes? Impacts of neighborhood revitalization policies on crime. Regional Science and Urban Economics, $60,73-84$.

Stodolska, M., \& Shinew, K. J. (2010). Environmental constraints on leisure time physical activity among Latino urban residents. Qualitative Research in Sport and Exercise, 2, 313-335.

Talen, E., \& Koschinsky, J. (2014). Compact, walkable, diverse neighborhoods: Assessing effects on residents. Housing Policy Debate, 24, 717-750.

Troy, A., \& Grove, J. M. (2008). Property values, parks, and crime: A hedonic analysis in Baltimore, MD. Landscape and Urban Planning, 87, 233-245.

Troyer, R. J., \& Wright, R. D. (1985). Community response to crime: Two middle-class anti-crime patrols. Journal of Criminal Justice, 13, 227-241.

UN-Habitat (2019). Safer Cities Programme. Retrieved from http://fukuoka.unhabitat. org/programmes/detail04_01_en.html (accessed 12 December 2019).

UNHSP, The United Nations Human Settlements Programme (2007). Enhancing Urban Safety and Security: Global Report on Human Settlements. Retrieved from www. un.org/ruleoflaw/files/urbansafetyandsecurity.pdf (accessed 20 February 2020).

Ward Thompson, C., Roe, J., \& Aspinall, P. (2013). Woodland improvements in deprived urban communities: What impact do they have on people's activities and quality of life? Landscape and Urban Planning, 118, 79-89.

Vaughan, C. A., Colabianchi, N., Hunter, G. P., Beckman, R., \& Dubowitz, T. (2018). Park use in low-income urban neighborhoods: Who uses the parks and why? Journal of Urban Health, 95, 222-231.

Wolfe, M. K., \& Mennis, J. (2012). Does vegetation encourage or suppress urban crime? Evidence from Philadelphia, PA. Landscape and Urban Planning, 108, 112-122.

Wyant, B. R. (2008). Multilevel impacts of perceived incivilities and perceptions of crime risk on fear of crime: Isolating endogenous impacts. Journal of Research in Crime and Delinquency, 45, 39-64.

Ye, C., Chen, Y., \& Li, J. (2018). Investigating the influences of tree coverage and road density on property crime. ISPRS International Journal of Geo-Information, 7, 1-14. 


\title{
5 Safety of urban park users The case of Poznań, Poland
}

\author{
Emilia Bogacka
}

\subsection{Introduction}

Urban parks are indispensable to proper functioning of cities and strongly affect the quality of life of city inhabitants (Camargo et al., 2017; Koramaz \& Türkoğlu, 2018). Some of them also play a fundamental function as facilities for recreational activities (Iqbal \& Ceccato, 2015, 2016). However, if parks feel unsafe, people are less likely to spend time in them. A major factor affecting the quality of urban spaces, parks included, is undoubtedly fear of crime (Franklin et al., 2008).

Although levels of fear are affected by a multitude of factors (Franklin et al., 2008), the characteristics of the physical and social environments of a park are important determinants of safety perceptions declared by park users (Ceccato \& Hansson, 2013; Iqbal \& Ceccato, 2016). In order to measure the relationship between the quality of the environment of a park and safety, researchers have long relied on Crime Prevention Through Environmental Design (CPTED) (Jeffery, 1971). CPTED is a strategy (or a set of principles) aiming at reducing crime and improving the sense of safety (Iqbal \& Ceccato, 2016). CPTED has already been used in studies devoted to residential districts (Armitage, 2018; Atlas, 2008; Cozens et al., 2001; Czapska, 2012; Klima et al., 2016; Lee et al., 2016; Sohn, 2016), regenerated areas (Carter et al., 2003), university campuses (Cozens \& Sun, 2018), transportation systems (Abenoza et al., 2018; Ceccato, 2013; Ceccato \& Uittenbogaard, 2014; Newton \& Ceccato, 2015) and parks (Bazregari \& Ostovareh, 2016; Beeler, 2011; Ceccato \& Hansson, 2013; Iqbal \& Ceccato, 2016; Salmani et al., 2015).

The aim of this study is to determine safety perceptions of users of an urban park and highlight elements that contribute to poor perceived safety. The analysis is focused on an urban park in Poznań, Poland-the Cytadela Park-to detect the issues that contribute to poor perceived safety by applying the principles of CPTED. This aim was accomplished by analyzing safety by the time of the day, and in relation to the physical and social environments of the park.

The analysis of a park in a Polish city constitutes an interesting case study. First, in Poland, as in many other European and Northern American cities, urban parks are frequent crime scenes. As many as 11.1 percent of all fights and batteries, 10.6 percent of rapes, 8.8 percent of personal injuries, 7.3 percent of 
cases of theft, 5.8 percent of assault and robberies, 5.5 percent of cases of breaking and entering and 5.2 percent of homicides occur in parks (Police statistics, 2016). At the same time, they are places of recreation. In Poznań, in particular, the use of parks as recreational areas is one of the most popular active pastimes and its role is increasing (The City of Poznan, 2013), therefore it is worth taking a closer look at the declared safety perceptions by park users in a broader context. This is particularly relevant considering that results of studies conducted among the inhabitants of Poznan in the years 2002-2013 (The City of Poznań, 2013) showed that residents declared relatively lower safety perceptions in urban parks and walking areas than elsewhere in the city (own home, neighborhood, train/bus stations and bus/tram stops, city center, urban parks and walking areas, residential districts with large-panel residential buildings) for both night time and day time.

Finally, another reason for having a Polish case study is the fact that CPTED principles have not been much discussed in the literature on examples from Poland (Czapska, 2012; Klima et al., 2016). Applying CPTED principles to a public place such as Cytadela Park, located in the liberal city of Poznań, may serve as a good example for other municipalities.

\subsection{Theoretical background}

\section{The origins and development of CPTED}

The foundations of CPTED can be traced back to the studies of Jane Jacobs who found that the "the bedrock attribute of a successful city district is that a person must feel personally safe and secure on the street" (Jacobs, 1961, p. 30). Similarly, Angel (1968), who studied street crime in Oakland claimed that the urban environment can have a direct impact on crime rate by separating certain areas, reducing or increasing access to others by creating or eliminating barriers. He pointed out that crime level is inversely proportional to human activity in the streets.

The role of environment in affecting the opportunities was discussed in depth by Jeffery (1971), who coined the term Crime Prevention Through Environmental Design. This author paid particular attention to the role of the environment in creating positive and negative experiences in potential perpetrators. He claimed that the environment can be used to control human behavior. About the same time, Newman (1972) also devoted his work to establish links between safety and architectural solutions. According to Newman, safety depends on symbolic and actual barriers which separate a given area, what he called 'Defensible space'. A defensible space must contain two elements. First, it must provide people with the ability to observe but, at the same time, also be observed. Second, inhabitants must be ready to intervene or inform the authorities in the case of a crime being committed.

There are six first-generation CPTED concepts: territoriality, surveillance, access control, target hardening, image of the place/maintenance and activity support. The notion of territoriality is a key term in CPTED. It relies on clear 


\section{0}

demarcation of areas by placing visible boundaries between different types of space. Its other goal is to reinforce the sense of ownership and belonging to develop a sense of owner's care for the given space in the users' minds. This demarcation may come in different forms: symbolic barriers in the form of signs, lines, inscriptions, changes in the color of walls or pavement, as well as actual barriers, i.e., the positioning of buildings, guard rails, fences, park/street furniture or proper shaping of vegetation (Reynald \& Elffers, 2009). CPTED also has other components. The purpose of surveillance is to reduce the sense of anonymity and to improve the natural disposition of people to observe their surroundings. Natural surveillance is performed spontaneously by inhabitants or users of a given area during their daily routines.

Access control is another component of CPTED that involves a clear demarcation of different types of space and creating areas with privileged user access to private and semi-private zones. Its purpose is to reinforce the sense of care about one's "own" space, liquidation of possible escape routes and creating a sense of being watched. Access control may be provided by installing barriers, enclosures and entry portals in a given space (Iqbal \& Ceccato, 2016). In addition, access control may be reinforced by target hardening. Target hardening is the most controversial component among CPTED's principles, since it involves installation of anti-burglary doors, appropriate locks, use of damage-resistant materials, and use of security alarm systems in houses and vehicles.

Safety is also about the maintenance and image of an area. The purpose of image of a place/maintenance is to liquidate the sense of anonymity, increase the sense of safety of authorized users and create social connections. This can be achieved as early as during the design phase by the selection of appropriate materials and plants, which reduces maintenance costs and facilitates repairs. Finally, activity support calls for shaping the space and using signs and markings to encourage people to use it in an appropriate manner. This has an impact on surveillance and strengthens social connections (Cozens et al., 2005). These basic principles of CPTED have evolved into what it is called "the CPTED second generation" including issues of social cohesion, connectivity, community culture and capacity threshold, but will not be discussed further since they are less relevant for the study of safety in parks.

\section{CPTED applied to parks}

Despite not being vast, the international literature contains examples of the use of CPTED principles to evaluate safety in urban parks. An example is the study by Hilborn (2009) who discussed the issues of risk and protective features of the physical environment in a park. This study is particular useful for conducting audits based on CPTED principles as it contains questions supporting the evaluation of lighting, sight lines, movement predictors, entrapments, signs, activity generators, maintenance, usage diversity, formal surveillance, and isolation. The article can also be used as a template for interviews with park users. In the same vein, there were other few studies, one being by Beeler (2011) who 
studied 18 parks in Berlin using surveys and field inspections. Jorgensen et al. (2012) studied the effect of concealment, presence or absence of people at recreation, and gender on fear of crime. Using CPTED principles as a background, Ceccato and Hansson (2013) assessed perceived safety in a park in Vilnius, Lithuania, using crime mapping, safety walks and interviews. Their study demonstrated advantages and challenges brought by these methods and drew implications for local urban planning.

Iqbal and Ceccato (2016) focused on assessing the use of CPTED principles to a park in Stockholm, Sweden. Authors employed a mixed method approach (crime mapping, field inspection, people counting, interviews) to provide a comprehensive view of safety problems in that highly crime-ridden inner-city park. Territoriality and target hardening were the two dimensions of CPTED more easily identified in the park. The authors noticed that the biggest challenge in using CPTED principles is the fact that some of these dimensions overlap each other when applied to features of a park. They also found other limitations, such as the inability of these principles to take into consideration the changing nature of parks seasonally or to simply analyze the park without taking its surroundings into consideration.

\subsection{Framing the study case}

This study focuses on Cytadela Park (Figure 5.1), which is the largest park in the municipality of Poznan, Poland, and has an area of $1 \mathrm{~km}^{2}$. In the park

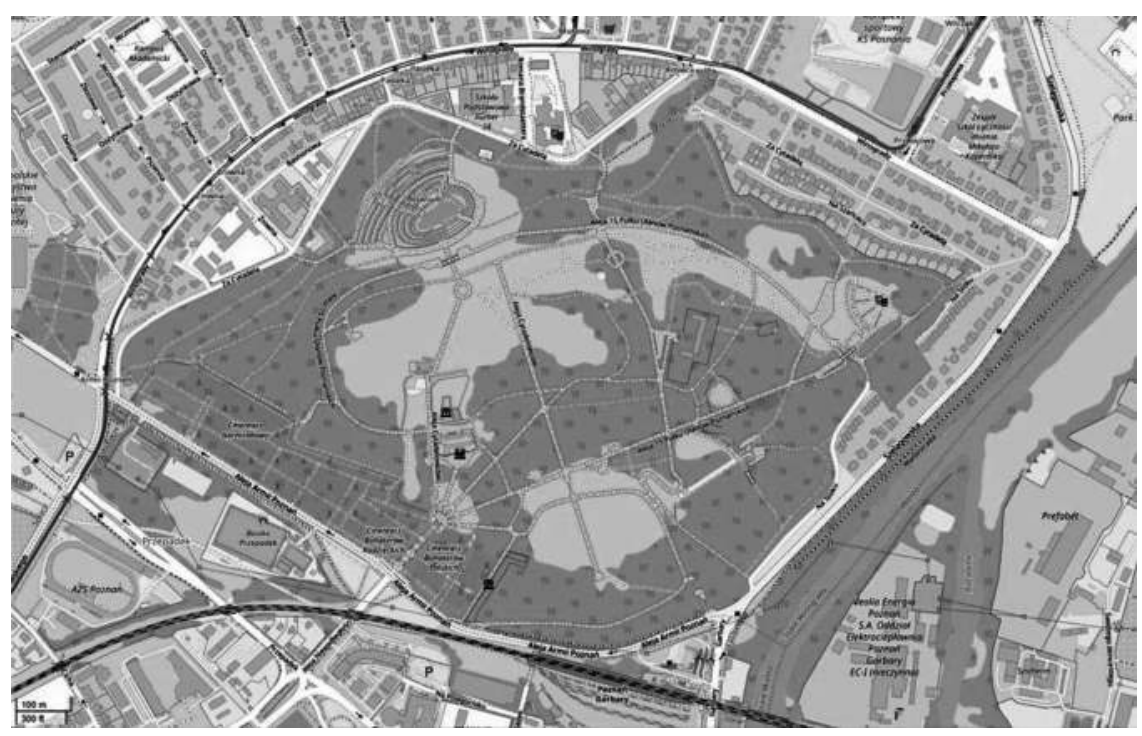

Figure 5.1 Cytadela Park.

Source: openstreetmap.org. 


\section{Emilia Bogacka}

there are fortifications (ravelins, bastions, trestle bridges, gates), cemeteries (including war cemeteries), two military museums, monuments, sculptures, and an amphitheater. The park also has two restaurants, which are open throughout the year, two open-air gyms and playgrounds for children. The size of the park, its location in the city center and various forms of terrain use attract many types of users: walkers (also with children or dogs), runners, cyclists, roller-skaters, people of all ages. In general, the park generates considerable human traffic. It is worth noting at this point that the central part of the park is well-maintained and organized (Figure 5.2), while its outskirts, where no trails are established, are the exact opposite.

Poznań is located in western Poland, half way between Warsaw and Berlin. It is inhabited by almost 540,000 people and covers an area of $261.9 \mathrm{~km}^{2}$. Urban vegetation covers 21.1 percent of the city's area; however, this also includes cemeteries and forests. There are 40 parks and they cover 5.3 percent of the city area. As many as 70 percent of Poznań inhabitants regularly use the city's recreational areas (The City of Poznań, 2013).

The occurrence of selected types of crime is greater in the Cytadela Park than it is in other administrative units of Poznań. This applies to car theft and drug offences but the exact location of these crimes is not provided by the local Police for this study.

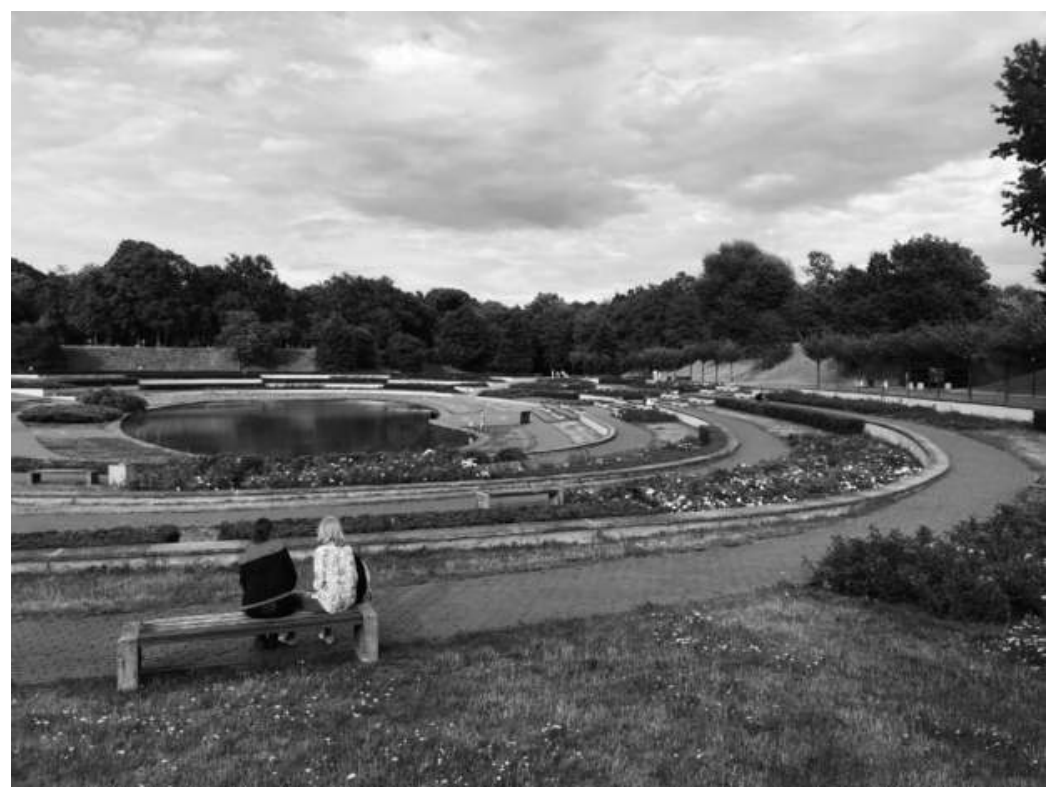

Figure 5.2 Rosarium in Cytadela Park.

Source: author's photograph. 


\section{Methods}

The primary method of data collection used in this study is an anonymous survey conducted with 501 users of the Cytadela Park (251 women and 250 men) about crime risk between October 2017 and January 2018. The survey was conducted by 51 geography students, who received proper training in the class, for the needs of the subject 'crime geography'. The response rate was 30 percent. There were no major problems with people's reactions to surveyors reported by students.

This chapter is also based on data collected through inventory, park observations and interviews with park users. The inventory was carried out by the author in September 2017 and covered recognition of land use, maintenance, problematic areas, location of street lights, rubbish bins and surveillance. The park observations were carried out four times in a good weather in September 2017 (10.00-12.00 and 16.00-18.00 on weekdays and 12.00-14.00 during the weekend to observe users during different hours of the day). Interviews were organized during inventory with two women and two men and were more like spontaneous, semi-structured conversations.

CPTED principles were used as a background for the analysis presented in Section 5 (Table 5.1 ) following the steps illustrated by previous studies in the international literature.

\subsection{Results}

The presentation of results is preceded by general information regarding the frequency and modes of use of the park. Then the first part of this section discusses safety by the time of the day. The second part focuses on the potential links between physical and social environment of the park and safety. The third part is devoted to safety perceptions by park users, including suggestions for safety improvements.

The survey results show that the frequency of park use is high: 58.8 percent of respondents visit a park at least once per week (10.6 percent every day, 11.0 percent four to six times per week, 22.4 percent two to three times per week, 14.8 percent once per week). It is therefore assumed that the knowledge of the

Table 5.1 CPTED principles and used methods

\begin{tabular}{lllll}
\hline CPTED principles & Survey & Inventory & Park observations & Interviews \\
\hline Territoriality & $\mathrm{x}$ & $\mathrm{x}$ & $\mathrm{x}$ & \\
Surveillance & $\mathrm{x}$ & $\mathrm{x}$ & $\mathrm{x}$ & $\mathrm{x}$ \\
Access control & & $\mathrm{x}$ & $\mathrm{x}$ & $\mathrm{x}$ \\
$\begin{array}{l}\text { Target hardening } \\
\text { Activity support }\end{array}$ & $\mathrm{x}$ & $\mathrm{x}$ & $\mathrm{x}$ & $\mathrm{x}$ \\
$\begin{array}{l}\text { Image of the place/ } \\
\text { maintenance }\end{array}$ & $\mathrm{x}$ & $\mathrm{x}$ & $\mathrm{x}$ & \\
\hline
\end{tabular}




\section{Emilia Bogacka}

study area is relatively good, users are familiar with the park. The park is used in various ways: walking is one of the most popular uses of a park: 40.2 percent of all respondents go for walks alone, 36.4 percent with family, 16.2 percent with children. Physical activity is another significant reason for visiting a park: 25.8 percent go jogging, 17.6 percent go cycling, 9.8 percent go roller-skating and 8.4 percent use the outdoor gyms. Finally, 18.8 percent of respondents use the park for other purposes, e.g., walking the dog, walks with their friends, as a shortcut to work or for resting.

Being victimized by a crime or witnessing one is important to determine safety perceptions (Demaris \& Kaukinen, 2005). However, the majority of respondents (69.2 percent) have never witnessed a crime at all, and more (85.3 percent) have never witnessed a crime in a park before. These values were even higher when it comes to being a victim of a crime- -86.3 percent have never been a victim of a crime, while 97.9 percent have never been a victim of a crime committed in a park. Very few people who were a victim of a crime reported it to the police. Only a fifth of the respondents stated they were concerned by the risk of being a victim of crime in the park.

\section{Safety by the time of the day}

Time of day had a considerable impact on the sense of safety of Cytadela Park users (Figure 5.3(a)). As many as 84.9 percent of respondents feel safe during the day, however, after dusk this number dropped significantly, to 25.7 percent. Conversely, 3.6 percent said they do not feel safe during the day, and 36.5 percent do not feel safe after dusk. It is also noteworthy that in the case of night-time, the answer "difficult to say" was the most frequent. Men felt safer than women during the day (respectively 85.2 percent and 84.71 percent positive responses). After dark, the situation was the opposite, women felt safer than men ( 31.15 percent vs. 20.4 percent positive responses). The safety diminished with age. Older visitors tend to feel less safe, regardless of the time of day. The groups in the ages 50 to 59 and 60+ and more felt the most unsafe (respectively 6.06 percent and 11.54 percent negative answers during the day, 44.12 percent and 69.24 percent after dusk).

Variation of safety perceptions by the time of day may be associated with the fact that relatively few people use the park during the dark hours of the day, in the evening, so they do not have an opinion on the sense of safety at that time. At this point, it is also worth mentioning the groups of night-time users of the park. The first group are the members of "Night Runners Poznań", who have been holding their regular weekly training sessions in the Cytadela Park since 2012 (by the end of January 2019 there have been 322 such meetings). The second group are people who use the park as a shortcut from the city center to the northern parts of the city. Interviews conducted with members of both of these groups show that they do not feel threatened in the park at night, mostly due to being part of a large group and being familiar with the park environments. 


\section{Safety and physical and social environment of the park}

Figure 5.3(b) illustrates park users' safety perceptions in relation to the physical and social environmental features of the park. Appropriate lighting, wellmaintained vegetation, and low-growing vegetation which allow visibility (observation and being observed), along with video surveillance show indications of having a positive effect on respondents' safety perceptions of the park. Other features with a positive impact on the sense of safety are the presence of other people, the company of a dog, and the presence of police or municipal police patrols. Features such as tall or overgrown vegetation reduce visibility and thus create favorable conditions for crime (hiding places) and negatively affect perceived safety.

The survey results showed that the most important feature for park users' safety is appropriate lighting (92.0 percent responses). The Cytadela Park only
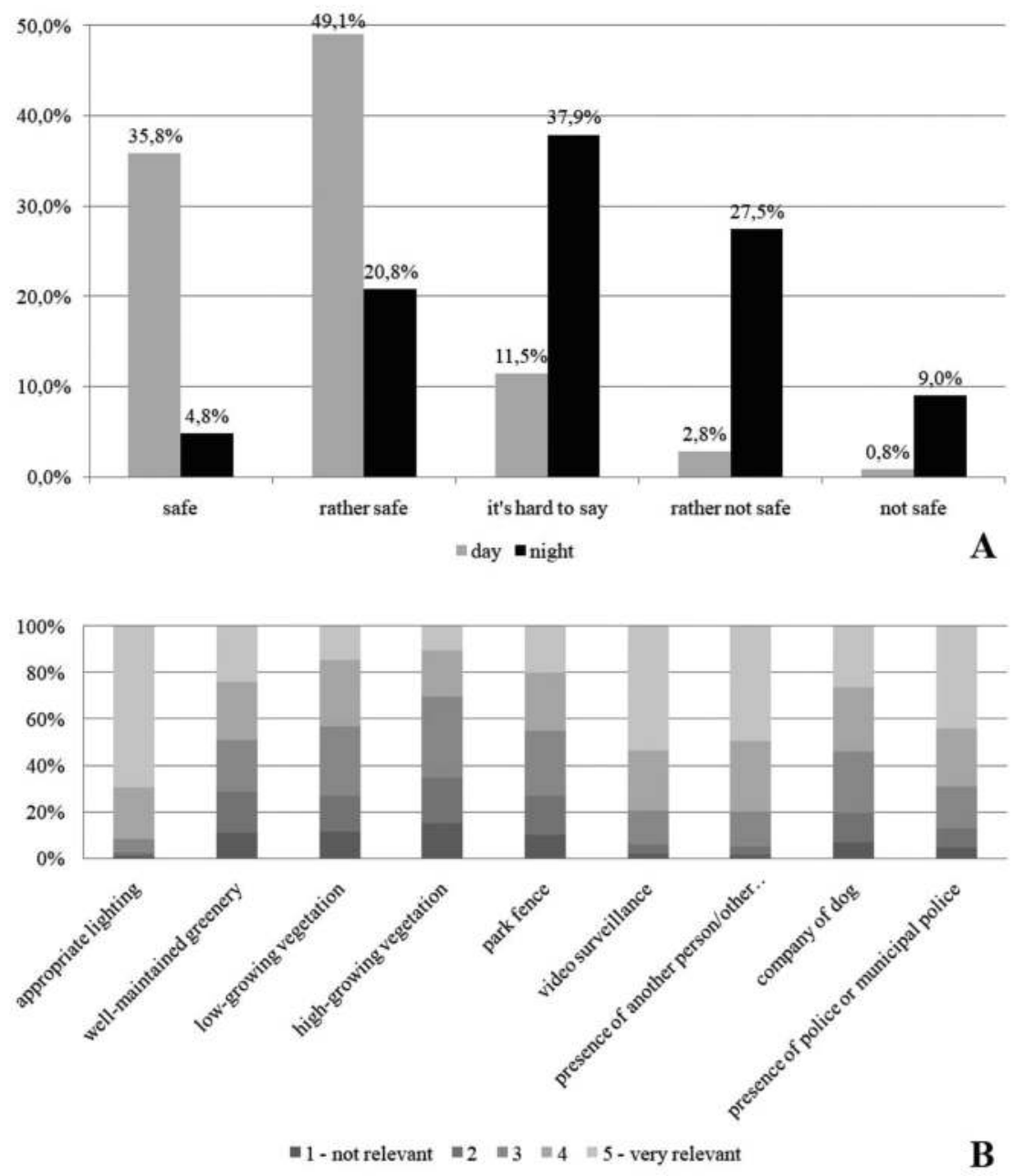


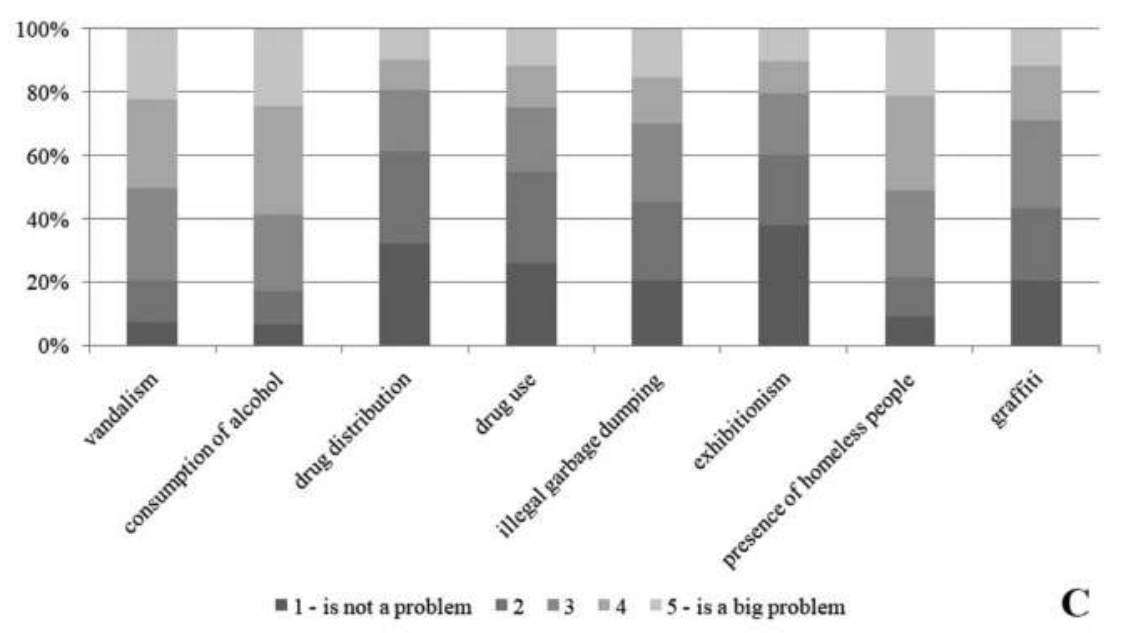

Figure 5.3 Survey results: (a) park users' safety perceptions-day and evening hours; (b) safety and physical and social environmental features of the park; (c) occurrence of selected negative safety phenomena in the park.

Source: author's own calculations based on survey results.

has lighting near the main paths in the central part of the park and in the rose garden. The majority of the park is unlit; therefore, the use of the park at night is very limited and only possible by either accepting walking in the dark or using a torch.

Another factor that also has an impact on safety is the company of another person/other persons (79.9 percent responses). Its favorable location between the city center and residential districts makes the park popular with people living in its vicinity, who use the park for various purposes. Owing to its great historic value and other attractions located in it, the park also attracts people living further away. As a result, the number of people in the park during the day is considerable. During the night, the park is used by the aforementioned "Night Runners Poznań" group. Their motto "You will never run alone" is another proof that the company of other people is conducive to safe use of the park.

Another factor that the respondents consider almost equally important as having other people's company is video surveillance (79.8 percent of responses). Video surveillance systems are installed in the park only near museums and restaurants. Finally, according to respondents, the presence of police/municipal police is also very important (69.3 percent positive answers). The company of dogs also influence the sense of safety of park users. The Cytadela Park is frequently used by dog owners as an area for walks.

Similar to other urban areas, parks may be sites of acts of social disorder, such as vandalism, consumption of alcohol, drug distribution, drug use, illegal garbage 
dumping, exhibitionism, presence of homeless people and graffiti. They are important because they affect safety perceptions of park users (Figure 5.3(c)). The factors that most affect negatively safety perceptions are alcohol consumption (58.8 percent of " 4 " and " 5 " scores added together), the presence of homeless people ( 51.2 percent) and vandalism ( 50.2 percent). It is worth noting that only these three phenomena are considered a problem by more than 50 percent of respondents. Other negative phenomena, such as drug distribution, illegal garbage dumps or graffiti, are not frequently pointed out as a big problem of the park. Interestingly, although the problem of garbage is present in the park, e.g., in the form of bottles and cans left behind after illegal consumption of alcohol, this was not mentioned by respondents.

\section{Suggestions for improvements}

Maintenance is the biggest challenge to ensure safety of the park, in particular in the areas with fortifications and surrounding areas. Unfortunately, while a small part of fortification buildings is used and well preserved (such as museums), most of them are ruins and may put visitors in danger. These are also places of alcohol consumption, illegal garbage dumps and physical damage.

The paths in the park have mixed types of surfaces and offer varied lighting (Figure 5.4(a)). The hard paths have garbage bins and some are lit (Figure $5.4(\mathrm{~b})$ ) and the natural paths (mostly on the outskirts of park) lack this infrastructure. Appropriate lighting (which would be very expensive) and ensuring the possibility of visitors throwing garbage in the bins, would provide a better image of these parts of Cytadela Park and, consequently, raise safety level.

The park is a place where young people gather, drink alcohol and listen to the loud music. This is perceived to be a safety problem during the day, for instance in the amphitheater (Figure 5.4(c)) and after sunset, in the high-greenery areas. The aforementioned amphitheater is not well supervised and is poorly maintained, with no seats, uneven surfaces, no real stage. To maximize safety, this place should be completely renovated to host various events and strengthen activity support in this area.

\subsection{Discussion of results}

CPTED principles are useful as a reference to assess the safety of park users. In the case of the Cytadela Park in Poznan, elements of CPTED, such as the image of the place/maintenance and surveillance, have the greatest impact on park users' perceived safety.

The most important features influencing safety (or lack of) were appropriate lighting, the company of another person/other persons and the presence of video surveillance. As previously mentioned, Cytadela Park is not well lit, and appropriate lighting would certainly positively affect park users' safety. Godbey and Mowen (2010) noted that lighting drastically improves safety and security in a park. Installation of additional lights may encourage 


\section{Emilia Bogacka}

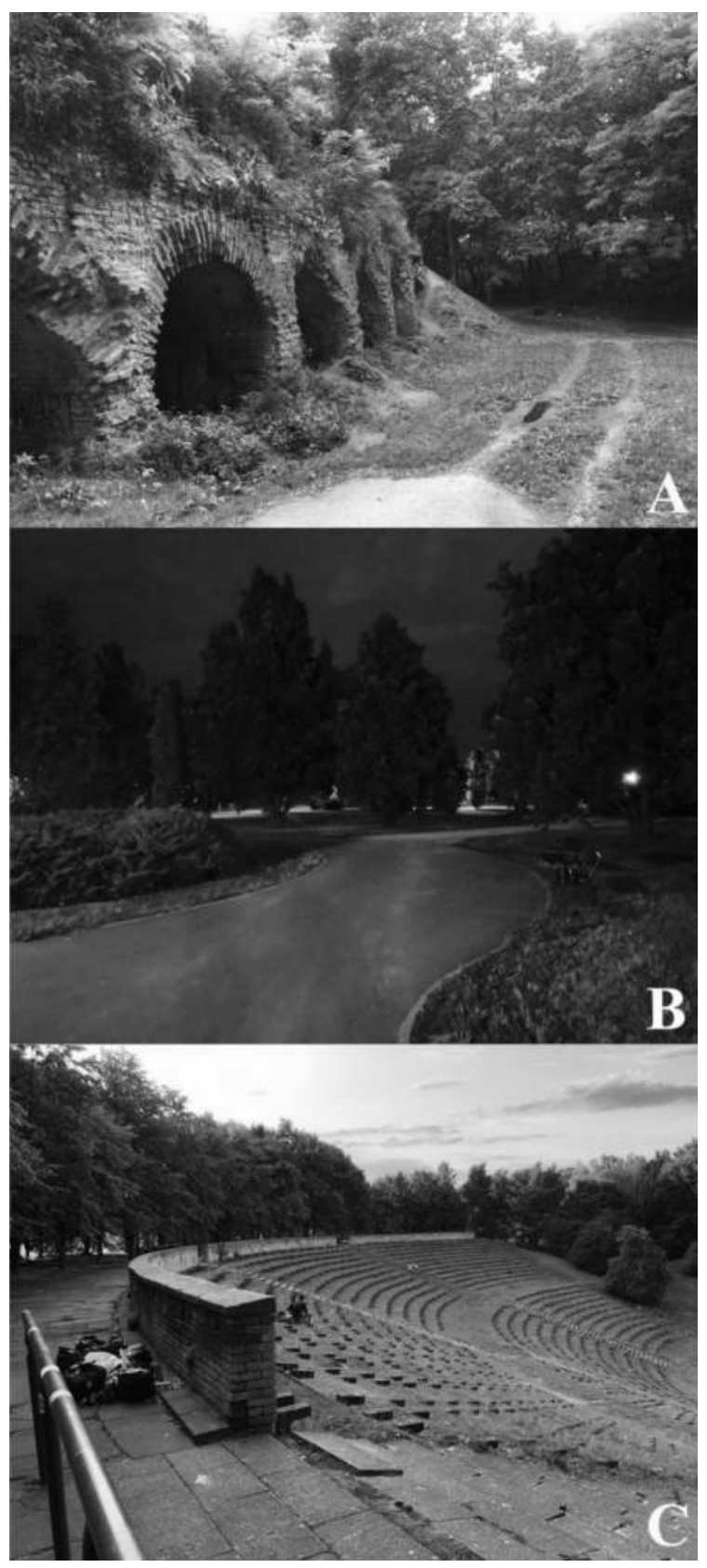

Figure 5.4 (a) Fortification ruins and mixed types of path surfaces; (b) lit paths by night; (c) amphitheater.

Source: author's photographs. 
people to use parks without them being worried for their safety. The same conclusions were drawn from the study by Fletcher (1983). This was also discussed in detail by Clarke (2008) who cites research conducted in the USA and in Great Britain which evaluated the impact of street lighting improvement on crimes committed at night. In six out of 11 cases described, improving street lighting yielded the desired effect of reducing the number of crimes committed.

The presence of other people was discussed by Özgüner and Kendle (2006) who claim that it has a positive impact on perceived safety. Cytadela is often used by physically active people, due to its good location and the possibility of use for various purposes. Note that the sense of safety is very important for those who use parks for physical activity (Costigan et al., 2017).

There is no video surveillance in the park, however there is an expectation that it would positively affect park users' safety. Surette and Stephenson (2019) pointed out the relationship between safety and video surveillance in their study. According to Ratcliffe (2006), the primary purpose of video surveillance is to increase the risk of being caught as experienced by the potential perpetrator and, if a crime is committed, facilitate its detection and the arrest of the perpetrator. However, studies by Ratcliffe (2006) and Ratcliffe et al. (2009) demonstrated that, even though in general cameras can serve to reduce criminal activity, there are locations where there is no benefit from installing them. Studies conducted by Brands and Schwanen (2014) involving night-time users of three Dutch cities- Utrecht, Rotterdam and Groningen-show that video surveillance has a very low impact on the sense of safety compared with on-street policing. Their studies were further expanded by Brands et al. (2015).

Vegetation is very important from the perspective of safety. In subject literature, areas with dense vegetation which limits visibility and can provide hiding places for potential attackers are considered to correlate positively with fear of crime (Talbot \& Kaplan, 1984; Michael \& Hull, 1994). Vegetation may also be an element that influences territoriality (Troy et al., 2012) and the better maintained it is, the stronger the effect (Brown \& Bentley, 1993).

Safety in the park can be also influenced by the presence of selected negative phenomena in the park. The study of Groff and McCord (2011) showed that the sense of safety in parks is not related to the threat of becoming a victim of a crime per se, but to the presence of particular groups of people in parks. Hillborn (2009) stated that a park is considered unsafe when criminal activity and lack of order have become the norm and local users consider it dangerous, avoid it or limit the time spent in it to the bare minimum. Criminal activity and lack of order are caused by vandalism, littering, animal feces, excessive consumption of alcohol, use of drugs as well as public sex, which may become the dominant activities in the park.

The top three negative issues in Cytadela Park are: alcohol consumption, the presence of homeless people and vandalism. In general, the consumption of alcohol in public places is prohibited in Poland. In Cytadela Park it is permitted 
only in designated areas: in restaurants and their gardens. While the wellmaintained parts of the park show no trace of illegal alcohol consumption, numerous liquor bottles and beer cans can be found at the outskirts of the park, especially near the remains of fortifications, as proof that alcohol is in fact consumed there.

It is interesting that the presence of homeless people is considered one of the major problems of the park by the respondents. Field inspections did not confirm its occurrence in the Cytadela Park. Additionally, studies of the homeless have been conducted in Poznań to learn about the places in which they stay, and parks are seldom listed. Unfortunately, detailed information on the locations chosen by the homeless is not provided in these studies (Municipal Family Support Centre, 2015). The problem of the homeless in the context of CPTED was discussed by Saville and Atlas (2016). According to the authors, typical illicit behaviors related to homelessness are: panhandling, loitering, trespassing, petty theft, littering and garbage, and bathroom incivility.

Vandalism, the third major negative phenomenon indicated by the respondents, is clearly visible in the park. The activity of vandals is especially pronounced in areas where no walking paths have been established, near entrances to fortifications as well as at the outskirts of the park. A good example of such activity is the destruction of information boards on fortifications or the removal of security devices preventing entrance to the fortifications. The central part of the park is free of damage.

Other, less severe, problems were drug distribution, illegal garbage dumps or graffiti. Studies by Kotlaja et al. (2018) showed that parks are not a "safe" environment for distribution and use of illegal drugs. Fletcher (1983) showed that vandalism and exhibitionism are not problems that are noticed by park users. Studies by Robinson et al. (2003) confirmed that garbage in public spaces may heighten the sense of fear.

\subsection{Conclusions and recommendations}

This study contributes to the research by determining the safety of urban park users in Cytadela Park in Poznan, Poland, and highlighting spots that contribute to poor perceived safety using CPTED principles. This study shows that, in the largest park of Poznan, perception of safety differs according to the time of day. It is higher during the day and much lower after dark. Environmental design elements have an impact on perceived safety. The most important for park users are appropriate lighting and video surveillance. Respondents feel safe when someone else is around, i.e., other persons, police or city guards, but also their dogs. They feel unsafe in the presence of alcohol consumption, or in presence of homeless people and vandalism.

The park can be split into two parts regarding safety perceptions of users. A neat part, with alleys, lighting, maintained greenery, several meeting places (restaurants, outdoor gyms, playgrounds) is eagerly used by people and 
considered safe. The second part, located on the park outskirts and near the fortifications and cemeteries, mostly without designated alleys, is unlit with few people around. From a safety perspective, both parts can be improved. Management of the park could consider organizing more social events that could bring more people to the area. Renovation of the amphitheater could be the starting point as this place is not frequently used due to poor technical conditions. There is much more work required with the second part of the park, which is neglected and requires huge financial resources, especially for renovation of fortifications and cemeteries. In addition, adding benches can improve surveillance while garbage bins and lighting can make it friendlier for park users.

Parks should be places where time can be spent in safe conditions, regardless of users' activity. Ensuring proper maintenance is a key issue in achieving comfortable use. Appropriate lighting may extend the hours of park use, promote social interactions and can lead to strengthening of natural surveillance. Although the results found here cannot be generalized to other parks elsewhere and further research using CPTED principles in parks is needed, the case of Cytadela Park provides a starting point to discuss the usefulness of CPTED principles in other Polish cities.

\section{References}

Abenoza, R. F., Ceccato, V., Susilo, Y. O., \& Cats, O. (2018). Individual, travel and bus stop characteristics influencing travelers' safety perceptions. Transportation Research Record, 2872, 19-28.

Angel, S. (1968). Discouraging Crime Through City Planning. Berkeley, CA: Institute of Urban \& Regional Development.

Armitage, R. (2018). Burglars' take on crime prevention through environmental design (CPTED): reconsidering the relevance from an offender perspective. Security Journal, $31,285-304$.

Atlas, R. (2008). 21st Century Security and CPTED: Designing for Critical Infrastructure, Protection and Crime Prevention. New York: CRC Press.

Bazregari, S., \& Ostovareh, M. (2016). The investigation of environmental security of Ladies Park using Crime Prevention through Environmental Design (CPTED) approach-case study-Qom Narges Park. Ciência e Natura, Santa Maria, 38, 814-820.

Beeler, J. N. (2011). Security Planning for Public Spaces: Testing a Proposed CPTED Instrument in Berlin, Germany (A thesis presented to the graduate school of the University of Florida in partial fulfillment of the requirements for the degree of Master of Arts in urban and regional planning). Gainesville: University of Florida.

Brands, J., van Aalst, I., \& Schwanen, T. (2015). Safety, surveillance and policing in the night-time economy: (re)turning to numbers. Geoforum, 62, 24-37.

Brands, J., \& Schwanen, T. (2014). Experiencing and governing safety in the night-time economy: nurturing the state of being carefree. Emotion, Space and Society, 11, 67-78.

Brown, B., \& Bentley, D. (1993). Residential burglars judge risk-the role of territoriality. Journal of Environmental Psychology, 13, 51-61.

Camargo, D. M., Ramirez, P. C., \& Fermino, R. C. (2017). Individual and environmental correlates to quality of life in park users in Colombia. International Journal of Environmental Research and Public Health, 14, 1250-1260. 


\section{Emilia Bogacka}

Carter, S. P., Carter, S. L., \& Dannenberg, A. L. (2003). Zoning out crime and improving community health in Sarasota, Florida: "Crime Prevention through Environmental Design". American Journal of Public Health, 93, 1442-1445.

Ceccato, V. (2013). Moving Safely: Crime and Perceived Safety in Stockholm's Subway Stations. Plymouth: Lexington.

Ceccato, V., \& Hansson, M. (2013). Experiences from assessing safety in Vingis Park, Vilnius, Lithuania. Review of European Studies, 5, 1-17.

Ceccato, V., \& Uittenbogaard, A. (2014). Space-time dynamics of crime in transport nodes. Annals of the Association of American Geographers, 104, 131-150.

Clarke, R. V. (2008). Improving street lighting to reduce crime in residential areas. Problem-Oriented Guides for Police Response Guide Series, 8. Washington, DC: US Department of Justice.

Costigan, S. A., Veitch, J., Crawford, D., Carver, A., \& Timperio, A. (2017). A crosssectional investigation of the importance of park features for promoting regular physical activity in parks. International Journal of Environmental Research and Public Health, 14, 1335-1345.

Cozens, P., Hillier, D., \& Prescott, G. (2001). Crime and the design of residential propertyexploring the perceptions of planning professionals, burglars and other users, Part 2. Property Management, 19, 222-248.

Cozens, P., Saville, P., \& Hillier, D. (2005). Crime Prevention through Environmental Design (CPTED): a review and modern bibliography. Property Management, 23, 328-356.

Cozens, P., \& Sun, M. Y. (2018). Exploring crime prevention through environmental design (CPTED) and students' fear of crime at an Australian university campus using prospect and refuge theory. Property Management, 37, 287-306.

Czapska, J. (2012). Zapobieganie przestępczośsi przez ksztattowanie przestrzeni. Teoria Badania. Praktyka. Kraków, Poland: Wydawnictwo Uniwerystetu Jagiellońskiego.

Demaris, A., \& Kaukinen, C. (2005). Violent victimization and women's mental and physical health: evidence from a national sample. Journal of Research in Crime and Delinquency, 42, 384-411.

Fletcher, J. E. (1983). Assessing the impact of actual and perceived safety and security problems on park use and enjoyment. Journal of Park and Recreation Administration, $1,21-36$.

Franklin, T. W., Franklin, C. A., \& Fearn, N. E. (2008). A multilevel analysis of the vulnerability, disorder, and social integration models of fear of crime. Social Justice Research, 21, 204-207.

Godbey, G., \& Mowen, A. (2010). The Benefits of Physical Activity Provided by Park and Recreation Services: The Scientific Evidence. Ashburn, VA: National Recreation and Park Association. www.nrpa.org/globalassets/research/godbey-mowen-research-paper.pdf.

Groff, E., \& McCord, E. S. (2011). The role of neighborhood parks as crime generators. Security Journal, 25, 1-24.

Hilborn, J. (2009). Dealing with crime and disorder in urban parks. Problem-Oriented Guides for Police Response Guide Series, 9. Washington, DC: U.S. Department of Justice.

Iqbal, A., \& Ceccato, V. (2015). Does crime in parks affect apartment prices? Journal of Scandinavian Studies in Criminology and Crime Prevention, 16, 1-25.

Iqbal, A., \& Ceccato, V. (2016). Is CPTED useful to guide the inventory of safety in parks? A study case in Stockholm, Sweden. International Criminal Justice Review, $26,150-168$.

Jacobs, J. (1961). The Death and Life of the Great American Cities. New York, USA: Random House.

Jeffery, C. (1971). Crime Prevention through Environmental Design. Beverly Hills, CA: Sage. 
Jorgensen, L. J., Ellis, G. D., \& Ruddell, E. (2012). Fear perceptions in public parks: interaction of environmental concealment, the presence of people recreating, and gender. Environment and Behavior, 45, 803-820.

Klima, E., Janiszewska, A., Grabski, L., \& Woldendorp, T. (2016). Improving the quality of life with CPTED methodology: high-rise housing in Widzew, Łódź. Journal of Place Management and Development, 9, 210-223.

Koramaz, E. K., \& Türkoğlu, H. (2018). Measuring and understanding urban parks' contribution to quality of life in Istanbul. Social Indicators Research, 138, 335-351.

Kotlaja, M. M., Wright, E. M., \& Fagan, A. A. (2018). Neighborhood parks and playgrounds: risky or protective contexts for youth substance use? Journal of Drug Issues, $48,657-675$.

Lee, J. S., Park, S., \& Jung, S. (2016). Effect of Crime Prevention through Environmental Design (CPTED) measures on active living and fear of crime. Sustainability, 8, 972-988.

Michael, S. N., \& Hull, R. B. (1994). Effects on Vegetation on Crime in Urban Parks. Blacksburg: Virginia Polytechnic Institute and State University, College of Forestry and Wildlife Resources, Department of Forestry.

Municipal Family Support Centre. (2015). Report on a Study of Homeless People Carried out in Poznań in January 21-22, 2015. https://mopr.poznan.pl.

Newman, O. (1972). Defensible Space-Crime Prevention through Urban Design. New York: Macmillan.

Newton, A., \& Ceccato, V. (2015). Theoretical perspectives of safety and security in transit environments. In V. Ceccato \& A. Newton (Eds.), Safety and Security in Transit Environments: An Interdisciplinary Approach. London: Palgrave MacMillan, 23-36.

Özgüner, H., \& Kendle, A. D. (2006). Public attitudes towards naturalistic versus designed landscapes in the city of Sheffield (UK). Landscape and Urban Planning, 74, 139-157.

Police statistics. (2016). Crime by Places of Commitment. Unpublished raw data.

Ratcliffe, J. (2006). Video surveillance of public places. Problem-Oriented Guides for Police, Response Guides Series, 4. Washington, DC: US Department of Justice.

Ratcliffe, J., Taniguchi, T., \& Taylor, R. (2009). The crime reduction effects on public CCTV cameras: a multi-method spatial approach. Justice Quarterly, 26(4), 746-770.

Reynald, D. M., \& Elffers, H. (2009). The future of Newman's defensible space theory: linking defensible space and the routine activities of place. European Journal of Criminology, 6(1), 25-46.

Robinson, J. B., Lawton, B. A., Taylor, R. B., \& Perkins, D. D. (2003). Multilevel longitudinal impacts of incivilities: fear of crime, expected safety, and block satisfaction. Journal of Quantitative Criminology, 19, 237-274.

Salmani, A., Saberian, O., Amiri, H., Bastami, M., \& Shemshad, M. (2015). Study on urban parks environmental safety in women viewpoints based on Crime Prevention through Environmental Design Approach (case study: Valiasar Park, Shahr-e_Qods, Tehran, Iran). Bulletin of Environment, Pharmacology and Life Sciences, 4, 95-102.

Saville, G., \& Atlas, R. (2016). White Paper on Homelessness and CPTED for International CPTED Association. ICA: Alberta, Canada

Sohn, D. W. (2016). Residential crimes and neighbourhood built environment: assessing the effectiveness of crime prevention through environmental design (CPTED). Cities, $52,86-93$.

Surette, R., \& Stephenson, M. (2019). Expectations versus effects regarding police surveillance cameras in a municipal park. Crime Prevention and Community Safety, $21,22-41$. 


\section{Emilia Bogacka}

Talbot, J., \& Kaplan, R. (1984). Needs and fears: the response to trees and nature in the inner city. Journal of Arboriculture, 10, 222-228.

The City of Poznań, (2013). Quality of life in Poznań. www.poznan.pl/mim/main/en/ quality-of-life-in-poznan,p,17048,17053,17791.html.

Troy, A., Grove, J. M., \& O'Neil-Dunne, J. (2012). The relationship between tree canopy and crime rates across an urban-rural gradient in the greater Baltimore region. Landscape and Urban Planning, 106, 262-270. 


\title{
6 The role of public places in Disability Hate Crimes (DHCs)
}

\author{
Antonio Iudici and \\ Riccardo Girolimetto
}

\subsection{Introduction}

Disability Hate Crimes (DHCs) is an under-reported phenomenon concerning any criminal offence considered to be motivated by hostility/prejudice against a person's actual or perceived disability. In this chapter, we identify any potential relationship that may exist between DHCs and public places in the extant literature in order to shed light on the role of such places in facilitating or hindering the occurrence of DHCs. "Public places" here is considered to be a large array of environments, such as urban areas, towns, buildings, but also social networks, where interactions between two or more ordinary people take place. In addition, wherever appropriate, the type of crimes reported and/or the preventive strategies characterizing these spaces are also discussed. To achieve this, Scopus, PubMed and Scholar databases were used to perform a scoping literature review by searching for keywords related to "disability hate crime". Why is this an important subject? (1) Fear, harassment and violence permeate the everyday lives of many disabled people in private as well as in public spaces; (2) most studies often neglect the role of environments in facilitating or hindering DHCs, situating these violent acts against disabled individuals in anonymous physical settings; and (3) it is necessary to locate disability as a cultural and political phenomenon contextualized within society, yet the literature on this field is lacking.

The structure of this chapter is as follows. The chapter starts with theoretical background, which is an overview of definitions: $\mathrm{HC}$ and DHC and theoretical frameworks dealing with disability. This is followed by the methods section, a description of the literature review, and data collection. Results are followed by conclusions and recommendations.

\subsection{Theoretical background}

\section{An overview of definitions: $\mathrm{HC}$ and $\mathrm{DHC}$}

The term 'hate crime' (HC) is generally used to define an act of violence, verbal or physical, in which the offenders target victims for their actual or perceived ethnicity, color, religion, disability, sexual orientation, gender, or national 
origin (Brereton, 2013; Macdonald, 2015; Sun, 2006). This broad definition finds its own genealogy within several US legislations of the twentieth century, such as the Hate Crime Statistics Act of 1990 and the Violent Crime Control and Law Enforcement Act of 1994 (Sun, 2006). Owing to these and other legal definitions, most previous researchers of $\mathrm{HC}$ tended to frame this phenomenon as

a manifestation of intergroup conflict or violence (e.g., Levin \& McDevitt, 2002; Levin \& Rabrenovic, 2001) and as motivated by the distinctiveness of the victim(s), because the offender only targets victims with different group memberships. This type of conceptualization of HC has influenced both clinical interventions with victims of hate crime and the research focus on the causality of hate crime. (Sun, 2006, p. 598)

As regard HCs provoked by the disability of the victim, there is evidence to support the claim that disabled people are at a higher risk of targeted violence, harassment and abuse (Goodley \& Runswick-Cole, 2011; Sin et al., 2010). The studies concerned with HCs focus on "minority-victimology", especially, with the construct of a disability hate crime (DHC) and its relative legislative declinations. In 2007, the UK public agency the Crown Prosecution Service (CPS) defined a DHC as 'any incident which is perceived to be based upon prejudice towards or hatred of the victim because of their disability or so perceived by the victim or any other person' (CPS, 2007, p. 7, cit. in Roulstone, Thomas, \& Balderston, 2011, p. 355). Moreover, in 2016, the Association of Chief Police Officers defined a DHC as a criminal offence perceived by the victim, or others, to be motivated by hostility or prejudice underpinned by a person's disability or perceived disability (Hall, 2018; Ralph, Capewell, \& Bonnet, 2016). Furthermore, the following year, the aforementioned CPS framed DHC as a crime carried out by a perpetrator's hostility towards the victim's disability, and their actual or perceived impairments (CPS, 2017). Furthermore, the definitions of DHCs converge into the semantic areas of discriminatory, unfair, abusive and violent behaviors aimed at people with disabilities, arising from beliefs characterizing people with impairments as a minority (Ralph, Capewell, \& Bonnet, 2016).

Consequently, there are two major interrelated issues concerning the criminal justice system and the criminological literature about DHC: (a) the absence of strong criteria with the capability to certify-through the police and the criminal justice system - whether or not a reported crime is motivated by prejudice or hostility towards the victim's disability, and (b) the seemingly peripheral nature of DHCs as an area of research in criminological inquiry (Roulstone \& Mason-Bish, 2013) because of it being anchored to the idea of "victimology", which dominates the discourse on HC (Gerstenfield, 2013).

A lack of a clear and common definition of DHCs and a parallel inconsistent response from the police and criminal justice system (Sin, 2016) leads such crimes to be under-reported in the official crime statistics when compared with the crimes related to ethnicity, color, religion, sexual orientation, gender, or national origin (Emerson \& Roulstone, 2014; Shakespeare, 2012; Sin et al., 
2010, 2012; Sin, 2016; Ralph et al., 2016; Richardson, et al., 2016). As Hall (2018) reported, the large-scale Crime Survey for England and Wales estimated that 62,000 DHC incidents occurred between 2012 and 2013, while, in the same period, the police recorded 1,841 such cases. Furthermore, Brereton (2013) highlights the misunderstandings among the agencies concerning what constitutes a DHC. Moreover, policy definitions lead to confusion and a lack of confidence in crime reporting (Brereton, 2013), and some authors highlight that there is a dearth of an effective multi-agency response (Richardson et al., 2016; Sin et al., 2010; Sin, 2016). Finally, Shakespeare (2012) suggests the scarcity of awareness about disability among the officers and the fact that people with disabilities are not considered credible witnesses, along with the inaccessibility of facilities, are the critical factors responsible for the lack of an adequate response from the authorities.

With respect to the dominance of "victimology" in HC discourses (Gerstenfield, 2013), several authors have problematized how most of the studies in this area focus more on victimization-i.e., an ingrained and inherent "vulnerability" —as an element of violence perpetrated against disabled people and less on those who commits these crimes and the locations and time in which they occur (Gerstenfield, 2013; Hall, 2018; Jenness, 1999, 2001; Macdonald, 2015; Roulstone et al., 2011). For instance, Macdonald (2015) notices how the notion of vulnerability may become a barrier within the legal system's preventive strategies that are meant to recognize DHCs. Macdonald's study discloses the risk of neglecting the fact that the hostility is aimed at disabled people, which stops disabled people from gaining full legal protection. Even though approaching the victims with a critical gaze is of primary importance during legal and/or criminal investigation, failing to critically look at that those who offend, i.e., the 'anonymous hateful', may lead to the consolidation of the prominent image of the offenders. Moreover, this approach may disregard the relationship between the victims and offenders, as well as the socio-spatial context in which DHCs occur, along with the entrenched social factors underpinning this phenomenon (Garland, 2012; Gerstenfield, 2013, Hall, 2018, Macdonald, 2015; Sin et al., 2010).

From Waxman's (1991) study on violence towards disabled people to the 2016 report from the Equality and Human Rights Commission (EHRC), DHCs and violence have been treated as ongoing social phenomena and parts of a much broader set of exclusionary practices that a disablist society suffers from (EHRC, 2016; Hollomotz, 2013; Roulstone \& Mason-Bish, 2013). This points to the fact that considering impairments per se as elements that trigger violence, harassment, abuse, etc. signifies a neglect towards the nuanced understanding of situational risks as well as the social background in which these events occur (Sin et al., 2010). As a social fact, the crime must be placed within space-time coordinates, a geographical space constituted by encounters between people's shared meanings, complex interactions between impairments, the wider social attitudes and behaviors of the actors, as well as the environmental and structural conditions (Hall, 2018; Sin, 2016). 
Even while acknowledging the relevance of studies that focus on disabled people by presuming them as vulnerable persons (Iudici, Bertoli, \& Faccio, 2017; Roulstone et al., 2011), this review chose to focus on the "dark side" or the "overshadowed background" of the literature on disability and crime. In fact, despite the fear, harassment, and violence permeating the everyday lives of many disabled people in private as well as public places (EHRC, 2016), most studies often neglect the role of environments in facilitating or hindering DHCs, situating these violent acts against disabled individuals in anonymous physical settings (Hall, 2018; Sin et al., 2010). Although it has been seen as a necessity to locate disability as a cultural and political phenomenon contextualized within society, there are practically no studies about the socio-spatial dynamics of DHCs (Alhaboby, al-Khateeb, Barnes, \& Short, 2016; Goodley \& Runswick-Cole, 2011; Hall, 2018; Ralph et al., 2016; Roulstone \& Mason-Bish, 2013). Therefore, this aspect of the social context remains under-represented in the studies on DHCs. This discloses the necessity of exploring this overshadowed area in order to assess its theoretical and practical implication in appropriately addressing DHCs. Thus, in this research we ascertain whether and how public places have been taken into account in DHC studies, with a focus on the kind of impact these places may have in hindering or facilitating these phenomena. The extant literature is reviewed to identify any potential relationship between DHCs and the public environments and, wherever appropriate, we reported the type of crimes or the preventive strategies characterizing these spaces.

\section{Theoretical frameworks dealing with disability}

There are two major theoretical frameworks or models, the medical and the social model, which are concerned with and inform the idea of "disability". The latter underlines the role of society in producing the disability in individuals that suffer from impairments, while the former places the cause of the deficit within the individual (Brittain, 2004; Forhan, 2009; Haegele \& Hodge, 2016; Roulstone \& Mason-Bish, 2013). Regardless of their differences, both perspectives have been subjected to several critiques (Haegele \& Hodge, 2016). The major criticism against both models is that they ignore the relationship between social experience and the fact of owning an impaired body with which other persons interact on interpersonal, social, cultural, economic and political levels (Marks, 1999; Haegele \& Hodge, 2016).

As regards the background of HCs, the EHRC identifies both socio-psychological and structural perspectives, i.e., the structural factors that may have an impact on HCs (which includes online or cyber hate crimes), along with identifying "how certain social processes (e.g., societal norms and values), and practices (e.g., the practices and interventions used by statutory agencies) may actually create a social context in which certain groups in society can become marginalized or stigmatized" (EHRC, 2016, p. 8). In this perspective, perceived or actual threats can be linked not only to economic stability and access to social resources, but also to people's sense of safety in the society and/or 
values and social norms. Through this perspective, DHCs are shaped as an ongoing process that often forms a part of the everyday experiences of hostility and prejudice faced by people with disabilities (EHRC, 2016).

To overcome the dichotomous medical-social framework, and in accordance with the mutual relationship between these theoretical approaches towards disability and HC highlighted by EHRC (2016), we chose to adopt an interactionist epistemological theoretical framework (Salvini \& Dondoni, 2011; Salvini, 2004) for the research, especially in the results and conclusions sections. According to the interactionist assumptions, reality cannot be separate from discourses (i.e., rules, roles, meanings, acts and actions of which each human being is simultaneously an actor and interpreter) that name and describe reality. In doing so, the discourse creates pragmatic effects (Salvini \& Dondoni, 2011; Salvini, 2004). Interaction, between the parts of every kind of system, is considered the main object of this theoretical framework, and language is considered to be the principal means of representing the state of social reality. The reality lived by individuals, in which they relate to each other not only through the discourses but also through the social situation in which they meet, is shaped by their own scripts, structures, schemes, narrative genres, conceptual architectures and physical or symbolic artefacts (Faccio, Iudici, Turco, Mazzucato, \& Castelnuovo, 2017; Turchi \& Perno, 2004; Turchi, 2009). As Haegele and Hodge (2016) highlight, it is the language that people use to describe those with disabilities that influences their expectations of and interactions with disabled people.

\subsection{Method}

\section{Scoping literature review}

Since this study aimed to explore whether public places have been taken into account in studies on DHCs and in what manner, a scoping literature review was chosen as the most suitable research strategy to accomplish this goal (Carr et al., 2017; Grant \& Booth, 2009). This strategy entails a preliminary assessment and a synthesis of research findings available in literature about a specific topic.

Furthermore, the choice has been made due to the paucity of studies concerning the object of this study. This method helps a researcher identify what has been accomplished previously, allowing for further identification of omissions or gaps for other researchers to build on (Grant \& Booth, 2009). To implement this research strategy, the recent or current literature was examined, identified and consolidated, with a focus on whether public places have had an impact on the studies on DHCs and if so, how (Grant \& Booth, 2009; Lipscomb, 2000). The major criterion for the selection of the studies for this review was that the research was peer-reviewed (Grant \& Booth, 2009). The aim of this kind of review was to explore and systematize the available data on the area to discover the lines along which future research can fill the identified gaps and omissions in the existing literature. 


\section{Data collection}

In order to investigate whether public places have been taken into account in the literature on DHCs we utilized the Scopus and PubMed databases to identify the role of public places in facilitating the occurrence of DHCs. We relied on these two databases to ensure the quality of the literature selected for the review and, as the other browsers opened to more complex and specific aspects, to not hinder the generalizability of this exploratory study. Due to the paucity of studies concerning precisely the object of this study, which is intended to be the first exploratory overview of this phenomenon, the authors of the current study first defined their main object of inquiry, namely public place. In order to do so, they drew on the definition provided by the Cambridge Dictionary (Cambridge University Press, 2019) as well as on their theoretical framework (Salvini, 2004) to define public place as every space (area, town, building, etc.). That is, physically or virtually, space meant and provided by the government to be available to everyone and which enables symbolic interactions between two or more ordinary people by rules, roles, meanings, acts, and actions characterizing a specific space. Second, all the studies that regarded the role of public places in DHCs or even mentioned them in passing were considered. Additionally, any kind of discrimination over type of disability, gender, nature, crimes, etc. was strictly avoided.

The articles were identified by searching for the main keyword "disability hate crime" and limited to printed articles, reviews, notes and editorials. The abstracts of the 95 selected documents were reviewed independently by the two authors. The aforementioned definition of a public place has been used by the authors to include those papers that reported the kind of pertinent spaces encompassed by our definition. In this preliminary abstract selection, given the exploratory value of this study and the paucity of studies concerning this topic, even articles that merely (or inexplicitly) mention the places of crimes were selected. In this step, the two authors discussed the retrieved abstract and used the definition of a public place to exclude 51 articles for:

(a) not being consistent with the research aim;

(b) not referring to any public place as the scene of the DHC;

(c) not being consistent with the definition of a public place provided by the authors and

(d) being duplicated.

Due to the paucity of studies, all the remaining 44 articles formed the sample for this review. These articles were published within a span of 27 years, between 1991 and 2019, and were independently read by the two authors to extract quotes that were relevant to the research objective. After a comparison between the two authors, the above step revealed that 19 articles did not refer to any public place related to DHCs. Therefore, this left the authors with only 25 papers for their consideration. In an effort to locate relevant articles not found 
in our search, and to give a wider introductive perspective, Scholar database was also searched, retrieving two relevant articles. Finally, the authors read the papers $(N=27)$ independently to identify the macro-themes representing how public places have been taken into account in the studies on DHCs, with a focus on how they are hindering or facilitating these phenomena. Finally, according to the criterion of greater representativeness of the collected data, the data were categorized into three macro categories: (a) public places as the backdrop to DHC occurrences; (b) public places as an active factor in facilitating DHC occurrences; and (c) public places as an active factor in hindering DHC occurrences. The authors then worked independently to present the study as the product of cross-comparison between the findings of the authors.

\subsection{Results}

Of the 32 initially identified publications that concerned DHC, only 20 were eligible for inclusion as they concern public places. Their content was organized in the three aforementioned categories.

From the data in the first category (public places as the backdrop to DHC occurrence), the authors gathered those articles that referred to public places where DHCs were most likely to occur. In the second category (public places as an active factor in facilitating DHC occurrences), the authors counted four contributions that highlight how the features of public places might have facilitated the perpetration of DHC. Finally, the last category (public places as an active factor in hindering DHC occurrences) contained those studies that considered which actions to take in public places, considering them as locations on which counter-strategies can be based to prevent DHCs.

\section{Public places as the backdrop to DHC occurrences}

In the literature, there were studies that shed light on an underground public dimension related to DHCs that has been overlooked in the studies about vulnerability and domestic violence against disabled people. As reported by Hall (2018), the following public locations in Kent (southeast England) have been described as places "where bad things happen" to people with learning disabilities: "school, college or day center $(43 \%)$; in the street as they were walking somewhere $(35 \%)$; in and around their homes $(28 \%)$; in their neighborhood $(28 \%)$; and on public transport (25\%)" (Hall, 2018, p. 4). This example underlines the fact that acts of abjection experienced by disabled people may occur everywhere, not only in private locations. Waxman (1991) was perhaps the first to shed light on the public dimension of violence against people with disability, and reported two cases of routine physical abuse in public places, namely a school and the outside of a local library. In particular, he described the episode of the murder of Cary Dickenson, a person with multiple disabilities, whose body was found in the trash can of a local library. Another instance was that of a student in Northern California, who had been repeatedly thrown in a cold pool 


\section{Antonio Indici and Riccardo Girolimetto}

by the teaching staff. Besides these locations, institutional care-place and workplace have been mentioned as other backdrops that prove that disabled people do not face violence only in domestic or private contexts (Waxman, 1991).

In accordance with the above-mentioned places, the annual Hate Crime Statistic reports, whose data for the five-year period between 1997 and 2001 were collected, identified school environment (college campus) (OR 0.10435) as the primary location of $\mathrm{HC}$ incidents, along with streets (OR 0.17593), residences (OR 0.58750) and government buildings (OR 0.02419) (McMahon et al., 2004). Since this data were used by McMahon and colleagues (2004) to examine the prevalence of DHCs compared with other kinds of HCs, they only provide a statistical correlation between crimes and places and do not explain the kind of impact specific locations have on violence.

Besides mentioning schools, workplaces and streets as the places where violent acts against people with disability occur, other studies identify locations such as public transport, high streets, social housing/community and institutions (such as those in the mental health system) (Carr et al., 2017; Clement et al., 2011; Hall, 2018; Mikton, Maguire \& Shakespeare, 2014; Roulstone et al., 2011; Shakespeare, 2012). As regards public transport, Clement and colleagues (2011) also noted the kind of violence (verbal) that is related to it by quoting the following lines from a victim: "I did say to, I think it was one of the inspector or whatever, well 'this train is overcrowded and I can't breathe' then I heard a bloke saying 'oh is the lunatic asking about the overcrowding" (Clement et al., 2011, p. 220). A more stirring example of DHCs occurring in a public location was described by Sherry (2013), which took place in a shopping center. In this case, two boys met and escorted a girl with disabilities to the local river, where a larger group subjected her to physical abuse.

As regards DHCs occurring in communities and institutions, in their systematic review, Mikton, Maguire, and Shakespeare (2014) reported a strong paucity in current literature about these events in spite of their prevalence. In fact, since a UNICEF report of 2005, widespread violence against disabled children in institutions (Mikton et al., 2014) and communities (Carr et al., 2017; Shakespeare, 2012; Garland, 2012) seems to be a proven fact; particularly as in these places, many disabled people live in isolation in vulnerable conditions (Shakespeare, 2012).

\section{Public places as active factors in facilitating $\mathrm{DHCs}$}

In the previous section, the authors limited their focus on those studies which mentioned the most likely scenes of DHC. Now, this study will refer to those articles that report how a specific location may facilitate DHC occurrences. By dealing with public places as crucial factors in violent acts against disabled people, this study identified and assessed three major places considered in the literature in terms of the contributing factors that may lead to different kinds of violence: public institutions, areas of poverty and deprivation, and virtual spaces. 
As regards public institutions (such as residential/community setting and school system), when they become segregated and exclusionary they may fail to recognize the diversity of their residents and, consequently, fail to restrain violence against the users and build bonds and safe spaces that safeguard the specificity and differences of identities (Balderston, 2014; Goodley \& Runswick-Cole, 2011). For instance, in user-led research involving disabled women who have experienced violence in segregated institutions (health, educational, and residential) and across impairment groups, Balderston (2014) reported how, in these spaces, a lack of control over the choice of personal support staff, activities, money, transport, etc. may increase the risk of sexual violence and, at the same time, decrease the possibility of safety (Balderston, 2014). Furthermore, other studies highlight the frequency of sexual abuse against people with disabilities in an institutional setting (such as day centers or residential homes) and the critical role of health and social care professionals in the prevention of sexual abuse (Balderston, 2014; Carr et al., 2017; Hall, 2018; Roulstone \& Mason-Bish, 2013; Sin et al., 2010; Sin, 2016). For instance, a care giver may display controlling behaviors such as controlling finances and removing the wheelchair of the one being cared for, that might not appear criminal (Roulstone \& Mason-Bish, 2013). When the perpetrator is a 'care giver', it does make one rethink how a dependent relationship, by its context, may give rise to an increased risk of abuse in a care-giving situation (Carr et al., 2017; Sin et al., 2010).

As for the school system, the current review identified the work of Goodley \& Runswick-Cole (2011) as the only study that focused on school-related violence outside of the common ways of studying the topic of bullying against people with disabilities. First, they identified the promotion of cost effectiveness and efficiency performance required as the structural characteristics that may lead to greater competition, selection, and social division to facilitate the retention of the disparity between the abled and the disabled learners (Goodley \& Runswick-Cole, 2011). Second, the nationalization of curricula across schools could create a logic of promoting key skills among the students to make them fit for advanced capitalistic societies (Goodley \& Runswick-Cole, 2011).

Furthermore, our focus on areas of poverty and deprivation revealed that inappropriate public housing or disproportionate institutionalization of disabled people can either lead to the production of social marginalization and isolation or accentuate the power imbalance between the actors who inhabit those places (Balderston, 2014; Hall, 2018; Macdonald, Donovan \& Clayton, 2017; Sin, 2016; Sin et al., 2010). As regards poor housing and deprived areas, the literature revealed a correlation between them and the occurrence of DHCs (Chakraborti \& Garland, 2012; Emerson \& Roulstone, 2014; Hall, 2018; Macdonald et al., 2017). For instance, a study by Macdonald et al. (2017) found a significant correlation between DHCs and the most deprived areas in Newcastle and Sunderland (i.e., 33 percent of all the incidents reported to Agencies against Racist Crime and Harassment, ARCH). Moreover, they reported that, among disabled people, there was a perceived fear of being sent to a more restrictive setting such as residential care (Macdonald et al., 2017). By observing social factors that may 


\section{Antonio Indici and Riccardo Girolimetto}

lead to different forms of violence in such spaces of segregation and deprivation, the difficulty in building local networks that may get people to engage in the prevention of anti-social behaviors can be noticed (Sin et al., 2010). Others have also highlighted the risk of isolation and marginalization of the people living in independent social housing sectors, often characterized by the provision of inflexible and inappropriate services (Macdonald et al., 2017; Sin, 2016; Sin et al., 2010), and the anticipation concerning the situational vulnerability risk involved in collocating disabled people in such places based on choices made by professionals involved in the housing decision (Sin, 2016).

Moreover, regarding the occurrence of a higher incidence of DHCs in these areas, some authors propose (a) the changing levels of diversity among the different marginalized communities living in close contact, underpinned by poverty; (b) the withdrawal of jobs and services; and (c) the climate of suspicion and marginalization as factors contributing to this problem (Hall, 2018; Macdonald et al., 2017). These conditions may underpin and lead to disabling social barriers, such as the dynamics of the tensions between different ethnicities as well as the risk of victimization, abuse, violence and harassment (Macdonald et al., 2017; Sin, 2016; Sin et al., 2010). Frequent examples of violent practices include intimidation, aggression, offensive language, as well as harassment and abuse. Sin et al. (2010) report the following forms of harassment in a case they studied: "house burgled, lit matches were thrown through their letter box, and used condoms, excrement and abusive letters delivered to their front door" (Sin et al., 2010, p. 21).

Advancements in digital technology, the internet and electronic communications introduced brand new virtual public spaces and commonplace means for interpersonal interaction. The spread of these tech-practices all over the world spawned new forms of violence. As the EHRC (2016) stated, cyber hate is a growing phenomenon which vastly outnumbers offline HCs. This study has drawn upon previous studies regarding digital communication channels, virtual environments and offender's anonymity to examine a new kind of online location that may give rise to vulnerable situations (Alhaboby et al., 2016, 2017a, 2017b; Burnap \& Williams, 2016). Creating fake accounts pretending to have a disability, targeting the victim's significant others, threatening victims and spreading false information are some examples of the prevarication strategies that are made possible through virtual spaces of interaction. Moreover, such virtual prevarication strategies may lead to social isolation, cyber harassment, hate speech and have a wider impact on the wellbeing of the victim (Alhaboby et al., 2017a). This may further result in distress, anxiety, mood disturbances, deterioration of health, suicide attempts and a lack of awareness/education/ training in supporting others (e.g., groups, police and healthcare professionals) (Alhaboby et al., 2016, 2017b; Burnap \& Williams, 2016).

\section{Public places as an active factor in limiting DHCs}

After describing how the characteristics of some public places may facilitate the perpetration of DHCs, the current study concentrates on how the structural 
conditions of such places may limit violence, harassment, abuse and crime. The focus of the study is on educational and virtual environments because, on the databases we utilized, no study that takes deprivation and poor housing into account from this perspective was found.

With regard to public places, such as local libraries across the city, and commercial and business premises, McClimens and Brewster (2017) proposed to consider these places as first accessible refuge zones, where staff in various commercial and business premises along the 'High St.' could offered support, in cooperation with the local police.

Based on the best practices addressing stigmatizing and discriminatory attitudes towards disabled people, certain formative and informative interventions (Richardson et al., 2016), in partnership with the police and experts, can make an educational environment a safe space by promoting a shift among the students about the idea of disability from an individual to a socio-relational and contextualized perspective. Maguire, Wilson, and Jahoda (2018) recommend the use of school-based lessons or an informed program of lessons as a strategy to address the stigma and discriminatory attitudes related to disability and also as a means to influence the views of the wider community of which the schools are a part (Maguire et al., 2018). The crucial issues that these interventions may focus on include (a) tackling the linguistic barrier that may produce stigmatizing labels that give rise to social exclusion/bullying/hate crime, (b) building partnerships for pooling resource (e.g., public agencies), and (c) paying attention to the structural factors that may lead young people towards marginalization (Maguire et al., 2018; Richardson et al., 2016). To support people with disabilities, and for citizens to feel more confident about recognizing and reporting DHCs, Maguire and colleagues (2018) analyzed other existing practices such as school assemblies as occasions to raise awareness about bullying and DHCs in synergy with statutory agencies (e.g., the police) and theatre workshops. Moreover, they illustrated a school intervention program that was developed in collaboration with teachers and educators, which included reflection sessions to understand the attitudes and behaviors of the students, and lessons dealing with the appreciation of difference and disability and the meaning of having a disability, with the aim of increasing the contact between the able-bodied and disabled persons (Maguire et al., 2018).

Furthermore, other suggestions came from Clement et al. (2011), who reported the use of HC posters in schools, which aimed not only to encourage the reporting of targeted harassment suffered by disabled people but also to send out messages to potential perpetrators. When the researchers asked the participants with intellectual disabilities to think about what would stop or prevent their harassment, they suggested school and community education, along with a change in public attitudes and more effective policing as the possible solutions (Clement et al., 2011). Similarly, Sin et al. (2010) pointed out the crucial role of the educational environment in challenging and preventing harassment and violent acts against people with disabilities, through effective policies offering support to those who report bullying or hate-related incidents (Sin et al., 2010). 


\section{6}

As for virtual public spaces such as social media, blogs, email channels and other instant messaging services, few studies have reported how the new virtual form of communication (e.g., social networking sites such as Twitter, Facebook, etc.) may be used as a medium to implement diagnostic prevention systems to promptly identify hate speech, threats, harassment, etc. (Alhaboby et al., 2016, 2017a; Burnap and Williams, 2016). For example, social media and victim support websites may become an effective way to explore the experiences of the disabled victims of cyber harassment to analyze the impact of cyber harassment on their lives with the help of a self-administered online survey (Alhaboby et al., 2016).

Furthermore, Burnap and Williams (2016) developed a supervised machine classification model for multiple protected characteristics (i.e., gender, ethnicity, disability, sexual orientation) to automatically identify instances of cyber hate posted to online social networks such as Twitter. Additionally, they suggest the development of a blended model that includes the knowledge of how the aforementioned protected characteristics may intersect with each other in cyber hate speech (Burnap \& Williams, 2016). From this perspective, Twitter is framed as a digital agora that promotes real-time interactions between larger groups of people and, therefore, is a suitable source of data (Burnap \& Williams, 2016).

\subsection{Conclusions and recommendations}

It is evident from the results that the lack of understanding of the context in which DHCs occur must be considered in future studies that aim to face violence against people with disabilities. In fact, given the dearth of knowledge on the role played by public places in DHCs, there is a need to reframe the nature of this phenomenon as a contextualized event that is shaped by social relations between the abled/disabled in a specific space and time. Future research should therefore take into account socio-spatial dynamics of DHCs, as well as the inherent social architecture and policies that seem closer to a disablist society than an inclusive one.

In short, concerning public places as an active factor in facilitating DHC occurrences, we noted:

1. A neglect of the situational vulnerability risk involved disabled people living in independent social housing sectors;

2. A critical impact of the care-giving situations (such as day centers or residential homes) where the increased dependency and the a lack of control over users' personal choices, may give rise to risk of abuse, decreasing the feelings of safety;

3. The role of the school system in promoting cost effectiveness and efficiency performance required within standardized criteria;

4. The impact of social networks in creating a situation of cyber harassment, cyber-hate speech and social isolation of the victims. 
With regard to public places as an active factor in hindering DHC occurrence, the following observations were made.

1. The crucial role of the educational environment in challenging and preventing harassment and violent acts against people with disabilities, in synergy with statutory agencies and an active role of students (e.g., theatre workshops).

2. The value of the cooperation between local police and local stores along main streets in the implementation of first accessible refuge zones, as suggested by McClimens and Brewster (2017) in the previous section. Public place as an active factor in limiting DHCs.

3. The possibility to use the internet and social networks as suitable sources of data for case-analysis and for monitoring DHC policies, as well as mediums to accommodate disabled people's needs by online research methods and interviews.

The reported observations shed light on the evident impact of public spaces in setting up the conditions for a vulnerability situation involving people with disabilities, along with the importance of taking into account the structural elements of those spaces in which DHCs occur.

Before considering new preventive practices, we should consider that, in order to safeguard specific special rights, society is involved in a creating and using process of differences and subdivisions based on the abled/disabled dichotomy as human characteristics, ignoring the contextual conditions that can produce disability. For instance, wheelchair spaces on public transport and other so-called "designated" disability spaces, poor housing in deprivation areas and schools that promote cost-effectiveness and efficient performance give rise to competition and social division between the able-bodied and the disabled. These are not spaces of inclusion but places where implicit traces mark the differences, and this may lead to exclusionary behaviors. It is the interaction of those using these places that make them what they are in a socio-symbolic negotiation of meanings.

Consistent with other researchers, we consider DHC as a social fact; hence, it is a product of the interactions between the victim and the perpetrator(s) in specific spaces and times that portrays disabled people as welfare recipients and individuals favored in the access to resources (e.g., Haegele \& Hodge, 2016; Hall, 2018; Jenness, 2001; Ralph et al., 2016; Salvini \& Dondoni, 2011). This is the reason why the authors of the current study propose a shift from inherent vulnerability to situational vulnerability (Hall, 2018; Sin et al., 2010; Sin, 2016). This perspective shift means not taking for granted where and when crimes and haterelated practices occur, as well as how places impact on them, by wondering whether attribution errors, false beliefs and stereotypes related to "vulnerability" and "disability" may constitute implicit assumptions in those policies that concern people with disabilities (e.g., school programs, social housing collocation process, care-giving situations) (Chakraborti \& Garland, 2012; Garland, 2012; Iudici \& Renzi, 2015; Iudici, Favaretto, \& Turchi, 2018; Ralph et al., 2016; Iudici, Antonello, \& Turchi, 2019). In addition, public places could represent a strategy 


\section{8}

for tackling DHCs, for example by the implementation of accessible refuge zones into urban areas. This implies a multi-agency working (Richardson et al., 2016; Sin et al., 2010; Sin, 2016) in order to involve all the social actors (i.e., social services, police, counsellors, therapists, disability experts, families, people with disability and the perpetrators of DHC) that inhabit specific places and constitute them as well as their dynamics. Therefore, the main aim of this study is to promote a new inclusive way to address DHC.

With regard to limitations, we consider our definition of public places as a restriction since it has been assembled by a specific theoretical framework, which has an inevitable impact on the generalizability of this study. Furthermore, we must consider the fact that collecting data from only few databases (Scopus, PubMed and Scholar) limits the possibility to draw upon different points of view concerning the area of research. Finally, concerning our research strategy (Grant \& Booth, 2009), conclusions may be impacted by content bias to the extent that significant sections of the literature may have been omitted by previous underlying authors' assumptions, or the validity of the statements made might not have been questioned.

Due to the paucity of studies taking into account public places as the main object of inquiry in DHC literature, the authors are of the view that future research can extend this inquiry to other sources of information, as well as engage this brand new line of research, maybe involving directly those social actors who live in places (both physical and virtual) where DHCs occur.

Given the crucial role of the social contexts in facilitating and hindering DHCs, we hope this explorative study may be useful for practitioners, and those who are involved in policies of intervention, in so far as we have tried to adopt and share a new perspective on this phenomena. The suggestions we make concern a shift from policies focusing on single actors (perpetrators or victims of DHCs) to policies regarding the whole social scenario, from the engagement of single experts for each disability to the involvement of all the actors in the contexts (virtual and physical), leaving labels behind, and starting a relationship between all territorial services to promote new inclusive ways to address DHCs.

\section{References}

Alhaboby, Z. A., al-Khateeb, H. M., Barnes, J., \& Short, E. (2016). 'The language is disgusting and they refer to my disability': the cyberharassment of disabled people. Disability \& Society, 31, 1138-1143.

Alhaboby, Z. A., Barnes, J., Evans, H., \& Short, E. (2017a). Cyber-victimization of people with chronic conditions and disabilities: a systematic review of scope and impact. Trauma, Violence, \& Abuse, 20, 398-415.

Alhaboby, Z. A., Barnes, J., Evans, H., \& Short, E. (2017b). Challenges facing online research: experiences from research concerning cyber-victimisation of people with disability. Cyberpsychology: Journal of Psychosocial Research on Cyberspace, 11, 1-8.

Balderston, S. (2014). Victimized again? Intersectionality and injustice in disabled women's lives after hate crime and rape. Gendered Perspectives on Conflict and Violence, 18, 17-51.

Brereton, S. (2013). Living in a different world: joint review of disability hate crime. Probation Journal, 345-350. 
Brittain, I. (2004). Perceptions of disability and their impact upon involvement in sport for people with disabilities at all levels. Journal of Sport and Social Issues, 28, 429-452.

Burnap, P., \& Williams, M. L. (2016). Us and them: identifying cyber hate on Twitter across multiple protected characteristics. EPJ Data Science, 5, 1-15.

Cambridge University Press (2019). Place | meaning in Cambridge Dictionary. https:// dictionary.cambridge.org/dictionary/english/place (accessed 20 February 2020).

Cambridge University Press (2019). Public | meaning in Cambridge Dictionary. https:// dictionary.cambridge.org/it/dizionario/inglese/public (accessed 20 February 2020).

Carr, S., Holley, J., Hafford-Letchfield, T., Faulkner, A., Gould, D., Khisa, C., \& Megele, C. (2017). Mental health service user experiences of targeted violence and hostility and help-seeking in the UK: a scoping review. Global Mental Health, e25, 1-20.

Chakraborti, N., \& Garland, J. (2012). Reconceptualizing hate crime victimization through the lens of vulnerability and 'difference'. Theoretical Criminology, 16, 499-514.

Clement, S., Brohan, E., Sayce, L., Pool, J., \& Thornicroft, G. (2011). Disability hate crime and targeted violence and hostility: a mental health and discrimination perspective. Journal of Mental Health, 20, 219-225.

CPS, T. C. (2017, August 25). Online Support Guide for Disabled Victims and Witnesses of Crime. CPS: www.cps.gov.uk/sites/default/files/documents/publications/guide-tosupport-for-disabled-victims-and-witnesses-of-crime.pdf (accessed 10 January 2020).

Emerson, E., \& Roulstone, A. (2014). Developing an evidence base for violent and disablist hate crime in Britain: findings from the life opportunities survey. Journal of Interpersonal Violence, 29, 1-19.

Equality and Human Rights Commission (EHRC) (2016). Causes and motivations of hate crime. www.equalityhumanrights.com/en/publication-download/research-report102-causes-and-motivations-hate-crime (accessed 16 December 2019).

Faccio, E., Iudici, A., Turco, F., Mazzucato, M., \& Castelnuovo, G. (2017). What works for promoting health at school: improving programs against the substance abuse. Frontiers in Psychology, 8, 1743.

Forhan, M. (2009). An analysis of disability models and the application of the ICF to obesity. Disability and Rehabilitation, 31, 1382-1388.

Garland, J. (2012). Dilemmas in defining hate crime victimisation. International Review of Victimology, 18, 25-37.

Gerstenfield, P. (2013). Hate Crimes: Causes, Controls and Controversies. London: Sage.

Goodley, D., \& Runswick-Cole, K. (2011). The violence of disabilism. Sociology of Health o Illness, 33, 602-617.

Grant, M. J., \& Booth, A. (2009). A typology of reviews: an analysis of 14 review types and associated methodologies. Health Information and Libraries Journal, 26, 91-108.

Haegele, J. A., \& Hodge, S. (2016). Disability discourse: overview and critiques of the medical and social models. Quest, 68, 193-206.

Hall, E. (2018). A critical geography of disability hate crime. Area, 51, 1-8.

Hollomotz, A. (2013). Disability and the continuum of violence. In A. Roulstone, \& H. Mason-Bish (Eds.), Disability, Hate Crime and Violence. London and New York: Routledge, 52-63.

Iudici, A., \& Renzi, C. (2015). The configuration of job placement for people with disabilities in the current economic contingencies in Italy: social and clinical implications for health. Disability and Health Journal, 8, 586-593.

Iudici, A., Bertoli, L., \& Faccio, E. (2017). The 'invisible' needs of women with disabilities in transportation systems. Crime Prevention and Community Safety, 19, 264-275.

Iudici, A., Favaretto, G., \& Turchi, G. P. (2018). Community perspective: how volunteers, professionals, families and the general population construct disability: social, clinical and health implications. Disability and Health Journal, 12, 171-179. 
Iudici, A., Antonello, A., \& Turchi, G. (2019). Intimate partner violence against disabled persons: clinical and health impact, intersections, issues and intervention strategies. Sexuality \& Culture, 23, 684-704.

Jenness, V. (1999). Managing differences and making legislation: social movements and the racialization, sexualization, and gendering of federal hate crime law in the U.S., 1985-1998. Social Problems, 46, 548-571.

Jenness, V. (2001). The hate crime canon and beyond: a critical assessment. Law and Critique, 12, 279-308.

Levin, J., \& McDevitt, J. (2002). Hate Crimes Revisited: American's War against Those who are Different. Boulder, CO: Westview.

Levin, J., \& Rabrenovic, G. (2001). Hate crimes and ethnic conflict: a comparative perspective. American Behavioral Scientist, 45, 574-755.

Lipscomb, C. E. (2000). Medical Subject Headings (MeSH). Bulletin of the Medical Library Association, 88, 265-266.

McClimens, A., \& Brewster, J. (2017). Intellectual disability, hate crime and other social constructions: a view from South Yorkshire. Journal of Intellectual Disabilities, 23(4), 486-497.

Macdonald, S. (2015). 'Community fear and harassment': learning difficulties and hate crime incidents in the north-east of England. Disability \& Society, 30, 353-367.

Macdonald, S. J., Donovan, C., \& Clayton, J. (2017). The disability bias: understanding the context of hate in comparison with other minority populations. Disability \& Society, 32, 483-499.

Maguire, R., Wilson, A., \& Jahoda, A. (2018). Talking about learning disability: promoting positive perceptions of people with intellectual disabilities in Scottish schools. International Journal of Developmental Disabilities, 65, 257-264.

Marks, D. (1999). Dimensions of oppression: theorising the embodied subject. Disability o Society, 14, 611-626.

McMahon, B. T., West, S. L., Lewis, A. N., Armstrong, A. J., \& Conway, J. P. (2004). Hate crimes and disability in America. Rehabilitation Counseling Bulletin, 47, 66-75.

Mikton, C., Maguire, H., \& Shakespeare. (2014). A systematic review of effectiveness of interventions to prevent and respond to violence against persons with disabilities. Journal of Interpersonal Violence, 29, 3207-3226.

Ralph, S., Capewell, C., \& Bonnet, E. (2016). Disability hate crime: persecuted for difference. British Journal of Special Education, 43, 215-232.

Richardson, L., Beadle-Brown, J., Bradshaw, J., Guest, C., Malovic, A., \& Himmerich, J. (2016). "I felt that I deserved it"-experiences and implications of disability hate crime. Tizard Learning Disability Review, 21, 80-88.

Roulstone, A., \& Mason-Bish, H. (2013). Disability, hate crime and violence. In A. Roulstone, \& H. Mason-Bish (Eds.), Disability, Hate Crime and Violence. London and New York: Routledge, 1-7.

Roulstone, A., Thomas, P., \& Balderston, S. (2011). Between hate and vulnerability: unpacking the British criminal justice system's construction of disablist hate crime. Disability \& Society, 26, 351-364.

Salvini, A. (2004). Psicologia Clinica (II ed.). Padova: Domeneghini Editore.

Salvini, A., \& Dondoni, M. (2011). Psicologia clinica dell'interazione e psicoterapia. Firenze: Giunti Editore.

Shakespeare, T. (2012). Blaming the victim: disability hate crime. Lancet, 380, 878.

Sherry, M. (2013). Feminist reflections on disability hate crime. Gendered Perspectives on Conflict and Violence: Part A (Advances in Gender Research), 18A, 53-66.

Sin, C. H. (2016). Commentary on "I felt I deserved it'-experiences and implications of disability hate crime". Tizard Learning Disability Review, 21, 89-94. 
Sin, C. H., Mguni, N., Cook, C., Comber, N., \& Hedges, A. (2010). Targeted violence, harassment and abuse against people with learning disabilities in Great Britain. Tizard Learning Disability Review, 15, 17-27.

Sin, C. H., Sheikh, S., \& Khanna, M. (2012). Police readiness for tackling hate crime against people with learning disabilities-areas for improvement and examples of good practice. Safer Communities, 11, 145-153.

Sun, K. (2006). The legal definition of hate crime and the hate offender's distorted cognitions. Issues in Mental Health Nursing, 27, 597-604.

Turchi, G. P. (2009). Dati senza numeri. Per una metodologia di analisi dei dati informatizzati testuali: M.A.D.I.T. Bologna: Monduzzi Editore.

Turchi, G. P., \& Perno, A. (2004). Modello medico e psicopatologia come interrogativo. Padova: Upsel Domeneghini.

Waxman, B. F. (1991). Hatred: the unacknowledged dimension in violence against disabled people. Sexuality and Disability, 9, 185-199. 


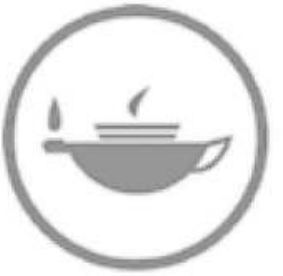

Taylor \& Francis Taylor \& Francis Group http://taylorandfrancis.com 


\section{Part III}

\section{The movement}

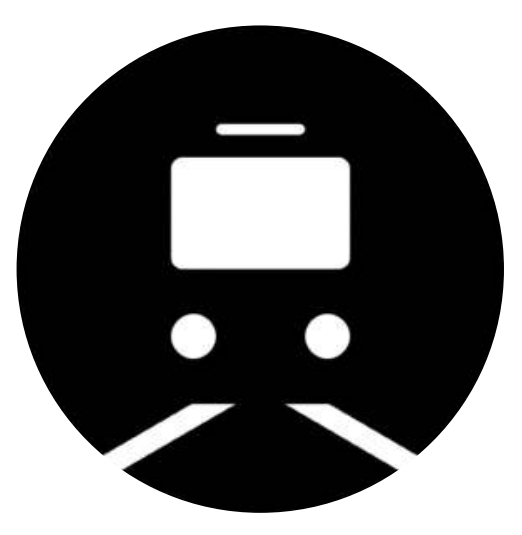




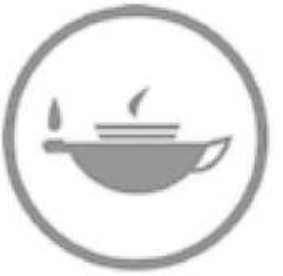

Taylor \& Francis Taylor \& Francis Group http://taylorandfrancis.com 


\title{
$7 \quad$ Youth safety in public transportation
}

\section{The case of eastern Mexico City, Mexico}

\author{
Javier Romero-Torres and \\ Vania Ceccato
}

\subsection{Introduction}

Worldwide, women are more likely than men to be exposed to unwanted sexual behavior while in transit and in public transportation (PT). This is partially because women travel by public transport more often than men do. In some countries, women constitute the so-called "transit captives", whereby they have limited access to non-public forms of transportation (such as private cars) and are therefore overly reliant on PT. The \#MeToo! Movement has shown that sexual harassment and sexual violence can happen anywhere, and in some public environments, such as buses and trains, they may include unwanted sexual behaviors that are often normalized by social and cultural norms. Given this, addressing the issue of sexual harassment has become an increasing part of the public transportation agenda (Ceccato \& Loukaitou-Sideris, 2020).

This chapter reports the experiences of sexual victimization, the safety perceptions of public transportation (PT), as well as a discussion of safety precautions taken by young people in eastern Mexico City, Mexico. The analysis is based on a survey of 381 university students collected in 2018 from the CU Nezahualcóyotl campus. The CU Nezahualcóyotl campus is located to the east of the metropolitan area of Mexico City. The metropolitan area was classified in 2012 by the United Nations as being the third most populated area of the world (UN-Habitat, 2012). Its PT ridership encompass over 15 million daily trips, which include over one million daily trips within the municipality of Nezahualcóyotl (INEGI, 2017).

Poor transit safety is a major social issue in Mexico City. A survey conducted by Reuters revealed that the transportation system of Mexico City was considered as the second most dangerous in the world (TRF, 2014) and that up to 90 percent of women riders of PT declared being victims of sexual assault, with most being young women (CONAPRED, 2009). Given this, the focus of this study is to analyze victimization and perceptions of safety among this age group in the bus and Metro system.

Sexual crimes encompass various types of sexual behaviors which can vary from sexual harassment to sexual assault, and to further complicate matters, the 
boundaries between these types of acts are blurred. In this study, we follow the definition suggested by Ceccato and Loukaitou-Sideris (2020):

1. Nonverbal sexual violence/abuse. It includes exhibitionism, showing sexually explicit pictures, or making sexual gestures.

2. Verbal sexual violence/abuse. It includes sexual comments, jeering or taunting, and asking questions about sexual activity.

3. Physical sexual violence/abuse. It may involve behaviors such as touching, kissing, and rape.

The chapter is structured as follows. First, the case study is introduced. Second, the data source is described as well as the characterization of the transportation modes. Third, the results and discussion are presented in relation to the type of crimes, place and mode of transportation, and types of precautions that students take to avoid victimization. Finally, the chapter finishes with the conclusion and policy recommendations.

\subsection{Background}

\section{The nature of sexual crimes in public transportation}

Sexual harassment and sexual violence come in many forms, and it is a common phenomenon in PT services worldwide. Since some PT environments are often places of convergence, crime opportunities, and sexual violence, it is an inherent part of the daily rhythmic flow of people passing by in these transit environments. Paradoxically, some of these sexual crimes happen in places where anonymity at particular times make these crimes possible, such as an empty bus or train station in the evening hours.

Previous research has indicated that the risk of victimization of sexual crimes and unwanted sexual behaviors varies across different types of individuals (age, gender, (dis)ability, LBGTQI status, IT literacy, previous victimization, frequency of use of public transportation, length of trip), over time (rush hours, off-peak hours, days of the week, weekends, and weekdays, seasonal differences) and by different public transportation modes and settings along the trip (Gekoski et al. 2015, 6).

Transit environments, such as bus stops or train stations can be considered as criminogenic places. In Mexico, for example, a survey by the National Survey of Victimization and Perception of Public Safety (ENVIPE, 2018), found that 43.4 percent of those interviewed indicated that they were robbed or assaulted during the use of PT in the metropolitan area of Mexico City. This is well above other crimes such as fraud or robbery at home. The survey also indicated that 90.7 percent of those interviewed felt unsafe during transit using PT. As a consequence, PT users modify mobility patterns such as changing the transportation mode or choosing an alternate stop (ENVIPE, 2017, 2018). 
Research has found that a majority of the victims of sexual harassment in transit systems are young people. The vast majority are university students aged 18 to 29 , an age group that is affected more than other age groups in regards to sexual harassment and assault (Beller, Garelik, \& Cooper, 1980; Tripathi, Borrion, \& Belur, 2017). In the next section, we discuss the case study, based on a survey of 381 university students collected in 2018 from the CU Nezahualcóyotl campus.

\section{Safety perceptions and behavior responses}

Previous research on fear of crime has evolved to suggest the existence of a complex relationship between individuals, lifestyles, as well as situational and contextual factors. The environment also plays a role in defining safety perceptions in transit environments (Otis, 2007; Lubitow et al., 2017). The vulnerability for sexual crimes differs greatly between different age groups but interacts with other factors such as gender, sexual orientation, and disability-and therefore previous victimization affects one's perceived safety. Safety perceptions also follow temporal patterns, whereby travelers often declare being more fearful when it is dark than during the day, see Chapter 5 .

Individuals who report higher levels of fear are those that are most likely to change and adapt how they move in space. Jackson and Gouseti (2012) indicates four main categories of behavioral responses to the fear of crime: avoidance behavior, protective behavior, behavioral and lifestyle adjustments, and participation in relevant collective activities. Avoidance behavior involves minimizing one's contact with certain types of people, routine activities, or places. If young riders feel unsafe travelling by bus at certain times, they may take an earlier bus or change the route. Protective behavior constitutes activities that are thought to prevent crime (putting up fences) as well as wider activities of selfprotection and safety improvement (traveling in groups). Behavioral and lifestyle adjustments involves a withdrawal from activities that are considered to be dangerous, such as taking public transportation in the evenings. Finally, collective activities include participation in groups, such as neighborhood watch programs or activities directed at elderly well-being.

\section{Hypotheses of study}

The study will examine the following hypotheses:

1. Women are more victimized than men in PT and transit environments.

2. Sexual harassment varies by type and transportation modes.

3. Safety perceptions vary by type of travelers, types of trips in buses and Metro and time of the day.

4. Travelers take precautionary measures to avoid sexual harassment in transit environments. 


\section{Javier Romero-Torres and Vania Ceccato}

\subsection{Case study}

This study is part of an international project about the perception of university students on security and victimization during transit in the public transportation system (Ceccato \& Loukaitou-Sideris, 2020). This paper reports on the case of Mexico City, using students at CU Nezahualcóyotl campus as the sample. The campus is embedded in the metropolitan area of the Valley of Mexico, in the municipality of Nezahualcóyotl belonging to the State of Mexico and boasts a population of 1,040,000 inhabitants. The campus belongs to the Autonomous University of the State of Mexico that houses 1,195 students. The majority of the students reside in surrounding municipalities in the eastern part of Mexico City such as Nezahualcóyotl, Chimalhuacán, Chalco Valley, and some municipalities (called alcaldias) of Mexico City, such as Iztapalapa (INEGI 2017).

The average travel time for students to reach the Nezahualcóyotl campus is 45 minutes with a fare payment of $16 \mathrm{MXN}$ (0.8 US\$). A third of the students take more than an hour to complete the trip, with half needing to transfer two or more times to other modes of PT. Around 19 percent of students use private modes of transport such as bicycle, motorcycle, car, or walking to arrive at the Nezahualcóyotl campus, while 81 percent use public transportation (PT). While students who use only one way to arrive on campus represent 36.2 percent, those who use two modes correspond to 41.2 percent, 19 percent complete their trip in four modes, and 3.6 percent do so with more than four modes. The higher number of transfers results in greater travel times, whereby trips with four or more sections of travel represents a duration of around 250 percent more compared with trips made in a single mode (Romero, 2014).

\section{Characterization by transportation mode}

The modes of PT that the students have access to throughout the stages of their trip include those with high standards such as the Metro and BRT (Bus Rapid Transit) and those with poor service characteristics such as vans and minibus. The latter presents levels of informality and disorganization and low standards, which Cervero (2000) classifies as paratransit, offering a service characterized by a hybrid service, man-truck and a capacity of up to 15 seats (Vuchic, 2007). For the results presented in this document, two modes of PT used by the students were considered: Metro and bus, which are defined as follows.

There are 12 Metro lines that make up the network of the Collective Transportation System (STC) of the urban area of Mexico City. Line A, Pantitlán-La $\mathrm{Paz}$, is the closest to the campus, it connects the municipalities east of Mexico City with Mexico City. The characteristics of this service are high frequencies, good service hours, and reliability. Buses are operated with a mixed vehicular configuration: vans, minibuses, and 30-seat buses; which implies a variable vehicle offer in time and space. 


\section{Characteristics of the sample of university students}

Table 7.1 shows the socio-demographic characteristics of the students, trip length and duration as well as victimization. The sample is characterized by a young sample, 98.1 percent were younger than 29 years. On average, 10 percent of the interviewees identified themselves as LGBTQI. Seventy-two percent of the interviewees identified as mixed race (mestizo), a population group prevalent in Mexico according to INEGI (2019). One out of four students takes between 15 and 30 minutes to arrive on campus, for 39.1 percent the trips take up to one hour, and for 24.3 percent the trips take up to two hours, which means that students must use motorized modes to carry out their transfers.

\subsection{Results}

As many as 90.1 percent of women declare being sexually victimized in the last three years while in transit, while for men victimization accounted for 65.2 percent (women: 92.1 percent in buses and 88.0 percent in Metro; men: 65.4 percent in buses and 64.9 percent in Metro) (Table 7.1). University students in Mexico City show the highest sexual victimization rate on buses and the second highest on the Metro when compared with those rates found in 17 other samples located in cities in five continents around the globe (for more detail see Ceccato and Loukaitou-Sideris, 2020). These results for female students in Mexico City are similar to those found in official statistics sources such as UN-Women (2018) which reports that 88.5 percent of female travelers are sexually harassed on public transportation in Mexico City. Despite these similarities, it should be noted that this study is based on a small sample of 383 university students (191 women and 188 men) travelling mostly by bus.

There is a small difference in victimization between buses and Metro for women but not for men. As many as 92.1 percent for women and 65.4 percent for men, declared to be victims of at least one sexual assault in buses, while in the Metro, the proportions of victimization are 88.0 percent and 64.9 percent, for women and men, respectively. However, it is unclear why the percentages of victimization for men are fairly constant regardless of mode of public transportation. Women who identify themselves as LGBTQI are more likely to be victimized on the Metro than in the bus. On the other hand, non-LGBTQI women are more likely to be victimized in the bus.

The proportion of sexual victimization increases with the duration of the trip (30-60 minutes reaches its peak) and then decreases again for both buses and Metro (Figure 7.1(a)). For instance, those who frequently travel by buses (5-7 trips per week) are more likely to be sexually victimized. However, we noticed an inverse pattern among those using the Metro (Table 7.1). This might be related to the types of environments (crowded carriages at peak times) and differences in guardianship experienced by the travelers in the Metro compared 


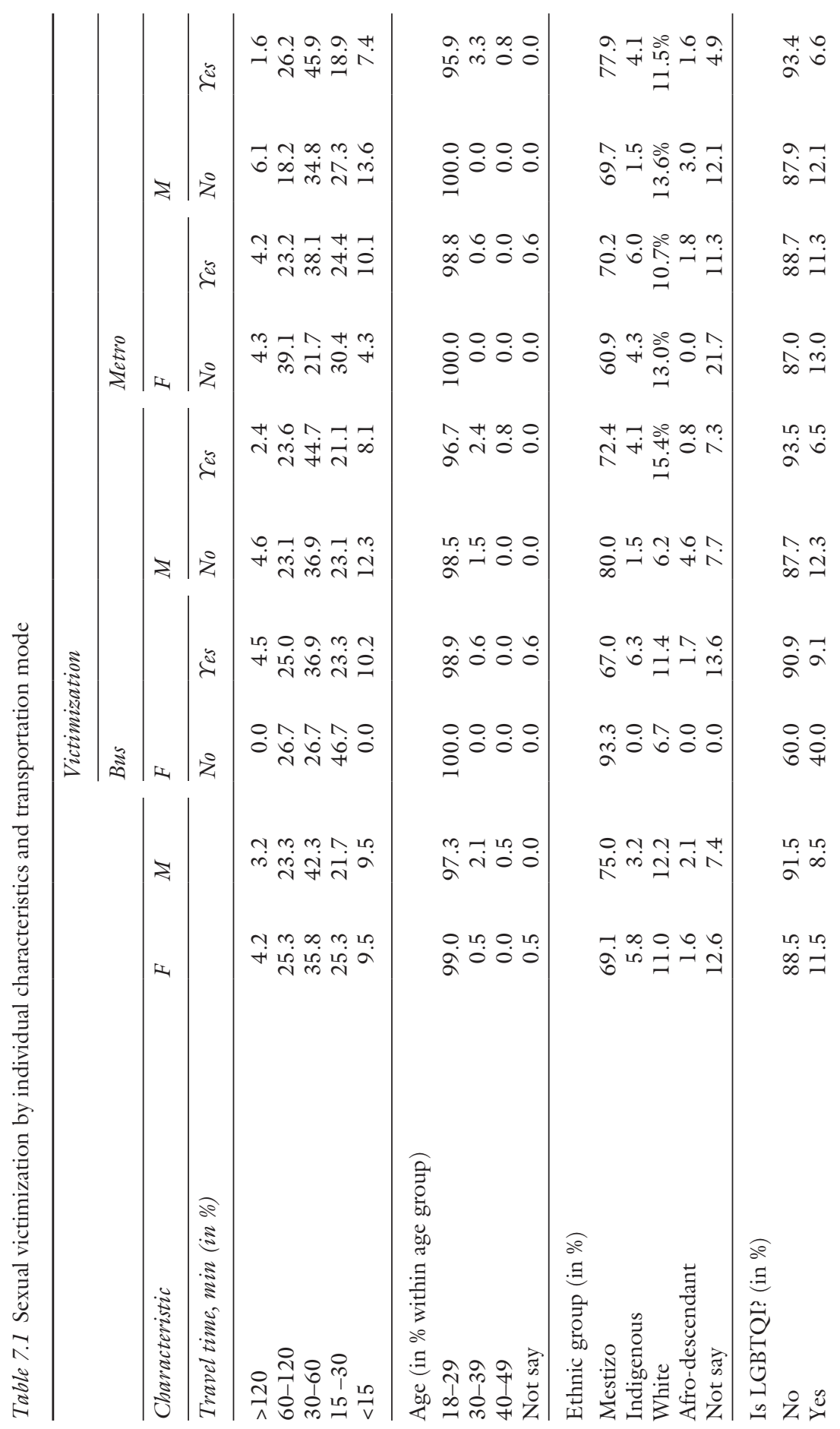




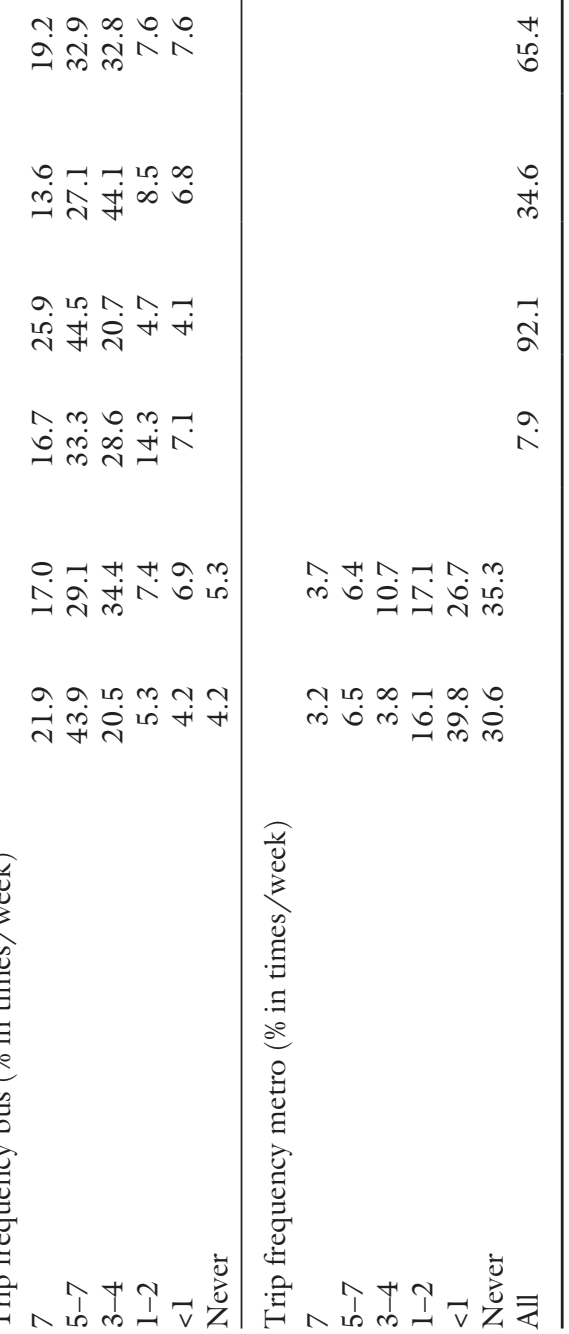

के

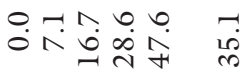

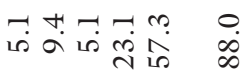

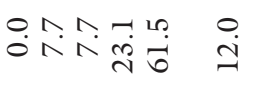

10

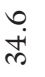

ลั

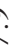




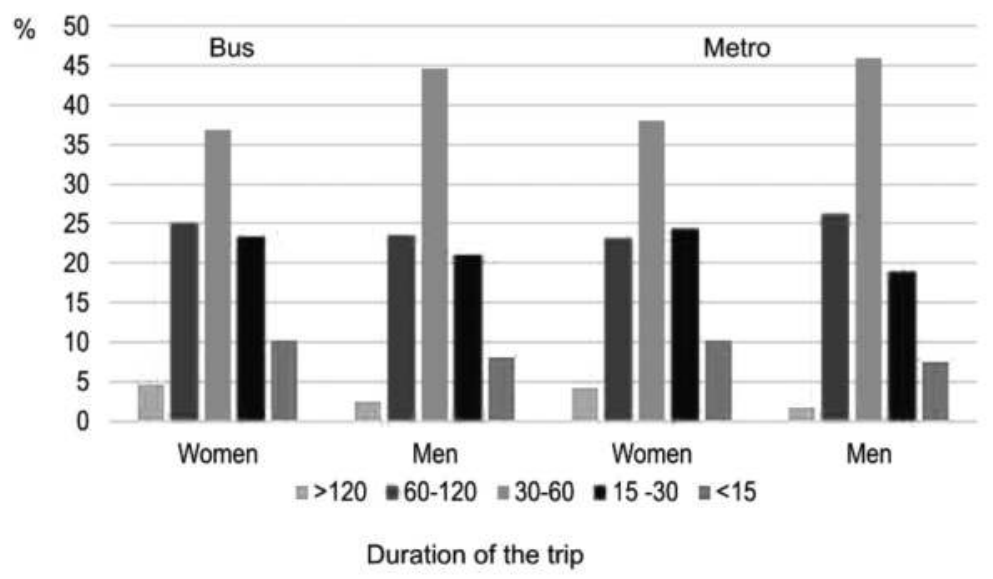

(a)

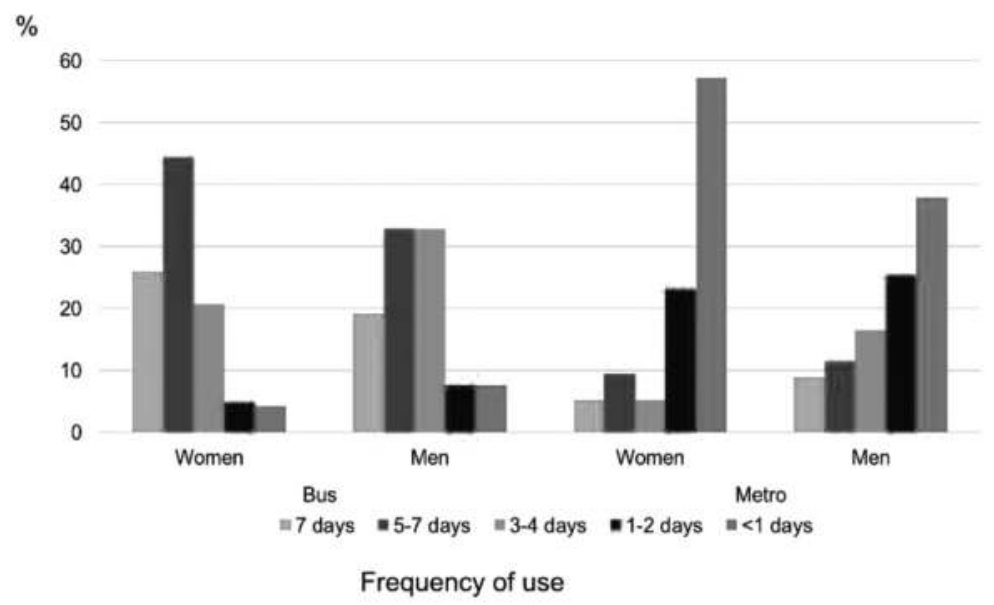

(b)

Figure 7.1 (a) Sexual victimization by duration of the trip and (b) frequency of use of PT.

with those found in buses and bus stops (Figure 7.1(b)), but also the fact that this sample comprises travelers using mostly buses (a larger sample of students using Metro would be necessary to confirm differences in victimization by transportation mode).

\section{Types of sexual harassment by location and gender}

Figure 7.2 illustrates the types of sexual victimization that students have experienced in the last three years. Verbal harassment is more frequent in buses, while non-verbal sexual harassments are more common in the Metro, with women representing most of the victims. The most common verbal sexual harassments for women are whistling, unwanted sexual teasing, and sexual remarks, while for 


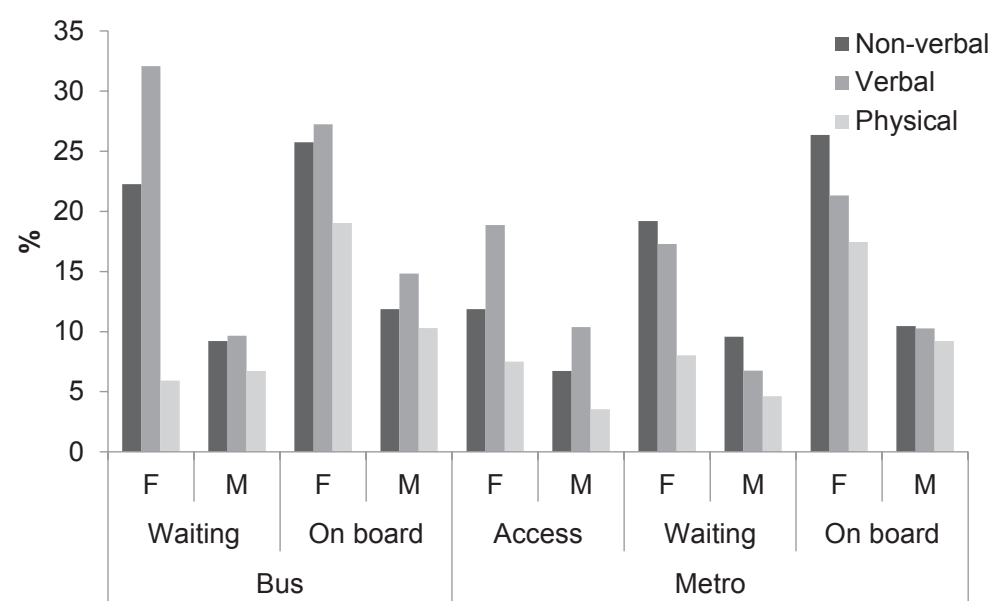

Figure 7.2 Types of sexual harassments in transit and by transportation mode. Access means on the way to/from bus stops and or Metro station.

men, the most common is to be asked to have sex with a stranger. These events often happen on the way to PT. The physical sexual crimes are the least experienced by the students, and are carried out with greater frequency on board the vehicle, in both bus and Metro. Victimization rates follow the types of transit environments in PT, they increase as the system becomes more crowded: on the way to the bus or train, platforms and stops, and finally on board the vehicle.

Table 7.2 shows other types of sexual victimization along the trip. Comments and whistles are the sexual assaults more commonly found (63.2 and 60.5 percent respectively) against women while waiting for the bus, followed by gestures and sending kisses. Against men it is more common whistling and stalking (with 22.3 percent and 17 percent, respectively). While on board the bus, gestures ( 63.3 percent) towards women and obscene language (31.4 percent) towards men are the most frequent types of offences. Physical sexual violence is the most common type of victimization declared by the students in both modes of PT. Asking to have sex is the most type of victimization by women (57.1 percent) and men (42.9 percent) on the way to the bus; sending kisses to women (34 percent) and harassment (17.6 percent) towards men are the most common types of offence while waiting, and gestures towards them and obscene language towards them persist while they remain inside the bus. During the use of the Metro, the victimization is maintained throughout the three stages, possibly explained by the homogeneity in the facilities of this transportation mode; while in the bus the differentiation persists, the conditions of the stops and interior of the bus are different. These findings suggest that the offenders may plan their actions towards their victims according to the transportation mode and the environments they involve. 


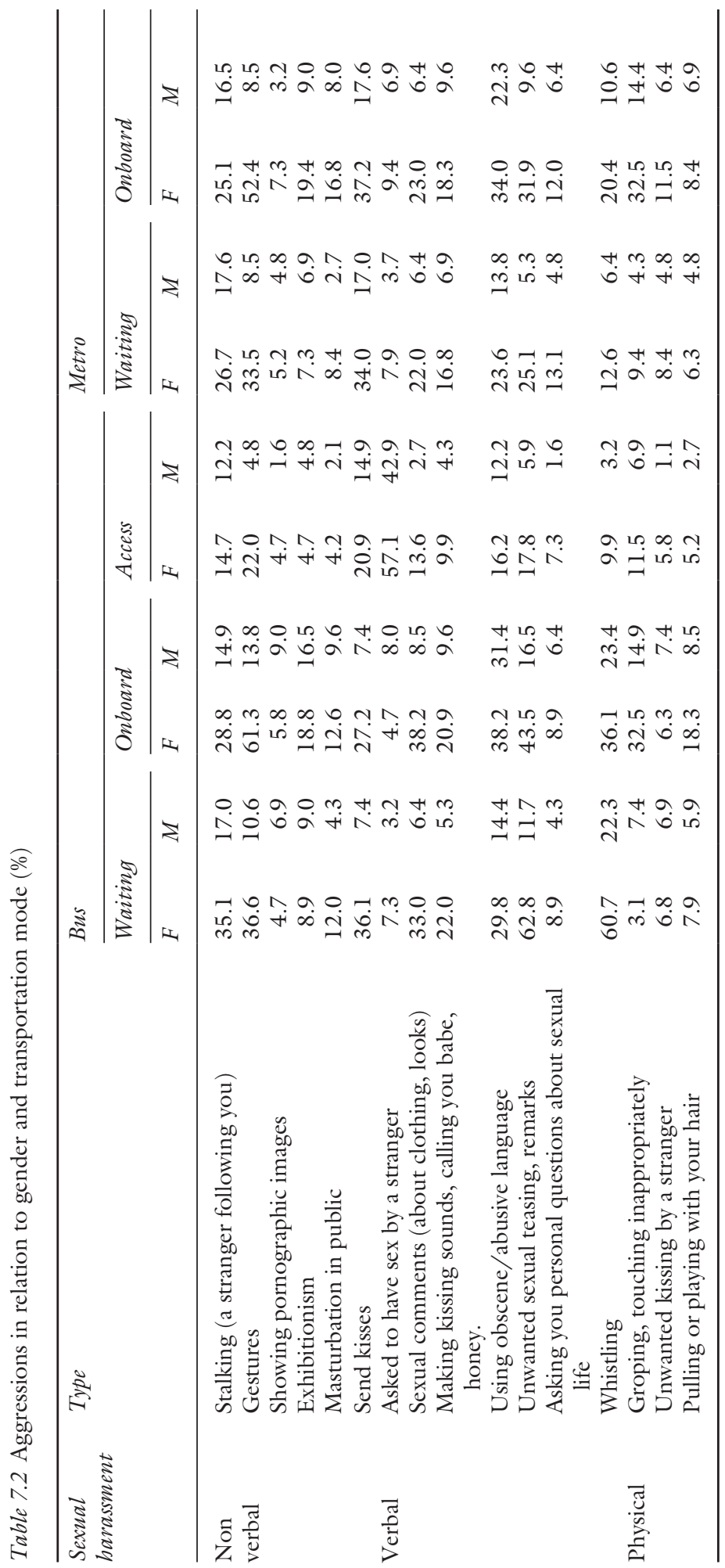




\section{Safety perceptions-day and night}

Only 1 percent of women and 7 percent of men declare feeling "always" or "often" safe after dark on the bus in Mexico City. Similarly, at the bus stop or walking to/from bus stop, only 2 percent of female students and 4 percent of male students declare feeling "always" or "often" safe after dark-these percentages are the lowest safest levels declared by students taking part in the global study comparing 18 city-samples around the world (Ceccato and Loukaitou-Sideris, 2020).

Figure 7.3 shows safety perceptions declared by university students by gender in Mexico City when using bus and Metro, by settings and by day and night. Men and women declare feeling less safe during evening/night hours than during the day. For buses, 36 percent of the students indicated that they sometimes felt safe waiting and on board the bus during the day. As many
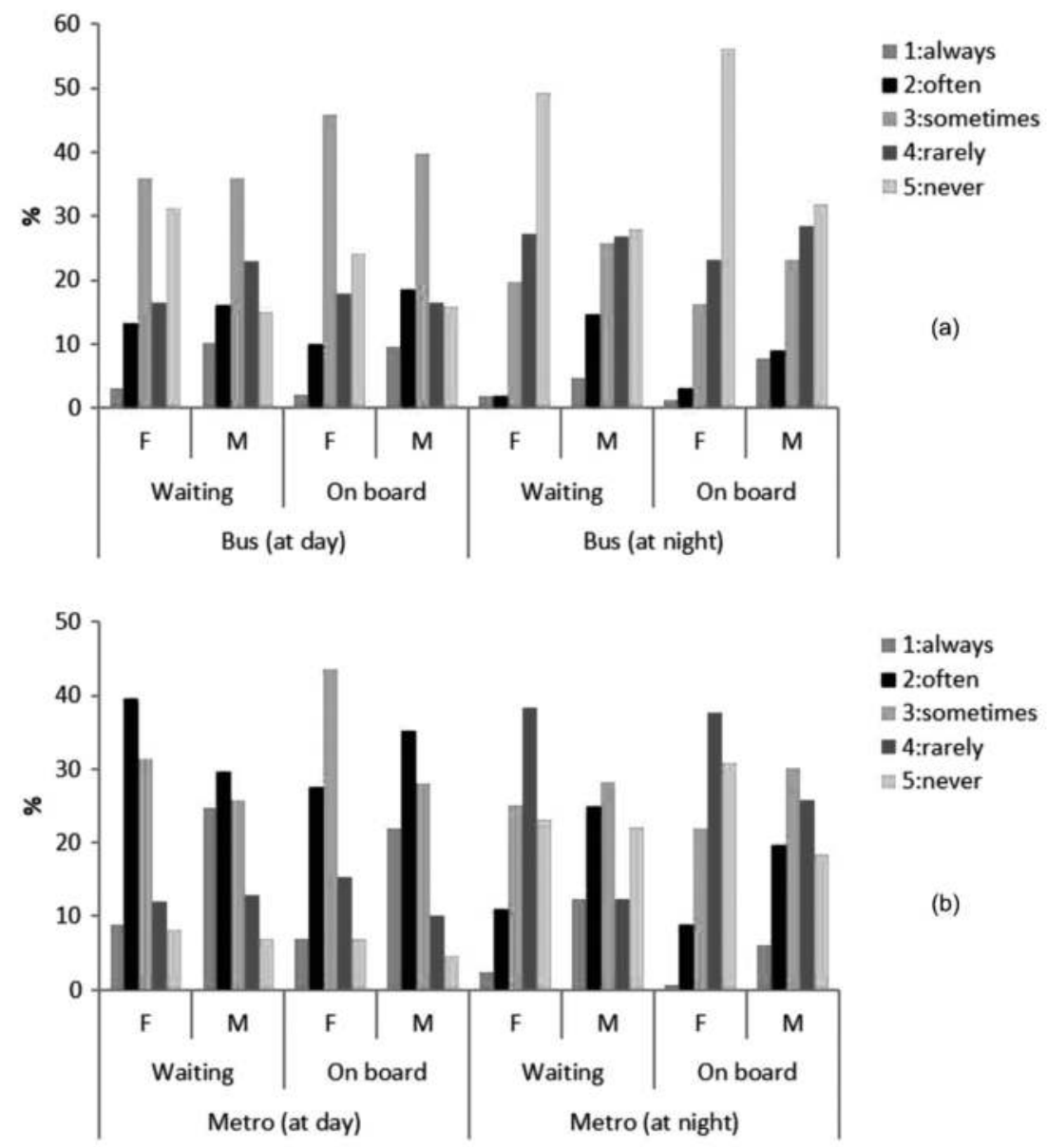

Figure 7.3 Perceived safety by gender, transportation mode, settings and time of day. 


\section{6}

as 47.6 percent of them indicated sporadic levels (rarely and never) of safety at the stop; those proportions decrease to 42.1 percent and 32.3 percent when students are on board the bus. Note that while for the frequency levels of safety always and often changes for men from 26.2 percent (waiting for the bus) to 28 percent (on board), for women the proportion decreases from 16.4 percent (waiting for the bus) to 12.2 percent (on board), indicating an increased risk for certain types of physical sexual harassment on board, such as groping.

Similarly, during the evening/night, the frequency of feeling less safe increases as they move from waiting at the bus stop to on board (waiting: 29 percent at night, while on board the bus the proportion is 37.3 percent). This indicates that, on board buses, women are more often victimized (in quantity or intensity) than when they are at the bus stop. Additionally, they might be at higher risk of other types of crimes such as thefts, pickpocketing on board buses. During the day, men declared feeling slightly safer on board the bus compared with waiting for the bus. In regard to overnight trips, they also feel less safe than during the day, whereby the perception of safety decreased by 28.1 percent on board the bus during the night compared with the day. Men feel less safe during the night and this insecurity is most likely explained by an increased risk of overall crimes, such as robbery or assaults, and to a lesser extent explained by sexual assaults.

Figure 7.3 shows higher levels of safety declared by the university students when using the Metro by day than those using the Metro by evening/night. According to the stage of the trip during the day, the safety experienced by women is reduced by 14 percent on board the Metro in relation to waiting for it, this is contrary to the increase of 2.7 percent that has been identified for men. What can be deduced from this is that certain types of sexual assaults intensify against women aboard the Metro car. For trips taken during evening/ nights, safety decreases from waiting to onboard by 19.7 percent for women and 11.5 percent for men.

\section{Precautions}

In Mexico City, travelling during the day, being accompanied by other people, and avoiding wearing jewelry, are common measures taken by students using the bus and Metro (Table 7.3). These precautions reflect lower levels of safety perceptions on the Metro and/or on the way to the Metro stations during the night (Figure 7.3). A small percentage (4.5 percent) of respondents even felt the need to also carry some type of weapon. While avoiding certain Metro stations or lines was a precaution taken by a higher percentage of students than avoiding certain bus lines, this is possibly explained by the fact that many students are captive bus commuters, with the bus being their only option to reach the campus. Avoiding carrying a wallet was more frequent for Metro riders, possibly because of crowding, not only on board, but also at the platforms and corridors during rush hour. 
Table 7.3 Mexico City student precautions while travelling on public transit (\%)

\begin{tabular}{lrc}
\hline Precautions & Bus & Metro \\
\hline Travel in the day & 11.7 & 11.5 \\
Always with someone & 10.9 & 15.1 \\
Avoid certain station or lines & 7.9 & 23.4 \\
Wearing certain clothes & 9.8 & 12.9 \\
Do not wear jewelry & 16.2 & 16.4 \\
Avoid carrying wallet & 8.9 & 14.5 \\
Carry a weapon & 4.5 & 5.1 \\
Wait for public transportation only in well-lit places & 15.2 & - \\
Wait for public transportation with other users & 14.9 & - \\
Other & - & 1.2 \\
\hline
\end{tabular}

Source: Authors.

\subsection{Discussion of results}

Women are victims of sexual assaults in greater proportion than men, confirming our first hypothesis. The risk of men being sexually harassed seems to be independent on the mode of transportation while, for women, the risk decreases when using the Metro compared with the bus. As suggested by the second hypothesis, victimization varies by type of sexual harassment (the most common is verbal sexual harassment) in both bus and Metro but may vary along the trip. Students were victimized by verbal and non-verbal types of harassment during their trip to the transit stop or when waiting for the transit vehicle. Some students also suffered physical harassment, while on board the transit vehicle.

In terms of our third hypothesis, we found that safety perceptions vary by type of travelers (women declare feeling more fearful than men) and types of trips in buses and Metro and on the way to the transport nodes (bus stops and Metro stations). Considering the transportation mode, the perception of safety is rated much higher when the user is onboard the Metro car in comparison with waiting on the platform. Safety perception decreases when trips are made in the evening/night in comparison with daytime.

Our fourth hypothesis was also confirmed: we found travelers take precautionary measures to avoid sexual harassment in transit environments. Signals of what one may call 'dysfunctional fear' can be clearly witnessed when one starts avoiding certain places (in this case, certain stations or lines) or certain times (for example, traveling alone during the evening). The findings show indications of behavioral adaptation as suggested by Jackson and Gouseti (2012), such as thinking about what clothes to wear, not choosing to carry a wallet, or not wearing jewelry.

\subsection{Conclusions and recommendations}

This chapter reports experiences of sexual victimization and perception of safety in public transportation (PT) by young people in eastern Mexico City, Mexico, 


\section{Javier Romero-Torres and Vania Ceccato}

using the answers of a survey carried out on 381 university students. Findings show that women are more victimized than men in PT and transit environments. The proportion of victimization in Mexico City is the highest among college students, compared with a survey of 17 cities across five continents carried out by Ceccato and Loukaitou-Sideris (2020). Such high victimization also varies by type of sexual harassment, transportation mode, length of trip, frequency of use of PT and transit settings (on board, waiting for the bus, on the way to Metro/bus stops). Students declared being more fearful during evening and nights than during the day, which leads them to take precautionary measures against potential victimization, such as avoiding travel during the evening, avoiding certain routes, making use of well-lit stops/stations, travelling with others, or even carrying a weapon. The above raises the issues of poor safety conditions as an impediment to the students' quality of life and, in general, the external costs of crime on mobility and on PT systems. Although the generalizability of this study is limited by the small sample size (respondents, especially among Metro users and area of study), it could serve as the basis for future large-scale surveys on transit environments in Mexico and elsewhere.

Safety perceptions and levels of victimization, in general, depend on the transportation mode and the time of travel (day or night), therefore public policies aimed at reducing sexual harassment and improving safety for travelers should consider these situational aspects when tackling sexual harassment in PT environments. Public policies aimed at reducing sexual transit crimes should consider different transportation modes at different stages of the trips. Knowing in more detail where and when most sexual harassment occurs is fundamental for future research, and also creates a set of realistic safety strategies to improve transit environments of young travelers in Mexico City.

Maintenance of the transportation infrastructure to increase the perception of user safety is also necessary. This can be achieved by improving lighting conditions in stations, stops, or modal exchange areas, and along pedestrian routes or establishments where there is a constant flow of people. It would be desirable to have security guards/police surveillance in and around the transportation systems, especially at stops, stations for bus routes, and on board wagons for the Metro system. From the above, constant monitoring should be carried out to assess the impact of these implementations on users' safety to redefine the strategies and modify them in order to provide feedback for mitigation measures. It is fundamental to consider users' perspectives when tackling safe conditions in PT environments, in particular the needs of women who are mostly likely to be targets of sexual harassment and have their life opportunities reduced by impaired mobility when using PT.

\section{References}

Beller, A., Garelik, S., \& Cooper, S. (1980). Sex crimes in the subway. Criminology, 18, $35-52$.

Ceccato, V., \& Loukaitou-Sideris, A. (2020). Transit Crime and Sexual Violence in Cities: International Evidence and Prevention. London: Routledge. 
Cervero, R. (2000). Informal Transport in the Developing World. United Nations Centre for Human Settlements (Habitat).

CONAPRED, Comisión Nacional para Prevenir la Discriminación (2009). La discriminación y violencia contra las mujeres en el transporte de la Ciudad de México. Documento de Trabajo No. E-18-2009, México D.F.

ENVIPE, Encuesta Nacional de Victimización y Percepción sobre Seguridad Pública (2017). Report, Instituto Nacional de Estadística y Geografía, México.

ENVIPE, Encuesta Nacional de Victimización y Percepción sobre Seguridad Pública (2018). Report, Instituto Nacional de Estadística y Geografía, México.

Gekoski, A., Jacqueline, M., Gray, M. H., Horvath, S. E., Aliye, E., \& Adler, J. (2015). 'What works' in reducing sexual harassment and sexual offences on public transport nationally and internationally: A rapid evidence assessment. Project Report. Middlesex University; British Transport Police; Department for Transport, London.

INEGI, Instituto Nacional de Estadística y Geografía (2017). Encuesta Origen-Destino en hogares de la Zona Metropolitana del Valle de México. Mexico: Aguascalientes.

INEGI, Instituto Nacional de Estadística y Geografía (2019). Mexico: Aguascalientes.

Jackson, J., \& Gouseti, I. (Eds.) (2012). Fear of Crime: An Entry to the Encyclopedia of Theoretical Criminology. Chichester: Wiley-Blackwell. http://eprints.mdx.ac.uk/15219/ (accessed 9 December 2019). www.mdx.ac.uk/_data/assets/pdf_file/0019/155800/ What-Works-in-Reducing-Sexual-Harassment-and-Sexual-Offences-on-Public-TransportNationally-and-Internationally.pdf (accessed 9 December 2019).

Lubitow, A., Carathers, J., Kelly, M., \& Abelson, M. (2017). Transmobilities: mobility, harassment, and violence experienced by transgender and gender nonconforming public transit riders in Portland, Oregon. Gender. Place \& Culture, 24, 1398-1418.

Otis, M. D. (2007). Perceptions of victimization risk and fear of crime among lesbians and gay men. Journal of Interpersonal Violence, 22, 198-217.

Romero, J. (2014). Definición de la ruta de transporte escolar de la UAP Nezahualcóyotl. Informe técnico, UAEM.

TRF-Thomson Reuters Foundation (2014). Most dangerous transport systems for women. Available at: http://news.trust.org//spotlight/most-dangerous-transport-systems-forwomen/ (accessed 24 May 2018).

Tripathi, K., Borrion, H., \& Belur, J. (2017). Sexual harassment of students on public transport: an exploratory study in Lucknow, India. Crime Prevention and Community Safety, $19,240-250$.

UN-Habitat (2012). Programa de las Naciones Unidas para los Asentamientos Humanos. Estado de las Ciudades de América Latina y el Caribe. www.cinu.mx/minisitio/ Informe_Ciudades/SOLACC_2012_web.pdf (accessed 29 November 2019).

UN-Women (2018). Encuesta sobre la violencia sexual en el transporte y otros espacios públicos en la Ciudad de México. www.unwomen.org/es (accessed 2 December 2019).

Vuchic, V. (2007). Urban Transit, Systems and Technology. USA: John Wiley. 


\title{
8 Transit safety among college students in Tokyo-Kanagawa, Japan
}

\author{
Victimization, safety perceptions \\ and preventive measures
}

\section{Seiji Shibata}

\subsection{Introduction}

Japan has a highly developed and extensive railway system. The railways are an essential daily means of transportation within the country. However, the increase in the number of criminal offences on railways during the early 2000s resulted in heightened public concern over passenger safety and the security of the railway system. The number of violent offences and nuisance crimes remains high even though the total instances of criminal offences have decreased rapidly in the country since the turn of the century (Nomura, 2017).

This study investigates the nature of women's transit safety in TokyoKanagawa by examining women's safety perceptions and victimization while in transit and exploring the relationship between women's experiences of victimization and their perceptions of crime preventive measures available in transit environments; in particular, surveillance cameras and women-only carriages.

College students were selected for the investigation as the Tokyo Metropolitan Police Department (2018) reported evidence that young women (in their teens and 20s) are most vulnerable to groping, a form of sexual harassment. This age group also relies heavily on railway services as a daily mode of commuting.

This chapter's study is novel as it is based on a recently available dataset collected in Tokyo as a study case, and which forms part of a global investigation conducted in conjunction with other cities by researchers from six continents: Africa, Asia, Australia/Oceania, Europe, North America and South America (Ceccato and Loukaitou-Sideris 2019). Although the results of the surveys in other countries are not reported in this chapter, our results contribute to understanding the current overall situation of transport safety for women by highlighting some of the trends in victimization and safety perceptions in Tokyo that are also found elsewhere.

\subsection{Background of Tokyo's transportation}

In large metropolitan areas such as Tokyo and Kanagawa, railway and subway lines serve as essential means for commuting in Japan. According to a report by East Japan Marketing and Communications, Inc. (2016), the cumulative number 
of weekly passengers in the Greater Tokyo Area, which includes Tokyo, Kanagawa, and other prefectures surrounding Tokyo, totals over 93 million, such that the daily number of 13 million passengers amounts to approximately one-third of the residential population in this area $(38$ million). A road traffic census conducted in 2010 demonstrated that railways, including subways, comprised 44.5 percent of Tokyo's commuting modes, compared with 2.5 percent by buses, and 9.4 percent by personal car (Statistics Bureau, Ministry of Internal Affairs and Communications, 2010).

In Tokyo Metropolis (population 13.7 million) alone, more than ten railway companies operate trains and subways. The number of lines operating in Tokyo exceeds 50, and along with the additional lines in the surrounding densely populated prefectures such as Kanagawa (population nine million), a total of nearly 100 lines are currently operating in Tokyo and Kanagawa. Unlike other countries, many of the railway and subway lines in Tokyo-Kanagawa are interconnected and share the same tracks. In addition, railway companies operate through a wide network of operatives, railways and subways, thus forming a sizeable and complex railway network. For this reason, hereafter in this chapter, we refer to both the railway and the subway as "the railway".

Although Tokyo's railway services are highly efficient and famed for their punctuality, they are also notorious for extreme rush-hour traffic. During morning rush hours, the congestion rate exceeds 180 percent, which is set as the upper limit for peak travel hours, and the rate approaches 200 percent on some commuter lines. According to the guidelines of the Japan Ministry of Land, Infrastructure and Transport, a congestion rate of 100 percent is one in which all passengers can have a seat, or hold on the straps or handrails, and passengers come into direct physical contact at a congestion rate of 180 percent, and such contact becomes oppressive at a congestion rate of 200 percent.

\section{The problem of groping on public transport}

In this context, a significant problem associated with railway travel in Japan, especially in Tokyo, is chikan, that is, groping or molestation. According to a survey by Japan's Gender Equality Bureau Cabinet Office (2000), 48.7 percent of women aged over 20 years reported at least one experience of being groped. The Tokyo Metropolitan Police reported that 51.3 percent of indecent acts, including groping, occurred on trains and an additional 20 percent took place in station buildings, such that over 70 percent of such incidents occurred in the context of railway use (cf. 0.8 percent in buses, Tokyo Metropolitan Police Department, 2018).

Most of the victims of groping are women, particularly younger women. According to the Tokyo Metropolitan Police, 42.6 percent of the victims of groping were in their 20 s, whereas 28.3 percent were between the ages of 10 and 20 and 11.3 percent were in their 30s (Tokyo Metropolitan Police Department, 2018). A survey of college students revealed that 37 percent of female students (and 6 percent of male students) reported they had experienced 


\section{Seiji Shibata}

groping while riding on a train (Otaka, 2017). An earlier survey that targeted women aged 18 to 29 showed that 33.7 percent of them had experienced groping in the last three years (Suzuki, 2000).

In Japan, groping is primarily categorized as a type of "public nuisance crime" and is controlled by the anti-nuisance ordinance, with some severe cases prosecuted as indecent assault. According to a white paper on crime published in 2015, the number of reported groping incidents (including in places other than trains) in 2006 was 4,601 throughout the country (National Police Agency, 2015).

The fact that groping is primarily controlled by the anti-nuisance ordinance rather than criminal law suggests that groping is legally considered a "minor" offence compared with other forms of sexual assault, such as rape. However, as Omata $(2002,2012)$ indicated, groping is the most common indignity endured by young women in Japan during their everyday lives, and experiences of being victimized by sexual groping have been found to be the most influential factors on their criminal risk perception and fear of crime. Research suggests women in other countries also suffer from forms of sexual harassment during transit (Ceccato, 2017; Dunckel-Graglia, 2013; Gekoski, Gray, Adler, \& Horvath, 2017; Madan \& Nalla, 2016; Neupane \& Chesney-Lind, 2014). However, as Loukaitou-Sideris and Fink (2009) indicated, the issue of women's safety on transit has received considerably less attention compared with the problem of women's fear of crime in other public spaces.

\section{Women-only cars as a countermeasure against groping}

In 2000, Keio Electric Railway, one of the railway companies operating in Tokyo, introduced women-only cars on a trial basis on late-night services, in response to complaints of groping on trains, before introducing them as a regular service the following year. In 2001, East Japan Railway (JR East), the largest railway company in Tokyo and adjacent areas, also began operating women-only cars on the Saikyo line, which was known for having the highest reported number of groping-related incidents. Other railway companies followed the lead and, in 2005, many of the railway companies in the Greater Tokyo Area began offering women-only car services on the commuter lines (Doi, 2005). Currently, most commuter lines in Tokyo have women-only car services, which typically operate during morning rush hours.

According to Whitzman (2013) and Lee (2017), several other countries have women-only train cars. The countries noted in their articles were Brazil, Mexico, Egypt, Iran, India, Pakistan, Indonesia, Malaysia, and South Korea. According to Whitzman (2013), 50 percent of the women in Bangladesh desired this type of service while only 2 percent of women in India deemed it to be a viable option. Dunckel-Graglia (2013) showed that over 50 percent of female respondents in Mexico City reported they always use women-only cars. Thus, the endorsement of women-only train cars differs from country to country. The results of a survey by Statistics Bureau, Ministry of Internal Affairs 
and Communications (2002) revealed the women-only car service is welcomed on the whole in Japan: 77 percent women and 66 percent men were in favor of the concept.

However, the effectiveness of the introduction of women-only cars on commuter lines as a countermeasure against groping has not been well-studied in Japan. According to the National Police Agency's (2015) white paper on crime, the total number of reported groping incidents decreased from 4,601 in 2006 to 3,722 in 2014; however, the number of such incidents occurring before 2006 was not included in their report; therefore, it remains unclear whether there was any significant change after the full-scale introduction of women-only cars. Additionally, our ability to identify the actual change in groping prevalence is limited because no railway operators currently disclose groping report rates to the public.

Several incidents have occurred in recent years in which groping suspects have fled on the tracks, causing immense delays or cancellations. Such delays or cancellations result in serious problems during rush hours because there are no alternative modes of transportation that can carry as many passengers as the railways. Groping is thus becoming a big problem for railway operations.

\section{CCTV cameras as a security measures on trains and platforms}

Railway companies in Tokyo installed surveillance cameras on station platforms and station buildings after the sarin gas attack on a Tokyo subway in 1995. However, surveillance cameras were not introduced on train cars until recently because of privacy concerns. As the number of criminal offences committed in trains increased in the early 2000s (Nomura, 2017), several railway companies began introducing surveillance cameras in train cars as a security measure over the last few years with the hope of deterring violence and groping.

Additionally, the 2020 Tokyo Olympic Games have driven the movement to place surveillance cameras on train cars, as world events such as the Olympic Games can become targets for terrorist attacks. JR East announced its plan to install surveillance cameras on all passenger cars on the Yamanote Line by the proposed start of the 2020 Olympic Games (Kyodo News, 2018). This central Tokyo loop route carries the largest number of passengers.

The Ministry of Internal Affairs and Communications Statistics Bureau survey of 2002 reported that 52.4 percent of men and 57.1 percent of women favored the installation of survey cameras on train cars as a measure for the prevention of groping and violence. However, a number of the respondents (26.9 percent of men and 22.0 percent of women) expressed dissatisfaction, asserting that it was unpleasant to be monitored by cameras and that such surveillance was ineffective because acts of groping could not be captured by the cameras because of the over-crowdedness of the trains.

Research on the railways in Japan is centered primarily on engineering aspects, such as the safety of facilities and systems. Although several surveys have 


\section{Seiji Shibata}

been conducted on such matters, limited scientific research has examined citizen's attitudes toward women-only cars or surveillance cameras on trains. The Statistics Bureau of the Ministry of Internal Affairs and Communications (2002) conducted a survey in March 2002 on women-only cars and surveillance cameras in the Tokyo area as part of a larger study of women's perspectives on transport services. However, this study is not only dated but was done before women-only cars had been fully operational on Tokyo area commuter lines. Over 15 years have passed since women-only cars were introduced full-scale into the commuter lines and surveillance cameras were rapidly installed in and around Tokyo, necessitating the current investigation.

\subsection{Data and methods}

Participants were recruited for the survey from panel members of a web survey company and comprised 400 college students (196 men, 196 women, and eight other) living in Tokyo/Kanagawa (age range 18 to 29). The web company collected an extensive database of panel members through various online services, such as e-commerce sites by offering respondents loyalty program points for survey participation. Potential respondents for the survey were randomly extracted from the targeted student pool and the people identified were subsequently asked to participate in the survey. The questionnaire was administered by the survey company via a web system until the quota (total 400 , and maleto-female ratio $1: 1$ ) was met.

The data collected from those who identified their gender as other than male or female were excluded from the analysis because their numbers were too small. Data from two other participants (one male and one female) were also excluded from the dataset because they answered that they never use the railway for commuting. The total sample size of our dataset was 390 (male=195, female $=195)$ with most $(N=381,97.69$ percent $)$ being Japanese and nine representing other nationalities (four East Asian, two Asian, and three mixed). Over three-quarters of the participants reported using the railway almost daily, and their commuting times ranged from 30 to 120 minutes. No gender differences were observed in the frequency of railway use and the commuting time (Table 8.1).

The questionnaire used in the survey was based on the aforementioned international research project on women's transit safety and administered in Japanese. The questionnaire included the following main topics: (1) the frequency of railway use and the length of commuting time; (2) safety and security perceptions of the railway; (3) experiences of harassment using railways and reporting of those experiences; and (4) effectiveness of security and safety measures.

To measure the frequency of railway use, participants were asked how often they used the railway in a typical week, with potential answers ranging from "never" to "every day". As mentioned above, data from those who answered "never" to this question were excluded from the dataset. Additionally, participants provided their typical door-to-door travel times on an average weekday. 
Table 8.1 Summary of the participants' frequency of railway use and commuting time

\begin{tabular}{llllll}
\hline \multicolumn{5}{l}{ Frequency of railway use } \\
\cline { 2 - 6 } & Everyday & $5-6$ days & $3-4$ days & 1-2 days & Less than once \\
\hline Women & 70 & 75 & 26 & 20 & 4 \\
Men & 62 & 81 & 29 & 19 & 4 \\
\hline \multirow{5}{*}{ Commuting time } & & & & \\
\cline { 2 - 6 } & More than 2 hrs. & $1-2$ hrs. & 30 min. -1 hr. & $15-30$ min. & Less than 15 min. \\
Women & 11 & 84 & 78 & 12 & 10 \\
Men & 11 & 91 & 61 & 16 & 16 \\
\hline
\end{tabular}

Note

$N=195$ for both men and women.

The questions on safety and security perceptions comprised four items on how often participants felt safe when they rode the train and were waiting on the station platform during the daytime and night-time, respectively. Responses were coded on a scale ranging from 1 (Always) to 5 (Never) and 6 for those who did not use it. The participants were also asked several multiple choice questions for which they could select all applicable answers. These included what the respondents considered to be significant problems on trains and platforms (e.g., darkness/poor lighting, litter or drunk people), and what prevented them from using the railway more frequently (e.g., cost, fear of a crash).

To measure their experiences with harassment, participants were queried on whether they had experienced harassment or criminal acts on the trains, platforms, and/or on their way to/from the station in the past three years. Also, participants were asked whether they had reported that experience to someone, and if they answered "yes", they were asked to whom they reported it (e.g., police, railway companies, their parents). For those who answered "no", they were asked to provide the reason for not reporting.

To determine their perceptions of the effectiveness of security and safety measures, participants were asked to choose the three most effective methods they believed would make railway travel safer from among a list of choices (Table 8.2).

The survey was conducted online in Japan from 6-13 June 2018, and was hosted by a commercial survey company (http://cross-m.co.jp). All the participants answered the questionnaire via a web system and received loyalty program points from the survey company as an incentive for completing the questionnaire. The entire survey, including questionnaires on other modes of transport, took approximately 25 minutes to complete.

In the analysis, effect sizes for proportion (Cohen's $h$ ) and association coefficients $(\varphi)$ were calculated to evaluate the size of the differences. Cohen's $b$ is a measure of the difference between two probabilities or proportions. It helps to 
determine whether the difference is not too small to be meaningful. The rule of thumb criteria set out by Cohen (1988) says the effect size is small when $b$ equals 0.2 , medium when it is equivalent to 0.5 , and large when it amounts to 0.8 .

\subsection{Results}

\section{Victimization of sexual harassment and transit crime}

Most of the participants indicated they had never experienced any type of harassment or crime listed in the questionnaire (for women, it varied from 65 percent to 84 percent depending on the settings and, for men, approximately 90 percent in all three settings, namely on trains, on platforms, and to/from the station). However, gender differences in harassment experience were evident. The total number of people who reported having experienced any of these forms of harassment included 28 men and 125 women; therefore, more than four times as many women as men experienced harassment. The most significant difference between men and women was observed in the rates of groping on the train (2.6 percent of men vs. 24.1 percent of women), such that the effect size of the gender difference was $h=0.70$. Additionally, there were medium-size gender differences in the rates of stalking on the way to/from the station ( 1.0 percent of men vs. 10.8 percent of women, $h=0.47$ ).

The number women who reported they had experienced at least one form of harassment was 68 (34.9 percent), and the number of women who reported they had been exposed to groping was 47 , which comprised nearly 70 percent of the women who had experienced harassment on a train. This number is also more than twice that of women who reported being stalked on the way to/ from the station, which was the second most experienced harassment among the female participants $(b=0.36)$. These results indicate that groping on the train car is by far the most common problem for women using railway transport.

Among the women who had reported they had been groped, 26 (55.3 percent) answered that they had not reported the incident to anyone. The most frequent reason for not reporting was "to avoid more trouble" $(15 / 26=57.7$ percent $)$ followed by "I was embarrassed" $(12 / 26=46.2$ percent). Additionally, women who answered they had reported their experience to someone reported mostly to a friend of theirs $(15 / 19=79.0$ percent $)$, and only four women answered they had reported it to the police or the train conductor/operator (two to the police and another two to the train conductor/ operator). Thus, the number of women who had reported it to officials was four out of a total of 47 persons ( 8.5 percent) who had been exposed to groping on trains.

Table 8.2 shows the actual experiences and perceptions of groping on trains among female participants. Pearson's chi-squared test with Yates' correction showed there were significant differences in the perception of sexual harassment on trains between those who had experienced groping on the train and those 
Table 8.2 Cross-tables between the experiences and perceptions of groping on trains among female participants

\begin{tabular}{|c|c|c|c|c|c|c|}
\hline \multirow{2}{*}{$\begin{array}{l}\text { Experience of } \\
\text { groping }\end{array}$} & \multicolumn{3}{|c|}{ Significant problem } & \multicolumn{3}{|c|}{ Preventing more use } \\
\hline & $r_{e s}$ & No & Total & $r_{e s}$ & No & Total \\
\hline Yes & 20 & 27 & 47 & 19 & 28 & 47 \\
\hline No & 27 & 121 & 148 & 20 & 128 & 148 \\
\hline Total & 47 & 148 & 195 & 39 & 156 & 195 \\
\hline
\end{tabular}

who had not $\left(\chi^{2}(1)=10.23, p=0.001, \varphi=0.23\right)$. Differences were also significant among responses of whether groping prevented more frequent use of railway $\left(\chi^{2}(1)=14.51, p<0.001, \varphi=0.27\right)$. These results indicate those who had experienced groping consider sexual harassment on trains to be more significant and that it prevented them from using the railway more often than those who had not experienced this form of harassment.

\section{Safety perceptions}

Figure 8.1 depicts participants' safety perceptions concerning their railway use during the daytime and night-time. According to the effect sizes, there was a small gender difference in the rate of participants who answered "always" to the question measuring perceptions of safety of the train during the daytime (24.1 percent in men and 14.9 percent in women, $h=0.23$ ). There were also small gender differences in the rates of participants who answered "always" and "rarely" to the question concerning the perceived safety of trains during the night-time (15.9 percent of men vs. 7.7 percent of women, $h=0.26 ; 8.2$ percent of men and 15.4 percent of women, $h=0.23$, respectively).

There were small gender differences in perceptions of safety on railway platforms during the daytime and night-time. The effect sizes of gender on the rates of answers "always" and "rarely" were 0.25 (24.1 percent of men and 14.4 percent of women) and 0.24 (5.6 percent of men and 12.3 percent of women), respectively for the question concerning the perceptions of safety on platforms during the day, and $0.4 \mathrm{l}$ for the rate of "always" responses to the question about night-time safety (10.8 percent of men and 17.4 percent of women). These results indicate women generally feel less safe than men when using railways, particularly at night.

The most frequent problem identified on the railways by nearly 30 percent to 40 percent of all respondents was drunk passengers on both the trains and the platforms. There were medium-sized differences in perceptions of problems by gender and settings (on the train, on the platform, or to/from the station) in the numbers of people who identified sexual harassment as a significant problem. The number of women who reported this issue as a problem on the train was 47 (24.1 percent), and it was over three times that of men for the same question (for women on the question about harassment on platforms, $h=0.48$ for both differences). 

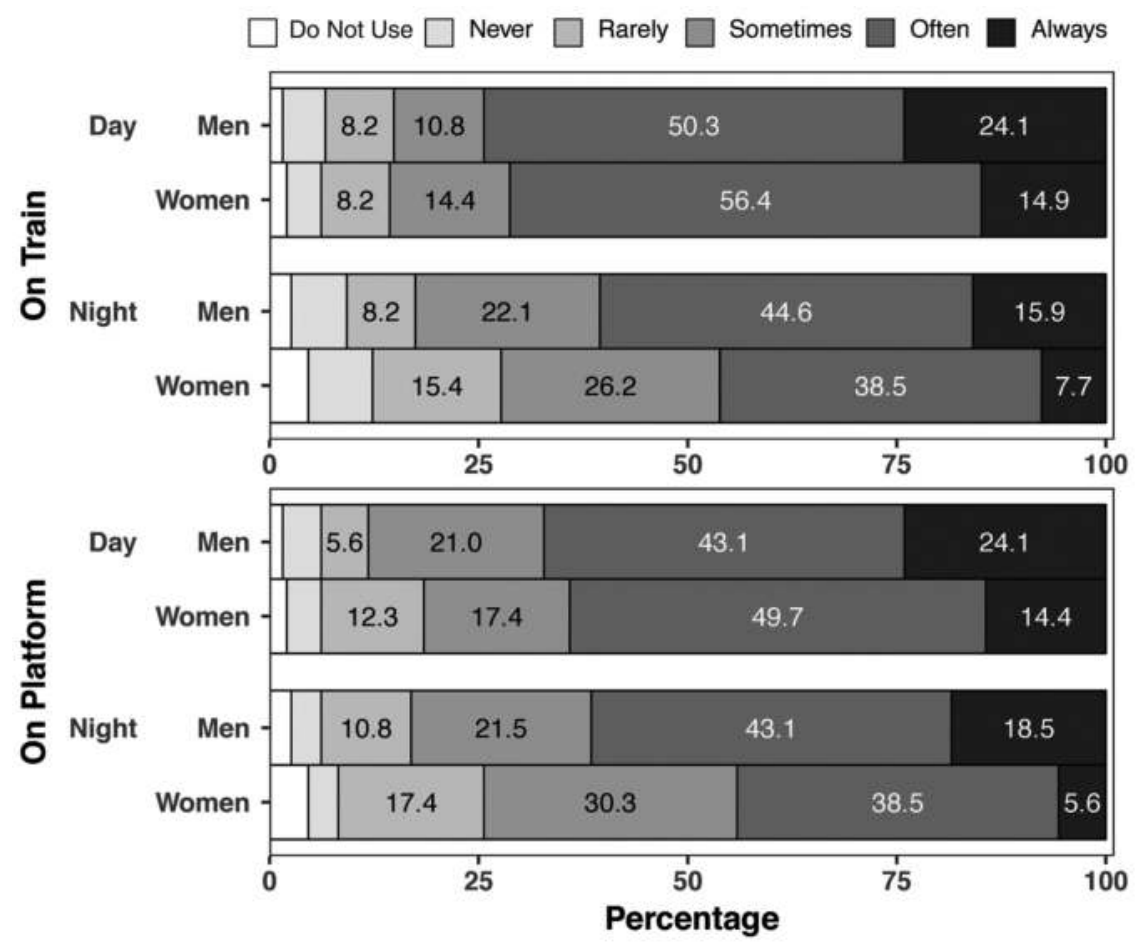

Figure 8.1 Results of participants' safety perceptions (\%) concerning their railway usage during daytime and night-time. The numbers on the low proportion groups ("never" and "do not use") are omitted.

The above-described safety conditions are confirmed by the results of the questions on factors that prevent the participants from using the railway more often (note the top four of the 16 items were the same among both men and women). The most common factor was the overcrowded service, followed by the cost, nuisance concerns, and multiple transfers, respectively. The Spearman's rank order correlation between male and female was $\rho=0.72$; thus, the overall rankings were similar for both genders. However, there was a notable difference of medium-to-large effect size in the responses concerning sexual harassment $(b=0.64)$ : the number of women who indicated this issue as a preventive factor was nearly ten times greater than that of men.

\section{Measures to improve safety}

Table 8.3 presents the number of participants who identified each of the listed measures that are expected to improve transit safety. The most effective measure was surveillance cameras in train cars or on railway platforms, as over 50 percent of the men and women believe surveillance cameras would improve the safety of 
Table 8.3 Respondents who identified measures that would make railway travel safer

\begin{tabular}{|c|c|c|c|c|c|c|c|}
\hline Measures & Total & $\%$ & Men & $\%$ & Women & $\%$ & $b$ \\
\hline $\begin{array}{l}\text { Survey cameras inside } \\
\text { train cars }\end{array}$ & 247 & 63.3 & 134 & 68.7 & 113 & 57.9 & 0.22 \\
\hline Survey cameras at platforms & 238 & 61.0 & 128 & 65.6 & 110 & 56.4 & 0.19 \\
\hline Police patrolling platforms & 194 & 49.7 & 99 & 50.8 & 95 & 48.7 & 0.04 \\
\hline $\begin{array}{l}\text { More police officers } \\
\text { patrolling train cars }\end{array}$ & 101 & 25.9 & 52 & 26.7 & 49 & 25.1 & 0.04 \\
\hline More lighting at platforms & 97 & 24.9 & 56 & 28.7 & 41 & 21.0 & 0.18 \\
\hline $\begin{array}{l}\text { Direct police line in each } \\
\text { train car }\end{array}$ & 84 & 21.5 & 34 & 17.4 & 50 & 25.6 & 0.20 \\
\hline Women-only cars & 83 & 21.3 & 16 & 8.2 & 67 & 34.4 & 0.67 \\
\hline $\begin{array}{l}\text { Direct police line at } \\
\text { platform }\end{array}$ & 72 & 18.5 & 34 & 17.4 & 38 & 19.5 & 0.05 \\
\hline $\begin{array}{l}\text { Digital timetable at } \\
\text { platforms }\end{array}$ & 41 & 10.5 & 23 & 11.8 & 18 & 9.2 & 0.08 \\
\hline
\end{tabular}

Note

$n=195$ in both men and women.

Cohen's $h$ is for the difference of the proportion between men and women.

railway travel. The Cohen's $h$ for proportions demonstrated there was a mediumto-large effect size difference between men and women concerning the effectiveness of women-only cars $(b=0.67)$, and the rate of women who claimed this measure would be effective in improving safety was higher than that of men.

The frequencies of female participants who agreed with the statement that surveillance cameras in train cars and/or women-only cars would improve the safety of railway travel were computed according to their encounters with groping on train cars. In this manner, the existence of differences in the women's perceptions of these security and safety measures were ascertained regarding their experiences of being groped on trains. Table 8.4 shows the

Table 8.4 Cross-tables between the experiences of groping and the perceptions of survey cameras and women-only cars among female participants

\begin{tabular}{|c|c|c|c|c|}
\hline \multirow[b]{2}{*}{ Measures } & \multirow[b]{2}{*}{ Groping } & \multicolumn{3}{|c|}{ Identified as effective } \\
\hline & & Yes & No & Total \\
\hline \multirow[t]{4}{*}{ Survey cameras } & Yes & 30 & 17 & 47 \\
\hline & & $63.8 \%$ & $36.2 \%$ & \\
\hline & No & 83 & 65 & 148 \\
\hline & & $56.1 \%$ & $43.9 \%$ & \\
\hline \multirow[t]{4}{*}{ Women-only cars } & Yes & 16 & 31 & 47 \\
\hline & & $34.0 \%$ & $66.0 \%$ & \\
\hline & No & 51 & 97 & 148 \\
\hline & & $34.5 \%$ & $65.5 \%$ & \\
\hline
\end{tabular}


resulting cross-tables in which the experience of being groped is mapped as the row and the perception of effectiveness is displayed as the column.

Table 8.4 indicates that previous groping victimization does not affect the perception of surveillance cameras and women-only cars. A slightly higher percentage of women who had experienced groping answered that having surveillance cameras would improve safety compared with those who had not faced this threat. However, the Pearson's chi-squared test revealed the difference was not statistically significant $\left(\chi^{2}(1)=0.59, p=0.443, \varphi=0.05\right)$.

\subsection{Discussion of the results}

In this study, we investigated transit safety among college students in TokyoKanagawa. The results demonstrated that fewer than half of women "always" or "often" felt safe for both trains and platforms during night-time, though most women reported feeling safe on trains and on platforms during the day. These results suggest that women feel much less safe during night-time.

\section{Experiences of groping}

The results concerning the experience of exposure to some form of harassment or crime demonstrated that 24.1 percent of female students had been exposed to groping while riding a train and this rate was by far the highest among crime experiences. The percentage of women who claimed they had experienced groping was lower than previously reported in other studies. For example, the Gender Equality Bureau Cabinet Office (2000) and the Tokyo Metropolitan Police Department (2018) reported that approximately 50 percent of women in their 20s claimed to have experienced groping at least once. The percentage obtained in this study was slightly less than half of those identified in these results. However, the responses in those reports represented participants' lifetime experience, whereas, in this study, the question regarded their experiences in the last three years only, which may account for these differences.

Although the victimization of groping occurred over ten times more on train cars than on the station platform or during their walk to/from the station, the perception of safety among female students did not differ much between these environments. According to the report from the Tokyo Metropolitan Police Department (2018), most arrests for nuisance crime occur during the morning and evening rush hours, and the number of arrests during the morning rush hours was larger than the arrests made during the evening rush hours. However, there was little difference in perceptions of train and station platform safety during the day versus at night, although the settings were perceived to be less safe at night than during the day.

Of note is that these results do not mean women do not view groping as a problem affecting their use of railway services. In response to the question asking about the factors that deter more frequent use of railway transport, 20 percent of women identified the fear of sexual harassment on the train among 
the primary factors. This percentage was nearly 10 times that for men. Also, it was the sixth-largest rate in female participants among the 16 listed items. Additionally, 24.1 percent of women considered sexual harassment to be a significant problem impacting railway use, which was the second most commonly identified item.

Additionally, over 90 percent of those who had been exposed to groping on a train did not report it to the officials, and over the half of those being groped reported it to no one. The main reason for not reporting was to avoid further trouble or that they were embarrassed, meaning the exposure to groping could have an impact on their safety perception on railway travel. Nonetheless, although the rates of those who took sexual harassment on trains more seriously were higher among those who had experienced groping, nearly 60 percent of those who had experienced groping did not consider groping on trains to be a significant problem that prevented them from using the railway often.

It is unclear the reason why this high rate of groping on the train had no significant effect on women's safety perception. However, a possible explanation is that there is no way of commuting other than using the railway; therefore, the impact of the experience could be underestimated as a means of reducing cognitive dissonance between the fact that groping occurs and that they use the railway almost daily. Similar patterns where victims tended to underestimate the impact of their own experience was also reported in rape victims. In Iwasaki (2000), none of the rape victims in her study reported the rape to the police and most of the victims explained the reason they did not report as "it was not that serious". As for this result, Iwasaki (2000) pointed out the possibility that the victims tried to protect themselves psychologically by underestimating its seriousness.

\section{Perceptions of women-only cars to tackle groping}

Over one-third of female students who responded to our survey claimed women-only cars would make railway travel safer. However, the prevalence of women in favor of women-only cars as safety measures was much smaller compared with that of people who considered surveillance cameras on trains and on platforms to be an effective anti-crime measure, which was 56 percent and 58 percent, respectively. Given that women-only cars have already been in operation over the past 15 years and yet surveillance cameras were considered effective by a higher proportion, it might be that womenonly cars are perceived to be less effective than claimed by railway companies and the police.

This assumption was also suggested by the study finding that encounters with groping on train cars did not increase the perception of female students that women-only cars were effective. Also, the number of women students who identified women-only cars as an effective means of improving railway travel safety was smaller even among those who had experienced groping than the number of women who found survey cameras in train cars helpful. 


\section{Seiji Shibata}

\section{Perceptions of surveillance cameras}

Most respondents of the survey considered surveillance cameras in train cars and on platforms to be effective safety and security instruments. Both men (nearly 70 percent) and women (nearly 60 percent) identified the cameras as a solution to the problem of crime committed in railway precincts. Approximately the same percentage of women $(57.1$ percent) and a lesser ratio of men (52.4 percent) responded that survey cameras should be installed on train cars to prevent or to reduce groping and violence on train cars in the survey conducted by the Statistics Bureau, Ministry of Internal Affairs and Communications (2002). The results of the present investigation suggest that over the last decade, railway passengers have gradually and increasingly accepted the institution of surveillance cameras inside train cars as viable security instruments.

Surveillance cameras, unlike women-only cars, have been proven to be effective in deterring groping. For example, it is said that the number of groping cases decreased by 60 percent when the Saikyo Line installed surveillance cameras on their train cars (Liu, 2011). In addition, four men who were suspected in 2017 of molesting a woman en masse on the Saikyo Line were identified through a surveillance camera recording and were arrested (Sankei Shimbun, 2017).

For men, the false accusation of groping has become a concern in their railway travel, and Okabe (2004) reported that approximately half of men took some measures, such as holding their strap handles with both hands, to avoid being wrongly accused of groping. These circumstances could explain the higher percentages of approval for surveillance cameras among men than women.

\section{Significant problems other than sexual harassment}

Overcrowding is another difficulty of railway travel and it is, perhaps, the most fundamental problem of the train services. It was, in fact, the factor most selected as a phenomenon that prevented both men and women from using the railway more frequently. According to a report by the Tokyo Metropolitan Police Department (2018), nearly 30 percent of groping cases occurred during the morning rush hours and another 20 percent during the evening rush hours. Hence, around half the molestation on train cars happens during the crowded morning and evening rush-hours. There is no doubt that congestion is one of the main environmental factors of groping.

\subsection{Conclusions, limitations and policy implications}

This study examined the safety of railway transport for women. To this end, it used survey data collected from 400 college students in Tokyo-Kanagawa, Japan. The survey results demonstrated that young women most commonly experience groping on train carriages. 
The outcomes of this investigation show that more than half of the respondents, both men and women, believed surveillance cameras in train cars would make their trip safer and approximately one-third of female respondents thought that women-only cars would do the same. The survey demonstrated equal to or greater surveillance-camera approval rates than those presented by the results of the 2002 survey conducted by the Statistics Bureau of the Ministry of Internal Affairs and Communications. Thus, the acceptance of surveillance cameras as an instrument of enhancing security seems to have gradually increased over the last decade. However, less than half the percentage of women reported in the survey by the Statistics Bureau of Ministry of Internal Affairs and Communications (2002) exhibited their approval in the survey for women-only cars as a safety measure. In addition, no difference was found in the approval rates offered by those who had experienced groping and those who had not. Thus, the effectiveness of this measure in improving women's safety during railway trips remains ambiguous as no clear relationship was established between the experiences and perceptions of women regarding groping and their attitudes toward womenonly cars.

This study shares several limitations with other studies of this type. First, our data do not include the actual usage of women-only cars by women; therefore, how many women regularly use women-only cars to avoid groping on the train remains unclear. Second, more often than not, there is a discrepancy between people's opinions and what actually proves to be effective. Because the data collected in our survey were limited to participants' subjective perceptions, we cannot determine the actual effectiveness of surveillance cameras and womenonly cars. Therefore, further and more systematic studies are needed to achieve a better understanding of college students' transit safety in Tokyo. Despite certain limitations in the data presented in this paper, studies in Japan on railway travel safety from perspectives other than the operational perspective have thus far been surprisingly few. It is hoped that this investigation can make a contribution to research on this topic

A policy implication on making railway travel safer could be derived from these results. Although the surveillance camera has been accepted as an effective safety and security instrument, no fundamental solution to the problem of groping can be found unless the problem of overcrowding is resolved. It is clear that overcrowding is the primary environmental factor facilitating groping, because around half the instances of such molestation are reported during the morning and evening rush-hours when overcrowding takes place.

Railway companies keep enhancing transportation capacity by increasing the number of trains or by adding cars to trains. However, the congestion during the morning and evening rush hours has not been substantially reduced. Several railway companies have recently started introducing commuter trains that have all seats reserved in the morning and evening commuting hours. This measure could be effective in solving the problem of congestion in the cars even though the issue of limited availability of stations and trains still exists for such services. Tokyo Metro, one of the major subway operators in Tokyo, started a trial 


\section{Seiji Shibata}

reward points system in April 2019. Reward points are given as incentives and may be used as electronic money by passengers who commute during off-peak hours (Tokyo Metro, 2019). It is hoped that such an attempt will lead to some reduction of congestion during peak hours (even though it may not mitigate the problem in its entirety, as long as the opening hours of schools and companies do not change) and, therefore, may also have an impact on sexual transit crime.

\section{References}

Ceccato, V. (2017). Women's transit safety: making connections and defining future directions in research and practice. Crime Prevention and Community Safety, 19, 276-287.

Ceccato, V., \& Loukaitou-Sideris, A. (2019). Transit safety among college students: an international study. Retrieved from www.kth.se/abe/om-skolan/inst/som/avdelningar/ urbana-studier/forskning/urban-community-sa/trygghet-i-kollektiv (accessed 20 February 2020).

Cohen, J. (1988). Statistical for the Behavioral Sciences. New Jersey: Lawrence Erlbaum Associates.

Doi, E. (2005). Single-sex cars on commuter trains cater to women in Japan. McClatchy DC Bureau. Retrieved from www.mcclatchydc.com/latest-news/article24447325. html (accessed 14 December 2019).

Dunckel-Graglia, A. (2013). Women-only transportation: how "pink" public transportation changes public perception of women's mobility. Journal of Public Transportation, $16,85-105$.

East Japan Marketing \& Communications, Inc. (2016). Shuto-ken rosen-gun to nobe riyōsha-sū/heikin jōsha jikan [The railway lines in the Greater Tokyo Area and its cumulative number of passengers/average travel time]. Retrieved 10 February 2019, from www.jeki.co.jp/transit/mediaguide/pdf/MD_matome4.pdf (accessed 14 December 2019).

Gekoski, A., Gray, J. M., Adler, J. R., \& Horvath, M. A. (2017). The prevalence and nature of sexual harassment and assault against women and girls on public transport: an international review. Journal of Criminological Research, Policy and Practice, 3, 3-16.

Gender Equality Bureau Cabinet Office. (2000). Danjo-kan ni okeru bōryoku ni kansuru chōsa [Survey on violence between men and women]. Retrieved 10 February 2019, from www.gender.go.jp/policy/no_violence/e-vaw/chousa/pdf/hllreport2-3.pdf (accessed 10 February 2019).

Iwasaki, N. (2000). Sexual victimization among Japanese college students: experiences in date/acquaintance rape and being "significant others" for the victims of sexual assaults. The Japanese Journal of Mental Health, 15, 52-61.

Kyodo News. (2018). JR east to install security cameras on all trains. The Japan Times. Retrieved from www.japantimes.co.jp/news/2018/04/03/national/jr-east-installsecurity-cameras-trains/ (accessed 10 February 2019).

Lee, A. (2017). Gender, everyday mobility, and mass transit in urban Asia. Mobility in History, 8(1), 85-94. Retrieved from www.berghahnjournals.com/view/journals/ mobility-in-history/8/1/mih080110.xml (accessed 10 February 2019).

Liu, J. (2011). Jōhō no shakai-chitsujo keisei kinō [Social order formation function of information]. Review of the Division of Correspondence Education, 14, 61-80.

Loukaitou-Sideris, A., \& Fink, C. (2009). Addressing women's fear of victimization in transportation settings. Urban Affairs Review, 44, 554-587. 
Madan, M., \& Nalla, M. K. (2016). Sexual harassment in public spaces: examining gender differences in perceived seriousness and victimization. International Criminal Justice Review, 26, 80-97.

National Police Agency (2015). WHITE paper on crime 2015. Retrieved 10 February 2019, from http://hakusyol.moj.go.jp/jp/62/nfm/mokuji.html (accessed 20 February 2020).

Neupane, G., \& Chesney-Lind, M. (2014). Violence against women on public transport in Nepal: sexual harassment and the spatial expression of male privilege. International Journal of Comparative and Applied Criminal Justice, 38, 23-38.

Nomura, T. (2017). On the activities of railroad police squads. IATSS Review, 41, 13-16.

Okabe, C. (2004). Study of the "carriage for women only". Kurume Shin-Ai Women's College Bulletin, 27, 57-66.

Omata, K. (2002). Long-term psychological Aftereffects of sexual victimization and influence of victim-assailant relationship upon them among Japanese female college students. Japanese Journal of Criminal Psychology, 40, 1-19.

Omata, K. (2012). The relationship of sexual victimization to risk perception of Japanese female college students. Surugadai University Studies, 44, 143-154.

Otaka, M. (2017). Survey on the incident of "Chikan" to University students. Bulletin of the Graduate School, Toyo University, 54, 65-76.

Sankei Shimbun (2017). JR Saikyō-sen de josei torikakomi shūdan-chikan utagai, 4 nin taiho [Four men arrested on JR Saikyo Line with the suspect of group groping]. The Sankei Shimbun. Retrieved from www.sankei.com/affairs/news/171127/afr1711270 020-nl.html (accessed 20 February 2020).

Statistics Bureau, Ministry of Internal Affairs and Communications (2002). Josei no shiten kara mita kōtsū-sābisu ni kansuru ankēto-chōsa [Survey on transport service from women's perspective]. Retrieved 11 February 2019, from www.mlit.go.jp/kisha/ kisha02/15/150813/150813_3.pdf (accessed 20 February 2020).

Statistics Bureau, Ministry of Internal Affairs and Communications (2010). 2010 Japan Census. Retrieved 10 February 2019, from www.stat.go.jp/data/kokusei/2010/ final/pdf/01-11_5.pdf (accessed 20 February 2020).

Suzuki, S. (2000). Jakunen-josei ni okeru chikan higai no jittai [Victimization by molesters among young females]. Research on Prevention of Crime and Delinquency, 40, 137-145.

Tokyo Metro (2019). Metopo wo katsuyō shita ofupīku purojekuto wo jisshi shimasu! [We will start an off-peak project using metopo!]. Retrieved from www.tokyometro. jp/news/images_h/metroNews20190315_27.pdf (accessed 18 December 2019).

Tokyo Metropolitan Police Department (2018). Konna jikan, basho ga nerawareru [Crime risks are high in these times and places]. Retrieved 10 February 2019, from www.keishicho.metro.tokyo.jp/kurashi/higai/koramu2/koramu8.html (accessed December 2019).

Whitzman, C. (2013). Women's safety and everyday mobility. In C. Whitzman, C. Legacy, C. Andrew, F. Klodawsky, M. Shaw, \& K. Viswanath (Eds.), Building Inclusive Cities: Women's Safety and the Right to the City (pp. 35-52). London: Routledge. 


\title{
9 Women and LGBTI youth as targets
}

\author{
Assessing transit safety in \\ Rio Claro, Brazil
}

\author{
Farid Nourani, Sérgio Luis Antonello \\ José Silvio Govone and Vania Ceccato
}

\subsection{Introduction}

Violence against women is a phenomenon that occurs in a variety of ways in all parts of the world (Amaral et al., 2013; Sokoloff \& Dupont, 2005). Brilhante, Moreira, Viera, and Catrib (2016) conducted a study on 450 articles from the Web of Science database, from 1982 to 2012, to understand the nature of gender violence, which suggests women are more often the target of these crimes. A vast majority of these articles dealt with some type of violence against women. Several initiatives have been implemented aiming at improving local knowledge and sharing information about the conditions under which crime occurs and the best ways to prevent it (Ceccato \& Paz, 2017; Gekoski et al., 2015; Loukaitou-Sideris, 2014; Vanier \& d'Arbois de Jubainville, 2017). One of these initiatives brought together researchers from 17 cities around the world, who in 2018 started to conduct a survey of university students in these 17 cities. Some preliminary results of this international partnership were presented and discussed at the Conference "Crime and Fear in Public Places: Patterns, Challenges and Actions", held from 17-18 October 2018 in Stockholm, Sweden.

This chapter presents results from one survey carried out with students from the São Paulo State University (UNESP) at Rio Claro, SP, Brazil. It focuses on the perception of transit safety among students and their victimization regarding sexual assault or harassment. Thus, this chapter contributes to the debate on the safety of urban mobility of university students, especially females, on public transport and, above all, attempts to show the authorities the need to implement effective public policies to mitigate the problem and promotion of the right to free movement in public spaces for the most vulnerable groups.

\subsection{The context of gender violence}

Gender-based violence is a persistent social problem, multiform and articulated by psychological, moral and physical facets, and may occur in a private-family environment, in workplaces, as well as in public spaces. Its manifestations are ways of establishing a relationship of submission or power, always implying 
situations of fear, isolation, dependence and intimidation for women (Bandeira, 2014). The root of this problem is related to the position of women's subjugation in patriarchal society (Silva, 2017). This conception of violence is the same that takes gender hierarchy into homo-affective relationships, in which the most masculine performances subjugate the most feminine (Carrara \& Heilborn, 2006).

In Brazil, since redemocratization in the 1980s, violence against women has attracted attention and has been raised as one of the priority problems to be tackled by public health and human rights organizations (Silva \& Oliveira, 2015). However, the theme only gained greater strength with the creation of Law 11,340/2006, known as Maria da Penha Law (Brasil, 2006).

Among the various types of violence against women, sexual violence stands out as one of the main causes of loss of healthy life years due to disability, as it has a significant negative impact on women's health (Drezett, 2003). This type of violence can cause harmful consequences to the victim in the short and long term, such as: depression, symptoms of dissociation, eating disorders, difficulties in sexual relations, sleep disorders and suicide attempts, among others (Williams, 2014). Among crimes of a sexual nature, sexual harassment is historically the most frequent, but it has been naturally neglected and even regarded with some "naturalness" by society, which considers it a joke (Benedicto, 2017; Silva, 2017).

According to Silva (2017), sexual harassment is offensive conduct of a sexual nature and, although less serious in comparison to rape, it is very common in Brazil. This behavior, whether in its verbal, nonverbal or physical form, has a strong embarrassing and destabilizing effect on the victim and affects their dignity by depriving them of their essential right to come and go.

A survey by Think Olga NGO in 2013 of 7,762 women in Brazil as part of a campaign against sexual harassment in public spaces (No more fiu-fiu campaign) showed that 99.6 percent of respondents said they had suffered harassment (98 percent of them have heard pickup lines in the street and 64 percent in public transport) (Think Olga, 2013).

Sexual harassment occurs most often in public transportation spaces, and in most cases is perpetrated by men against females (Ceccato, 2017; Stringer, 2007). This type of insecurity in urban mobility has serious socioeconomic impact on society and especially on women's lives (Silva, 2017). It may seriously impair women's roles in the economy as a whole, as it limits women's access to study and work, preventing them from breaking the cycles of poverty in which they live (Ceccato, 2017; Feliciano, 2016). Silva (2017) states "there is no awareness of the psychological damage that harassment and sexual violence cause to women using public transport and how much this damage limits their individual freedom and autonomy" (Silva, 2017, p. 4). This type of abuse has been under-reported and barely faced by relevant public authorities, whether in the political or legal-criminal context.

One of the important contributions of scholarly works is to make the consequences of sexual harassment, mistakenly regarded as innocent, more visible and to raise awareness of the negative impacts of these crimes on the prosperity of the whole society. This chapter aims to contribute in this context and is 
structured as follows. It first addresses the issues of women's victimization and sexual harassment in public spaces. Then the main hypotheses of this study are presented followed by a description of the case study, data and methods. Results are discussed later followed by some conclusions. The chapter also reveals the places belonging to the urban transportation system where participants feel most unsafe, as well as discusses a set of measures that can be implemented to improve safety among university students.

\section{Feeling of insecurity: the fruit of a society in crisis}

Fear of crime, also referred to as "sense of insecurity" has increasingly occupied the agenda of scientists and public safety managers. Warr (2000) defines fear of crime as a sense of alertness or fear caused by a notion or expectation of danger. According to Carvalho \& Oliveira (2016) the fear of crime negatively affects people, often more than the crime itself. Thus, both crime and fear of crime would benefit from approaches that treat them as distinct social problems, demanding different policies and actions by public authorities and managers.

In Brazil, there is usually a very high sense of insecurity due to high rates of violence. Violence in Brazil has significantly increased in recent years. According to the Atlas of Violence of 2018 (IPEA \& FBSP, 2018), in the 2010 decade, the homicide rate in Brazil grew 14 percent on average. Statistics on violence against women are also very bleak in Brazil. The IPEA reports the national average rates of rape per 100,000 inhabitants in the period from 2012 to 2016 as 30.32 for adult women and 51.4 for girls under 13 (IPEA \& FBSP, 2017). Ramos (2017) reports that in a survey conducted in 103 cities in Brazil, 30 percent of the women interviewed declared having suffered some kind of personal and direct violence only in the last year and more than 66 percent of all respondents admitted having witnessed some scene of violence against women in their neighborhood last year.

Violence against the LGBTI $^{1}$ population is also a matter of concern since it has been increasing in recent years. According to a survey conducted by the Gay Group of Bahia (Valente, 2018), in 2017 there was an increase of 30 percent in murders of LGBTI people compared to 2016.

According to Silva, Gregoli, and Ribeiro (2017) the rate of violence against women in public places is also high and is inversely proportional to their age. In general, 40 percent of women over the age 16 have experienced some form of aggression in public places. However, among younger women, the aggressions were even more frequent. More than 60 percent of women between the ages of 16 and 24 reported having suffered this type of violence in the last 12 months. Whereas among those aged 25 to 34,50 percent have suffered some type of violence perpetrated in public places during the same period.

Aggressions and offenses against women in public environments, especially in components of the urban transportation system, spaces shared by a large number of people, illustrate well the cultural and social tolerance of violence against women. Regretfully, this reality is not restricted to Brazil. Different 
forms of violence against women and girls in public places occur in different parts of the world, reducing women's freedom of movement (Ceccato \& Paz, 2017; Gekoski et al., 2015; Madan \& Nalla, 2016; Newton, Partridge \& Gill, 2014). Ceccato (2017) analyzes research conducted in different countries, all presenting similar characteristics regarding sexual harassment in public transportation. Sexual violence is concentrated in the busiest central stations and occurs during peak hours in the morning and in the afternoon (Ceccato \& Paz, 2017), when a large number of people transit through these spaces.

Statistical data from the Public Security Department of the São Paulo State show a 30 percent increase in sexual offenses from December 2017 to December 2018 in the state of São Paulo, mainly in the countryside of the state (SSP-SP, 2019). A survey conducted in the city of São Paulo by Datafolha (Datafolha, 2014) shows 63 percent of women have been victims of sexual harassment, with young women being among the main victims. In this survey, among the places cited by the victims, public transportation leads with 35 percent. In the case of women, 49 percent reported having suffered sexual harassment on public transportation, and 38 percent of them suffered physical harassment (Datafolha, 2014).

\section{Hypotheses of the study}

Based on a preliminary analysis carried out for the Crime and Fear in Public Places Conference held in October 2018 at the Royal Institute of Technology (KTH) in Stockholm, Sweden, it was reported that the LGBTI student group had a higher relative index of sexual victimization. However, based on the literature and a more critical look at statistics, in accordance with the perception and observations of the authors, the following two hypotheses were suggested.

First, the most vulnerable group is women. The high degree of victimization of women in Brazil, and in many other countries, is notorious and results from a cultural heritage of devaluation of women due to the strong gender bias caused by the perpetuation of machismo. Second, in the case of LGBTI women, this prejudice is potentiated by homophobia, producing a higher incidence of aggression against individuals in this group.

It is also expected that, among college students, the proportion of female LGBTI is greater than the proportion of male LGBTI. This fact, of course, leads to a higher rate of victimization of the entire LGBTI student group.

\subsection{Framing the case study}

\section{Rio Claro, São Paulo: youth safety among university studies}

Rio Claro is a medium sized city, with an area of $500 \mathrm{~km}^{2}$, a population of about 205,000 inhabitant and a demographic density of about 374 inhabitants $/ \mathrm{km}^{2}$ located in the eastern region of São Paulo State (a southeast region of Brazil), $173 \mathrm{~km}$ away from its capital (São Paulo city) by highway. The region of Rio 
Claro is characterized by a massive presence of diversified and specialized industrial centers.

However, official statistics of the São Paulo State Department of Public Security present high criminality rates for Rio Claro. According to this source (SSP-SP, 2018), the average homicide rate of Rio Claro in the period of 2013-2017 is almost twice the average rate of the state, or of the city of São Paulo, the largest metropole of the country, in the same period.

In Rio Claro there are no metro, train or trolley services. The only public mass transit service is the bus system, which includes 58 buses distributed in 27 routes that serve 600 bus stops from $5 \mathrm{a} . \mathrm{m}$. to midnight. The bus service is characterized by a poor distribution of lines, low frequency, and bus overcrowding during rush hours. Therefore, many residents give up riding the bus and use other transport modes such as bicycles, motorcycles and ride-hailing services.

The survey used in this study was applied to the students of São Paulo State University (UNESP) at Rio Claro Campus. UNESP is a multi-campus university, comprising 34 units in 24 cities in the state of São Paulo. At the Rio Claro Campus there are 3,253 students, from which 48.7 percent are female and 51.3 percent are male.

\section{Data and methods}

In this study, a survey was conducted using a structured questionnaire, both online and paper-and-pencil methods. The online survey was applied via Google Form and the paper-and-pencil survey was applied by distribution of the questionnaires to the students in different places on Campus, where the participants themselves completed the questionnaire.

A total of 569 students' responses were collected from May to August 2018. From the total number of questionnaires applied on paper about 19 percent of the responses were discarded due to lack of answers to some mandatory questions. Thus, the sample of this study constitutes 462 validated questionnaires. Subsequently, the answers collected on paper were typed by the CEAPLA team using the same online survey already created on the Google Form platform. The profile of the participants is detailed in section 9.4 of this chapter (Figure 9.1).

The survey consists of 38 questions that address participants' demographics, their sense of transit safety and their victimization in public transportation, as well as its consequences in their urban mobility. Furthermore, participants' views on unsafe places and their suggestions for improving the safety of those places were collected.

These questions address the following issues regarding transit safety: the fear of using public transportation, the main impediments to using the bus service, the impact of fear on students' behavior in transit, their victimization by sexual assault or harassment, and participants' suggestions for intervention to improve the safety of public transportation.

Since this chapter focuses on the perception of transit safety among university students and, more specifically, their victimization regarding sexual assault 


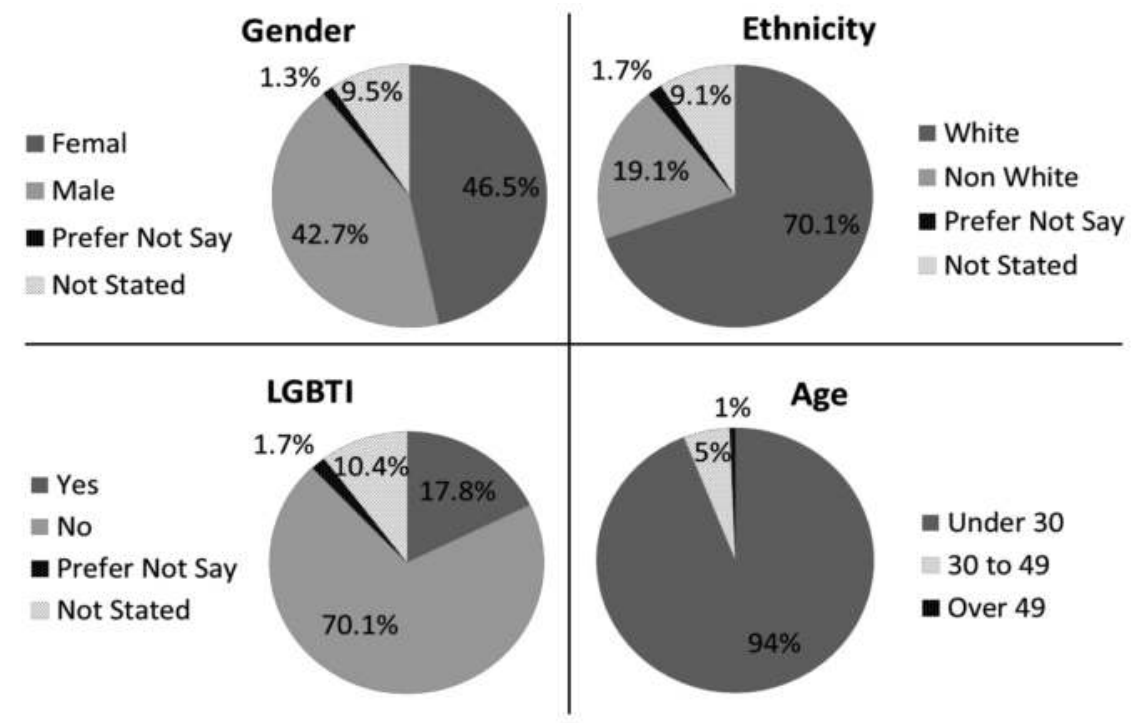

Figure 9.1 Profile of survey participants.

or harassment, the analysis considered predominantly ten questions among all questions in the survey and correlated them with individual aspects of respondents such as gender, ethnicity and their identification as LGBTI, in an attempt to address the intersectionality of the perception of transit safety among students.

The analyses were performed using the corresponding Google Forms data sheet and the features of the Microsoft Excel software. The cross tabulation method was used to understand and explain the correlation between different variables. The concepts of Relative Risk and Odds Ratio were used in some analyses to evaluate the results.

\subsection{Results and discussions}

There is a balance between female and male students ( 46.5 percent female and 42.7 percent male) among participants' responses. Figure 9.1 shows the distribution of the respondents in terms of gender, ethnicity and age. Students who claimed to belong to the LGBTI group represent 17.8 percent of the total number of participants. Considering the ethnicity of participants, 70.1 percent declared themselves as white, while 19.1 percent declared themselves belonging to non-white ethnicities. The vast majority of participants (94 percent) are less than 29 years of age.

In this study, only 19 percent of the students identified themselves as belonging to non-white ethnicity relative to the national distribution of about 


\section{Farid Nourani et al.}

47 percent (IBGE, 2010), and this portion of the population predominantly do not belong to the classes with high purchasing power, made up of a majority of white people. In general, the students at public universities in Brazil, especially in the case of universities who occupy a high position in the ranking of the best universities of the country, such as UNESP, come from a privileged strata of society. Therefore, this sample does not reflect the actual composition of Brazilian society.

\section{Nature of victimization/perceived safety}

In order to assess students' safety sense in public transportation, four specific questions were added to the survey. Figures 9.2 and 9.3 show a summary analysis of students' responses to these questions. Approximately 58 percent of the students reported they feel safe when traveling during daytime (Figure 9.2). Nevertheless, this percentage decreases to 22.7 percent among those who traveled at night-time (Figure 9.3).

The problem is even greater when analyzing the sense of safety during waiting time at bus stops. During daytime, on average only 32.2 percent of students feel safe while waiting at the bus stop. The most critical index (16.8 percent) belongs to the women's group. In a more in-depth analysis, even during daytime, worse indices stand out: more than 85.0 percent of non-white women and 88.0 percent of LGBTI women report feeling unsafe while waiting at the bus stop, whereas in respect to non-white LGBTI women the rate reaches 100.0 percent. This sense of insecurity also prevails in 83.3 percent of nonwhite LGBTI men when waiting for buses during daytime.

After dark, however, the average number of students who feel safe while waiting at the bus stop drops dramatically to only 6.4 percent. Waiting at the

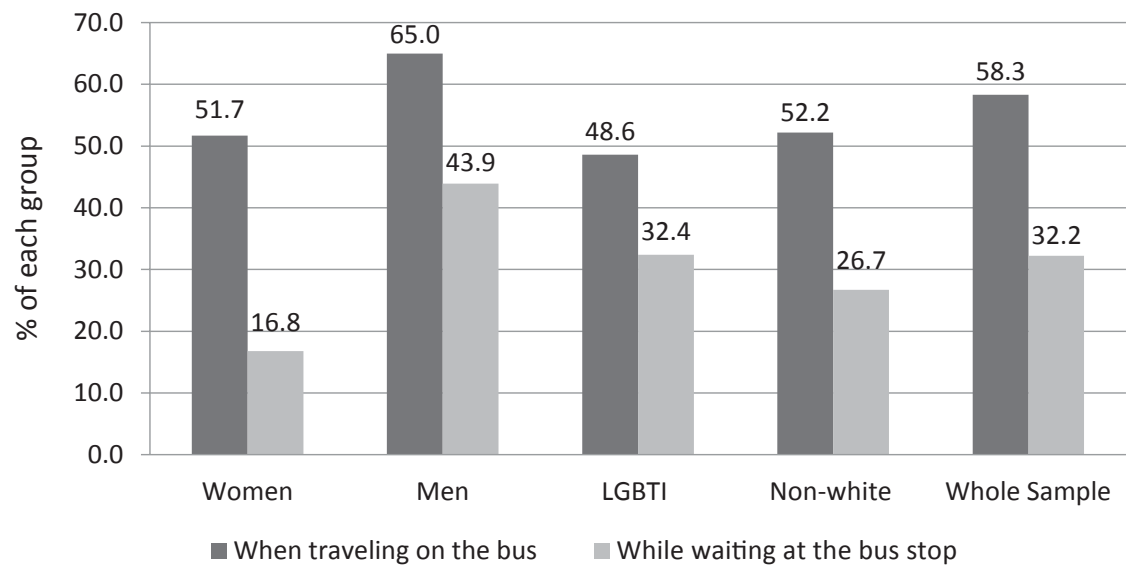

Figure 9.2 Students' perception of public transportation safety during daytime. 


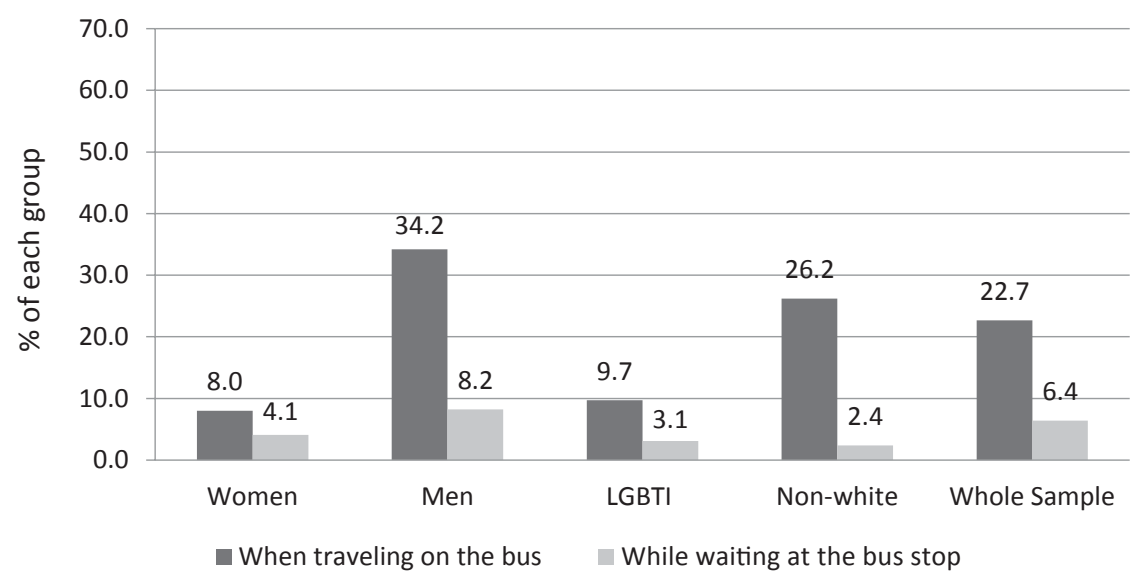

Figure 9.3 Students' perception of public transportation safety after dark.

bus stop after dark becomes a great problem for all groups of students who answered the question regarding this item of analysis, ranging from a minimum of 91.8 percent in the case of the male group to 97.6 percent in the group of non-white students (Figure 9.3).

Travel safety on the bus also requires attention. Among students participating in the survey, only 8 percent of women and 9.7 percent of LGBTI group feel safe traveling at night on public transportation. The indices of other group are also very low (Figure 9.3).

Figure 9.4 shows the main impediments for students to use the bus service more frequently. As the graphs in this figure show, on average 18.5 percent of women said that reasons related to some form of victimization prevent them from using the bus more frequently. The fear of being a victim of a crime on the way to the bus stop and/or waiting at the bus stop is indicated by all groups as the greatest impediment to increasing their frequency of using public transportation. In fact, the fear of gender-based violence in public transport proportionally affects more women than any other social group, hindering their freedom of movement in city spaces.

The survey also evaluates students' perceptions about the most significant problems (among a list of 14 options) while using bus transportation, both on the bus and at the bus stop. Analysis of responses indicates the following ranking of most cited problems: poorly guarded/empty most of the day (for 95.5 percent of respondents), poorly illuminated (for 93.3 percent of respondents), pickpocketing (for 80.9 percent of respondents), robbery (for 78.1 percent of respondents), isolated (for 74.7 percent of respondents), vandalism/litter (for 59.0 percent of respondents) and sexual harassment (for 51.7 percent of respondents).

Four of these options were selected for further analysis because of their relevance to influencing sexual victimization: poorly guarded/empty most of the day, 


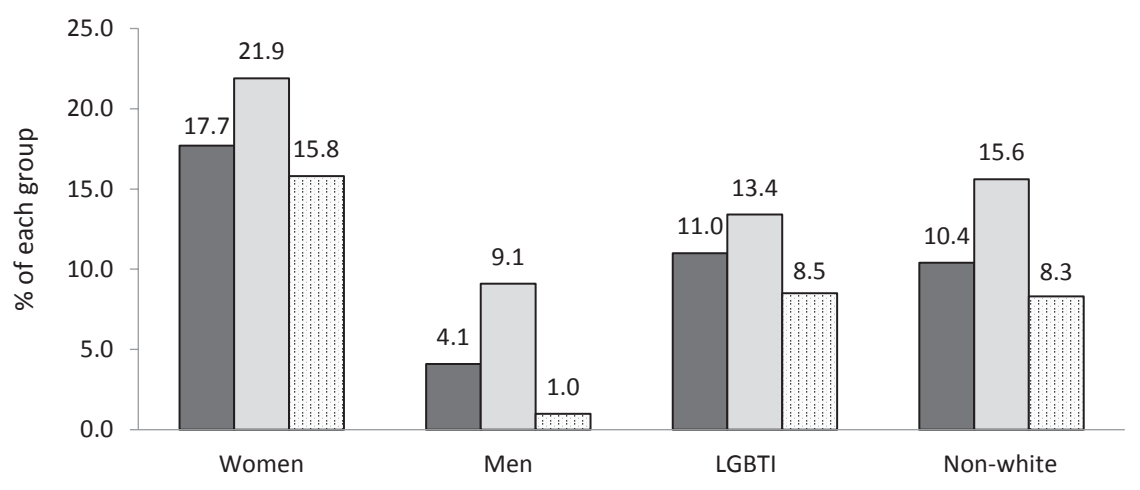

$\square$ Fear of being a victim of a crime, abuse or harassment while use the bus

$\square$ Fear of being a victim of a crime, abuse or harassment while walking and/or waiting for buses

$\square$ Fear of sexual harassment while use the bus

Figure 9.4 Main impediments for students to use bus service more frequently.

poorly illuminated, isolated and sexual harassment. Except in the case of sexual harassment, for the three other problems the students' concerns about bus stop conditions are approximately six times higher than about conditions of the trips on the bus, regardless of the group they belong to (Table 9.1). There is a slight variation in the case of non-white people, where their concerns about the bus stop conditions are about nine to 12 times higher than the concerns about the conditions of the trips on the bus.

However, in the case of sexual harassment, there is no difference between the students' concerns about bus or bus stop conditions (bold numbers in the Table 9.1). Nevertheless, there is a considerable difference between groups of female and male students. Women's concerns about transit problems are more than double that of men, both on the bus and at the bus stops. The reason for this can be the overcrowding of the bus, a condition that favors the occurrence of sexual harassment.

There are also three explicit questions in the survey that make it possible to obtain the participants' victimization data regarding three types of crime:

(a) sexual assault or harassment;

(b) some other serious crimes (aggravated assault, robbery, rape);

(c) theft/pickpocket, jewelry snatching or robbery.

Table 9.2 shows the intersectionality of the students' responses to these three types of crime analyzed. The first row of each crime type, in this table, shows the percentage of students victimized regarding that type of crime, in the second column, followed by the distribution of victims according to gender, 
Table 9.1 Intersectionality of students' concerns about public transportation

\begin{tabular}{|c|c|c|c|c|c|c|c|}
\hline \multirow[t]{3}{*}{ Type of concern } & \multirow{3}{*}{$\begin{array}{l}\text { \% Total } \\
\text { Resp. }\end{array}$} & \multicolumn{6}{|c|}{$\%$ of each group } \\
\hline & & \multicolumn{2}{|c|}{ Gender } & \multicolumn{2}{|c|}{$L G B T I$} & \multicolumn{2}{|c|}{ Ethnicity } \\
\hline & & $F$ & $M$ & $\Upsilon$ & $N$ & $W$ & $N W$ \\
\hline $\begin{array}{l}\text { Poorly guarded/ } \\
\text { empty most } \\
\text { of the day }\end{array}$ & 95.5 & 100 & 82.1 & 39.0 & 38.0 & 38.6 & 37.5 \\
\hline on the bus & 16.9 & 24.0 & 10.5 & 4.9 & 7.1 & 7.4 & 3.1 \\
\hline at the bus stop & 93.8 & 96.2 & 82.1 & 37.8 & 37.3 & 37.7 & 37.5 \\
\hline $\begin{array}{l}\text { Poorly } \\
\quad \text { illuminated }\end{array}$ & 93.3 & 96.2 & 83.2 & 37.8 & 37.3 & 38.0 & 37.5 \\
\hline on the bus & 15.7 & 17.7 & 12.6 & 7.3 & 6.2 & 6.8 & 4.2 \\
\hline at the bus stop & 92.7 & 94.9 & 83.2 & 37.8 & 37.3 & 37.7 & 37.5 \\
\hline Isolated & 74.7 & 84.8 & 59.0 & 30.5 & 29.9 & 31.8 & 31.2 \\
\hline on the bus & 9.6 & 10.1 & 8.4 & 2.4 & 4.6 & 4.5 & 3.1 \\
\hline at the bus stop & 72.5 & 83.5 & 55.8 & 30.5 & 28.7 & 29.0 & 31.2 \\
\hline Sexual harassment & 51.7 & 70.9 & 31.6 & 54.5 & 46.8 & 49.6 & 56.8 \\
\hline on the bus & 43.8 & 62.0 & 27.3 & 48.5 & 40.3 & 44.4 & 43.2 \\
\hline at the bus stop & 46.6 & 62.0 & 29.5 & 48.5 & 42.5 & 45.2 & 48.7 \\
\hline
\end{tabular}

Note

Percentage calculated in relation to the total number of individuals in each group who answered the question.

Table 9.2 Intersectionality of victims regarding three types of crime analyzed

\begin{tabular}{|c|c|c|c|c|c|c|c|}
\hline \multirow[t]{3}{*}{ Type of crime } & \multirow{3}{*}{$\begin{array}{l}\% \text { students } \\
\text { victimized }\end{array}$} & \multicolumn{6}{|c|}{$\%$ of victims } \\
\hline & & \multicolumn{2}{|c|}{ Gender } & \multicolumn{2}{|l|}{$L G B T I$} & \multicolumn{2}{|c|}{ Ethnicity } \\
\hline & & $F$ & $M$ & $\Upsilon$ & $N$ & $W$ & $N W$ \\
\hline $\begin{array}{l}\text { Sexual assault or } \\
\text { harassment }\end{array}$ & 17.3 & 71.3 & 18.8 & 32.5 & 57.5 & 66.3 & 23.8 \\
\hline $\begin{array}{l}\% \text { of victims in the } \\
\text { group itself }\end{array}$ & - & $26.5^{*}$ & 7.6 & $31.7^{*}$ & 14.2 & 16.4 & $21.6^{*}$ \\
\hline $\begin{array}{l}\text { Other serious crime } \\
\text { (aggravated assault, } \\
\text { robbery, rape) }\end{array}$ & 9.3 & 51.2 & 39.5 & 21.0 & 72.1 & 72.1 & 21.0 \\
\hline $\begin{array}{l}\% \text { of victims in the } \\
\text { group itself }\end{array}$ & - & 10.2 & 8.2 & 11.0 & 9.6 & 9.6 & 10.0 \\
\hline Theft/pickpocket & 6.0 & 46.4 & 46.4 & 28.6 & 67.9 & 78.6 & 14.3 \\
\hline $\begin{array}{l}\% \text { of victims in the } \\
\text { group itself }\end{array}$ & - & 6.0 & 6.6 & 9.8 & 5.9 & 6.8 & 4.4 \\
\hline
\end{tabular}

Note

* Percentage values of victims in the most victimized groups. 
belonging to the LGBTI group, and ethnicity of the students. The second row of each crime type shows the percentages of victims among the total number of respondents in each subgroup. For example, in the case of sexual assault or harassment, the total number of victims represents 17.3 percent of the participant students, whereas female victims represent 26.5 percent of all women participants and male victims scored 7.6 percent of all male participant students.

Of these three types of victimization (Table 9.2) sexual assault or harassment occurs more frequently than the other two, with a rate of 17.3 percent among all participants versus 9.3 percent and 6.0 percent of the other two types of crime respectively.

In general, the highest percentage among the victims is women, especially in the case of sexual assault or harassment ( 71.3 percent) considering the fairly balanced distribution of genders in the sample (Figure 9.1). This is 13 percent higher than the rate of sexual victimization of women in the city of São Paulo (Datafolha, 2014), the biggest city of the country.

Another important finding of this study is the high rate of under-reported crime. In the case of sexual harassment victims, the vast majority of 80 percent did not report the criminal offenses. In the case of other serious crimes, 54.5 percent also did not officially report the facts. Between students who were victims of robbery on public transport, almost 60 percent did not seek the authorities to denounce the crime they suffered.

This non-reporting can be attributed to the socio-cultural environment of the country, where there is a high rate of urban violence, together with the skepticism of the population in relation to the police and the judicial system (Dantas, 2015).

Table 9.3 shows the distribution of victims in the case of sexual assault or harassment. When analyzing the data in this table it is observed that the most vulnerable groups are LGBTI with 31.7 percent of victims (120 percent more than non LGBTI), women with 26.5 percent of victims ( 250 percent more than men) and non-whites with 21.6 percent of victims (30 percent more than whites). This discrepancy is not observed in relation to the other two types of crimes.

Comparing victimization rates between women and men in each group reveals that the victimization rate of women is considerably higher than that of men in all groups. Thus, considering the percentages of victims within each subgroup, a new classification of vulnerable groups stands out: women LGBTI (80.8 percent), non-white women (79.0 percent), white women (77.4 percent) and non-LGBTI women (73.9 percent).

It is worth noting the high ratios of female victims to male victims (Ratio 1) in each group, which, in descending order, are 5.25 in the LGBTI group, 4.1 in the white group, 3.8 in the total sample, 3.75 in the non-white group, and 3.1 in the non-LGBTI group. These ratios confirm that, in this study, women represent the most victimized group, taking into account the fact that the vast majority of victims are female (71.3 percent) and that the ratio of the female 


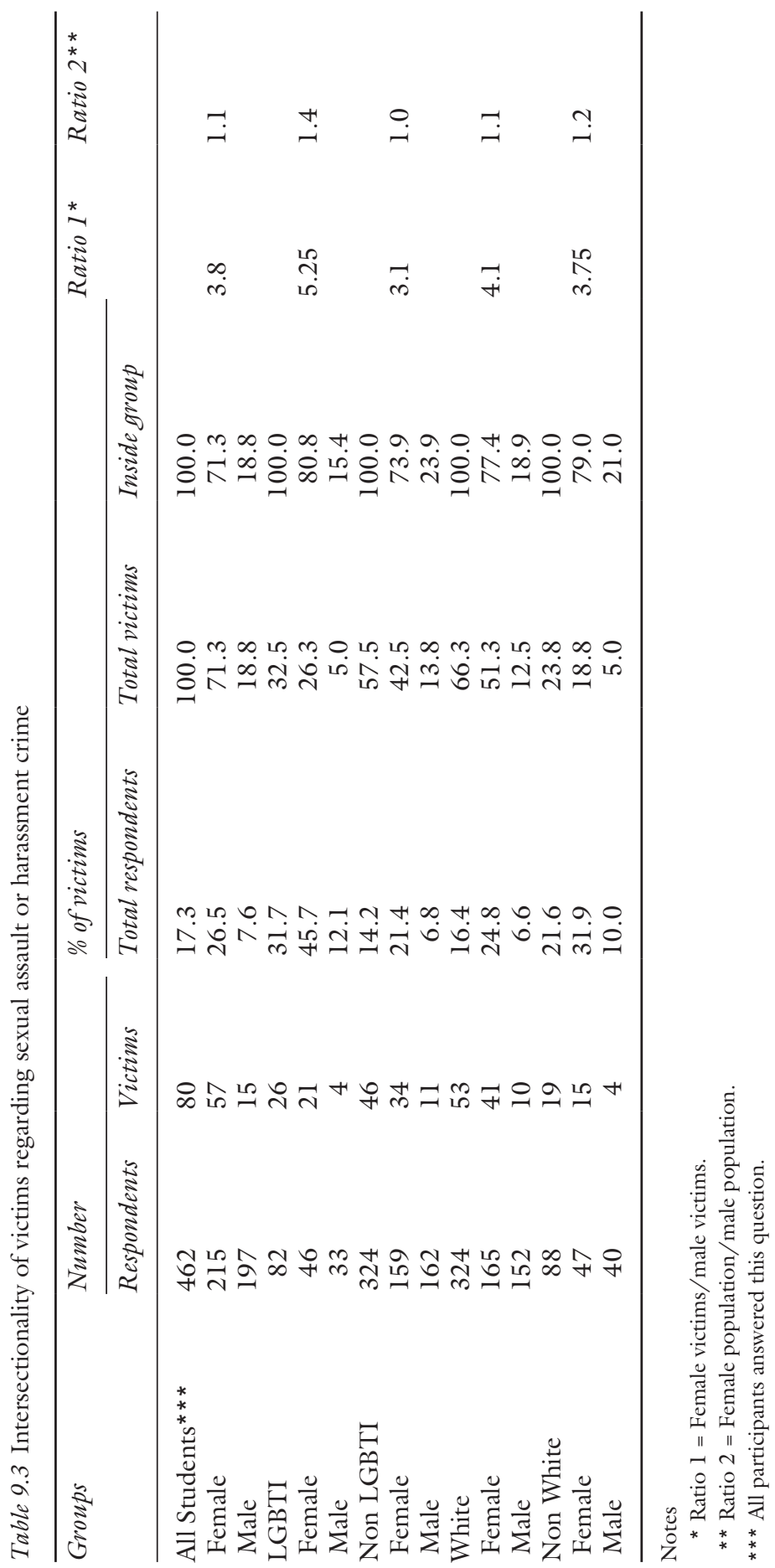


population to the male population (Ratio 2) is always around 1.1, with the exception of the LGBTI group, where it is 1.4 but this group presents the highest proportion of female victims (5.25 times more than male).

Although the LGBTI group had a higher relative victimization rate than women (31.7 percent vs. 26.5 percent-about 20.0 percent higher), a more indepth analysis reveals another finding. Based on the data in Table 9.3, the ratio of LGBTI individuals to non-LGBTI individuals is 0.25 while the ratio of LGBTI victims to non-LGBTI victims is 0.56 . This means that the victimization of the LGBTI group is 2.2 times greater than the non-LGBTI group, while the same analysis in the case of women and men in the whole sample results in a value of $3.5(3.8 / 1.1)$, which is almost 60 percent higher.

\section{The impact of poor safety on mobility}

About 42 percent of participants answered the question about the need to take some precautions when using the bus. Figure 9.5 shows the percentages of participants in each group who feel the need to take some precautions or not. As this figure shows, more than 80 percent of all groups, except men, expressed the need to take some precautions.

Overall, 76.4 percent of the students who answered this question say they take some precautions when using public transportation. In other words, more than three-quarters of the students are forced to change their habits in an attempt to avoid becoming another victim in the public transportation system. This is a serious concern for the youth. This means that three in four students are forced to think constantly about strategies to escape the attacks of criminals.

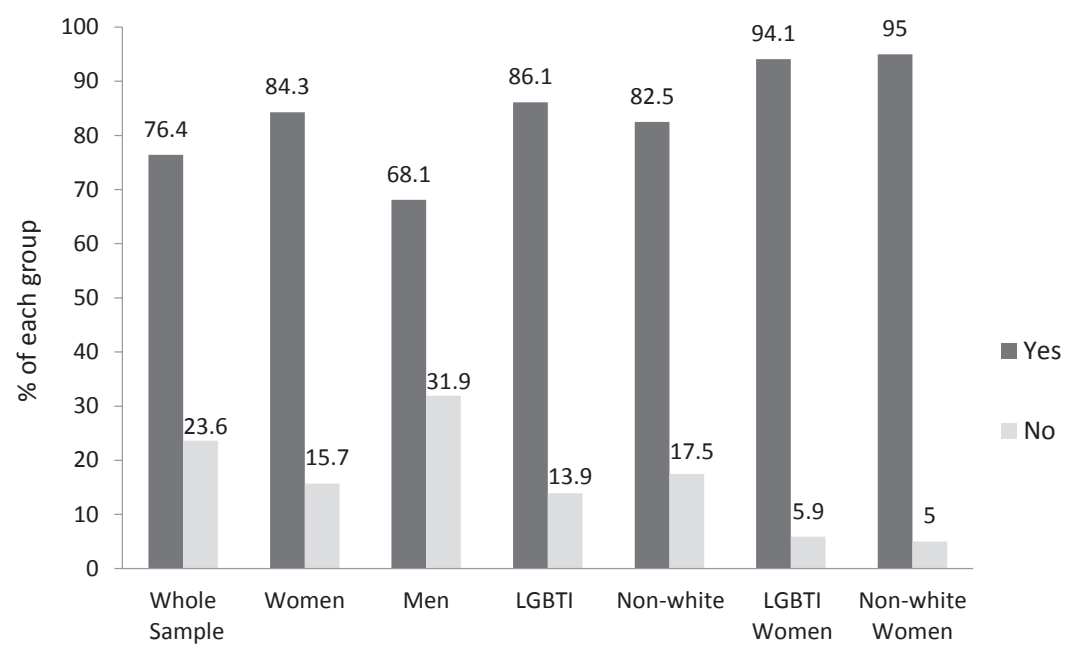

Figure 9.5 Percentages of students in each group who take some precautions in public transportation. 
In this study, the most mentioned precautions by students are: waiting for bus only at well-lit places (53.3 percent of respondents), avoiding particular bus stops (52.0 percent of respondents), travelling only during daytime (41.5 percent of respondents), not wearing jewelry (40.1 percent of respondents), avoiding carrying purses or wallets (38.8 percent of respondents), waiting for transit only if other people are around (38.2 percent of respondents) and dressing in an appropriate way (34.2 percent of respondents). It is important to note that the two most mentioned precautions refer to factors that involve some failures of the public transportation service infrastructure.

Analysis on the precautions taken by students from different groups reveal no significant differences. For women, LGBTI and non-white groups, the first two precautions mentioned above are the most important. In the case of men, however, the first precaution taken is to avoid particular bus stops and the second is to avoid carrying bags or wallets.

\section{How to improve safety on urban transit}

As previously reported, this study highlights some of the major problems that lead to a reduced sense of safety, especially at night, both at bus stops or on the way to the bus stops, in public transportation users, as pointed out by students. This illustrates some simple failures of the bus transportation infrastructure and is in line with participants' views on measures that could make public transportation safer.

More than 41 percent of the participants expressed their opinion voluntarily on what could make public transport safer. In the opinion of these participants, the five measures that best contribute to improving safety in public bus transportation are: better lighting at bus stops (77.1 percent), police patrols at bus stops (58.3 percent), cameras (CCTV) on the bus (50.0 percent), cameras (CCTV) at bus stops (48.4 percent), and digital timetables at bus stops (46.9 percent). All the different groups of students share the same opinion about these five measures, with a small change in their rank. However, all of them, without exception, indicated the improvement of lighting at bus stops as the best way to improve safety in public transportation.

The sense of safety in public transportation may be improved through a moderate investment of public funds with private sector partnerships, since, most suggested improvements, in line with the most cited problems, represent simple actions to implement or some minor adjustments to public transport policies which normally do not require a significant investment.

It is believed that offenses of less aggressive potential can be more easily reduced by raising awareness of public transportation users, as well as the population at large. Simple educational campaigns, focusing on these less critical issues, can contribute to the reduction of offenses that greatly afflict users and are among the most reported by the students. Aiming at greater effectiveness, these campaigns would need to be done on a large scale and carried out in schools to reach children and adolescents. In addition, other age groups of the 
population should also be reached simultaneously by campaigns in traditional communication media such as newspaper, television and radio, as well as the internet and directly on buses and bus stops.

\subsection{Conclusions and recommendations}

Two hypotheses motivated this study about students' perceptions regarding safety in urban public transportation, with a focus on sexual assault victimization. Both hypotheses were confirmed by the results of the research obtained from data analysis considering the intersectionality of the results. In the case of the first hypothesis, the results show that women represent the largest victim group of any type of crime analyzed, representing at least 71.3 percent of all victims in the case of sexual assault or harassment, which corroborates statistics on the high level of victimization of women in Brazil and in many other countries.

A more detailed analysis of some results provided confirmation of the second hypothesis. Although the LGBTI group had the highest relative percentage of victims ( 31.7 percent), it was possible to observe that the number of female LGBTI victims is 5.25 times greater than male LGBTI victims, while the LGBTI female population in this study is only 40 percent larger than male LGBTI. Thus, one of the conclusions of this study is that the most victimized group is women and among them, the most vulnerable are LGBTI women.

Other astonishing observations stand out from the analyses of the survey results. One is that the percentage of students who are in fear when using the bus service is very high, reaching 94.6 percent at night and 69.4 percent in the daytime. Analysis also showed that at least 17.3 percent of students reported experiencing one of the three types of violence addressed in the survey, where sexual assault or harassment was most frequently mentioned (71.3 percent).

Moreover, 75 percent of all students (three in four) are forced to think constantly about strategies to escape criminal attacks. Would this not be a life full of fear? What consequences does this fear bring to the personal life and professional performance of these young people? Attempting to answer these questions may set up an excellent choice for future research. Another interesting potential research project would be to apply this survey to the generic group of young people in Rio Claro city in order to compare their victimization with that of the UNESP students.

The fear of the vast majority of students in using the public transportation system (about 80.0 percent) is another striking observation. This may be indicative of the student's low frequency of bus use. Problems in the urban transportation system infrastructure fuel this fear, since during daytime about 70 percent of students are afraid while waiting at the bus stop and at night this fear can affect more than 97.0 percent of students. Improvements in street and bus stop lighting, and increased local policing could improve students' sense of safety and thereby increase the frequency of use of public transportation.

Another surprising finding is the high under-reporting rate among the participants of this study, which could be considered as citizens' skepticism towards 
the Brazilian legal system and the ineffectiveness of law enforcement. These facts represent one of the weaknesses of criminal justice in Brazil. Under-reporting negatively affects the planning of preventive actions by public security institutions, as it prevents accurate mapping of crime occurrences.

To reduce the likelihood of occurrences of abuse and violence against women in Rio Claro's public transport system, three lines of action seem to be promising and effective. The first concerns research and more detailed studies of the identified problems. The second line of action involves improvements to the public transport system infrastructure and the third corresponds to educational actions and programs.

In terms of research, what can contribute significantly is identifying the most vulnerable bus stops in the city and the most critical time period of these stops, both during the daytime and after dark. Another necessary investigation is to identify, considering Rio Claro's socio-cultural reality, the appropriate approach for an educational program or campaign capable of changing men's view of women and encouraging women to report abuse and violence.

Regarding the improvement of the public transport system infrastructure in Rio Claro, what can bring more appreciable benefits, at least increase the level of users' safety perception, would be the implementation of the following measures: install good lighting at bus stops and surrounding areas; relocate some problematic bus stops to safer places nearby; install CCTV cameras with face recognition software, both on the buses and at bus stops; install digital timetables at bus stops and install geolocation and tracking systems on buses to feed digital timetables; install digital displays on buses to run sexual harassment prevention education campaigns and real-time messaging.

In the educational sphere there are two promising fronts of action: create regular and massive educational anti-harassment campaigns based on the best detected approaches by previous researches and create an educational program for different age groups at schools to change the view of individuals from childhood on equality of gender and reduce the predominant machismo in Brazilian society by modifying men's view of women.

\section{Note}

1 LGBTI is a gender status and stands for Lesbian, Gay, Bisexual, Transgender/Transsexual and Intersexed.

\section{References}

Amaral, N. A., Amaral, C. A., \& Amaral, T. L. M. (2013). Mortalidade feminina e anos de vida perdidos por homicídio/agressão em capital brasileira após promulgação da Lei Maria da Penha. Texto e Contexto-Enfermagem, 22, 980-988.

Bandeira, L. M. (2014). Violência de gênero: a construção de um campo teórico e de investigação. Sociedade e Estado, 29, 449-469. www.scielo.br/pdf/se/v29n2/08.pdf (accessed 20 February 2020).

Benedicto, E. A. F. (2017). A mulher e o direito a cidade: Assédio Sexual X Cantada. SXXIX Simpósio Nacional de História, Universidade de Brasília, Brasília, 24-28. 
www.snh2017.anpuh.org/resources/anais/54/1491153147_ARQUIVO_ednabenedicto. pdf (accessed 20 February 2020).

Brasil (2006). Presidência da República. Lei 11.340, de 7 de agosto de 2006. www.planalto. gov.br/ccivil_03/_ato2004-2006/2006/lei/111340.htm (accessed 20 February 2020).

Brilhante, A. V. M., Moreira, G. A. R., Vieira, L. J. E. S., \& Catrib, A. M. F. (2016). Um estudo bibliométrico sobre a violência de gênero. Saúde Soc. São Paulo, 25, 703-715. Retrieved from www.scielo.br/pdf/sausoc/v25n3/1984-0470-sausoc-2503-00703.pdf (accessed 20 February 2020).

Carrara, S., \& Heilborn, M. L. (2006). Gênero e diversidade na escola: formação de profissionais de educação nas temáticas de gênero, orientação sexual e relações étnico-raciais. Rio de Janeiro: Cepesc; Brasília, DF: SPM.

Carvalho, J. R., \& Oliveira, V. H. (2016). Prevalência da Violência Doméstica e o Impacto nas Novas Gerações. Relatório Executivo I-Primeira Onda. Universidade Federal do Ceará. www.compromissoeatitude.org.br/wp-content/uploads/2016/12/PesquisaNordeste_Sumario-Executivo.pdf (accessed 20 February 2020).

Ceccato, V. (2017). Women's transit safety: making connections and defining future directions in research and practice. Crime Prevention and Community Safety, 19, 276-287.

Ceccato, V., \& Paz, Y. (2017). Crime in São Paulo's metro system: sexual crimes against women. Crime Prevention and Community Safety, 19, 211-226.

Dantas, A. C. (2015). Mediação policial, segurança pública e segurança humana: Uma abordagem reflexiva [Police mediation, public security and human security: a reflexive approach]. Direito, Estado e Sociedade, 46, 72-100.

Datafolha (2014). Termômetro Paulistano-Assédio Sexual Contra as Mulheres. http:// media.folha.uol.com.br/datafolha/2014/04/14/termometro-paulistano-assedio-sexual.pdf (accessed 20 February 2020).

Drezett, J. (2003). Violência sexual contra a mulher e impacto sobre a saúde sexual e reprodutiva. Revista de Psicologia da UNESP, 2, 36-50.

Feliciano, R. (2016). "Avisa quando chegar": O Assédio que paralisa as mulheres. www. metropoles.com/materias-especiais/combate-ao-assedio-no-transporte-publicoempodera-as-mulheres (accessed 20 February 2020).

Gekoski, A., Gray, J. M., Horvath, M. A. H., Edwards, S., Emirali, A., and Adler, J. R. (2015). 'What Works' in Reducing Sexual Harassment and Sexual Offences on Public Transport Nationally and Internationally: A Rapid Evidence Assessment. London: British Transport Police and Department for Transport.

IBGE (2010). Censo Demográfico 2010: Características da população e dos domicíliosTabelas de Resultados. https://ww2.ibge.gov.br/english/estatistica/populacao/censo2010/ caracteristicas_da_populacao/tabelas_pdf/tab3.pdf (accessed 20 February 2020).

IPEA \& FBSP (2017). Atlas da violência 2017 [Atlas of Violence in 2017]. Brasília: IPEA-Instituto de Pesquisa Econômica e Aplicada and FBSP-Fórum Brasileiro de Segurança Pública. www.ipea.gov.br/atlasviolencia/arquivos/downloads/8891-1250170602atlasdaviolencia2017.pdf (accessed 20 February 2020).

IPEA \& FBSP (2018). Atlas da violência 2018 [Atlas of Violence in 2018]. Brasília: IPEA-Instituto de Pesquisa Econômica e Aplicada and FBSP-Fórum Brasileiro de Segurança Pública. www.ipea.gov.br/atlasviolencia/arquivos/downloads/86267457-2852-180604atlasdaviolencia2018.pdf (accessed 20 February 2020).

Loukaitou-Sideris, A. (2014). Fear and safety in transit environments from the women's perspective. Security journal, 27, 242-256.

Madan, M., \& Nalla, M. K. (2016). Sexual harassment in public spaces: examining gender differences in perceived seriousness and victimization. International Criminal Justice Review, 26, 80-97. 
Newton, A. D., Partridge, H., \& Gill, A. (2014). Above and below: measuring crime risk in and around underground mass transit systems. Crime Science, 3, 1.

Ramos, S. (2017). Violência, violências: mais agredidas ou mais atentas? In Visível e Invisível: A Vitimização de Mulheres no Brasil. Fórum Brasileira de Segurança Pública. www. forumseguranca.org.br/wp-content/uploads/2017/03/relatorio-pesquisa-vs4.pdf (accessed 20 February 2020).

Silva, A. R. N. (2017). Assédio e violência no transporte público e o vagão feminino: Análise da política pública de segurança sob uma perspectiva de gênero. TCC-Especialização em Gênero e Direito da Escola da Magistratura do Estado do Rio de Janeiro. www.emerj.tjrj.jus.br/revistas/genero_e_direito/edicoes/1_2017/pdf/AneliseRoquedo NascimentoSilva.pdf (accessed 20 February 2020).

Silva, R. V., Gregoli, R., \& Ribeiro, H. M (2017). Resultado de pesquisa expõe tolerância social à violência contra as mulheres em espaços públicos. In Visível e Invisível: A Vitimização de Mulheres no Brasil. Fórum Brasileira de Segurança Pública. www.forumseguranca. org.br/wp-content/uploads/2017/03/relatorio-pesquisa-vs4.pdf (accessed 20 February 2020$)$.

Silva, L. E. L., \& Oliveira, M. L. C. (2015). Violência contra a mulher: revisão sistemática da produção científica nacional no período de 2009 a 2013. Ciência \& Saúde Coletiva, 20, 3523-3532.

Sokoloff, N. J., \& Dupont, I. (2005). Domestic violence at the intersections of race, class, and gender: challenges and contributions to understanding violence against marginalized women in diverse communities. Violence against Women, 11, 38-64.

SSP-SP (2018). Dados Estatísticos do Estado de São Paulo. www.ssp.sp.gov.br/estatistica/ pesquisa.aspx (accessed 20 February 2020).

SSP-SP (2019). Violência contra as Mulheres—ocorrêncais registradas. www.ssp.sp.gov. br/Estatistica/ViolenciaMulher.aspx\#/sideEstatistica

Stringer, S. M. (2007). Hidden in Plain Sight: Sexual Harassment and Assault in the New York City Subway System. New York: Manhattan Borough President Office.

Think Olga NGO (2013). Chega de Fiu Fin—Resultado da Pesquisa. https://thinkolga. com/2013/09/09/chega-de-fiu-fiu-resultado-da-pesquisa/ (accessed 20 February 2020).

Valente, J. (2018). Levantamento aponta recorde de mortes por homofobia no Brasil em 2017. Agência Brasil. http://agenciabrasil.ebc.com.br/direitos-humanos/noticia/ 2018-01/levantamento-aponta-recorde-de-mortes-por-homofobia-no-brasil-em (accessed 20 February 2020).

Vanier, C., \& d'Arbois de Jubainville, H. (2017). Feeling unsafe in public transportation: a profile analysis of female users in the Parisian region. Crime Prevention and Community Safety, 19, 251-263.

Warr, M. (2000). Fear of Crime in the United States: Avenues for Research and Policy. Discussion paper, National Institute of Justice/NCJRS, Rockville, MD, USA. www. ncjrs.gov/criminal_justice2000/vol_4/04i.pdf (accessed 20 February 2020).

Williams, L. C. A. (2014). Virginia Woolf's history of sexual victimization: a case study in light of current research. Psychology, 5, 1151-1164. 


\title{
10 An analysis of transit safety among college students in Lagos, Nigeria
}

\author{
Smart E. Otu and Augustine Agugua
}

\subsection{Introduction}

Fear and actual crime on Public Transport System (hereafter known as PTS) can have a negative effect on how the service is used, and thus on the sustainability of the city. Safety therefore remains one of the most important qualities of good transport whether public or private. It is often noted that if people do not feel safe on a public and private transport system, they are less likely to use it, let alone linger in it (Iveson, 2018). Safety implies less crime or no crime at all. To all intents and purposes, crime implies risk to the physical safety of both passengers and staff, as well as financial losses, but it is more about risk to the physical and emotional well-being of commuters especially those using public transport. Worldwide, women are often more sexually victimized while in transit then men (Loukaitou-Sideris, Liggett \& Iseki, 2001; Smith, 2008; Ceccato and Paz, 2017).

In countries such as the UK, Japan, and countries of the European Union, public transport providers are committed to providing security to their citizenry, and their policy is, in general, gender-sensitive (see for example Gekoski et al., 2015). For instance, providers continue to send messages by advising commuters to regulate their behavior to stay safe. However, in countries of the Global South, such as Nigeria, such commitment is a far cry from being found. Instead, women are adopting their own coping strategies, such as changing their dressing code and taking precautionary measures to avoid sexual crime victimization while using public transportation. The lack of attention and sensitivity to the role of gender in public transport safety in Nigeria, and the fact that no factors of race, age, disability, socio-economic status, sexuality and gender intersect to influence public and private investors' approach to PTS with regard to safety in Nigeria, is the singular most important motivation for this study.

The main aim of this chapter is to report transit safety conditions in bus/ tricycle and motorcycle stops as experienced by college students in Lagos, Nigeria. That is, how do undergraduates of the University of Lagos, especially female ones, rate the level of safety of public transport services? The objectives are twofold: (1) to document the various and degrees of crimes, delinquency and antisocial behaviors most experienced by Nigerian female undergraduates using PTS; (2) to build on the emerging data and suggest new approaches to 
the design and delivery of urban public transport services to support the complex needs of all urban residents in Nigeria. The data for this analysis were collected as part of a global research project conducted in multiple cities from six continents: Africa, Asia, Australia/Oceania, Europe, North America, and South America. For more details, see Ceccato and Loukaitou-Sideris (2020).

\section{Statement of the problem}

Police records show that crime and disorder on PTS are not uncommon, and they include mainly stealing, robbery, obtaining by pretense (OBT), unlawful possession, assaults, insults and outright molestation and harassment by both touts and drivers (Otu, 2017). In a sarcastic, but well-founded treatise and warning to visitors to Africa, written two decades ago and entitled 'So You're Planning a Trip to Africa', Scott Bidstrup (1999, 3 and cited in Otu, 2003, 56) illuminates the seriousness of crime, especially armed robbery on PTS in Nigeria. Bidstrup warned the would-be-visitors to Nigeria to be wary of armed bandits when travelling on Nigerian roads. As he put it inter alia:

... Never travel at night. Armed robbery is always every time in Nigeria, but is much worse at night.... Daytime travel isn't safe, but it is much safer than night times travel. Never carry all your money with you. If you get robbed, and they find your money (and yes, they will, no matter how clever you think you are), you'll end up penniless in a country that doesn't know the meaning of the words "credit cards", "wire transfers", "ATM", or "bank credit"...

$($ Otu, 2003, 56)

Of all the crimes and safety issues confronting public transport users, robbery, assault and pickpocketing, sexual harassment or the fear of it, in their various forms, remain the most common ones. Sexual harassment remains the crime most faced by women who use PTS. This includes stalking, unwanted touching, obscene gestures, voyeurism, unwanted sexual comments or jokes, unwanted offensive and invasive interpersonal communication through electronic devices or social media, and sex-related insults. Kalms and Korsmeyer (2017a, 2017b) are of the view that the fear of sexual harassment in urban areas predisposes girls and women to regularly modify their behavior to reduce their risk of harassment. Extended, this explains the reason why more women and girls are less likely to undertake travel using PTS compared with their male counterparts.

In terms of time, many cannot afford to travel late. And whenever they do, women and girls make the most meticulous decisions about their clothing, finding a male to go out with them and/or trying to limit their movements to particular areas of the city (see also Kalms \& Korsmeyer, 2017a, 2017b). In Nigeria, there are instances when girls and women have refused to board public transport because of the dominance of males/boys in the bus, taxi or coach (Otu, 2017). The socio-psychological implication is that women are internalizing and 
taking very seriously, the traditional message that safety from sexual harassment is solely their responsibility.

\section{Theoretical framework}

The broad conceptual model of Environmental criminology theory (Bottoms \& Wiles, 1997; Clarke \& Eck, 2003) is relevant to this study because it examines how the convergence of a number of factors in a public space results in the occurrence of crime. It draws insights from the principles and assumptions of the three most influential and traditional theories of environmental criminology, namely rational, routine activities and crime pattern theories (see Brantingham \& Brantingham, 1993; Clarke \& Eck, 2003; Cohen \& Felson, 1979; Cornish \& Clarke, 1986).

However, Crime Pattern Theory (a strand of environment criminological theory) is reviewed and adopted here because it synthesizes all the elements of other environmental criminology theories, with the central point of departure being that crime is simply an event that occurs when an individual with some criminal readiness level meets a suitable target in a situation sufficient to activate that readiness potential. Crime Pattern Theory, which focuses on the public transport arena, talks about nodes, paths, edges, crime generators and crime attractors as key in explaining the complex interaction of settings involving the structures of PTS. Brantingham and Brantingham (1993) examined static crime events on PTS and found that public transport stations may be either crime generators, crime attractors or just fear generators.

Public transport operations in metropolitan Lagos involve all key elements of Crime Pattern Theory of both the offenders and the victims: suitable targets (for example, staff, passengers, presence of large liquidity and valuable property), motivated offenders (for example, unemployed youths, area boys, loiters, touts [agberos]), and the absence of capable guardians (for example, police officers, security staff, CCTV cameras) (see Otu, 2017). Although, there is a remarkable improvement on PTS in Lagos in the past couple of years, it is still apparently unsystematic, poorly organized and managed especially in relation to international best practices. The physical characteristics of bus stops/stations lack measures such as fencing, lighting, open design and security hardware that would prevent crime and disorder; they also lack other state and local council support services (see also Harris, 1971).

\subsection{Previous studies on transit safety around the world}

Of all the factors that influence the choice of a mode of transportation for one's routine activities, safety stands out as the most important. Chen and Gursoy (2001) reported that satisfaction and reliability are affected by two behavioral attitudes, which are perceptions of safety and comfort during a journey. Borhan, Ibrahim, Syamsunur, and Rahmat (2019) revealed that many respondents, 
especially the women they interviewed, were concerned about reckless driving and violation of traffic rules, which not only give an impression of - but also reflected the fact that - the safety of passengers was being compromised.

Women consider security as the main criterion in choosing public transportation (Nurdden, Rahmat, \& Ismail, 2007). A good customer service provided by an employee or a bus driver can evoke a good perception about public transportation in general and buses in particular. Further, Borhan et al. (2019) explained that a number of respondents they interviewed complained about the attitude of the bus drivers who failed to show regard for users, and did not treat passengers with respect. Both Okpara (1988) and Otu (2017) noted that the activities of the touts-locally known as agberos - were a source of worry to public transport users, especially females who are subjected to undignified treatments in the name of hustling for customers. Overall satisfaction of bus users is therefore directly affected by the negative experiences they have when using public transport, such as delays, or bad treatment from employees of the bus providers (Friman, 2004; Friman, Edvardsson, \& Gärling, 1998). What this suggests is that bus operators must seek to enhance customer service in an effort to further enhance customers' satisfaction.

PTS is fraught with additional challenges, thus restraining the preference for it. These challenges include unavailability or inaccessibility to some residents, its erratic schedules and long travel times due to frequent stops and pick-ups (see also Borhan et al., 2019). All these make using private car a more comfortable and attractive option.

Although men are more often victims of crime on public transport than women (Morgan \& Smith, 2006, cited in Smith, 2008; Smith \& Cornish, 2006), for women, fear of crime is obviously higher (Guilloux, 2012; Smith, 2008). This is exemplified by the elaborate protective measures that women impose on themselves. A recent study showed that all women are more likely to adopt specific transport practices that range from vigilance to avoidance for fear or real victimization (Guilloux, 2015).

Sexual harassment, mugging and assault remain a fear among women more than men (see TTC et al., 1989 cited in Smith, 2008; Smith, 2008). It is also revealed that certain types of crime are peculiar to some countries more than to others. In 2016, Colombia, Mexico and Venezuela, for example, were particularly at risk of kidnappings (Control Risks, 2016). This is also reflected on public transport, particularly taxis, where what is known as "express kidnapping" or a "millionaire tour" [paseo millonario] can happen. In these crimes, the passenger is forced by accomplices who get into the taxi to withdraw cash from cash machines (Cawley, 2014).

On crime and deviant behavior on the PTS, the social milieu has been identified as a strong risk factor (see Loukaitou-Sideris et al., 2001). According to the International Centre for Crime-Prevention (n.d.), several studies have shown that crime is correlated with districts surrounding transit stops: crime at transit stops is generally higher when the crime rate in the areas in which the stops are situated is high (see also Loukaitou-Sideris et al., 2001). This is valid for both 
transit stops and the vehicles themselves, since crime on public transport vehicles is higher on routes that go through zones with high crime rates (Newton, 2004). So, environments characterized by high densities of passengers (overcrowding), e.g., in buses, carriages or stations, are commonly a fertile territory for sexual harassment and other types of sexual abuse and harassment (Ceccato \& Paz, 2017). This argument falls in line with the general sociology-criminology causes of crime. Although overcrowding is not considered here to be a cause of sexual crime against women in transit, it is definitely a facilitator.

UITP (2014) on environment-crime-PTS found that, in France for example, violence against staff is more common in disadvantaged districts; and there is more fraud on buses in districts with high levels of violence (Le Parisien, 2011). In highly clustered parks in Lagos and Port Harcourt, there are reports of pickpocketing, robbery and various kinds of deviant behaviors aimed towards women. Some studies show that offences are more common on public transport when the surrounding districts have lower socio-economic levels (see, for example, Loukaitou-Sideris et al., 2001), particularly a high unemployment rate (Cozens, Neale, Whitaker, \& Hillier, 2003). For example, in Bogotá, the probability of a homicide near a bus stop (TransMilenio) is five times greater in a poor district than in other districts (Schäfer, 2015).

This literature review has shown the gap which exists in the study of public safety and crime on PTS in a developing country such as Nigeria. The lack of robust research on the diverse crime and safety issues on public transport in Lagos metropolitan city opens up a vista of areas to explore. As such, the present research provides the much-needed database for comparative studies at the international level.

\subsection{The case study}

Lagos is a cosmopolitan city in all senses. It is nicknamed the 'Centre of Excellence' because all political, economic, social and cultural activities which reflect the diverse nature of Nigeria are found in the city. It, equally, is a home for many residents who come from different ethnicities, socio-economic backgrounds, nationalities, languages/dialects and religious beliefs. Lagos is arguably the most or second-most populated city in Nigeria, with a vibrant economy and well-developed public and private transport system (Otu, 2017). According to National Bureau of Statistics, Demographic Statistics Bulletin (2017), Lagos's population was projected to hit 12,550,598 in 2016 (note that the last time population census was conducted in Nigeria was 2006, so population growth since then has been based on projection). Road traffic congestion management and parking infrastructural planning in metropolitan Lagos is a very big challenge to Lagos state government.

Lagos, unarguably, is a city that has one of the most extensive road networks (with beautifully designed flyovers) in the whole sub-Saharan Africa region. While this road network is supported by suburban train and state and local powered ferry services, they are underdeveloped. A modern rail system, spanning part of 
the Federal Government Revitalizing Rail Project, is currently under construction. The state government is struggling to make PTS safe and comfortable through numerous reforms and policies. All this notwithstanding, compared with other cities in the western world, reported cases of crime and disorder on public transport in Lagos are a source of concern to all critical stakeholders.

Public transport plays a critical role in ensuring the mobility of a large proportion of households in Lagos. Salau (2015) explained that with a population of over 20 million people, about 80 percent of the total daily passengers' trips in Lagos metropolis were made by public transport. Estimates of transport demand in metropolitan Lagos in 1990 ranged from seven million to 10 million passenger trips daily, of which over 95 percent were undertaken by road, primarily by private cars, public buses and taxis, and commercial motorcycles (Opeifa, 2012). In specific terms, between 80 and 85 percent of passenger trips are made by public transport (Opeifa, 2012). Figure 10.1 illustrates the outdoor environment of public transportation in Nigeria.

As it affects Metropolitan Lagos, public transport stations are crowded by people who do not know one another, thus creating the enabling environment for crime and disorder to occur with ease. As an illustration, at certain periods in people's routine activities, the crowds and the characteristics they exhibit (e.g., commuters using public transport during morning and evening rush hours or festive periods) would yield suitable conditions for certain kinds of crime (e.g., attracting offenders who believe they have greater opportunity either to pickpocket, steal valuables or displaying some kinds of unwanted sexual behavior). By this, both the stations and periods act as crime attractors. Brantingham and Brantingham $(1993,1995)$ further explained that fear of crime on PTS can be generated in a number of ways: (i) if the surroundings appear unclean, (ii) if stations appear uncared for, and (iii) if stations are not properly lit or are poorly supervised.

(a)

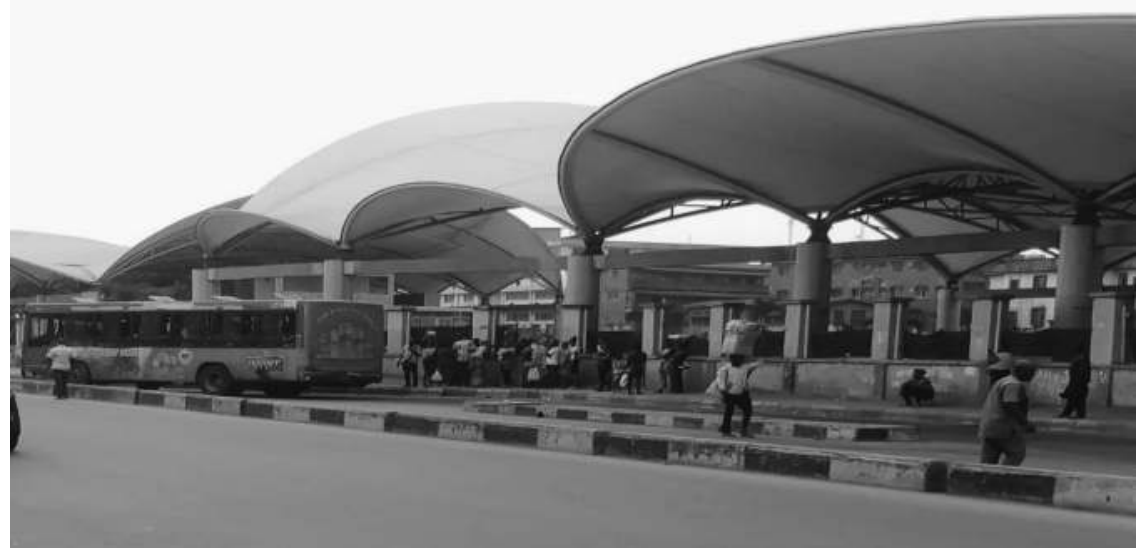


(b)

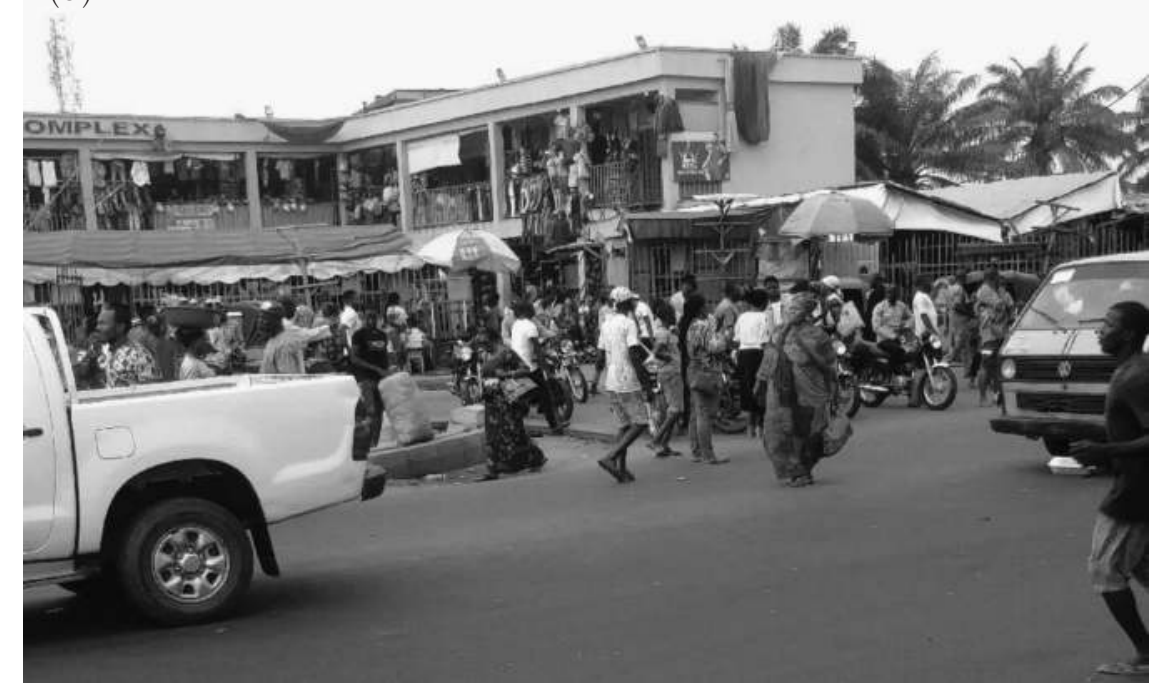

Figure 10.1 (a) A typical modern LAMA and LAMTA bus station. (b) Molue bus station in Lagos, Nigeria.

Source: Picture taken by author during the course of the research.

There are many crimes, such as armed robbery, sexual misconducts, theft, pickpocket, assault, violence, bag and purse snatching, which characterize PTS in Lagos. These crimes are more of a reflection of the disorganized social context (milieu) of public transport spaces in Lagos (unclean environment, poorly lit and supervised stations/parks), and of course, individual predisposing factors. There are certain individual behaviors which are associated with both the operation and use of PTS in Lagos, and which further provide additional crime generators and attractors for motivated offenders. These behaviors include users of public transport carrying large amounts of cash and/or valuables, dressing in certain ways, not been security conscious. The many motivated offenders include the agberos (motor park loaders), young and unemployed men and women who mill around and hawk items in and around the park stations. In addition, PTS in Lagos lacks effective guardians (security systems and personnel). Most parks are also not manned by state security agents or private security.

\section{Data and methodology}

This study is based on answers from a (cross-sectional) survey of tertiary students about safety in public transportation. The study, which is a part of a larger international project, attracted 270 valid responses on an internet-based 
questionnaire administration exercise, with about 95 percent of the respondents being Nigerian citizens. Collation of data on the experiences of commuters, especially undergraduate females using the diverse forms of PTS in Lagos metropolitan city, has provided us with first-hand information.

The online crowd-mapping technique employed targeted University of Lagos undergraduates who use public transport to and from campus. This represents a kind of digital campaign which encourages undergraduate public transport users, especially women and girls, to disclose their experiences within the broad context and themes provided by experts on public transport issues across the different continents and countries.

Our potential respondents were identified by pasting instructions at strategic locations on the campus as well as on a Google-created platform, inviting and stating that only those students who stay outside the campus and have reason to use PTS (bus, coaches, canoes, taxis, etc.) to commute to and from campus are eligible to participate in the study. Our recruited research assistants from the social sciences and statistics departments assisted us with the exercise. Unfortunately, because there are no statistics on public transport users among the population, we were unable to draw on a definitive list of public transit users but merely relied on willing participants. The quantitative data-generating technique used here has, as its merit, the advantage of measuring the reactions of our respondents on a wide range of questions, thus allowing the comparison and statistical aggregation of the data generated simultaneously across several countries of the world (see also Patton, 1990).

The process of data analysis started with sifting and editing the retrieved questionnaires for computer processing and analysis. The quantitative data generated from the survey were subsequently analyzed using descriptive statistical methods, and they were subjected to univariate level of analysis. At the univariate level, a simple percentage distribution pattern of the matrix type was used to disaggregate the necessary variables for the purpose of describing, summarizing and finding patterns in the data. This was done to answer the questions raised at the beginning of the study.

\section{The description of the sample}

The majority (94 percent) of the respondents were between the ages of 18 and 29 years, 5 percent were between 30 and 39 years, while 0.4 percent were between 40 and 49 years. In terms of gender, 42 percent of the respondents were male, 55.2 percent were female, 2 percent were transgender, while 0.7 percent of the respondents did not respond to the question. On sexual orientation of the respondents, the analysis reveals that 6 percent of the respondents admitted being homosexual, 82 percent are straight, 5 percent preferred not to disclose, while 8 percent of the respondents did not respond to the question. In terms of race/ethnic composition, 14 percent of the respondents were either black or African American, 0.4 percent were White/Caucasian, 0.7 percent were Hausa, 27 percent were Igbo, 37 percent, a majority, were Yoruba, 
0.4 percent came from the mixed race, while 21 percent were from another race/ethnic group category that was not specified. A description of the profile of the respondents is found in Table Al0.1.

\subsection{Results}

\section{Patterns of perceived safety by gender}

Women by far declared themselves to feel more often unsafe than men while in transit (Figure 10.2). In terms of perceived safety, a larger proportion of respondents who expressed feelings of lack of safety were females. For instance, 61 percent of women and 55 percent of men always feel unsafe using bus/keke napep (tricycle) or motorcycle stops at night. Similarly, 45 percent of female respondents and 39 percent of male respondents sometimes feel unsafe using bus/keke napep (tricycle) or motorcycle stops at night.

There are also gender differences in perception of safety while waiting at bus, keke napep (tricycle) or motorcycle stops during daytime and night-time (47 percent of males and 53 percent of females always feel unsafe, while for sometimes it is 40 percent of males and 62 percent of females). The sense of feeling unsafe becomes glaring and widens when it is dark for our respondents. While 33 percent of males always feel unsafe, a huge 67 percent of females always feel unsafe when it becomes dark. Whenever it is dark at the bust/keke/ tricycle stations, 31 percent and 69 percent, respectively, of males and females sometimes feel unsafe.

More often, female respondents declare feeling unsafe while walking to the station. In line to the gender differences of the general perception of safety found in the literature, we found that 50 percent of males and 58 percent of females expressed feelings that they always feel unsafe on the way to the station while 35 percent of males and 65 percent of females sometimes feel unsafe.

\section{Patterns of perceived safety by age}

Age is an important dimension as far as perception of safety is concerned. Older students tend to express more often concerns about their safety than the younger group (Figure 10.3). Considering feelings of safety by age, 5 percent and 8 percent of those younger than 30 and those above 30 years, respectively, expressed that they always feel unsafe using the use bus, keke napep (tricycle) or motorcycle. For those who sometimes feel unsafe, the figures are 20 percent and 15 percent respectively. While waiting at the bus, keke napep (tricycle) or motorcycle stop during the day, 9 percent of those younger than 30 and 13 percent of those older than 30 always feel unsafe, while 14 percent and 8 percent respectively sometimes feel unsafe. After dark, while the majority (33 percent) of those who were younger than 30 years said that they always feel unsafe, 23 percent of those older than 30 years always feel unsafe using public transportation after dark. Twenty-three percent of those younger than 30 years 


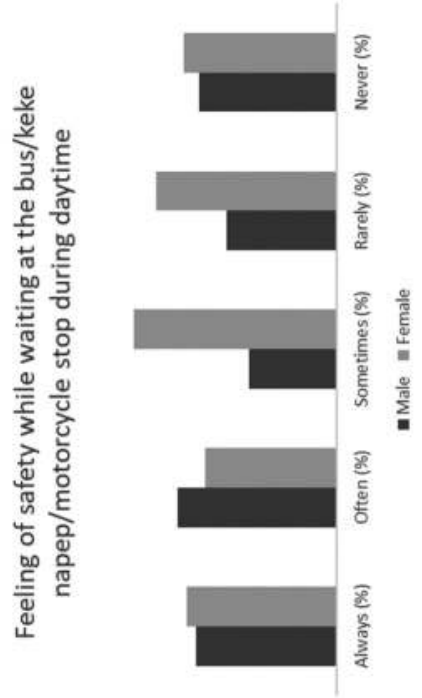

๓용용유요응

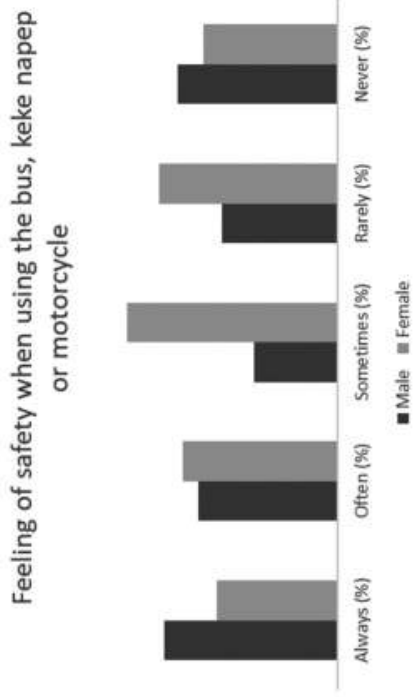

유용ㅇㅇㅇㅇㅇㅇ

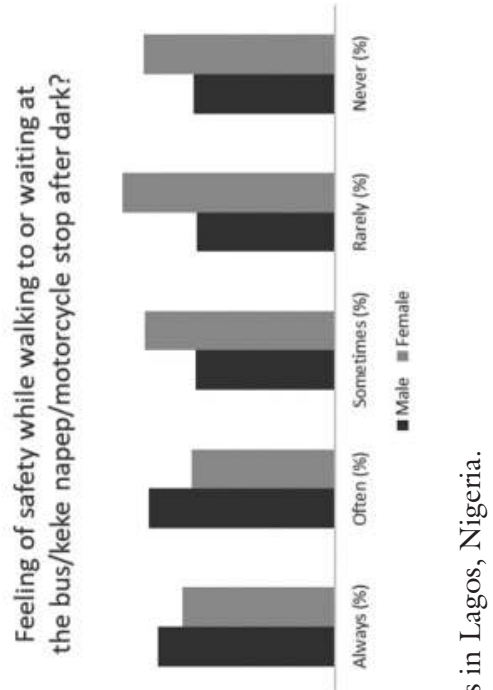

용용유융

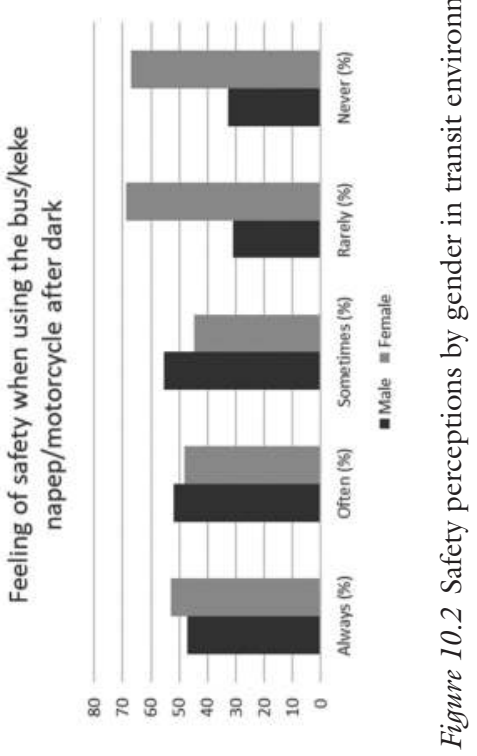




\section{Feeling of safety when using the bus/keke napep/motorcycle by age group}

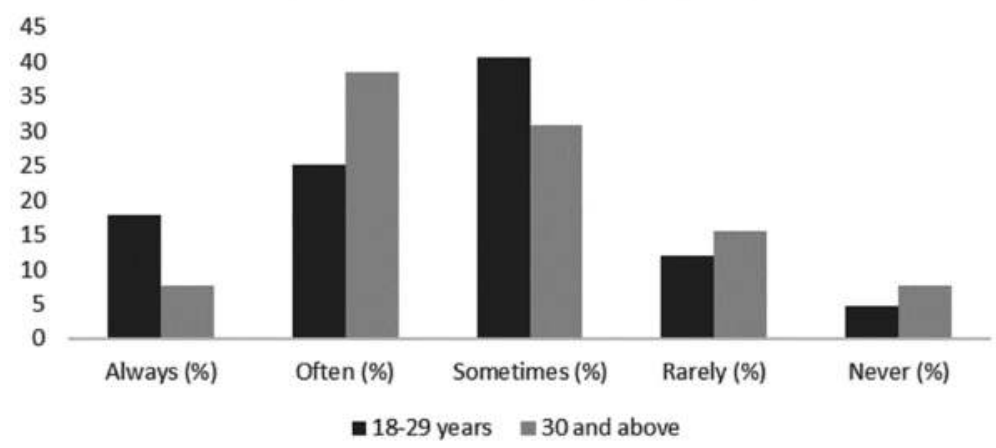

Figure 10.3 Safety perceptions by age groups in transit environments in Lagos, Nigeria.

and 15 percent of those older than 30 years sometimes feel unsafe using the bus, keke napep (tricycle) or motorcycle after dark. Thirty-seven percent of those below 30 years always feel unsafe while walking to the station, compared with 17 percent of those 30 years and above. Twenty-four percent of those younger than 30 years and 8 percent of those above 30 years sometimes feel unsafe while walking to the station, whether in the day or at night.

\section{Perception of safety problems while in transit}

Our respondents identified several problems most often encountered while using bus/keke napep (tricycle) and at the bus/keke napep (tricycle) or motorcycle stops (Table 10.1). These included drug use/abuse, presence of drunk people, manhandling and jewelry snatching. However, the most encountered problems were the use of obscene language ( 11 percent); pickpocketing (14 percent); poorly guarded/empty (6 percent); poorly illuminated area (9 percent); robbery; sexual harassment; vandalism/littering, and verbal/physical threats (13 percent). There are several reasons for entertaining fear while using public transport modes whether in the day or night. These range from antisocial behavior of others (17 percent), cost of tickets (10 percent). Other important fears are of sexual harassment on the bus/tricycle or motorcycle (4 percent), and fear of terrorist attack (4 percent). Interestingly, a large number ( 13 percent) said they had fear of traffic crashes (accidents). Other sundry reasons for non-use of public transport were for exercise and to save money, just staying on campus (immobility), stress and lack of comfort, lack of information about bus/tricycle or motorcycle schedules and the fact that service is always overcrowded. Seven percent of respondents declared that it is because it slows journey time, and 9 percent said there were unreliable or infrequent bus/tricycle or motorcycle services. 
Table 10.1 Respondents' concerns about using buses, tricycle or motorcycles in Lagos, Nigeria

\begin{tabular}{lcc}
\hline & Frequency & Percentage (\%) \\
\hline $\begin{array}{l}\text { Concern about antisocial behavior of others (such as; } \\
\quad \text { drinking, cursing, smelling badly, etc.) }\end{array}$ & 45 & 16.7 \\
Cost of tickets & 26 & 9.6 \\
Dirty environment during the walk to the bus/ & 2 & 0.7 \\
$\quad$ tricycle or motorcycle tickets & & \\
Do not understand how to buy bus/tricycle or & 1 & 0.4 \\
$\quad$ motorcycle tickets & 10 & 3.7 \\
Fear of sexual harassment on the bus/tricycle or & 11 & 4.1 \\
$\quad$ motorcycle & 36 & 13.3 \\
Fear of terrorist attack & & \\
Fear of traffic crashes & 12 & 4.4 \\
Fear of victimization getting to and waiting for the & 2 & 0.7 \\
$\quad$ bus/tricycle or motorcycle & 2 & 0.7 \\
For exercise and save, I often walk & 1 & 0.4 \\
I stay on campus & 1 & 0.4 \\
Its stressful & & \\
Lack of comfort & 3 & 1.1 \\
Lack of information about bus/tricycle or motorcycle & 2 & 0.7 \\
$\quad$ schedules & 24 & 8.9 \\
Many transfers & 18 & 6.8 \\
Overcrowded services & 1 & 0.4 \\
Slow journey times & & \\
The size of the tricycle is small & 278 & 8.5 \\
Unreliable or infrequent bus/tricycle or motorcycle & & 0.7 \\
$\quad$ service & & 17.8 \\
Other & & \\
No response & & \\
Total & & \\
\hline
\end{tabular}

In terms of sexual harassment, Table 10.2 shows the most common types of behavior that women encounter while in transit: unwanted sexual looks, using obscene/abusive language, calling you babe, honey sweetheart, groping, touching inappropriately but also indecent exposure and sexual comments.

\section{Perception of risk and precautionary measures}

When asked about why respondents do not use bus, keke napep (tricycle) or motorcycle transit more often to commute to campus, interestingly, 73 percent of the females declared it is due to fear of victimization while getting to or waiting at the bus stop or platform. In specific terms, 87.5 percent of the females declared that it is because of fear of sexual harassment in its various forms.

Public transport users in Nigeria do take some precautionary measures to guard themselves against both anticipated and unanticipated crimes, delinquent acts and other bad behaviors. Analysis of data reveals that 15 percent of the respondents described measures taken while using public buses/tricycle or 
Table 10.2 Problems of sexual harassment respondents encountered at the bus/tricycle/ motorcycle stops within the past 3 years in Lagos, Nigeria

\begin{tabular}{lrc}
\hline & Frequency & Percentage (\%) \\
\hline Asking one personal questions about sexual life. & 1 & 0.7 \\
Calling you babe, honey sweetheart & 33 & 12.2 \\
Giving me phone numbers & 1 & 0.4 \\
Groping, touching inappropriately & 32 & 11.9 \\
Indecent exposure & 16 & 5.9 \\
Making kissing sounds & 3 & 1.1 \\
Pulling or playing with your hair & 3 & 1.1 \\
Sexual comments & 14 & 5.2 \\
Showing pornographic images & 4 & 1.5 \\
Stalking & 29 & 10.7 \\
Unwanted sexual looks & 41 & 15.2 \\
Unwanted sexual teasing, remarks & 4 & 1.5 \\
Using obscene/abusive language & 34 & 12.6 \\
Whistling & 14 & 5.2 \\
Nothing & 2 & 0.7 \\
Others & 7 & 2.6 \\
No response & 32 & 11.6 \\
Total & 270 & 100.0 \\
\hline
\end{tabular}

motorcycle include always travelling with someone else, 0.7 percent said avoiding carrying purses and wallets, and 8 percent said avoiding particular bus/tricycle or motorcycle stops. Other measures include carrying some kind of weapons, dressing in a certain way, and another ( 5 percent) said being alert. Interestingly, some respondents said they do not take any cautionary measure except only to pray and believe in the grace of God. By and large, the most common cautionary measure was travelling only during daytime (27.0 percent of the respondents subscribe to this measure). There are also avoiding wearing jewelry, sitting close to the driver, waiting for transit at well-lit places, and waiting for transit only if other people are around. Table 10.3 illustrates the types of precautionary measures taken by respondents of the survey while in transit.

\subsection{Recommendations for safety improvement}

On what could be done to make traveling in public transport safe, our respondents responded enthusiastically. Several measures and strategies suggested included the use of cameras (CCTV) at bus stops and on the bus/tricycle or motorcycle (10.4 percent), 13 percent said it is the use of digital timetables at bus/tricycle or motorcycle stops, and 5 percent suggested having direct police hotlines-direct to police station/division within the precinct of the bus station-at bus/tricycle or motorcycle stops. Other suggestions were improved lighting at the bus/tricycle or motorcycle stops (12 percent), more police officers patrolling buses/tricycle or motorcycles (35 percent), and 4 percent said women-only buses/tricycles or motorcycles. 
Table 10.3 Precautionary measures taken by users of bus/tricycle/motorcycle stops

\begin{tabular}{|c|c|c|}
\hline & Frequency & Percentage (\%) \\
\hline Always travelling with someone else & 40 & 14.8 \\
\hline Avoiding carrying purses, wallets & 2 & 0.7 \\
\hline Avoiding particular bus/tricycle or motorcycle lines & 13 & 4.8 \\
\hline Avoiding particular bus/tricycle or motorcycle stops & 21 & 7.8 \\
\hline Being conscious of your environment & 1 & 0.4 \\
\hline Carrying some kind of weapon & 6 & 2.2 \\
\hline Dressing in a certain way & 14 & 5.2 \\
\hline \multicolumn{3}{|l|}{ Ensuring the degree of self-awareness is high, also } \\
\hline I try to be very much aware of my environment & 1 & 0.4 \\
\hline $\begin{array}{l}\text { I make sure all my valuables are in my bag and my } \\
\text { bag is always in front with me holding it tight } \\
\ldots \text { it is either I am with someone or I wait }\end{array}$ & & \\
\hline for bus if only males are there & 1 & 0.4 \\
\hline $\begin{array}{l}\text { No precaution per say because only prayer and } \\
\text { the grace of God can save }\end{array}$ & 3 & 1.1 \\
\hline Not wearing jewelry & 3 & 1.1 \\
\hline Sitting close to the driver & 8 & 3.0 \\
\hline Travelling only during daytime & 73 & 27.0 \\
\hline Waiting for transit at well-lit places & 23 & 8.5 \\
\hline Waiting for transit only if other people are around & 25 & 9.3 \\
\hline Others & 4 & 1.5 \\
\hline No response & 32 & 11.9 \\
\hline Total & 270 & 100.0 \\
\hline
\end{tabular}

\subsection{Discussion}

Commuters' safety is essential to public transport users in large towns, cities and metropolises. Our analysis reveals that safety, either while walking to a bus stop or waiting there, is a real concern among Nigerian public transport users, particularly female undergraduates, a majority of whom are represented in our sampled respondents. Fifty-five percent of males and 61 percent of females always feel unsafe while 39 percent of males and 45 percent of females 'sometimes' feel unsafe using bus/keke napep (tricycle) or motorcycle, taxis and buses. These figures, when pulled together, present a clear picture of the prevalence of fear and/or lack of a sense of safety when either moving to or waiting at public transport stops.

Although both men and women do feel unsafe when they use the PTS, they have starkly different experiences of public transport as they travel around the city (Lieberwirth, 2017). This accounts for the difference in the manner they commute from one place to another. We found in our study that greater numbers of University of Lagos female students (61 percent) do not feel safe at all and, as such, may have at one time or the other been victimized either walking to or waiting at the bus stops. This figure compares to 55 percent of male respondents, who said they always feel unsafe using PTS. Kalms and Korsmeyer $(2017 \mathrm{a}, \mathrm{b})$ explained that the observable difference in experiences 
(and perhaps safety feelings) between men and women who travel around cities can be attributed to the age-old trope of seeing women as the weaker sex and prone to vulnerability. Our findings confirm this difference in experience and the cautionary steps being taking while travelling. In a study by the University of California, these differences were found to be products of a long history of gender inequality, which reinforces rigid binary definitions of femininity and masculinity. It is argued that gender inequalities in transport use open myriad additional concerns (Lieberwirth, 2017).

Guilloux (2012) and Smith (2008) show that although both men and women do exhibit fear while using public transport, for women fear of crime is obviously higher. This explains the protective measures that women impose on themselves. A recent study showed that all women are more likely to adopt specific transport practices that range from vigilance to avoidance for fear of victimization (Guilloux, 2015). Kalms and Korsmeyer (2017a, 2017b) explained that women, and young and old people feel more at risk in areas near to public transport. These spaces include pedestrian subways and bridges, stations, access areas and bike paths. The feeling of fear by our respondents is understandable when we realized that in many cities in Nigeria, public transport facilities are poorly provided or simply not available. The presence of some delinquent behaviors being exhibited by both agberos (touts), drivers and co-commuters may have fueled the fear, especially by women.

In addition, of all the crimes and safety issues confronting our respondents particularly women and girls who utilize public transport for their daily activities, fear of sexual harassment, terrorist attack, and traffic crashes, remain the most common ones. While sexual harassment remains visible and takes several forms, the common forms include stalking, unwanted touching, obscene gestures, voyeurism, unwanted sexual comments or jokes, and unwanted offensive looks. Kalms and Korsmeyer $(2017 \mathrm{a}, \mathrm{b})$ are of the view that the fear of sexual harassment in urban areas predisposes girls and women to regularly modify their behavior to reduce their risk of harassment. In extreme cases, women and girls are less likely to undertake travel using the PTS than their male counterparts, make the most meticulous decisions about their clothing, find a male to go with and/or try to limit their movements to particular areas of the city (see also Kalms and Korsmeyer 2017a, 2017b). In this study, fewer than one-third (31 percent) of male respondents experienced sexual harassment, in contrast to 46 percent of the female respondents who experienced the same crime. Of course, this is in tandem with the findings of other studies (see for example, TTC et al., 1989, cited in Smith, 2008).

There are several crimes and socially deviant behaviors identified by our respondents as constraints to their use of public transportation to move about for their routine activities. Drug use/sales remains a significant one. In addition there is the presence of drunk people, the use of obscene language, and panhandling. Other constraining behaviors are pickpocketing, being poorly guarded, poor illumination, robbery, sexual harassment, vandalism/littering, verbal/physical threats, and violent crime (aggravated assault and murder). 
These findings are in line with the findings of Borhan et al. (2019) and Otu (2017). For these authors, the PTS is fraught with additional challenges, restraining the preference of it. These challenges include unavailability or inaccessibility to some residents, its erratic schedule and long travel time due to frequent stops and pick-ups, robbery insults and assaults. Smith and Cornish (2006) identified crimes against users, crimes against employees of transit systems, line-of-route related offenses, graffiti and vandalism as some of the challenges faced by public transport users. These and our findings constitute additional sources of fear and feelings of lack of safety by our undergraduate public transport users.

The main reason(s) for entertaining fear whether in the day or night among our respondents is antisocial behavior of others. When we sum up the number of people who said it is because of fear of terrorist attack, and being victimized, then the picture of the correlation between the use of public transport and feelings of safety becomes compelling. Interestingly, a few of our respondents (13 percent) said it is the fear of traffic crashes (accidents), and cost of tickets (10 percent). Social Exclusion Unit (2003) found that, when the cost of a ticket is high, it became a constraint among residents of England.

The fear of crime and feelings of being unsafe when using public transport have made users devise different cautionary measures for survival and conviviality (for more on behavior modifications, see Kalms and Korsmeyer, 2017a, $2017 \mathrm{~b}$ ). Analysis of data reveals that 15 percent of the respondents always avoid travelling alone, while others avoid particular public transport lines and stops. In extreme case, some public transport users carry some kind of weapon, or defensive objects; dress in a certain way, especially among females, including not wearing jewelry; being overtly conscious and alert; and making sure all valuables are in a bag which is held tight. Prayer and submission to the "will and grace of God' is also favored by Nigerian undergraduate females using public transportation. The majority, however, favored travelling during daytime. At least 27 percent of our respondents take this path.

\subsection{Conclusion and policy implications}

This chapter set out to report transit safety conditions experienced by college students in Lagos, Nigeria, using answers from a small sample survey of tertiary students. Findings from this study indicate that students who attend school from town, and who use public transportation, are susceptible to all forms of unwanted sexual behaviors and miscreant activities. This challenges us to answer the question as to what could be done to improve safety on PTS and reduce fear among students That is, what are the policy implications of dour findings?

First, the conscious design of facilities, internal design of vehicles, and the environments (routes) that public transport traverses should be improved. For example, bus stops/stations should be designed in a manner that they have separate waiting rooms for both males and females; coaches and buses should have a section designated for females; while designated routes should be reserved for 


\section{Smart E. Otu and Augustine Agugua}

some coaches/buses, as is currently done by the Lagos State Transport Authority. This suggestion aligns with Crime Prevention Through Environmental Design (CPTED) which is increasingly being used in PTS, such as train stations (see Public Transport Safety, n.d).

As transport networks are part of the urban environment (Public Transport Safety, n.d), the CPTED interventions we recommend here must envision and include a Safe Women project, which should involve re-designing public spaces to help prevent sexual aggression. CPTED is concerned with altering the physical environment to impact offender decision-making. This should include improvements to pedestrian walkways along the main access routes to the transport system, ensuring they are well lit and equipped with safety equipment, as well as improving lighting in the city center and residential areas (see also UN Women, n.d.). Ceccato, Uittenbogaard, and Bamzar (2013) explained that lighting seems to play a role in variations in the crime rate. A study in the UK found that poorly lit places increased fear of crime (Crime Concern, 2004).

Table A10.1 The profile of respondents

\begin{tabular}{|c|c|c|}
\hline Variables & Frequency & Percentage (\%) \\
\hline \multicolumn{3}{|l|}{ Age } \\
\hline $18-29$ & 255 & 94.4 \\
\hline $30-39$ & 14 & 5.2 \\
\hline $40-49$ & 1 & 0.4 \\
\hline Total & 270 & 100.0 \\
\hline \multicolumn{3}{|l|}{ Gender } \\
\hline Male & 115 & 42.6 \\
\hline Female & 149 & 55.2 \\
\hline Transgender & 4 & 1.5 \\
\hline Prefer not to say & 2 & 0.7 \\
\hline Total & 270 & 100.0 \\
\hline \multicolumn{3}{|l|}{ Sex status (LGBTQI) } \\
\hline Yes & 16 & 5.9 \\
\hline No & 220 & 81.5 \\
\hline Prefer not to say & 13 & 4.8 \\
\hline No response & 21 & 7.8 \\
\hline Total & 270 & 100.0 \\
\hline \multicolumn{3}{|l|}{ Race/ethnicity } \\
\hline Black/African American & 37 & 13.7 \\
\hline White/Caucasian & 1 & 0.4 \\
\hline Hausa & 2 & 0.7 \\
\hline Igbo & 74 & 27.4 \\
\hline Yoruba & 99 & 36.7 \\
\hline Mixed Race & 1 & 0.4 \\
\hline Others & 56 & 20.7 \\
\hline Total & 270 & 100.0 \\
\hline
\end{tabular}


Second, mechanisms should be put in place that can facilitate easy and prompt reporting of incidents of crime and antisocial behavior to the appropriate authorities. To achieve this requires sensitization of the people mostly likely to use public transport.

Third, security should be enhanced through effective use of motorized and foot patrols by special units of the police around major bus/train/ferry/canoe stops in and around Lagos metropolis. Engage public transport providers to do more to establish greater security for their customers through the provision of CCTV cameras, alarm buttons and visible state and private security guards on public transport routes and spaces. Police patrols, both at the buses/tricycle and around the platforms, is a strong preventive measure. Visible police patrols has been highlighted as the densities of passengers (overcrowding), e.g., in buses, carriages, and stations, are commonly a fertile territory for sexual harassment and other types sexual abuse and harassment. Sherman and Eck (2002), and Weisburd and Eck (2004) share in this view when they suggested that policing geared towards reducing crime is specifically beneficial if it is targeted at highcrime locations.

Finally, since our findings support the extant literature that females, and old and low income people - a majority of whom are public transport users-are more likely to be victimized, express fear, and are less likely to report to the appropriate authority when victimized, a modern PTS that is gender- age- and class-sensitive, safe and accessible should constitute part of the overall revolution of public transport policy.

\section{References}

Bidstrup, S. (1999). So you're planning a trip to Africa. A page of advice travellers to Africa. www.pe.net/ bidstrup/advice.htm (accessed 16 February 2020).

Borhan, M., Ibrahim, A. N. H., Syamsunur, D., \& Rahmat, R. A. (2019). Why public bus is a less attractive mode of transport: a case study of Putrajaya, Malaysia. Periodica Polytechnica Transportation Engineering, 47, 82-90.

Brantingham, P. L., \& Brantingham, P. J. (1993). Environment, routine and situation. Toward a pattern theory of crime. In R. Clarke and M. Felson (Eds), Routine Activity and Rational Choice: Advances in Criminological Theory, New Jersey: Transactional Publishers.

Brantingham, P. L., \& Brantingham, P. J. (1995). Criminality of place: crime generations and crime attractors. European Journal on Criminal Policy and Research, 3, 5-6.

Bottoms, A. E., \& Wiles, P. (1997). Environmental criminology. In M. Maguire, R. Moran, \& R. Reiner (Eds), The Oxford Handbook of Criminology (pp. 620-656).

Cawley, M. (2014). Aumento de secuestro 'express' es señal de la evolución criminal de Colombia. http://es.insightcrime.org/noticias-del-dia/aumento-desecuestro-expressigno-de-la-evolucion-criminal-de-colombia (accessed 11 September 2018).

Ceccato, V., Uittenbogaard, A., \& Bamzar, R. (2013). Security in Stockholm's underground stations: the importance of environmental attributes and context. Security Journal, 26, 33-59.

Ceccato, V., \& Paz, Y. (2017). Crime in São Paulo's metro system: sexual crimes against women. Crime Prevention and Community Safety, 19, 211-226.

Ceccato, V., \& Loukaitou-Sideris, A. (2020). Transit Crime and Sexual Violence in Cities: International Evidence and Prevention. London: Routledge. 


\section{Smart E. Otu and Augustine Agugua}

Chen, J., \& Gursoy, D. (2001). An investigation of tourists' destination loyalty and preferences. International Journal of Contemporary Hospitality Management, 13, $79-85$.

Clarke, R., \& Eck, J. (2003). Become of Problem-solving Crime Analyst in 55 SMALL STEPS. Devon, UK: William Publishing.

Cohen, L., \& Felson, M. (1979). Social change and crime rate trends: a routine activity approach. American Sociological Review, 44, 588-608.

Cornish, D., \& Clarke, R. (1986). The Reasoning Criminal. New York: Springer-Verlag.

Control Risks (2016). Risk Map. https://riskmap.controlrisks.com/ (accessed 28 August 2018).

Cozens, P., Neale, R., Whitaker, J., \& Hillier, D. (2003). Managing crime and the fear of crime at railway stations-A case study in South Wales (UK). International Journal of Transport Management, 1, 121-132.

Crime Concern (2004). People's Conceptions of Personal Security and their Concerns About Crime on Public Transport: Research Findings. London: Department for Transport.

Friman, M. (2004). The structure of affective reactions to critical incidents. Journal of Economic Psychology, 25, 331-353.

Friman, M., Edvardsson, E., \& Gärling, T. (1998). Perceived quality of public transport service: inference from complaints and negative critical incidents. Journal of Public Transportation, 2, 69-91.

Gekoski, A. Gray, J., Horvath, M., Edwards, S., Emirali, A., \& Adler, J. R. (2015). 'What Works' in Reducing Sexual Harassment and Sexual Offences on Public Transport Nationally and Internationally: a Rapid Evidence Assessment. Project Report. Middlesex University; British Transport Police; Department for Transport, London.

Guilloux, M. (2012). La prévention des violences faites aux femmes dans les transports collectifs français. Montréal: CIPC.

Guilloux, M. (2015). Les violences faites aux femmes dans les transports collectifs terrestres: Synthèse de l'étude exploratoire. Paris: Ministère de l'Écologie, du Développement durable et de l'Énergie.

Harris, O. (1971). A Methodology for Developing Security Design Criteria for Subways. Washington, DC. Urban Mass Transit Administration, Report No. UMTA-URT-5 (70)-71-4 (accessed 10 November 2018).

International Center for the Prevention of Crime (n.d.) www.crime-prevention-intl.org (accessed 10 November 2018).

Iveson, D. (2018). Edmonton to host world leaders on safe public spaces. https:// myemail.constantcontact.com/News-Release-Edmonton-to-host-world-leaders-onsafe-public-spaces.html?soid=1127191170163\&aid=nzHCBnlJIf0 $($ accessed 10 November 2018).

Kalms, N., \& Korsmeyer, H. (2017a). Gender makes a world of difference for safety on public transport. www.smh.com.au/lifestyle/gender-makes-a-world-of-difference-forsafety-on-public-transport-20170718-gxd8ee.html (accessed 1 January 2019).

Kalms, N., \& Korsmeyer, H. (2017b). Preventing sexual harassment in Australian public transport spaces through gender-sensitive co-design with women and girls. Uncovering how the safety of women and girls is challenged in public transport spaces. www. monash.edu/mada/research/labs/xyx-lab-monash-space-gender-communication-lab (accessed 1 January 2019).

Lagos State Government (2002). Lagos State Development Indicators Report. lhttps:// lagosstate.gov.ng/ (accessed 10 July 2018).

Le Parisien (2011). Frauder dans le bus deviant la règle. Le Parisien.fr. www.leparisien. $\mathrm{fr} / \mathrm{une} /$ frauder-dans-le-bus-devient-la-regle-17-01-2011-1230490.php (accessed 20 December 2018). 
Lieberwirth, R. (2017). Gender makes a world of difference for safety on public transport. https://theconversation.com/gender-makes-a-world-of-difference-for-safety-onpublic-transport-80313 (accessed 20 December 2018).

Loukaitou-Sideris, A., Liggett, R., \& Iseki, H. (2001). The geography of transit crime: documentation and evaluation of crime incidence on and around Green Line Stations in Los Angeles. Journal of Planning Education and Research, 22, $135-151$.

Morgan, R., \& Smith, M. J. (2006). Crimes against passengers: theft, robbery, assault and indecent assault. In D. B. C. M. J. Smith (Ed.), Secure and Tranquil Travel: Preventing Crime and Disorder on Public Transport (pp. 77-102). London: Jill Dando Institute of Crime Science.

National Bureau of Statistics (2017). Demographic Statistics Bulletin. Nigeria. Available at https://nigerianstat.gov.ng/download/775 (accessed 25 April 2020).

Newton, A. D. (2004). Crime on public transport: 'static and 'non-static' (moving) crime events. Western Criminology Review, 5, 25-42.

Nurdden, A., Rahmat, R. A. O. K., \& Ismail, A. (2007). Effect of transportation policies on model shift from private car to public transport in Malaysia. Journal of Applied Sciences, 7, 1014-1018.

Okpara, E. E. (1988). The role of touts in passenger transport in Nigeria. The Journal of Modern African Studies, 26, 327-335.

Opeifa, K. (2012). How do we harness electricity to transform social infrastructure? 7 th Lagos Economic Summit on Powering the Lagos Economic Real Opportunities, Endless Opportunities.

Otu, S. E. (2003). Armed robbery in the south eastern states of contemporary Nigeria: a criminological analysis. Unpublished Doctoral thesis (D. Litt. Phil.) Department of Criminology, University of South Africa (Unisa), Pretoria.

Otu, S. E. (2017). Patterns and modus operandi of crime and disorderly conduct on the public transport system in Abakaliki, Nigeria: a descriptive analysis. In E. C. Viano (Ed.) Cyber Crime, Organised Crime, and Societal Responses, Internal Approach (pp. 341-365). Switzerland: Springer International Publishing.

Patton, M. Q. (1990). Qualitative Evaluation and Research Methods. Newbury Park, CA: Sage Publications.

Public Transport Safety (n.d). Preventing crime on urban public transport. www.jstor. org/stable/1147664? seq=1.

Salau, T. (2015). Public transportation in metropolitan Lagos, Nigeria: analysis of public transport users' socioeconomic characteristics. Urban, Planning and Transport Research, 3, 132-139.

Schäfer, I. (2015). Ciudades latinoamericanas estudian cómo predecir el crimen. El País.com. http://internacional.elpais.com/internacional/2015/07/30/actualidad/1438211440_ 366876.html (accessed 10 July 2018).

Sherman, L., \& Eck, J. (2002). Police for crime prevention. In: Sherman, L., Farrington, D., Welsh, B. and Layton MacKenzie, D. (Eds), Evidence-Based Crime Prevention. London: Routledge.

Smith, M. J., Belenko, S., Staehs, G., Arriola, R., Shea, R., Truitt, L., \& Harsch, D. (1986). Transit Crime Study, Vol. 1, Summary of Findings and Policy Recommendations. New York: New York City Criminal Justice Agency..

Smith, M. J. (2008). Addressing the security needs of women passengers on public transport. Security Journal, 21, 117-133.

Smith, M. J., \& Cornish, D. B. (Eds) (2006). Secure and Tranquil Travel: Preventing Crime and Disorder on Public Transport. London, UK: UCL, Jill Dando Institute of Crime Science. 


\section{Smart E. Otu and Augustine Agugua}

Social Exclusion Unit. (2003). Making the connections: Final report on transport and social exclusion.www.ilo.org/wcmsp5/groups/public/@ed_emp/@emp_policy/@invest/ documents/publication/wcms_asist_8210.pdf (accessed 2 January 2019).

Toronto Travel Commission (TTC), Metro Action Committee on Public Violence against Women and Children (METRAC), and the Metro Toronto Police Force (MTPF) (1989). Moving Forward: Making Transit Safer for Women. Toronto, Canada: TTC, METRAC, and MTPF.

UN Women. (n.d.). Encouragez les organismes de transports publics et privés à intégrer des perspectives sexo spécifiques dans leurs opérations quotidiennes. Retrieved from www.endvawnow.org/fr/articles/288-encouragez-les-organismesde-transports-publics-etprives-a-integrer-des-perspectivessexospecifiques-dans-leurs-operations-quotidiennes. html (accessed and interpreted by expert 2 February 2019).

UITP (2014). Rapport Sûreté 2013. Paris: UTP.

Weisburd, D., \& Eck, J. (2004). What can police do to reduce crime, disorder and fear? The Annals of the American Academy of Political and Social Science, 593, 42-65. 


\section{Part IV}

\section{The users' perspective}

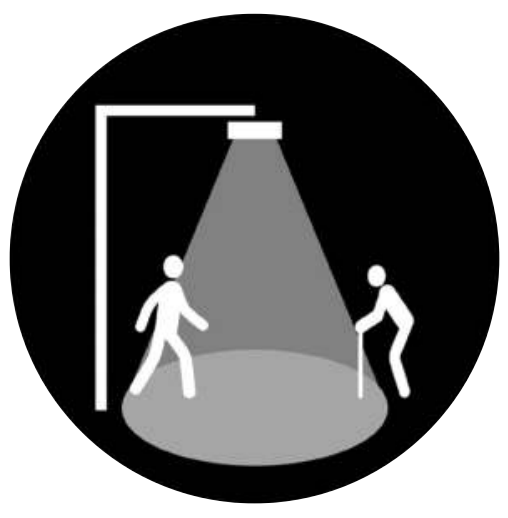




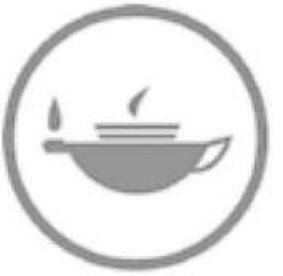

Taylor \& Francis Taylor \& Francis Group http://taylorandfrancis.com 


\section{Contested gendered space \\ Public sexual harassment and women's safety work}

Fiona Vera-Gray and Liz Kelly

\subsection{Introduction}

In October 2017, the revelations of systemic sexual violence in the American entertainment industry sparked global interest in what had been, up until that point, a commonly trivialized form of men's violence: the routine sexual harassment of women. What followed was a unique moment in recognizing and problematizing sexual harassment not only in workplaces, but also in one of the most understudied contexts-public space.

That public space is gendered space has not been a focus for mainstream academic analysis, but such a framing offers important insights. Bea Campbell (1993), in Goliath, argues that in the United Kingdom in the mid-1990s, riots in a number of cities, were sites of struggle: “over young men's criminality and control over their shared streets” (Campbell, 1993, 168), “... increasingly regulated by organized crime and masculine tyrannies" (Campbell, 1993, 177). In urban studies, the recent concepts of "the right to the city" and "the right to security" lack this critical lens, with a few notable exceptions (see, for example, BeeBeejaun, 2017). Struggles over space continue to be about the right to be seen, to be heard, with new political formations, including fundamentalisms invoking gender segregation and limitations of access to public space for women. Belonging in public space is both different for women and differs between women: for example, the possibility of not being observed/judged is accentuated if you are minoritized or gender non-conforming. Yet despite international policy and research focus on crime and fear in public, we still need to contend seriously and analytically with why public space remains a 'conducive context' (Kelly, 2016) for violence against women and girls.

Mapping the impacts of this context is not only a matter of finding out more about what is done to women and girls in public, but of increasing our understandings of how women and girls respond. From changing routes home to choosing seats on public transport, physically reducing themselves in public, to using headphones and sunglasses as a way of feeling invisible, women and girls globally are routinely making strategic decisions to avoid sexual harassment and other forms of sexual violence. Different women, at different times, are acutely aware of their surroundings, tuned into the presence of unknown men. When 


\section{Fiona Vera-Gray and Liz Kelly}

considered in isolation, such changes can be dismissed as an annoying but necessary result of living in a world where occasionally strangers may do you harm. But when seen across the course of a woman's life, these adaptations come to be understood as responding to a particularly gendered message: that women need to be less - less vocal, less visible, less free-in order to be safe.

When these routine strategies are made visible, the impact of men's practices on women and girls comes to be understood not only in terms of their safety, but also their freedom (Vera-Gray, 2018). This highlights the existence of a form of invisible work mandated for women and girls in public, something which one of us has conceptualized as 'safety work' (Kelly, 2012). This chapter sets out the concept of safety work in the context of women's fear and women's freedom in public, drawing on our respective previous research and thinking about these issues. We begin by locating our discussion firmly in the legacies of women's claiming a place in public space.

\subsection{A woman's place}

Feminist research and activism has a long history of engaging with the range and extent of what is often talked about as men's intrusions onto and into the minds, bodies, and space of women and girls in public. The second wave feminist insistence that the personal is political was a challenge to prioritization of the (male coded) public sphere, and the diminishment of the (female coded) private: a foundation in western intellectual traditions in law, political science and other disciplines. That said, the focus in early feminist history on 'separate spheres' as a legitimation of patriarchy was complicated by later work paying attention to how this was inflected by class and race (Fox-Genovese, 1988; Vickery, 1993). Within this contestation sat earlier challenges in the nineteenth and twentieth centuries to the gender segregation of public spaces. Women in public were a cause of anxiety in the white middle classes at the beginning of the twentieth century and this is still the case globally for many women into the twenty-first century: an association with looseness and prostitution, a sexual availability being read into women's presence.

The separate sphere perspective is now understood as an ideology or discourse, since women as individuals and through suffrage movements recognized that exclusion from, or limitations within, public space symbolized restrictions on women's place in the social, political, economic and political arenas. Suffragists occupied public space as collective women and increasingly as angry women: organizing public presence through processions (Liddington, 2006) and making public speeches were claims to occupy it as a political act, a location for resistance and protest. Unsurprisingly, critiques rebuked women for the abandonment of domesticity and femininity: opposition was fierce, with many having to run the gauntlet of jeering crowds of men, jostled when entering public buildings for meetings. Half a century later, black women would take to the streets in the USA as part of the civil rights movement, making their own claims for rights and justice (Crawford, Rouse, \& Woods, 1990), and 20 years 
later still in South Africa, women protested in huge numbers their opposition to the pass laws and apartheid (Federation of South African Women 1954-63, 2013). Claiming such public presence is embodied and emotive-a combination of strength, determination and anxiety-requiring risking opposition and even encountering violence from men and state agencies.

These movements did not, however, create a right for women to occupy public space on the same terms as men. One of the early challenges of the Women's Liberation Movement in many locations was public space harassment, which was a frequent experience of women (Greer, 1971). In the 1970s there were many papers documenting women's experiences in public urban spacecomments, "wolf whistles", being touched on public transport. That women felt, and were, excluded from many spaces was a focus for activism at individual local and national levels: one of the first widely publicized actions in London in 1971 protested against the refusal of Wimpy Bars to serve unaccompanied women after 10p.m. (Scott, 2010). By the end of the 1970s, however, the focus had shifted to sexual harassment in employment (Farley, 1978; MacKinnon, 1979), with the aim of providing legal remedies for individuals rather than a more collective approach to changing social norms. This shift continued into a focus on educational contexts, from schools to universities. It meant that despite the history of feminist work in this area, public space as an arena, and everyday life as the context, came to be largely absent from the wider violence against women policy and research agenda.

The rise of social media has enabled a revisiting of these more mundane manifestations, with various platforms harnessed as tools to share experiences that support and validate women's experiential realities. The non-profit Hollaback! movement, established in 2005, is perhaps one of the most global, currently running in 31 countries, while another American-based site, "Stop Street Harassment", has developed as an online blog space and a resource hub for research and prevention work on street harassment (Kearl, 2010). In 2012, a website and Twitter account created in England to record experiences of "everyday sexism" also went global, spreading to over 15 countries and collecting more than 50,000 entries within just 18 months (Bates, 2014), while in India, the 2011 publication of a study on women's safety and freedom in Mumbai's public spaces begun a movement of women "loitering" as a political and social statement across cities in India and now Pakistan, with supporters encouraged to share their acts on social media (Phadke, Khan, \& Ranade, 2011).

This wave of activism in the new public space of the internet offers a unique opportunity to understand more about the lived experience of sexual harassment with many platforms enabling women and girls to record and publish intrusions "in real time". In this, social media has been conceptualized as a counter-public, providing avenues for informal justice and enabling a recognition, and validation, of harm (Fileborn, 2016; Salter, 2013). More than this, the use of online tools for documenting public sexual harassment has also revealed the extent to which women and girls change their behavior-not only due to the reality but because of the possibility of experiencing sexual violence 
in public space. These changes, and the beliefs that underpin them, provide a new lens on an old problem, commonly referred to as the "fear of crime paradox".

\subsection{Gendering the fear of crime}

A prolonged focus for criminologists has been described as women's disproportionate, paradoxical and even "illogical" fear of crime (Riger \& Gordon, 1981). Put simply, the paradox is that relatively consistently, across studies, across decades, and across contexts, women report significantly higher levels of fear of crime than men-often two or three times more-yet routinely crime statistics show that women actually have a lower rate of victimization than men do (Hale, 1996). This gender difference is by far the most consistent finding in all of the fear of crime literature. What the fear of crime paradox tells us is that gender matters as a predicator for the levels with which an individual will both fear and experience crime, but it does not tell us how.

Typically, there are three main explanations given for the paradox, all of which may work together. The first is that gender roles mean that women are more likely to admit their fears. Gender stereotypes typically attach vulnerability to women and fearlessness to men. This explanation suggests that women are more likely to report their fear of crime in surveys, and that men may struggle to admit to a realistic estimate of their levels of fear. The second explanation is that the fear of rape or sexual assault is a type of fear that is particular to women. It is a fairly well-accepted statement now that across the world rape is significantly under-reported. So the combination of this under-reporting of rape, and the fact that this is the type of crime women are actually most fearful of, helps to elucidate why women report more fear but less crime. The third explanation looks to "what counts" as crime, and thus what is counted. This argument suggests that the difference is not just about a difference between levels of fear of crime, but also about how such crime is defined and measured: that crime and victimization surveys and legal frameworks systematically exclude practices that women are more likely than men to have. This is evidenced in the very data that underpin the paradox, sexual harassment is notably absent from the victimization surveys on which it is based. This analysis raises the possibility that what we are seeing is not a paradox at all, but the result of a male as norm understanding of what counts as crime.

Considering women's safety work however, offers a possible fourth explanation, one that works alongside rather than in competition with the others. Here we draw on feminist geographers such as Gill Valentine (1989) and Rachel Pain (Koskela \& Pain, 2000; Pain, 1991, 2000) whose work on the relationship between sexual harassment, fear, and the built environment suggests that such harassment can be understood as a spatial expression of patriarchy, functioning to reinforce and reproduce women's exclusion from public life more broadly. The adaptations women make to their behavior in order to participate in public space-adaptations that have been well documented in 
arenas such as public transport for example (Gardner, Cui, \& Coiacetto, 2017; Hsu, 2011; Lewis, 2018)-aim to minimize the potential to not only be victimized but to be blamed for that victimization. Such behaviors provide a challenge to the idea that women's fear of crime is irrational. Instead, the disparity between fear and reality is revealed as not only logical, but perhaps even causal. To understand this more we need a more detailed account of what safety work is, what it does, and, importantly, what it means.

\subsection{The invisible work of being a woman}

During the 1970s and 1980s the concept of "invisible work" was developed as a way of bringing the range of women's work more fully into view. One of the key studies looking at this was from 1978, conducted by Pamela Fishman. Fishman was interested in what could be learnt about gender through considering casual conversations between women and men. What she found was an asymmetrical division of labor in talk between heterosexual couples, with women asking more questions, filling more silences, and needing to do more to be heard. Women were doing the work of the conversation, ensuring it flowed smoothly and felt natural, even if this meant they had to adopt a backseat in relation to expressing their own views. Such labor was made invisible as it was a form of "women's work". As Fishman says, being "related to what constitutes being a woman, with what a woman is, the idea that it is work is obscured. The work is not seen as what women do, but as part of what they are" (Fishman, 1978, 405; emphasis in original).

The idea of extra work hidden, as just part of what women are, is particularly interesting when we take an intersectional perspective attuned to the differences between women. Judith Rollins' work in the 1980s speaks powerfully to this. Published in 1985, Rollins' study, Between Women, focuses on the forms of invisible work required by African-American women doing paid domestic labor for white women employers. Where unearthing the invisibility of women's housework had previously been the study of sociological interest (Oakley, 2018), Rollins explored the complexities of the experience of African-American women hired as domestic help. Her work revealed the literal nature of their invisibility, where sometimes they would be treated as if they were not actually seen by white women, who, for example, would turn down the heat or lock the door when they left as if no one else were in the house. She also highlighted the ways in which deference functioned as a form of work that was an invisible and yet necessary part of the role. Acts such as lowering one's eyes, slouching, or speaking in poor English, were required by the African-American women in order to validate the racial superiority of the white women.

That such acts were understood by those undertaking them as a requirement, absorbed into part of the role, connects to the work of American sociologist Arlie Hochschild (1983) on the management of emotion. Hochschild developed the concepts of emotion work and emotional labor during a study of female flight attendants in the late 1970s. Emotion work, for Hochschild, is the 


\section{2}

Fiona Vera-Gray and Liz Kelly

work involved in dealing with or managing other people's emotions, and emotional labor refers to this kind of management done during work for a wage. As with Fishman's findings, Hochschild found this work fell largely to women and was rendered invisible. And just like Rollins' study, though invisible and unpaid this work was required, a silent embedded necessity stitched into the fabric of the role itself.

Taking the idea of invisible work into the realm of violence against women, two forms of labor are revealed. The first, violence work, refers to the work women do in the aftermath of violence to rebuild their sense of self and belonging (Kelly, 2017). To be violated is to have your bodily autonomy, sense of self and connection to others disrupted, indeed recent understandings of the harms of image-based sexual abuse have drawn on the concept of "social rupture" to describe this (McGlynn \& Johnson, 2018; McGlynn, Rackley, \& Johnson, 2019). Being at home within one's body and in company are challenging, and the legacies of abuse remain for many years, potentially a whole lifetime. Violence work refers to the work victim-survivors do to undo the harms, make their lives liveable: much of this will be entirely invisible, since it consists of internal rumination, while other aspects are more visible in the purchase of self-help books, seeking out support and counseling. The point here is that it demands time and energy, which could have been spent on other projects.

Connected to, but separate from, violence work is the work women do as a precursor to stop the violence happening at all-safety work (Kelly, 2012). Such work can become an automatic reflex, especially when in public space alone as a woman: so automatic that we no longer notice the strategies that we use in our attempts to limit or avoid intrusions. Like other forms of invisible work, safety work is hidden because it is related to the very core of what being a woman isnot seen as something women $d o$ but as something that they are (Vera-Gray, 2016). Instead of an optional addition, safety work comes to be understood as a requirement (Vera-Gray, 2016, 2018), producing a set of gendered expectations that have a huge amount of influence over our actions and beliefs.

\subsection{Women's embodied safety work}

Studies on the different strategies women use in public space have broadly separated these into avoidance behaviors, those used to isolate or remove oneself from danger, and self-protective behaviors, those designed to minimize risk when facing danger (Riger \& Gordon, 1981). Both types of actions can be seen in the changes women make to where and how they move in public, something that reveals the ways in which women and girls routinely trade their freedomin this case freedom of movement-in order to feel safer.

One of the largest studies conducted on sexual harassment in Europe found that almost half of the 42,000 women surveyed had restricted their freedom of movement based on the fear of gender-based violence (FRA, 2014). However restricting movement is not the only form of safety work women and girls conduct on a routine basis. Research has shown that where restricting movement is not 
possible or desirable, women and girls have learnt bodily strategies to prevent or minimize the possibility of men's intrusion. In one of the first in-depth studies conducted in America, Carol Brooks Gardner (1995) outlined seven strategies of women's responses to men's intrusion that involve the body: invoking an absent protector; ignoring, blocking and repressing (the pretense that "nothing is happening"); staged compliance; answering and/or acting back; redefining the situation (for example by using comedy to shift the encounter from intrusive to humorous); scening and flaunting (that is using the intrusion or attention for their own ends); and official and informal complaints. She found that "the most common restrictive behaviors women said they regularly engaged in related to being 'on guard' while in public, particularly when they are alone" (Gardner, 1995, 113). Similarly, Esther Madriz's (1997b) study of women's fear of crime based on interviews with Black, Latina and White women living in New York City revealed women's use of a range of bodily strategies to minimize the possibility of experiencing harassment as well as minimizing the harmful impact such harassment may have. Madriz conceptualized these behaviors in terms of self-isolation; hardening the target; strategies of disguise; looking for guardians; ignoring or denying fears; carrying protection; and fighting back, including accessing police protection.

Our own research has also shown the ways in which many women and girls learn to adapt their appearance and clothing (Kelly, 1988; Vera-Gray, 2016, 2018). In particular, one of us has argued that what underpins women's safety work is an understanding of the "unsafety of femininity" (Vera-Gray, 2018), with physical characteristics associated with a feminine appearance, such as long hair, jewelry, red dresses and lipstick, positioned by women as to be avoided either always or in particular contexts, such as being alone or at night. This underlying message of womanhood as a site of unsafety has implications not only for accessories and attributes that can be added or removed, but suggests something much deeper about a sense of unsafety entangled with the female body itself.

This leads on to a key but often missed form of safety work, a change to women's embodiment through the process of strategic alienation (Vera-Gray, 2016). Alongside a change to movements and clothing, some women try to find a way of being in the world without being wholly present, where to be present as a woman in public is to be vulnerable. Our work has found that one of the most obvious ways of doing this is through finding some kind of barrier, such as sunglasses or headphones, often used both to create a separation and to create the illusion of a separation between self and world (see Vera-Gray, 2016, 2018). This is not to claim that the use of such accessories is limited to women or that it is always about creating safety through distance. Sunglasses and headphones, like being distracted by a phone or choosing to sit somewhere a bit away from people on public transport, are also ways that people in general try to create a sense of their own private space in public. But this distancing can serve a particular purpose for women wanting to put some space between themselves and a world that feels unsafe, a distancing that for some comes to sit between themselves and their bodies. If a woman's body is unsafe in the world, and the 


\section{Fiona Vera-Gray and Liz Kelly}

risk is understood as not only being in the world but in the body itself, then reducing the risk means reducing the body. Instead of clothing then, the adaption here is to women's embodiment: a feeling of (or desire to be) smaller and less visible in the world.

However, the possibilities of invisibility are not available to all women in the same way. Here is where an intersectional perspective is as important to understanding the functions and meanings of safety work. Logan (2015) gives an excellent overview of the research on the importance of intersectionality when addressing public sexual harassment. Age, for example, can not only affect the level of harassment a women or girl experiences (see for example FRA, 2014; Madriz, 1997a), research has also found it greatly affects a woman's visibility. For younger women it can make it harder to disappear, while for women who are older, it can mean that invisibility is experienced but not necessarily desired (Vera-Gray, 2016). The impact of racialization has been shown not only in research (for example Chen, 1997; Fogg-Davis, 2006; Madriz, 1997a, 1997b) but also in the work of two of the UK's leading women's organizations. A powerful short film created by Imkaan, a specialist organization for groups working to challenge violence against women of color; and the End Violence Against Women Coalition (EVAW), a coalition of over 80 groups and individuals working on violence against women throughout the UK, uses women's testimonies to highlight the public sexual harassment of young women from black and minoritized ethnic groups (Imkaan, 2016). The accounts given reveal how such harassment works to produce a feeling of unbelonging heightened by an inescapable visibility-seen but discounted; a "recognition-based harm" (Vera-Gray \& Fileborn, 2018).

Sexuality also can make women more or less visible as targets for sexual harassment in public. Valentine (1993) addresses the ways in which heterosexual hegemony is reproduced and expressed through space through the ways in which a fear of violence inhibits the expression of lesbian and gay sexualities. Although she looks specifically at environments such as workplaces and hotels, her analysis can be extended into public space and applied to the experience of sexual harassment, with research suggesting, for example, that heterosexual women can often find a safety in being in public with their partner in ways unavailable to women with female partners (Steinbugler, 2005; Vera-Gray, 2016), and that butch lesbian, as well as queer masculine, women bear the brunt of homophobic violence against lesbians due to the (assumed) visibility of their sexuality (Inness \& Lloyd, 1995; see also MacKay, 2019 for a detailed discussion of the contemporary experience of butch lesbian and queer masculine identities).

With the importance of an intersectional approach in mind, we believe that more attention is needed in research and practice to understand the full extent and range of women's embodied safety work. Such methods of resistance, though often acknowledged in feminist studies of the early 1990s (Kelly, 1988; Kelly \& Radford, 1990; Stanko, 1990; Wise \& Stanley, 1987), have been less focused on more recently and are not captured in prevalence data on men's 
violence against women - the data relied upon for the claim that women's fear of crime outweighs their experience. It is here that we suggest safety work may provide a fourth explanation for the fear of crime paradox. Given that surveys attempting to measure the prevalence of sexual harassment in public are unable to account for the amount that is blocked, it is possible, though rarely acknowledged, that the safety work that women perform because of their fear of crime may in fact be reducing their levels of victimization. This would mean that it not so much a paradox we are seeing here but a relationship of effect, where the fear is having an influence on women's behavior and that this altered behavior may be reducing the amount of crime they experience. We conceptualize this as a different kind of paradox, a catch-22 based in the impossibility of achieving the "right" amount of panic.

\subsection{The right amount of panic}

The safety work that women conduct in public is not only in response to individual actions by individual men. Instead, the vast majority of women's safety work is conducted before anything happens "just in case". Women learn to adapt their behavior and movements, habitually limiting their own freedom in order to prevent, avoid, ignore, and ultimately dismiss what they experience as ordinary. Over time the repetition of this behavior comes to be unnoticed: what started off as work comes to be thought of as just common sense. This what we mean by safety work for women becoming a requirement, something a woman is rather than something a woman does. When it is not performed, or not performed successfully, women are perceived not only as having done something wrong, but as being something wrong.

This perception is reinforced by seemingly well-meaning campaigns and comments targeted at giving "safety advice" to women on how to prevent sexual violence. A clear example of this comes from Australia where, in 2018, Victorian police responded to the rape and murder of Eurydice Dixon by Jaymes Dodd, a male stranger who followed her through a public park, not with outrage over the man's actions but with a statement claiming that "people"-in this case a stand in for women-need to have more "situational awareness" (Davey, 2018). Such comments work to infantilize womenfocused on what is understood as reasonable advice, the underlying message is that women lack reason. They also fail to acknowledge the extent of work women already perform as a matter of habit. Eurydice Dixon was killed just 900 meters away from her home, soon after she had texted her boyfriend one of the "almost home safe" messages that many women are all too familiar with sending. These kinds of messages, rarely required in the same way of men, are just a small demonstration of just how situationally aware women and girls are, and are another form of gendered safety work that commonly goes unremarked.

Experiences of harassment from childhood through to their adult years, combined with routine safety advice, positioning women as responsible for preventing sexual violence, means that contrary to these kinds of police-led 


\section{6}

messages, many women have developed a highly attuned sense of their environment and those within it. Women talk about responding to the environment and intrusive men within it using an escalation calculation, drawing on a template of risk to evaluate the safest course of action (Vera-Gray, 2016). This evaluation includes not only an assessment of the man himself, but of the entire situation-including whether other people would intervene should the men's actions escalate. The calculation does not always end at the end of the encounter: it can continue after initial action is taken, assessing the consequences, adjusting the response. It is complex, nuanced, and skillful, looking forward to the future, drawing on lessons from the past, to establish how to act in the present. And yet none of this is acknowledged in comments such as those of the Victorian police, or in campaigns that encourage women to "look after" themselves and each other, such as those seen in England and many other countries worldwide (Vera-Gray, 2018). Instead, these comments, demonstrate just how unrecognized is the sheer scale of the work women already do. This lack of acknowledgment, though deplorable, is understandable when we examine the logic of safety work more closely. What we find is that it is not only the work itself that is invisible, but also the times it is successful.

The vast majority of women's safety work is pre-emptive; attempting to evaluate "the right amount of panic" (Vera-Gray, 2018) in a situation where they can only ever count the times it doesn't work. The problem here is that success is an absence of what might happen. As such, this absence can always be attributed to the fact that it was never going to happen at all. It is equally as likely, yet hardly ever considered, that sometimes, maybe many times, women are, without remark or recognition, preventing sexual violence. Sue Wise and Liz Stanley highlight how the possibility of women's success here is hidden from view: "The amount that sexual harassment is thwarted is a social invisibilitywe can't see that women have skillfully and successfully assessed and dealt with a complicated social situation because success here is an 'absence' of a predicted outcome" (Wise \& Stanley, 1987, 171).

What is revealed by examining the reasoning of safety work is that women are doomed to fail as the only times that we can measure are the times their strategies are unsuccessful. The pre-emptive nature of safety work is intended to prevent the very forms of escalation that would confirm whether such work was needed in the first place. With no way to know when they're getting it right, women are caught: blamed if they do not act to prevent sexual violence, yet unable to claim any success for the inevitable, numerous, times that they do. This means that there can never be a "right" amount of panic for women and girls in public places, no matter how much they are told to be more aware or to take more precautions. There can only ever be too much panic-because "nothing really happened" (Kelly \& Radford, 1990)—or not enough, because something did. Women are caught in a catch-22 which renders the work they do invisible, and as a consequence leads many academics to regard their fear of crime as a paradox. What is needed is a way of recognizing women's safety work for the expert negotiation that it is, as well as firmly locating it within an 
understanding of public space as gendered. We choose to end this exploration considering an avenue that we believe can do just this, although it fell into disrepute for several decades: feminist self-defense.

\subsection{Feminist self-defense as space for action}

Across contexts from Kenya to Canada, there is a growing dialogue seeking to reclaim feminist self-defense (Sarnquist et al., 2014; Senn et al., 2015). Although considered a radical intervention in the 1970s and incorporated into the services offered by many Rape Crisis Centers, critiques of self-defense led to ambivalence about its usefulness and its eventual replacement with prevention initiatives focused largely on giving information about what does and does not constitute sexual consent. Luckily, in the last decade, there has been a resurgence in considering its potential contribution to sexual violence prevention, a contribution that is based around the way it changes gender norms.

In Aoeteroa, New Zealand, a national network of accredited teachers of feminist self-defense has been in operation for over 30 years. Although originally targeting adult women, the Women's Self Defence Network Wāhine Toa (WSDN-WT) now focuses on school-aged girls, delivering their training to almost 10,000 girls each year, as well as delivering to women in communities that are specifically targeted for sexual violence due to geographic, cultural and/ or disability-related isolation. In 2016, the outcomes of this work was evaluated using the accounts of over 3,000 participants, from seven-year-old girls to adult women, including a high proportion who were Māori and Pasifika (Jordan \& Mossman, 2016). The results reveal that contrary to accusations that it is victim-blaming, feminist self-defense may in fact provide a crucial route for undoing how women and girls have been taught to blame ourselves. The evaluation found significant improvements in the importance girls and young women placed on help-seeking for themselves and others in the aftermath of sexual violence-suggesting the program helps to challenge the ways that women are taught to be silent.

This promising evaluation is not alone. A considerable body of research now exists showing that feminist self-defense has positive consequences for women, including increased self-esteem, capability, assertiveness, physical skills, and, crucially a reduction in women's fear of crime (Kelly \& Sharp-Jeffs, 2016). Studies on effective rape prevention have also shown that feminist self-defense is positively associated with rape avoidance, brings no increased risk of physical injury, and can form part of a support process in how it helps to reduce the levels of trauma symptoms experienced in the aftermath of an assault (Brecklin \& Ullman, 2004; Senn et al., 2015). Yet in spite of the weight of research in its favor, feminist self-defense is still misunderstood and misrepresented. Mention it today in relation to the prevention of sexual violence and you will usually be met by the questions and criticisms that seem to follow it regardless of evidence of its success. These largely revolve around the claims that self-defense only focuses on stranger attacks, it excludes women with physical limitations, and it 
upholds an individualist approach, focused on addressing violence just one woman at a time. There are also the long-standing arguments that prevention should be about changing men's behavior, not women's, and that ultimately self-defense is victim-blaming.

While we have previously addressed these critiques in detail (see Kelly \& Sharp-Jeffs, 2016; Vera-Gray 2018), we want to highlight here a key issue: that is, what we mean when we talk about self-defense. In contrast to the current exchange of freedom for safety that underpins much of women's safety work, and can ground self-defense approaches based on martial-arts techniques, we see feminist self-defense as focused not on increasing "safety" so much as on expanding women's "space for action" (see Jeffner, 2000; Kelly, 2003; Coy, 2009; Vera-Gray, 2016), a concept that builds on Norwegian sociologist Eva Lundgren's (1998) work on "life-space". While physical techniques can be learned and practiced, the fundamental skill taught in feminist self-defense is the belief not only in our own capability to respond in situations of immediate threat, but ultimately a belief in women's - all women's - right to be safe and free, and a confidence in their abilities to ensure this is respected. This marks a shift in what is meant by "self-defense" from the idea of it being about defending against an individual's actions, to the idea of a defense against the weight of gendered norms that situate women's bodies as something acted on rather than acted through. In such a reframing, self-protection becomes not only about protection during a possible event, but a way of building resilience and resistance to the weight of a society that positions women as weak, unreliable and unsafe.

Such a reorientation supports a return to earlier feminist efforts to create a right for women to occupy public space on the same terms as men. We see feminist self-defense as pushing against the taken-for-granted practices we noted earlier, that women should be smaller, less visible and unchallenging in public space. In this, it offers a possibility worth pursuing of women actually feeling they have a right to the city, that they can belong in public space on their terms, rather than gendered business as usual.

\section{References}

Bates, L. (2014). Everyday Sexism: The Project that Inspired a Worldwide Movement. London: Simon \& Schuster.

BeeBeejaun, Y. (2017). Gender, urban space, and the right to everyday life. Journal of Urban Affairs, 39, 323-334.

Brecklin, L. R., \& Ullman, S. E. (2004). Correlates of post-assault self-defense/assertiveness training participation for sexual assault survivors. Psychology of Women Quarterly, 28, 147-158.

Campbell, B. (1993). Goliath: Britain's Dangerous Places. London: Methuen.

Chen, Edith Wen-Chu. (1997). Sexual harassment from the perspective of Asian-American women. In C. R. Ronai, B. A. Zsembik, \& J. R. Feagin (Eds), Everyday Sexism in the Third Millennium. New York: Routledge, 51-62.

Coy, M. (2009). Milkshakes, lady lumps and growing up to want boobies: how the sexualisation of popular culture limits girls' horizons. Child Abuse Review: Journal of the British Association for the Study and Prevention of Child Abuse and Neglect, 18, 372-383. 
Crawford, V., Rouse, J. A., \& Woods, B. (Eds) (1990). Women in the Civil Rights Movement: Trailblazers and Torchbearers, 1941-1965. Bloomington: University of Indiana Press.

Davey, M. (2018). 'Men need to change': anger grows over police response to Eurydice Dixon's murder'. Guardian. 15 June 2018. www.theguardian.com/australia-news/ $2018 /$ jun/15/men-need-to-change-anger-grows-over-police-response-to-comedians (accessed 19 February 2019).

Farley, L. (1978). Sexual Shakedown: The Sexual Harassment of Women in the Working World. London: Melbourne House.

Federation of South African Women 1954-63 (2013). "Strijdom ... You have struck a rock”. Historical Papers Research Archive. Collection Number AD1137. Johannesburg. www.historicalpapers.wits.ac.za/inventories/inv_pdfo/AD1137/AD1137-Cb2-3-4001-jpeg.pdf (accessed 2 February 2019).

Fileborn, B. (2016). Justice 2.0: street harassment victims' use of social media and online activism as sites of informal justice. British Journal of Criminology, 57, 1482-1501.

Fishman, P. (1978). Interaction: the work women do. Social Problems, 25, 397-406.

Fogg-Davis, \& Hawley, G. (2006). Theorizing black lesbians within black feminism: a critique of same-race street harassment. Politics \& Gender, 2, 57-76.

Fox-Genovese, E. (1988). Within the Plantation Household: Black and White Women in the Old South. Chapel Hill: University of North Carolina Press.

FRA (2014). Violence Against Women: An EU-Wide Survey Main Results. European Union Agency for Fundamental Rights. http://fra.europa.eu/sites/default/les/fra2014-vaw-surveymain-results_en.pdf (accessed 2 February 2019).

Gardner, C. B. (1995). Passing by: Gender and Public Harassment. Berkeley: University of California Press.

Gardner, N., Cui, J., \& Coiacetto, E. (2017). Harassment on public transport and its impacts on women's travel behaviour. Australian Planner, 54, 8-15.

Greer, G. (1971). The Female Eunuch. New York: McGraw-Hill.

Hale, C. (1996). Fear of crime: a review of the literature. International Review of Victimology, 4, 79-150.

Hochschild, A. (1983). The Managed Heart. Berkeley: University of California Press.

Hsu, H. P. (2011). How does fear of sexual harassment on transit affect women's use of transit? Women's Issues in Transportation: Summary of the 4th International Conference, $2,85-94$.

Imkaan (2016). "I'd Just Like to be Free": Young Women Speak out about Sexual Harassment. www.youtube.com/watch?v=1J-qpvibpdU (accessed 26 August 2019).

Inness, S. A., \& Lloyd, M. (1995). "GI Joes in Barbie Land": recontextualizing butch in twentieth-century lesbian culture. The National Women's Studies Association Journal, $7,1-23$.

Jeffner, S. (2000). Different Space for Action: The Everyday Meaning of Young People's Perception of Rape. Presentation at ESS Faculty Seminar, University of North London.

Jordan, J., \& Mossman, E. (2016). Skills for Safety: An Evaluation of the Value, Impact and Outcomes of the Girls' and Women's Self Defence in the Community. WSDN-WT. http://wsdn.org.nz/research/ (accessed 26 August 2019).

Kearl, H. (2010). Stop Street Harassment: Making Public Places Safe and Welcoming for Women. Westport: Praeger.

Kelly, L. (1988). Surviving Sexual Violence. Oxford: Polity Press.

Kelly, L., \& Radford, J. (1990). 'Nothing really happened': the invalidation of women's experiences of sexual violence. Critical Social Policy, 10, 39-53.

Kelly, L. (2003). The wrong debate: reflections on why force is not the key issue with respect TO trafficking IN women for sexual exploitation. Feminist Review, 73, 139-144. 


\section{0}

Fiona Vera-Gray and Liz Kelly

Kelly, L. (2012). Standing the test of time? Reflections on the concept of the continuum of sexual violence. In J. Brown \& S. Walklate (Eds), Handbook on Sexual Violence (pp. xvii-xxvi). London: Routledge.

Kelly, L. (2016). The conducive context of violence against women and girls. Discover Society, I March 2016. Available at https://discoversociety.org/2016/03/01/theorisingviolence-against-women-and-girls/ (accessed 26 August 2019).

Kelly, L. (2017). Foreword. In F Vera-Gray (Ed.), Men's Intrusion, Women's Embodiment: A Critical Analysis of Street Harassment. Oxon: Routledge.

Kelly, L., \& Sharp-Jeffs, N. (2016). Knowledge and Know-How: The Role of Self-defense in the Prevention of Violence against Women. Report prepared for the Directorate General for Internal Policies, Citizen's Rights and Constitutional Affairs: Women's Rights and Gender Equality, European Union. www.europarl.europa.eu/supporting-analyses.

Koskela, H., \& Pain, R. (2000). Revisiting fear and place: women's fear of attack and the built environment. Geoforum, 31, 269-280.

Lewis, S. (2018). Sexual Harassment on the London Underground: Mobilities, Temporalities and Knowledges of Gendered Violence in Public Transport. Doctoral dissertation, Loughborough University.

Liddington, J. (2006). Rebel Girls: The Fight for the Vote. London: Virago.

Logan, L. S. (2015). Street harassment: current and promising avenues for researchers and activists. Sociology Compass, 9, 196-211.

Lundgren, E. (1998). The hand that strikes and comforts: gender construction and the tension between body and soul. In R. E. Dobash \& R. P. Dobash (Eds), Rethinking Violence Against Women (pp. 169-198). Thousand Oaks, CA: Sage.

Mackay, F. (2019). Always endangered, never extinct: exploring contemporary butch lesbian identity in the UK. Women's Studies International Forum, 75.

MacKinnon, C. A. (1979). Sexual Harassment of Working Women: A Case of Sex Discrimination. New Haven, CT: Yale University Press.

Madriz, E. (1997a). Latina teenagers: victimization, identity, and fear of crime. Social Justice, 24, 39-55.

Madriz, E. (1997b). Nothing Good Happens to Good Girls. Berkeley: University of California Press.

McGlynn, C., \& Johnson, K. (2018). It's time the government recognised the harm of upskirting and image-based sexual abuse. Huffington Post, 10 December 2018 (accessed 23 January 2019).

McGlynn, C., Rackley, E., \& Johnson, K. (2019). Shattering Lives and Myths: A Report on Image-based Sexual Abuse. Durham University; University of Kent. http://dro.dur. ac.uk/28683/ (accessed 27 August 2019).

Oakley, A. (2018). The Sociology of Housework (reissue). Bristol: Policy Press.

Pain, R. (1991). Space, sexual violence and social control: integrating geographical and feminist analyses of women's fear of crime. Progress in Human Geography, 15, $415-431$.

Pain, R. (2000). Place, social relations and the fear of crime: a review. Progress in Human Geography, 24, 365-387.

Phadke, S., Khan, S., \& Ranade, S. (2011). Why Loiter? Women and Risk on Mumbai Streets. London: Penguin.

Riger, S., \& Gordon, M. T. (1981). The fear of rape: a study in social control. Journal of Social Issues, 37, 71-92.

Rollins, J. (1985). Between Women: Domestics and Their Employers. Philadelphia: Temple University Press.

Salter, M. (2013). Justice and revenge in online counter-publics: emerging responses to sexual violence in the age of social media. Crime, Media, Culture, 9, 225-242. 
Sarnquist, C., Omondi, B., Sinclair, J., Gitau, C., Paiva, L., Mulinge, M., Corn, D., \& Maldonado (2014). Rape prevention through empowerment of adolescent girls. Pediatrics. 133, el226-el232.

Scott, S (2010). Writing our own history: storming the Wimpy bars. In D. Cameron, \& J. Scalon (Eds), The Trouble and Strife Reader (pp. 178-181). London: Bloomsbury.

Senn, C. Y., Eliasziw, M., Barata, P. C., Thurston, W. E., Newby-Clark, I. R., Radtke, H. L., \& Hobden, K. L. (2015). Efficacy of a sexual assault resistance program for university women. New England Journal of Medicine, 372, 2326-2335.

Stanko, E. (1990). Everyday Violence: How Women and Men Experience Sexual and Physical Danger. London: Pandora.

Steinbugler, A. C. (2005). Visibility as privilege and danger: heterosexual and same-sex interracial intimacy in the 21 st century. Sexualities, 8, 425-443.

Valentine, G. (1989). The geography of women's fear. Area, 21, 385-390.

Valentine, G. (1993). (Hetero) sexing space: lesbian perceptions and experiences of everyday spaces. Environment and Planning D: Society and Space, 11, 395-413.

Vera-Gray, F. (2016). Men's Intrusion, Women's Embodiment: A Critical Analysis of Street Harassment. London: Routledge.

Vera-Gray, F. (2018). The Right Amount of Panic: How Women Trade Freedom for Safety. Bristol: Policy Press.

Vera-Gray, F., \& Fileborn, B. (2018). Recognition and the harms of "Cheer Up". The Philosophical Journal of Conflict and Violence, II, 78-96.

Vickery, A. (1993). Golden age to separate spheres? A review of the categories and chronology of English women's history. The Historical Journal, 36, 383-414.

Wise, S., \& Stanley, L. (1987). Georgie Porgie: Sexual Harassment in Everyday Life. London: Pandora Press. 


\title{
12 Sexual harassment in public spaces in India
}

\section{Victimization and offending patterns}

\author{
Mahesh K. Nalla
}

\subsection{Introduction}

Over the past decade, sexual harassment $(\mathrm{SH})$ of women in public spaces as a form of violence against women has received considerable attention in both developing and developed countries. SH, an improper behavior that has a sexual dimension and intonations includes nonverbal, verbal, and physical actions, mostly by males, toward females at any time of the day or night (Neupane \& Chesney-Lind, 2014; Madan \& Nalla, 2016). By "sexual harassment in public spaces" we mean forms of SH provocations that are not limited to what occurs on public streets, parks, and marketplaces but includes public transport spaces such as buses, bus-stops, trains and train stations, and other public transit spaces.

India, like many other countries, is no exception to the occurrence of $\mathrm{SH}$ (Jagori \& UN Women, 2011). SH is widespread, particularly in mega-cities such as Delhi, where, for over 98 percent of the population, public transport (including taxis and auto-rickshaws) is the only means to get to work, school, or attend to family matters (Madan \& Nalla, 2016). The insecurities of urban spaces and $\mathrm{SH}$ in public spaces drew worldwide attention following an event that occurred in 2012 in Delhi, India. A 23-year-old woman was sexually harassed in a moving public bus by a group of young men, including the driver and the conductor. This harassment escalated to the victim being beaten-up, gang raped, and brutally tortured, resulting in her death. This incident, which later came to be referred to as Nirbhaya (the fearless, who tried to fight off the six offenders) drew thousands of protestors - facilitated through social media and the media-who spilled into the streets all over the country demanding government action to this extremely pervasive and much neglected form of violence against women.

While there is a smattering of literature on the subject in India, most of the prior work focuses on $\mathrm{SH}$ victimization in public spaces, and we found very little work that focuses on offenders. The aim of the current research is to examine the extent of sexual harassment in public spaces in India with a focus on victimization as well as the self-reported behaviors of offenders. Additionally, we examine the congruence between reported victimization rates and self-reported offending patterns as well as $\mathrm{SH}$ offending patterns of their male friends. 


\subsection{Theoretical considerations}

For many developing countries, particularly in South Asia, $\mathrm{SH}$ in public spaces remains a concern because of traditional cultures and religions that have a bearing on women's place in public spaces (Niaz, 2003). Prior research, which is grounded in the framework of the patriarchy, identifies structural forces that influence male dominance and masculinity, which in turn shape gender roles in social and economic spheres (Acker, 1992; Hearn \& Parkin, 2001). MacKinnon (1979), drawing on observations based on socio-cultural perspectives, noted that $\mathrm{SH}$ occurred in societies with unequal power distance and where sexual requirements are imposed on the "weaker" party, in this instance, women. The work of MacKinnon (1979) and others (e.g., Uggen \& Blackstone, 2004) suggests that men and women are socialized differently with varying expectations among genders. For instance, men are stereotypically expected to pursue qualities of domination, leadership, and sexual initiative while women are expected to be submissive and nurturing, resulting in men often pursuing women to gain power and self-interest (Luthar \& Luthar, 2007).

Other competing theoretical perspectives that shed light on and are relevant to SH victimization relate to work advanced by Cohen and Felson (1979), which suggests that victimization is likely to be higher when people remove themselves from their routine activities. This could lead people (in this case, women) to have diminished guardianship, creating more opportunities for motivated offenders. Applying these principles to SH, Ceccato (2014) observed that the likelihood of $\mathrm{SH}$ victimization occurring increases when a potential victim intersects with a motivated offender in the absence of or decreased vigilance. Victimization is often interconnected to personal and lifestyle characteristics, many of which are unavoidable, such as going to school, work, and running errands (shopping, visiting family, etc.) (Tseloni \& Pease, 2004). Furthermore, in countries such as India, which is the second-largest producer of fruits and vegetables in the world, women represent nearly 50 percent of those employed in the supply chain of fruit, vegetables, fresh produce markets and small businesses. This creates greater opportunities for them to be in public spaces (Gurung, 2006). For many of these women, public transportation is the only means to get around, and it is often inadequate relative to the population, resulting in overcrowding and thus creating greater vulnerability to women commuters (Parikh, 2018).

\section{Prior research on SH in public spaces in India}

A number of studies on $\mathrm{SH}$ of women in public spaces in both developed (Macmillan, Nierobisz, \& Welsh, 2000) and developing countries (for a review see Madan \& Nalla, 2016; Ceccato \& Paz, 2017) have addressed gender violence in public spaces. In India, in the past decade, many studies have addressed gender violence specifically related to sexual harassment. There were a few researchers who addressed women's safety and how they negotiate everyday 


\section{Mabesh K. Nalla}

risks in public spaces in metro cities such as Mumbai (Phadke, 2005; Bharucha \& Khatri, 2018), Kolkota (Sur, 2014), Chennai (Natarajan, 2016) and other smaller cities in northeastern India (Bhattacharyya, 2016). The findings from these studies show that an overwhelming percentage of the respondents reported public spaces as being unsafe due to fear of crime and victimization, with specifically fear of sexual harassment being the most significant factor. These findings highlight women's safety and fear of sexual violence in their everyday life, a finding echoed in Western research (Macmillan et al., 2000).

One of the earliest surveys examining the incidence of $\mathrm{SH}$ in public spaces (buses) prior to the Nirbhaya incident was conducted in the South Indian city of Chennai with a small sample of respondents $(N=100)$ (Chockalingam \& Vijaya, 2008). Findings showed a high incidence of female victimization in the age group of 15-35 who had experienced unwanted touching and groping. The offenders were described by their victims to be between 35 and 70 years old, well-dressed and seemingly educated, and targeting women who wore nontraditional South Indian clothes.

One of the most systematic studies done to assess $\mathrm{SH}$ victimization in public spaces in Delhi in $2010(N=5,000)$ highlighted the various forms of sexual harassment women face while in public spaces such as markets, bus terminals and roadsides (Jagori \& UN Women, 2011). The report found that nearly 66 percent of women and girls experience $\mathrm{SH}$ in public spaces with 51.4 percent reporting public transport buses as the most common public spaces where maximum sexual harassment occurs. This finding is not surprising given that, in metro cities such as Mumbai, an estimated 88 percent of the residents rely on public buses and metros, and in Delhi 43 percent of residential households rely on public transport (Badami \& Haider, 2007). The inadequate public transport services in India's cities contribute to overcrowded situations (Pucher, Korattyswaroopam, \& Ittyerah, 2004) making it easier for offenders to participate and escape detection after committing $\mathrm{SH}$.

Despite the significance of the Nirbbaya incident in 2012, very few studies have since been conducted in India that addressed this issue. One of the earliest studies following Nirbhaya was a study conducted with a small convenient snowball sample of 20 women, aged 18 to 30 years, from the middle and upper-middle classes in Delhi (Dhillon \& Bakaya, 2014). Interviews with respondents on their experiences in the city revealed that between 50 percent and 100 percent reported some form of $\mathrm{SH}$ as they commuted to work or walked to the market, to a movie theater, or, in essence, used public spaces.

One of the few large-scale systematic research studies was conducted in Delhi Metro area in 2014, drawing a sample of 1,387 males and females by employing a multistage cluster and quota sampling technique (Madan \& Nalla, 2016). The findings show that public transport was the main mode of transportation for nearly 99 percent of males and females. Compared with males (50.9 percent), females (26.8 percent) felt unsafe in public spaces and over half the women in the sample reported being a victim (57.6 percent) of $\mathrm{SH}$ or knew a friend or family member who was a victim (48.3 percent) in the last 12 months 
(Madan \& Nalla, 2016). Overall, while there is a general congruence between genders in terms of seriousness of $20 \mathrm{SH}$ behaviors, the differences, however minor, were statistically significant with women rating them as more serious (Madan \& Nalla, 2016).

A more recent study with a sample of 1,600 respondents who travel by public buses, drawn from multiple cities in India, reported that 554 (34.9 percent) reported sexual harassment with groping being the most frequent, more often than even catcalls and sexually-laced comments (Lea, D'Silva, \& Asok, 2017). A survey of 300 women in Mumbai, selected randomly from among those walking in the market areas and to and from metro stations, revealed that 77.2 percent experienced $\mathrm{SH}$ in the form of lewd comments, catcalls, and insinuating songs. Additionally, 30 percent reported stalking, 29 percent reported being groped, and 7 percent molested (Bharucha \& Khatri, 2018). Using a convenient but systematic sample of 200 female students from two women's colleges in Lucknow in the state of Uttar Pradesh, another study assessed the incidence and frequency of $\mathrm{SH}$ victimization experienced in a variety of modes of transportation, which included buses, taxi-cabs, threewheeled min-cabs (Tripathi, Borrion \& Belur, 2017). Findings from this study confirmed findings from prior research (Madan \& Nalla, 2016) in that of all forms of public transportation, buses were considered the least secure and 100 percent of the respondents indicated that they were either personally a victim or witnessed a physical or verbal form of SH. Given that data are from college students, the findings of the Lucknow study, as in other studies (Dhillon \& Bakaya, 2014; Neupane \& Chesney-Lind, 2014), finds young women at greater risk of SH. Findings from the central Indian city of Bhopal reveal that 88 percent of women were harassed while using public transport and 40 percent reported facing harassment on a regular basis (Bhatt, Menon, \& Khan, 2018). Interestingly, however, 100 percent of public bus drivers and conductors did not believe it was a prevalent issue and another 30 percent believe that women were equally responsible for SH perpetrated against them (Bhatt, et al., 2018).

Unlike serious sexual offenses such as rape, which has the propensity to occur more frequently among acquaintances and other non-strangers, $\mathrm{SH}$ is more prevalent among strangers (Macmillan et al., 2000). Among the reasons for the causes of $\mathrm{SH}$, the respondents felt that migrant men from small towns are not only patriarchal but "awed" by Delhi women who are independent and travel alone, prompting men to demean or sexually harass women to put them down (Dhillon \& Bakaya, 2014). The reasons attributed by female victims of SH for men engaging in SH were slightly different in another study from a Southern Metro city of Chennai. Natarajan (2016, p. 6) noted that college students attributed the reasons to patriarchy ("male domination," "discrimination," "cultural values"), differential ("socialization of boys and girls") and situational ("alcohol," "boredom," "more women seeking education and employment" and "lack of bystander intervention") reasons. Among the reasons attributed to males' behavior for this were a patriarchal mindset (77 percent), absence of fear of the law ( 57 percent), lack of effective police patrol (45 percent), poor street 
lighting (13 percent), and women's choice of apparel (11 percent). These findings are similar to other prior studies (Natarajan, 2016).

In summary, four major themes emerge from prior research. The first theme relates to women's fear of public spaces and the associated fear of victimization. The second thread relates to the high incidence and prevalence of victimization among younger women of various forms of $\mathrm{SH}$ occurring in a variety of public spaces. The third relates to gender differences in perceived seriousness of $\mathrm{SH}$. The final theme relates to victims' perceptions of why males engage in $\mathrm{SH}$. While this research adds to our understanding of $\mathrm{SH}$ prior research, with the exception of a couple of studies, findings are often drawn from sample sizes employing a convenient sampling framework with a focus exclusively on the incidence of $\mathrm{SH}$ in general with a limited focus on victims. This exploratory research therefore attempts to contribute to the sparse literature on $\mathrm{SH}$ with greater attention to offenders' self-reported participation in SH behaviors. More specifically, we examine (1) the gender differences in perceptions of imagery of what constitutes $\mathrm{SH}$; (2) a comparison of the awareness of $\mathrm{SH}$ laws and their enforcement between victims and offenders; (3) congruence in the rates of reported female victimization of SH and males' self-reported offending; and, (4) congruence between self-reported offending and male friends' participation in $\mathrm{SH}$.

\subsection{Current study}

\section{Context}

In India, street sexual harassment is euphemistically referred to as "eve-teasing", a long recognized social problem and a reference that trivializes the seriousness of various forms of offensive behaviors against women. This phrase interestingly, however, does not appear in any Penal Codes in India. Worse, such behaviors are not taken seriously, and are accepted as a minor nuisance and a lighthearted ritual associated with young men's transition to adulthood. Others suggest that these behaviors are often brushed off by men as jocular and lighthearted practices that are validated culturally across the country (Bhattacharyya, 2015).

Delhi, the National Capital Territory (NCT), India, with over 18 million people is the fifth most populous city in the world. Delhi has the highest recorded crime compared with all other geographic distributions in India according to the 2016 National Crime Record Bureau (NCRB) report (2017) and is considered one of the most unsafe cities in the world (Gaynair, 2013). Delhi NCT also reported the highest rate of crimes against women for rape and other sexual offenses per 100,000 women in India (86.96 compared to a national average of 22.16) (National Crime Records Bureau, 2015, p. 24). Among crimes against women, Delhi also has the distinction of highest rate of crimes per 100,000 relating to sexual harassment under the categories of Insult to the modesty of women (15.1 vs. 1.6 national average), and Assault on women with intent to outrage her modesty (47.9 vs. 13.7 national average) (National Crime Records Bureau, 2015, p. 32). 


\section{Data and method}

Data for the study were drawn from a larger study conducted in 2014. Drawing from prior work (Jagori \& UN Women, 2011; Neupane \& ChesneyLind, 2014), and contextualizing it to the local cultural setting, we constructed a survey questionnaire (bilingual, English and Hindi) drawing from various themes pertaining to sexual harassment in public spaces. A total of 20 sexual harassment behaviors were identified that fell into three broad categories (listed in Table 12.3, later): nonverbal, verbal, physical. In addition, all of these behaviors are cited as examples in the Indian Penal Code under various sections noted above. All respondents (both male and female) were asked to rate the seriousness of behaviors constituting sexual harassment on a seven-point scale $(0=$ not at all serious, $1=$ not serious, $2=$ less serious, $3=$ neutral, $4=$ somewhat serious, 5 = serious, $6=$ very serious).

\section{Sample}

Using multistage cluster and quota sampling strategies, we drew between 250 and 275 respondents from each of the five primary zones (North, East, West, South and Central) in Delhi, the capital city of India. Data collection for this study lasted nearly 60 days (pencil and paper method) and resulted in a total of 1,387 respondents ( male $=621 / 45$ percent; female $=766 / 55$ percent). The demographic breakdown of the respondents is presented in Table 12.1 .

The educational background of victims and offenders was fairly evenly distributed: primary $=23.3$ percent vs. 23.6 percent; secondary $=24.8$ percent vs . 22.4 percent; high school=22 percent vs. 29 percent; and, college and higher $=30.5$ percent vs. 24.8 percent. A similar distribution was apparent in monthly income levels ( 1 US\$ = Indian Rupees ₹ 72), for victims and offenders: those earning less than $₹ 10,000=54.8$ percent vs. 47.4 percent; $₹ 10,001$ to $25,000=23.5$ percent vs. 33.9 percent; and, those earning $₹ 25,001$ and more $=21.7$ percent vs. 17.7 percent. Nearly 77 percent of the victims and 65 percent of the offenders were ever married (includes currently married or married in the past).

Regarding place of residence, 92.9 percent out of 766 females live in Delhi. Among males, 87.8 percent of the 621 live Delhi. 93.8 percent of victims and 87.2 percent of offenders live in Delhi. However, relative to the number of victims (6.2 percent) who live on the fringes of the city (e.g., Noida, Ghaziabad, Gurgaon, and Faridabad), there were nearly twice as many offenders (12.8 percent) from outside Delhi. Given the small number of $N$ for participants living outside Delhi, these percentages appear exaggerated.

The primary purpose of the use of public transportation for the majority of victims (75 percent) compared with offenders (39.7 percent) was visiting friends, family and shopping. A majority of the offenders are employed (78 percent). However, 43.1 percent of offenders, compared with 5.8 percent victims use public transportation for work or business. This suggests that a 
Table 12.1 Descriptive statistics of victims $(N=467,60.7 \%)$ and offenders $(N=317)$

\begin{tabular}{|c|c|c|}
\hline Categories & $\%$ * victims & $\%$ * offenders \\
\hline \multicolumn{3}{|l|}{ Education } \\
\hline l = Primary education & 22.8 & 23.6 \\
\hline $2=$ Secondary education & 24.8 & 22.4 \\
\hline $3=$ High school & 22.0 & 29.0 \\
\hline $4=$ College and above & 30.5 & 24.8 \\
\hline \multicolumn{3}{|l|}{ Income (per month, in INR) } \\
\hline $1=$ Less than 10,000 & 54.8 & 47.4 \\
\hline $2=10,001-25,000$ & 23.5 & 33.9 \\
\hline $3=25,001$ and above & 21.7 & 17.7 \\
\hline \multicolumn{3}{|l|}{ Relationship status } \\
\hline $\mathrm{l}=$ Never married & 22.6 & 34.9 \\
\hline $2=$ Ever married & 77.4 & 65.1 \\
\hline \multicolumn{3}{|l|}{ Place of residence } \\
\hline 1 = Delhi & 93.8 & 87.2 \\
\hline $2=$ Around Delhi* * & 6.2 & 12.8 \\
\hline \multicolumn{3}{|l|}{ Public transport-purpose } \\
\hline $\mathrm{l}=$ Visit friends $/$ family $/$ shopping & 75.0 & 39.7 \\
\hline $2=$ School $/$ college & 16.2 & 17.7 \\
\hline $3=$ Work $/$ business & 5.8 & 43.1 \\
\hline $4=$ Other & 3.2 & 3.7 \\
\hline
\end{tabular}

majority of offenders who harass women are employees who commute to and from work.

\subsection{Imagery of sexual harassment}

One of the questions in the survey related to capturing respondents' imagery of behaviors that constitute SH. All females $(N=766)$ and males $(N=621)$ were asked to describe what sexual harassment means to them, to which 1,201 and 1,016 comments were received from females and males respectively. These responses were coded to group comments that fit into broader themes and categories (Figure 12.1). The most common imagery of $\mathrm{SH}$ for both females (28.1 percent) and males (26.7 percent) is sexual teasing/jokes and comments, suggesting a close resemblance between the two groups of respondents. An interesting imagery that was reported by both females and males are "forceful sexual relations/rape," which is a more violent form of sexual crime, and "forceful attempt to kiss/have sex". Although, comparatively, more females' (14.6 percent) compared with males' (9.3 percent) imagery of $\mathrm{SH}$ was described as rape, a similar disparity in the opposite direction was found for females (13.3 percent) and males (21.6 percent) regarding forceful attempt to kiss/have sex. Together, 


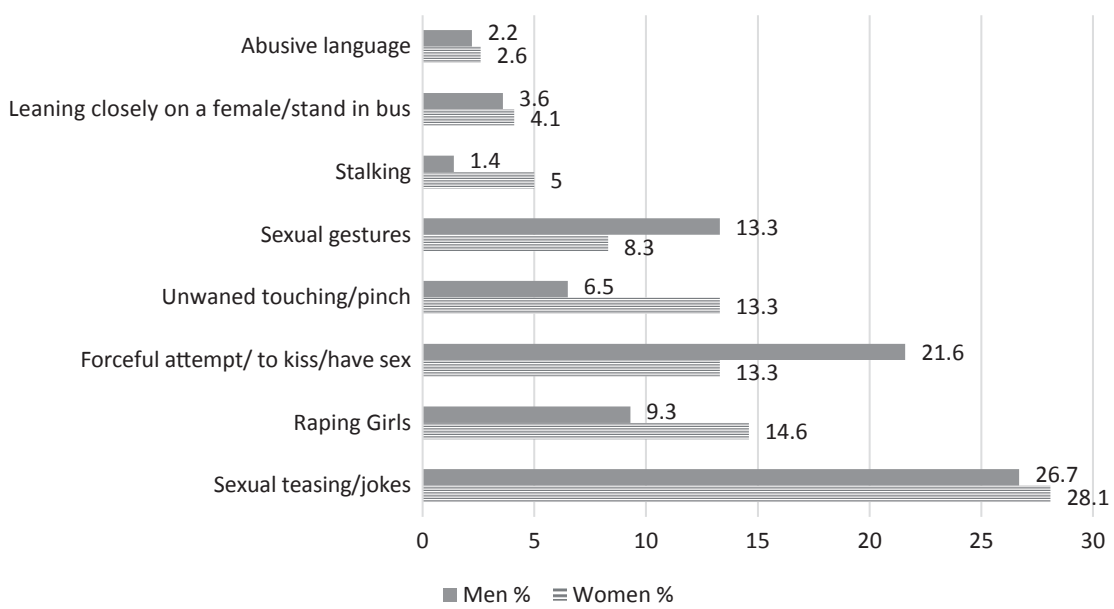

Figure 12.1 Percentage comparisons of the imagery of $\mathrm{SH}$ for females $(N=766)$ and males $(N=621)$

these two categories represented close to a third of all imagery related to sexual harassment. Nearly twice as many females (13.3 percent) compared with males (6.5 percent) described unwanted touching and pinching as imagery associated with $\mathrm{SH}$, while fewer females (8.3 percent) reported sexual gestures representing SH compared with men (13.3 percent). More women ( 5 percent $)$ described stalking as SH experience compared with males (1.4 percent) while the numbers and the gap for genders relating to leaning closely on a female or using abusive and profane language was rather small. Comments that were undecipherable or representing similar images noted in the figure were not represented.

\subsection{Profiles of victims and offenders-age}

The average age of the respondents is 36.3 years. The age range for the victims was 18 to 74 and the youngest age at which a victim first reported SH experience was 10 years of age. For offenders, the age range was 18 years to 80 years old; however, that survey did not have the question regarding the age at first time offending in the survey. Description relating to age break down for both victims and offender is presented in Figure 12.2. The trend lines suggest that there is a close alignment in spikes and lows for both groups for the ages around 24 through 50 years.

A closer look at the breakdown of age groups for prevalence of victimization and offending shows some categories that are more compatible. Twenty-seven percent of victims and 30.3 percent of the offenders were in the age group of 18 to 25 years. However, an overwhelming majority of 80.7 percent victims and 71.8 percent offenders were 40 years and under. Among the offenders, close to 


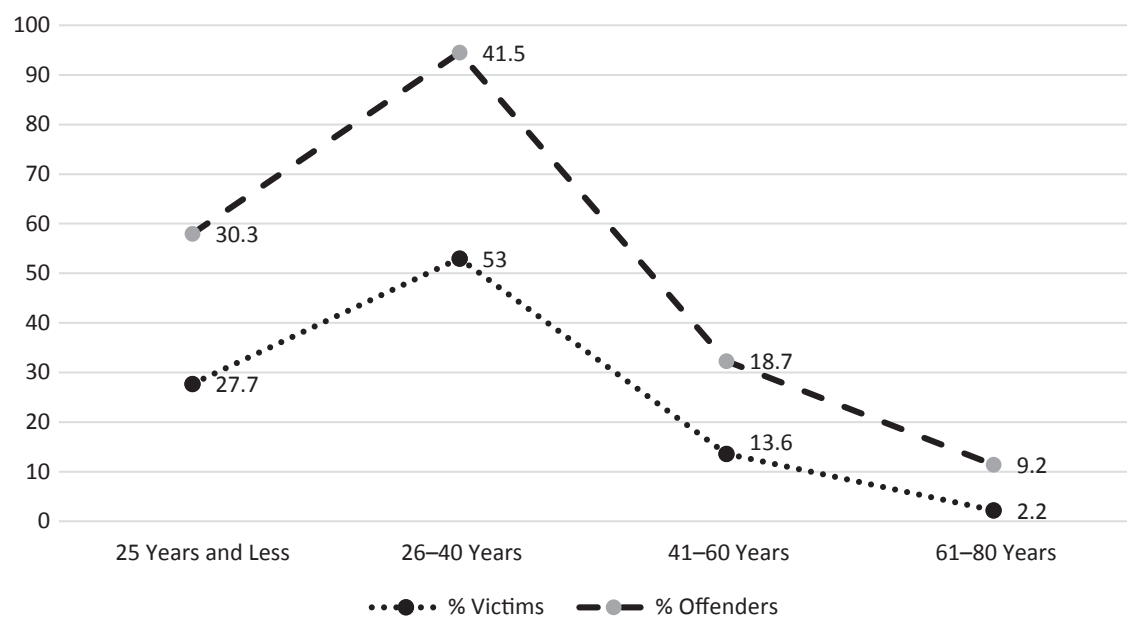

Figure 12.2 Frequency and age distribution of victims and offenders.

a third were 40 years and above with 12 percent in the age group of $41-50$, 6.7 percent in the age group of 51-60. A surprising finding from our data was that 9.2 percent of offenders were in the age group of 61 and above compared with only 2.2 percent of victims. Even more interesting is the finding of senior citizens $(N=11,3.4$ percent) self-reporting as offenders were in the age group of 70 and 80 years.

\section{Victims/offender views on awareness and effectiveness of SH laws}

A vast majority of the victims (83.5 percent) and offenders (95.8 percent) are aware of the Nirbhaya event (Figure 12.3). Surprisingly, however, only about two-fifths of the victims (38.1 percent) and offenders (42.2 percent) are aware of laws that punish $\mathrm{SH}$ offenders. Less than a third of victims believe the effectiveness of SH laws (30.8 percent vs. 29.2 percent) or that $\mathrm{SH}$ laws are effectively enforced (30.9 percent vs. 33.8 percent). However, the respondents had more positive views of the role of media in informing citizens about $\mathrm{SH}$ (58.5 percent vs. 46.9 percent).

\section{Victimization and self-reported offending}

From among the 766 females in the sample, 467 (61 percent) reported one or more forms of sexual harassment and 425 women ( 55.5 percent) knew a friend or family member who was victimized. Among the victims, 325 (42.2 percent) noted that they were harassed in the last 12 months, of whom a fifth were harassed at least once, 17.4 percent between two and five times, and 5 percent 


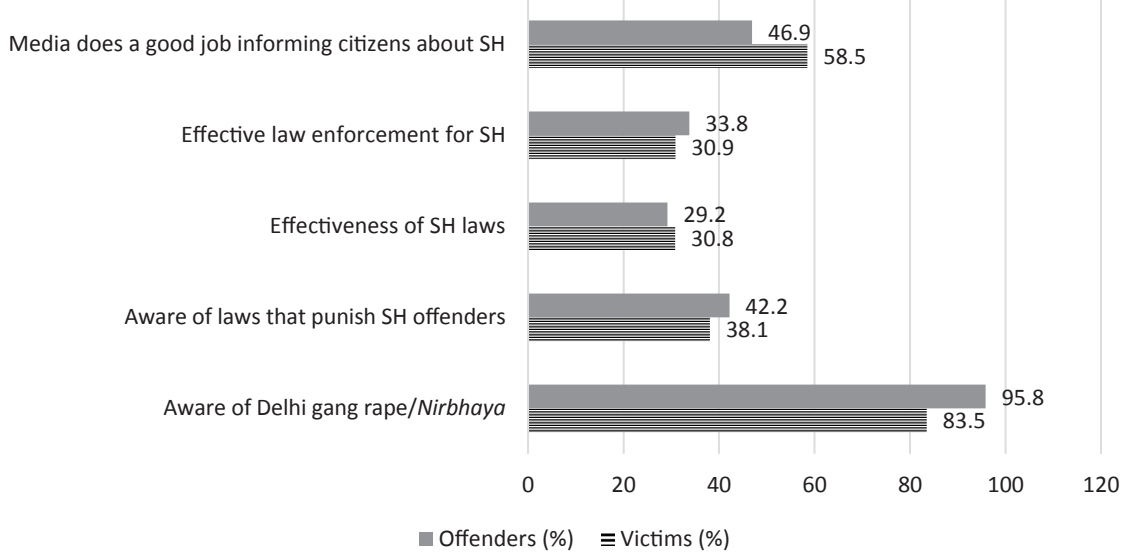

Figure 12.3 Percentage of victims $(N=467)$ and offenders $(N=317)$ awareness of SH laws and their effectiveness.

six or more times. Seventy-nine percent of these victimizations occurred during daytime. From among the sample of 621 males, 317 (51.l percent) reported to have engaged in one or more forms of sexual harassment. The SH self-reported offenders noted they know a male friend ( $N=389,62.6$ percent) who also engaged in $\mathrm{SH}$ offending.

In Table 12.2, we present the percentage comparisons of victims' reporting and self-reported offenders for 20 specific types of $\mathrm{SH}$ behaviors. In addition, for each behavior, we also presented the gap/concordance rates between the two. The findings are presented from the highest to lowest percentage of victimization experiences for each $\mathrm{SH}$ behavior. The top four forms of $\mathrm{SH}$ victimization are unwanted deliberate touch/pinching (80.9 percent), leaning closely on a female or pushing loosely/slowly (77.5 percent), standing close or brushing up against a female (68.2) and whistling (57.4 percent). In contrast, 60.5 percent of offenders admitted to leaning closely on a female or pushing loosely/slowly which was the highest percentage of self-reported $\mathrm{SH}$ behavior followed by standing close or brushing up against a female (46.2 percent), whistling (40.9 percent), and unwanted deliberate touch/pinching (38.4 percent). Compared with selfreported offending, between a third and half of all victims reported stalking (44.7 percent vs. 17.1 percent), referring as babe or honey or similar words (42.1 percent vs. 26.7 percent), unwanted sexual looks or gestures (41.3 percent vs. 7.5 percent), or using obscene or abusive language (39.1 percent vs. 9.5 percent). Among these behaviors, the largest gap or lack of concordance between victim and offender reports were found for unwanted sexual looks or gestures (33.8 percent), using obscene or abusive language (29.6 percent), and stalking (27.6 percent). It is unclear from the data if gaps exist in gender differences for certain types of non-verbal and verbal SH categories, particularly a behavior such as unwanted 
Table 12.2 Comparison of percentage of victimization $(N=467)$ and self-reported offending $(\mathrm{N}=317)$ of $\mathrm{SH}$ behaviors

\begin{tabular}{|c|c|c|c|}
\hline & Victims (\%) & Offenders (\%) & $\begin{array}{l}\text { Concordance } \\
\text { rate } \%\end{array}$ \\
\hline $\begin{array}{l}\text { Unwanted deliberate touch/ } \\
\text { pinching }\end{array}$ & 80.9 & 38.4 & 42.5 \\
\hline $\begin{array}{l}\text { Leaning closely on a female or } \\
\text { Pushing loosely/slowly }\end{array}$ & 77.5 & 60.5 & 17 \\
\hline $\begin{array}{l}\text { Standing close or brushing up } \\
\text { against a female }\end{array}$ & 68.2 & 46.2 & 22 \\
\hline Whistling & 57.4 & 40.9 & 16.5 \\
\hline Stalking/A stranger following you & 44.7 & 17.1 & 27.6 \\
\hline $\begin{array}{l}\text { Referring as a girl babe or } \\
\text { honey or similar words }\end{array}$ & 42.1 & 26.7 & 15.4 \\
\hline Unwanted sexual looks or gestures & 41.3 & 7.5 & 33.8 \\
\hline Using Obscene/Abusive Language & 39.1 & 9.5 & 29.6 \\
\hline $\begin{array}{l}\text { Unwanted sexual teasing jokes } \\
\text { remarks or comments }\end{array}$ & 30.1 & 11.3 & 18.8 \\
\hline $\begin{array}{l}\text { Kissing sounds howling and } \\
\text { smacking lips at a female }\end{array}$ & 29.3 & 12.5 & 16.8 \\
\hline Poking with penis & 26.6 & 6.2 & 20.4 \\
\hline $\begin{array}{l}\text { Sexual comments about the } \\
\text { clothing anatomy or looks }\end{array}$ & 25.8 & 8.7 & 17.1 \\
\hline Patting on the buttocks & 24.8 & 4.8 & 20 \\
\hline Putting hands on the shoulders & 23.4 & 10.3 & 13.1 \\
\hline Pulling or playing with the hair & 19.5 & 7.6 & 11.9 \\
\hline $\begin{array}{l}\text { Asking personal questions } \\
\text { about sexual life }\end{array}$ & 10.5 & 10.8 & 0 \\
\hline $\begin{array}{l}\text { Asked/asking for sexual } \\
\text { favor(s) }\end{array}$ & 8.9 & 5.9 & 4 \\
\hline $\begin{array}{l}\text { Showing pornography/ } \\
\text { naked pictures }\end{array}$ & 8.0 & 3.7 & 4.3 \\
\hline $\begin{array}{l}\text { Exposing genitals/masturbating in } \\
\text { front of the women }\end{array}$ & 3.8 & 2.5 & 1.3 \\
\hline
\end{tabular}

sexual looks or gestures as offenders may not be even aware their looks make women uncomfortable.

In the next categories comprising verbal and physical behaviors, compared with self-reported offenders, reported victimization of $\mathrm{SH}$ ranged from a third to one-fifth of total victimization rates. Among them are unwanted sexual teasing (30.1 percent vs. 11.3 percent), kissing/howling sounds/smacking lips (29.2 percent vs. 12.5 percent), poking with penis (26.6 percent vs. 6.2 percent), sexual comments about clothing/anatomy (25.8 percent vs. 8.7 percent), patting on buttocks (24.8 percent vs. 4.8 percent), putting hands on shoulders (23.4 percent vs. 10.3 percent), and pulling/playing with hair (19.5 percent vs. 7.6 percent). Of these, with the exception of pulling/playing with hair (11.9 percent) and putting 
hands on shoulders (13.1 percent), the remaining behaviors had a lower concordance rates with a gap of 17 to 20 percentage points.

Among the $20 \mathrm{SH}$ behaviors, about 10 percent or fewer victims and offenders reported $\mathrm{SH}$ experiences for four types. Among these, a comparison of victimization and self-reported offending numbers show asking personal questions about sexual life (10.5 percent vs. 10.8 percent), asked/asking for sexual favors (8.9 percent vs. 5.9 percent), showing pornography/naked pictures (8.0 percent vs. 3.7 percent), and exposing genitals/masturbating in front of women (3.8 percent vs. 2.5 percent). Of these behaviors, while the percentage of both victimization and offending were lower, the concordance rates were higher than all other forms of SH behaviors. Asking personal questions about sexual life (-0.3 percent) and exposing genitals/masturbating in front of women (1.3 percent) had the highest concordance rate while the other two had about 4 percent concordance rate.

A comparison between open-ended responses of imagery of what constitutes $\mathrm{SH}$ behaviors in Figure 12.3 and victimization rates reported in Table 12.1 show a glaring discrepancy for some categories. Though there are many other responses from the open-ended imagery question that resembles the language used in the $20 \mathrm{SH}$ behaviors listed in Table 12.2, we picked the six highest percentage responses. From among the six, just one category unwanted sexual teasing had the highest concordance rate for imagery and actual victimization (28.1 percent vs. 30.1 percent). The remaining five behaviors have a large gap in the percentage of imagery and actual victimization and are: unwanted deliberate touch/pinching (13.3 percent vs. 80.9 percent), leaning closely on a female or pushing loosely/slowly (4.1 percent vs. 77.5 percent), stalking (5 percent vs. 27.6 percent), unwanted sexual looks or gestures (8.3 percent vs. 41.3 percent), and using obscene or abusive language (2.6 percent vs. 39.1 percent).

\subsection{Self-reporting $\mathrm{SH}$ offenses versus their male friends' $\mathrm{SH}$ offenses}

In this study we also examine the concordance rates between self-reporting $\mathrm{SH}$ offenders and $\mathrm{SH}$ offending patterns of their male friends. Findings are presented in Table 12.3.

Findings from Table 12.3 show a rather high degree of correspondence between the self-reported offending patterns and those claimed to have been perpetrated by their male friends. With the exception of few behaviors (e.g., whistling, groping/squeezing breasts, and asking for sexual favors) which had a gap of 4 to 6 percentage points, the remaining behaviors differed by a margin of 3 percent or less. The greatest concordance between self-reported offending and offending by a friend was for leaning closely/pushing female, use of obscene language, patting on the buttocks, and unwanted deliberate touch/ pinching; and exposing genitals/masturbating in front of women. The congruence between self-offending and friend's offending may be a function of offenders' perpetration occurring in the company of friend/s. 
Table 12.3 Comparison of percentage of self-reported offending and offending by their male friends

\begin{tabular}{|c|c|c|c|}
\hline & Offender (\%) & $\begin{array}{l}\text { Offender's male } \\
\text { friend (\%) }\end{array}$ & Concordance \% \\
\hline $\begin{array}{l}\text { Unwanted deliberate touch/ } \\
\text { pinching }\end{array}$ & 38.4 & 37.4 & 1.0 \\
\hline Leaning closely/pushing female & 60.5 & 60.4 & 0.1 \\
\hline $\begin{array}{l}\text { Standing close/brushing } \\
\text { up against a female }\end{array}$ & 46.2 & 49.6 & -3.4 \\
\hline $\begin{array}{l}\text { Referring as a girl babe or } \\
\text { honey etc. }\end{array}$ & 26.7 & 24.3 & 2.4 \\
\hline Whistling & 40.9 & 34.9 & 6.0 \\
\hline Stalking/following you & 17.1 & 20 & -2.9 \\
\hline $\begin{array}{l}\text { Asking questions about } \\
\text { sexual life }\end{array}$ & 10.8 & 14.2 & -3.4 \\
\hline Obscene/Abusive Language & 9.5 & 9.9 & -0.4 \\
\hline $\begin{array}{l}\text { Sexual jokes/teasing jokes } \\
\text { remarks }\end{array}$ & 11.3 & 14 & -2.7 \\
\hline Pulling/playing with hair & 7.6 & 5.7 & 1.9 \\
\hline Kissing sounds/smacking lips & 12.5 & 10.1 & -2.4 \\
\hline $\begin{array}{l}\text { Sexual comments on clothing/ } \\
\text { anatomy/looks }\end{array}$ & 8.7 & 12.5 & -3.8 \\
\hline Asking for sexual favor(s) & 5.9 & 10.1 & -4.2 \\
\hline Sexual looks/gestures & 7.5 & 10.5 & -3.0 \\
\hline Putting hands on shoulders & 10.3 & 8.3 & 2.0 \\
\hline $\begin{array}{l}\text { Touching/rubbing/squeezing } \\
\text { breasts }\end{array}$ & 6.2 & 11.9 & -5.7 \\
\hline $\begin{array}{l}\text { Showing pornography/naked } \\
\text { pictures }\end{array}$ & 3.7 & 5.5 & -1.8 \\
\hline Poking with penis & 6.2 & 7.1 & -0.9 \\
\hline Patting on the buttocks & 4.8 & 4.3 & 0.5 \\
\hline $\begin{array}{l}\text { Exposing genitals/masturbating } \\
\text { in front of women }\end{array}$ & 2.4 & 3.6 & -1.2 \\
\hline
\end{tabular}

\subsection{Discussion}

In this study, we assessed victimization as well as offending patterns of $\mathrm{SH}$ in public spaces following the Nirbhaya event in 2012 in Delhi, India. One of the findings relates to perceived gender differences in the imagery related to what constitutes sexual harassment. Findings from this study suggests that imagery of SH for both a majority of offenders (30.9 percent) and victims (27.9 percent) produced an image of rape and forceful attempt to have sex, which according to the IPC are violent crimes against women and do not fall into statutes relating to sexual harassment. This finding may have some implications to understanding offenders' attitudes towards $\mathrm{SH}$ in general. That is, for some offenders, the propensity to engage in less serious forms of 
sexual violence (e.g., sexual teasing, comments, touching, etc.) may seem less harmful and more acceptable since they believe they are not engaging in what they believe is sexual harassment in the form of rape and forceful attempt to kiss or have sex with a woman. The data in this study does not offer the opportunity to tease out if such a disconnect between perceptions and actual behavior of offenders is present. Future research is well worthwhile pursuing if such a disjunction exists for some offenders.

A second finding from this research suggests that although over 95 percent of the victims and offenders are aware of Nirbhaya incident, more than half of them are not aware of the existence of laws that punish sexual harassment and close to two-thirds do not believe the effectiveness of these laws and their enforcement. This finding is critical from the perspective of $\mathrm{SH}$ prevention efforts for both victims and offenders. Clearly, government efforts to publicize the seriousness as well as the legal implications for violating SH laws is critical to preventing and mitigating these forms of crimes. Only about half of all victims and offenders believe the media does a good job of informing the public of the problem of SH. This suggests media outlets have to assume a greater role and responsibility in educating the larger population of the problem.

A third finding from this study relates to a presence of a wider age range for both victims and offenders along the age spectrum in comparison to prior research. For victims, consistent with prior literature, younger women have greater propensity for being harassed. However, findings from this study shed light on the age range of the victims that concentration of higher victimization rates is in the age group of $26-40$ years ( 53 percent). Overall, nearly 81 percent of the victims are in the age group of 18 and 40 years with the remainder in the age group of 41 and 80 years. Interestingly, however, of the latter group nearly 10 percent of all victims are 61 years and above.

Findings regarding self-reporting offenders from this research are perhaps a major contribution to the literature on SH. In contrast to the stereotype of the offender being young, good-looking, and well-educated (Natarajan, 2016), our finding shows a slightly different picture. Offenders' age groups are well distributed with about a third under 30 years of age, but, interestingly, 15.9 percent of all offenders are 51 years and above, stretching well into their 70 s. While 96 percent of all offenders heard and are familiar with the Nirbhaya case, they reported having committed $\mathrm{SH}$. Additionally, although fewer than half of the offenders $(42.2$ percent) knew there were punishments associated with $\mathrm{SH}$ offending, fewer than a third believed that neither the SH laws (29.2 percent) nor $\mathrm{SH}$ enforcement of laws (33.8 percent) were effective. These perceptions may have some impact on their behavior and willingness to engage in $\mathrm{SH}$.

\subsection{Limitations and implications for future research}

An important finding from this study is that for many of the $\mathrm{SH}$ behaviors included in this study, the concordance rates for victimization and offending is fairly significant for many categories, with the exception of behaviors that either 
require fairly deliberate physical contact or nonverbal behaviors that are obvious and noticeable (e.g., showing pornography, genitals, or masturbating in front of a woman). But for many other behaviors, there are considerable gaps or differences between the two groups. One factor to consider is the infrastructure surrounding mobility and public transport facilities in cities such as Delhi, which is woefully inadequate for the city's population size, and the consequences these factors have on women's experiences. Many of the behaviors recognized as SH in public spaces listed in research do not lend themselves to being convenient for filing formal complaints. For instance, SH behaviors in public spaces such as unwanted sexual comments or remarks about clothing or anatomy or leaning closely or pushing against a woman in crowded situations (a quick Google search for images of crowded buses in India will offer an imagery and context) can be vague and leaves no evidence. The researchers traveled in public buses to gain first-hand experience when the data for the study were gathered in Delhi in 2014. Often, there are long lines at public bus stops and metro stations most all day. When buses arrive at a bus stop, they are tightly packed and leaning like sardines and leaning to one side with the weight of the people hanging on to any little foothold they can find, leaving no room for people to either get out or get in. Passengers are often reluctant to move to let people out for fear of losing their spot on the bus as new passengers push in to find any standing room that is available. The conditions are often chaotic with every passenger's single-minded goal being to board the bus. Given these physical conditions, identifying the perpetrator or the motive for some of the SH behaviors in public spaces becomes complicated. These factors are important precursors for researchers and policymakers to pursue in efforts to ameliorate $\mathrm{SH}$ problems.

Another area for possible future direction in research relates to patterns of offending. The offending patterns of the self and male friends are closely aligned, suggesting a couple of possibilities. The first is that sexual harassment occurs in a group context; that is, rather than an offender acting out alone, they are more likely to perpetrate in groups. The second possibility is that for some SH behaviors where detection is likely (e.g., touching/squeezing breasts) the degree of risk associated with detection or confrontation may result in the offender being more voyeuristic and self-indulgent, resulting in a slighter bigger margin; that is, relatively less concordance with the offender's own behavior. Finally, for some behaviors (e.g., touch/pinching or leaning closely) that occur in packed, moving buses in Indian cities where entry and exit from buses is difficult, physical contact between humans is virtually impossible to avoid under such circumstances. Perhaps offenders and victims' perspectives on similar behaviors could differ in terms of offending and victimization. Unfortunately, we do not have the data to draw inferences to these assumptions other than to consider them as important issues for future research.

\subsection{Conclusion and policy implications}

Profound issues stemming from globalization and traditional cultural tendencies have created unfavorable settings for women in public spaces. $\mathrm{SH}$ as a specific 
form of sexual violence in South Asian countries draws greater attention because of the disjunction between the prevalence of sexual harassment and the governments' inability to counteract such phenomena (Niaz, 2003). Findings from this research draw attention to two important factors from policy perspectives. The first relates to mobility and access to quality public transit infrastructure to create a greater sense of safety and security for women to participate and contribute to the overall economic and social advancement of the nation. As evidenced in this study and others, infrastructure can play a large part in the degree and prevalence of SH (e.g., overcrowded buses). As such, a goal of any democratic nation should be to demonstrate fair and equal treatment of all its citizens, including keeping women safe from $\mathrm{SH}$ wherever possible.

The second factor relates to the state's demonstration of its ability to effectively enforce the laws to reach a degree of deterrence in the eyes and minds of potential offenders. The large number of $\mathrm{SH}$ offenders that do not believe the state has either effective laws or effective enforcement of SH laws speaks volumes and could increase boldness among perpetrators of violence against women in public spaces. In addition, the state educational departments could institute curricular changes to introduce subject matter in schools to educate and sensitize students to this subject from an early age. Finally, findings from this research also point to the importance of media in educating the public about criminal laws and penalties relating to $\mathrm{SH}$ for both potential victims and potential offenders. Given the large fan following that entertainment and sports personalities enjoy in India, the media can play a critical role in bringing public service messages and dedicated news coverage of this form of social problem to a larger audience.

\section{References}

Acker, J. (1992). Gendered institutions: from sex roles to gendered institutions. Contemporary Sociology, 21, 565-569.

Badami, M. G., \& Haider, M. (2007). An analysis of public bus transit performance in Indian cities. Transportation Research Part A: Policy and Practice, 41, 961-981.

Bharucha, J., \& Khatri, R. (2018). The sexual street harassment battle: perceptions of women in urban India. The Journal of Adult Protection, 20, 101-109.

Bhatt, A., Menon, R., \& Khan, A. (2018). Women's Safety in Public Transport: A Pilot Initiative in Bhopal. Gurgaon, India: WRI Ross Center for Sustainable Cities.

Bhattacharyya, R. (2015). Understanding the spatialities of sexual assault against Indian women in India. Gender, Place \& Culture, 22, 1340-1356.

Bhattacharyya, R. (2016). Street violence against women in India: mapping prevention strategies. Asian Social Work and Policy Review, 10, 311-325.

Ceccato, V. (2014). The nature of rape places. Journal of Environmental Psychology, 40, 97-107.

Ceccato, V., \& Paz, Y. (2017). Crime in São Paulo's metro system: sexual crimes against women. Crime Prevention and Community Safety, 19, 211-226.

Chockalingam, K., \& Vijaya, A. (2008). Sexual harassment of women in public transport in Chennai City: a victimological perspective. The Indian Journal of Criminology of Criminalistics, 29, 167-184. 


\section{Mahesh K. Nalla}

Cohen, L. E., \& Felson, M. (1979). Social change and crime rate trends: a routine activity approach. American Sociological Review, 44, 588-608.

Dhillon, M., \& Bakaya, S. (2014). Street harassment: a qualitative study of the experiences of young women in Delhi. SAGE Open, 4, 1-11.

Gaynair, G. (2013). ICRW survey: 95 percent of women and girls consider New Delhi unsafe. International Centre for Research on Women. www.icrw.org/news/icrwsurvey-95-percent-of-women-and-girls-consider-new-delhi-unsafe/ (accessed 19 August 2019).

Gurung, C. (2006). The Role of Women in the Fruit and Vegetable Supply Chain in Maharashtra and Tamil Nadu, India: The New and Expanded Social and Economic Opportunities for Vulnerable Groups Task Order Under the Women in Development IQC. Washington, DC: US Agency for International Development.

Hearn, J., \& Parkin, W. (2001). Gender, Sexuality, and Violence in Organizations. Thousand Oaks, CA: Sage.

Jagori \& UN Women (2011). Safe Cities Free of Violence Against Women and Girls Initiative: Report of the Baseline Survey Delhi 2010. New Delhi: Jagori \& UN Women.

Lea, S. G., D'Silva, E., \& Asok, A. (2017). Women's strategies addressing sexual harassment and assault on public buses: an analysis of crowdsourced data. Crime Prevention and Community Safety, 19, 227-239.

Luthar, H. K., \& Luthar, V. K. (2007). A theoretical framework explaining cross-cultural sexual harassment: integrating Hofstede and Schwartz. Journal of Labor Research, 28, 169-188.

MacKinnon, C. (1979). Sexual Harassment of Working Women: A Case of Sex Discrimination. New Haven, CT: Yale University Press.

Macmillan, R., Nierobisz, A., \& Welsh, S. (2000). Experiencing the streets: harassment and perceptions of safety among women. Journal of Research in Crime and Delinquency, 37, 306-322.

Madan, M., \& Nalla, M. K. (2016). Sexual harassment in public spaces: examining gender differences in perceived seriousness and victimization. International Criminal Justice Review, 26, 80-97.

Natarajan, M. (2016). Rapid assessment of "eve teasing" (sexual harassment) of young women during the commute to college In India. Crime Science, 5.

National Crime Records Bureau. (2015). Crime in India 2016. Delhi: Ministry of Home Affairs. https://timesofindia.indiatimes.com/realtime/Crime_in_India_2016_Complete_ PDF.PDF.

National Crime Records Bureau. (2017). Crime in India 2016. Delhi: Ministry of Home Affairs. https://timesofindia.indiatimes.com/realtime/Crime_in_India_2016_Complete_ PDF.PDF.

Neupane, G., \& Chesney-Lind, M. (2017). Violence against women on public transport in Nepal: sexual harassment and the spatial expression of male privilege. International Journal of Comparative and Applied Criminal Justice, 38, 23-38.

Niaz, U. (2003). Violence against women in South Asian countries. Archives of Women's Mental Health, 6, 173-184.

Parikh, A. (2018). Politics of presence: women's safety and respectability at night in Mumbai, India. Gender, Place \& Culture, 25, 695-710.

Phadke, S. (2005). "You can be lonely in a crowd" the production of safety in Mumbai. Indian Journal of Gender Studies, 12, 41-62.

Pucher, J., Korattyswaroopam, N., \& Ittyerah, N. (2004). The crisis of public transport in India: overwhelming needs but limited resources. Journal of Public Transportation, $7,1-20$. 
Sur, P. (2014). Safety in the urban outdoors: women negotiating fear of crime in the city of Kolkata. Journal of International Women's Studies, 15, 212-226.

Tripathi, K., Borrion, H., \& Belur, J. (2017). Sexual harassment of students on public transport: an exploratory study in Lucknow, India. Crime Prevention and Community Safety, 19, 240-250.

Tseloni, A., \& Pease, K. (2004). Repeat personal victimization: random effects, event dependence and unexplained heterogeneity. The British Journal of Criminology, 44, 931-945.

Uggen, C., \& Blackstone. A. (2004). Sexual harassment as a gendered expression of power. American Sociological Review, 69, 64-92. 


\title{
13 Does context matter?
}

\section{Older adults' safety perceptions of neighborhood environments in Sweden}

\author{
Vanessa Stjernborg and \\ Roya Bamzar
}

\subsection{Introduction}

The world is experiencing a demographic shift; as life expectancy increases, so too does the population of older adults. According to the United Nations (2018) this significant shift will have an impact on most sectors of society. Urbanization is another global trend causing major changes in our landscape, such as growing and divided cities, featuring segregation among other things (Ceccato, 2012). The stigmatization of urban areas and neighborhoods is repeatedly associated with insecurity, danger, and crime. One tangible development in urban areas in Sweden, for example, is the growing use of control technologies such as cameras, fences, door codes, and lockers in response to real and/or imagined insecurity in the city (Stjernborg, Tesfahuney \& Wretstrand, 2015). Such a development triggers fear of others and of public spaces, and it affects everyday mobility and housing access among other things (England \& Simon, 2010; Sandercock, 2005). Images of the city affect everyday geographies, and there is a long tradition of research that investigates the relation between fear and the city (e.g., Bannister \& Fyfe, 2001; Ceccato, 2012; England \& Simon, 2010; Shirlow \& Pain, 2003).

Urbanization and changing demographics also mean that increasing numbers of people will be ageing in urban environments (Burdett \& Sudjic, 2008; WHO, 2007), and fear of crime can be an issue of great concern for many older adults (e.g., Ceccato and Bamzar, 2016; Craig, 2018). Older adults, as a group, are often regarded as frail and vulnerable and are often considered to experience higher levels of fear in relation to their victimization (Craig, 2018). However, some researchers criticize the common view associating ageing with poor safety perceptions and point out that this phenomenon can create stereotypes of ageing and people's fearfulness (WHO, 2019a; Bazalgette et al., 2011; Pain, 1997, 1999).

In this chapter, we examine safety perceptions of older adults in two Swedish neighborhoods in different urban contexts: Stockholm and Malmö. This is achieved by reporting the everyday lives of older adults in these neighborhoods, with a special consideration to daily mobility, social participation, fear of crime, 
and behavioral responses. An important question is, how does fear affect daily life? The chapter draws upon in-depth data from two case studies, which serve as examples of how daily life may be affected by fear of crime in two different settings. The results point to interesting similarities and also important differences in relation to fear of crime and older adults' responses to that fear.

The chapter begins with a discussion of older adults and fear, in particular fear of crime. It then addresses questions about fear of crime in relation to everyday mobility, mental maps, and social participation. This is followed by a presentation of the two neighborhoods and the methods used. Thereafter, a synthesis of the results from the two cases is presented followed by a discussion about the experienced fear of crime and its possible triggers and its implications for older adults and their everyday mobility.

\section{Older adults and fear of crime}

Two decades ago, Pain (1999) called for a more critical approach to age as a demographic characteristic. She refers to age as something largely used by criminologists as a descriptive category; however, we argue here that it is essential to consider that older adults comprise a highly diverse group (e.g., Bazalgette et al., 2011; Pain, 1999). Although it has been shown that older adults often experience higher levels of fear of crime, studies focusing on the underlying mechanisms of such fear are still limited (De Donder et al., 2012), although not absent (e.g., Hanslmaier, Peter, \& Kaiser, 2018; De Donder et al., 2012; Bazalgette et al., 2011; De Donder, Verté, \& Messelis, 2005; Ziegler \& Mitchell, 2003). Bazalgette et al. relate the following:

... older adults are a highly heterogeneous group, therefore we must be wary of studies that feed into or are modelled on stereotypes that overemphasize the influence of age on people's experiences, without considering their other characteristics. Such stereotypes must be challenged....

(Bazalgette et al., 2011, p. 57)

Older adults are associated with a variety of stereotypical images that affect their lives in different ways and on different levels. There are many "misconceptions, negative attitudes and assumptions about older adults" (WHO, 2019a); for example, older adults are portrayed as weak, fragile and dependent, which creates substantial barriers and limits freedom and the possibility to take control over one's life. Recent studies suggest that stereotypes of older adults have become even more negative in recent years (Levy, 2017).

However, many of the opportunities and barriers in the lives of older adults have been shown to be influenced not so much by their age as by personal characteristics (e.g., gender, ethnicity, education, class) or by the broader context of their lives (e.g., De Donder et al., 2005; Pain, 1999). Studies have also found that factors such as marital status, health and disability, living in an urban or deprived area, and reading the newspaper regularly all significantly contribute to 


\section{Vanessa Stjernborg and Roya Bamzar}

the fear of crime in older age (see Bazalgette et al., 2011, p. 57). Other studies have identified the significance of loneliness, which is a result of the lack of participation in both social and cultural life (De Donder et al., 2005), and low levels of life satisfaction (Hanslmaier, 2013) as contributing to fear of crime in later life. Ziegler and Mitchell (2003, p. 173) state that " 'old age' per se is not the cause" of the fear of crime.

Charles and Carstensen (2009) found that, in addition to the devastating consequences of isolation and exclusion, social and emotional functioning changes little with age and that the need for social participation, for example, remains the same throughout life. However, Western culture often associates old age with negative qualities, considering it "a time of decline physically and mentally, and of social and spatial withdrawal" (Pain, 1999, p. 3).

\section{Everyday mobilities and the fear of crime}

A substantial body of literature has being developed that emphasizes the role context plays on mobility (e.g., Cresswell, 2010; Hanson, 2010). The new mobilities paradigm (Sheller \& Urry, 2006), or the mobilities turn (Urry, 2007), arose from the critique of the static view of movement-a critique directed at both social science and at the field of transport planning (Sheller \& Urry, 2006). Researchers emphasize the importance of including a wider perspective when studying the everyday mobility of people, which includes "social, cultural, and geographical context-the specifics of place, time and people" (Hanson, 2010, p. 8).

Regarding the specifics of place, older adults often have a strong relation to their home neighborhood (Scharf, Phillipson, \& Smith, 2003). However, different settings offer different conditions. For example, some researchers identify older adults in deprived neighborhoods as particularly vulnerable (Phillipson, 2004; Smith, 2009). However, it is important to keep in mind that fear of crime refers to a subjective and "emotional reaction characterized by a sense of danger and anxiety" (Garofalo, 1981, p. 840). There is also a substantial body of literature that shows that the relationship between fear and crime is not necessarily coherent (e.g., Rader, 2017).

\section{Mobility, mental maps and fear of crime}

Mobility is shaped by various tangible and intangible factors, some are individual others are contextual. Mental maps can be used to express a person's individual perceptions of different places and influence our views on where we would or would not like to live and which places we would like to visit or avoid (Gould \& White, [1974] 2002). Mass media and public discourses largely contribute to psychological and/or perceived barriers and often support the stigmatization of places (Wacquant, 2007; Rogers \& Coaffee, 2005). The news media has also been accused of contributing to the creation of mental and physical boundaries, which strongly influence our mental maps. Individual mental maps 
can affect where one goes and lead to avoidance behavior (e.g., Koskela, 1997) and to the adoption of certain mobility strategies, such as taking detours or talking on a mobile phone while walking home.

Four categories of behavioral responses to the fear of crime have been identified: avoidance behavior, protective behavior, behavior and lifestyle adjustments, and participation in relevant collective activities (categories developed by Miethe, compiled and presented in Jackson \& Gouseti, 2013). All of these behavioral responses involve restrictions in everyday life and everyday mobility. For example, older adults may avoid using public transport, or they might avoid certain places, neighborhoods, or types of people. Protective behavior includes activities that are thought to prevent crime (e.g., putting up fences) as well as activities aimed at self-protection and safety improvement (e.g., travelling in groups). Behavioral and lifestyle adjustments involve a withdrawal from activities that are considered dangerous, such as visiting bars or using public transport at night. Collective activities include participation in groups, such as neighborhood watch program activities directed at older adults' well-being (Jackson \& Gouseti, 2013).

\section{Social participation and fear of crime}

Social participation is about the involvement in activities that provide interactions with others in society or the community (see Levasseur et al., 2010, p. 2144). There is strong evidence that social cohesion and community participation are important dimensions of neighborhoods, often associated with positive health effects and well-being of the population (e.g., Dupuis-Blanchard, Neufeld, \& Strang, 2009; Mendes de Leon, 2005). With age and changing life situations, such as retirement, health conditions, loss of a partner or family members and friends, people's social networks decline (Oh \& Kim, 2009). A shrinking network in later life tends to increase the importance of external but local social contacts in the neighborhood (Stjernborg, 2017a; Campbell \& Lee, 1992). The neighborhood has also been identified as playing an important role in determining levels of fear of crime, and some studies have found that poor safety perceptions seem to be associated with the lack of social participation in the neighborhood (De Donder et al., 2005). Opportunities for developing social contact within a neighborhood are not, however, evenly distributed (Lager, Van Hoven, \& Huigen, 2015). In the next section, we introduce the two neighborhoods and some of their main important characteristics as the background of the analysis.

\subsection{Current study}

The study districts are two neighborhood areas, Hässelby Gård and Seved, which are located in the two major cities of Sweden, Stockholm and Malmö, respectively. The case of Hässelby Gård includes a sample of older adults living in senior housing (Hässelgården), while in the case of Seved, the researcher followed older adults living in general apartments in the area. Table 13.1 shows the characteristics of the two neighborhoods. 
Table 13.1 Characteristics of the two neighborhoods

\begin{tabular}{|c|c|c|}
\hline & $\begin{array}{l}\text { Hässelby Gärd } \\
\text { (in the city of Stockholm) }\end{array}$ & $\begin{array}{l}\text { Seved } \\
\text { (in the city of Malmö) }\end{array}$ \\
\hline Distance to city center & $\begin{array}{l}\text { Neighborhood on the } \\
\text { outskirts of Stockholm, } \\
15 \mathrm{~km} \text { from the city } \\
\text { center }\end{array}$ & $\begin{array}{r}\text { Centrally located } \\
\text { neighborhood }\end{array}$ \\
\hline $\begin{array}{l}\text { When most buildings were } \\
\text { constructed }\end{array}$ & $1950 \mathrm{~s}$ & $1930 \mathrm{~s}$ and $1940 \mathrm{~s}$ \\
\hline Number of residents & 11,300 residents $(2017)$ & 4,500 residents $(2015)$ \\
\hline Older people & $\begin{array}{l}\text { Approx. } 15 \text { percent } \\
\text { of the population }\end{array}$ & $\begin{array}{l}\text { Approx. } 8 \text { percent of the } \\
\text { population }\end{array}$ \\
\hline Land use of neighborhood & $\begin{array}{l}\text { Single-family and multi- } \\
\text { family housing, mostly } \\
\text { rental apartments } \\
\text { Centrum shopping area } \\
\text { Bar/restaurants } \\
\text { ATMs } \\
\text { Metro station }\end{array}$ & $\begin{array}{l}\text { Single-family and multi- } \\
\text { family housing. Both } \\
\text { rental and privately } \\
\text { owned apartments. } \\
\text { A common square with } \\
\text { some services such as } \\
\text { shops, a meeting } \\
\text { place for people in the } \\
\text { neighborhood, and so on } \\
\text { Close to public transport/ } \\
\text { bus }\end{array}$ \\
\hline Foreign background & $\begin{array}{l}\text { More than } 60 \text { percent of } \\
\text { the residents }\end{array}$ & $\begin{array}{l}\text { More than } 60 \text { percent of } \\
\text { the residents }\end{array}$ \\
\hline Income levels & $\begin{array}{l}\text { Lower than among people } \\
\text { who live in Stockholm } \\
\text { City in general }\end{array}$ & $\begin{array}{l}\text { Lower than among people } \\
\text { who live in Malmö City } \\
\text { in general }\end{array}$ \\
\hline Elderly fear of crime* & $\begin{array}{l}\text { Older population of } \\
\text { Hässelby Gård tend } \\
\text { to be more fearful than } \\
\text { those living in the city } \\
\text { center of Stockholm }\end{array}$ & $\begin{array}{l}\text { Residents of Seved tend to } \\
\text { be more fearful than } \\
\text { those in the district of } \\
\text { Södra Innerstaden in } \\
\text { general and even more } \\
\text { insecure than the average } \\
\text { resident of Malmö }\end{array}$ \\
\hline
\end{tabular}

Note

* According to Stockholm Municipality (2012) and Stjernborg et al. (2015).

The area in Hässelby Gård, which is a large neighborhood on the outskirts of Stockholm, is close to a metro station and other services. Hässelgården senior housing is located 15 kilometers from Stockholm city center, and it takes 40 minutes for the residents to commute to the central parts of the city by train. The property was built in 1973 and consists of four different blocks of five-story buildings, of which two blocks are rented by older citizens aged 65 years and older. Consequently, those apartments are segregated by age from the other buildings. One block is occupied by students, and the other block is a nursing and care home. Micasa Fastigheter (a subsidiary of Stockholm Stadshus) owns 
the housing development. A metro station, a supermarket, and a bank are all within a 500 meter walk from the senior housing. People who are 65 years and older and registered in the City of Stockholm have permission to apply for these apartments. The rental cost of Hässelgården senior housing is among the lowest in Stockholm. There are 119 apartments in this senior housing complex-of which one-third are studio apartments, and two-thirds are two-room apartments. Some of the apartments have been partially adapted to suit the needs of older adults.

Seved is centrally located in the city of Malmö and is close to public transport and city services. Most of the apartments are small, and living in crowded quarters is an ongoing problem. In the past decade Seved has attracted a great deal of negative media coverage. A critical discourse analysis of daily newspaper articles shows that the neighborhood is "predominantly construed as unruly and a place of lawlessness" (Stjernborg et al., 2015, p. 7).

A senior group was followed for almost one and a half years. The senior group is an initiative taken by the municipality to strengthen networking among older adults and to encourage social participation in the neighborhood. An adult education association, the city museum, the city theatre, and the city archives joined in co-operation, which is unique from a Swedish perspective. Around 20 activities were arranged in the same year. The activities are free for older adults and financed through a shared financing arrangement with a limited budget. Examples of activities within the neighborhood were traditional parties in the common square, activities involving children in the area, and city farming. Activities outside the neighborhood included visiting different museums and theatres, guided city tours, Christmas fairs, and barbeques at the beach.

\section{Data and methods}

In this chapter, comparative case studies are employed as a method to analyze and synthesize similarities, differences, and patterns across the two cases that focus on the fear of crime among older adults in two different settings in Sweden. Comparative case studies can use both qualitative and quantitative methods to capture similarities and differences among two or more cases that have a common goal of producing knowledge (Goodrick, 2014), which was the case in this study. Table 13.2 shows the characteristics of the older participants in the two cases.

In Hässelgården senior housing, a survey with 43 questions was conducted between June and August 2014. Most of the survey questions were structured, with a few open-ended questions. The questions focused on the older residents' use of space, safety perception, history of victimization, and fear of crime. A pilot test was conducted with six participants to enrich the design of the survey and the questions. Most of the participants declined to participate in face-toface interviews for different reasons. Overall, 27 of the 56 surveys given were collected (response rate 50 percent); of these, 37 percent were face-to-face interviews and the rest were questionnaires. Some comparisons were also made by using the Stockholm Safety Survey from 2014. 
Table 13.2 Characteristics of the participants in the two case studies

\begin{tabular}{|c|c|c|}
\hline Characteristics & Hässelgården Senior Housing & Seved Senior Group \\
\hline Gender & Around two-fifths females & A majority were females \\
\hline Age & $\begin{array}{l}\text { Around half of the participants } \\
\text { were younger older }(65-74) \\
\text { and half older }(75-85)\end{array}$ & $\begin{array}{l}\text { Mixed age (between } 60 \\
\text { and } 93 \text { years) }\end{array}$ \\
\hline $\begin{array}{l}\text { Number of people in } \\
\text { household }\end{array}$ & $\begin{array}{l}\text { A majority were living in a } \\
\text { single-person household }\end{array}$ & $\begin{array}{l}\text { A majority were living in a } \\
\text { single-person household }\end{array}$ \\
\hline Ethnicity & A majority were native Swedish & $\begin{array}{l}\text { A majority were native } \\
\text { Swedish }\end{array}$ \\
\hline Housing & $\begin{array}{l}\text { All participants were living in } \\
\text { senior housing }\end{array}$ & $\begin{array}{l}\text { All participants were living } \\
\text { in their own apartment }\end{array}$ \\
\hline Time of residence & $\begin{array}{l}\text { A majority had lived in their } \\
\text { apartments less than five years } \\
\text { (about one-fifth less than a } \\
\text { year) }\end{array}$ & $\begin{array}{l}\text { Most had lived in the } \\
\text { neighborhood for many } \\
\text { years (some for } 20-30 \\
\text { years, and a few had lived } \\
\text { there their whole lives) }\end{array}$ \\
\hline
\end{tabular}

Outdoor environmental features in the senior housing area and the immediate surroundings were inspected. Features included the presence of a resting area, proper lighting, dark/hidden corners, condition of the entrance area, and overall opportunities for natural surveillance. A multi-method approach was used to investigate the possible association between older adults' safety perceptions, their use of space and mobility, and characteristics of the environment.

In Seved, a qualitative approach was used: the researcher followed both a senior group and staff workers in the area. The senior group consisted of around 40 participants at the time of the study and was continually growing. The empirical material collection started in December 2011 and lasted until April 2013. During this time period, the researcher visited the Seved neighborhood on a regular basis, attended planning and working group meetings, and joined program activities, which required site visits a couple of times per month. The researcher became a familiar face among participants and staff. The empirical material collection ended after saturation (see Glaser \& Strauss, 1967).

The empirical material consists of participant observations, including conversations and field notes (carefully taken in a field diary in direct connection with every meeting/activity), and interviews, with the purpose of collecting observations, experiences, and reflections; therefore, it was a substantive sampling (Gold, 1997).

The interviews were conducted after participating in meetings and activities for almost one year. Seven participants were interviewed (six women and one man) through a convenience sample. The interviews were semi-structured, covering background questions about marital status, children, and other similar topics, and overall themes such as activities in everyday life, the neighborhood, social relations and participation, and safety perception. The interviews were 
tape recorded and transcribed. Multiple readings of the field diary and interviews were conducted for the analyses.

In both studies, the four categories developed by Miethe, and compiled and presented in Jackson and Gouseti (2013), were used as an analytical tool. Findings will be presented in the results showing similarities and differences between the two cases. Themes for discussion in this chapter are daily mobility, social interaction, fear of crime, and behavioral responses.

\subsection{Results}

Hässelgården senior housing is located in a neighborhood on the outskirts of Stockholm. Most of the older adults that participated in the study were newcomers (Table 13.1). A majority of them are women living alone, and their health status is generally good.

Seved is a centrally located neighborhood close to public transport and city life, and most of the participants have been living in the area for many years. They live both in two-person and single-person households, with a larger share in the latter. Participants' health status is varied; some have functional limitations and use walking aids, while others do not. Some make use of home care service, while others manage everyday life routines themselves.

\section{Daily mobility and social participation}

Most of the participants living in Hässelgården senior housing explain that they go out more often during summer, although they are active sometimes during the colder months of the year. Unexpectedly, most of the older adults prefer to go out after 4.00 p.m., when it is dark; this may be explained by the fact that, during those hours, there are more people in the streets, which may make them feel safer. Most of their social activities occur close to home, and on average, they go out once a day to run errands or take a short walk.

Because they belong to a senior group in Seved, older adults are all quite active and strive to go out every day. The municipality is behind this initiative, making an important contribution to promote social participation among older people who otherwise would risk loneliness and exclusion. For some of the participants, the senior group has given "life a new meaning", as one of them explained. Most of the older adults agree that they are out more as a result of being part of the senior group, and therefore they have increased mobility because of a larger social network and more daily activities. Increases in mobility mainly involve walks within the neighborhood with friends from the senior group, walks to the meeting place from home, and trips outside the neighborhood through arranged activities.

\section{Fear of crime}

The results show that older adults in Hässelgården display a higher level of fear of crime compared with the older adults living in the same neighborhood or 
Table 13.3 Summary of the results of the two cases

\begin{tabular}{|c|c|c|}
\hline Results & Hässelgården Senior Housing & Seved Senior Group \\
\hline $\begin{array}{l}\text { Social participation/ } \\
\text { daily mobility }\end{array}$ & $\begin{array}{l}\text { Participants often socialize } \\
\text { inside the senior housing. } \\
\text { Most participants try } \\
\text { to go out every day to } \\
\text { do errands or take a short } \\
\text { walk }\end{array}$ & $\begin{array}{l}\text { Participants often } \\
\text { socialize outside in the } \\
\text { neighborhood-taking } \\
\text { walks, doing different } \\
\text { activities at the local } \\
\text { meeting place, and so on. } \\
\text { Most participants try to } \\
\text { go out every day }\end{array}$ \\
\hline $\begin{array}{l}\text { Places considered } \\
\text { unsafe }\end{array}$ & $\begin{array}{l}\text { Areas that can be regarded } \\
\text { as more isolated, for } \\
\text { example, the petrol } \\
\text { station and bus station }\end{array}$ & $\begin{array}{l}\text { None expressed explicitly, } \\
\text { but many of the } \\
\text { participants mentioned a } \\
\text { street under camera } \\
\text { surveillance as an example } \\
\text { for not being } \\
\text { afraid in the neighborhood } \\
\text { ("they even walk on this } \\
\text { particular street") }\end{array}$ \\
\hline \multicolumn{3}{|l|}{ Behavioral responses } \\
\hline \multirow[t]{2}{*}{ - Avoidance behavior } & $\begin{array}{l}\text { Not going out in the } \\
\text { neighborhood at certain } \\
\text { times of day when there } \\
\text { are fewer people } \\
\text { around }\end{array}$ & $\begin{array}{l}\text { Not being out late in the } \\
\text { evening, which appeared } \\
\text { to be a common strategy } \\
\text { for many of the older } \\
\text { persons }\end{array}$ \\
\hline & $\begin{array}{l}\text { Not walking or residing } \\
\text { in the places declared to } \\
\text { be unsafe }\end{array}$ & $\begin{array}{l}\text { Avoiding places outside the } \\
\text { neighborhood such as } \\
\text { lively commercial streets } \\
\text { in the city center } \\
\text { (mentioned by a few } \\
\text { of the participants) }\end{array}$ \\
\hline \multirow[t]{2}{*}{ - Protective behavior } & $\begin{array}{l}\text { Staying in the immediate } \\
\text { environment around the } \\
\text { building, which is } \\
\text { surrounded with bushes } \\
\text { and other "boundaries" } \\
\text { separating the public and } \\
\text { private spaces }\end{array}$ & $\begin{array}{l}\text { Crossing the street or } \\
\text { choosing another route } \\
\text { to avoid, for example, } \\
\text { a group of youths who } \\
\text { are standing on the } \\
\text { pavement }\end{array}$ \\
\hline & & $\begin{array}{l}\text { Being accompanied by } \\
\text { somebody else if going } \\
\text { out in the evening }\end{array}$ \\
\hline $\begin{array}{l}\text { - Behavior and } \\
\text { lifestyle } \\
\text { adjustments }\end{array}$ & $\begin{array}{l}\text { By choosing a longer route } \\
\text { to do the daily shop; the } \\
\text { shorter route feels less safe } \\
\text { because it passes a bar and } \\
\text { there are fewer people } \\
\text { around (distance decay } \\
\text { strategy) }\end{array}$ & \\
\hline $\begin{array}{l}\text { - Participation in } \\
\text { relevant collective } \\
\text { activities }\end{array}$ & $\begin{array}{l}\text { Mainly conducting collective } \\
\text { activities close to their living } \\
\text { environment }\end{array}$ & \\
\hline
\end{tabular}


elsewhere in Stockholm. Around two-fifths of the study participants declare poor levels of perceived safety when they are outside in their own neighborhood. The areas near the petrol station and bus stops are regarded as the most threatening, as both are surrounded by high-rise buildings, desolate streets, and parking lots, which often reflect a lower level of natural surveillance. Compared with the Stockholm Safety Survey results, there are commercial areas near the metro station with many shops in the neighborhood of Hässelby that are regarded as unsafe by the older residents. The same patterns are observed on a city level. A majority of the older adults feel less safe in the city's large shopping and entertainment areas.

In Seved, few of the older adults agreed with the unsafe picture of the neighborhood portrayed by the media, which they think is grossly exaggerated. Only one of the residents suggested feeling unsafe when leaving home. This person was new in the group and referred to reports in the news media about the dangers of Seved. However, after being a part of the group for a couple of months, he gradually came to feel safer in the area.

Several seniors in Seved emphasized changes in the residential composition of the resident population and mentioned immigrants as the new neighborhood "problem", and they spoke of how empty apartments led to an influx of families. According to them, this inflow, paired with increased vandalism and other disturbances, gives the impression that it is a low-income neighborhood. Despite this, they claim that overall they feel safe being outdoors in the neighborhood. They often mention that they know people in the area and, for example, regularly meet younger people or people with other cultural backgrounds when they are out in the area.

\section{Behavioval responses}

Table 13.3 shows that older adults in both Hässelgården and Seved show signs of behavioral responses due to fear. Older adults in Hässelgården can choose to take a longer route and walk farther to the shops for their daily needs, as they feel safer taking that route even though they could take a shorter one to a closer shopping area. The closer shopping area is associated with bars, which some of the seniors regard as unsafe or risky.

Results from Hässelgården also suggest that safety perceptions follow a distance decay from older adults' homes; they feel safer close to home (such as an entrance or around in garden areas) but less so as the distance increases from these locations. The garden areas are surrounded with bushes, which may discourage strangers from entering the area. The physical design, outdoor furniture, and flower beds create a sense of ownership in clear and specific zones, so residents feel a sense of belonging to this area, an extension of the building. The area includes seating with a clear view of the garden, allowing for social interaction, and it is visible from windows and balconies. Natural surveillance is possible year round because the area is surrounded by low-rise buildings. In the summer, residents gather in the garden weekly to barbeque and socialize. 
During this meeting time, they may plan a collective activity, such as watching a movie or exercising. As suggested by Jackson and Gouseti (2013), these collective activities at the entrance ensure safety.

Protective behaviors mentioned by some seniors in Seved include crossing the street or choosing another route if, for example, some young people are standing on the pavement, which might be an indication on the "fear of others" (Sandercock, 2005). They may avoid going out by themselves when they have to go out in the evenings. Avoidance behavior also occurred in that many of the older adults chose not to be out late in the evening (time avoidance).

The older adults in Seved were influenced by the negative media reports. None of them had witnessed anything extraordinary happen on Rasmusgatan (a street that has repeatedly been given negative exposure in mass media), but teenagers and young people are often visible there. Several of them said that they "even walk on Rasmusgatan", which is a way of emphasizing that despite the risk they express their agency and walk freely in the whole neighborhood.

Several of the older adults also spoke about how other people tell them to be careful, based on what they have heard and read about Seved. They describe this as inconvenient, as they do not agree. Remarkably, some of the Seved residents refer to the fear of being victimized in other places outside the neighborhood based on what they have read in the newspapers, and a few of them avoid those areas, regarding them as too risky (often these are lively commercial streets in the city center).

\subsection{Discussion of the results}

Results show that older adults in both Hässelgården and Seved expressed behavioral responses due to the perceived risk of being victimized by crime where they live. Older adults described how fear of crime led to avoidance behavior as initially described in previous studies (Koskela, 1997, Jackson \& Gouseti, 2013). In the case of Seved, those behaviors mostly meant time avoidance. In the case of Hässelgården, poor safety perceptions led to both time and place avoidance (e.g., feeling compelled to take longer routes for daily shopping, taking detours or avoiding being out in the late evenings). Older adults were influenced by their mental maps of risk (e.g., Koskela, 1997), which affect their everyday mobility in different ways. For the older adults in Hässelgården, fear of crime meant behavior and lifestyle adjustments as well, such as participation in collective activities but mostly restricted to indoors or close to the senior housing.

There is a common notion that older adults are more likely than others to express fear and some refer to older adults in deprived areas as particularly vulnerable. This is certainly true for some, but not necessarily all in our areas of study. Despite the reputation of several safety problems in Seved, the neighborhood was overall perceived by senior residents as fairly safe. In Hässelgården, the picture was different. Older adults had their mobility limited by rumors of crime.

According to the World Health Organization, stereotypes of being fearful can exclude and marginalize older adults in their communities (WHO, 2019a, 2019b). 
Municipal efforts on behalf of older adults in Sweden are largely based on age-segregated meeting places offering inside activities. Different forms of agesegregated housing have increased as well (e.g., 55-plus living or 65-plus living), often located in the outskirts, which among other things means that more and more older adults are dependent on having sufficient public transport options to be able to continue being active citizens.

Based on stereotypes and the notion that older adults are more fearful than other groups, the participants from Seved should hypothetically experience fear of crime in daily life. They live in a neighborhood often described in the media as "lawless" (Stjernborg, 2017b, 2015) and portrayed as a neighborhood with socio-economic challenges. Yet, findings shows indications that this is not the case. In Seved, despite health and functional limitations, older adults were all active at the time of the study, and a common notion is that "the senior group" has given their lives a new meaning and most certainly also been a contributing factor for place attachment and reducing feelings of fear. Similarly, previous research has highlighted the relationship between place attachment and the fear of crime (e.g., De Donder et al., 2005).

In Hässelgården senior housing, people live in an age-segregated area, which may limit social participation and contacts with other residents in the area. Most of the study participants were also newcomers to the neighborhood. This might be part of the reason why residents in Hässelgarrden seem to have more behavioral responses to the fear of crime than older adults in Seved senior group. In other words, older adults in Seved had all been living in the area for a long time. They were active (despite functional limitations), went outdoors daily, and knew people in the area. The older adults in Hässelgården generally did not have a large social network in the neighborhood. Despite running daily errands, they often socialized indoors, which can be regarded as their "comfort zone". In addition, Hässelgården is a larger neighborhood in the outskirts of Stockholm, which may trigger feelings of fear because of distance to basic services. In addition, living in an age-segregated area may partially explain the residents' fear of crime, given that they may talk, spread the word, or even exaggerate when hearing about someone else's victimization.

\subsection{Conclusion}

The aim in discussing these cases has been to contribute to a more in-depth discussion about the role of context in characterizing safety perceptions in later life. The two cases, showing the experiences of older adults in these two different settings and contexts, have served as examples of how daily life may be affected by fear of crime.

Although residents of the two neighborhoods show some similarities in terms of socio-economic/demographic status at the individual and neighborhood levels, the importance of the context (both social and geographical aspects) in the discourse of older adults' fear of crime cannot be overlooked. Even though the conclusions in this study are exploratory and further studies 


\section{Vanessa Stjernborg and Roya Bamzar}

are needed to confirm some of the relationships illustrated in this chapter, the meaning of social participation in the neighborhood should be highlighted. In efforts to better meet the needs of older adults and to develop age-friendly neighborhoods, the role of the context of daily life should be further investigated. It is also important that municipalities and other actors understand their roles in supporting a "healthy ageing" (WHO, 2019c). Feelings of fear might lead to restricted daily mobility and can have a negative effect on social participation, which in turn can cause exclusion and lead to more fear.

The example of initiatives that engage older adults (as shown in Seved) illustrates the importance of supporting mobility of older adults from several angles, for healthy ageing, creating opportunities for social participation and creating integrated and vital neighborhoods. However, from a Swedish perspective, such efforts are unusual, and much of the currently routines are grounded on the idea of age-segregated meeting places and age-segregated housing, which might limiting older adults to indoor activities. Nevertheless, since this study is limited in character, future research should be devoted to the role of context for everyday mobility in later life. Equally important are future studies that can assess the effectiveness of initiatives for older adults that enhance social participation locally, everyday mobility and ensure viable and age-friendly cities.

\section{References}

Bannister, J., \& Fyfe, N. (2001). Introduction: fear and the city. Urban Studies, 38(5-6), 807-813.

Bazalgette, L., Holden, J., Tew, P., Hubble, N., \& Morrison, J. (2011). "Ageing is not a policy problem to be solved ...”: Coming of age. Demos report, www.lgcplus.com/ Journals/3/Files/2011/4/7/Coming_of_Age.pdf (accessed 10 January 2019).

Burdett, R., \& Sudjic, D. (Eds.) (2008). The Endless City. London: Phaidon Press.

Campbell, K. E., \& Lee, B. A. (1992). Sources of personal neighbor networks: social integration, need, or time? Social Forces, 70(4), 1077-1100.

Ceccato, V. (Ed.). (2012). The Urban Fabric of Crime and Fear. Heidelberg, New York: Springer Dordrecht.

Ceccato, V., \& Bamzar, R. (2016). Elderly victimization and fear of crime in public spaces. International Criminal Justice Review, 26, 115-133.

Charles, S. T., \& Carstensen, L. L. (2009). Social and emotional aging. Annual Review of Psychology, 61, 383-409.

Craig, M. D. (2018). Fear of Crime among the Elderly: A Multi-method Study of the Small Town Experience. Florence: Routledge.

Cresswell, T. (2010). Towards a politics of mobility. Environment and Planning D, $28,17-31$.

De Donder, L., De Witte, N., Buffel, T., Dury, S., \& Verté, D. (2012). Social capital and feelings of unsafety in later life: a study on the influence of social networks, place attachment, and civic participation on perceived safety in Belgium. Research on Aging, $34,425-448$.

De Donder, L., Verté, D., \& Messelis, E. (2005). Fear of crime and elderly people: key factors that determine fear of crime among elderly people in West Flanders. Ageing International, 30, 363-376. 
Dupuis-Blanchard, S., Neufeld, A., \& Strang, V. (2009). The significance of social engagement in relocated older adults. Qualitative Health Research, 19, 1186-1195.

England, M. R., \& Simon, S. (2010). Scary cities: urban geographies of fear, difference and belonging (Special issue). Social \& Cultural Geography, 11, 201-207.

Garofalo, J. (1981). The fear of crime: causes and consequences. Journal of Criminal Law \& Criminology, 72, 839-857.

Glaser, B., \& Strauss, A. (1967). The Discovery of Grounded Theory: Strategies for Qualitative Research. Chicago: Aldine.

Gold, L. R. (1997). The ethnographic method in sociology. Qualitative Inquiry, 3, 388-402.

Goodrick, D. (2014). Comparative Case Studies, Methodological Briefs: Impact Evaluation 9. Florence: UNICEF Office of Research.

Gould, P., \& White, R., ([1974] 2002). Mental Maps (2nd ed.). London: Routledge.

Hanslmaier, M. (2013). Crime, fear and subjective well-being: how victimization and street crime affect fear and life satisfaction. European Journal of Criminology, 10, 515-533.

Hanslmaier, M., Peter, A., \& Kaiser, B. (2018). Vulnerability and fear of crime among elderly citizens: what roles do neighborhood and health play? Journal of Housing and the Built Environment, 33, 575-590.

Hanson, S. (2010). Gender and mobility: new approaches for informing sustainability. Gender, Place and Culture, 17, 5-23.

Jackson, J., \& Gouseti, I. (2013). Fear of crime: an entry to the encyclopedia of theoretical criminology. Retrieved from http://papers.ssrn.com/sol3/papers.cfm?abstract_ id=2118663 (accessed 14 February 2020).

Koskela, H. (1997). "Bold walk and breakings": women's spatial confidence versus fear of violence. Gender, Place \& Culture: A Journal of Feminist Geography, 4, 301-319.

Lager, D., Van Hoven, B., \& Huigen, P. (2015). Understanding older adults' social capital in place: obstacles to and opportunities for social contacts in the neighborhood. Geoforum, 59, 87-97.

Levasseur, M., Richard, L., Gauvin, L., \& Raymond, E. (2010). Inventory and analysis of definitions of social participation found in the aging literature: proposed taxonomy of social activities. Social Science \& Medicine, 71, 2141-2149.

Levy, B. R. (2017). Age-stereotype paradox: opportunity for social change. The Gerontologist, $57,118-126$.

Mendes de Leon, C. (2005). Social engagement and successful ageing. European Journal of Ageing, 2, 64-66.

Oh, J.-H., \& Kim, S. (2009). Aging, neighborhood attachment, and fear of crime: testing reciprocal effects. Journal of Community Psychology, 37, 21-40.

Pain, R. (1997). "Old age" and ageism in urban research: the case of fear of crime. International Journal of Urban and Regional Research, 21(1), 117-128.

Pain, R. (1999). Theorising age in criminology. The British Criminology Conferences: Selected Proceedings, 2.

Phillipson, C. (2004). Urbanisation and ageing: towards a new environmental gerontology. Ageing \& Society, 24, 963-972.

Rader, N. (2017). Fear of crime. Oxford Research Encyclopedia, Criminology and Criminal Justice, DOI: 10.1093/acrefore/9780190264079.013.10 (accessed 14 February 2020).

Rogers, P., \& Coaffee, J. (2005). Moral panics and urban renaissance: policy, tactics and youth in public space. City, 9, 321-340.

Sandercock, L. (2005). Difference, fear and habitus: a political economy of urban fear. In J. Hiller \& E. Rooksby (Eds). Habitus: A Sense of Place (pp. 219-233). Aldershot: Ashgate.

Scharf, T., Phillipson, C., \& Smith, A. (2003). Older adults's perceptions of the neighborhood: evidence from socially deprived urban areas. Sociological Research Online, 8, 1-12. 


\section{Vanessa Stjernborg and Roya Bamzar}

Sheller, M., \& Urry, J. (2006). The new mobilities paradigm. Environment and Planning A, 38, 207-226.

Shirlow, P., \& Pain, R. (2003). The geographies and politics of fear. Capital and Class, $60,15-26$.

Smith, A. E. (2009). Ageing in Urban Neighborhoods: Place Attachment and Social Exclusion. Bristol: Policy Press.

Stjernborg, V. (2017a). The meaning of social participation for daily mobility in later life: an ethnographic case study of a senior project in a Swedish urban neighborhood. Ageing International, 42, 374-391.

Stjernborg, V. (2017b). Experienced fear of crime and its implications for everyday mobilities in later life: an ethnographic case study of an urban Swedish neighborhood. Applied Mobilities, 2, 134-150.

Stjernborg, V., Tesfahuney, M., \& Wretstrand, A. (2015). The politics of fear, mobility, and media discourses: a case study of Malmö. Transfers, 5, 7-27.

Stockholm Municipality (2012). Stockholms öpergripande trygghetsmätning. Stockholm: Stockholmstad

United Nations (2018). Ageing. Retrieved from www.un.org/en/sections/issuesdepth/ageing/.

Urry, J. (2007). Mobilities. Cambridge: Polity Press.

Wacquant, L. (2007). Territorial stigmatization in the age of advanced marginality. Thesis Eleven, 97, 66-77.

World Health Organization (WHO) (2007). Global Age-friendly Cities: A Guide. Retrieved from www.who.int/ageing/publications/Global_age_friendly_cities_Guide_ English.pdf (accessed 14 February 2020).

World Health Organization (WHO) (2019a). Ageism. Retrieved from www.who.int/ ageing/ageism/en/ (accessed 14 February 2020).

World Health Organization (WHO) (2019b). Fact File: Misconceptions on Ageing and Health. Retrieved from www.who.int/ageing/features/misconceptions/en/.

World Health Organization (WHO) (2019c). What is healthy ageing? www.who.int/ ageing/healthy-ageing/en/ (accessed 8 November 2019).

Ziegler, R., \& Mitchell, D. B. (2003). Aging and fear of crime: an experimental approach to an apparent paradox. Experimental Aging Research, 29, 173-187. 


\title{
14 Individual and spatial dimensions of women's fear of crime
}

\author{
A Scandinavian study case
}

Anna Yates and Vania Ceccato

\subsection{Introduction}

In 2012, a Gallup Poll revealed that 28 percent of women reported feeling unsafe when walking alone in their neighborhood at night compared with only 18 percent of men (Gallup, 2012). Whilst such statistics, which emphasize broad gender disparities in perception of safety, are far from uncommon (Fox, Nobles \& Piquero, 2009; Franklin \& Franklin, 2009; Pain, 2000; Valentine, 1992; Whitzman, 2007), the characteristics shared by women who declare being fearful are significantly lesser known. Although there has been quantitative research into the characteristics shared by women who report feeling unsafe, such as their age, socio-economic status, previous victimization (Krulichová, 2018; Ferraro \& La Grange, 1987; Warr, 1985), this research tends to treat these individual characteristics as distinct in spite of their pivotal interconnections (Liu \& Polson, 2016; Pain, 2001; May, Rader \& Goodrum, 2009). We submit here that those who are fearful are not a homogeneous group. They significantly vary on their degree of fear, in turn a function of who they are and the environments to which they are exposed. Knowing about women's various degrees of fear helps us to predict its impact, from mild precautionary measures (avoid certain routes and/or times) to mobility impairment and isolation but also engagement on local safety issues (Ceccato, 2017).

In the era of the \#MeToo! Movement, fear of sexual harassment and violence seems to be a global concern. In order to improve the understanding of the nature of women's fear of crime and its impact, this chapter also considers the spatialities of their fears, in other words, how their degree of fear affects women's usage of the public realm. The attention of this chapter will thus be focused on (but not be limited to) the most fearful women in the context of a Scandinavian city. Using theories of intersectionality (Crenshaw, 1991; Davis, 2011), this study hence aims to understand the dimensions of women's fear, namely the ways in which gender, ethnic background, age, and other aspects linked to where women live shape their varied levels of declared fear of crime.

This chapter will investigate:

1. The nature of fear among women who fear the most, in particular, by assessing how gender intersects with other individual characteristics, such as age and ethnicity. 
2. The spatial characteristics of women's fear and how this compares across women and impacts on their mobility in public space.

3. Whether the most fearful women tend to engage in activities understood to prevent crime, in comparison with the sample of women who declare feeling safe.

Despite the abundance of research on safety and perceived safety, the intersecting characteristics of the most fearful women has been identified as a significant gap (Pain, 2001). Owing to its reputation as being both safe and perceived as such, Stockholm, the capital of Sweden, has been subject to limited research on fear in comparison with Western European and North American cities (Hummelsheim et al., 2011). Recent findings have denounced Stockholm as a place where high rates of sexual violence are recorded and where an increasingly high percentage of the female population avoid going out in the evening (Eurostat, 2017; BRA 2017). Learning from this, the aforementioned limited research proves problematic and justifies further study. It is also in Sweden where the \#MeToo movement has had a major media impact (e.g., Aftonbladet, 2018).

For these reasons, the study first explores levels of fear and women's characteristics in Stockholm using cross-tables. Then, regression models are used to assess the impact of women's fear of crime on their behavior, controlling for individual characteristics.

The structure of this chapter is as follows. First, the relevant literature on perceived safety and the main important aspects that may affect fear are discussed, followed by the hypotheses. The case study and methodology are then presented, followed by a discussion of results. The chapter concludes with commentary on the implications for both research and practice.

\subsection{Fear of crime at individual level: theory and hypotheses}

\section{Nature of fear of crime}

Given that the emotional and physical reactions to crime are unique to each individual, the concept of fear of crime has inherited a diverse range of definitions which Pain (2001) argues acts as a limitation in comparative studies. Empirical results collated from surveys on fear of crime are highly varied, given that, in some cases, they do not access the same underlying construct (Hale, 1996; Lorenc et al., 2012). Fear of crime suffers from conceptual confusion and hence, researchers need to develop a better, more united conceptual understanding (De Donder, 2009; Jackson, 2005; Semmens, 2007; Yin, 1980). For this reason, we emphasize that the most successful definitions are those that appreciate the way in which fear of crime continuously acts to constrain activities in everyday life. Contributing to pivotal ongoing research on the conceptualization of fear of crime, this chapter will employ Gordon and Riger's (1989, p. 2) definition of fear of crime as a 'sense that one must always be on guard, 
vigilant and alert'. The attention of this research will be confined to those women who express the highest fear of crime owing to the fact that the consequences of their perception of safety are the most serious and restrictive in their everyday life (Henderson \& Bialeschki, 1993; May, Rader \& Goodrum, 2009; Stanko, 1990).

Nevertheless, of great concern is the increased realization that fear of crime's extent and consequences are far from evenly distributed. Amongst current surveys, the finding that women report a higher fear of crime than men is consistent (Pain, 2000; Tjaden \& Thoennes, 2006; Valentine, 1992). This is in part believed to be due to their fear of sexual violence and harassment, a phenomenon that Ferraro (1996) refers to as the 'shadow of sexual assault'. However, it is essential to refrain from stereotyping all females as equally fearful. How a woman perceives her safety is not a sole function of her gender and a plethora of factors ranging from age, ethnic background, relationship status, or any previous personal experiences (Gordon \& Riger, 1989; Pain, 2001; Stanko, 1990; Ceccato, 2017); but her safety is embedded in a network of moral political geographies, that involves old and newer types of fears (Pain \& Smith 2008; Alexander \& Pain, 2012).

Previous research has most commonly examined the relationship between fear of crime and individual-level characteristics such as gender and age (Ferraro \& La Grange, 1987; Warr, 1985). Within these studies, it is reported that those who declare feeling the most unsafe-women and elderly-were less likely in reality to become a victim. This phenomenon has been referred to as the "vulnerability perspective', whereby individuals who understand themselves to be at a greater physical disadvantage when facing a threat consequently report a higher fear of crime (Scarborough et al., 2010). The vulnerability perspective is commonly used to explain the relationships between particular demographic characteristics and heightened fear of crime. Significant among these demographic characteristics are gender and age and, to a lesser degree, relationship status and ethnic background (ethnic minorities, for example, feeling more fearful than the rest of population) (Scarborough et al., 2010). Gender statusLGBTQI-is also recognized as an important factor in defining different levels of fear given varied levels of victimization (Ceccato and Loukaitou-Sideris, forthcoming). Associated with relationship status is the concept of 'altruistic fear' (Warr, 1985). This refers to where an individual may fear that a person other than themselves will be a victim of crime. This notion can hence be applied to understand why individuals who are married and/or with children report an elevated fear of crime. Based on past research, it can be hypothesized that older women, married with children or grandchildren and of immigrant background are likely to be the most fearful (Ferraro \& La Grange, 1987; Scarborough et al., 2010; Warr, 1985)

Irrespective of the type of individual characteristics studied, former studies have tended to superficially treat these aspects of an individual's social identity as separate and distinct. For this reason, we shall now draw on Crenshaw's (1991) concept of intersectionality. Since its emergence in the black feminist 


\section{8}

movement, intersectionality has been used in feminist research on fear of crime to investigate how different aspects of social identity work together in distinct ways to determine the nature and geography of fear (Day, 1999; Pain, 2001; Zhao, 2013). This reiterates the crucial point that neither a person's gender, race nor class for example can explain fear of crime alone (Lewis, 2013; Pain, 2001). Despite its evident potential in research on fear of crime, its increased usage in feminist research is matched with a rising number of critiques that must be addressed. One criticism targets the 'identities' examined in intersectional analysis. Zhao (2013) critiques the limited number of 'identities' invoked in classic intersectional analyses. To develop the analytical potential of intersectionality, she maintains the paradigm must be open to development and, thus, include new categories alongside the conventional 'race', 'gender' and 'class' debate. Learning from theories of intersectionality (Crenshaw, 1991; Davis, 2011), we must understand how an individual's perception of crime is a function of a complex interplay of individual and area-level factors. Ortega and Myles (1987), for example, report how elderly females report a higher fear of crime than elderly males. However, the fear of elderly African American women is far higher than that of elderly white males and females (Ortega \& Myles, 1987; in the Swedish context, see Ceccato \& Bamzar, 2016). Similarly, Skogan and Maxfield (1981) discuss how lower-income ethnic minorities living in urban areas report higher feelings of unsafety than those living in rural communities (in Sweden, see Ceccato, 2018). Learning from the results of previous studies, it is evident that intersections between demographic characteristics and spatialities must be considered.

\section{Spatial mobilities and fear}

Research indicates that women are more fearful in public than private space. This proves somewhat paradoxical given most attacks against women occur in the domestic sphere by individuals known to them (Koskela and Pain, 2000). This spatial paradox is the result of a long-standing gender division of space whereby women learn to understand public space as exclusively masculine whilst the home is perceived as a feminine 'safe haven' (Valentine, 1992). In the public realm, women attach fears to specific environments at both micro-scale, such as high-rise environments (Gifford, 2007; Newman, 1972) public transport nodes (Ceccato, 2012; Uittenbogaard, 2014), or retail environments (Ceccato \& Tcacencu, 2018), and macro-scale-entire neighborhoods and entire areas (Brunton-Smith \& Jackson, 2011). In response to their fears, women may avoid particular spaces or neighborhoods to reduce their risk of potential victimization (Stanko, 1990).

They understand themselves at risk due to poor lighting and the presence of 'nooks and crannies' (Crowe, 2013, p. 251) that restrict their ability to survey the environment for potential threats and increase the possibility of a potential perpetrator to attack unnoticed (Hale, 1996; Valentine, 1989). It is important to review the relationship between fear of crime and the physical and social 
conditions of the local neighborhood (Sampson, 1988). This may explain why women may report a higher fear of crime in some neighborhoods.

Looking at the physical conditions of the neighborhood, one must draw upon Kelling and Wilson (1982) broken window theory. Visual signs of disorder such as graffiti, public drunkenness, or litter indicate to potential perpetrators that locals are unresponsive to misconduct in the neighborhood, potentially lacking the social cohesion needed to prevent any crime. Socially integrated neighborhoods generate self-help networks and support, which are generally understood to alleviate an individual's fear of crime, as they feel more confident in their ability to cope with potential risks (Valentine, 1990). Based on this, it is anticipated that those who are more fearful live in neighborhoods with limited social cohesion and evidence of physical incivilities. That being said, however, some research has questioned the validity of these findings, emphasizing the presence of strong social bonds in run-down neighborhoods and weak social bonds in gated communities (Wacquant, 2008; Valentine, 1990). In response to this mixed picture, this study will thus contribute to ongoing research investigating the relationship between social contacts and physical visual cues in the neighborhood environment. Whilst the physical conditions of neighborhoods are predominantly understood and analyzed at a local scale, the aforementioned social factors operate at a much broader scale, associated with wider processes. One example of this is the process of 'othering' (Lemanski, 2006; Sandercock, 1997). Fueled by the media (Castell, 2010) and the police (Palidda, 2011), individuals' fears at local scale are often closely tied to their wider fears of encountering and living in close proximity to individuals of different ethnic backgrounds.

\section{Fear and its effects on behavior}

Those individuals who report to be the most fearful are the most likely to change and adapt how they move in space. At this point, it is important to draw upon Jackson and Gray's (2009) concept of functional and dysfunctional fear. In some cases, place-time avoidance-including the aforementioned-should be perceived positively as they are in fact 'functional' (Gray, Jackson, \& Farrall, 2011). By that, it is meant that their actions successfully reduce both their fears and likelihood of victimization without negatively affecting their quality of life. In some cases, fear becomes the main motivation for them to take action by supporting activities that make crime and victimization more difficult to occur, such as participating in night patrols or neighborhood watch schemes (Gray et al, 2011). On the other hand, for some, their fears do not solely manifest in a restricted use of public space but in self-confinement, making them 'prisoners in their own homes' (Henderson \& Bialeschki, 1993, p. 45). In this case, this is a clear example of what Jackson and Gray (2009) refer to as 'dysfunctional fear' whereby their fears reduce their quality of life.

What thus emerges from the literature is that fear of crime is a function of a complex interplay of factors at various scales. What is less clear, however, is what 
these dimensions precisely are, and how they intersect. This study will therefore build on current studies that investigate the relationship between fear of crime and individual and area-level characteristics. However, the attention of this research will be almost exclusively focused on women and those who perceive themselves to be very unsafe, given the consequences of their perception of safety can be the most restrictive and detrimental (Henderson and Bialeschki, 1993; Stanko, 1990).

Influenced by previous research on fear of crime and its dimensions, we have proposed the following hypotheses:

1. Women vary in their expression of fear, with some expressing fear more than others. Informed by an intersectional framework (Crenshaw, 1991; Davis, 2011), the women who declare themselves to be the most fearful exhibit particular individual characteristics that are intertwined with one other.

2. The women who report being the most fearful are the most likely to adapt their behavior, such as restricting their mobility in public space (Jackson \& Gray, 2009; Henderson \& Bialeschki, 1993; Stanko, 1990).

3. Women who report being the most fearful are the most likely to convert their concerns into constructive action (Jackson \& Gray, 2009).

\subsection{Framing the case study}

\section{The study area}

The study area is Stockholm municipality, the capital of Sweden. The attention of this study is confined to the municipality, which covers an area of $216 \mathrm{~km}^{2}$ and has a total population of 910,000 . It is an archipelago that is well-connected in terms of infrastructure in the form of bridges, roads, subways, trams, commuting trains and buses. The municipality performs well in measures of well-being in comparison with other capital cities in terms of health, income and wealth, jobs and earnings, housing, education and safety (Stockholm Stad, 2018a). On average, the percentage of residents who are non-Swedish nationals is 31 percent (Stockholm Stad, 2018a). However, in its peripheral suburbs, this figure rests at $86-90$ percent. In these suburbs, general unemployment rates are three times higher and average income is two times lower than in comparison with the rest of the city (Stockholm Stad, 2018a). Like many other European cities, Stockholm is thus affected by social, economic and spatial segregation. This affects the declared perceived safety and consequently the housing market (Ceccato \& Wilhelmsson, 2011, 2012).

More significantly for this study however, according to EuroStat (2017), is that 96 percent of the population agreed or somewhat agreed that their neighborhood was safe. High percentages were also recorded in other Scandinavian capitals. In non-Nordic capitals, around 75 percent of the population on 
average declared feeling safe in their neighborhood. The lowest levels were reported in Greek, Italian and Bulgarian cities where the percentage of the population who reported feeling safe dropped below 75 percent. In Sweden overall, the proportion of women that declare feeling unsafe is 36 percent, which can be compared with 19 percent of men. Women also avoiding going out to a much greater extent than men; 10 percent of the women in the population avoid going out alone late in the evening in their residential area because of fear of being attacked. The corresponding figure for men is 2 percent. The proportion of those who declared feeling unsafe is particularly large among the youngest and oldest women in the survey; among men, on the other hand, there are significantly smaller differences between the age groups (BRÅ, 2017, 2019).

Four out of five Stockholm residents feel safe (Stockholm stad, 2018b). Fear regarding going out into their own residential area in the evening is unevenly distributed across space and by types of residents. Figure 14.1 illustrates the overall percentage of respondents declaring feeling fearful in different districts.

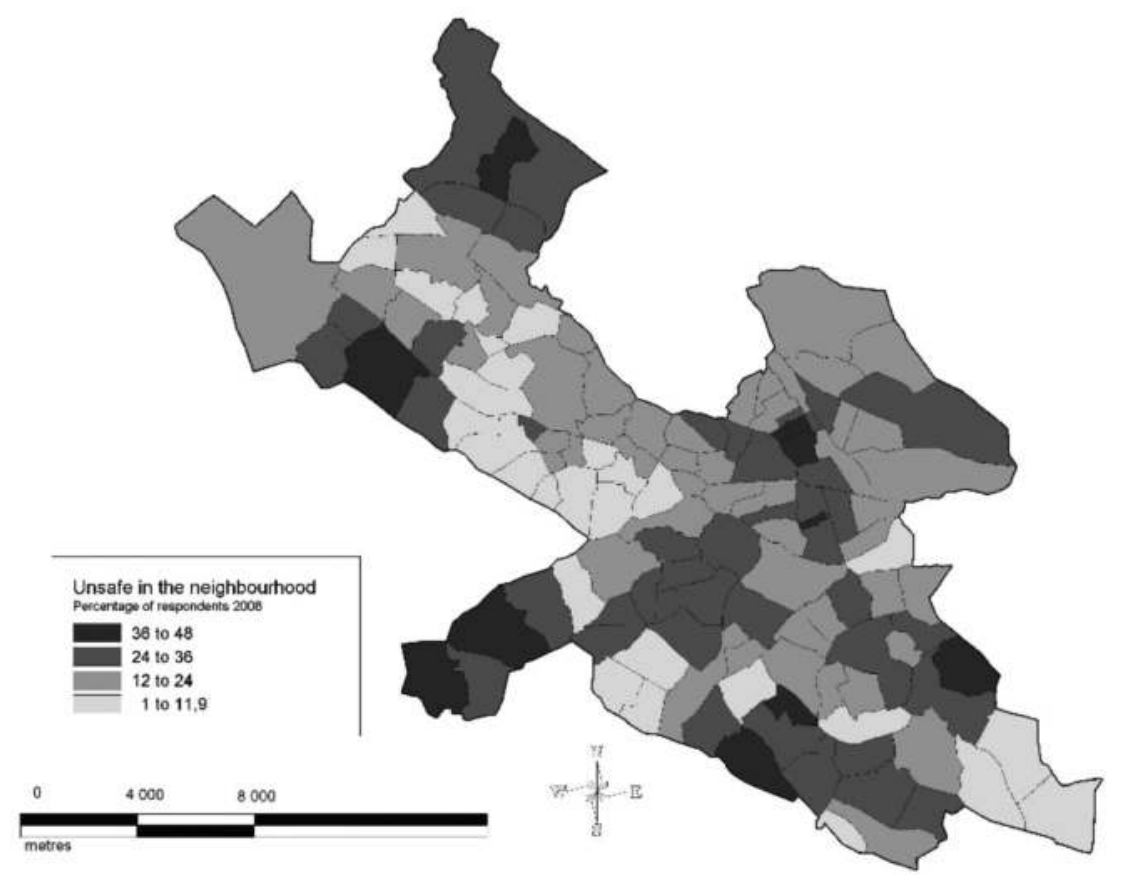

Figure 14.1 Stockholm by respondents who declare feeling fearful in the neighborhood (percent).

Data source: Stockholm safety survey, response rate is 51 percent.

Source: Author. 


\section{Data and methods}

The safety survey datasets from 2008, 2011 and 2014 were imported into SPSS after a process of data cleaning (e.g., excluding missing values, outliers). The overall aim of each survey adheres with the city council's goal of creating a safer city, thus the data can be compared with results of previous surveys. Data are collected through a mail survey with a random sample of registered domicile 16-79 years (not longitudinal). In 2014, there was a random sample of 32,279; 16,434 responded to the survey, giving a response rate of 51.1 percent. This has been fairly constant since 2008 when the survey started.

\section{Pre-analysis}

The three datasets were merged to form one large dataset that thus contained the survey question and responses from every year. There were two main reasons for doing this. First, the focus of our paper is confined to the most fearful women. If using cross-sectional data, of one year only, these women would compose a very small proportion of the population. The three datasets were therefore collapsed into one to increase the data robustness. Second, the focus of this paper is also confined to investigating the impact of fear on women's behavior, avoidance of places for instance. If using cross-sectional data, of one year only, the limited data would make it difficult to discuss the potential variety of types of places that this group of women avoid. Whilst we do not wish to denigrate the importance of considering the temporal dimensions of women's fear, this aspect is outside the scope of this study and our respective focus on the spatiality of women's fear.

Due to some differences between each survey's format, each dataset was reorganized to ensure that the survey questions and their respective responses were aligned with one another. For example, perceived safety in one's residential area was originally categorized on a scale from 1 to 5 , from 'very safe' to 'very unsafe' (How secure or insecure do you feel collectively in your neighborhood?). Since the focus of this research is predominantly confined to women who report feeling 'pery unsafe', a dichotomous variable was generated that split responses between 1,2,3,4 (Safe) and 5 (Very unsafe). Ten other variables were similarly transformed to improve analysis (see appendix 14.1). They were transformed to produce fewer but broader categories. Data points with missing values were filtered out for the analysis.

Cross-tabulation using chi-square tests were then used to generate comparisons between distributions of two or more variables, for example, the difference between men and women in terms of their fear of crime. Before investigating the common attributes shared by women who reported feeling most unsafe, women's and men's fear of crime were first compared on the basis of results collected from the Safety Survey in 2008, 2011 and 2014. Analysis using crosstabulation thus, in part, investigated the strength of the relationship between women who reported feeling very unsafe compared with the remaining female 
participants in terms of their individual characteristics: age, relationship status, number of children, ethnic background and whether they had been previously victimized. In order to evaluate hypotheses of variables in contingency tables, the chi-square test was used or, in the case of small expected frequencies, Fisher's Exact Test. The Pearson correlation coefficient was used in order to test independence between variables after some basic descriptive data analysis to identify remaining outliers and missing data. It must be appreciated that crosstabulation does not indicate causality. Therefore, to test Hypotheses 2 and 3, we modelled women's fear and behavior using binary logistic regression.

\section{Modelling women's fear}

Three sets of models were applied: the first model assessed the nature of women's fear. The dependent variable $Y$ is (a) women who declared most fearful ( $\mathrm{l}=$ Yes, very unsafe, often unsafe, $\mathrm{No}=0)$. The second model tests whether fear affects behavior, namely through place avoidance (Table 14.2, later). The dependent variable $Y$ indicates whether they engage in avoidance behavior ( 1 = Yes, keep away from certain places/streets, using the alternatives: always, often, do not go out fear of being a crime victim), among most fearful women and among (b) all unsafe women, No=0). The third model tests functional fear, for instance, expressing a pro-active behavior such as asking help from neighbors to watch their homes (Table 14.3, later). The dependent variable $Y$ indicates whether they engage in pro-active behavior $(1=$ Yes, we have neighbors looking out for the residence when we are absent, among (a) most fearful women and (b) all unsafe women, $\mathrm{No}=0$ ).

\subsection{Results}

\section{Gendered fear and the most fearful}

Women consistently reported a higher fear of crime than men $\left(\chi^{2}(1\right.$, $N=54,095)=1,138.468, p<0.000)$. Whilst 21 percent of male respondents declared feeling ' unsafe' in their neighborhood, the figure stood at 34 .1 percent for women. This difference is fairly stable in all three years. Although women declare feeling more fearful than men, they are far from being a homogeneous group. Among them, 29 percent felt very safe, 36.9 percent felt safe, 29.5 percent felt quite unsafe, 3.8 percent felt unsafe $\left(\chi^{2}(1, N=54,095)=2,088.562\right.$, $p<0.00)$. However, the attention of this chapter is confined to the most fearful women, who represent 0.8 percent of all women. Below, we discuss women's profile in terms of safety perceptions.

Amongst women who reported feeling 'very unsafe', most female respondents tended to be single $\left(\chi^{2}(1, N=54,095)=29.799, p<0.07\right)$ with children $\left(\chi^{2}(1, N=17,631)=23.372, p<0.005\right)$. The most fearful women tended to have between two to four children. Concerning their ethnic background, the vast majority were not born in Sweden $\left(\chi^{2}(1, N=29,815)=32.991, p<0.00\right)$. 


\section{4}

Finally, most female respondents who declared feeling 'very unsafe' had been a victim of crime in the last 12 months $\left(\chi^{2}(1, N=28,795)=30.736, p<0.00\right)$. In summary, women who reported feeling the most unsafe were below the age of 30 years, with 2-4 children, non-native born (born in a country other than Sweden) and had been previously victimized.

\section{Women's fear, neighborbood context and effects on behavior: exploratory analysis}

Women who report being 'most unsafe' are also the most likely to adapt and restrict their mobility in public space. Findings show that 45.9 percent of women who declared feeling 'very unsafe' in their neighborhood reported that if the opportunity arose, they would move away from their current residential area due to the perceived extent of crime. Only 3.2 percent of the remaining sample felt the same $\left(\chi^{2}(1, N=53,439)=1,367.586, p<0.000\right)$. In order to better understand women's fear of crime, the level of social cohesion in respondents' neighborhoods was also investigated.

Compared with the rest of the women in the sample, women who felt unsafe tended to have a more negative picture about neighbors and their own neighborhoods. Findings show that although 31.5 percent of respondents felt that neighbors helped each other, only 23.3 percent of women who declared feeling 'very unsafe' witnessed neighbors supporting one other $\left(\chi^{2}(1\right.$, $N=49,889)=113.954, p<0.000)$. In the same way, 24.6 percent of female respondents who reported feeling 'very unsafe' in their neighborhood felt that they could trust people in their residential area, whereas, the figure stood at 39.4 percent for the remaining population. They also tend to live in neighborhoods where physical incivilities are present and where they have been a victim of vandalism. Whilst 15.1 percent of very fearful women observe some form of vandalism where they live, only 7.4 percent of the remaining population had been a victim of vandalism $\left(\chi^{2}(1, N=53,451)=20.183, p<0.000\right)$.

Fear is not homogeneously distributed across the neighborhood and appears to be triggered by certain environmental features in the neighborhoods. Amongst women that declared feeling most fearful, 56 percent worried about spending time close to the metro or train station; however, only 12.9 percent of the remaining population felt the same $\left(\chi^{2}(1, \quad N=53,224)=408.035\right.$, $p<0.000)$. Similarly, 56.7 percent of women who reported feeling 'very unsafe' overall, expressed worry when walking home from/to the aforementioned metro and/or train station, whilst only 21.1 percent of the remaining population felt unsafe $\left(\chi^{2}(1, N=53,386)=181.150, p<0.000\right)$. What emerges is a stark difference between how very fearful women and the remaining population express their safety in public places, in particular transport nodes and on the way from/to them. Although the most fearful women express higher levels of fear of crime in their neighborhood than the rest of women in the sample, it is still unclear whether and to what extent this fear affects their mobility through public space. However, results from the cross tables and chi-square analysis 
indicate significant associations between an individual's perceived safety and their mobility in their neighborhood. Amongst those women who reported feeling 'very unsafe' in their neighborhood, 64.6 percent reported that they actively kept away from certain places and streets to avoid being exposed to any violence or threats $\left(\chi^{2}(1, N=50,356)=185.460, p<0.000\right)$. There are indications that women who report these events are the most fearful and are more likely to convert these concerns into action. Amongst those who report being the most fearful, 29.2 percent among those who declare being most fearful ask neighbors to keep an eye on their property (and vice versa), against 4.1 percent of the rest of female sample.

In the next section we identify both individual and neighborhood level factors affecting women's fear. Then, we assess whether fear helps explain women's behavior controlling for individual and neighborhood factors.

\section{Modelling fear, neighborbood context and effects on behavior: confirmatory analysis}

Table 14.1 shows the modelling results of the binary logistic regression for two groups of women: (a) most fearful women (composed of those feeling very unsafe, often unsafe, or those who do not go out for fear of being a crime victim) and (b) all unsafe women (composed of women who declared that they felt sometimes unsafe or expressed some degree of fear plus (a)). This means that (b) it is constituted by all women in the sample who declared some level of fear, from mild to severe levels of fear, including (a).

\section{Individual characteristics}

The most fearful group of respondents tends to be women born abroad. They also tend to live by themselves, were crime victims (in the last 12 months) and are older than the rest of the sample. For example, if the person was born abroad, her odds of belonging to the most fearful group of women increases by 41.7 percent. Age affects those women who express more moderate levels of fear. In terms of age, for every unit in increase in age, the model estimates show an increase by less than 1 percent for the most fearful women and 2.3 percent for all unsafe women (the odds ratio is 1.023 for an additional year in age). After controlling for all variables in the model, if the person lives alone, her odds of being fearful increases by 27.4 percent among the most fearful women (a), in comparison with only 8.4 percent for the remaining unsafe women (b).

\section{The neighborhood context}

The neighborhood context is also relevant to explain differences in declared fear among female respondents; in particular for the most fearful women (four out of five variables are significant). Among the most fearful women, they rarely exchange favors or chat and struggle to recognize people in their own neighborhood. 


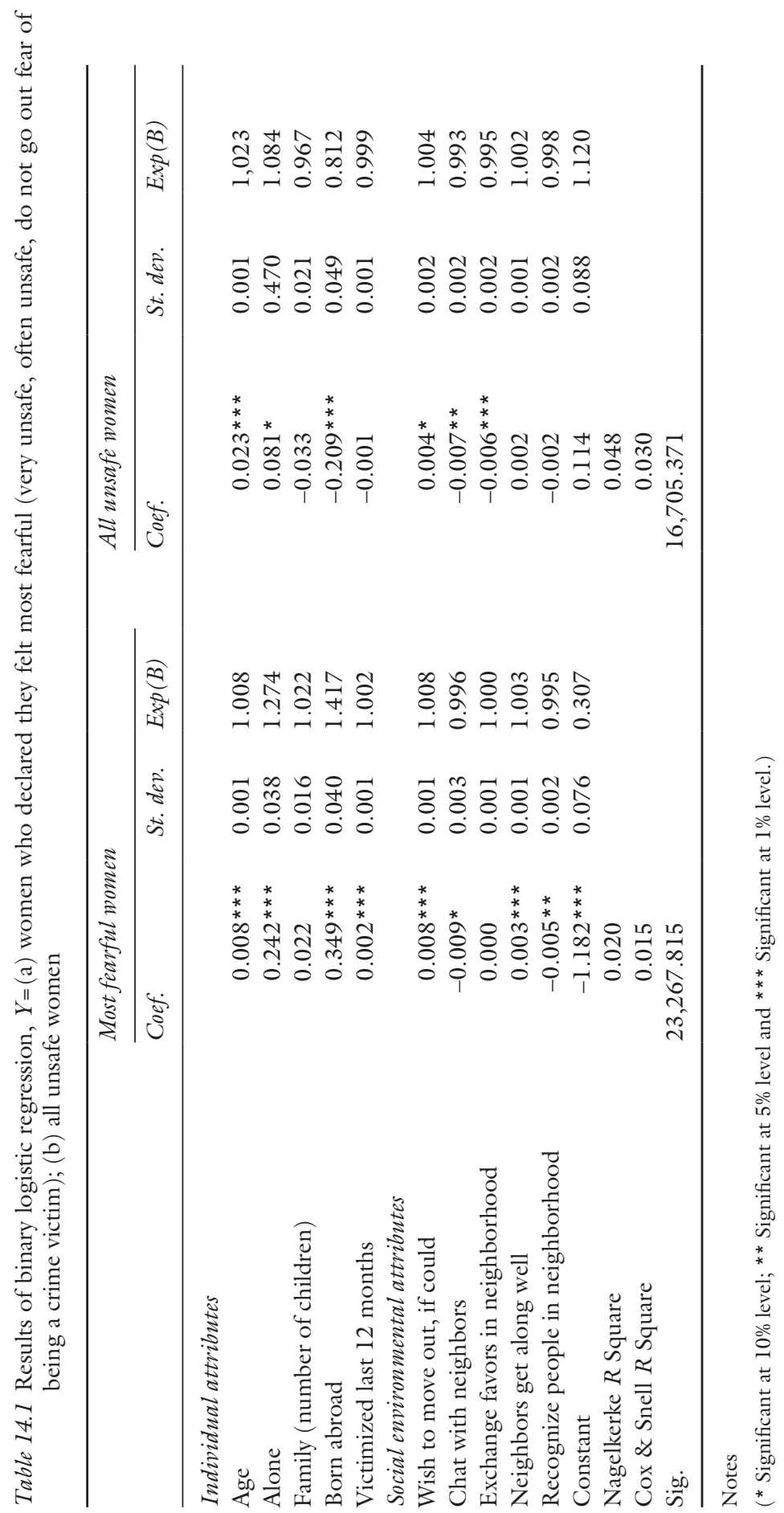


Unexpectedly, controlling for all other variables in the model, for every extra neighbor that they get along with, the odds of them declaring being fearful increases by 3 per cent. For both groups, fear levels are associated with the desire to moving away from where they currently reside, that is, if they had the economic resources. There are indications that among those women who declare a moderate level of fear, the fact that they do not exchange favors with neighbors negatively affects their perceived safety. However, among the most fearful women, their declared levels of fear are not affected by whether they exchange favors with neighbors.

\section{Fear impact on behavior: dysfunctional and functional fear}

Table 14.2 shows the results of the binary logistic regression that, after controlling for other variables, women's fear in the neighborhood does not lead to place avoidance. The dependent variable in this model is an indicator of women's place avoidance in the neighborhood (keep women away from certain places/streets, always, often, or do not go out for fear of being a crime victim), while the covariate is fear in the neighborhood among (a) most fearful women and among (b) all unsafe women.

Place avoidance is triggered by poor social contact with neighbors rather than actual fear of crime experienced in the neighborhood. Those who avoid places and declare some degree of fear (b), exhibit signs of poor contact with neighbors (do not recognize people in the neighborhood, do not chat or change favors with neighbors) and wish to move out from the area if possible. Yet, neighborhood context variables are more important to explain place avoidance for the overall female population than amongst those who fear the most (only two neighborhood variables came out significant for most fearful women (a) and four out of five for all unsafe women (b)).

For the overall sample, being a victim of crime in the last 12 months appeared to not have an impact on whether they showed signs of dysfunctional fear. However, for the most fearful group of women, victimization leads to place avoidance. This is the only individual factor affecting dysfunctional fear among the most fearful women (Table 14.2). Age, ethnic background and relationship status (family) are significant individual factors that help explain the variation of dysfunctional fear among women declaring some degree of fear (b). This group tends to be native Swedes, older, live by themselves and non-crime victims.

There are clear differences between the most fearful women and the unsafe women with regards expressions of functional fear. Asking neighbors to look out for one's residence when one is absent (as a measure of agency against of crime) only happens in neighborhoods by women with low or moderate levels of fear (Table 14.3 (b)). For the most fearful women, fear experienced in the neighborhood does not lead to action or engagement, contrary to what was initially expected in Hypothesis 3. Here again, poor social contact in the neighborhood 


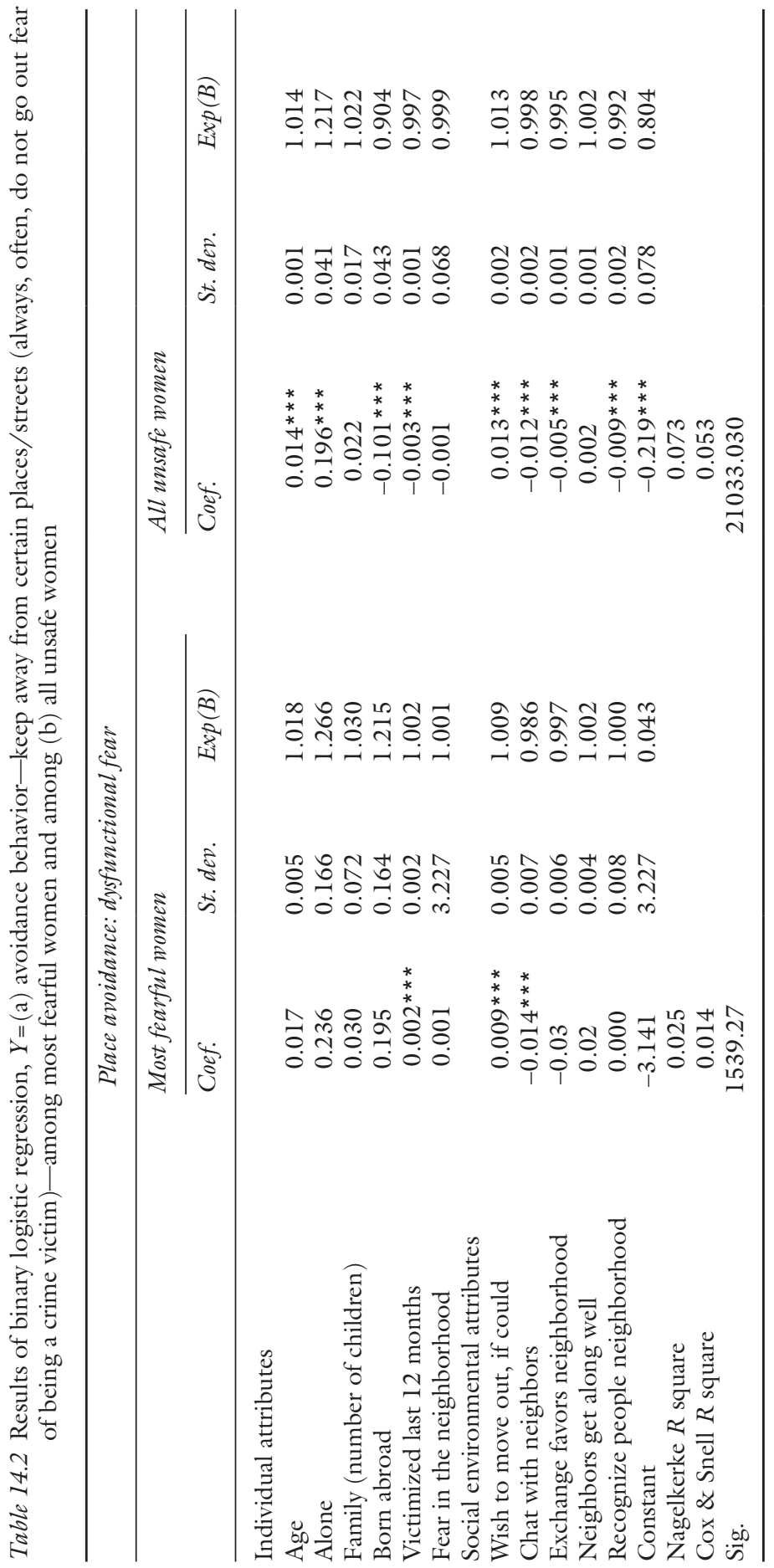


may lead to precautionary behavior, in particular amongst those that show low or moderate fear levels.

Overall, women ask neighbors to look out for their residence when they are absent, most often when they are young individuals with families, than the most fearful ones. They are often Swedish born that have not being victimized by crime and do not show high levels of fear where they live, even when they would prefer to live somewhere else and experience poor levels of social cohesion. Note that all variables that indicate social interaction in neighborhoods show a negative sign (Table 14.3), which indicates the overall low levels of social engagement in precautionary measures.

Amongst those who fear the most, being older, having kids and experiencing victimization increases the odds of showing functional fear when compared with the rest of women. Asking neighbors to look after their homes is a decision influenced not only by women's individual characteristics but also by how one feels about their neighborhood. However, this is more likely to happen among women who declare low or moderate degree of fear than those categorized as most fearful. Finally, individual characteristics such as victimization and age, play a bigger role in determining functional fear than the neighborhood social characteristics tested in this study.

\subsection{Discussion of results}

It is no surprise that fear of crime is gendered. Our findings indicate that women reported a higher fear of crime than men. This result resonates with previous research (e.g., Ferraro, 1996; Lee, 2007; Valentine, 1992; Macassa et al., 2018) and acts to justify this paper's specific focus on women's fear of crime that aims to investigate fear as a function of multiple individual characteristics and neighborhood contexts. The implications of findings for future research and policies will be discussed in the conclusion.

Informed by intersectional analysis, our exploratory analysis indicates that the most fearful women were relatively young, single with children, from an immigrant background and had been previously victimized. Drawing on Warr's (1985) notion of 'altruistic fear', women with children tend to report a higher fear of crime than women without children, as they fear for not only their own safety but for the safety of their children.

Albeit that individual characteristics are a significant determinant of a women's perception of safety, it is of equal importance to review the relationship between women's fear of crime and their respective neighborhood (Sampson, 1988). Confirming what is reported in mainstream literature, women who feel most unsafe tend to live in neighborhoods that show signs of both physical and social incivilities, poor social contact, poor social cohesion and/or low collective efficacy (Sampson, 1988; Kelling \& Wilson, 1982).

When modelling fear as a function of individual and neighborhoods characteristics, the picture becomes more mixed. Although most individual characteristics remain important in explaining fear of crime among all types of women, 


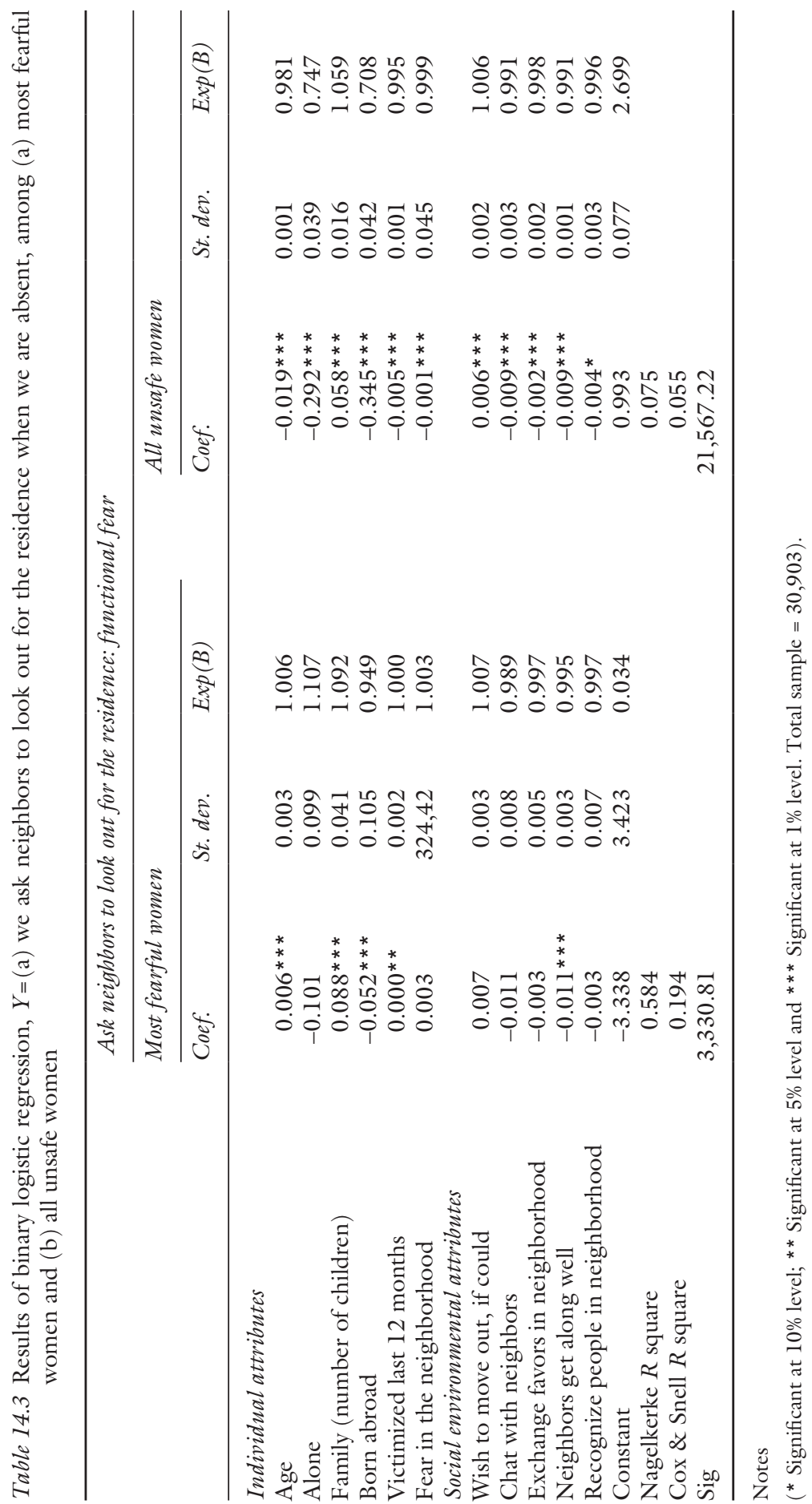


the neighborhood context is the most relevant when explaining variation of declared fear among the most fearful women (four out of five variables are significant) than for those with moderate fear. This thus reiterates the importance of including neighborhood variables in future intersectional research investigating women's fear of crime.

Nevertheless, whilst this model does not include socio-economic status, one can hypothesize that the most fearful may live in segregated areas, often suffering from social and economic deprivation. In order to gain a better insight into the spatiality of their fear of crime, our level of analysis must shift from a broad scale to a finer scale. Within the neighborhood, transport nodes and the way to/from them are a point of concern when examining women's victimization and transit fear (Ceccato, 2012; Uittenbogaard, 2014; Ceccato \& LoukaitouSideris, 2020).

The initial hypothesis that women's fear of crime would lead to place avoidance (Jackson \& Gray, 2009) does not hold in this case (Table 14.2). For the most fearful group of women, previous victimization leads to place avoidance but not fear of crime. Moreover, amongst women who are less fearful, poor social interactions (such as not recognizing people in their neighborhood, having poor contact with neighbors, not exchanging favors) in the neighborhood increases their odds of exhibiting signs of dysfunctional fear, including place avoidance behavior. Similarly, fear does not affect women's agency by promoting constructive action (indicated here by asking neighbors to look for their homes while absent). This finding also refutes Hypothesis 3 that expected some expression of functional fear.

More interestingly, not being able to recognize people in one's neighborhoodan indicator of poor social bonds-is a strong predictor of functional and dysfunctional fear. The mechanisms linking local social bonds and women's precautionary behavior are difficult to disentangle using our current modelling strategy. However, we can argue that whilst poor social bonds help explain variation in women's precautionary measures, it is possibly fear of crime (that turned out non-significant) which indirectly affects women's behavior. As suggested by Sandercock (1997), fear of crime can translate into "fear of others" which leads to poor social bonds that often causes animosity between individuals and gives expression to the "fear of the unknown". Rapid changes in an area especially with rapid population inflow-in the form of waves of different types of immigration-are argued to have an impact on residents' sense of safety, regardless of whether crime levels change or not (Hunter, Krannich, \& Smith, 2002). The perceived social distance between different types of residents, in this case, because of their ethnic background, can be maximized by people themselves. This can give expression to $u s-t h e m$ feelings (as part of an othering process, namely when one transforms the difference into otherness). Further research needs to investigate the relationship between the community changes (expressed by changes in their environment), quality of social interactions and women's functional and dysfunctional fear regardless of its levels. 


\subsection{Conclusions and recommendations}

This study sought to examine the nature and the spatial dimensions of women's fear of crime. Findings show that the most fearful women share a number of similarities: they are often previously victimized and born abroad. Whilst elderly women are commonly recognized as more fearful than younger individuals, attention should turn to equally consider the fearful, young, single mother, whose fears are often lesser known and deemed less worthy of intervention. Further research could consider intersections between age, family structure and socio-economic status to compare how fears operate for differently situated young women.

Findings also show that the most fearful women were most likely to restrict their use of public space through avoiding certain places, confirming what has been previously established in previous research (Henderson \& Bialeschki, 1993; Stanko, 1990; Bastomski \& Smith, 2017). However, contrary to what was initially expected, for the most fearful women, fear experienced in the neighborhood does not lead to place avoidance or acts of functional fear (e.g., asking neighbors to look out for one's residence when one is absent). Instead, poor social contacts at neighborhood level is more closely associated with behavior changes. These results have important theoretical implications.

Fear should not be understood as an enduring, fixed trait that is inherently gendered but rather a phenomenon that every individual can experience to a varying degree at different points in their life (Fattah \& Sacco, 1988). Some of them are related to individual characteristics and others intertwined with the environment that individuals are exposed to. This calls for a holistic approach to safety that encompasses an understanding of the intersectionality of victimization and fear, in a frame that goes beyond age or gender and looks for intersections of an individual's characteristics and environmental contexts. Through implementing a combination of individual and neighborhood policies, we can hope women's fear of crime can be better tackled, and a more inclusive and equitable use of public space can be achieved. In practice, this demands, for instance, mobility policies that are non-gender neutral, sensitive to the mobility needs of individuals and that encompass a whole journey perspective to women's safety.

Another important theoretical contribution is the fact that it is difficult to disentangle fear of crime (as a measure of safety) from closely related theoretical constructs. Multifaceted aspects that go beyond individual characteristics and neighborhood conditions determine what causes fear. The fact that most fearful women seems to respond (by expressing functional and dysfunctional fear) to the quality of the social environment but not to fear is an example of such complexity. One could speculate that poor contact with neighbors leads to fear of others and, in turn, place avoidance. However, the scope of this paper does not permit us to make any further speculations on the direction and relationship between these factors. This thus emerges as a limitation that could be further explored in future research. 
Appendix 14.1 Dataset of the study

\begin{tabular}{|c|c|c|c|}
\hline Data type & Variable & Description & Unit \\
\hline $\begin{array}{l}\text { Dependent } \\
\text { variable }\end{array}$ & Perceived safety & $\begin{array}{l}\text { How secure do you } \\
\text { feel in your } \\
\text { neighborhood? }\end{array}$ & Categorical \\
\hline \multirow[t]{6}{*}{$\begin{array}{l}\text { Individual } \\
\text { attributes }\end{array}$} & Gender & $\begin{array}{l}\text { Gender of the } \\
\text { respondent }\end{array}$ & Categorical \\
\hline & Age & $\begin{array}{l}\text { Age of the } \\
\text { respondent }\end{array}$ & Categorical \\
\hline & Relationship status & $\begin{array}{l}\text { Relationship status } \\
\text { of the } \\
\text { respondent }\end{array}$ & Categorical \\
\hline & Children & $\begin{array}{l}\text { How many the } \\
\text { children the } \\
\text { respondent has }\end{array}$ & Categorical \\
\hline & Ethnic background & $\begin{array}{l}\text { Ethnic background } \\
\text { of the } \\
\text { respondent }\end{array}$ & Binary \\
\hline & $\begin{array}{l}\text { Previous incidents } \\
\text { of victimization }\end{array}$ & $\begin{array}{l}\text { Whether the } \\
\text { respondent has } \\
\text { been a victim } \\
\text { of crime over the } \\
\text { last year }\end{array}$ & Binary \\
\hline \multirow[t]{5}{*}{$\begin{array}{l}\text { Spatial } \\
\quad \text { dimensions }\end{array}$} & $\begin{array}{r}\text { Satisfaction with } \\
\text { neighborhood }\end{array}$ & $\begin{array}{l}\text { If you could choose } \\
\text { freely, would you } \\
\text { move from your } \\
\text { current } \\
\text { neighborhood? }\end{array}$ & Categorical \\
\hline & $\begin{array}{l}\text { Social cohesion in } \\
\text { neighborhood }\end{array}$ & $\begin{array}{l}\text { Agree or not with } \\
\text { the following } \\
\text { statements about } \\
\text { your neighborhood }\end{array}$ & Categorical \\
\hline & $\begin{array}{l}\text { Public transport } \\
\text { nodes }\end{array}$ & $\begin{array}{l}\text { Perception of safety } \\
\text { at/on the way } \\
\text { home from the } \\
\text { metro station }\end{array}$ & Categorical \\
\hline & $\begin{array}{l}\text { Perceived safety } \\
\text { in the residential } \\
\text { area }\end{array}$ & $\begin{array}{l}\text { If you go out alone } \\
\text { late in the area } \\
\text { you live, do you } \\
\text { feel safe or unsafe, } \\
\text { or do you worry } \\
\text { about being } \\
\text { exposed to a crime } \\
\text { of any kind in your } \\
\text { neighborhood }\end{array}$ & Categorical \\
\hline & $\begin{array}{l}\text { Functional and } \\
\text { dysfunctional fear }\end{array}$ & $\begin{array}{l}\text { Whether the } \\
\text { respondents } \\
\text { avoid places. }\end{array}$ & Categorical \\
\hline
\end{tabular}


Future studies should explore new strategies when modelling women's fear in relation to individual and environmental characteristics where women live, perhaps using, for instance, multilevel models and testing theoretically driven interaction factors. Moreover, the analytical framework could have involved other control variables, such as socio-economic conditions of respondents and the temporal dimension of fear of crime.

Another limitation of this study is that it has focused on women's victimization only, and therefore neglected fear among men and those who are potentially more at target from hate crimes, such as those belonging to the LGBTQI community. Data permitting, future research should aim at gathering evidence about fear experienced by gay and transgendered persons for example-a group that are often targets of harassment and sexual violence (Gekoski et al., 2015).

Finally, learning from Ditton, Chadee, and Khan (2003), the data utilized and analyzed in this paper could be combined with qualitative methods in future research. Combining these methods is believed to better uncover and identify clear explanations for perceptions of safety. This in turn would contribute to ongoing discussions regarding the conceptualization of fear of crime, commonly identified as an issue in contemporary literature.

Despite these limitations, this chapter has contributed to a better understanding of women's fear of crime in a Scandinavian capital. Unlike previous research, which has tended to solely concentrate on one dimension (often individual factors), this chapter has attempted to explore women's fear of crime by investigating and mapping its various dimensions. Furthermore, this research has also provided a unique perspective on women's fear of crime by focusing on women who reported to feel the most unsafe. The fact that women's safety is closely tied to the quality of social interactions at the neighborhood level lead us to think about the need of social programs or schemes that focus on establishing and building strong social ties. This in turn, can alleviate women's fears, maximize their agency and improve their navigation through public space.

\subsection{Acknowledgments}

This research was undertaken while Anna Yates was a visiting fellow at the Department of Urban Planning and the Built Environment, KTH Royal Institute of Technology, Sweden. The authors would like to express their thanks to Nicklas Roth from Stockholm municipality for providing the dataset used in this analysis.

\section{References}

Aftonbladet (2018). Ny undersökning: Så förändrade \#Metoo Sverige. www.aftonbladet. se/nyheter/a/J1Rwkm/ny-undersokning-sa-forandrade-metoo-sverige (accessed 25 April 2019).

Alexander, C., \& Pain, R. (2012). Urban security: whose security? Everyday responses to urban fears. In V. Ceccato (Ed.), The Urban Fabric of Crime and Fear (pp. 37-53). Dordrecht: Springer. 
Bastomski, S., \& Smith, P. (2017). Gender, fear, and public places: how negative encounters with strangers harm women. Sex Roles, 76, 73-88.

Brunton-Smith, I., \& Jackson, J. (2011). Urban fear and its roots in place. In V. Ceccato (Ed.), The Urban Fabric of Crime and Fear (pp. 55-82). Dordrecht: Springer.

BRÅ-Brottsförebyggande rådet (2017) Swedish Crime Survey 2017. Stockholm: BRÅ.

BRÅ—Brottsförebyggande rådet (2019) Den nationella Trygghets undersökning: Om utsatthet, otrygghet och förtroende. Stockholm: BRÅ.

Castell, P. (2010). The Swedish suburb as myth and reality. In Castell, P. (Ed.), Managing Yard and Togetherness: Living Conditions and Social Robustness through Tenant Involvement in Open Space Management. Gothenburg: Chalmers University of Technology.

Ceccato, V. (2012). The Urban Fabric of Crime and Fear. Dordrecht: Springer.

Ceccato, V. (2017). Women's victimisation and safety in transit environments. Crime Prevention and Community Safety, 19, 163-167.

Ceccato, V. (2018). Fear of crime and overall anxieties in rural areas: the case of Sweden. In M. Lee \& G. Mythen (Eds.), The Routledge International Handbook on Fear of Crime. London: Routledge, 354-367.

Ceccato, V., \& Bamzar, R. (2016). Elderly victimization and fear of crime in public spaces. International Criminal Justice Review, 26, 115-133.

Ceccato, V., \& Loukaitou-Sideris, A. (2020). Transit Crime and Sexual Violence in Cities: International Evidence and Prevention. London: Routledge.

Ceccato, V., \& Tcacencu, S. (2018). Perceived safety in a shopping centre: a Swedish case study. In V. Ceccato \& R. Armitage (Eds.), Retail Crime: International Evidence and Prevention. Cham: Springer International Publishing.

Ceccato, V., \& Wilhelmsson, M. (2011). The impact of crime on apartment prices: evidence from Stockholm, Sweden. Geografiska Annaler: Series B, Human Geography, 93, 81-103.

Ceccato, V., \& Wilhelmsson, M. (2012). Acts of vandalism and fear in neighbourhoods: do they affect housing prices? In V. Ceccato (Ed.), The Urban Fabric of Crime and Fear (pp. 191-213). Dordrecht: Springer.

Crenshaw, K. (1991). Mapping the margins: intersectionality, identity politics, and violence against women of color. Stanford Law Review, 43, 1241-1299.

Crowe, T. (2013). Crime Prevention through Environmental Design. Oxford, UK: Butterworth-Heinemann.

Davis, K. (2011). Intersectionality as buzzword: a sociology of science perspective on what makes a feminist theory successful. In H. Lutz, M. T. Herrera Vivar \& L. Supik (Eds.), Framing Intersectionality: Debates on a Multi-Faceted Concept in Gender Studies (pp. 43-54). Farnham: Ashgate.

Day, K. (1999). Embassies and sanctuaries: women's experiences of race and fear in public space. Environment and Planning D: Society and Space, 17, 307-328.

De Donder, L. (2009). Feelings of insecurity in context: theoretical perspectives for studying fear of crime in late life. International Journal of Economics and Finance, 1, 1-20.

Ditton, J., Chadee, D., \& Khan, F. (2003). The stability of global and specific measures of the fear of crime: results from a two wave Trinidadian longitudinal study. International Review of Victimology, 10, 49-70.

Eurostat: Statistical Office of the European Communities (2017). EUROSTAT: Regional Statistics: Reference Guide. Luxembourg: Eurostat.

Fattah, E. A., \& Sacco, V. F. (1989). Crime and Victimization of the Elderly. New York: Springer-Verlag.

Ferraro, K. (1996). Women's Fear of victimization: shadow of sexual assault? Social Forces, 75, 667-690.

Ferraro, K., \& La Grange, R. (1987). The measurement of fear of crime. Sociological Inquiry, 57, 70-97. 
Fox, K., Nobles, M., \& Piquero, A. (2009). Gender, crime victimization and fear of crime. Security Journal, 22, 24-39.

Franklin, C., \& Franklin, T. (2009). Predicting fear of crime. Feminist Criminology, $4,83-106$.

Gallup (2012). Women feel less safe than men in many developed countries. https:// news.gallup.com/poll/155402/women-feel-less-safe-men-developed-countries.aspx (accessed 1 May 2019).

Gekoski, A., J, M., Gray, M. H., Harvarth, S. E., Aliye, E., \& Adler, J. (2015). 'What Works' in Reducing Sexual Harassment and Sexual Offences on Public Transport Nationally and Internationally: A Rapid Evidence Assessment. London: British Transport Police and Department for Transport.

Gifford, R. (2007). The consequences of living in high-rise buildings. Architectural Science Review, 50, 2-17.

Gordon, M., \& Riger, S. (1989). The Female Fear. New York: The Free Press.

Gray, E., Jackson, J., \& Farrall, S. (2011). Feelings and functions in the fear of crime: applying a new approach to victimisation insecurity. British Journal of Criminology, 51, 75-94.

Hale, C. (1996). Fear of crime: a review of the literature. International Review of Victimology, 4, 79-150.

Henderson, K., \& Bialeschki, M. (1993). Fear as a constraint to active lifestyles for females. Journal of Physical Education, Recreation \& Dance, 64, 44-47.

Hummelsheim, D., Hirtenlehner, H., Jackson, J., \& Oberwittler, D. (2011). Social insecurities and fear of crime: a cross-national study on the impact of welfare state policies on crime-related anxieties. European Sociological Review, 27, 327.

Hunter, L. M., Krannich, R. S., \& Smith, M. D. (2002). Rural migration, rapid growth, and fear of crime. Rural Sociology, 67, 71-89.

Jackson, J. (2005). Validating new measures of the fear of crime. International Journal of Social Research Methodology, 8, 297-315.

Jackson, J., \& Gray, E. (2009). Functional fear and public insecurities about crime. British Journal of Criminology, 50, 1-22.

Koskela, H., \& Pain, R. (2000). Revisiting fear and place: women's fear of attack and the built environment. Geoforum, 31(2), 269-280.

Kelling, G., \& Wilson, J. (1982). Broken windows: the police and the neighbourhood safety. Atlantic Monthly, 249, 29-38.

Krulichová, E. (2018). The relationship between fear of crime and risk perception across Europe. Criminology \& Criminal Justice, 19, 197-214.

Lee, M. (2007). Inventing Fear of Crime: Criminology and the Politics of Anxiety. Cullompton: Willan Publishing.

Lemanski, C. (2006). Residential responses to fear (of crime plus) in two Cape Town suburbs: implications for the post-apartheid city. Journal of International Development, $18,787-802$.

Lewis, G. (2013). Unsafe travel: experiencing intersectionality and feminist displacements. Signs: A Journal of Women in Culture and Society, 38, 869-892.

Liu, E., \& Polson, E. (2016). The colors of fear: a multilevel analysis of fear of crime across Houston area neighborhoods. Journal of Ethnicity in Criminal Justice, 14, 307-326.

Lorenc, T., Clayton, S., Neary, D., Whitehead, M., Petticrew, M., Thomson, H., Cummins, S., Sowden, A., \& Renton, A. (2012). Crime, fear of crime, environment, and mental health and wellbeing: mapping review of theories and causal pathways. Health \& Place, 18, 757-765.

May, D., Rader, N., \& Goodrum, S. (2009). A gendered assessment of the "Threat of victimization": examining gender differences in fear of crime, perceived risk, avoidance, and defensive behaviors. Criminal Justice Review, 35, 59-182. 
Macassa, G., Winersjö, R., Wijk, K., Macgrath, C., AhmadiI, N., \& Soares, J. (2018). Fear of crime and its relationship to self-reported health and stress among men. Journal of Public Health Research, 6, 1010.

Newman, O. (1972). Defensible Space. New York: Macmillan.

Ortega, S., \& Myles, J. (1987). Race and gender effects on the fear of crime: an interactive model with age. Criminology, 25, 133-152.

Pain, R. (2000). Place, social relations and the fear of crime: a review. Progress in Human Geography, 24, 365-387.

Pain, R. (2001). Gender, race, age and fear in the city. Urban Studies, 38, 899-913.

Pain, R., \& Smith, S. J. (2008). Fear: critical geopolitics and everyday life. In R. Pain \& S. J. Smith (Eds.), Fear: Critical Geopolitics and Everyday Life (pp. 1-24). Aldershot: Ashgate.

Palidda, S. (2011). Racial Criminalization of Migrants in the 21st Century. Ashgate Publishing.

Sampson, R. (1988). Local friendship ties and community attachment in mass society: a multilevel systemic model. American Sociological Review, 53, 766-779.

Sandercock, L. (1997). Towards Cosmopolis. Chichester: John Wiley and Sons.

Scarborough, B., Like-Haislip, T., Novak, K., Lucas, W., \& Alarid, L. (2010). Assessing the relationship between individual characteristics, neighborhood context, and fear of crime. Journal of Criminal Justice, 38, 819-826.

Semmens, N. (2007). Towards an understanding of 'FEAR' as an intangible cost of crime. International Review of Victimology, 14, 219-235.

Stockholm Stad (2018a). Statistisk årsbok for Stockholm. http://statistik.stockholm.se/ attachments/article/38/Statistisk $\% 20 \%$ C3\%83\%C2\%A 5 rsbok $\% 20 f \% C 3 \% 83 \% \mathrm{C} 2 \%$ B6r\%20Stockholm\%202017.pdf (accessed 1 May 2019).

Stockholm stad (2018b). Trygghetsmatningen 2017. www.stockholm.se/trygghetsmatningen (accessed 29 April 2019).

Skogan, W. G., \& Maxfield, M. G. (1981). Coping With Crime-Individual and Neighborhood Reactions. Thousand Oaks: Sage.

Stanko, E. (1990). Everyday Violence: How Men and Women Experience Sexual and Physical Danger. London: Pandora.

Tjaden, P., \& Thoennes, N. (2006). Extent, Nature, and Consequences of Rape Victimization: Findings from the National Violence Against Women Survey. Washington, DC: US Department of Justice.

Uittenbogaard, A. (2014). Assessing guardianship opportunities at underground stations. Security Journal, 27, 147-163.

Valentine, G. (1989). The geography of women's fear. Area, 21, 385-90.

Valentine, G. (1990). Women's fear and the design of public space. Built Environment, $16,288-303$.

Valentine, G. (1992). Images of danger: women's sources of information about the spatial distribution of male violence. Area, 24, 22-29.

Wacquant, L. (2008). Urban Outcasts: A Comparative Sociology of Advanced Marginality. Cambridge, UK: Polity Press.

Warr, M. (1985). Fear of rape among urban women. Social Problems, 32, 238-250.

Whitzman, C. (2007). Stuck at the front door: gender, fear of crime and the challenge of creating safer space. Environment and Planning A, 39, 2715-2732.

Yin, P. (1980). Fear of crime among the elderly: some issues and suggestions. Social Problems, 27, 492-504.

Zhao, Y. (2013). Intersectionality, the production of difference and Norwegian transnational adoptees' identity work. NORA-Nordic Journal of Feminist and Gender Research, 21, 201-217. 


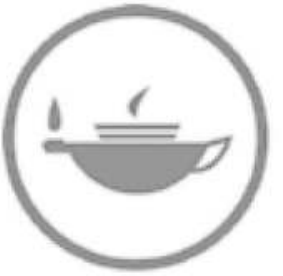

Taylor \& Francis Taylor \& Francis Group http://taylorandfrancis.com 


\section{Part V}

The metrics

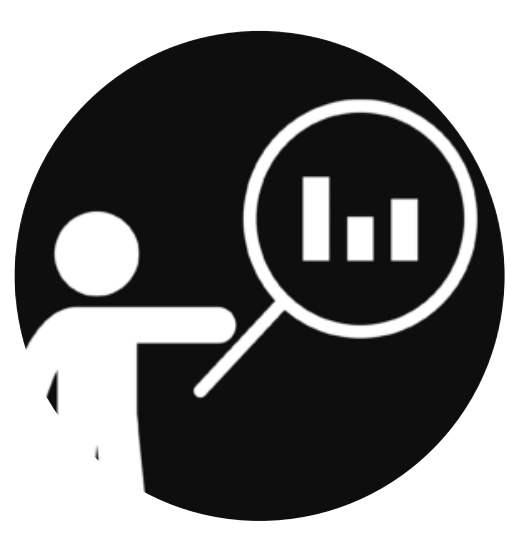




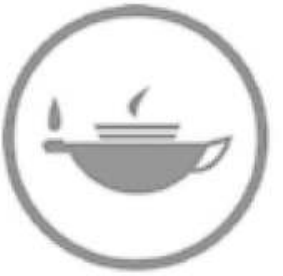

Taylor \& Francis Taylor \& Francis Group http://taylorandfrancis.com 


\title{
15 Contextual determinants of fear of crime in public transit
}

\section{An Ecological Momentary Assessment (EMA) pilot study}

\author{
Yasemin Irvin-Erickson, \\ Ammar A. Malik \\ and Faisal Kamiran
}

\subsection{Introduction}

Public transit users are particularly vulnerable to the negative consequences of fear of crime. In public transit settings, when fear of crime outpaces actual crime rates, a potentially significant number of people will not use or reduce use of public transit on account of fear (Badiora, Ojewale, \& Okunola, 2015). Negative consequences of fear of crime necessitate identification of context-specific conditions that trigger fear in public transit settings. This information can inform policy decisions in important ways in relation to the design and management of public spaces and public transit, and community safety practices in and around public transit.

The purpose of our pilot study presented in this chapter is to demonstrate the utility of Ecological Momentary Assessments (EMAs) to identify the relationship between transit specific contextual factors and fear of crime. EMAs are a data collection method in which information about individuals' experiences, emotions, and behaviors is collected in real-time via smart devices, as individuals go about their lives (Raento, Oulasvirta, \& Eagle, 2009).

In our pilot study in Lahore, Pakistan, we deployed EMAs through a mobile survey app and we collected real-time and near real-time context-specific data on fear of crime. Specifically, with this innovative approach, we conducted our pilot study to answer the following research question: what vehicle, station/stop, and environment specific factors might be affecting public transit users' fear of crime? The methodology piloted in our study can help advance the theoretical explanations of fear of crime in public settings, and especially in public transit settings. Our study methodology and results can also provide important insights and guidelines to researchers and practitioners in the fields of criminology, city planning, public safety, and transportation.

\subsection{Contextual determinants of fear of crime}

Individuals' observations of built and social environments as they go about their lives could affect their cognition of their risk of victimization and trigger 
feelings of worry, which may be altogether expressed as fear of crime. Elements of physical environment have been the most frequently studied aspect of places in the literature as various researchers have successfully shown the contextual element of people's fear and perceived risk (Lorenc et al., 2012, 2013; Pain, 2000).

Among the many theories that have been used to explain fear of crime, theories of social disorder have been the ones that most directly focus on the role of the built and social environments in shaping people's fear of crime and perceived risk of crime. Social disorder theories posit that disorderly activities and signs of disorder in communities creates fear of crime. Specifically, Broken Windows Theory (Wilson \& Kelling, 1982) suggests that perceptions of physical and social deterioration in individuals' environment can increase their sense of vulnerability and then result in a higher fear of crime among residents, reduced social control, and eventually an increase in crime. The propositions of social disorder theories about this relationship between perceived physical and social incivilities and fear and perceived risk of crime have been well supported by existing research (Lorenc et al., 2012).

For instance, physical signs of problems and neglect in the immediate environment such as graffiti, vacant and vandalized buildings, and abandoned cars have been associated with increased levels of fear. Furthermore, problems in the social environment such as the presence of disorderly individuals (i.e., people under the influence, people begging, homeless individuals) or signs of disorderly behavior such as the presence of litter and drug paraphernalia have also been closely linked with people's increased fear of crime (Cozens, Neale, Whitaker, \& Hiller, 2003; Farrall, Jackson, \& Gray, 2009; Hale, 1996; Innes \& Jones, 2006; Liska, Lawrence, \& Sanchirico, 1982; LaGrange, Ferraro, \& Supancic, 1992; Skogan \& Maxfield, 1981; Vrij \& Winkel, 1991; Warr, 1990; Waters, Neale, \& Mears, 2007).

Lighting has also been frequently cited as a correlate of people's worry of victimization (Lindgren \& Nilsen, 2012; Nasar \& Jones, 1997; Pain, 1997; Painter 1989; Herbert \& Davidson, 1994). Finally, yet importantly, places with few people around (Burgess, 2002; Koskela \& Pain, 2000; Pain \& Townshend, 2002 ) and crowdedness at places (Patterson, 1985) can also induce increased levels of fear.

The different research studies we reviewed on the relationship between perceived physical incivilities and signs of disorder posit that there is a relationship between fear of crime, perceived risk of crime, and contextual factors. However, with the exception of two recent studies by Chataway, Hart, Coomber, and Bond (2017) and Chataway, Hart, and Bond (2019), no other studies to the best of our knowledge attempted to collect information about these contextual correlates of fear of crime in the immediate environment of individuals.

In 2017, Chataway et al. (2017) used a mobile phone survey application to send EMAs to a convenience sample of 20 students at an Australian university as the participants travelled close to 10 georeferenced areas in their 
study area over a three-month data collection period. The authors collected data on the following indicators: (1) the demographic information about the participants (which was collected only once when the participants first launched the app); and participants' perceptions of (2) worry, (3) likelihood of victimization, (4) consequences of victimization, (5) control over crime, (5) beliefs about the incidence of crime; and (6) social and physical environment. Although the authors of this study collected context-specific data on correlates of fear of crime, the worry measure utilized in this study was retrospective. The authors captured study participants' fear of victimization in the past month by asking them about their worry with a four-item response; "l" indicating that the respondent experienced worry "not once in the past month" and " 4 " indicating that the respondent experienced worry "everyday" in the past month. In the same study, to measure participants' perceptions about their immediate environments, the authors asked seven questions to capture respondents' perceptions of physical and social incivility. The respondents were asked how much of a problem they felt the following conditions were in their immediate environments: (1) vandalism/graffiti; (2) garbage in the streets; (3) dogs out of control; (4) drug use in the open; (5) drinking in the street; (6) teenagers hanging around, and (7) not enough things for young people to do.

The authors asked seven more questions to capture participants' perception of social cohesion in their immediate environment. Specifically, the participants were asked to what degree they agree with the following statements: (1) the people who live here can be relied upon to call the police if someone is acting suspiciously; (2) if any of the children or young people around here are causing trouble, local people will tell them; (3) if I sensed trouble whilst in this area, I could raise attention from people who live here for help; (4) this area has a close, tight-knit community; (5) this area is a friendly place to live; (6) this area is a place where local people look after each other; and (7) most people who live in this area trust one another. The results from this study showed that perceived social cohesion was a statistically significant correlate of fear of crime while perceived incivility was not. Looking at the direction of the relationship between these variables, although an increase in perceived social cohesion was observed to be associated with a decrease in the odds of worry about personal crime, an increase in perceived incivilities was associated with a decrease in the odds of worry about personal crime. Despite the statistical insignificance of the relationship between perceived incivilities and odds of worry, the direction of the relationship between the two is surprising. However, this study is limited in its exploration of the relationship between fear of crime and perception of social cohesion and incivilities since the authors collected immediate environment specific data only on participants' perception of incivilities and social cohesion, and not on their worry of victimization. In other words, the perception of incivilities and social cohesion represented the immediate environment while worry of crime did not.

A more recent study by Chataway et al. (2019) advanced upon the methodology of Chataway et al. (2017) by introducing real-time measures of 


\section{Tasemin Irvin-Erickson et al.}

fear of crime in their mobile data collection efforts. In this new study, the authors sent EMAs to 72 study participants in Queensland, Australia via a mobile survey application in a three-month data collection period. Similar to the Chataway and colleagues' 2017 study, the authors collected data on demographics of the study participants; participants' perceptions of worry, belief, consequences, control and likelihood of victimization; and participants' perceptions of incivilities and social cohesion in their immediate environment. The results from this new study showcased that, unlike the results from the Chataway and colleagues' 2017 study, an increased perception of lack of social cohesion and increased levels of physical incivility in a person's environment were both statistically significantly related with higher levels of perceived risk of victimization and worry about crime. While discussing these results, Chataway and colleagues (2019) emphasize the importance of distinguishing between retrospective (reflective on past) and transitionary (context-dependent/ real-time) assessments of fear and risk of victimization. This recent study further demonstrates the need for incorporation of EMA methods to capture context-specific and real-time information on fear of crime and perceived risk of victimization.

\subsection{Current study}

In this study, we piloted an EMA methodology to collect real-time information about contextual correlates of individuals' fear of victimization. Our methodology, including our mobile survey application app and pilot sample and study extent, is explained in detail in our forthcoming article (Irvin-Erickson et al., 2020). Our pilot study aims to add to the existing literature on fear of crime, by collecting context-specific data on individuals' public transit experiences and their fear of crime and perceived victimization risk at different stages of their journey, namely waiting at a public transit stop, walking to and from a public transit stop, and traveling in a vehicle.

\section{Methodology}

\section{Data}

The data for our pilot study was collected from a convenience sample of six adult students (three male, three female) enrolled at a university in Lahore, Pakistan over a four-day data collection period. Each of the pilot participants was assigned a travel route in Lahore and completed several EMAs in the data collection period (eight to nine surveys per participant a day over the course of four days). The pilot participants were prompted to complete their surveys via our custom-built mobile survey application as they came within 50 meters of one of the 26 georeferenced Bus Rapid Transit (BRT) stations in Lahore. Study participants were also encouraged to fill out surveys at any other times and places of their preference. Study participants were required to complete a 
training at the beginning of the pilot and were administered an informed consent protocol (for details of this training please see Irvin-Erickson et al., 2020). Participants were provided with a smart phone, a wireless data plan, and a modest daily allowance for food and drinks. Pilot participants completed a total of 220 EMA reports in the data collection period.

\section{The mobile survey application}

Our team developed a custom-built application to deploy our EMAs in Android smartphones. We were able to capture the time and location of EMAs submitted via the GPS capability of the smartphones. We were further able to push EMAs to our respondents as they came in close proximity of the BRT stations in the study extent using the same GPS capability. Although the main aim of the study was to capture real-time information about respondents' travel experiences and fear of crime, we also provided retrospective reporting options to our respondents to ensure respondents' safety in high-risk or uncomfortable situations.

If the respondent was prompted to complete an EMA (if they were pinged), they had two options: (a) they either completed their EMA in real time or (b) they clicked a "respond later" button in the app and completed the EMA later. In case "b", the app recorded both the time and location of the original EMA prompt, and the time and location of the later EMA submission.

If the respondent wanted to report an "ongoing" fear event: (a) they either clicked "Start Survey" button in the app and completed the EMA in real time or (b) they clicked a "respond later" button in the app and completed the EMA later. After conferral with our project's Institutional Review Board, pilot respondents were instructed not to complete surveys in real time while traveling in a public transit vehicle, and to only use "Report Later" and "Report Past Incident" options due to the increased victimization risk such observations in a vehicle in transit can pose to pilot participants.

Lastly, if the respondent wanted to report a "past" fear event, the respondent clicked "Start Survey" and "Report Past Incident" buttons in the app, indicated the time and location of fear incident; and completed the survey later. In this case, the app recorded both the time and location of fear event as indicated by the respondent, and the time and location of the later EMA submission. Out of the 220 EMAs submitted by the respondents, 47 EMAs (21 percent) were submitted with the "report later" option; three EMAs (1 percent) were submitted with the "report a past experience" option, 103 EMAs (47 percent) were reported in real-time in response to the pings from the app as respondents came in close proximity to one of the 26 georeferenced BRT stations, and 67 EMAs (31 percent) were reported un-prompted in real-time by the respondents. In instances where the respondents used the app's "report past incident" option, the time difference between the actual fear event and EMA submission time ranged between 12 and 32 minutes. 


\section{Fear of crime survey instrument}

We collected data on the following indicators using our survey instrument: (1) respondent's fear of crime; (2) respondent's perceived risk of victimization; (3) respondent's stage of journey; (4) respondent's observations about the immediate environment (i.e., indicators of physical incivility and crowdedness); (5) time and location of EMA submissions; and (6) time and location of fear experiences (if different from the time and location of EMA submissions).

\section{Dependent variables}

There is an ongoing debate in criminology about conceptualization and operationalization of fear of crime and perceived risk of victimization. These discussions include a critique of very broad measurements of fear of crime as both a feeling and cognition, and researchers' inability to discern between the two concepts. With the exception of the study by Chataway et al. (2019), there is no other study, to the best of our knowledge, that measured both fear of victimization and perceived risk of victimization in real-time.

In our study, we measured fear of crime by asking respondents at the moment (or at the time of the experience) how fearful they are (or they were) of becoming a victim of one of the four crimes: physical assault, mugging, pickpocketing or sexual harassment. The respondents rated their fear on a scale of $\mathrm{l}$ to $5, \mathrm{l}$ being "not at all fearful" and 5 being "extremely fearful." Similarly, we measured respondents' perceived risk of victimization by asking them at the moment (or at the time of the experience) how likely they perceive they are (or they were) to experience one of the four crimes. The respondent rated their likelihood on a scale of 1 to 5,1 being "not at all likely" and 5 being "extremely likely."

A series of correlation analyses we ran between fear and perceived risk measures at the beginning of our analysis revealed very strong and positive relationships between fear of crime and perceived risk of crime for each of the four crime categories included in our analysis. The crime categories included in our analysis were mugging, sexual harassment, pickpocketing, and physical assault, and Spearman's rho statistic between fear and perceived risk ranged between 0.8 and 0.9 for each of these four crime categories. Accordingly, we treated both fear of crime and perceived risk of victimization variables as dependent variables in our regression models and explored if similar context and situation specific factors account for respondents' ratings of fear of crime and perceived risk of victimization.

We created a composite index of fear by summing up the ratings for fear for each crime category. We calculated a reliability coefficient (Cronbach's alpha) to test the internal consistency of this composite fear scale (Cronbach's alpha $=0.86$ ). Additional confirmatory factor analysis of fear ratings for four different crime categories further produced one component with eigenvalues of 0.82 and above. 


\section{Independent variables}

\section{Crowdedness}

Crowdedness was a binary variable. If the respondent was traveling in a public transit vehicle and reported that the vehicle was crowded or there were not enough seats in the vehicle, this variable was coded as " 1 ", and otherwise coded as " 0 ". If the respondent was walking or waiting at a public transit stop and reported any one of the following conditions at the time of an observation, crowdedness was coded as " 1 " and if else, coded as " 0 ": there are many pedestrians; there are vendors around; the respondent is close to a street market, an entertainment theatre; or a taxi stand.

\section{Journey stage}

Journey stage was a nominal variable comprised of three categories: walking, waiting at a public transit stop, and traveling in a public transit vehicle.

\section{Perceived incivility}

Perceived incivility was a scale variable. This measure took a value between 0 and 5 based on how many of the following conditions the respondent reported if traveling on a vehicle: there are drunk people around; there is loud music playing in the vehicle; there are beggars in the vehicle; there are verbal altercations between people; vehicle is in poor condition, or based on how many of the following conditions the respondent reported if walking/waiting at a stop: I can see trash lying around; I hear loud music around, there are beggars around; there are drunk people around.

\section{Time of the day}

Time of the day was a nominal variable with two categories: rush hour and nonrush hour. Rush hour reports (reports between 7 a.m. and 11 a.m. and reports between 4 p.m. and 8 p.m.) were coded as "l" and the reports during non-rush hours (any time other than rush hours) were coded as "0". Almost 90 percent of the responses $(n=190)$ in our pilot study were received between $7 \mathrm{a} . \mathrm{m}$. and 5 a.m.

\subsection{Analysis and results}

We estimated an ordinal logistic regression to assess the relationship between crowdedness, journey stage, perceived incivility, time of the day, and fear of crime and perceived risk of victimization. We chose ordinal logistic regression because: (1) our dependent variables (i.e., fear of crime and perceived risk of crime) were ordinal variables; (2) our independent variables were categorical or continuous; (3) there was no multicollinearity between our independent 
variables (tolerance values were more than 0.1 and VIF values were less than 10). The unit of analysis in our study were the EMA reports from the respondents $(N=220)$.

Table 15.1 presents the descriptive statistics for the variables included in our ordinal regression models. For both fear of crime and perceived risk of victimization variables, the average rating across all EMA reports was close to 10 out of the max 20 points possible (Min: 4, Max: 18, $n=216$ ). In 87 percent of all EMA reports $(n=191)$, respondents indicated that they experienced a crowded environment. The average incivility rating across all EMAs was 1.8 (min: 0, max: $5, n=220$ ). The majority of the EMAs were submitted in relation to travel experiences while waiting at a stop (42 percent) or walking to or from a transit stop (38 percent).

Looking at the goodness of the fit of our fear of crime regression model, the statistically significant chi-square statistic along with the high pseudo R-square (chi-square $=105.612, p<0.001 ;$ Negalgarke $R$-square $=0.38$ ) indicated that, the full model was an improvement over the intercept only model. As illustrated in Table 15.2, the results from the ordinal logistic regression showed that incivility had a positive relationship with fear of crime. Specifically, for every unit of increase in perceived incivility in the EMAs, the odds of fear of crime was 2.2 times higher $(\operatorname{Exp}(B): 2.2 ; 95$ percent $C I, 1.83$ to 2.63$)$, a statistically significant effect (Wald statistic $=73.15, p<0.001$ ). In the same regression model, in comparison to EMAs in which respondents observed crowded situations, EMAs in which there was not a perception of crowdedness, the odds of fear of crime was 72 percent less $(\operatorname{Exp}(B): 0.28,95$ percent CI, 0.12 to 0.66$)$, a statistically significant effect (Wald statistic $=8.52, p<0.01$ ). Looking at the relationship between journey stage and fear of crime, in comparison to traveling in a transit vehicle, walking $(\operatorname{Exp}(B): 0.40$, Wald: $5.19, p<0.05)$ was a statistically significantly less fearful journey stage. Time of the day was not a statistically significant correlate of fear of crime.

Table 15.1 Descriptive statistics for the observations included in the OLS model

\begin{tabular}{lllll}
\hline Report characteristics & Average & Frequency & Minimum & Maximum \\
\hline Fear rating (0-20) & 9.65 & 216 & 4 & 18 \\
Perceived risk rating (0-20) & 9.56 & 216 & 4 & 18 \\
Crowdedness & & & & \\
Crowded & $87 \%$ & 191 & - & - \\
Not crowded & $13 \%$ & 29 & - & - \\
Incivilities (0-5) & 1.8 & 220 & 0 & 5 \\
Journey stage & & & & \\
Traveling on a vehicle & $20 \%$ & 44 & - & - \\
Waiting at a stop & $42 \%$ & 93 & - & - \\
Walking & $38 \%$ & 83 & - & - \\
Time of the dayRush hour & $29 \%$ & 63 & - & - \\
Non-rush hour & $71 \%$ & 157 & - & - \\
\hline
\end{tabular}


Table 15.2 Ordinal logistic regression results of fear of crime $(n=216)$

\begin{tabular}{|c|c|c|c|c|c|c|c|}
\hline & \multicolumn{7}{|c|}{ Fear of crime } \\
\hline & Estimate & $S E$ & Wald & p-value & $\operatorname{Exp}(B)$ & $\begin{array}{l}\text { Lower } \\
\text { bound }\end{array}$ & $\begin{array}{l}\text { Upper } \\
\text { bound }\end{array}$ \\
\hline Incivility & 0.79 & 0.09 & 73.15 & 0.000 & 2.20 & 1.83 & 2.63 \\
\hline $\begin{array}{l}\text { Not Crowded } \\
\text { (reference: } \\
\text { crowded) }\end{array}$ & -1.25 & 0.43 & 8.52 & 0.004 & 0.28 & 0.12 & 0.66 \\
\hline $\begin{array}{l}\text { Non-rush hour } \\
\text { (reference: rush } \\
\text { hour) }\end{array}$ & -0.48 & 0.27 & 3.11 & 0.078 & 0.61 & 0.36 & 1.05 \\
\hline $\begin{array}{l}\text { Walking (reference: } \\
\text { traveling in a } \\
\text { vehicle) }\end{array}$ & -0.89 & 0.39 & 5.19 & 0.023 & 0.40 & 0.18 & 0.88 \\
\hline $\begin{array}{l}\text { Waiting at a Stop } \\
\text { (traveling in a } \\
\text { vehicle) }\end{array}$ & -0.65 & 0.36 & 3.25 & 0.071 & 0.51 & 0.25 & 1.05 \\
\hline
\end{tabular}

The results of the ordinal logistic regression analysis of perceived risk of victimization were very similar to the fear of crime model. First, the goodness of the fit tests of our perceived risk of victimization model showed that our full model was an improvement over the intercept only model (chi-square $=105.612$, $p<0.001$; Negalgarke $R$-square $=0.39$ ). As illustrated in Table 15.3, the results from the ordinal logistic regression showed that incivility had a positive relationship with perceived risk of victimization. Specifically, for every unit of increase

Table 15.3 Ordinal logistic regression results of perceived risk of victimization $(n=216)$

\begin{tabular}{|c|c|c|c|c|c|c|c|}
\hline & \multicolumn{7}{|c|}{ Perceived risk of victimization } \\
\hline & Estimate & $S E$ & Wald & p-value & $\operatorname{Exp}(B)$ & $\begin{array}{l}\text { Lower } \\
\text { Bound }\end{array}$ & $\begin{array}{l}\text { Upper } \\
\text { Bound }\end{array}$ \\
\hline Incivility & 0.78 & 0.09 & 72.18 & 0.000 & 2.18 & 1.82 & 2.61 \\
\hline $\begin{array}{l}\text { Not crowded } \\
\text { (reference: } \\
\text { crowded) }\end{array}$ & -1.06 & 0.42 & 6.13 & 0.013 & 0.34 & 0.14 & 0.80 \\
\hline $\begin{array}{l}\text { Non-rush hour } \\
\text { (reference: } \\
\text { rush hour) }\end{array}$ & -0.53 & 0.27 & 3.82 & 0.051 & 0.58 & 0.34 & 1.00 \\
\hline $\begin{array}{l}\text { Walking (reference: } \\
\text { traveling } \\
\text { in a vehicle) }\end{array}$ & -1.01 & 0.39 & 6.66 & 0.010 & 0.36 & 0.16 & 0.78 \\
\hline $\begin{array}{l}\text { Waiting at a stop } \\
\text { (traveling } \\
\text { in a vehicle) }\end{array}$ & -0.62 & 0.36 & 2.91 & 0.088 & 0.53 & 0.26 & 1.09 \\
\hline
\end{tabular}


in perceived incivility in the EMAs, the odds of perceived risk of victimization was approximately 2.2 times higher $(\operatorname{Exp}(\mathrm{B}): 2.18 ; 95$ percent $\mathrm{CI}, 1.82$ to 2.61 ), a statistically significant effect (Wald statistic $=72.18, p<0.001$ ). In the same regression model, in comparison to EMAs in which respondents observed crowded situations, EMAs in which there was not a perception of crowdedness, the odds of perceived risk of victimization was 66 percent less $(\operatorname{Exp}(B): 0.34,95$ percent CI, 0.14 to 0.80 ), a statistically significant effect (Wald statistic $=6.13$, $p=0.01$ ). Looking at the relationship between journey stage and perceived risk of victimization, in comparison to traveling in a transit vehicle, walking $(\operatorname{Exp}(B): 0.36$, Wald: $6.66, p=0.01)$ was a statistically significantly less risky journey stage. In the perceived risk of victimization model, in comparison to EMAs during rush hours, for EMAs during non-rush hours, the odds of perceived risk of victimization was 42 percent less $(\operatorname{Exp}(B): 0.58,95$ percent $C I$, 0.34 to 1 ), a statistically significant effect (Wald statistic $=3.82, p=0.05$ ).

\subsection{Discussion}

Our study aimed to demonstrate the utility of EMAs deployed through smartphone technology to capture fear of crime and perceived risk of victimization in an individual's natural environment and different stages of their public transit journey. The results from our pilot study show that EMAs via smartphones can close the gap in the fear of crime literature by providing much necessary insight into spatio-temporal triggers of fear of crime at different stages of journey in public transit settings and other public settings. The findings from our study exemplifies how EMAs can (1) advance the measurement of fear of crime, perceived risk of crime, and other potential outcomes; (2) collect real-time information on individuals' experiences in real-life; and (3) inform policy decisions in important ways in relation to the design and management of public spaces and public transportation, and community safety practices.

\section{Utility of EMAs for collecting context-specific information about fear of crime and perceived risk of crime}

The results from our pilot study show that fear of crime and perceived risk levels are affected by many context-specific factors. Fear of crime and perceived risk levels can be different at different times, different modes of transit, and different stages of travel and both can be strongly influenced by perceived level of incivilities and experiences of crowdedness in and around public transit. With the exception of recent studies by Chataway et al. (2017) and Chataway et al. (2019), no other studies have systematically collected real-time context specific data on correlates of fear of crime and perceived risk of crime. The results from these studies and our study suggest that EMAs can be used successfully in the study of fear of crime to identify the dynamic nature of fear of crime and perceived risk of victimization in individuals' natural environments. 


\section{Measurement of fear of crime and perceived risk of crime, and other outcomes}

The results from our pilot study show that, as also supported by recent work by Chataway et al., (2017) and Chataway et al. (2019), EMAs coupled with smartphone technology can advance not only fear of crime research but also any study of human behaviors, experiences, and emotions in individuals' natural environments.

\section{Implications and recommendations for future research and practice}

The methodology of our study can be relevant for researchers and practitioners in many fields including but not limited to Criminology, Transportation, Urban Planning, Architecture, Sociology, Public Health, and Peace Engineering. As discussed in the limitations section, owing to the small number of participants in our study, we were not able to use our respondents as our unit of analysis. Future research with larger samples using the EMA methodology can consider how individual effects play into context-specific correlates of perceptions, emotions, and behaviors of individuals in real-time settings. Furthermore, future studies on the construct validity of measurements from EMAs can drastically extend the existing literature on the measurement of fear of crime and perceived risk of crime.

Our pilot study showed that EMAs can provide critical information on spatiotemporal triggers of fear of crime in public transit settings and other public settings. This insight can inform policy decisions in important ways in relation to the design and management of public spaces and public transportation, and community safety practices. Time and place-relevant information on fear of victimization can guide practitioners to apply the principles of evidence-based crime prevention strategies such as situational crime prevention and crime prevention through environmental design to respond to fear, risk, and victimization incidents to reduce or remove the triggers for these experiences. Furthermore, EMAs can be used to elicit context-specific feedback from transit users for improving public transit and public spaces. Public transit users' safety needs might be different at different stages of their journey and different design, management, and staffing issues in and around public transit can contribute to a heightened sense of fear of crime and perceived risk of crime. This requires a comprehensive and holistic response strategy that involves practitioners from inside and outside of public safety to reduce individuals' fear and to motivate their use of public transit options and public spaces.

Researchers in the field of Criminology and other fields should more effectively utilize smartphone technology and EMAs to expand upon the literature on various topics in human geography including but not limited to fear of crime and perceptions of safety at various places. This can provide local policymakers and practitioners with invaluable information on physical and social determinants of 
individuals' activities in their natural environments and, in turn, help them formulate effective strategies to respond to a variety of issues based on empirically valid data.

\section{Limitations of the study}

Our study had its own limitations and these limitations should inform the future research on fear of crime and EMAs. First, we completed the pilot testing of our methodology with a convenience sample of six respondents over 4 days. Second, 90 percent of the EMAs in our pilot study were reported during the daytime hours. Third, at the beginning of our study, we provided training to our pilot participants acknowledging this kind of a training might bias our results. We decided to develop this training during our conferral with our project's Institutional Review Board because this was a first kind of an EMA study to be implemented in our study setting and we wanted to minimize the potential harm to the pilot participants. Our training included: (1) an informed consent protocol; (2) information about how to use the app; (3) the routes of observation around the BRT stops; (4) a short psychological counseling session on the risks that might be associated with participating in the study; (5) a short session on legal requirements of reporting crime while participating in the study; (6) a practice session to collect data with the app; and (7) a custom pamphlet including information on whom to contact if respondents run into issues during data collection including the contact information of project staff, the project's legal and psychological counsellors, and support services available through local NGOs.

We suggest the following remedies to address our study limitations for future research. First, during a larger scale project, having a larger study sample that is representative of the study population can allow researchers to (1) use respondents as the units of analysis to correlate individuals' characteristics/past experiences with real-time fear and (2) to increase the external validity of their study findings. Second, as observed in our study and as supported by the literature (see Chataway et al. 2017), EMAs can make participants more alert to and more observant of their surroundings. Future and large-scale implementation of EMAs should consider the safety of the individuals involved in data collection and the potential bias that can be introduced by providing safety training to respondents in a study. One way to troubleshoot this kind of a bias can be to accept the data from the first couple of days to a week of a longer data collection effort as a burn in period and to discard such data.

\subsection{Conclusion}

As explained earlier in detail, our study has its own limitations. Yet, we still believe our study makes significant contributions to the measurement of context-specific fear and perceived risk of crime (and other context-specific experiences) in real time as people go about their lives. We showcased through 
our study that asking people about their fear of crime and perceived risk of crime in different stages of their public transit journeys provides a unique opportunity to capture environment-specific correlates of fear and perceived risk including individuals' perceptions of incivility, experience of crowdedness, and time effects. Although our study focuses on a specific application of EMAs to capture fear of crime and perceived risk of victimization, this pilot study demonstrates that smart device technology coupled with EMAs can be a promising data collection tool to capture better measures of behaviors, experiences, and emotions in individuals' natural environments. Understanding the contextspecific correlates of behaviors, experiences, and emotions can provide practitioners in the field of criminology and other fields with additional insight for more effective strategies to respond to triggers of fear.

\subsection{Acknowledgments}

We acknowledge the support of the International Development Research Centre (IDRC), the Hewlett Foundation, the Department for International Development (DFID), the WorldBank Group (WBG) and the Sexual Violence Research Initiative (SVRI) for the work that underlies this paper. We would like also to thank Dr. Mangai Natarajan, Arslan Ihsan, Assad Sarwar, Fatima Abbas, Alexandra Ricks, and Emily Reimal for their continuous support with our research activities and the editors of this book and anonymous peer-reviewers for their valuable feedback.

\section{References}

Badiora, A. I., Ojewale, O. S., \& Okunola, O. H. (2015). Perceived risk and fear of crime in public transport nodes: the experience from Nigerian transit environment. International Journal of Criminal Justice Sciences, 10, 139-151.

Burgess, J. (2002). 'But is it worth taking the risk?': how women negotiate access to urban woodland: a case study. In R. Ainley (Ed.), New Frontiers of Space, Bodies and Gender. London: Routledge, 133-146.

Chataway, M. L., Hart, T. C., \& Bond, C. (2019). The social-psychological process of fearing crime: developing and testing a new momentary model of victimisation worry. Australian \& New Zealand Journal of Criminology, 52(4), 462-482.

Chataway, M. L., Hart, T. C., Coomber, R., \& Bond, C. (2017). The geography of crime fear: a pilot study exploring event-based perceptions of risk using mobile technology. Applied Geography, 86, 300-307.

Cozens, P., Neale, R., Whitaker, J., \& Hillier, D. (2003). Managing crime and the fear of crime at railway stations-a case study in South Wales (UK). International Journal of Transport Management, 1, 121-132.

Farrall, S. D., Jackson, J., \& Gray, E. (2009). Social Order and the Fear of Crime in Contemporary Times. Oxford, UK: Oxford University Press.

Hale, C. (1996). Fear of crime: a review of the literature. International Review of Victimology, 4, 79-150.

Herbert, D., \& Davidson, N. (1994). Modifying the built environment: the impact of improved street lighting. Geoforum, 25, 339-350. 
Innes, M., \& Jones, V. (2006). Neighbourhood Security and Urban Change: Risk, Resilience and Recovery. York, UK: Joseph Rowntree Foundation.

Irvin-Erickson, Y., Malik, A. A., Kamiran, F., \& Natarajan, M. (2020). Utility of ecological momentary assessments to collect data on fear of crime. International Journal of Comparative and Applied Criminal Justice. Online first DOI: 10.1080/01924036. 2020.1719532, 1-13.

Koskela, H., \& Pain, R. (2000). Revisiting fear and place: women's fear of attack and the built environment. Geoforum, 31, 269-280.

LaGrange, R. L., Ferraro, K. F., \& Supancic, M. (1992). Perceived risk and fear of crime: role of social and physical incivilities. Journal of Research in Crime and Delinquency, $29,311-334$.

Lindgren, T., \& Nilsen, M. R. (2012). Safety in residential areas. Tijdschrift voor economische en sociale geografie, 103, 196-208.

Liska, A. E., Lawrence, J. J., \& Sanchirico, A. (1982). Fear of crime as a social fact. Social Forces, 60, 760-770.

Lorenc, T., Clayton, S., Neary, D., Whitehead, M., Petticrew, M., Thomson, H., Cummins, S., Sowden, A., \& Renton, A. (2012). Crime, fear of crime, environment, and mental health and wellbeing: mapping review of theories and causal pathways. Health \& Place, 18, 757-765.

Lorenc, T., Petticrew, M., Whitehead, M., Neary, D., Clayton, S., Wright, K., Thompson, H., Cummins, S., Sowden, A., \& Renton, A. (2013). Fear of crime and the environment: systematic review of UK qualitative evidence. BMC Public Health, 13, 496.

Nasar, J. L., \& Jones, K. M. (1997). Landscapes of fear and stress. Environment and behavior, 29, 291-323.

Pain, R. H. (1997). Social geographies of women's fear of crime. Transactions of the Institute of British Geographers, 22, 231-244.

Pain, R. (2000). Place, social relations and the fear of crime: a review. Progress in Human Geography, 24, 365-387.

Pain, R., \& Townshend, T. (2002). A safer city centre for all? Senses of community safety in Newcastle upon Tyne. Geoforum, 33, 105-119.

Painter, K. (1989). Crime Prevention and Public Lighting with Special Focus on Women and Elderly People. London: Middlesex Polytechnic.

Patterson, A. H. (1985). Fear of crime and other barriers to use of public transportation by the elderly. Journal of Architectural and Planning Research, 2(4), 277-288.

Raento, M., Oulasvirta, A., \& Eagle, N. (2009). Smartphones: an emerging tool for social scientists. Sociological Methods \& Research, 37, 426-454.

Skogan, W. G., \& Maxfield, M. G. (1981). Coping with Crime: Individual and Neighborhood Reactions. Beverly Hills, CA: Sage Publications.

Vrij, A., \& Winkel, F. W. (1991). Characteristics of the built environment and fear of crime: a research note on interventions in unsafe locations. Deviant Behavior, 12, 203-215.

Warr, M. (1990). Dangerous situations: social context and fear of victimization. Social Forces, 68, 891-907.

Waters, J., Neale, R., \& Mears, K. (2007). Design and Community Regeneration: Investigating Personal Safety Concerns of Older People in Socio-economically Deprived Communities in South Wales. Pontypridd: University of Glamorgan.

Wilson, J. Q., \& Kelling, G. L. (1982). Broken windows. Atlantic Monthly, 249, 29-38. 


\title{
16 Mapping Open Drug Scenes (ODS)
}

\author{
Mia-Maria Magnusson
}

\subsection{Introduction}

Drug use and distribution in public places, areas known as Open Drug Scenes (ODS), is a common problem in societies around the globe (UNODC, 2009). Despite differences in legislation, culture and societal organization, the problems connected to ODS are the same or at least very similar across cities in Europe, Canada, and the United States. In these areas, ODS create problems for both the community and the police (EMCDDA, 2015). ODS revolve around complex patterns of drug use involving multiple substances, often including heroin, amphetamine, cocaine, cannabis, buprenorphine, new psychoactive drugs such as mephedrone, prescribed medications such as benzodiazepines, zopiclone and diazepam, methadone, and crystal meth (Connolly, 2012). Open drug markets have been found in suburbs outside of bigger cities (Harocopos \& Hough, 2005). But, typical ODS are located close to transportation hubs and in central business districts (Ceccato, Haining \& Kahn, 2007; Ceccato, 2013). Some notorious open drug scenes include Hastings Street in Vancouver (McNeil et al., 2014), Vesterbro in Copenhagen (Frank \& Bjerge, 2014), the 18th arrondissement in Paris (EMCDDA, 2015), and the old central bus-station in Tel Aviv (Bonny-Noach \& Ronel, 2018).

In Sweden, a well-known open drug scene, Plattan, has been located around Stockholm's central rail station area and has had drug-related problems since 1965 when it was built (Ceccato, Haining \& Signoretta, 2002, p. 35). Compared with other European countries, drug use is low in Sweden (EMCDDA, 2017). But open use and distribution of drugs has been increasing according to police reports and the media. Public drug use and distribution in the suburbs has gained attention in the last decades in some places in combination with gun violence (Police Authority, 2017). The open distribution and use of drugs have effects on living environments, safety issues and other crimes and create problems for neighborhoods and communities (Sturup, Rostami, Mondani, Gerell, Sarnecki \& Edling, 2019). In tackling these problems, the police and other authorities around the globe have adopted both punitive and harm reduction strategies, sometimes in combination (Olsen, 2017). Swedish police use, for example, motivational interviews in which police officers try to motivate addicts 
and link abusers to health care. This tactic has not proven to be effective on ODS (Magnusson, in press). Alongside the approach of Problem Oriented Policing, POP (Goldstein, 1990) there is a need to obtain a better understanding of ODS in Sweden, and in particular in Stockholm, to suggest interventions to tackle them and their impact.

The term ODS is found in the European literature but with no particular local reference. Falk (1981), for example, referred to ODS when drug users get together to sell and use drugs in public spaces as an open drug scene. Later, Bless et al. (1995) defined an ODS as all situations where individuals are caught using or selling drugs. Given vague definitions, this study defined an ODS as: "a geographic area, sustained in space and time, where use and dealing of drugs takes place in the public and is perceived as problematic by authorities and/or the public".

The aim of this study is to investigate the spatial nature of ODS in Stockholm, Sweden and explore how ODS might influence surroundings and communities. This is achieved by mapping and presenting descriptive statistics of ODS and their surroundings. Further, the possibilities of generating a typology for ODS in Stockholm County, Sweden is explored.

Previous international research on ODS is presented followed by the Swedish research evidence on ODS. Data and methods are presented, followed by the results from the analysis. The chapter concludes with a discussion of the results and implications for future research.

\subsection{Theoretical background}

\section{Current research}

Urban ODS vary greatly in size, visibility, and location (Bless et al., 1995). Yet, they do share some common features including polydrug use, health issues, public nuisance complaints, public consumption of alcohol, loud behavior, begging, intoxication, and other crimes (EMCDDA, 2015). The distribution of crime is uneven and follows Weisburd and Amram's (2014) law of crime concentration, where crime often concentrates at drug hot spots (Weisburd \& Green, 1995; Weisburd \& Mazerolle, 2000). There is also evidence of a spatial overlap of drug crimes and violence (Lum, 2008; Weisburd \& Mazerolle, 2000; Gerell, Sturup, Magnusson, Rostami, Nilvall, \& Khoshnood, unpublished). ODS also seem to intensify other social harms, such as competition between dealers that ends up in violence (Poret \& Téjédo, 2006). Youths and vulnerable groups may be more likely to use drugs if they are in close proximity to ODS (Werb, Kerr, Fast, Qi, Montaner, \& Wood, 2010).

Since the 1980s, a wide range of criminal justice interventions have been introduced to combat ODS (Mazerolle, Soule, \& Rombouts, 2005, 2007). Reductions in crime and problematic behaviors have been found in studies exploring POP approach (see Weisburd \& Green, 1995; Mazerolle et al., 2005). 'Pulling levers' interventions (Kennedy, 1996), in which multiple agencies use 
deterrence strategies to act together, have also seen some positive effects on containing drug markets (Corsaro \& Brunson, 2013).

Research on police responses to ODS shows that strictly repressive efforts can temporarily disrupt the open drug scene (Connoly, 2006; Frank \& Bjerge, 2014), but can also prevent abusers from getting drug treatment (McNeil et al., 2014). Interventions that adopt a strict healthcare approach, without police enforcement, have been shown to increase the growth of ODS and drug use (Klingemann, 1996; Waal, Clausen, Gjersing, \& Gossop, 2014). There is also research suggesting that gun violence and high homicide rates may be a consequence of drug prohibition. Disrupting ODS may paradoxically increase violence without additional regulatory actions (Werb, Rowell, Guyatt, Kerr, Montaner, \& Wood, 2011). Overall, there has been a struggle to offer solutions to the complex problems of drug markets faced by communities and local police departments (Mazerolle et al., 2005; Olsen, 2017). However, research generally shows that cooperation among multiple agencies offers the most long-term solution to the many problems of ODS (Connoly, 2006, 2012).

Swedish research on ODS is limited. Evaluations of police efforts at combatting ODS show weak results (Goldberg, 1993; Magnusson, in press). Adding to the problems is the changed tendency of the violence in Sweden. In Sweden, high levels of shootings, especially in vulnerable neighborhoods has gained a lot of attention in the media, in government reports (National Council for Crime Prevention 2015, 2018) and recently also in research (Sturup et al., 2018, Sturup et al., 2019). There has been a steep increase in gun violence in Sweden over the last 20 years, with an especially high rate among males aged 15-29 years compared with other West European countries (Sturup et al., 2019). Swedish ODS have recently been associated with gun violence (Gerell et al., unpublished). There are also near repeat patterns of the shootings at the open drug markets in Stockholm, which are chronic in the vulnerable neighborhoods (Gerell et al., unpublished). These locations seem to be in need of effective interventions.

\section{Research questions}

How many ODS are there in Stockholm County and where? What characterizes these ODS? Which are the criminal activities associated with ODS and how do they influence their surroundings? Is it possible to find different types of ODS?

\section{Hypotheses}

ODS can be detected in many places in the Stockholm County and some of them share similar characteristics. Due to the recent media attention and police focus these locations might be new and unestablished. Drug customers on the ODS might affect violence and therefore also safety. The ODS might be differentiated in means of violence, where shootings represent the worst violence, having a negative impact on safety perceptions of these neighborhoods. These 
areas might be the same as the vulnerable areas appointed by the Swedish national police.

\subsection{The case study}

\section{The study area}

Stockholm is the largest county in Sweden with 2.3 million inhabitants and it comprises 26 municipalities, the largest one being the Swedish capital, with 972,647 people in 2019 (SCB, 2019). The county is divided into three police districts, the north, the city and the south. The police have 19 local police departments in total within the Stockholm region (eight in the north, two in the city, eight in the south and one at Gotland).

\section{Data}

Data for this study come from the police records, the survey on police employees and crime statistics from the police. Data from outside the police are necessary to provide a more accurate inventory of ODS. The citizen survey is added to the analysis to expand the perspective on the ODS.

\section{Open drug scene survey}

The mapping of ODS was conducted with the assistance of police employees' knowledge on the ODS locations. In 2017, a web-survey was sent to all 19 Stockholm police departments from the regional strategic department to the chiefs of the local departments seeking participation from the personnel. All 19 local departments participated with 18 departments providing completed surveys. Some departments reported one ODS in their area while others with as many as six. One department, which was responsible for Sweden's biggest airport, Arlanda, reported the absence of any ODS in their area. Thus, Arlanda was excluded from the study. Together, the 18 departments identified 48 ODS for which they completed surveys $(N=48)$. All responses were coded in IBM SPSS version 23 for analysis.

The surveys comprised close-ended questions for the following: geographical spatial characteristics, information of the drug scene: clientele, dealers and users, distributed drugs, symptoms, age and size. Police responses, organizational strategies and collaborations at the scene were surveyed with open-ended questions and then thematized. A total of 97 variables on each ODS were collected and analyzed.

In addition to responding to the surveys, all departments were also asked to precisely indicate the open drug scene on a map that was provided along with the questionnaire. These responses were returned via electronic drawing on the computer, or by printing the map, drawing on the paper, and scanning the image.

All mapped and drawn ODS $(N=48)$ were plotted in geographical maps for visual presentation and mapped by coordinates. They were converted into 
shapefiles in the software ARCGIS. An index of severity comprised by the characteristics on the ODSs was created to separate severe ODSs from milder ones.

\section{Crime data}

Crime statistics from all outdoor violent crimes occurring in Stockholm county and reported to police during 2017 were gathered and added to the maps ( $N=2,795)$. This category of violent crimes (e.g., assaults, threats, molestations, and robberies) was chosen to get a general overview of the situation. These crimes were transformed into regional hotspots. The hotspots were created with Kernel density estimation and with the bandwidth 306 and cell size 36. The used classification was Natural breaks (Jenks).

Buffer zones were created in GIS. Buffer zones were 200 meter radius areas surrounding the ODSs drawn by the police employees. In total the ODSs with buffer zones covers 0.29 percent of the total regional land area.

To get a more nuanced understanding, specific crime types were studied, some of which were included in the general outdoors violence measure above. The five crime types: robbery ( $N=615$ against persons only), outside violence ( $N=2,096$ outside assault only), prostitution $(N=28$ purchase of sex), murder ( $N=75$ including attempts), knife and weapon crimes $(N=1,105)$ are used to explore the crime concentrations on the ODSs with the buffer zones.

All reported shootings, regardless of indoor or outdoor, in the region in 2017 were separately recorded $(N=129)$. The gun violence data were collected from the Stockholm police and contain confirmed incidents of illegal discharges of firearms. A layer of the shootings was created in GIS as a shapefile through their coordinates.

\section{Community survey}

Data from the citizen fear of crime survey were also added to the maps. This survey is conducted every three years and is sent out to random residents, age 16 to 79 years, in the Stockholm municipalities. Data collected by this survey could only be mapped for the 24 ODSs found in the Stockholm municipalities by districts (stadsdelsområde). In 2017, 17,669 individuals surveyed responded to the surveys, which is equivalent to 55 percent of the sample. Two questions were used in study. (i) "Do you feel that there are problems with drug trafficking that are open on the streets or squares in your residential area or in connection with this?" Possible responses were: No; Yes, to a small extent; Yes, to a great extent; Yes, it does exist but is not a problem. (ii) "How safe or insecure do you feel in your residential area?" Possible responses were: Very Safe; Safe; Fairly Safe, Unsafe, and Very Insecure.

These data were then transferred to GIS and put out on the maps where the layer of ODSs was mapped. Then the different responses were divided into low, medium and high problems (Question 1) and unsafety (Question 2) and colored in different shades of gray to depict the different responses between the 
communities. These levels are created in GIS with natural breaks. Then this was transformed into a layer in GIS.

\section{Vulnerable neighborhoods}

In Sweden, the "vulnerable neighborhoods" term has been used in police reports to label neighborhoods where criminal networks have a large impact in the local community (Police Authority, 2015, 2017). In 2017, the Swedish police identified a total of 61 neighborhoods as vulnerable following a large survey of local police department responses to problems and data on working conditions combined with demographic statistics such as unemployment and school grades (Police Authority 2017). Vulnerable neighborhoods have the effects of criminal networks in threats and blackmailing against inhabitants or workers in the community, and the prevalence of crime and disorder such as violence and shootings and open drug markets (Police Authority, 2017). In this study, vulnerable neighborhoods in Stockholm County $2017(N=25)$ were also added to the analysis of ODSs.

\section{Methods}

Three sources were used to inventory ODS, as defined above. The first source was a survey on ODS in the Stockholm region conducted by police departments. The survey answers were analyzed descriptively and geographic locations identified in survey responses were mapped in the geographic information system (GIS). The second source for the inventory of ODS was official police crime data. The third source for the inventory of ODS was the citizen fear of crime survey of Stockholm. All sets of data were analyzed and mapped in GIS ArcMap 10.2.

GIS is an information system that is designed to work with data referenced by spatial or geographic coordinates. In the field of policing, the integration of GIS has had a revolution-like impact (Markovic, 2007). Crime mapping has been used widely in tactical and strategic crime analysis (Chainey \& Ratcliffe, 2005; Levine, 2006). The information gained from crime mapping analysis is used for applications such as focusing resources on hot spots and crime prevention efforts in specific neighborhoods (Levine, 2006). Studying geographic places with spatial analysis has been done increasingly in Sweden. For example, in a study of sexual assault, Ceccato (2014) used a GIS approach to study the physical features, characteristics, and patterns of the places where sexual offenses occur. Ceccato explored the characteristics of the "places of rape", and discussed connections between the victim and crime place (Ceccato, 2014).

\section{Typology}

Since there seems to be both inner city and suburban locations where open use and dealing of drugs takes place in Stockholm County, this study used the descriptive analysis from the survey, the geographical patterns, crime data intersection 
and listed vulnerable areas to create a typology of ODS. Based on descriptive statistics, outdoor violence data, the shootings, vulnerable areas and the citizen survey data, the ODS were divided into separate groups, and by exploring different types of variables to use for division into the groups different types of ODS were identified.

\subsection{Results}

There were 48 ODS mapped by the local police departments which translate to about two ODS per 100,000 residents. They are spread all over the county with 18 in the south area, six in the inner city area and 24 in the north area (Figure 16.1).

One clear pattern found related to the communities and neighborhoods is that 90 percent of the ODSs are perceived to be located in residential areas close to where people live. Most of them are located on the local square (75 percent) where the local city center is placed ( 86 percent). The ODS location is also of interest in relation to the community organization, on the squares and in the local city centers, the local health care, stores and social services are often placed. Yet another more worrying fact is ODS location in relation to children and youth care: 71 percent of the ODSs are reported to be located close to youth centers, 61 percent near schools and 51 percent near day-care centers. The areas associated with drug use and distribution are viewed as static (74 percent) even though the activities move around at the location.

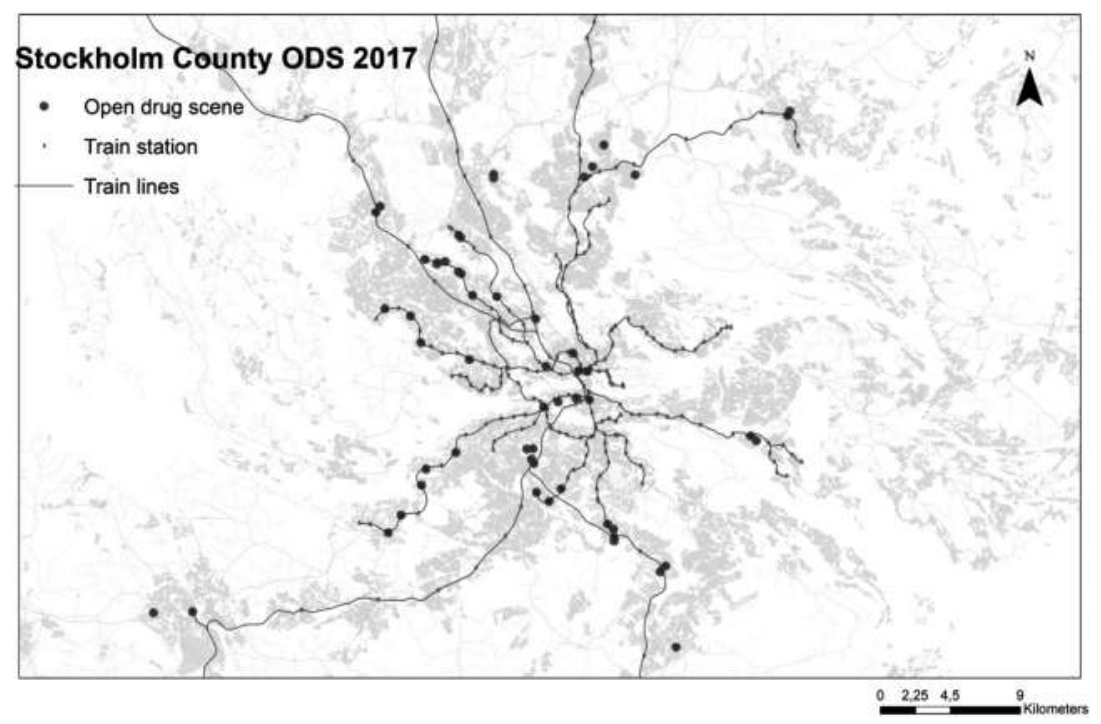

Figure 16.1 Open drug scenes in Stockholm county, 2017.

Source: Author. 
Age

ODS have been present in these neighborhoods for a while, others are more recent. ODS can be classified in "four age groups": 0-2 years of age, 2-5 years, 5-10 years and 10 years or older. Findings show that 48 percent of the ODS $(N=23)$ were 10 years or older. When including age level 3 (5-10 years old) the study found that 60 percent of the ODS $(N=29)$ were five years or older.

\section{Drug scene members}

Interesting to the analysis is the characteristics of the clientele at the ODSs. The users were reported to be of all ages with "age unknown" as a big group (30 percent) and 58 percent of the drug scenes have users from both the age group under the age of 20 and the age group 20 years or older. The age of the dealers differed slightly from the users, reportedly. The dealers were young (15-19 years) at almost a third of the drug scenes (29 percent) and only 8 percent of the drug scenes have older (20 years and older) dealers. In 17 percent of ODS $(N=8)$ opioid treatment patients were regularly found using and distributing drugs.

The participants' relation to the neighborhood was also analyzed. The ODS users were both locals ( 44 percent), and those traveling to the ODS ( 27 percent). The patterns among dealers were perceived to be different. The dealers to a large extent were locally connected to the scenes. Seventy-one percent $(N=34)$ of the ODSs had local dealers and only 6 percent $(N=3)$ had outside dealers. The drug scenes were also connected to the criminal networks in the neighborhood at many places in the region. Fifty-six percent of ODSs $(N=27)$ were reportedly associated with criminal networks known by the local police.

\section{Substances}

Substances vary greatly in value and effect and the substances openly used and distributed might also influence the drug scene, its participants, and the surroundings. At 82 percent of the ODSs $(N=39)$ there was public smoking of cannabis. The four most common distributed substances were cannabis (100 percent of the ODS), cocaine (60 percent of the ODS), synthetic opioids (49 percent) and amphetamine (42 percent). The main drugs at 69 percent of the ODS ( $N=33$ ) were a combination of cannabis, cocaine and tramadol (synthetic opioid).

\section{The perceived impact of $O D S$}

What happens at ODSs is also important for the community. Most ODSs have public disturbances. Some of the disruptive characteristics of the ODSs seemed common while others were unusual. The need to analyze these characteristics became clear and an index was created to indicate the impact of ODS on communities.

The assumption is that the more symptoms of disruption that are perceived in the area, the greater the negative impact of ODS on communities. These 
Table 16.1 Disruption in the area associated with ODS

\begin{tabular}{lll}
\hline Indexed variables & \% of the ODS \\
\hline 1 & The place generates discomfort/inconvenience to the public & 94 \\
2 & The place is perceived as unsafe & 79 \\
3 & The place is a hot spot for crime & 69 \\
4 & The place attracts new users and other vulnerable groups & 67 \\
5 & Young persons are advised not to visit the place & 50 \\
6 & The public avoids the place & 44 \\
7 & Informal zone of tolerance for deviant behavior & 15 \\
\hline
\end{tabular}

variables of interest were scored and related to each other. Seven symptoms of disruption were analyzed (Table 16.1). On the reliability test of Cronbach's alpha, the index was tested and gave a value of 0.71 . This means that our index is reliable in measuring ODS disruption as an impact on the area. More than half of the ODSs had five or more symptoms of disruption. ODSs with five or more symptoms were thus classified as severely disrupted.

To explore if there was a correlation between age of ODS and disruption, the age variable was combined with the index. Overall, only a weak correlation was found $(r=0.28, p=0.56)$ between different disruptive characteristics of the index and age. However, there was a group of 15 old ODSs with many symptoms of disruption. Thus, most of the old ODS had lots of disruptive characteristics on the surrounding areas.

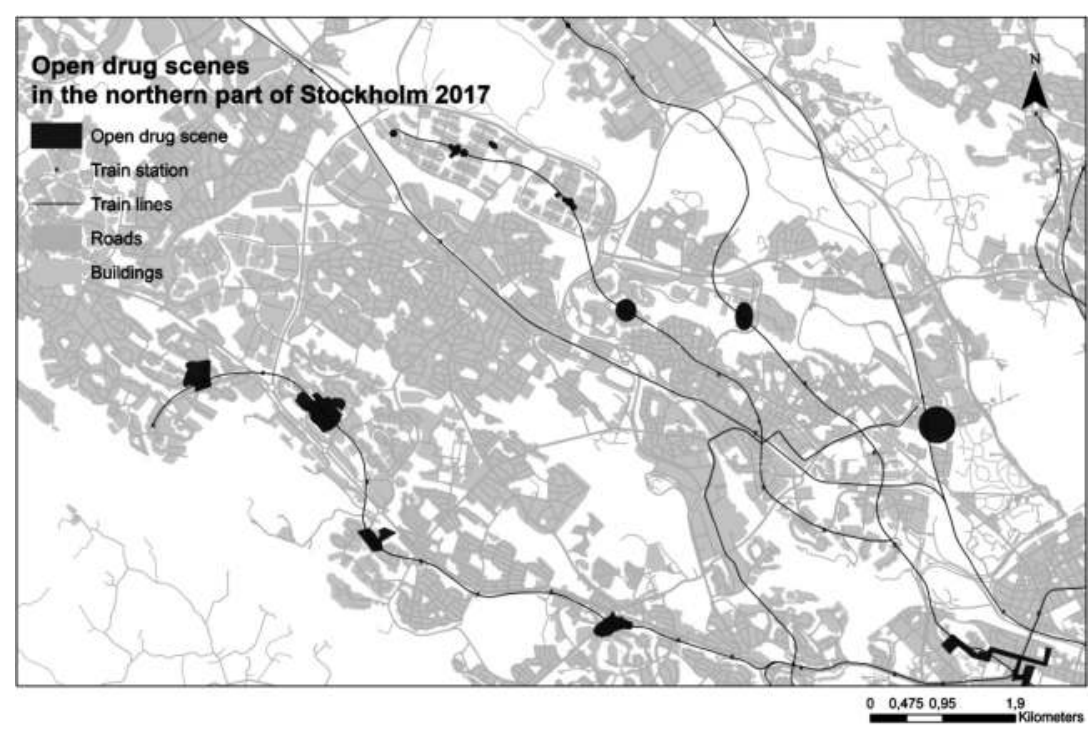

Figure 16.2 ODS and train lines in the northern part of Stockholm, 2017.

Source: Author. 


\section{Mia-Maria Magnusson}

The ODSs were distributed with some obvious geographical patterns. First the connection to public transportation was evident (Figure 16.2). Eighty-two percent of the ODSs $(N=39)$ were located at transportation nodes, mostly on, or in direct proximity to subway or commuter train stations and a few at local bus stations. In Stockholm the public transportation system is spread throughout the region with subway lines, commuter train lines, and bus lines covering all trafficked parts of the county.

\section{Hot spots of violence}

The hot spots of violent crime were intersected with the ODS areas. When added to the drug scene layer in GIS a clear pattern was found: 65 percent of the ODSs $(N=31)$ in Stockholm coincided with the regional hot spots for outdoor violent crime. Many of the ODSs were locations of hotspots of violence. Two of the inner city ODS had the biggest hot spots of violence in the region. These two ODSs were located at two of the busiest areas of the city and one of the ODSs was the oldest and most well-known ODS, Plattan. Plattan was built in 1965, and has since then been troubled with drug sales, drug use, and high crime concentrations. The police have struggled with containing the spread of narcotics and undermining the unique position Plattan holds in drug circuits.

\section{Shootings}

The second data layer put on top of the drug scenes consisted of data of all shootings $(N=129)$ in the region in 2017 (Figure 16.3). The shootings were intersected with the ODS areas.

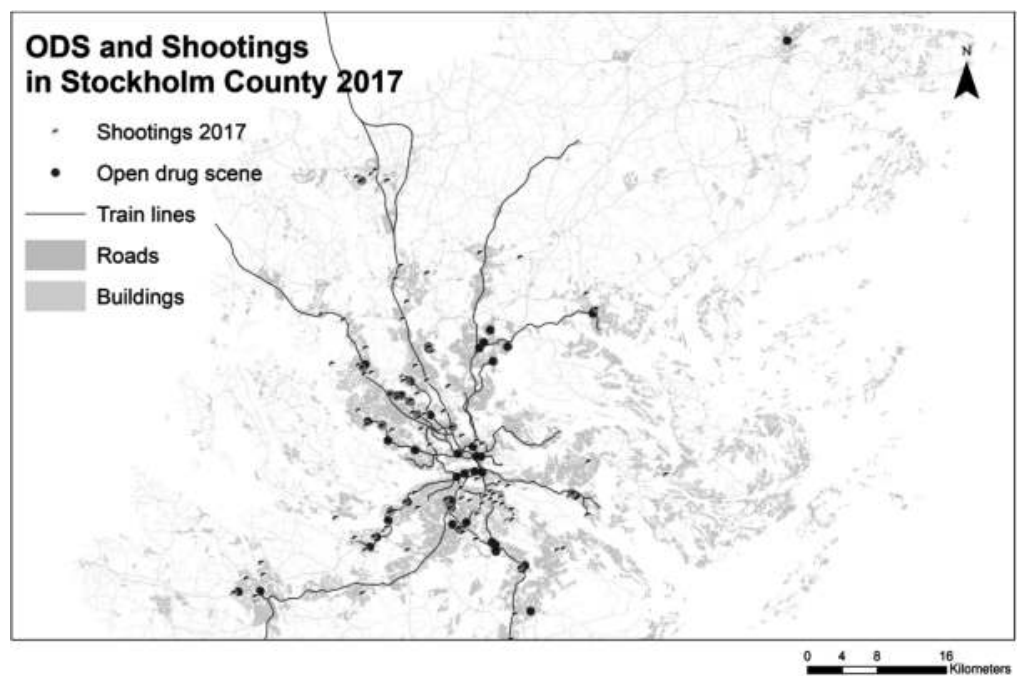

Figure 16.3 ODS and shootings in Stockholm county 2017.

Source: Author. 
Seventy percent of the ODSs $(N=34)$ in the Stockholm region had at least one shooting in 2017. Twenty-four ODS had a shooting at the location and 12 ODS within two blocks from the ODS. Gun violence and shootings send strong signals of danger and add problems to ODS with existing issues. An analysis of the number of the shootings was also done to see which of the 129 shootings in the County in 2017 were located at ODS or in their proximity (at the most one block away). Fifty shootings were located at ODS, 39 percent of all the shootings in the county in 2017. There are also ODS with no shootings and there are shootings at other locations than ODS. The ODS without shootings $(N=14)$ were qualitative analyzed and 50 percent of them $(N=7)$ were in the youngest group ( $0-2$ years). Ninety percent of the youngest ODS ( $N=7$ out of 8 ) had no shootings.

\section{Crime concentration-buffer zones analysis}

In this step, five types of crimes were analyzed. As seen in the analysis of violent crimes, the ODSs were connected to hot spots of violent crimes in the region. In the analysis of buffer zones, several violent crimes were concentrated at the ODS (Table 16.2). Despite the total area of the buffer zones only accounting for 0.29 percent of the regional land area, a large percentage of crime took place within them. Thirty percent of all outdoor assaults and 22 percent of murders occurred inside the buffer zones.

\section{Citizen safety}

The citizen safety survey data were then analyzed to explore if the mapped ODS were locations of citizen unsafety. First, the question in the survey on open drug trade was analyzed to relate to the ODS mapped from the police survey data. In the communities where there were several ODS found by the police departments, survey respondents expressed high levels of problems with open drug trade. Second, survey respondents indicated poor safety perceptions in communities where many ODS were located.

In Figure 16.4, ODS are combined with shootings, unsafety measures and vulnerable areas.

Table 16.2 Crime concentration in ODS

\begin{tabular}{ll}
\hline Crime type & $\%$ \\
\hline Outside assault & 30 \\
Weapon and knife crime & 24 \\
Murder & 22 \\
Robbery & 22 \\
Purchase of sex & 12 \\
\hline
\end{tabular}




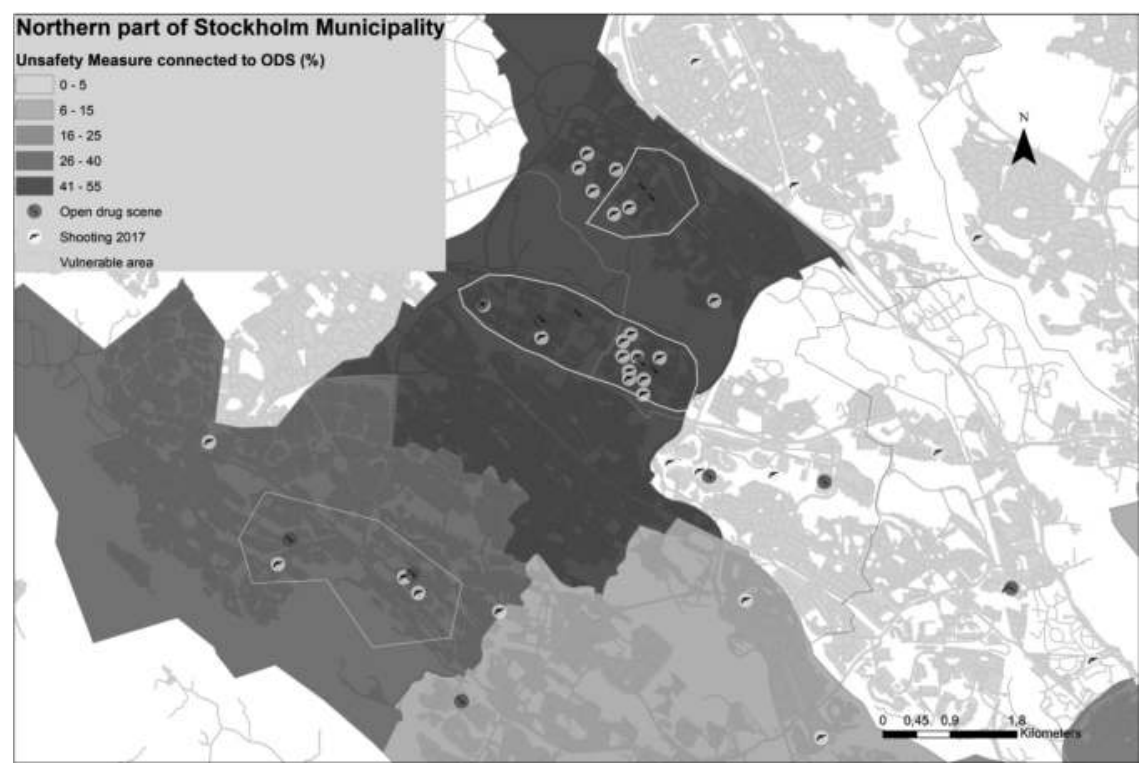

Figure 16.4 Open drug scenes, shootings and perceived safety measures in the northern part of Stockholm municipality.

Source: Author.

\section{Vulnerable neighborhoods}

The listed areas of vulnerable neighborhoods where criminal networks have a large impact in the local community were then intersected with the ODS. Twenty-one of the ODS in the Stockholm region were located in neighborhoods listed as vulnerable or particularly vulnerable. Of the 21 ODS, 18 had criminal networks that sell the drugs.

The ODSs in these neighborhoods had higher prevalence of criminal network distribution of drugs as well as more symptoms of disorder (Table 16.3). The police survey included questions of how the ODS were tackled by the local departments. The ODS in particularly vulnerable neighborhoods had less police resources allocated to the location.

Table 16.3 ODS and vulnerable neighborhoods

\begin{tabular}{lllll}
\hline ODS per neighborhood & $\begin{array}{l}\text { Severe } \\
\text { ODS (\%) }\end{array}$ & $\begin{array}{l}\text { Criminal } \\
\text { network (\%) }\end{array}$ & $\begin{array}{l}\text { Old ODS 5yrs } \\
\text { or more (\%) }\end{array}$ & $\begin{array}{l}\text { Police resource } \\
(\%)\end{array}$ \\
\hline Particularly vulnerable (8) & 75 & 100 & 100 & 13 \\
Vulnerable (13) & 54 & 76 & 31 & 53 \\
Unlisted (27) & 44 & 28 & 50 & 50 \\
\hline
\end{tabular}


Table 16.4 The typology of ODS in Stockholm, 2017

\begin{tabular}{|c|c|c|c|c|}
\hline & Type 1 City ODS & $\begin{array}{l}\text { Type } 2 \text { Vulnerable } \\
\text { Suburb ODS }\end{array}$ & $\begin{array}{l}\text { Type } 3 \text { Suburb } \\
\text { ODS }\end{array}$ & Other \\
\hline Location & $\begin{array}{l}\text { Business/shopping/ } \\
\text { big transportation } \\
\text { node }\end{array}$ & $\begin{array}{l}\text { Residential/local } \\
\text { center/train } \\
\text { station }\end{array}$ & $\begin{array}{c}\text { Residential/local } \\
\text { center/train/ } \\
\text { bus station }\end{array}$ & \\
\hline Area & Normal & Vulnerable & Normal & \\
\hline Unsafety & High/Medium & High & Medium/Low & \\
\hline Crime & Medium/Low & $\begin{array}{l}\text { Shootings, murders } \\
\text { violent crimes }\end{array}$ & $\begin{array}{l}\text { Mixed nuisance, } \\
\text { violent crimes }\end{array}$ & \\
\hline \multirow[t]{3}{*}{ Clientele } & Mixed clientele & Criminal networks & Mixed clientele & \\
\hline & Many heavy users & Young clientele & Alcohol use & \\
\hline & Drawing crowds & Local dealers & & \\
\hline Substances & $\begin{array}{l}\text { All drugs inc heroin, } \\
\text { opioids }\end{array}$ & $\begin{array}{l}\text { Cannabis, cocaine, } \\
\text { synthetic opioids }\end{array}$ & $\begin{array}{l}\text { Mixed } \\
\text { substances }\end{array}$ & \\
\hline Age ODS & Old & Old and medium & Mixed & \\
\hline Index & Severe & Severe & Mixed & \\
\hline$N=$ & 6 & 18 & 12 & 12 \\
\hline
\end{tabular}

\section{ODS typology}

A typology was created where three types of ODS could be clearly grouped. Three types of ODS with characteristics were found:

1. The City ODS type, which has been in place for some time (at least 10 years), has severe disruption and is located in a business area at a big transportation hub with medium/high unsafety measures in the citizen survey, with mixed crimes and clientele with heavy abusers, and draws lots of people, and all possible substances are sold.

2. The vulnerable suburb ODS, located in a vulnerable area, at the local center near a train station, with high measures of unsafety in the citizen survey, with shootings, murders and violent crimes and local criminal networks present in the dealing, focused on cannabis, cocaine and synthetic opioids, and severe disruption in the index.

3. The suburb ODS are also located in local centers but not in vulnerable areas and with lower measures of unsafety, with less disruption, and more mixed clientele, substances and crimes. Then there are one third of the ODS that do not fit any of the three types and do not share characteristics enough to be grouped together as a Type 4. These ODS makes up the "Other" category (see Table 16.4).

\subsection{Discussion of results}

The ODS in Stockholm are overall situated in the inner city and at residential areas in communities close to public transportation nodes, most often metro and train stations, most likely to maximize accessibility to the selling market. 


\section{Mia-Maria Magnusson}

They are not a new phenomenon and many have even existed for a decade or longer. Findings do not show clear evidence about their development and whether they might have increased in size or severity. The oldest ODS have more severe characteristics (such as being established crime hotspots and unsafe areas) but shootings occur in all age categories of ODS but less in the youngest ones $(0-2$ years old $)$.

Principles of routine activity can be helpful to understand the location of ODS, which indicate that crime is likely to occur when motivated offenders, suitable targets and the absence of capable guardians come together in a particular place and time (Cohen \& Felson, 1979). Transportation nodes facilitate ODS, since these are locations where large amounts of people are passing every day. Since the drug trade is dependent on users and dealers in the cover of crowds and access to easy getaways, these locations are logical for the activity. In comparison with the United States, where transportation is dependent on cars, which require a drug market to have easy driving routes (Haroscopos \& Hough, 2005), the locations described in this study are somewhat different and are dependent on public transportation. A similar pattern was found by Ceccato et al. (2007) in Brazil.

Furthermore, there is crime concentration in and around nodes and paths that are most frequented where a potential offender comes into contact with a suitable target at times when guardianship is lacking (Cohen \& Felson, 1979). Since the ODS are located at transportation nodes this might be one of many explanations of the crime concentrations found here. The collections of places that are connected to one another via paths, streets or transportation lines are also the focus of crime patterns theory (see Brantingham \& Brantingham, 2013). Transportation offers easy access and escape and lots of people.

\section{Violence}

This research suggests that ODS are hotspots for violent crimes outdoor and are places of crime concentration. Even minor violence can be very disturbing and affect the community if done in public spaces (Felson \& Eckert, 2018). Drug sales within an apartment might do less harm than public or open air drug markets (Felson \& Eckert, 2018). When adding violence to these places the people passing or living at these locations might be strongly harmed. The participants are exposed to great dangers and need to take major risks. The community members with no part in the drug market, might withdraw from the social spaces due to fear.

There is a known interplay between poverty and structured violence. Factors such as social demography and variables on social disorganization also matter as to where drug markets are located. Some areas have more illegal businessfriendly environments, are more tolerant or incapable of disrupting the drug market activity (McCord \& Ratcliffe, 2007).

One characteristic that might help to answer the differences of crime distribution over neighborhoods could be the concepts of collective efficacy, briefly 
explained as the mutual trust and shared expectations to intervene and the agency of social networks in neighborhoods (see Sampson, Raudenbush \& Earls, 1997). More recently, Gerell (2018) found a connection between low collective efficacy and high levels of violence in micro places. This tells us that the location of drug markets in neighborhoods has a close connection to social factors but also that the social factors might be connected to the development of ODS. The citizen willingness to report and intervene varies greatly between places due to the closeness to housing and collective efficacy differences (Gerell, 2017; Skogan, 1990). Criminological theories of broken windows (Wilson \& Kelling, 1982), collective efficacy (Sampson et al., 1997) and spiral of decay (Skogan, 1990) suggest that areas of low social resources and high levels of crime might make the stronger members in communities move away (Gerell, 2017). In this study, the combination of ODS, shootings and vulnerable neighborhoods seems particularly troubling. Further research on this development is needed. For instance, what comes first? The ODS or the negative social development or some other confounding factor?

When looking at the descriptive statistics from this theoretical perspective, it could be argued that the different variables concerning the surrounding public, geography, police presence and criminal behavior at the ODS could affect the surroundings. Open drug sales can send signals that society has no control over the distribution of sales, which might increase insecurity. Drug sales sites tend to be in areas where insecurity is high which may be further aggravated by open drug sales, especially when combined with lethal gun violence. Insecurity leads to less willingness to help keep order, which results in a lower collective ability. Insecurity can also cause resource-intensive people to move from an area.

Furthermore, in this study, all ODS in the particularly vulnerable neighborhoods were old. The numbers of shootings in Sweden have increased in the last 20 years, but with a big peak starting in 2006 (Sturup et al., 2018). The areas in Stockholm with recurrent gun violence have been dealt with and numerous actions are being taken by the police owing to high levels of crime and lethal violence. Could the shootings be connected to the establishment of gangs and criminal networks? Could it be that the shootings are connected to conflicts within and between the criminal networks over turfs and money from drug distribution? If so, is there a time limit to the shootings connected with when the turfs are set? Then the development of the ODS that are newly established and have not had any shootings yet are particularly interesting. In these areas the police and other actors should focus more efforts in order to stop this negative development to more vulnerable areas with high prevalence of gun violence. Some of the newly established ODS are in areas with no social disadvantage and then the collective efficacy might explain the lack of shootings. The collective efficacy in these areas might have contained the violence and made it harder for criminal networks to get established and grow. The newly established ODS might lack shootings until the criminal networks have established their turfs and have areas to protect. Nevertheless there is much to be gained from early intervention by the authorities in these emerging and nascent ODS. 
In drug crimes, money is an important element. Drug trafficking is based on a market with calculated interactions among market participants, which has similarities with legal markets. As the property rights in this market are not protected by the police and the actors cannot use the court system, often violence is used instead to settle conflicts (Poret \& Téjédo, 2006). The substances sold at the drug scenes might be connected to the amount and severity of the violence of the locations. In the ODS in vulnerable neighborhoods, cannabis, cocaine and tramadol are the most common substances. In contrast, in the US, the most violent drug markets are those dealing methamphetamine due to lucrative markets and criminal gangs running the distribution (DEA, 1996). The shootings might be connected to the dealing of cocaine in Sweden, as the drug itself has an influence on aggressive behavior and the drug involves more money than cannabis or tramadol per unit. The more lucrative the business, the more market shares to protect and so the more violence might be needed (Friman, 2009).

Furthermore, this study has shown that ODS can be divided into different types, and that this division can be understood through the lens of criminological theories. The typology can be used to design specific interventions geared towards the different types of ODS. Research in North America and Australia has shown that drug law enforcement contributes to gun violence (Werb et al., 2011). Understanding what strategies work against the violence might be the first issue to analyze in the more violent drug scenes, whereas other actions might be suggested for the other types of drug scenes. Hot spot policing has been the subject of numerous evaluations, and the evidence suggests that it is effective. Hot spot policing involves identifying these locations and dedicating police resources to them. The underlying logic behind hot spot policing is that if police work in areas where the proportion of crime is highest, they can most efficiently reduce crime at the aggregate level (Mastrofski, Weisburd, \& Braga, 2010). ODS Types 1 and 3 might be suitable places for hot spot policing, whereas harm-focused policing strategies (see Ratcliff, 2015) might be better on open drugs scenes Type 2 .

\subsection{Limitations and conclusion}

There are two main limitations of this study, both connected to the collection of the data. This study is based on data from only the year of 2017, this might impose problems to the patterns found. The data are also from only one city, which makes generalizations unreliable. Bigger sets of data from several years would give stronger patterns and more robust results. In addition, the fact that the survey responses are from police employees poses another set of limitations. Other perspectives, for example, from the municipal workers, high school students, rehabilitation personnel, might show other places of drug use and dealing. On the other hand, the police are important actors at these places and their knowledge and engagement in research is central for implementation of new strategies (Magnusson, 2018). There is also the issue concerning the fact 
that crime statistics only show reported crimes. Hibdon and Groff (2014) argue that there are problems with police data on the location of crime because it only captures crimes discovered by (or reported to) police. Police might miss places where undetected or unreported drug problems exist. Population density may also affect police presence, and thereby police statistics. In addition, in Sweden, the National Council of Crime Prevention reported excess police attention to youth drug crime in socially disadvantaged areas compared with "richer" areas. This was despite a high frequency of self-reported use of drugs in the citizen survey (National Council of Crime Prevention, 2018). A study on drug delivery reported similar results (Beckett, Nyrop, \& Pfingst, 2006). Furthermore, even within the police, there can be large discrepancies between different police datasets (Lum, 2008). In this study however, the citizen survey responses on drug trade areas and high measures of unsafety correspond to the location of the ODS found by the police.

This study investigated the spatial nature of ODS in Stockholm, Sweden, showing that there are 48 ODS in the region, and just above 50 percent of them have a clear negative impact on neighborhoods and communities through shootings, crime concentration and poor declared perceived safety of residents. Combining the citizen safety data with the layer of shootings and vulnerable areas produces clear patterns of troublesome overlap. Where residents feel unsafe, there are several ODS, shootings at the drug scenes and the areas are listed as vulnerable areas.

\subsection{Research and policy recommendations}

While novel in its perspective, this study's findings are exploratory, drawing on theoretical and empirical evidence found from several patterns of interest connected to the ODS in Stockholm County-but there is more to explore. As the drug sales most often include illicit economies, robberies and thefts might be common at and around ODS. This needs further attention. More research is needed on these places and future research could benefit from medical data, such as data on overdoses. The increasing numbers of overdoses in Sweden have been grounds for political debate and could be useful in connection to ODS and enhance the typology.

The knowledge that ODSs are located at transportation stations could be used both by the police and the societal organization for construction and building. The police might prioritize the time and location of patrol to intervene but also to prevent drug crimes and the consequences of them. The typology of drug scenes might further give ideas on the kind of intervention that might be appropriate. The old and established ODS in the inner city might lose some of their grip due to police presence and repressive interventions, while the same tactic at ODS in the vulnerable areas might result in more violence, turf wars and gang-affiliated shootings due to police seizures of drugs with high street values, due to the connection to established local criminal networks. 
The typology in this study can also provide experts with ideas on the cooperation at ODS. Since cooperation with multiagency actors is needed to show long-term results (Connolly, 2006, 2012) the choice of actors is important. Which actors to include in cooperation at the ODS might vary due to type of ODS. If shootings, severe disruption and unsafety as in Type 2 ODS are the main issues in vulnerable areas; then parents, schools and the criminal networks themselves could be part of the solution. Whereas, in the inner city ODS, business owners, Stockholm city building offices, transportation companies and health care representatives might be better partners in finding solutions to nuisance, heavy abusers and unsafety at public transportation.

ODS needs attention from both practitioners and research to overcome the impact they have on the community. The interplay between the police practice and research seems central to create evidence-based strategies needed to move away from unsafety and violence surrounding the ODS.

\section{References}

Beckett, K., Nyrop, K., \& Pfingst, L. (2006). Race, drugs, and policing: understanding disparities in drug delivery arrests. Criminology, 44, 105-137.

Bless, R., Korf, D. J., \& Freeman, M. (1995). Open drug scenes: a cross-national comparison and urban strategies. European Addiction Research, 1, 128-138.

Bonny-Noach, H., \& Ronel, N. (2018). Everyday substance insecurity among homeless injection drug users in Israel's largest open drug scene. Journal of Drug Issues, $48,645-656$.

Brantingham, P., \& Brantingham, P. (2013). Crime pattern theory. In R. Wortley \& L. Mazerolle (Eds.), Environmental Criminology and Crime Analysis (pp. 78-91). London: Willan Publishers.

Ceccato, V. (2013). Moving Safely: Crime and Perceived Safety in Stockholm's Subway Stations. Plymouth: Lexington Books.

Ceccato, V. (2014). The nature of rape places. Journal of Environmental Psychology, 40, 97-107.

Ceccato, V., Haining, R., \& Signoretta, P. (2002). Exploring crime statistics in Stockholm using spatial analysis tools. Annals of the Association of American Geographers, 22, 29-51.

Ceccato, V., Haining, R., \& Kahn, T. (2007). The geography of homicide in São Paulo, Brazil. Environment and Planning A, 39, 1632-1653.

Chainey, S., \& Ratcliffe, J. (2005). GIS and Crime Mapping. London: Wiley.

Cohen, L. E., \& Felson, M. (1979). Social change and crime rate trends: a routine activity approach. American Sociological Review, 44, 588-605.

Connoly, J. (2006). Responding to Open Drug Scenes and Drug-related Crime and Public Nuisance: Towards a Partnership Approach. Strasbourg: The Pompidou Group's Criminal Justice Platform.

Connoly, J. (2012). A Better City For All: A Partnership Approach to Address Public Substance Misuse and Perceived Anti-social Behaviour in Dublin City Centre. Dublin: Strategic Response Group.

Corsaro, N., \& Brunson, R. K. (2013). Are suppression and deterrence mechanisms enough? Examining the "pulling levers" drug market intervention strategy in Peoria, Illinois, USA. International Journal of Drug Policy, 24, 115-121. 
DEA Publications (1996). Methamphetamine Situation in the Unites States. Springfield, Virginia: US Drug Enforcement Administration.

European Monitoring Centre for Drugs and Drug Addiction [EMCDDA] (2015). Drugs Policy and the City in Europe. Luxembourg: Publications Office of the European Union.

European Monitoring Centre for Drugs and Drug Addiction [EMCDDA] (2017). European Drug Report; Trends and Development. Luxemburg: Publications Office of European Union.

Falk, P. (1981). Auflösung einer öffenen Drogenszene. Kriminalistik, 5, 256-259.

Felson, M., \& Eckert, M. A. (2018). Crime and Everyday Life: A Brief Introduction. Thousand Oaks, CA: SAGE Publications.

Frank, V. A., \& Bjerge, B. (2014). From zero tolerance to non-enforcement: creating a new space for drug policing in Copenhagen, Denmark. Contemporary Drug Problems, $41,261-291$.

Friman, H. R. (2009). Drug markets and the selective use of violence. Crime, Law and Social Change, 52, 285-295.

Gerell, M. (2017). Neighborhoods without community: collective efficacy and crime in Malmö, Sweden (Doctoral dissertation, Malmö University, Faculty of Health and Society).

Gerell, M. (2018). Bus stops and violence, are risky places really risky? European Journal on Criminal Policy and Research, 24, 351-371.

Gerell, M., Sturup, J., Magnusson, M-M., Rostami, A., Nilvall, K., \& Khoshnood, A. (Unpublished manuscript). Open drug markets, vulnerable neighborhoods and gun violence in two Swedish cities.

Goldberg, T. (1993). Narkotika Avmystifierad-ett socialt perspektiv. Stockholm: Carlsson bokförlag.

Goldstein, H. (1990). Problem-Oriented Policing. New York: McGraw-Hill.

Haroscopos, A., \& Hough, M (2005). Drug Dealing in Open Air Markets. ProblemOriented Guides for Police. Problem-Specific Guides Series: No. 31. US Department of Justice. Office of Community Oriented Policing Services, USA.

Hibdon, J., \& Groff, E. (2014). What you find depends on where you look: using emergency medical services call data to target illicit drug use hot spots. Journal of Contemporary Criminal Justice 2014, 30, 169-185.

Kennedy, D. M. (1996). Pulling levers: chronic offenders, high-crime settings, and a theory of prevention. Valparaiso University Law Review, 31, 449.

Klingemann, H. K. (1996). Drug treatment in Switzerland: harm reduction, decentralization and community response. Addiction, 91, 723-736.

Levine, N. (2006). Crime mapping and the Crimestat program. Geographical Analysis, $38,41-56$.

Lum, C. (2008). The geography of drug activity and violence: analyzing spatial relationships of non-homogenous crime event types, Substance Use \& Misuse, 43, 179-201.

McCord, E. S., \& Ratcliffe, J. H. (2007). A micro-spatial analysis of the demographic and criminogenic environment of drug markets in Philadelphia. Australian \& New Zealand Journal of Criminology, 40, 43-63.

McNeil, R., Shannon, K., Shaver, L., Kerr, T., \& Small, W. (2014). Negotiating place and gendered violence in Canada's largest open drug scene. International Journal of Drug Policy, 25, 608-615.

Magnusson, M. M. (2018). Bridging the gaps by including the police officer perspective? A study of the design and implementation of an RCT in police practice and the impact of pracademic knowledge. Policing: A Journal of Policy and Practice.

Magnusson, M. M. (In press). Preventing relapse into drug crime through motivational talks at a drug scene in Stockholm: a randomized controlled trial of a law enforcement tactic. Cambridge Journal of Evidence-Based Policing. 


\section{Mia-Maria Magnusson}

Markovic, J. (2007). Book Review: Chainey, S., \& Ratcliffe, J. (2005). GIS and Crime Mapping. London: Wiley. (422 pp., \$60.00 paperback). Social Science Computer Review, 25, 279-282.

Mastrofski, S. D., Weisburd, D., \& Braga, A. A. (2010). Rethinking policing: the policy implications of hot spots of crime. In N. A. Frost, J. D. Freilich \& T. R. Clear (Eds.), Contemporary Issues in Criminal Justice Policy (pp. 251-264). Belmont, CA: Wadsworth, Cengage Learning.

Mazerolle, L., Soule, D., \& Rombouts, S. (2005). Drug law enforcement: the evidence. Monograph No 05. DPMP Monograph Series. Fitzroy: Turning Point Alcohol and Drug Centre.

Mazerolle, L., Soule, D. W., \& Rombouts, S. (2007). Drug law enforcement: a systematic review. Police Quarterly, 22, 87-94.

National Council for Crime Prevention (2015). Skjutningar 2006 och 2014Omfattning, spridning och skador. Kortanalys $7 / 2015$.

National Council for Crime Prevention (2018). Konstaterade fall av dödligt våld 2017. En granskning av anmält dödligt våld 2017.

Olsen, H. (2017). Open drug scenes and police strategies in Oslo, Norway. Journal of Scandinavian Studies in Criminology and Crime Prevention, 18, 1-16.

Police Authority (2015). Vulnerable neighborhoods-social risk, collective ability and unwanted incidents [Utsatta områden-sociala risker, kollektiv förmåga och oönskade händelser]. Nationella Operativa Avdelningen (NOA). Stockholm: Swedish National Police.

Police Authority (2017). Utsatta områden [Disadvantaged areas]. Stockholm: Swedish National Police.

Poret, S., \& Téjédo, C. (2006). Law enforcement and concentration in illicit drug markets. European Journal of Political Economy, 22, 99-114.

Ratcliffe, J. H. (2015). Towards an index for harm-focused policing. Policing, 9, 164-182.

Sampson, R. J., Raudenbush, S. W., \& Earls, F. (1997). Neighborhoods and violent crime: a multilevel study of collective efficacy. Science, 277, 918-924.

SCB (2019). Folkmängd $i$ riket, län och kommuner 31 mars 2019 och befolkningsförändringar 1 januari-31 mars. www.statistikdatabasen.scb.se.

Skogan, W. G. (1990). Disorder and Decline: Crime and the Spiral of Decay in American Neighborhoods. New York: Free Press.

Sturup, J., Rostami, A., Gerell, M., \& Sandholm, A. (2018). Near-repeat shootings in contemporary Sweden 2011 to 2015. Security Journal, 31, 73-92.

Sturup, J., Rostami, A., Mondani, H., Gerell, M., Sarnecki, J., \& Edling, C. (2019). Increased gun violence among young males in Sweden: a descriptive national survey and international comparison. European Journal on Criminal Policy and Research, 25, 365-378.

UNODC (2009). World Drug Report 2009. Vienna: United Nations Office on Drugs and Crime.

Waal, H., Clausen, T., Gjersing, L., \& Gossop, M. (2014). Open drug scenes: responses of five European cities. BMC Public Health, 14, 853.

Weisburd, D., \& Green, L. (1995). Policing drug hot spots: the Jersey City drug market analysis experiment. Justice Quarterly, 12, 711-736.

Weisburd, D., \& Mazerolle, L. G. (2000). Crime and disorder in drug hot spots: implications for theory and practice in policing. Police Quarterly, 3, 331-349.

Weisburd, D \& Amram, S. (2014). The law of concentrations of crime at place: the case of Tel Aviv-Jaffa. Police Practice \& Research, 15, 101-114.

Werb, D., Kerr, T., Fast, D., Qi, J., Montaner, J. S., \& Wood, E. (2010). Drug-related risks among street youth in two neighborhoods in a Canadian setting. Health o Place, $16,1061-1067$. 
Werb, D., Rowell, G., Guyatt, G., Kerr, T., Montaner, J., \& Wood, E. (2011). Review: Effect of drug law enforcement on drug market violence: a systematic review. International Journal of Drug Policy, 22, 87-94.

Wilson, J. Q., \& Kelling, G. L. (1982). Broken windows: the police and neighborhood safety. The Atlantic. www.theatlantic.com/magazine/archive/1982/03/brokenwindows/304465/(accessed 3 September 2007). 


\title{
17 "Fear in 280 characters"
}

\section{A new approach for evaluation of fear over time in cyberspace ${ }^{1}$}

\author{
Francisco J. Castro-Toledo, \\ Tobias Gretenkort, Miriam Esteve \\ and Fernando Miró-Llinares
}

\subsection{Introduction}

Most of the literature on fear (and fear of crime) is associated with the characteristics of spaces in cities and public realms (Castro-Toledo, 2019). This chapter focuses instead on the phenomenon of fear in cyberspace, through the analysis of emotional linguistic responses of online social media (tweets). A method to quantify fear of terrorist attacks through linguistic sentiment analysis is proposed. We analyze emotional linguistic responses to terrorist attacks over time using a sample of more than two million tweets collected on three occasions: after the attacks on Charlie Hebdo, Nice, and Barcelona between 2015 and 2017. We posit that these aspects render our understanding of fear in online social networks more fine-grained and help us understand how online social media spread messages of fear of attacks through the medium of language.

We propose that the validation of this method is of practical interest in the detection, analysis, and possibly even the prediction of waves of fear of crime in the digital realm. The relevance of tweets in this work is twofold. First of all, they're easy to gather and present an opportune option to analyze public discourse with very little delay between generation and collection of data. On the other hand, Twitter exhibits growing relevance in the public discourse as tweets are sometimes even singled out in traditional media. Furthermore, we follow Miró-Llinares \& Johnson (2018) in that the social organization of cyberspace can sensibly be compared to the organization of physical space, with Twitter representing a specific macroplace in cyberspace.

In this chapter, we explore some of the traditional methodological approaches to fear and fear of terrorist attacks, after which we establish the relevance of both linguistics and its relation to emotion for this study. Subsequently, the generation of hypothesis from this interdisciplinary framework is reported, as well as testing, results and discussion of the findings. The chapter concludes with some recommendations for future research and the value of this line of investigation of research on fear of crime. 


\subsection{Theoretical framework}

\section{Fear of crime: definition and methodological approaches}

Our investigation deals with the specific emotive response to terrorist attacks in the cyberspace, with a strong emphasis on how the authors' linguistically encoded emotion can be used to track fear across time and different "places" (i.e., hasthags) in cyberspace. In this vein, we understand fear as the emotion of fear arising in a specific moment and place upon the possibility of perceiving oneself as the victim of a crime. While this is a general definition of fear of crime (Castro-Toledo, Perea-García, Bautista-Ortuño \& Mitkidis, 2017), we deem the aspect of possible victimization and the fear this creates in an individual as pertinent enough to extend this definition to the specifics of terrorist attacks.

Despite the intuitiveness of the concept, fear of crime remains a complex and hard-to-measure phenomenon (Castro-Toledo, 2018). Researchers have engaged in a methodological debate between old and new methods to measure fear of crime (Jackson 2005; Tseloni \& Zarafonitou, 2008). While older approaches tackle the question of intensity of experiences of fear of crime, newer approaches try to observe the frequency with which those experiences are made in everyday life. To these authors, the methodological change from intensity to frequency seems to imply a significant improvement in the measurability of fear of crime.

Within the above-described methodological context, the major proportion of studies in crime sciences focuses on gathering information through self-reports (Castro-Toledo, 2019). Importantly, these methods of analysis have two main types of limitations. The first limitation lies in the diverse problems related to the external validity and precision of measurement instruments, in particular the presumption that research participants are able to explicate with precision the type of cognitive processes and emotional states they go through in experiencing fear of crime (Levine \& Parkinson, 2014). The second limitation is that the traditional fear of crime methodologies try to collect emotional data through hypothetical scenarios of victimization or through contemplating real episodes of fear that are distant in time (Ferraro \& LaGrange, 2000; Hale, 1996; Hardyns \& Pauwels, 2010; Yang \& Hinkle, 2012).

In contrast to data based on self-reports, new methods account for fear of crime with real-time data. This type of data is currently under-exploited, as pointed out in a recent study on physiological measures associated with the experience of fear of crime (Castro-Toledo, Perea-García, Bautista-Ortuño \& Mitkidis, 2017; Noon, Beaudry, Schier, \& Knowles, 2019) and app-based studies (Solymosi \& Bowers, 2018), among other research contributions.

\section{Fear in cyberspace}

To date, online social networks are one of the most abundant sources of information about patterns of criminological interest (e.g., Burnap et al., 2015; 
Esteve, Miró-Linares \& Rabasa, 2018; Miró-Llinares, Moneva, \& Esteve, 2018). In general terms, Big data allows us to collect data as they are generated and compared over time (Bello-Orgaz, Jung, \& Camacho, 2016; McAfee, Brynjolfsson, Davenport, Patil \& Barton, 2012). Twitter and other platforms put Application Programming Interface (APIs) to the users' disposition, to establish direct communication with their servers. This way, researchers can easily compile data in terms of both the discursive content (speech) of tweets and a wide array of relevant metadata (for example, IDs, hashtags, text length, geolocation, etc.). Nevertheless, research on this social media platform is still scarce or almost not existent for fear of crime (Solymosi \& Bowers, 2018). To exploit this resource, we resorted to formulate an interdisciplinary paradigm of criminological Big Data analysis and computational linguistic sentiment analysis and used it to compare different crime events and Twitter users' emotional reactions over time.

Our interest in online discursive contents is based on the tightly established relationship between emotion and language on the levels of theory, neurolinguistics and computational linguistics (Wierzbicka, 1994; Van Lancker \& Pachana, 1998). In this context, the analysis of linguistic material with computational methods is known as NLP, or 'natural language processing' and presents one of the most promising fields for the future of applied linguistics. Previous studies speak to the utility of the written text approach (Salas Zárate, Paredes Valverde, Rodríguez García, Valencia García, \& Alor Hernández, 2017; Shivhare, 2012) and its capability of evaluating emotional content of an utterance based on non-contextual linguistic information (Asghar, Khan, Bibi, Kundi, \& Ahmad, 2017). In addition, the interest in the emotive content of words led to the development of big databases in which emotional values are attributed to lexical elements by human judges without any context for the judged words to appear in (examples of databases that can be found in Spanish are: Stadthagen-Gonzalez, Imbault, Pérez Sánchez, \& Brysbaert, 2015; Stadthagen-González, Ferré, Pérez-Sánchez, Imbault, \& Hinojosa, 2017).

However, there are several practical and scientific restrictions with regards to sentiment analysis. On the one hand, it appears to be, from a psychological standpoint, uncertain which emotions are basic to the human psyche and how they are expressed in human vocabulary (Barrett, 1998; Christie \& Friedman, 2004). The debate between those psychologists postulating clear-cut distinguished discrete basic emotions such as fear, anger, surprise, happiness and disgust (following Ekman, 1999) and those questioning and opposing the existence of basic universal discrete emotions (Barrett, 2017) is reminiscent of this uncertainty.

On the other hand, sentiment analysis functions, such as the polarity function from R's qdap package (Goodrich, Kurkiewicz, \& Rinker, 2019) for linguistic analyses, often lack the appropriate scientific basis to be used in this context. The aforementioned case, for instance, makes use of predefined lists of positive and negative words, which give a given phrase a base polarity (positive or negative) which is then corrected for through the analysis of syntactic 
elements such as negation (inverting the base polarity), augmenting words such as "very" (boosting the base polarity value) and the like. The methodological problem at hand is that base polarity is arbitrarily assigned and does not make use of experimentally justified values as the aforementioned emotional norms do (e.g., Stadthagen-Gonzalez, Imbault, Pérez Sánchez, \& Brysbaert, 2015; Stadthagen-González, Ferré, Pérez-Sánchez, Imbault, \& Hinojosa, 2017).

However, the supplied parameters based on the Theory of Constructed Emotion as formulated by Barrett (2017) are useful to avoid some of the above limitations. She argues that the postulation of concrete basic emotions such as fear, anger, happiness, disgust and sadness cannot be held up in the light of recent psychological discoveries, and that basic emotions can and should be broken down into more primitive parameters. The title of her theory is reminiscent of the idea that "emotions" are cognitively constructed experiences that are integrated in a context from two basic "affects", that is reactions to external stimuli, namely valence and arousal. Valence is the affective positivity of a response toward a stimulus, while arousal refers to the affective activation. Higher-order emotions then are integrations of these base affects. A simple example of this is "happiness" which is the integration of "positive" and "active" (i.e., high valence and arousal) while "relaxation" integrates "positive" and "inactive" (i.e., high valence and low arousal).

This is well integrated into modern views of language, which postulate multimodal integration of word meaning from interaction memory, emotion and other parameters. In this view, a word is not stored in the brain as a linguistic description of meaning, but is integrated from the memories and emotions that are connected to its usage and interaction in the past (Barsalou, 1999). Hence, we have no reason to believe that only vocabulary which signals "fear" directly can be attributed to fear of crime. Rather, emotive information can be retrieved from language through a variety of different methods and measures, such as the valence and arousal as we have previously proposed (Gretenkort, Castro-Toledo, Esteve \& Miró-Llinares, in press). In this study, we have determined that readers of tweets attribute a higher potential to promote fear of crime among readers when valence is low, and arousal is high.

Previous analysis on Twitter also have shown how linguistically encoded emotivity is organized in cyberspace. Differences in emotive response to tweets for instance vary according to hashtags mentioned in tweets and the literal meaning of hashtags, among others (Wang, Wei, Liu, Zhou, \& Zhang, 2011). In particular, the hashtag \#Islam has been found to co-occur with \#jihad, \#terror, and \#igiveup (Wang et al., 2011, p. 1038). More recently, the popular hashtag \#StopIslam has been found to be one where "[...] [e]xtremist groups can rely $[\mathrm{on}][\ldots]$ with a lower expectancy of any message dilution by means of counter-narrative" (Blanquart \& Cook, 2013, p. 7). The different "populations" of hashtags thus also show different reactions to different topics, both according to the hashtag as such and to the way the hashtag construes the event. That is, the hashtag \#PrayForBarcelona construes the terrorist events in 
2017 as one requiring solidarity with the victims, while \#StopIslam construes the same event as a reason to oppose Islam in civil society.

\section{Hypotheses of study}

Given this context, the increasing interest in applied linguistics in cybersecurity and the export of the concept of place from physical space to cyberspace (MiróLlinares \& Johnson, 2018) allow us to assess new hypotheses about whether crime or fear of crime in digital contexts is randomly distributed in space and time. Specifically, we want to put forth a methodology to respond to three hypotheses generated from the previous observations. Hence, we shall analyze in this study, how the linguistically encoded emotive response to terrorist attacks changes over the course of 24 hours after these attacks, with the method proposed in Gretenkort et al. (in press). At the same time, we will compare the emotional responses across three different terrorist events in the current political panorama in Europe, namely Charlie Hebdo (2015), Nice (2016), and Barcelona (2017). Likewise, and to ensure the validity of our method, we shall attempt to replicate the findings of Wang et al. (2011) and Blanquart et al. (2013) with regards to the differences between hashtags. In summary of the previous explanations, we formulated the following three hypotheses to test:

$\mathrm{H}_{1}$ : The emotional response to a tweet can be described as a function of event, hashtag and time elapsed after the attack.

$\mathrm{H}_{2}$ : The emotive profile of each tweet will depend on the way the event is construed by the hashtag (i.e., event description, expression of solidarity, defense against Islam)

$\mathrm{H}_{3}$ : The emotive response to each tweet will depend on the hashtag that is was authored under.

\subsection{Data and methods ${ }^{2}$}

\section{Sample}

We base our study on a corpus supplied by the center CRIMINA for the study and prevention of crime at Miguel Hernández University. For the compilation of this corpus, we used the API Search that Twitter supplies. Implementing a Python-based algorithm that interacts with the API and specifies the filtering parameters, we obtained a JSON file, which was then exported as a CSV file with 41 attributes for each compiled tweet. The algorithm implemented to our ends mainly uses six types of data, of which four are supplied by the Twitter developer for authentication. The last two parameters were the vectors that store the language code ("es") and the hashtags or keywords (i.e., aforementioned 
hashtags). With the authentication data establishing a connection to the API, a listener was implemented which, upon detection of an event matching the defined parameters, recorded and stored relevant tweets in JSON format. Upon error, the script notified the research team.

The compiled corpus contains more than two million tweets published during the first 24 hours after the attacks of Charlie Hebdo $(280,000$ tweets collected during 7 January 2015), Nice (720,000 tweets collected during 14 July 2016) and Barcelona (1,050,000 tweets collected during 17 August 2017). More specifically, and with a purpose of making comparative analysis, tweets were collected from the following hashtags: \#charliehebdo, \#nice, \#barcelona, \#jesuischarlie, \#prayfornice, \#prayforbacerlona, and \#stopislam. Cleaning the data and preparing it for analysis included the steps of (1) excluding all the nonSpanish tweets, and (2) ruling out retweets; that is, keeping only unique tweets. This resulted in a database of exactly 336,960 tweets in Spanish, with 157,370 tweets in reply to the attacks on Barcelona, 64,278 concerning Charlie Hebdo, and 115,312 in reference to the Nice attacks. The distribution of tweets around different hashtags was as follows: \#Barcelona 152,726, \#CharlieHebdo 51,696, \#JeSuisCharlie 6,396, \#Niza 103,016, \#PrayForBarcelona 2,926, \#PrayForNice 12,056, \#StopIslam 8,144.

These could be grouped according to speech acts contained in the hashtags for further analysis as follows. We regrouped those hashtags that contained (a) a mere linguistic reference to the event as such, with no further (obvious) judgement (\#Niza, \#Barcelona, \#CharlieHebdo) under the label "event report", (b) those which carry an open expression of solidarity through a linguistically bounded association with the victims (\#JeSuisCharlie) or request for support (\#PrayForBarcelona, \#PrayForNice) under the label "expression of solidarity", and (c) the remaining hashtag (\#StopIslam) under its own category, since it carries a linguistically distinct message, namely the open request for opposition against "Islamic terror".

\section{Procedure and analysis}

As indicated before, we build upon an earlier contribution (Gretenkort et al., in press), where the effect of our measure of emotive valence and arousal was found to have an impact on the amount of fear of crime that participants read into different tweets. In this study, a low amount of valence combined with a high amount of arousal led to a perception of tweets to be more promotive of fear of crime. We shall try to expand on this paradigm to detect the effect of time passed by after a given terrorist event. To do that, we used two lists of affective norms for Spanish (Stadthagen-Gonzalez et al., 2015, 2017), two datasets in each which over 10,000 words of the Spanish language were rated with regards to their emotive content by 512 (Stadthagen-Gonzalez et al., 2015) and 2010 (Stadthagen-Gonzalez et al., 2017) participants respectively. The lists contain ratings across seven emotive dimensions (valence, arousal, happiness, disgust, anger, sadness, and fear), the first two indicating how positive (valence) or activating 


\section{2}

Francisco J. Castro-Toledo et al.

(arousal) a word is (Stadthagen-Gonzalez et al., 2015) and the second indicating how much happiness, disgust, anger, sadness, or fear the words contain (Stadthagen-Gonzalez et al., 2017). Note that the lists contain both explicitly emotional words ("happy", "sad") and not typically emotional words such as "monk". The lists do not discriminate between emotional and non-emotional words, but it is important to note that using these lists we can calculate emotive expressions using almost every word in a tweet (as long as it is present either list). On the other hand, in accordance with the Theory of Constructed Emotion (Barrett, 2017), we elaborated a measure for valence (polarity) and one for arousal (activation), such as to quantify the emotive content of each tweet.

To do so, a computer algorithm written in $\mathrm{R}$ (1) tokenized each tweet, (2) searched for the tokens in a list of over 10,000 experimentally generated emotive norms for Spanish words $(x)$ (Stadthagen-González et al., 2015), and (3) calculated the emotive value for each tweet as the geometrical mean $(e=3)$ of each word's emotive value $\left(i_{\mathrm{x}}\right)$ within the tweet:

$$
\text { emotive value }_{\text {tweet }}=\left(\sum_{x=1}^{n} i_{x}{ }^{3}\right)^{\frac{1}{3}}=\sqrt[3]{i_{1}{ }^{3}+i_{2}{ }^{3}+\cdots+i_{n}{ }^{3}}
$$

With this measure in place, calculations on the Twitter data could be made to test the aforementioned hypotheses one through three. Each hypothesis was tested for their corresponding null-hypothesis, thus enabling us to rule out random phenomena as explanatory models for our data and putting forth our alternative hypotheses.

To assess $\mathrm{H}_{1}$, we created several linear models with the $1 \mathrm{~m}$ function of R's stats package. We will only report the best performing model. We created a model to check for the emotional profile's development (dependent variable) over time (independent variable) of tweets combined with interaction effects for events and emotions classified by a hashtag (independent variable). The corresponding model was expressed as follows:

$$
\operatorname{lm}(\text { emotive value } \sim \text { created_at * emotion * event }+ \text { hashtag })
$$

To check for the significance of each of the formula's terms, we used the anova function of R's stats package.

$\mathrm{H}_{2}$ was tested with the tweets regrouped under the classes "event description", "expression of solidarity", and "Stop Islam". We fitted a linear model to predict emotive value for each tweet from the class of hashtag it pertained to, and the emotion under investigation:

$$
\operatorname{lm}(\text { emotive value } \sim \text { class of hashtag * emotion })
$$

To address hypothesis $\mathrm{H}_{3}$, we analogously fitted a linear model with the $\mathrm{lm}$ function from R's stats package (R Core Team, 2013) with the emotive value of 
each tweet as a dependent variable, and both hashtag and emotion (valence vs. arousal) as independent variables:

$$
\operatorname{lm}(\text { emotive value } \sim \text { hashtag * emotion })
$$

To account for the significance of the model's terms (i.e., hashtag and emotion), we applied an ANOVA over the model (Chambers \& Hastie, 1992) with the anova function from R's stats package.

\subsection{Results}

\section{$\mathrm{H}_{1}$-Development over time}

Our hypothesis aimed to find differences in the development of tweets' emotional profiles over time and across different events and hashtags. The corresponding variance analysis of our linear model yields significant results for all main effects plotted in the model: time elapsed after the attack $F$ ( 1 , $336,376)=5,738.8382, \quad p<0.001$, emotion $F(1,336,376)=26,982.0510$, $p<0.001$, event $F(2,336,376)=803.7335, p<0.001$, hashtag $F(6,336$, $376)=162.2486, p<0.001$. In addition, significant and meaningful interactions could be detected between emotions and time elapsed after the attack $F(1,336,376)=411.9118, p<0.001$, and emotion and event $F(1,336$, $376)=2,122.1449, p<0.001$. The mixed linear model accounts for around 11 percent of the variance in the data $R^{2}=0.1067, F(17,336,380)=2,364$, $p<0.001$, with 14 out of 17 terms (including main and interaction effects, see the Appendix for complete statistical analysis on Github) significantly contributing to the accuracy of the model. We can thus reject the null-hypothesis, namely the independence of emotive values of tweets from the terms modelled in our analysis. Our alternative hypothesis states that emotive values of tweets can be predicted from the event, hashtag and time elapsed after the terrorist attack, for each of the tested emotional base affects.

Figure 17.1 shows the development of tweets' emotional profiles during the first 24 hours after each attack and grouped by hashtags. Free scales allow for a comparison of tendencies between different events.

\section{$\mathrm{H}_{2}$-Emotive value by speech act classes of hashtag}

The executed ANOVA shows highly significant main effects for both the class of hashtag, $F(2,336,388)=125.8, p<0.001$ and the emotion to be investigated, $F(1,336,388)=1,887.3, p<0.001$, including an interaction effect between these two, $F(2,336,388)=264.0, p<0.001$. More concretely, this means that expressions of solidarity (\#JeSuisCharlie, \#PrayForBarcelona, \#PrayForNice) modulate arousal in tweets by $\beta=0.13, t(336,338)=49.76$, $p<0.001$ while the hashtag \#StopIslam modulates arousal even stronger $\beta=0.23, t(336,338)=54.22, p<0.001$. The opposite effect can be detected for 

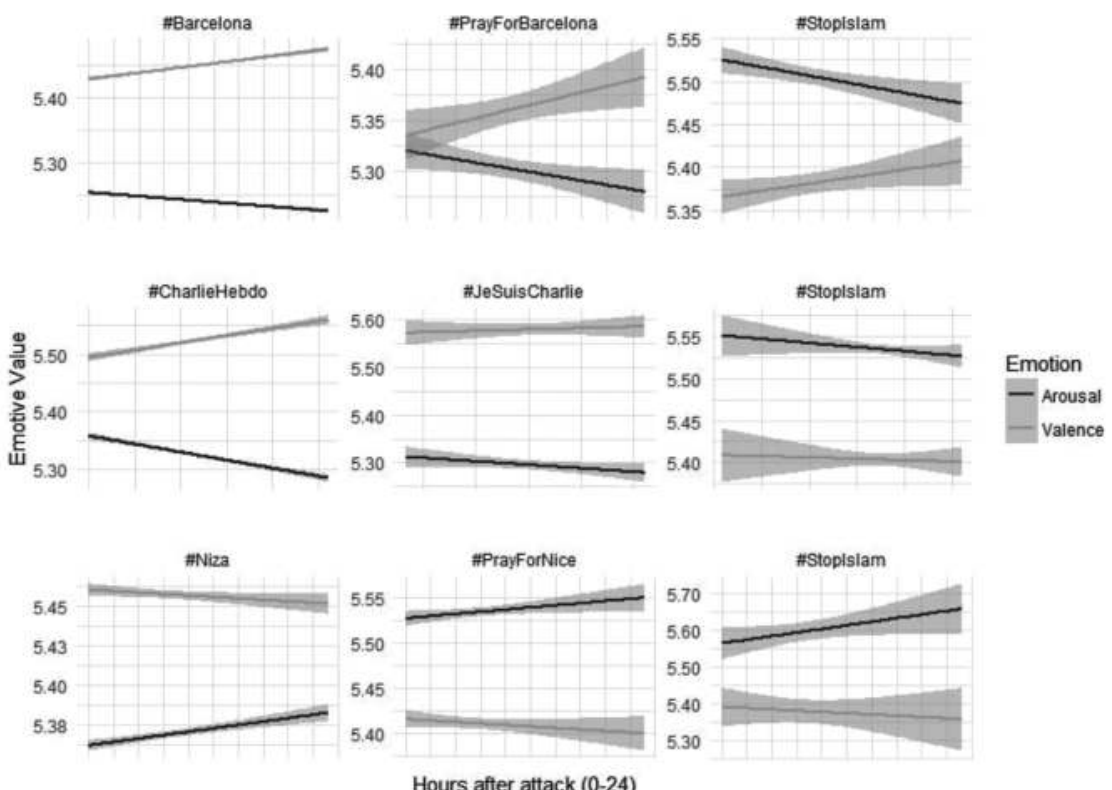

Hours after attack $(0-24)$

Figure 17.1 Development of tweets' emotional profiles during the first 24 hours after each attack and grouped by hashtags. Free scales allow for a comparison of tendencies between different events. The shaded areas around the linear models represent standard error.

valence in which expressions of solidarity modulate the intercept by $\beta=-0.14$, $t(336,338)=-37.63, p<0.001$ and the hashtag \#StopIslam even more so $\beta=-0.29, t(336,338)=49.19, p<0.001$ (Figure 17.2). The model furthermore explains around 9 percent of the variance in the data $R^{2}=0.0864, F(5$, $336388)=6,367, p<0.001$. The null-hypothesis is thus rejected in favor of the alternative hypothesis, namely that the linguistic construction of the hashtag in question (solidarity, report, opposition) does impact the emotive profile of tweets for each emotion measured.

Figure 17.2 indicates the emotive values of tweet across different classes of hashtags (descriptive, solidary, opposed). Error bars indicate bootstrapped mean confidence intervals without assuming a normal distribution.

\section{$\mathrm{H}_{3}$-Emotive value by hashtag}

The executed ANOVA shows that there are highly significant main effects for both the hashtag, $F(6,336380)=1401.1, p<0.001$, and the emotion to be tested, $F(1,336380)=27362.5), p<0.001$. In addition, we found a highly significant interaction effect between these two variables $F(6,336380)=1620.7$, $p<0.001$. We refrain from reporting the statistics of each possible combination 


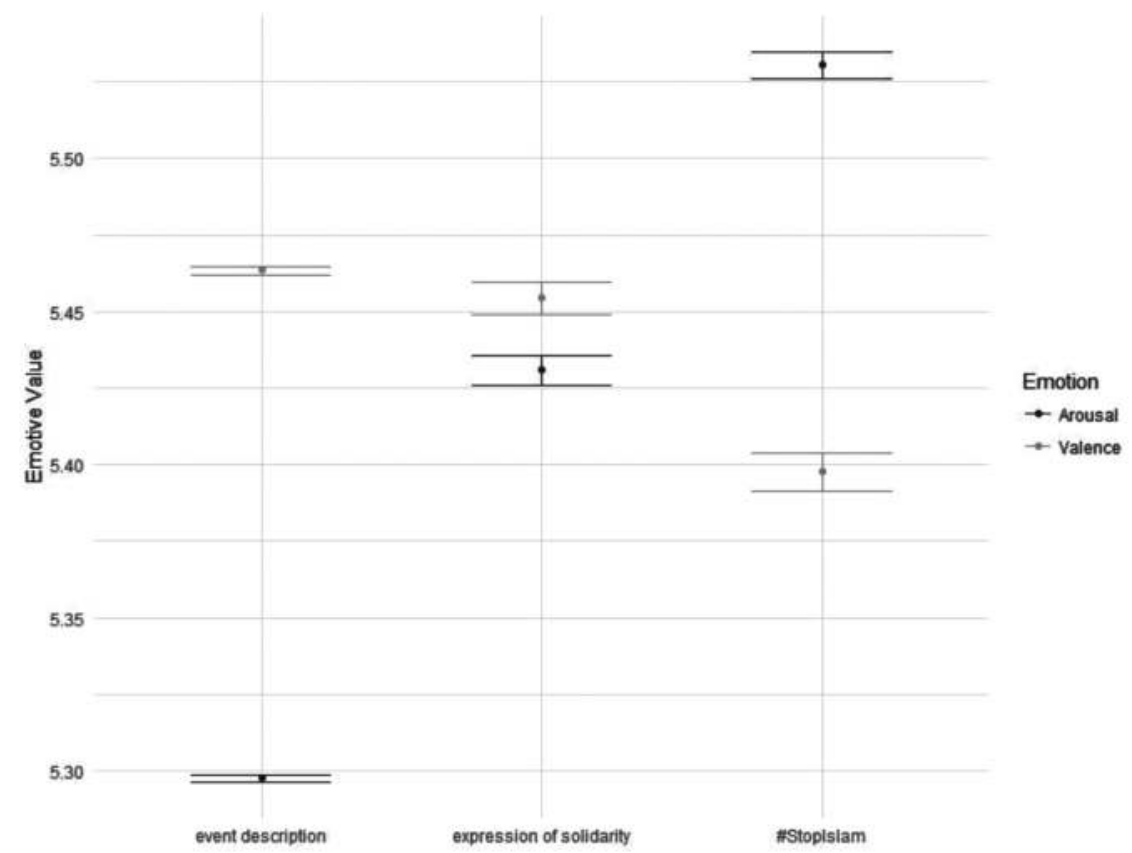

Figure 17.2 Emotive values of tweets across different classes of hashtags (descriptive, solidary, opposed). Error bars indicate bootstrapped mean confidence intervals without assuming a normal distribution.

between hashtags and emotions to maintain ease in reading. However, all of these contrasts are (as would have to be expected given the variation in data sources and events) significant and the linear model does significantly account for almost 12 percent of the variance in the data, $R^{2}=0.1191, F(13$, $336380)=3499, p<0.001$ (Figure 17.3). We can thus reject the null-hypothesis and elaborate on our alternative hypothesis, namely that the emotional profile of tweets across the basic affects valence, and arousal does depend on the hashtag that tweets are created under. Figure 17.3 illustrates the distribution of emotive values (valence and arousal) across different hashtags. Hashtags are ordered by mean valence per tweet in descending order.

\subsection{Discussion}

\section{The relevance of time}

First, we observe that it was possible to model the emotive responses to terrorist events as a function of the event, the hashtag and the elapsed time after the attack. This means that our proposed method of analysis does identify all the differences that we would expect in tweets from the literature. What we 


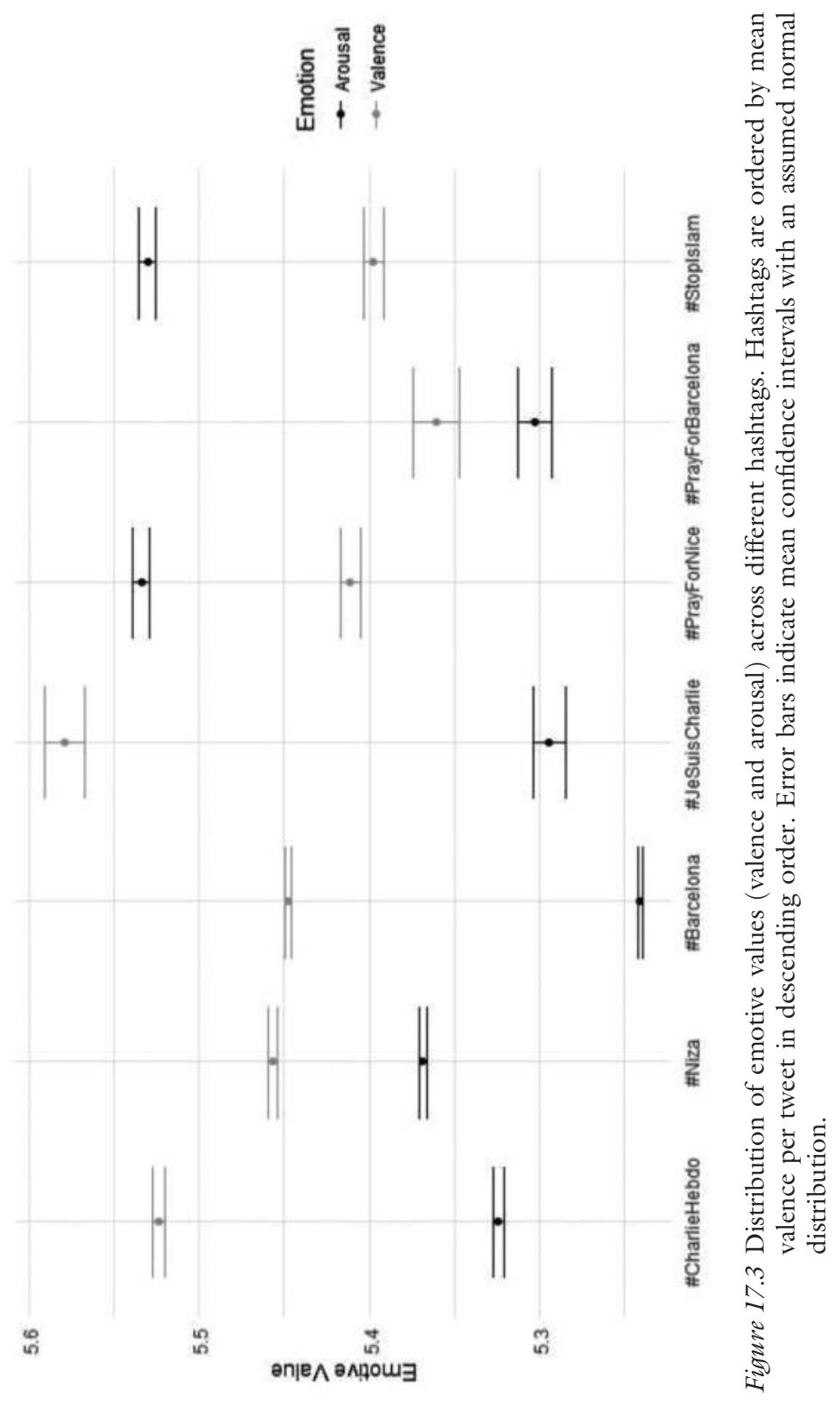


observe concretely in our analysis (Figure 17.1) is that, overall, valence increases as a function of time, and arousal decreases as a function of time, as if the emotional response to terrorist events was "cooling" over time, resulting in more positive and less aroused tweets after some time has elapsed. The other general rule to be observed is that valence usually has a higher value than arousal. There are two core deviations from this rule which require further investigation. First, the hashtags \#PrayForNice and \#StopIslam (across events) (1) show higher values in arousal than all the other hashtags. This seems to indicate that these hashtags behave fundamentally different from the other ones in that users tweet under them with more aroused vocabulary. We take this to be indicative of the fact that these hashtags are used as valves for emotional responses, while they are possibly more permissive toward radical, or anti-Islamic content.

Furthermore, the emotive responses to terrorist attacks on Nice do not develop in the same way as all the others. Tweets referring to the Nice attacks, under all hashtags, show a decrease in valence and an increase in arousal over the first 24 hours after the attack. This shows that fear of crime with regards to the Nice attacks behaves differently from the other events. We argue that the development of sentiment is a linear function of time, which can be modulated by hashtags and event, as reflected in our model. We explain this with the general attitude that authors assume toward Islam and events of terror subsequently (Blanquart et al., 2013). That is, the author's inherent interest to evoke images of terror (Wang et al., 2011) and hence fear in readers modulates the effect of discourse generally cooling down when time elapses after an event. Addressing the question of why tweets on the Nice attacks behave differently from the others, one could argue that the mediatic repercussion of this attack on Twitter is stronger, because we are here dealing with the second highly received terrorist attack in France after Charlie Hebdo. However, this assertion gives rise to new hypotheses which will have to be tested individually and is out of the scope of this chapter.

\section{Relevance of hashtags as grouped by speech acts}

First and foremost, the results of our analysis of $\mathrm{H}_{2}$ seems to corroborate our intuitions on hashtag usage. We can observe significant differences between the three groups of hashtags in the distribution of valence and arousal. We note that, when groups are ordered in the fashion of event description (a), expressions of solidarity (b), and \#StopIslam (c), we detect an increase in arousal, but a decrease in valence along this order. This follows our intuition on speech acts (Searle, 1969), namely that the linguistic expression of fear of crime, or its operationalization through valence and arousal, is not only somehow dependent on the different hashtags, but that the linguistic construction of these spaces plays a fundamental role in evoking fear of crime. It would correspond to a descriptive speech act (a) to be generally more positive (or at least less negative) than other speech acts, and to be less aroused than expressions of solidarity (b), which are almost equal in valence, but do present a more aroused vocabulary. \#StopIslam, 
with its Islamophobic tendencies (c), is constructed even more radically, since the level of arousal surpasses the level of valence, which makes this hashtag different from the other two. There are severe limitations in this abstraction however, as we are comparing small groups of hashtags with (1) very little variation within the analyzed speech acts and (2) a superficial motivation for the analysis of these speech acts, because this study is oriented toward criminology rather than linguistics. In the future, more studies need to conclude what our findings do not contradict at least. While our study is designed to detect if hypertextual space on twitter is ordered (whether by hashtags or speech acts) with regards to emotional expressions of fear of crime, more conclusive studies should yield results on what orders this space, that is to say whether each hashtag is distinct, or whether we can abstract from this fine-grained level of appraisal through the application of speech act theory. Our analysis reproduces the findings of Wang et al. (2011) who state that the construction of the event in the hashtag itself is indicative of the discourse and the reactions that the hashtag evokes. Our method thus reproduces earlier findings and does not stand in contrast to other methodologies employed.

\section{Relevance of hashtags}

Our results uncovered furthermore that there are distinct distributions of emotive values for each hashtag, and that there are significant contrasts between them. Apparently, this makes it possible to describe different hashtags in terms of the emotional response they provoke with regards to terrorist attacks. Even though co-variance is relatively low (only 12 percent of the variance can be accounted for by our models), which hinders our method from classifying single tweets and attributing them to a hashtag a priori, we are able to distinguish the evoked emotional values by hashtags if we have a sufficiently large dataset. This means that the overall trend can be relevantly accounted for and that our method produces the anticipated results with regards to research conducted on hashtags in the past (e.g., Blanquart \& Cook, 2013).

Furthermore, we can use this assessment to describe reactions in certain cyberplaces on Twitter and how they are different from one another (Miró-Llinares \& Johnson, 2018). We are, for example, able to order hashtags by mean valence, resulting in \#JeSuisCharlie having the highest level of valence, that is the most positive vocabulary in the analyzed corpus, while \#PrayForBarcelona has the lowest. This aligns with the diagnosis that \#JeSuisCharlie was a highly engaging hashtag which, first and foremost, expressed solidarity and support with the victims (De Cock \& Pizarro Pedraza, 2018), while \#Barcelona (even though it expresses solidarity) evokes more negative vocabulary. This could be based on the fact that we analyzed Spanish tweets exclusively and that Spanish users are more affected by terrorist events actually taking place in Spain. Also, Barcelona was the most recent of the analyzed terror attacks, meaning that responses could have become more negative over time. This could be analyzed in a separate, future study. 
It is even more striking, that, usually, the response in arousal measured in the data, stays behind the response in valence, except for two hashtags, namely \#PrayForNice and \#StopIslam (Figure 17.3). We have discussed this under $\mathrm{H}_{1}$. Unfortunately, it is out of the scope of this chapter to analyze the semantic fields that are used under these hashtags, because it requires a different methodology altogether. In any case, our method proves to be useful for the identification of different spaces on Twitter, that foster different images and linguistic behavior and is also in line with the observation that \#StopIslam resorts to different emotive strategies in the construction of the topic.

\section{Relevance to fear of crime}

While our measure is not directly aimed at the identification of fear of crime, the relevance of our data analysis with this topic rests upon the results of an earlier contribution (Gretenkort et al., in press). As pointed out earlier, participants judged those tweets as more provocative or promotional of fear of crime, which exposed a great deal of arousal and little positivity. We use this to link the previously discussed features of our measure and its organization in cyberspace. Our measure of emotional variables and the attribution of certain properties goes well together with the methodological stance taken by Castro Toledo (2018) and the predictions made in the introduction to this chapter. The general contribution to a better understanding of fear of crime lies in the exploitation of large amounts of data, which corroborates the works cited, and the confirmation of its structural organization through linguistic features on Twitter.

\subsection{Conclusions}

This chapter has shown that, contrary to traditional research models or those based in self-reported measures, research applied to fear of terrorist attacks allows us to introduce methodological designs that can access indicators associated with emotional experiences in real time. That is, the current method does not collect the information in the very moment research participants (or Twitter users) experience fear, but instead the experience is plotted and conserved in a linguistic expression of emotivity that can be analyzed and accounted for as if it were measured at the time of experience.

Furthermore, utterances on Twitter are less cognitively shaped than selfreported entries, in that they are announced spontaneously which supports our method. However, it has to be recognized that the usage of big data is limited to the analysis of data. This is less trivial than it appears. Big volumes of data aren't useful in the analysis and prevention of crime unless data inputs are contrasted with those human factors that are either (a) not (yet) measurable, or (b) responsible for the pollution of data, the selection of data, and the interpretation of data. This is important to point out because the ontologies that are implemented in models of automatic data detection and classification of 
discursive content in social media on the scale of big data are limited and sometimes erroneous (Miró-Llinares et al., 2018). This is why we pointed out that the current method seems to be suitable for the analysis a posteriori of labelled data, in order to detect trends in massive data, while abstracting and classifying single data points isn't possible with the method proposed. This argument would have come into play if we had tried to predict which hashtags a Tweet includes or to build something like a hate-speech classification machine. On a slightly different note however, this method is useful to state differences between events with regards to (a) different groups articulating their concerns with regards to a given topic or event, while (b) also enabling differences between events and how they are received on a level of fear of crime.

In summary of these considerations, we state that our method aims to measure the inherent emotive dimensions of valence and arousal in the vocabulary of tweets, so as to analyze different emotive responses to terrorist attacks online and to diagnose possible differences in emotive responses according to the hashtags under which tweets are published. With this approach, we hope to take a step toward more real-time oriented research, moving away from selfreports as a measure for psychological effects of crime. Please note that our psycholinguistic analysis is not oriented toward fear as a concrete emotion, but to fear of terrorism attack as a social and criminological phenomenon. Our measurement is thus the encoding of emotive reactions in tweets that respond to a concrete crime event. We hope to contribute with this study to the construction of a bridge between 'unmeasurable' (or 'hard-to-measure') variables and data, and thus transition from mere data to actual information, which has also been termed Smart Data (George, Hass, \& Pentland, 2014) and which is one of the key elements to improvement of decision making.

Future investigation in this area could lead to the identification of new interdisciplinary accounts at the intersection between criminology and linguistics. Furthermore, we suppose that this and similar types of algorithms could be used for the prediction and/or detection of fearful discourse around a given topic, when implemented in a continuously operating system on ongoing datastreams. In general, we encourage researchers to build more data-driven tools for the analysis of discourse in the context of crime research, as this will add to the replicability and validity of research by widening the scope of research and complement tools such as self-reports.

In our current situation, the different social networks (including Twitter) have ended up becoming genuine mirrors of users' emotions in cyberspace. Expressions of insecurity, of moral panic or fear of crime in general, or of terrorist attacks in particular, have found in these cyberplaces channels structurally suitable for a massive emotional diffusion, and for which we still do not have enough evidence to evaluate their impact accurately. And although the emotional experience is still embedded in the specific subjects, the characteristics of these cyberplaces force us to rethink and redefine the validity of the accumulated knowledge on the functioning of the fear of crime, especially the methodologies for measuring it in cyberspace. 


\section{Notes}

1 This study has received funding from the European Union's Horizon 2020 research and innovation programme under grant agreement No 740773.

2 All relevant computer code and the statistical report appendix are available at: https:// github.com/TobiDschi/linguistic_criminology. For access to the data, please contact the corresponding author.

\section{References}

Asghar, M. Z., Khan, A., Bibi, A., Kundi, F. M., \& Ahmad, H. (2017). Sentence-level emotion detection framework using rule-based classification. Cognitive Computation, 5,234 .

Barrett, L. F. (1998). Discrete emotions or dimensions? The role of valence focus and arousal focus. Cognition and Emotion, 12, 579-599.

Barrett, L. F. (2017). The theory of constructed emotion: an active inference account of interoception and categorization. Social Cognitive and Affective Neuroscience. Advance online publication.

Barsalou, L. W. (1999). Perceptions of perceptual symbols. Behavioral and Brain Sciences, 22, 637-660.

Bello-Orgaz, G., Jung, J. J., \& Camacho, D. (2016). Social big data: recent achievements and new challenges. Information Fusion, 28, 45-59.

Blanquart, G., \& Cook, D. M. (2013). Twitter influence and cumulative perceptions of extremis support: a case study of Geert Wilders. Proceedings of the 4th Australian Counter Terrorism Conference, Perth, Western Australia, 2-4 December 2013. Perth, Australia: ECU.

Burnap, P., Rana, O. F., Avis, N., Williams, M., Housley, W., Edwards, A., ... \& Sloan, L. (2015). Detecting tension in online communities with computational Twitter analysis. Technological Forecasting and Social Change, 95, 96-108.

Castro-Toledo, F. J. (2018). Fear of Crime in the Technological Era. New Methodological Horizons, New Ontological Scope (Doctoral Dissertation). Universidad Miguel Hernández, Elche (Spain).

Castro-Toledo, F. J. (2019). Sociedad tecnológica y miedo al crimen. Buenos Aires: Editorial BdeF.

Castro-Toledo, F. J., Perea-García, J. O., Bautista-Ortuño, R., \& Mitkidis, P. (2017). Influence of environmental variables on fear of crime: Comparing self-report data with physiological measures in an experimental design. Journal of Experimental Criminology, 13, 537-545.

Chambers, J. M., \& Hastie, T. J. (1992). Statistical Models in S. Pacific Grove, CA: Wadsworth \& Brooks/Cole.

Christie, I. C., \& Friedman, B. H. (2004). Autonomic specificity of discrete emotion and dimensions of affective space: a multivariate approach. International Journal of Psychophysiology. 51, 143-153.

De Cock, B., \& Pizarro Pedraza, A. (2018). From expressing solidarity to mocking on Twitter: Pragmatic functions of hashtags starting with \#jesuis across languages. Language in Society, 47, 197-217.

Ekman, P. (1999). Basic emotions. In T. Dalgeish \& M. Power (Eds.), Handbook of Cognition and Emotion. New Jersey: John Wiley \& Sons.

Esteve, M., Miró-Llinares, F., \& Rabasa, A. (2018). Classification of tweets with a mixed method based on pragmatic content and meta-information. International Journal of Design \& Nature and Ecodynamics, 13, 60-70. 


\section{Francisco J. Castro-Toledo et al.}

Ferraro, K. F., \& LaGrange, R. L (2000). The measurement of fear of crime. In J. Ditton and S. Farrall (Eds.), The Fear of Crime (pp. 277-308). London: Ashgate.

George, G., Hass, M. R., \& Pentland, A. (2014). Big data and management. Academy of Management Journal, 57(2), 321-236.

Goodrich, B., Kurkiewicz, D., \& Rinker, T. (2019). qdap: Bridging the Gap Between Qualitative Data and Quantitative Analysis. Version 2.3.2. Retrieved from: https://cran. r-project.org/web/packages/qdap/index.html (accessed 17 February 2019).

Gretenkort, T., Castro-Toledo, F. J., Esteve, M., \& Miró-Llinares, F. (In press). Disseminating fear in 140 characters. A pilot study on Twitter following the Barcelona terror attacks. In L. Ströbel (Ed.), Emotion Concepts. Aachen: RWTH University.

Hale, C. (1996). Fear of crime: a review of the literature. International Review of Victimology, 4, 79-150.

Hardyns, W., \& Pauwels, L. (2010). Different measures of fear of crime and survey measurement error. In M. Cool, B. De Ruyver, M. Easton, L. Pauwels, P. Ponsaers, G. Walle, T. Vander Beken, F. Vander Laenen, G. Vermeulen, \& G. Vynckie (Eds.), Governance of Security Research Papers Series III, New Empirical Data, Theories and Analyses on Safety, Societal Problems and Citizens' Perceptions (pp. 19-39). Antwerp: Maklu.

Jackson, J. (2005). Validating new measures of the fear of crime. International Journal of Social Research Methodology, 8, 297-315.

Levine, G., \& Parkinson, S. (2014). Experimental Methods in Psychology. London: Psychology Press.

McAfee, A., Brynjolfsson, E., Davenport, T. H., Patil, D. J., \& Barton, D. (2012). Big data: the management revolution. Harvard Business Review, 90, 60-68.

Miró-Llinares, \& Johnson, S. (2018). Cybercrime and place: applying environmental criminology to crimes in cyberspace. In G. Bruisna \& S. Johnson (Eds.), The Oxford Handbook of Environmental Criminology. Oxford: Oxford University Press.

Miró-Llinares, F., Moneva, A., \& Esteve, M. (2018). Hate is in the air! But where? Introducing an algorithm to detect hate speech in digital microenvironments. Crime Science, $7,15$.

Noon, M. S., Beaudry, J. L., Schier, M. A., \& Knowles, A. (2019). Eyes wide open: exploring men's and women's self-reported and physiological reactions to threat and crime. Journal of Experimental Criminology, 15, 1-28.

R Core Team (2013). R: A Language and Environment for Statistical Computing. R Foundation for Statistical Computing, Vienna, Austria. www.R-project.org/ (accessed 12 December 2019).

Salas Zárate, M. P., Paredes Valverde, M. A., Rodríguez García, M. Á., Valencia García, R., \& Alor Hernández, G. (2017). Sentiment analysis based on psychological and linguistic features for Spanish language. In G. Alor-Hernández \& R. Valencia-García (Eds.), Current Trends on Knowledge-Based Systems (pp. 73-92). Cham: Springer International Publishing.

Searle, J. R. (1969). Speech Acts. Cambridge: Cambridge University Press.

Shivhare, S. N. (2012). Emotion detection from text. In D. C. Wyld (Ed.), Computer Science \& Information Technology (CS \& IT) (pp. 371-377). Academy \& Industry Research Collaboration Center (AIRCC).

Solymosi, R., \& Bowers, K. (2018). The role of innovative data collection methods in advancing criminological understanding. The Oxford Handbook of Environmental Criminology, 210, 210-237.

Stadthagen-González, H., Ferré, P., Pérez-Sánchez, M. A., Imbault, C., \& Hinojosa, J. A. (2017). Norms for 10,491 Spanish words for five discrete emotions: happiness, disgust, anger, fear, and sadness. Behavior Research Methods. Advance online publication. 
Stadthagen-Gonzalez, H., Imbault, C., Pérez Sánchez, M. A., \& Brysbaert, M. (2015). Norms of valence and arousal for 14,031 Spanish words. Behavior Research Methods, $49,111-123$.

Tseloni, A., \& Zarafonitou, C. (2008). Fear of crime and victimization: a multivariate multilevel analysis of competing measurements. European Journal of Criminology, $5,387-409$.

Van Lancker, D., \& Pachana, N. A. (1998). The influence of emotions on language and communication disorders. In B. Stemmer \& H. A. Whitaker (Eds.), Handbook of Neurolinguistics (pp. 301-311). San Diego: Academic Press.

Wang, X., Wei, F., Liu, X., Zhou, M., \& Zhang, M. (2011). Topic sentiment analysis in Twitter: a graph-based hashtag sentiment classification approach. In B. Berendt, A. de Vries, W. Fan., C. McDonald, I. Ounis, \& I. Ruthven (Eds.). Proceedings of the 20th ACM International Conference on Information and Knowledge Management, Glasgow, Scotland, UK, 24-28 October 2011. New York: Association for Computing Machinery, pp. 1031-1040.

Wierzbicka, A. (1994). Emotion, language, and cultural scripts. In S. Kitayama \& H. R. Markus (Eds.), Emotion and Culture: Empirical Studies of Mutual Influence (pp. 133-196). Washington, DC: American Psychological Association.

Yang, S. M., \& Hinkle, J. C. (2012). Issues in survey design: using surveys of victimization and fear of crime as examples. In Gideon, L. (Eds.), Handbook of Survey Methodology for the Social Sciences (pp. 443-462). New York: Springer. 


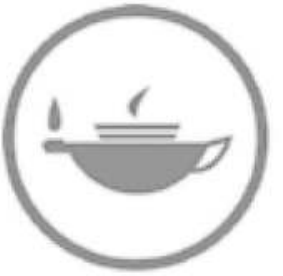

Taylor \& Francis Taylor \& Francis Group http://taylorandfrancis.com 


\section{Part VI}

The intervention

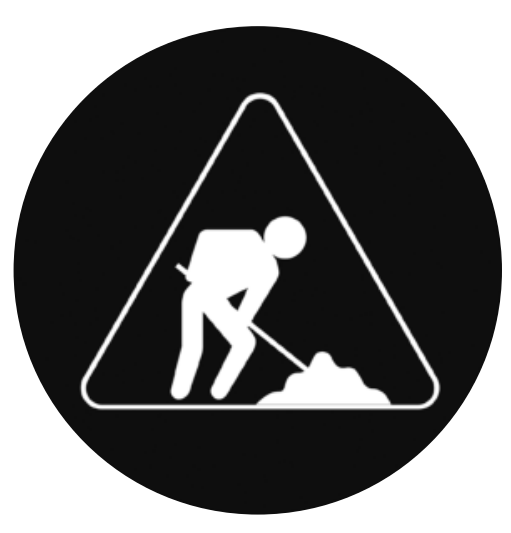




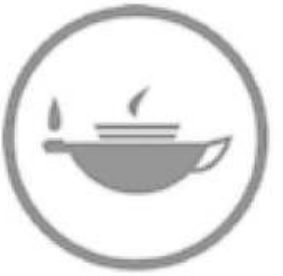

Taylor \& Francis Taylor \& Francis Group http://taylorandfrancis.com 


\title{
18 Fear of the dark
}

\author{
The potential impact of reduced \\ street lighting on crime and fear \\ of crime ${ }^{1}$
}

Pia Struyf

\subsection{Introduction}

Since the fifteenth century, street lighting has been installed in cities such as Paris and London as a means to combat crime (Boyce, 2014; Painter, 1999; Palmer, 2000). By 1850, most of the major cities worldwide had public lighting powered by gas, which later was replaced by exterior electric lighting systems (Boyce, 2014). At that time, providing public lighting had the specific aim of combating crime and maintaining public order, which gave rise to the "good lamp is the best police" metaphor (Bouman, 1991). Since the 1960s, the increasing crime rate led to local US governments and scientists investing in the crime prevention effect of public lighting (i.e., the installation of street lighting, or increases in the amount, or the intensity, of street lighting in dark public places), and its effect on fear of crime (Lee et al., 2016; Wright, Heilweil, Pelletier, \& Dickinson, 1974).

More recently, policymakers have shifted their interest toward the reduction of street lighting and its effects on the economy and the environment. In an era of climate change and economic cutbacks, local authorities around the world are considering reducing the amount of street lighting to decrease carbon emissions and save costs. Different interventions have been considered. For example, permanent or part-night switch-off (i.e., street lighting is only switched off during certain hours at night) and dimming lights, or replacing the existing lamps by more energy-efficient LEDs. In addition, new technologies have made smart, or intelligent applications, of street lighting possible. These promise to reduce energy waste and luminous pollution by providing public light only when necessary: illuminating a public space when a person approaches, and switching itself off when the person passes a certain spot, for example (Haans \& de Kort, 2012).

Despite the hypothetical benefits to the environment and the economy of reduced street lighting, evidence suggests that citizens consider the installation of street lighting as a "basic service" provided by the government, and express serious concerns about the possible impact of reduced street lighting on the occurrence of crime (Green, Perkins, Steinbach, \& Edwards, 2015). It is assumed that less public lighting will result in increased crime rates and unsafe public 


\section{Pia Struyf}

places. These concerns and assumptions generate fear amongst citizens, which affects both their mobility and use of public places (Steinbach et al., 2015).

Fear of crime is a broad concept which carries many sub-constructs, each with large variations in sensed risk, concern, anxiety, worry, and fear, resulting in the absence of a widely accepted definition. Consequently, measuring fear of crime constitutes a methodological challenge. According to Ferraro and LaGrange (1987), fear of crime is a perception that is solely based on subjective interpretations of objective risk, resulting in physical and psychological reactions such as a high heart rate and isolation. Different factors are highlighted as having an influence on the occurrence of fear of crime, such as biological (i.e., gender and age), psychological, and societal factors. Fear of crime has an uncomfortable effect on people and ought not be overlooked. However, scientific research on the impact of reduced street lighting on crime and fear of crime is still limited, and so local government decision-makers who consider reducing street lighting, are doing so through scientifically ill-informed processes.

This chapter critically reflects upon the impact of street lighting on crime and the fear of crime, with a particular emphasis on the effect of reduced street lighting. Together with an analysis of the relevant scientific databases, the extant literature, specifically the international literature on the impact of street lighting initiatives from 1960-2019, was investigated and reviewed. The synthesis of scholarly knowledge on the topic generated the following research questions:

1. Does street lighting affect crime and fear of crime?

2. What are the difficulties in measuring the effect of street lighting on crime and fear of crime?

3. Can we generalize about the impact of reduced street lighting on crime and fear of crime based on the scientific knowledge about street lighting installation, and the limited research on the reduction of street lighting?

4. What, if any, conflicting interests arise for local governments?

5. What lessons can be learned for research and practice?

This chapter critically evaluates the extant research on the impact of street lighting on crime and fear of crime and the methodological difficulties in measuring this. Further, the limited research on the impact of reduced street lighting on instances of crime and the fear of crime will be explored. The discussion will reflect on the expected impact of reduced street lighting on crime, the fear of crime, and the conflicting interests surrounding reduced street lighting policies. Finally, the chapter considers how far one can make generalizable conclusions based upon the available evidence, and the extent to which the findings provide a sound basis for future research and a secure platform for policymakers.

\subsection{Methodology}

The initial literature review was undertaken by scanning relevant scientific databases (i.e., Web of Science and Sage) using the following keywords: public 
lighting; street lighting; crime; antisocial behavior; wellbeing; fear of crime; improvements; reductions. Further, the snowball sampling method was used by screening the bibliographies of the found articles up until the point of saturation. No geographical criteria were adopted, although, only publications written in English were included.

On the basis that the intervention being researched was either a reduction in lighting (defined as permanent, partial, or dimmed lighting; or where lamps have been replaced with LEDs), or an increase in lighting (defined as the installation of new street lighting or an increase in the amount or intensity of street lighting in dark public places), the selection of articles was based on the following two criteria: (i) that the outcome was either the prevalence of crime or fear of crime (the incidence of traffic collisions was excluded), and; (ii) that the study was conducted between 1960 and 2019. Both qualitative and quantitative studies were included to reflect methodological nuance and advantages. The selected studies were all conducted in the United States and the United Kingdom, as studies that met the inclusion criteria were not found in other locations. $^{2}$

\subsection{The potential impact of (reduced) street lighting on crime and fear of crime}

\section{Street lighting as a crime prevention strategy}

Historically, darkness has always been associated with disorder and crime. Since the 1960s, several US local governments invested in the implementation of street lighting due to the increasing crime rate (Wright et al., 1974). Studies that examined the impact of increased street lighting on crime are numerous but come up with mixed results. Wright et al. (1974), evaluated a lighting project in Kansas City where incandescent lamps were replaced by mercury and sodium lights. They found that this initiative led to a decrease in the prevalence of certain types of crime, particularly robbery with violence and assault.

In contrast, Tien, O'Donnell, Barnett, and Mirchandani (1977), evaluated 15 street lighting projects in the US, and found no statistically significant effect of street lighting on crime. The authors selected street lighting projects based on five criteria: (i) the measured outcome must be the prevalence of crime; (ii) highway lighting projects were excluded as their focus is on vehicle safety rather than pedestrian safety; (iii) a population of at least 25,000; (iv) the projects were completed after 1970; and (v) the selected projects must provide pertinent evaluation-related information. In response to the Tien et al. review, Boyce (2014) pointed out that the studies included had several limitations, including inappropriate or inadequate measurements, and imprecise statistical analyses, which questioned their reliability (Boyce, 2014).

In the 1980s, several lighting projects were implemented by local governments in the United Kingdom. Atkins, Husain, and Storey (1991), researched the impact of street lighting in London on the prevalence of crime. They analyzed 
crime rates before and after relighting initiatives and compared these results to control areas where no such initiatives were taken. Critics argued that the assumption of Atkins et al. was restricted to the effect of street lighting on night-time crime (Pease, 1999). The study of Atkins et al. concluded that:

... no evidence could be found to support the hypothesis that improved street lighting reduces reported crime. Although some areas and some crime types did show reductions in night-time crime relative to the daytime control, the dominant overall pattern, from which the study draws its authority, was of no significant change.

(Atkins et al., 1991, p. viii)

Throughout the 1990s, Painter (1996, 1999; Painter \& Farrington, 1997) conducted substantial research on the impact of street lighting on crime. Her major comment on the previously conducted studies concerned the limited reliability of the police-recorded crime data that were used, due to the clustering of crime types and the low level of reported crimes (Boyce, 2014). A switch from police data to victim surveys offered a counterbalance to the difficulties with the first type of data source. However, victim surveys can only offer reliable results when a random sample is used to avoid selection bias. Using on-street pedestrian surveys in the treatment areas, before and after relighting initiatives were carried out after dark, Painter examined the impact of lighting on pedestrians' experiences of particular crimes (i.e., violence against the person, vehicle crime, and harassment) in a limited area in London. She concluded that street lighting does have a significant effect on crime. Further, she suggested that street lighting elicits a diffusion of benefits, implying that street lighting has a positive effect on non-relit streets nearby (Painter \& Farrington, 1999). For these areas, Painter found small decreases in crime, albeit that "most of the reductions reported relate more to threatening and disorderly incidents than to crime" (Painter, 1996, p. 197).

In a further study in Dudley, Painter and Farrington (1997) used two different data sources to examine the impact of street lighting on crime levels in a treatment and a control area, before and after street lighting improvements (the replacement of mercury lamps with high-pressure sodium lights). On the one hand, Painter and Farrington conducted interviews with randomly selected adult residents of the two investigated areas. These interviews showed that residents in the treatment area experienced less crime after the changes in street lighting compared to the control area. On the other hand, they carried out a self-reported delinquency survey from youngsters (age 12 to 17) living in both areas, which showed a larger decrease in admitted offenses in the relit area compared with the non-relit area.

In 2002 and 2008, Farrington and Welsh conducted two similar systematic reviews including eight American and five British studies, examining the impact of street lighting on crime (Farrington \& Welsh, 2002; Welsh \& Farrington, 2008 b). Five criteria were taken into account when selecting the included 
studies: (i) the main intervention in the studies was improved street lighting; (ii) the outcome measure was crime (mostly violent and property crimes); (iii) the studies must be of high methodological quality with measures before and after in treatment and control areas; (iv) the studies involved at least one treatment and one comparable control area; and (v) the areas examined in the studies must have at least 20 crimes in order for any change to have statistical significance.

The results of the eight American studies were mixed. Four studies reported results that confirmed the impact of street lighting, whereas the other four found no evidence of a crime prevention effect. In some cases, increases in certain types of crime were observed. This could be explained by increased reporting of crime to the police, as opposed to an increase in actual crime on the basis that offences are more visible to citizens when street lighting is increased. Overall, the meta-analysis conducted by Farrington and Welsh suggested a near-significant 7 percent decrease in crime in the relit areas of the included American studies. In contrast, the five British studies reported more uniform conclusions. The meta-analysis showed an overall 20 percent significant decrease in crime in the treatment areas compared with the control areas (Farrington \& Welsh, 2002; Welsh \& Farrington, 2008b).

Marchant $(2004,2005)$ argued that the statistical claims and methods used by Farrington and Welsh were unfounded, and further that there is a conflict between the evidence of the different studies and the interpretation of Farrington and Welsh. Two principal statistical errors were raised. The first, observed by Marchant was the 'unit of observation' error, by which he claims that related crimes (e.g., through repeat offending) were treated as statistically independent events. This resulted in a large variability in what the true underlying level of crime was. The second was the 'regression towards the mean' error, caused by comparing areas with different crime levels from the start. The treatment areas had higher crime rates than the control areas, resulting in a spurious increase in crime being recorded when comparing the two. Marchant stated that, based on this review, it was not possible to conclude that street lighting decreased or increased the prevalence of crime. Farrington and Welsh (2006) responded that regression to the mean only caused a 4 percent decrease in crime, which is a much smaller number than the overall decrease in crime attributed to street lighting.

More recently, Chalfin, Hansen, Lerner, and Parker (2019) conducted the first randomized controlled trial to examine the crime reducing effects of street lighting in New York City. To avoid selection bias, they randomly assigned the provision of street lighting to the city's public housing developments. Their focus was on index crimes (i.e., serious violent crimes) committed in 2016, based on the official police data of the NYPD from March 2011 to August 2016. The authors concluded that the provision of street lighting led to a 36 percent reduction in night-time index crimes, and a 4 percent reduction in overall index crimes, concluding that violent crimes can be especially sensitive to situational factors. It is notable that the lighting interventions made during this 


\section{Pia Struyf}

research, provided more light than other public lighting facilities, and further that the temporary nature of the interventions could have had an influence on the results. In a similar vein, the study does not consider the possible displacement of crime as a consequence of the installations.

To summarize, whilst the international literature overall is inconclusive on the crime prevention effect of street lighting (Boyce, 2014; Pain, MacFarlane, Turner, \& Gill, 2006; Steinbach et al., 2015), it is arguable that the more recent evidence supports the assumption that street lighting reduces crime, and thus, makes a difference. Nevertheless, it is very difficult to compare the results of the different studies in any meaningful way for five principal reasons. First, the studies discussed above lack an accepted definition of the concept of crime, indeed each study operationalizes 'crime' in different ways. Second, different studies examined different crime types and used different clusters of crimes. Third, different data sources were used, from police-recorded crime data to victim surveys and self-report surveys. Fourth, the different studies considered areas with diverse socio-economic characteristics and different crime rates. Fifth, all studies examined different types of 'improvements' to street lighting; inter alia relighting and changes in intensity.

\section{Street lighting as a fear of crime prevention strategy}

Although there is a worldwide decrease in crime, the fear of crime seems to remain at relatively stable levels (Eysink \& Foekens, 2018). As there is no causality between fear of crime and actual experienced victimization, fear of crime is a phenomenon created mostly by stories from other people's experiences, and general stories about crime and victimization, all of which could explain the overestimation of the least frequent crimes, and an underestimation of the most frequent crimes by citizens (Innes, 2017; Slovic, 2000). Consequently, this paradoxical relationship between crime, fear of crime, and the widespread impact of fear of crime on individuals, highlights the significance of studying the effect of street lighting on fear of crime.

Tien et al. (1977) were amongst the first to investigate the impact of street lighting on fear of crime in the US, by conducting an attitude survey in 15 US areas. Their results were straightforward, with 66 to 82 percent of the questioned residents and police officers reporting feeling "somewhat or much safer" after the installation of street lighting. Later, Atkins et al. (1991) researched the attitudes and behavior of residents in Earlsfield, London. They used self-reporting questionnaires before, and after, the relighting initiative in both treatment and control areas. The authors concluded that:

$\ldots$ in the relit or 'treated' areas, there was no general increase in feelings of safety about being out in the area after dark. There was however an observable improvement in women's perceptions of security, following re-lighting: this was statistically significant.

(Atkins et al. 1991, p. 14) 
No significant effects were noticed in the travel behavior of the respondents in the treatment area after the relighting was implemented. However, the implementation of street lighting was a popular measure with the respondents who were very much in favor. The most important limitations to this research was the comparatively short period in which the assessment was done and the small sample size (Atkins et al., 1991).

Later research echoed some of these findings. Painter (1996), for example, reported that street lighting led to decreased fear of crime, even when 'actual' changes were not consciously registered by residents. She argued that street lighting encourages more intensive use of public places after dark, which results in more natural social control of these areas (Painter, 1996). Similarly, Calvillo Cortés and Falcón Morales (2016) published research that examined the relationship between emotions and outdoor urban lighting. They compared three universities in three different countries (Mexico, Spain and France), where they used situation-response questionnaires to measure emotions to different lighting images. According to this study, the amount of visual information perceived in a place has an influence on people's emotions. When visual information was barely available, and the intensity of lighting was scarce, more respondents reported feelings of fear (Calvillo Cortés \& Falcón Morales, 2016).

Visibility in this context, namely the ability to see what is going on in the immediate surroundings, together with "eyes on the street" or natural surveillance, are significant factors when considering fear of crime. Different characteristics of the environment and public lighting have an impact on the feelings of safety in public places. For citizens, high levels of prospect (i.e., open view), low levels of concealment (i.e., few hiding opportunities for potential offenders), and low levels of entrapment (i.e., possibility to escape) are crucial elements in the assessment of a situation, and the potential to feel safe in public places (Dastgheib, 2018; Fisher \& Nasar, 1992). Other aspects, such as facial recognition, glare, and the color of light sources, play an equally important role in the assessment of street lighting where citizens' fear of crime is concerned (Boyce, 2014).

In summary, the presence of street lighting does result in less feelings of unsafety among citizens and more mobility after dark. Nevertheless, measuring the fear of crime is challenging. Fear of crime is often measured by examining attitudinal and behavioral changes of citizens, which results in very complex analysis and statistical interpretation (Atkins et al., 1991). Surveys for example, can be influenced by the type of questions asked, and by the phrasing used. Hypothetical questions are generally used in surveys to examine behavioral and attitudinal changes and reactions, although this type of question makes it difficult to value the results, if the respondents were not actually in the described situation (Ditton, 2000; Ramsay \& Newton, 1991). Therefore, it is important to keep the potential bias of responses in mind. 


\section{Pia Struyf}

\section{The effect of reduced street lighting on crime}

Whilst research on the impact of street lighting on crime and the fear of crime has been largely inconclusive and scarce respectively, academic research on the effect of reductions in street lighting on both crime and fear of crime also remains limited, with only a handful of recent studies touching the surface of this area. Perkins et al. (2015) for example, investigated the impact on crime of four street lighting adaptation strategies, by analyzing geolocated police data of eight areas in England and Wales (Perkins et al., 2015). For the same study, they conducted a rapid appraisal on the health and well-being concerns of the public after the implementation of four reduction strategies, namely, permanent switch-off, part-night switch off, dimming, and replacing traditional lamps by more energy-efficient LEDs (Steinbach et al., 2015). The study suggested that reduced street lighting had no significant increase on crime rates, although the opposite is generally assumed amongst citizens. Based on street lighting data and police data, permanent and part-night switch-off initiatives were not associated with an increase in crime, although dimming the street lights and replacing the lamps by LEDs were associated with a small reduction in crime, but their estimates were imprecise.

More recently, Davies and Farrington (2018) conducted a controlled before and after study of the effects on crime when switching off street lighting in Maldon, Essex (UK). The authors compared the treatment area with a demographically similar control area (Braintree, Essex), both served by the same police department (Essex Police). For both areas, only the urban wards with relatively high crime rates were taken into account. After comparing police recorded crime rates of the treatment (i.e., part-night lighting system since 2007) and control areas, three years before and after the introduction of the part-night lighting system, the authors concluded that switching off street lighting had the effect of a relative increase on burglary and vehicle crime. However, at the same time, criminal damage did not change, whilst violence showed a relative decrease in the treatment area, and might be explained by a decrease in people using public places after dark. As crime does not inevitably result in more (reported) crime, part-night lighting systems might be an interesting scenario for local governments who wish to reduce their public lighting, the authors conclude.

Overall, there seems to be evidence to suggest that reducing or switching off street lighting does not necessarily result in increases in crime, in the way that is mostly presumed. However, the available research is inconclusive and limited, with both studies showing certain limitations in terms of generalizability. First, the results of both studies are specific to the context of England and Wales, and therefore, cannot be generalized to other countries where lighting regimes and local government responsibilities differ. Second, in Perkins et al. (2015), only a small number of areas that implemented a permanent switch-off were included, so results concerning the lighting reduction strategy were imprecise. Similarly, in Davies and Farrington (2018), the size of the treatment area was relatively 
small compared with the control area, meaning any conclusions drawn are open to doubt. Finally, both analyses were based on police data, which are always partial since they are dependent on the willingness of citizens to report offences to the police, and the inclination of the police to register them (Skogan, 1975).

\section{The effect of reduced street lighting on fear of crime}

As noted above, studies concerned primarily with the effect of reduced street lighting on fear of crime are still limited. It is important to note that fear as a result of reduced street lighting does not exclusively mean fear of crime. Citizens are also fearful of tripping, physical injuries, and traffic accidents (Pain, 2000). Perkins at al.'s (2015) study focused on road safety, fear of crime, mobility, and the ability to see the night sky. They found that citizens expressed very strong and polarized views on public fora with an emphasis on the potential negative effects of reduced street lighting on their health and well-being, and a deep concern for their safety when walking at night. However, during the group interviews conducted by Perkins et al., they noticed that the opinions expressed were more modest. They recorded a greater emphasis on the possible positive effects of street lighting reductions, such as the reduction of carbon emissions and being able to see the stars at night. During their individual indepth interviews, a low degree of awareness about the reductions in street lighting amongst interviewees was noteworthy; several mentioned that they had not noticed any changes in street lighting. Yet in these interviews, respondents also expressed their concerns about personal safety and mobility. According to several respondents, mostly women, fear of the dark affected their mobility, as they were less likely to go out in the dark by foot, and were more likely to use the car or take a taxi. This fear of the dark is also strongly linked to unfamiliarity with places and situations. The household surveys carried out by Perkins et al., did not report any significant association between fear of crime levels and reduced street lighting; although it is possible that fear of the dark affected the well-being of citizens in other ways (Green et al., 2015).

Based on only one study, it is not possible to draw any generalizable conclusions on the impact of reduced street lighting on fear of crime, although the study of Perkins et al. suggests that people do change their behavior, and do feel less safe when street lighting is reduced in their area. As fear of crime affects the psychological and social abilities of people, more nuanced research that avoids some of the methodological pitfalls alluded to above is likely to give more fruitful outcomes.

\subsection{Discussion}

Notwithstanding the scarcity of empirical research on the subject, this chapter has critically examined the available international literature on increased and reduced street lighting with regard to crime and the fear of crime. It has been attentive to the hypotheses that might be generated based on their findings. In 
the literature, reduced street lighting is reflected as having the reverse effect of increased or installing street lighting. This reasoning is questionable. Most of these studies underplay the complexity of the social context, and are consequently less attentive to the diverse elements that might have unexpected and confounding effects on both the prevalence of crime and fear of crime. This makes any findings partial, and creates difficulties for both analytical and prescriptive conclusions about the impact of reduced street lighting on crime, and on the fear of crime.

Based on the analysis of the literature, two hypotheses can be put forward that explain the assumed crime prevention effect of street lighting. The first hypothesis asserts that street lighting provides visibility, which could deter potential offenders by increasing the possibility of crimes being detected and offenders identified (Atkins et al., 1991; Tien et al., 1977; Welsh \& Farrington, 2008a; Wright et al., 1974). According to situational crime prevention theories and the first generation of Crime Prevention Through Environmental Design (CPTED), it is possible to prevent crime by manipulating the urban context to influence the behavior and decision-making processes of offenders.

Based on this hypothesis, can we anticipate an increase in crime? This assumption, based largely on rational choice premises embedded in situational crime prevention, is highly questionable. First, as Wortley (2010) argues, situational crime prevention reduces its focus almost exclusively to target-hardening, thus neglecting the social context where interacting factors of crime, such as poverty, inequality, discrimination and poor parenting, are likely to play a role (Wortley, 2010). Second, attention should be paid to the possibility of crime displacement to nearby non-relit areas (Wright et al., 1974). This displacement of crime could be an unintended outcome of the installation or increase of street lighting and could result in increased crime rates in nearby areas. Further, increases in crime rates in a certain, potentially unlit area, do not necessarily indicate an overall increase in crime rates. Third, in-depth research is necessary on the decision-making processes of offenders, such as burglars (Ramsay \& Newton, 1991). In the study of Bennett and Wright (1984) for example, no mention was made about the lighting conditions affecting the interviewed burglars when choosing their target (Ramsay \& Newton, 1991). Based on these critiques, a rational choice approach does not offer a nuanced enough analytical toolkit to consider the impact of reduced street lighting on crime and fear of crime.

A second widely asserted hypothesis relates to the increased social cohesion created by street lighting. This hypothesis asserts that street lighting provides visibility, which leads to an increased use of public places during darkness. Therefore, more people are present in specific public places, leading to more natural surveillance, which results in less crime and citizens feeling safer. Further, the presence of street lighting, seen as a symbol of the positive attention of local governments, promotes certain neighborhoods and militates against the degradation of these areas. The logic at play is that social cohesion leads to community pride and informal social control of the own neighborhood 
(Boyce, 2014; Farrington \& Welsh, 2004). When considering the reduction of street lighting, it is generally assumed by citizens and other actors that fear of crime will be higher as a consequence of darker public places. In this respect, attention must be paid to confounding variables, such as the familiarity with the place and the reputation of a certain neighborhood. Therefore, no conclusive prediction can be made, based on this hypothesis, about the impact of reduced street lighting on crime and fear of crime.

\subsection{Conflicting interests and lessons learned}

Although reducing street lighting may cause a reduction in carbon emissions and bear down on financial costs, the perceptions of being (un)safe cannot be overlooked. On the one hand, local, national and international authorities are taking action against the environmental changes by decreasing carbon emissions, as well as more subjective factors such as light pollution, by reducing street lighting. On the other hand, there are simultaneous investments in crime prevention initiatives, seeking to protect citizens against different types of crimes. Crime prevention measures often have the paradoxical effect of reigniting the fear of crime, due to the increased awareness of risks (Innes, 2017), and reduced street lighting is seen as a measure that increases these senses, and are consequently difficult to overrule on grounds of the environmental protection or financial probity. I would suggest that there is no logical reason to suppose that environmental imperatives, and taking account of the fears of citizens, are mutually exclusive. However, authorities that decide to reduce street lighting must be aware of these conflicting values and must be scientifically informed during their decision-making process.

There seems to be little evidence to support switching off all street lighting permanently. Instead, consideration should be given to strategies that provide for "the right amount of light", meaning that lighting must be adequate to the specific situation calculated as a balance between energy savings and comfortable citizens. For example, good illumination is necessary in parks to facilitate natural surveillance and increase feelings of safety amongst passers-by (Iqbal \& Ceccato, 2016). In residential areas, on the other hand, street lighting can be switched off during certain hours of the night when citizens are unlikely to be regularly using public space. As stated by Davies and Farrington (2018), partnight switch off can be an effective and justifiable street lighting regime, but only after a thorough assessment of the context and needs of the neighborhood. To advise local governments in their street lighting regime, more scientific research must be carried out with attention to the particular social and physical environment.

Future studies then, on the effect of (reduced) street lighting on crime and, especially the fear of crime, need to develop methodological approaches that allow for a clear operationalization of these concepts. This makes it possible to compare studies at a more comprehensive level to accommodate different types of crime and fear of crime. A triangulation of methods could also help to 
counteract the limitations of different methods and avoid the forms of bias noted in this chapter. For example, it could be helpful to combine several forms of data, such as police-recorded data, self-reported offending data, victim surveys, and pedestrian counts, in a mixed methods study that is able to draw more nuanced findings. To conclude, clear operationalization of the concepts, and triangulation of methods is necessary to ensure the validity, credibility, and generalization of findings.

\subsection{Conclusion}

This chapter examined the limited literature on the impact that (reduced) street lighting can have on crime and the fear of crime. The studies in the literature show mixed results, but they do indicate that street lighting can have a crime reducing effect and can reduce fear of crime. However, there is no concomitant link between reduced street lighting and an increase in the prevalence of crime. The literature concerning the impact of reduced street lighting on fear of crime is too scarce to make conclusions. However, reduced street lighting might raise the awareness among citizens of the possible risks and negative effects of reduced street lighting, but also stresses its positive consequences, such as environmental benefits. Nevertheless, citizens did report some degree of behavioral changes during the night-time, such as their mobility. These findings should provide more scientific knowledge to local governments in their decision-making processes concerning the reduction of street lighting to save costs and reduce carbon emissions, which should be balanced against the well-being of their citizens.

The findings of this chapter are subject to three limitations. First, a literature review was conducted to offer a summary of the scientific knowledge related to the effect of (reduced) street lighting on crime and fear of crime. No systematic review or meta-analysis was done, so the conclusions should be interpreted as preliminary. Additionally, we must be aware of the possible publication bias in social sciences and, thus, possible distortion of the findings discussed in this chapter (Franco, Malhotra, \& Simonovits, 2014). Second, only a limited series of street lighting adaptation regimes were reviewed, with restricted attention for other, "smart", alternatives, such as street lighting that illuminates when a person passes by. Third, it remains unclear what the influence was (or could be) of other crime prevention initiatives that existed alongside street lighting. It is a challenge to measure the impact of interventions that have the objective of preventing certain behavior or emotions; thus, the impact of increased and reduced street lighting needs to be evaluated not only within the social contexts in which they are deployed, but also in their potential interaction with other prevalent crime prevention initiatives.

\section{Notes}

1 This chapter is based upon findings from a research project funded by Provincie West-Vlaanderen, Belgium. Alongside this literature review, a practical guide for local 
governments was written (Struyf, Enhus, Melgaço, \& Bauwens, 2019). The guide highlighted the most important findings on the impact that reduced street lighting has on crime and fear of crime, as well as providing practical information and advice to local governments wishing to implement reduced street lighting.

2 There is also research available on this topic not written in English (i.e., Ceccato, Vasquez, Langefors, Canabarro, \& Petersson, 2019, pp. 76-80).

\section{References}

Atkins, S., Husain, S., \& Storey, A. (1991). The Influence of Street Lighting on Crime and Fear of Crime. London: Home Office Crime Prevention Unit.

Bennett, T., \& Wright, R. (1984). Burglars on Burglary: Prevention and the Offender. Brookfield, USA: Avebury Publishing.

Bouman, M. J. (1991). The 'Good lamp is the best police' metaphor and ideologies of the nineteenth-century urban landscape. American Studies, 32, 63-78.

Boyce, P. R. (2014). Human Factors in Lighting. Boca Raton: CRC Press.

Calvillo Cortés, A. B., \& Falcón Morales, L. E. (2016). Emotions and the urban lighting environment: a cross-cultural comparison. SAGE Open, 6, 1-8.

Ceccato, V., Vasquez, L., Langefors, L., Canabarro, A., \& Petersson, R. (2019). Trygg stadsmiljö. Teori och praktik för brottsförebyggande \& trygghetsskapande àtgärder. Stockholm, Sweden: Institutionen för samhällsplanering och miljö, Kungliga Tekniska Högskolan.

Chalfin, A., Hansen, B., Lerner, J., \& Parker, L. (2019). Reducing crime through environmental design: evidence from a randomized experiment of street lighting in New York City. NBER Working Paper Series, 25798.

Dastgheib, S. (2018). Light and Perception of Safety In-between Buildings. The Role of Lighting in Perception of Safety from a Female Perspective in In-between Spaces of Residential Areas. Stockholm: KTH School of Architecture and Built Environment.

Davies, M. W., \& Farrington, D. P. (2018). An examination of the effects on crime of switching off street lighting. Criminology \& Criminal Justice, 1-19.

Ditton, J. (2000). Crime and the city. British Journal of Criminology-an International Review of Crime and Society, 40, 692-709.

Eysink, M., \& Foekens, P. (2018). The fear drop. In M. Lee \& G. Mythen (Eds.), The International Handbook of Fear of Crime (pp. 446-466). New York: Routledge.

Farrington, D. P., \& Welsh, B. C. (2002). Effect of Improved Street Lighting on Crime: A Systematic Review. London: Home Office.

Farrington, D. P., \& Welsh, B. C. (2004). Measuring the effects of improved street lighting on crime. A reply to Dr. Marchant. British Journal of Criminology, 44, 448-467.

Farrington, D. P., \& Welsh, B. C. (2006). How important is 'Regression to the mean' in area-based crime prevention research? Crime Prevention \& Community Safety, 8, 50-60.

Ferraro, K. F., \& LaGrange, R. (1987). The measurement of fear of crime. Sociological Inquiry, 57, 70-101.

Fisher, B. S., \& Nasar, J. L. (1992). Fear of crime in relation to three exterior site features: prospect, refuge, and escape. Environment and Behavior, 24, 35-65.

Franco, A., Malhotra, N., \& Simonovits, G. (2014). Publication bias in the social sciences: unlocking the file drawer. Science, 345, 1502-1505.

Green, J., Perkins, C., Steinbach, R., \& Edwards, P. (2015). Reduced street lighting at night and health: a rapid appraisal of public views in England and Wales. Health o Place, 34, 171-180.

Haans, A., \& de Kort, Y. A. W. (2012). Light distribution in dynamic street lighting: two experimental studies on its effects on perceived safety, prospect, concealment, and escape. Journal of Environmental Psychology, 32, 342-352. 
Innes, M. (2017). From fear to understanding. 'Making' and managing public reactions to crime, disorder and policing. In N. Tilley \& A. Sidebottom (Eds.), Handbook of Crime Prevention and Community Safety (pp. 470-487). London: Routledge.

Iqbal, A., \& Ceccato, V. (2016). Is CPTED useful to guide the inventory of safety in parks? A study case in Stockholm, Sweden. International Criminal Justice Review, 26, 150-168.

Lee, J., Park, S., Jung, S., Lee, J. S., Park, S., \& Jung, S. (2016). Effect of Crime Prevention through Environmental Design (CPTED) measures on active living and fear of crime. Sustainability, 8,872 .

Marchant, P. (2004). A demonstration that the claim that brighter lighting reduces crime is unfounded. British Journal of Criminology, 44, 441-447.

Marchant, P. (2005). Shining a light on evidence-based policy: street lighting and crime. Criminal Justice Matters, 62, 18-45.

Pain, R. (2000). Place, social relations and the fear of crime: a review. Progress in Human Geography, 24, 365-387.

Pain, R., MacFarlane, R., Turner, K., \& Gill, S. (2006). 'When, where, if, and but': qualifying GIS and the effect of streetlighting on crime and fear. Environment and Planning, 38, 2055-2074.

Painter, K. A. (1996). The influence of street lighting improvements on crime, fear and pedestrian street use, after dark. Landscape and Urban Planning, 35, 193-201.

Painter, K. A. (1999). The social history of street lighting (part 1). Lighting Journal, 64, 14-24.

Painter, K. A., \& Farrington, D. P. (1997). The crime reducing effect of improved street lighting: the Dudley project. In R. V. Clarke (Ed.), Situational Crime Prevention: Successful Case Studies. www.ncjrs.gov/App/Publications/abstract.aspx?ID=259348.

Painter, K. A., \& Farrington, D. P. (1999). Street lighting and crime: diffusion of benefits in the Stoke-on-Trent project. Crime Prevention Studies, 10, 77-122.

Palmer, B. D. (2000). Cultures of Darkness: Night Travels in the History of Transgression. New York: Monthly Review.

Pease, K. (1999). A review of street lighting evaluations: crime reduction effects. In K. A. Painter \& N. Tilley (Eds.) Surveillance of Public Space: CCTV, Street Lighting and Crime Prevention (pp. 47-76). Cincinnati, OH: Criminal Justice Press.

Perkins, C., Steinbach, R., Tompson, L., Green, J., Johnson, S., Grundy, C., ... Edwards, P. (2015). What is the Effect of Reduced Street Lighting on Crime and Road Traffic Injuries at Night? A Mixed-Methods Study. Southampton, UK: NIHR Journals Library.

Ramsay, M., \& Newton, R. (1991). The Effect of Better Street Lighting on Crime and Fear: A Review. London: Home Office Crime Prevention Unit.

Skogan, W. G. (1975). Measurement problems in official and survey crime rates. Journal of Criminal Justice, 3, 17-32.

Slovic, P. (2000). The Perception of Risk. New York: Earthscan.

Steinbach, R., Perkins, C., Tompson, L., Johnson, S., Armstrong, B., Green, J., ... Edwards, P. (2015). The effect of reduced street lighting on road casualties and crime in England and Wales: controlled interrupted time series analysis. Journal of Epidemiology and Community Health, 69(11), 1118-1124.

Struyf, P., Enhus, E., Melgaço, L., \& Bauwens, T. (2019). De impact van ingrepen in de openbare verlichting op criminaliteit, onveiligheidsgevoelens en verkeers(on)veiligheid. Praktijkgids voor lokale bestuurders en -administratie. Brussels: Vrije Universiteit Brussel.

Tien, J. M., O’Donnell, V. F., Barnett, A. I., \& Mirchandani, P. B. (1977). Street Lighting Projects. Washington: National Institute of Justice. 
Welsh, B. C., \& Farrington, D. P. (2008a). Effects of improved street lighting on crime. Campbell Systematic Review, 4(1), 1-51.

Welsh, B. C., \& Farrington, D. P. (2008b). Effects of improved street lighting on crime: a systematic review. Campbell Systematic Reviews, 4. http://campbellcollaboration. org/lib/project $/ 45 /$.

Wortley, R. (2010). Critiques of Situational Crime Prevention. http://discovery.ucl.ac. uk/1301877/1/Wortley_2010_SCP_criticisms.pdf.

Wright, R., Heilweil, M., Pelletier, P., \& Dickinson, K. (1974). The Impact of Street Lighting on Crime. Ann Arbor, MI: University of Michigan. 


\title{
19 Evaluating harm-reduction initiatives in a night-time economy and music festival context
}

\author{
Laura Garius, Bethany Ward, \\ Kirsty Teague and Andromachi Tseloni
}

\subsection{Introduction}

Large licensed outdoor music festivals have emerged as part of a general expansion of licensed recreational activities in the night-time economy (NTE) and are "a major source of income and tourism" (UNESCO, 2015, p. 7). Attendees of music festivals and NTE venues have much in common; engaging in similar patterns of increased alcohol consumption and polysubstance use (Martinus et al., 2010), and at increased risk of alcohol-related harm, including hospitalization, as well as violent and sexual victimization (Garius, 2016; White Ribbon Campaign, 2016). The Modern Crime Prevention Strategy (Home Office, 2016 , p. 35) highlights alcohol as a key driver of crime and sets out a range of actions to tackle alcohol-driven crime, including increasing the safety of nighttime economy spaces. One example of a harm-reduction initiative designed to encourage positive behavior change is the "Drinkaware Crew": a group of people trained by the Drinkaware Trust to look after the welfare of young adults on a night out. Working in pairs, the Drinkaware Crew mingle with patrons to promote a positive social atmosphere and provide assistance to those who may be vulnerable as a result of excessive alcohol consumption (Drinkaware, 2016).

The aim of this study is twofold. First, it evaluates the "Drinkaware Crew" harm-reduction initiative developed as a result of Drinkaware's "Drunken Nights Out" campaign (Christmas \& Seymour, 2014) using routinely collected data. This is achieved by monitoring police recorded crime levels before and after the Drinkaware Crew intervention. Second, it evaluates the feasibility of adapting this initiative from a night-time economy to a music festival context. This is achieved by using participant observation, semi-structured interviews with "Festival Crew" members and festival stakeholders, and activity logs completed by Crew members as part of a pilot study operating across two UK-based music festivals.

Drawing on environmental criminology theories, this chapter contributes to this area of knowledge by reporting the societal impact of the Drinkaware Crew initiative using a quantitative outcome evaluation, and by assessing whether the 
Drinkaware Crew initiative is transferable beyond the NTE context in which it currently operates.

\subsection{Theoretical background}

\section{Alcobol-related harm in night-time economy venues}

Excessive alcohol consumption is known to be a catalyst for public nuisance, anti-social behavior, and interpersonal violence (De Vocht et al., 2016): an assumption supported by data (ONS, 2017b). Many factors distinctive to the NTE environment, including high concentrations of licensed premises (Newton \& Felson, 2015), the convergence of a large number of strangers and acquaintances (Hobbs, Winlow, Hadfield, \& Lister, 2005), high levels of alcohol consumption, poor venue management, and an absence of capable guardianship, cumulate in the high prevalence of crime (Elvins \& Hadfield, 2003).

The public health community have long recognized the importance of the environment when considering crime prevention (Mair \& Mair, 2003, p. 209). Felson and Clarke (1998) state that an individual's behavior is a direct product of the interaction with their physical settings and that environments can provide opportunities for crime. This approach regards crime as patterned by the routine activities of daily life, and the convergence in time and space of a motivated offender and suitable target, in the absence of capable guardianship (Cohen \& Felson, 1979). Both NTE venues and music festivals are considered crime generating locations, also referred to as "risky facilities" (Clarke \& Eck, 2003). They experience a high concentration of crime because they facilitate the convergence of large numbers of potential targets and offenders.

When selecting human targets, offenders make choices according to the perceived vulnerability of the target and their own ability to overcome the victim; revealing a degree of rationality during the commission of an offence (Felson, 1996; Rebocho \& Silva, 2014). Alcohol consumption is a particularly salient predictor of target-selection in cases of unwanted sexual attention (Kavanaugh, 2013) as personal guardianship is lowered, physical coordination is impaired, and communicative skills (beneficial for de-escalation) are diminished (Sampson \& Lauritsen, 1990). Furthermore, uncomfortable, poorly managed, and unkept venues also contribute to increased levels of interpersonal aggression (Graham, Bernards, Osgood, \& Wells, 2006) due to such environments indicating a lack of capable guardianship (Wilson \& Kelling, 1982). Formal measures of guardianship may include the presence of police, CCTV and security personnel, however, "natural supervision of the environment by ordinary individuals" (Mayhew, Clarke, Sturman, \& Hough, 1976, p. 30) minimizes opportunities for committing crime, an idea consistent with the situational crime prevention principle of "increasing the risks" and "removing the excuses" associated with committing crime (Cornish \& Clarke, 2003).

With regard to patron vulnerability and the physical space, opportunities for sexual aggression concentrate on dancefloors and other areas typified by 
movement and crowding (Becker \& Tinkler, 2015; Graham et al., 2014). In areas of crowding, aggressive sexual overtures may be more easily disguised as accidental bump-ins and may be less visible to bystanders and security staff (Graham, Wells, Bernards, \& Dennison, 2010). High patron-density can also facilitate physical opportunities for violence by increasing the convergence of potential offenders and targets, as well as psychological opportunities for violence by increasing frustration as a consequence of overcrowding and competition for services (Marsh \& Kibby, 1992).

While the primary function of bars, to facilitate interaction between strangers and acquaintances, can result in opportunities for romantic connections (Fileborn, 2017), this also gives rise to unwanted sexual attention common within NTE venues (Fileborn, 2016). The majority of patrons, both male and female, have either witnessed or directly experienced sexual aggression involving female targets and male initiators (Graham et al., 2010, 2014; Kavanaugh, 2013). Despite a growing awareness of sexual harassment (Abbey et al., 2014; Becker \& Tinkler, 2015; Brooks, 2018; Graham et al., 2014), limited attention has been paid to lower-level sexual harassment in the NTE context in terms of its scale, impact, and regulation.

Clubs and festivals have much in common, including demographic characteristics of patrons. Festival sites mirror many of the issues associated with NTE venues including alcohol-related harm, violence (Martinus et al., 2010), antisocial behavior (Mackellar, 2014) as well as forms of sexual harassment, including groping, verbal abuse and assaults (White Ribbon Campaign, 2016). Due to the parallels observed between these different environments, harm-reduction initiatives designed to reduce criminogenic opportunities in NTE venues may also be transferable to a music festival context.

\section{Drinkaware's harm reduction initiatives}

Following research by Christmas and Seymour (2014), which examined norms and rituals in the night-time economy and the role that Drinkaware could play in reducing alcohol-related harm on 'drunken nights out', Drinkaware implemented an evidence-based behavior change intervention in the form of the "Drinkaware Crew" within a number of night-time economy (NTE) venues across England and Wales. The Drinkaware Crew are specially trained staff who work in pubs, bars and clubs to reduce drunken anti-social behavior amongst 18 to 24 year olds. They are trained by Drinkaware, and employed by venues, to identify vulnerable individuals within the venue(s) and promote a positive atmosphere (Drinkaware, 2016). Operating in pairs, Crew members carry a radio to communicate with existing venue services (for example, security personnel) and a replenishable toolkit bag to facilitate patron-interaction containing wipes/tissues, pen and paper, sick bags, lollipops, and information regarding local public transport links. The Drinkaware Crew also wear Drinkaware-branded, brightly colored uniforms with "here to help" slogans; distinguishing them from formal surveillance staff (Christmas \& Seymour, 2014). The Drinkaware 
Crew align with the concept of informal guardianship (Cohen \& Felson, 1979) by providing peer-guardianship over patrons and increasing bystander awareness.

Informed by evidence that patrons at music festivals are similarly vulnerable to risks of alcohol-related harm and victimization (Martinus et al., 2010), the Drinkaware Crew initiative was adapted from the night-time economy to a music festival context. The initiative was piloted at two UK-based music festivals over Summer, 2017 (Festival A and Festival B). Ten Drinkaware Crew members operated between 2-11 p.m. across a total of seven festival days: with six Drinkaware Crew members operating at Festival A and four at Festival B. The Drinkaware "Festival Crew" also operated in pairs, wore Drinkaware-branded uniforms with "here to help" slogans, and carried radios to communicate with existing on-site services. Festival-specific adaptations for the Festival Crew included climate-specific toolkit additions (sunscreen, water bottles, ponchos) and on-site training held immediately prior to the Crew's first shift at the festivals. The training content was amended to enable Crew members to identify signs, and areas, of patron-vulnerability specific to the festival(s). Crucially, the Festival Crew were intended to act as a roaming satellite service and function as a "triage" to existing festival service-provision: including welfare, security, and first aid festival services (which are traditionally more stationary).

Drawing on both international and national literature, we anticipate that: (1) the "Drinkaware Crew" initiative is capable of reducing opportunities for alcohol-related harm within night-time economy venues; and (2) the Drinkaware "Festival Crew" can be successfully adapted from a night-time economy context to a music festival context.

\subsection{Methodology}

\section{Evaluation of the "Drinkaware Crew"}

A quantitative outcome evaluation of the original "Drinkaware crew" initiative-delivered in one NTE venue in "City A" and in two NTE venues in "City B"-was undertaken in order to assess the societal impact of the initiative operating in the night-time economy. Exploratory analysis of police recorded crime data (PRC) was utilized; including all violent and sexual crimes reported to the police recorded as having occurred within the venues of interest from approximately one year prior to the Drinkaware Crew initiative beginning, until one year after the onset (monthly violent and sexual crime counts spanning 2015 to 2017). Crime counts for the venues in which Drinkaware Crew members were active (test venues) were compared to control venues.

Unlike national victimization survey data (Crime Survey for England and Wales), or Hospital Episode Statistics, PRC data records crimes at the nighttime economy venue-level: vital when determining how environmental factors 
inform venue-level risk. PRC was obtained from two police forces, City A and City B. Data included any sexual or violent offences that happened either inside or immediately outside of the venues of interest (test and control venues) for a year prior to the onset of the initiative and for one year after its commencement. To gain more contextual information about incidents, victims, and offenders, available offence details such as time and date were requested as well as offender and victim socio-demographic information. City A and B were selected by Drinkaware based upon the dates of the initiatives' implementation in those cities.

In City A, data were available for the test venue (test venue $\mathrm{Al}$ ) in which the initiative was active, and a comparable venue in which no initiative was active-matched on venue size-which acted as a control venue to compare trends against. In City B, data were provided for two test venues (test venue B1 and B2) which had both implemented the Drinkaware Crew initiative at different time periods. There was no comparable test venue for test venue $\mathrm{Bl}$, therefore crime data regarding all other NTE venues within City B which fell under the definition of a "nightclub" were used as a control. To allow the control to be comparable to the test venues, the crime rate per 1,000 patrons (derived from venues' maximum capacities) was calculated for each venue, and then averaged. To provide a visual representation of trends in police recorded violent and sexual offences within NTE venues, trend graphs were generated. These plotted the monthly crime rate per 1,000 patrons for all test venues and for the control venue in City A, and the average of the crime rate per 1,000 patrons in all nightclubs in City B. The rate per 1,000 patrons is calculated as follows:

$$
\text { Rate per } 1000 \text { patrons }=\frac{\text { monthly crime count }}{\text { venue capacity }} * 1000
$$

Owing to the low crime counts in the dataset, when trend graphs were first generated large fluctuations were present. To combat this, three-month rolling averages were calculated to smooth the trend line, making trends easier to establish. To complement the descriptive interpretation of the trend graphs, effect size calculations were also undertaken; taking the difference between the average crime count for the period of the intervention and dividing this by the standard deviation of the pre-intervention period. This is known as a standard mean difference (Olive \& Franco, 2008). These are interpreted such that anything below 0.2 is considered a small effect size, 0.5 medium and 0.8 large. Standard mean difference is calculated as follows:

Standard mean difference $(d)=$ average pre intervention count - average intervention period count 


\section{Evaluation of the "Festival Crew"}

A process evaluation was undertaken in order to test the feasibility and acceptability of the Drinkaware Crew model in a music festival context. Process evaluations are used to "assess fidelity and quality of implementation, clarify causal mechanisms and identify contextual factors associated with variation in outcomes" (Moore et al., 2015, p. 1). The present evaluation used mixed methods to determine: (1) fidelity to the service-model; (2) frequency and scope of service delivery; and (3) the quality of implementation. Fidelity to the servicemodel, in particular adherence to the service-model, is the extent to which the delivery of a service adheres to the delivery as intended by the service-developers (Dane \& Schneider, 1998); with markers including training content and execution. The frequency and scope of service delivery captures the quantity of service provided; with markers including the volume, duration, and nature of interactions. Quality of implementation reflects the way in which the service is executed during the evaluation period; with markers including perceptions of the service's efficacy and relevance.

The process evaluation draws on (1) observation of the Festival Crew training as well as the Festival Crew in operation (70 hours of observation); (2) semistructured interviews conducted with the Festival Crew $(n=9)$; (3) semistructured interviews with key festival stakeholders, including festival welfare staff, festival organizers, senior Drinkaware Staff, and the Crew trainers $(n=10)$; and (4) Festival Crew activity log entries, in order to identify how closely the Festival Crew in operation mirrored intended service-delivery in a music festival context.

Overt participant observation and the completion of reflective diaries were undertaken by two researchers throughout the Festival Crew training/operation at both Festival A and Festival B. The majority of the data, including observations, interviews, and activity log entries were collected at the intervention sites, as is appropriate for process evaluation (Helitzer \& Yoon, 2002).

Semi-structured interviews were audio recorded and transcribed scripts were used for line by line thematic analysis: "a method for identifying, analyzing and reporting patterns (themes) within data" (Braun \& Clarke, 2006, p. 79). Adhering to the guidance of Braun and Clarke (2006), the researchers first reviewed all interview transcripts to ensure familiarity with the data. Major topics of interest were then identified and coded within the narratives and then grouped thematically (using NVivo software). Following the authors' review and definition of such themes, the final stage of analysis involved the selection of specific excerpts from the transcripts in order to illustrate the presented themes.

Festival Crew activity logs were completed online by each Crew pairing at the end of each festival day. The activity logs were designed to record the estimated volume and type of interactions provided per shift from the perspective of the Festival Crew members themselves, as well as to provide open-ended textboxes for Festival Crew members to describe any standout interactions (Drinkaware, 2017). A total of 20 independent Festival Crew log entries were submitted and analyzed over the intervention period (reporting 1,110 total 
patron interactions across both festivals). The quantitative activity log data were analyzed using IBM SPSS. Simple descriptive statistical analysis was undertaken due to limitations associated with the data. The qualitative activity log data were analyzed using thematic analysis in NVivo.

\subsection{Results}

\section{Evaluation of the "Drinkaware Crew"}

When examining the night-time economy test venue Al in City A (Figure 19.1), it can be seen that in the period between March and July 2015 (one year prior to the initiative), and in the same period of the following year (post the commencement of the initiative), that the crime rate is similar. This suggests no change due to the initiative. The increase in the crime rate in the latter part of 2015 was also mirrored in 2016, however the drop in crime experienced between October 2015 and January 2016 was not repeated in the following year whilst the initiative remained in place, thus crime records remained higher whilst the Drinkaware Crew were active. In the early months of 2016, the control venue had much higher crime counts than the test venue, however this was reversed during the implementation period, with crime higher in the test venue.

In Figure 19.2 it can be seen that during the initiative period in city B there was an increase in the crime rate in test venue $\mathrm{Bl}$. This occurred alongside the control venue remaining relatively constant. The aforementioned increase does not rise above levels prior to the initiative period. This increase is sustained after the end of the initiative period, also proceeding to rise higher than any pre-or during-initiative level. Following this however, there was a drop in the crime rate in test venue $\mathrm{Bl}$ to levels below those of the city average at the end point of the dataset. In test venue B2 a large proportion of the monthly crime counts are 0 , due to a low number of crimes occurring in the venue, possibly attributed to the smaller venue size compared with other venues analyzed. This makes it difficult to ascertain any trend, and therefore to interpret any effect of the initiative.

In City A, a small decrease in crime counts was found whilst the intervention was ongoing in test venue $\mathrm{Al}$, whereas at the control venue a moderate increase in crime was found. This would suggest a small, but positive crime reduction effect of the intervention, contrasting this with the much larger increase in the control venue suggests the effect of the intervention was larger than the standalone standard mean difference test result (Table 19.1). In City $\mathrm{B}$, an increase in crime was found within both test venues (B1 and B2) during the intervention, and within the control venues during the two separate time periods. This increase was largest in test venue $\mathrm{Bl}$, with all other venues experiencing only a small increase. Overall, this analysis would suggest an inconclusive effect of the initiative in the test venue in City A, and a negative effect at the test venues in City B. 

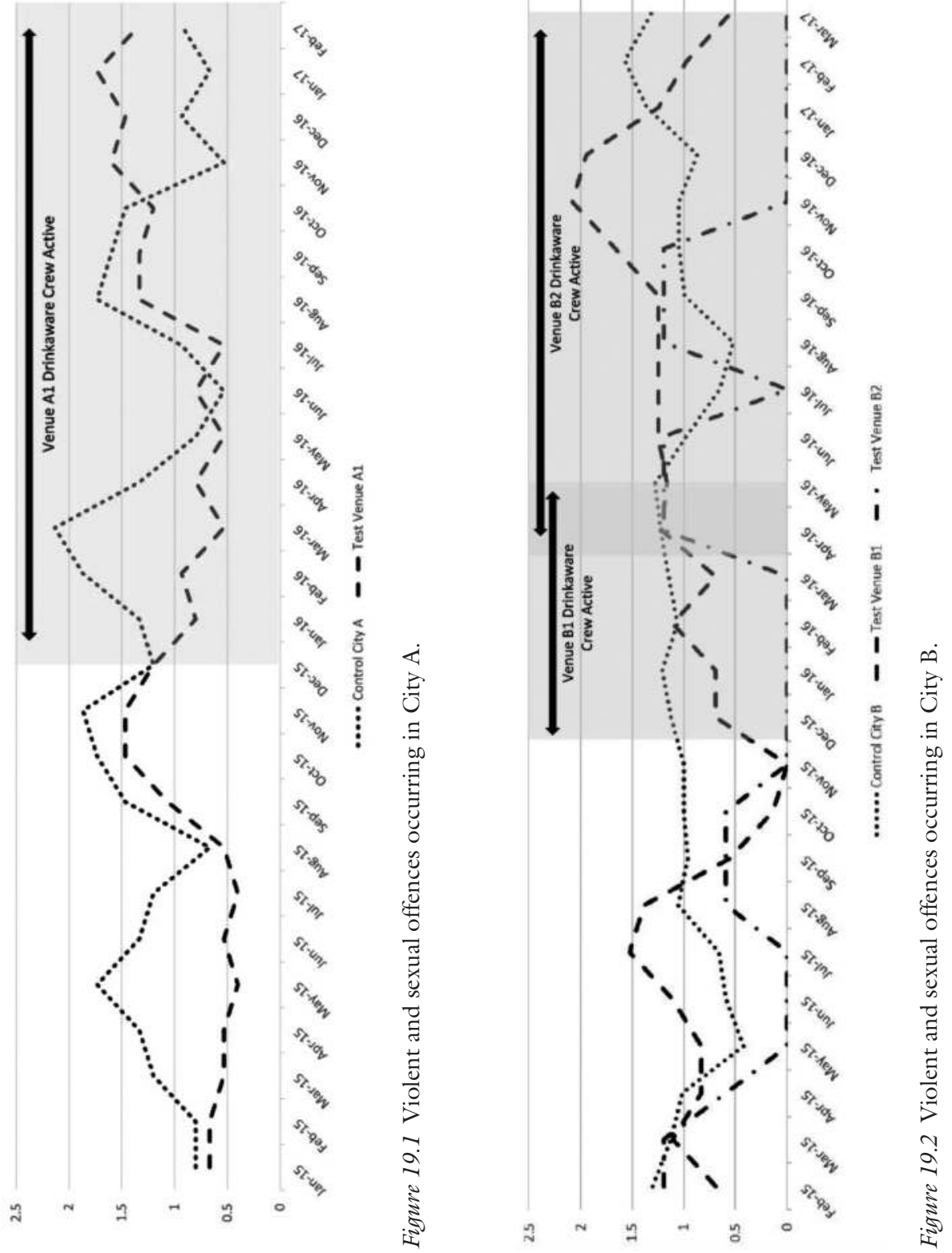
Table 19.1 Table of standard mean difference tests

\begin{tabular}{lll}
\hline Location & Venue & Standard mean difference \\
\hline City A & Test Venue Al & 0.160 \\
& Control Venue & -0.503 \\
City B & Test Venue B1 & -0.529 \\
& Control period 1* & -0.138 \\
& Test Venue B2 & -0.136 \\
& Control period 2* & -0.144 \\
\hline
\end{tabular}

Note

* In both cases this includes all venues excluding the two test venues ( $\mathrm{B} 1$ and $\mathrm{B} 2$ ), using the time period of the intervention.

\section{Evaluation of the "Festival Crew"}

Observation of the Festival Crew training, as well as semi-structured interviews with the Festival Crew members, were used to examine fidelity to the service-model. Both observation and interview data indicate that the training successfully prepared the Festival Crew for their role in practice, and the training material/delivery was adapted appropriately to the festival context. Crew members reported feeling suitably prepared for their role, and either agreed or strongly agreed that they felt able to deliver the majority of tasks associated with the intended service: (1) mingling with patrons; (2) offering care to people in distress; and (3) providing practical support to individuals who were vulnerable as a result of alcohol intoxication, as well as those at risk of sexual harassment/unwanted sexual attention. In terms of being able to work in partnership with existing festival staff, and escalate incidents to existing staff via radio communication, confidence levels varied among the Festival Crew. The trainers' familiarity with the festival sites, as well as an on-site tour of the festival grounds, enabled the Festival Crew to identify locations of increased harm (stage fronts, queues for food/drink/toilet services, festival-site periphery). Crew interviews also highlighted that due to on-site training taking place immediately prior to shifts, they were easily able to put into practice the skills and knowledge acquired-executing the initiative as intended:

Right after [training], we went round the site, so we didn't have to wait. Everything we covered in theory we then did in practice.

(Festival Crew Member 1, Festival A)

Analysis of the Festival Crew activity logs, as well as observation of the Festival Crew in operation, were used to examine the frequency and scope of service-delivery. Across both festivals, a total of 1,110 patron-interactions were recorded in the Festival Crew activity logs. Interactions were recorded by the Crew as either "providing practical assistance" (95 percent of 
interactions), or "providing emotional support" (5 percent of interactions). The Festival Crew were also required to estimate the proportion of male and female patrons supported: with the Crew estimating 54 percent of all patrons supported to be female $(n=602)$ and 46 percent to be male $(n=508)$. Providing assistance to patrons outside of the venue, which is offered as part of the night-time economy venue initiative, was beyond the scope of service-provision in the festival adaptation due to insurance requirements. This was observed by the researchers to leave a notable gap in service-provision.

Practical support provided at the festivals primarily included information provision and supporting patrons experiencing alcohol-intoxication and climaterelated issues. Typically, patron vulnerability resulted from excessive alcohol consumption, this was as expected, and toolkits contained sick bags and water to assist in these matters. Patron-vulnerability was exacerbated by environmental conditions, for example, Festival A experienced temperatures up to $31^{\circ} \mathrm{C}$. As alcohol increases heat absorption and results in heat-related illness (Hoffman, 2001), weather-specific items (sunscreen, water bottles) were critical additions to the adapted festival toolkit.

Variation in the volume and type of Crew interactions were also observed across a number of situational factors. Service-demand was observed by the researchers to vary by time of day across both festivals: with the number of patrons requiring support concentrating later in the day, often following the headline act's exit and on patrons' departure from the site. Variation in support by music genre (categorized by the headline artist $^{l}$ ) was also observed across both festivals. Supported by the analysis of activity-log entries, a concentration of Festival Crew interactions resulted when: (1) "indie rock" headlined (24 percent of total interactions, $n=261$ ); and (2) "electronic dance music (EDM)" headlined (19 percent of total interactions, $n=215$ ).

Semi-structured interviews with key festival stakeholders, observation of the Festival Crew in operation, and Festival Crew activity logs were used to examine the quality of service-implementation. The Festival Crew recorded the escalation of 8 percent of all interactions $(n=90)$ to existing festival services (medical, welfare, or security staff), demonstrating that the Festival Crew were able to successfully manage the vast majority of interactions independently (92 percent, $n=1,020)$; providing relief to existing festival services as intended. Semistructured interviews conducted with festival stakeholders confirmed that the Festival Crew were successfully implemented as a "triage" service; specifically, as a mobile outreach satellite operation due to other services remaining largely static. Therefore, the Festival Crew effectively occupied a unique gap in festivalstaff infrastructure:

I would love to have the Crew integrated into a common process that we put together through planning ... certainly with the medics and the security and welfare team and the dedicated Drinkaware Crew.

(Festival Organizer, Festival A) 
It is helpful ... having people as eyes and ears out there is amazing. I think it's [Festival Crew] a brilliant idea to do that and, given more resources, we'd be out there, but we haven't got them and we're not going to get them, so we focus on where we can work effectively, which is in this tent.

(Welfare Staff Member, Festival A)

Furthermore, the approachability of the Festival Crew, conveyed by the "here to help" uniform design and friendly interaction-style, successfully distinguished the Festival Crew from more formal measures of guardianship at the festival.

Most of the interactions that we have, besides the ones where we go and check on people, people see us walking past them and they see the T-shirts and they literally scream, "here to help" and we turn around. They call us. That's how we're identifiable.

(Festival Crew Member 1, Festival A)

Most people are really apprehensive about going to security ... if you've got a friendly face or somebody on the ground that could provide a bit help; it's amazing. People feel a lot more comfortable to talk to us.

(Festival Crew Member 3, Festival A)

\subsection{Discussion}

In assessing the impact of the "Drinkaware Crew" initiative in night-time economy venues based on police recorded crime data (PRC), it can be concluded that there was an increase in recorded crime in test venues in City B and an inconclusive effect on recorded crime in the test venue in City A. This was an unexpected result with regards to existing literature, which predicts a reduction in alcohol-related harm resulting from increased venue-level guardianship (Cohen \& Felson, 1979). However, there is also a body of literature which demonstrates that increases in PRC may reflect changes in recording and reporting practicesrelated to changing police practices as well as changes in public attitudes-as opposed to reflecting true changes in crime (Smith \& Allen, 2004).

There is a reliance upon both the reporting of crime by victims, and correct recording of crimes by police for offences to be included in PRC. Moreover, violent and sexual offences are the least likely crime types to be correctly recorded by the police, with errors in 67 percent of violent offences, and 74 percent of sexual offences (HMIC, 2014). ONS (2017a) analysis found a 22 percent increase in police recorded violence against the person offences from 2015 to 2016 , and a 20 percent increase in police recorded sexual offences, despite no statistically significant change in such crimes being found in the Crime Survey for England and Wales (CSEW) victimization survey (ONS, $2017 b)$. Therefore, we may attribute some of the apparent crime increases shown in the data to be evidence of improved and increased reporting to police and improved police recording practices. 
Analysis of the CSEW undertaken by the ONS reveals that less serious offences are the least likely to be represented in PRC (ONS, 2017b). A report by the Ministry of Justice, the Home Office, and the ONS (2013) found that only 15 percent of victims of the most serious sexual offences reported the incident to the police, and we may deduce from previous analysis that this percentage may be lower for victims of less serious assault. Improving national attitudes has increased reporting and recording of violent and sexual assaults (ONS, $2017 \mathrm{~b}$ ), and it is hypothesized that this may have occurred at a venue level. This may therefore account for some of the disparity between the test and control venues.

In assessing the implementation of the "Festival Crew" initiative at two large-scale music festivals in 2017, the initiative was found to be implemented successfully as a harm-reduction service; enhancing existing festival operations. The Festival Crew operated as a roaming service and were observed assisting distressed patrons and being actively vigilant for vulnerable patrons around the perimeters of the site who may be less visible or less able to actively seek assistance. Whilst intoxicated, adult patrons (approximately 18-24 years old) made up a large proportion of patron interactions (similar to the original, night-time economy based "Drinkaware Crew" interactions), the Festival Crew also supported older intoxicated patrons, children in distress, and offered support tailored to weather-dependent scenarios.

Support volume and type were recorded by the activity logs as varying by a number of situational factors (day of the week, musical genre, patrondemography). Whilst the increased support of female patrons mirrors existing literature (Graham et al., 2014), diversity in the age of patrons supported was greater than expected. A diversification in patronage has been identified within licensed contexts previously (Garius, 2016), however, a large presence of children, and corresponding Crew interactions pertaining to lost children and promoting child safety, were not anticipated in the scope of service delivery.

Activity log analysis indicated that 80 percent of patrons supported on the nostalgic-pop headlined festival-day were female $(n=32)$. Such variation could reflect variation in festival patronage. Newton and Felson (2015, p. 5) stress that "the denominators of crime (rates) are an essential component to aid our examination of crime risk". Figures regarding total patron attendance (and patron socio-demographic characteristics) by festival/festival-day (through which comparable support rates per population could be calculated) were unavailable.

The total number of patron interactions recorded in the activity logs $(1,110$ interactions) was observed by the researchers as being an underestimation of the total support given. A number of limitations were associated with the design/ completion of the activity logs, including that separate incidents/interactions were not recorded individually. Instead, totals by overall support category (practical support, emotional support) were estimated by Festival Crew members. Inferential statistical analysis of these data was therefore not possible. 


\subsection{Conclusion and recommendations}

Existing literature, as well as government strategies such as the Modern Crime Prevention Strategy (Home Office, 2016), highlight the necessity of harmreduction initiatives focusing on the immediate social (as well as physical) environment in order to reduce opportunities for alcohol-related harm and victimization (Wortley, 1998; Graham et al., 2010). However, it is imperative that we are also able to evaluate these schemes (Sanderson, 2002).

When evaluating the impact of the Drinkaware Crew initiative using routinely collected data (police recorded crime) for City A, the data suggest an increase in all crime types during the initiative period. In City B, in test venue $\mathrm{Bl}$, the average number of crimes per month was lower during the initiative period than the pre-initiative period, however it continuously rose during the initiative period. This rise continued post the termination of the initiative. Test venue B2 in City B did not provide much evidence of an impact of the initiative due to the very low crime rates in the venue, with only seven such events occurring throughout the entire data series. In conclusion, although data analysis suggests that the impact of the "Drinkaware Crew" has not reduced crime within the venues studied, this paper does not conclude that the initiative had the impact of increasing crime in NTE venues. Rather, it concludes that the data are unreliable for the purpose of evaluation of this initiative due to a series of limitations associated with PRC data: this is in addition to existing evidence that sexual crime, particularly "lower-level" sexual crime, is especially subject to reporting/recording practices (ONS, 2017b).

The low proportion of offences reported to, and recorded by, the police not only reduces the reliability of the evaluation's results, but also affects the type of analyses that can be undertaken. Inferential analysis could not be undertaken, thus the conclusions that can be drawn from these analyses are limited. Additional limitations to using PRC data include difficulties in gaining access to venue-level crime. Whilst we were successful in obtaining data in two (Cities A and B) out of three data requests, this was a lengthy process lasting 4-6 months. In addition, due to forces having different recording practices and data formats, the preparation of data was complex.

In order to carry out more conclusive analyses, alternative data sources must be considered, with one option being venue-acquired data. It is anticipated that venues would maintain information regarding incidents occurring within the venues. These are expected to capture more low-level incidents that are not captured by PRC data. It is, however, unlikely that these venuerecords would capture all opportunistic predation incidents that occur in areas of low visibility. An issue with the use of these data would be the formatting of venue-records into a usable format. It is expected that this would be a time-consuming process for each venue included in an evaluation-and as this is not a routinely collected data source, it would require both test venues' compliance and the recruitment of control venue(s) in order to test the initiative's effectiveness. 
Whilst it is not possible from the process evaluation of the Festival Crew initiative to draw final conclusions in relation to outcomes, or indeed impact, the potential for impact was evident. Throughout the observation period, festival-goers utilized the Drinkaware Crew to reduce alcohol-related harm for both themselves and others. This is also supported by interviews with existing festival stakeholders. Recommendations to further improve the adaptation of the initiative to the festival context include: (1) heightened visibility, both in terms of a social media presence to promote the service at the festivals and an increased Festival Crew-to-patron ratio; (2) further integration of Crew into existing staff infrastructures; (3) a defined Drinkaware space at festivals to facilitate on-site training and store kit, and to protect refreshment breaks for Festival Crew without disruption from festival patrons; and, finally, (4) measures to improve data collection (activity log validity and reliability).

Festival Crew activity log data provided evidence of high levels of engagement with patrons throughout the intervention period. However, the activity logs were limited in their ability to capture valid, reliable measures of the scope and scale of service-provided, and the impact this initiative may have had. A preexisting artificial cap of 80 incidents had been applied to each support category per Crew pairing per day to minimize anomalous results via the activity log online-portal. However, Festival Crew member interviews, and researcherobservation, found that this cap was often exceeded due to the large demand for service at the festival(s). Researcher-observation revealed a lack of consistency between Festival Crew members' recording of support provided. Whilst some Crew members recorded "low-level" interactions within their activity log, others chose not to record more "minor" events/interactions. This restricts the reliability of entries between the Crew members.

Recommendations to improve activity log accuracy include: (1) incorporating user-friendly, printed guides/templates containing interaction inclusion/ exclusion criteria within the toolkit; (2) encouraging completion of logs in stages throughout shifts; and (3) dedicating a greater proportion of training to log-completion best-practice. Possible solutions to improve data collection include the use of clickers to count the number of patron interactions, or a live activity-log app completed via Festival Crew members' mobile phones. Given the current limitations of Festival Crew activity log data, the availability and suitability of festival venue-acquired data should be explored in order to evaluate demand for service-provision.

Clarity is required when evaluating behavior change initiatives to ascertain whether such initiatives do indeed result in more "optimal outcomes" than other intervention-types (Kosters \& Van der Heijden, 2015). However, this chapter concludes that the data currently available are unable to definitively establish outcomes-although demand for service-provision is clear in both night-time economy and music festival contexts. Licensed venues are required to adhere to the following licensing objectives under The Licensing Act 2003: the prevention of crime and disorder, public safety, the prevention of public nuisance, and the protection of children from harm. Inclusion of the Drinkaware Crew initiative 
in licensed venues allows NTE venues, and festivals, to meet their responsibility of holding a license to sell alcohol. Similarly, the Modern Crime Prevention Strategy (Home Office, 2016, p. 33) emphasizes that those with a stake in the night-time economy have a responsibility to work collaboratively to deliver such behavior change interventions to "ensure that people can enjoy a safe night out without fear of becoming a victim of alcohol-related crime or disorder". However, initiative developers must work closely with the venues in which they operate in order to effectively evaluate initiatives-given the need for harmreduction schemes to be evidence-based and given the limitations of existing routinely collected data.

\section{Funding}

This work was supported by the Drinkaware Trust. Drinkaware is primarily funded by voluntary and unrestricted donations from UK alcohol producers, retailers and supermarkets, based on an agreement between the UK government and the alcohol industry. The funders of Drinkaware have no involvement in or influence over the activities of the charity which is governed by an independent Board of trustees. Drinkaware had no involvement in the analysis and findings reported in this work.

\section{Note}

1 Headline artists across both festivals included (Nostalgic pop (4 percent of total interactions), alternative ( 9 percent), punk (13 percent), modern pop ( 15 percent), nostalgic rock (16 percent), EDM (19 percent), indie rock ( 24 percent), (each musical genre played for an equal amount of time-one festival day).

\section{References}

Abbey, A., Wegner, R., Woerner, J., Pegram, S. E., \& Pierce, J. (2014). Review of survey and experimental research that examines the relationship between alcohol consumption and men's sexual aggression perpetration. Trauma, Violence, \& Abuse, 15, 265-282.

Becker, S., \& Tinkler, J. (2015). "Me getting plastered and her provoking my eyes" young people's attribution of blame for sexual aggression in public drinking spaces. Feminist criminology, 10, 235-258.

Braun, V., \& Clarke, V. (2006). Using thematic analysis in psychology. Qualitative Research in Psychology, 3, 77-101.

Brooks, V. (2018). Sex: Why We Need to Research it More Post \#MeToo. The Conversation. https://theconversation.com/sex-why-we-need-to-research-it-more-post-metoo101994.

Christmas, S., \& Seymour, F. (2014). Drunken Nights Out: Motivations, Norms and Rituals in the Night-Time Economy. London: Drinkaware. www.Drinkaware.co.uk/ media/1567/Drinkaware_drunken-nights-out-report_full-report_vfinal-pdf-versionwithout-page-breaks-_dec-2014-amend.pdf.

Clarke, R. V., \& Eck, J. E. (2003). Become a Problem-solving Crime Analyst: In 55 Small Steps. London: Jill Dando Institute of Crime Science.

Cohen, L. E., \& Felson, M. (1979). Social change and crime rate trends: a routine activity approach. American Sociological Review, 44, 588-608. 
Cornish, D. B., \& Clarke, R. V. (2003). Opportunities, precipitators and criminal decisions: a reply to Wortley's critique of situational crime prevention. In M. Smith \& D. B. Cornish (Eds.). Theory for Situational Crime Prevention, Crime Prevention Studies, Vol. 16. Monsey, New York: Criminal Justice Press, 41-96.

Dane, A. V., \& Schneider, B. H. (1998). Program integrity in primary and early secondary prevention: are implementation effects out of control? Clinical Psychology Review, $18(1), 23-45$.

De Vocht, F., Heron, J., Campbell, R., Egan, M., Mooney, J., Angus, C., Brennan, A., \& Hickman, M. (2016). Testing the impact of local alcohol licencing policies on reported crime rates in England, Journal of Epidemiology and Community Health, 71, $137-145$.

Drinkaware. (2016). 'Drunken Nights Out'-Campaign Summary. www.drinkaware.co. $\mathrm{uk} /$ research/our-research-and-evaluation-reports/drunken-nights-out-campaignsummary/.

Drinkaware. (2017). Helping Create a Safer Night-Time Economy: Drinkaware Crew Pilot. London: Drinkaware.

Elvins, M., \& Hadfield, P. (2003). "West End stress area. Night-time economy profiling: a demonstration project". Department of Sociology and Social Policy, University of Durham, Durham.

Felson, R. B. (1996). Big people hit little people: sex differences in physical power and interpersonal violence. Criminology, 34, 433-452.

Felson, M., \& Clarke, R. V. (1998). Opportunity Makes the Thief. Police Research Series, Paper 98. Policing and Reducing Crime Unit, Research, Development and Statistics Directorate. London: Home Office.

Fileborn, B. (2016). Reclaiming the Night-time Economy: Unwanted Sexual Attention in Pubs and Clubs. Basingstoke: Palgrave Macmillan.

Fileborn, B. (2017). 'Staff can't be the ones that play judge and jury': young adults' suggestions for preventing unwanted sexual attention in pubs and clubs. Australian \& New Zealand Journal of Criminology, 50, 213-233.

Garius, L. (2016). Opportunities for Physical Assault in the Night-Time Economy in England and Wales, 1981-2011/12 (Doctoral dissertation, Loughborough University).

Graham, K., Bernards, S., Osgood, D. W., \& Wells, S. (2006). Bad nights or bad bars? Multi-level analysis of environmental predictors of aggression in late-night large-capacity bars and clubs. Addiction, 101, 1569-1580.

Graham, K., Wells, S., Bernards, S., \& Dennison, S. (2010). "Yes, I do but not with you": qualitative analyses of sexual/romantic overture-related aggression in bars and clubs. Contemporary Drug Problems, 37, 197-240.

Graham, K., Bernards, S., Wayne Osgood, D., Abbey, A., Parks, M., Flynn, A., Dumas, T., \& Wells, S. (2014). "Blurred lines?" Sexual aggression and barroom culture. Alcoholism: Clinical and Experimental Research, 38, 1416-1424.

Helitzer, D., \& Yoon, S. (2002). Process evaluation of the adolescent social action program in New Mexico. In A. Steckler \& L. Linnan (Eds.). Process Evaluation for Public Health Interventions and Research (pp. 83-109). San Francisco: Jossey-Bass.

HMIC (2014). Crime-recording: making the victim count. The final report of an inspection of crime data integrity in police forces in England and Wales. Her Majesty's Inspectorate of Constabulary, November 2014. www.justiceinspectorates.gov.uklhmic/ wpcontent/uploads/crime-recording-making-the-victim-count.pdf.

Hobbs, D. Winlow, A., Hadfield, P., \& Lister, S. (2005). Violent hypocrisy: governance and the night-time economy. European Journal of Criminology, 2, 161-183.

Hoffman, J. L. (2001). Heat-related illness in children. Clinical Pediatric Emergency Medicine, 2, 203-210. 
Home Office (2016). Modern Crime Prevention Strategy. London: Home Office. www. gov.uk/government/publications/modern-crime-prevention-strategy.

Kavanaugh, P. R. (2013). The continuum of sexual violence women's accounts of victimization in urban nightlife. Feminist Criminology, 8, 20-39.

Kosters, M., \& Van der Heijden, J. (2015). From mechanism to virtue: evaluating nudge theory. Evaluation, 21, 276-291.

Mackellar, J. (2014). Event Audiences and Expectations. Oxon: Routledge.

Mair, J. S., \& Mair, M. (2003). Violence prevention and control through environmental modifications. Annual Review of Public Health, 24, 209-225.

Marsh, P., \& Kibby, K. (1992). Drinking and Public Disorder. Oxford: Alden Press.

Martinus, T., McAlaney, J., McLaughlin, L. J., \& Smith, H. (2010). Outdoor music festivals: cacophonous consumption or melodious moderation? Drugs: Education, Prevention and Policy, 17, 795-807.

Mayhew, P., Clarke, R. V., Sturman, A., \& Hough, J. M. (1976). Crime as Opportunity. London: Her Majesty's Stationery Office.

Moore, G. F., Audrey, S., Barker, M., Bond, L., Bonell, C., Hardeman, W., Moore, L., O'Cathain, A., Tinati, T., Wright, D., \& Baird, J. (2015). Process evaluation of complex interventions: Medical Research Council guidance. British Medical Journal, 350, 1-7.

Newton, A., \& Felson, M. (2015). Editorial: crime patterns in time and space: the dynamics of crime opportunities in urban areas. Crime Science, 4, 1-5.

Olive, M. L., \& Franco, J. H. (2008). (Effect) size matters: and so does the calculation. The Behavior Analyst Today, 9, 5-10.

ONS (2013). An Overview of Sexual Offending in England and Wales. Newport: ONS. https://assets.publishing.service.gov.uk/government/uploads/system/uploads/ attachment_data/file/214970/sexual-offending-overview-jan-2013.pdf.

ONS (2017a). User Guide to Crime Statistics for England and Wales. Newport: ONS. http://doc.ukdataservice.ac.uk/doc/8140/mrdoc/pdf/8140_userguidecrimestats.pdf.

ONS (2017b). Overview of Violent Crime and Sexual Offences. Newport: ONS. www.ons. gov.uk/peoplepopulationandcommunity/crimeandjustice/compendium/focusonviolentcrimeandsexualoffences/yearendingmarch2016/overviewofviolentcrimeandsexualoffences.

Rebocho, M. F., \& Silva, P. (2014). Target selection in rapists: the role of environment and contextual factors. Aggression and Violent Behavior, 19, 42-49.

Sampson, R. J., \& Lauritsen, J. L. (1990). Deviant lifestyles, proximity to crime, and the offender-victim link in personal violence. Journal of Research in Crime and Delinquency, 27, 110-139.

Sanderson, I. (2002). Evaluation, policy learning and evidence-based policy making. Public Administration, 80, 1-22.

Smith, C., \& Allen, J. (2004). Violent Crime in England and Wales. London: Home Office.

UNESCO. (2015). Festival Statistics: Key Concepts and Current Practices. 2009 UNESCO Framework for Cultural Statistics Handbook No. 3. Montreal, Canada: UNESCO. www.uis.unesco.org/culture/Documents/fcs-handbook-3-festival-statistics.pdf.

White Ribbon Campaign (2016). Safe Music: Making Gigs and Festivals Safer for Women. A Report by The White Ribbon Campaign. www.whiteribboncampaign.co.uk/ node $/ 273$.

Wilson, J. Q., \& Kelling, G. L. (1982). Broken windows. Atlantic Monthly, 249, 29-38.

Wortley, R. (1998). A two-stage model of situational crime prevention. Studies on Crime and Crime Prevention, 7, 173-188. 


\title{
20 Crime and fear in Hollygrove-building neighborhood resilience
}

\author{
Mateja Mibinjac and \\ Gregory Saville
}

\subsection{Introduction}

Back then, this was one of the most murderous neighborhoods in the country.... And we still have serious problems. The difference is, now we are doing something about them.

(Edmondson, 2010, para. 7)

In this chapter we present a case study of a neighborhood in New Orleans, Hollygrove, a place formerly suffering high crime, violence and fear of crime. Using an Action Research (AR) case study, we showcase how a group of residents can achieve lasting improvements in their neighborhood when empowered to do so. Our case study centers on an AR cycle in which we equipped local residents with problem-solving skills and then empowered them to take ownership of their problems and act to resolve them.

We begin by describing the high-crime conditions in Hollygrove, the resulting impact on livability and how the residents' fear of crime disengaged them from their neighbors. While the residents were determined that they did not want to return to this kind of environment after Hurricane Katrina, these conditions persisted following the hurricane, thus signaling they needed assistance in learning how to address safety and livability concerns.

This chapter covers 2008 to 2018, however, even today programs continue to emerge and evolve. We rely on basic descriptive statistics, site observations, and accounts from residents and members of the AARP (formerly the American Association of Retired Persons) to assess how conditions changed from the early years. Finally, the work reported here draws theoretically from the famous Chicago School of Human Ecology at the University of Chicago in the 1930s (Chicago School of Sociology, n.d.).

The choice of the Hollygrove neighborhood emerged from consulting work in New Orleans by a SafeGrowth consulting team led by one of the authors (Saville), in collaboration with the Louisiana chapter of AARP, a few years after Hurricane Katrina. This presented unique circumstances in which Hollygrove provided a natural AR case study in collective efficacy and CPTED programming. 


\subsection{Theoretical framework}

Social ecology is the theoretical framework that informs community capacity building, a concept known in the crime prevention literature for decades, however methods to implement it have remained piecemeal and understudied. This is true even during the successful work of the Chicago Area Project, the earliest example of social disorganization and community capacity building starting in the 1930s (Burgess, Lohman, \& Shaw, 1937).

By the 1980s a group of criminologists began to write more consistently on the topic, especially in regards to how local community organizations prevent crime (Kohfeld, Salert, \& Schoenberg, 1981; Lavrakas \& Herz, 1982; Lewis, Grant, \& Rosenbaum, 1988; Skogan, 1988). The most notable recent example of this work is the collective efficacy research of Robert Sampson (Sampson, 2004, 2012; Sampson, Morenoff, \& Gannon-Rowley, 2002; Sampson \& Raudenbush, 2001). We term this process neighborbood activation (Mihinjac, 2018). To illuminate the intricacies of this process this chapter provides a case study on some action research in one neighborhood of New Orleans that implemented such an approach, a neighborhood planning process now termed SafeGrowth (Saville, 2009).

The final theoretical component of this study is a neighborhood planning system called SafeGrowth. Emerging out of Crime Prevention Through Environmental Design (CPTED) projects during consulting work in the early 2000s (Saville, 2009), it incorporates basic First Generation CPTED, such as crime opportunity reduction using natural surveillance, territorial control and area clean-ups. It also adds Second Generation CPTED, such as social programming like community events and activities for youth, to help reinforce crime prevention effectiveness. Second Generation CPTED ties social programs to specific neighborhood problems and areas, which in turn reinforces physical opportunity crime reduction strategies (Cleveland \& Saville, 1997). It is now well represented in the crime prevention literature as part of a broader program for community development (Abramovic \& Van Dusen, 2004; Cozens, 2007; DeKeseredy, Donnermeyer, \& Schwartz, 2009; Letch et al., 2011; Olajide, Lizam, \& Adewole, 2015; Saville \& Cleveland, 2013) and, as a method to enhance collective efficacy, is the mainstay for SafeGrowth planning.

\section{Background - the problem of disengagement}

The neighborhood of Hollygrove is a low-income community west of the New Orleans central business district (Figures 20.1(a) and 20.1(b)). The neighborhood assumes the geographical area of 0.627 square miles with a population of 5,851 residents in 2016 (The Data Center, 2018). The majority (95 percent) of residents are African-American and in the years following Hurricane Katrina, seniors above 50 years in age comprised over 31 percent of the Hollygrove population (The Data Center, 2018). Despite its median income level of 


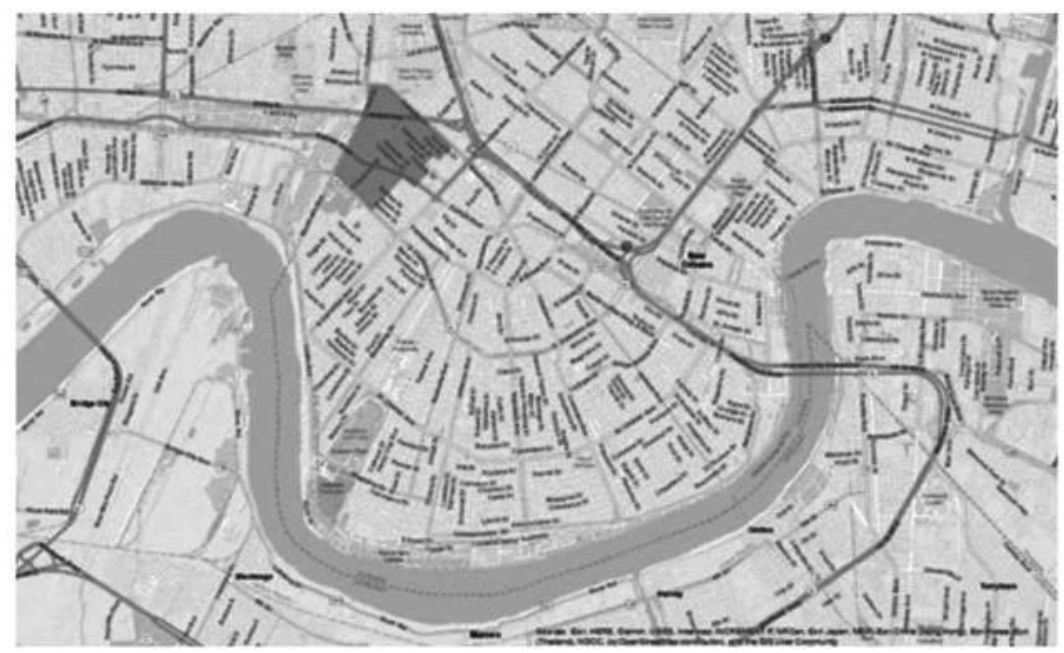

a

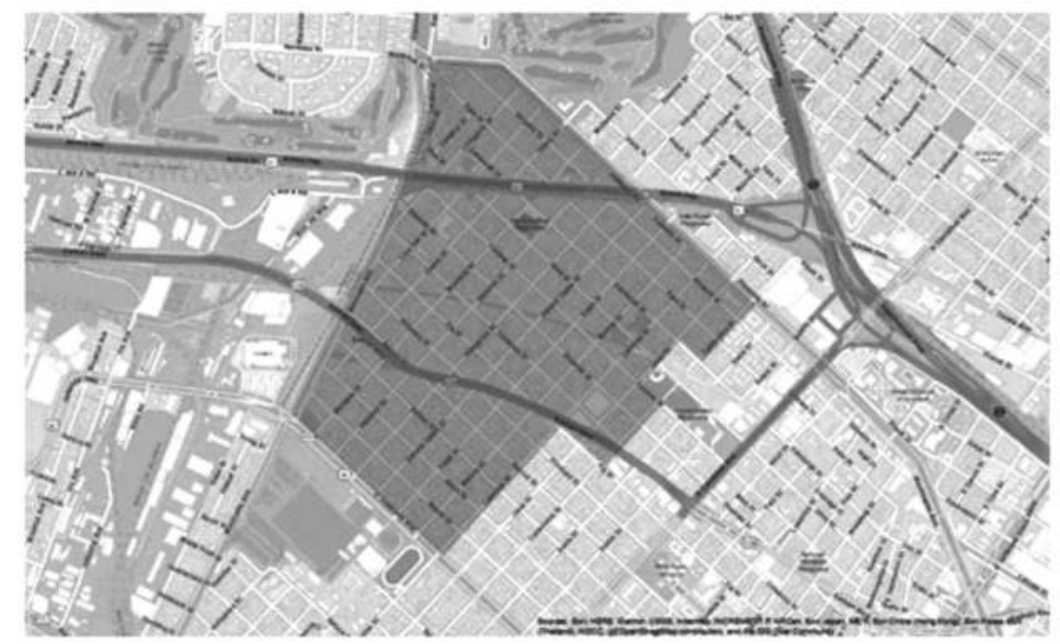

b

Figure 20.1 (a) Hollygrove neighborhood in relation to New Orleans CBD. (b) The Hollygrove neighborhood boundaries.

Source: Extracted from ESRI (2019).

$\$ 59,424$ in 2016 being higher than the New Orleans' median income $(\$ 38,681), 39$ percent of Hollygrove population still lives below the poverty level (City-Data.com, 2016).

Hollygrove homes had front porches where residents once socialized with each other, but by 2005 much of that social activity had dissipated due to 
high crime and fear. Each year there were over a dozen murders in the community, shootings were common and drug dealing was rampant (Childs, 2009).

For many years Hollygrove was a community where residents were too fearful to go outside to enjoy their neighborhood due to illicit drug dealing and shootings. In particular, children were vulnerable from gang activity and seniors were trapped inside their homes too fearful to regularly use the nearby convenience store or parks. Fear is a powerful motivator for residents to remain aloof and alienated from local life and they are not likely to work together to resolve their own problems in such conditions. In such a place, residents remove themselves from their environment and resort to calling municipal authorities to respond and repair problems that arise.

Unfortunately, the quality of New Orleans municipal services is ranked among the lowest of 150 major US cities (McCann, 2018), it has a consistently high municipal debt (City of New Orleans, 2015a), and the murder rate is among the highest in the country (FBI, 2015). This results in a municipality that cannot fully service areas such as Hollygrove, leaving the neighborhood with decades of infrastructure and service neglect. Roads and sidewalks are in disrepair, street lights are out of service, abandoned homes remain blighted and police services have been sub-standard. Additionally, until recently, the police department had a long history of corruption and distrust by residents (Ramsey, 2015; Walker, Alpert, \& Kenney, 2001).

In such conditions, fear, understandably, becomes the common denominator among residents which both limits their enjoyment and safety, and also traps them behind the walls of their homes. The socio-cultural backcloth coupled with decades of neglect, led to local attitudes of mistrust and apathy towards municipal government; people simply did not think anyone was going to help improve their quality of life. In addition to these poor livability conditions, in 2005, Hollygrove was also devastated by a severe natural disaster.

Hurricane Katrina struck New Orleans in August, 2005 creating a disaster of major proportion with over 1,800 deaths and 108 billion US dollars in property damage (Zimmermann, 2015). Prior to the hurricane, the neighborhood had 6,919 residents living in 2,655 households (The Data Center, 2018), mostly small, raised bungalow homes (Tudor, 2018). Approximately 1,000 (17 percent) residents permanently left their homes in the aftermath of the storm and with population rising to around 5,851 residents and 2,116 households by 2016, Hollygrove never regained its pre-hurricane population levels (The Data Center, 2018).

Since hundreds of Hollygrove residents never returned in the years following the hurricane, hundreds of homes in the neighborhood were either condemned as unlivable or left with significant storm damage. Moreover, when residents returned to rebuild their neighborhood, the violence, gangs and fear that existed prior to the Hurricane also returned. That is the historical context in which AARP chose Hollygrove as a place to apply their new livability policy and the SafeGrowth program as a means to accomplish that. 


\subsection{Methodology}

\section{Research design}

Case study

A case study is both a research design and method of analysis (Yin, 2012). It represents a common methodology in social sciences especially for examining poorly understood phenomena such as neighborhood capacity building in disadvantaged communities. In our study we integrated surveys, site observations, informal interviews, field research, and fear and crime data to analyze in detail the Hollygrove residents' journey of building resilience.

We also chose this method because findings from case studies provide a rich starting point for generating and testing the hypotheses relevant for real-life practice, an approach that helps advance theory (Flyvbjerg, 2011; Stake, 1978). Our study follows a long line of case study research from the earliest human ecology studies that employed site observations (Hughes, 1943), to interviews about resident attitudes and fears of crime (Whyte, 1943).

\section{Action research}

Because of its change-oriented methodology, Action Research (AR) was an ideal companion to this case study and a leading methodology for guiding and understanding the Hollygrove residents' journey towards building resilience. Action research is characterized as a systematic way to investigate and solve local problems that affect people in their everyday lives (Stringer, 2014).

In $\mathrm{AR}$, researchers and participants (participants are those who reside and work in the study area) form teams to solve problems of direct relevance to participants while improving practice and advancing theory. The collaborative team process is inherently participatory and democratic (Carr \& Kemmis, 1983) with team participants identifying their own problems and solutions that are relevant for them while the researchers help provide direction without taking over (Stringer, 2014).

As AR proceeds it is often necessary for teams to refine solutions, therefore the process is repeated in a cyclical fashion (Figure 20.2). Such an iterative approach helps enhance the team's understanding of the problem and deepens the commitment to engage in action.

The action-based form of research extends back to early theorizing in criminology, particularly work from the early ecological studies of the last century that signaled a shift from passive and non-interventionist studies to change-focused research in social practice (Lewin, 1946). In fact, references to ecological studies in criminology are not possible without some reference to studies from the University of Chicago's sociology program. Thus, our use of a case study with action research clearly aligns with the early ecological traditions in crime theorizing, and we concluded it was ideally suited to study the complex socio-cultural conditions that existed in Hollygrove prior to, and following, Hurricane Katrina. 


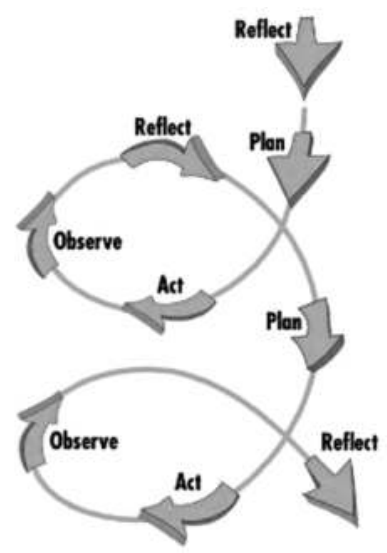

Figure 20.2 The basic action research cycle.

Source: Center for Education Innovation, The Hong Kong University of Science and Technology (n.d.).

\section{Research procedure}

The AR cycle, in SafeGrowth also termed action-based practice (Hodgkinson \& Saville, 2018), provides a roadmap for both a research procedure and a method to apply problem-solving strategies. Action-based practice contains the objective of teaching the participants skills crucial for community capacity building.

The first opportunity to rebuild the neighborhood and tackle crime problems emerged when the residents were approached by the Louisiana chapter of the national non-profit organization, AARP. The AARP had recently expanded its mandate to help provide livable communities for seniors (AARP, 2018) and, in the case of Hollygrove, that meant reducing crime.

Of all the steps and actions the residents undertook throughout the process, one of the most important included collecting data and information continually throughout their project work, a process that helped them generate and then refine strategies to achieve the objective of safety and livability. This is an important iterative element of action-based practice since, due to the natural cycles in city politics, funding and land development policies, not all strategies will have permanent lifespans and may need modification. This was the case with a program called the Hollygrove Market and Farm, described below.

SafeGrowth in Hollygrove followed some research and action steps common for all AR:

1. REFLECTION on current environment by residents and AARP.

Residents and AARP originally met and began to explore the extent of fears in the neighborhood and the perceptions of residents. The initial meetings allowed AARP to identify stakeholders for future planning and the kinds of 
expertise required in the neighborhood. This included a realization there was very little knowledge of crime prevention programming, a crucial skill lacking in Hollygrove.

2. PLANNING initial meetings with neighbors to map out problems and strategies.

AARP and residents worked together to identify strategies to improve livability. However, it became clear that the issues of high crime and fear were well entrenched and generic programs focusing only on quality-of-life, such as walkability and recreation, would not suffice. Thus, an analysis on crime and safety, and training in crime prevention, was critical prior to any programming on livability. A decision was made to implement both community leadership training (the Livable Communities Initiative) and also CPTED training (part of SafeGrowth workshops) as a part of livability programming.

3. ACTION: AARP launches the Livable Communities Initiative.

To initiate the process, from November 2008 to April 2009, AARP partnered with Louisiana State University (LSU) and developed a "Livable Communities Academy". This comprised a series of short workshops to teach leadership and engage residents. The participants (i.e., "community of practice") voluntarily participated in these weekly workshops and were later pivotal in leading change in Hollygrove.

Additionally, AARP reached out to one of the authors of this chapter (Saville) requesting CPTED training and they were advised how the social aspects of CPTED, termed Second Generation CPTED, were a crucial part of neighborhood change. The combination of First Generation CPTED, Second Generation CPTED, livability programming, and AR, helped further refine SafeGrowth as a neighborhood planning system.

One positive result from this early work involved problems with official crime reporting. As the AARP began to provide initial programming it became clear under-reporting of crime and distrust of police was a major issue. AARP assembled a Crime and Safety project team with local residents and this led to "hotsheets", one of the first initiatives to address crime:

... a decades long history of mistrust in the local police kept residents from sharing information. The Crime and Safety project team developed what was called a 'Safe Drop' hotsheet that provided an anonymous method for sharing tips. The hotsheets were dropped at every door in the neighborhood with a stamped envelope that the residents could mail directly to their local police precinct or to churches that were participating. Within a month of the hot sheet program, the New Orleans Police Department collected enough evidence to identify an active shooter in the neighborhood and arrest him ... With the arrest of the active shooter, residents said that gunfire in the neighborhood began to drop almost immediately.

(Tudor, 2018, pp. 121-122) 
4. ACTION: Technical assistance and crime analysis, prevention and CPTED training.

One preliminary step for providing technical assistance in SafeGrowth/ CPTED during the summer of 2009 was posting a research assistant to directly work with AARP in Hollygrove. This assistant worked on the ground to help analyze crime, and fear of crime, information. That research later produced fear of crime maps within Hollygrove that helped teams more effectively target their efforts onto high fear and crime areas in the neighborhood.

In August of 2009, subsequent planning and training steps commenced in the form of training in First and Second Generation CPTED. The teams later used their skills to identify and tackle most pressing safety concerns and developed plans for improvement.

5. ACTION: Subsequent data collection, site visits and safety audits.

Groups from the CPTED training were tasked with developing a series of field projects to build their capacity to solve crime and fear problems. The strategies they adopted included enhancing the physical environment with clean-ups, better lighting, and dealing with abandoned buildings. The physical changes were combined with social strategies, such as community events and recreational programs, to enhance both territorial control and emphasize collective efficacy.

6. OBSERVATION: On-going observation by residents.

As implementation of various strategies proceeded, the residents' observations were crucial for informing the implementation process. In traditional crime analysis, researchers need to wait for reported incidents, for written police reports, and then data collection in order to analyze results. That process could easily take weeks, and often months. Of course, that means throughout implementation, if some strategy was ineffective, such as lighting outside a local bar, additional alcohol-related crime would occur and people would continue to be victimized. In the AR method, that is considered an unacceptable wait time and therefore daily site observation by residents, along with AARP staff, was crucial for assessing preliminary results.

7. REFLECTION: Reflection on results by residents and researchers, and subsequent planning and meetings to refine strategies.

As observations were reported to various Hollygrove teams, the participants were able to reflect on the progress of their strategies. For example, in 2009 their recommendation for improved lighting by the city municipality was met with resistance and red tape. After a number of months, when no new lighting appeared on their streets (and a homicide took place at a high crime bar in the neighborhood), residents acted on their own. They obtained support from a local church to pay for a spotlight, installed their spotlight across from the high crime bar, and watched as night-time crime outside the bar subsided. In 2011 they refined their approach and solicited the help of local police and justice officials to raid the bar thereby uncovering an illicit drug operation, allowing them to permanently remove the bar license and close the property. 


\section{REPEAT CYCLE}

In Hollygrove, AR proceeds in a cyclical fashion and this was reinforced between first SafeGrowth/CPTED training in August 2009 and a second SafeGrowth/CPTED training in July 2010. Technical assistance was requested for both analysis and for promoting the work to the municipal leadership and, in December 2011, some of the new Hollygrove community leaders presented their results to the larger community. Repeating AR cycles in this way helped promote their successes, such as the Soul Steppers senior's walking club concept that ended up spreading through neighborhoods across the whole city (see description below).

\section{Data and methods}

Data and methods presented in Figure 20.3 show the types of information that were collected and analyzed by the residents and researchers.

\section{Surveys}

From the launch of project work in 2008, AARP conducted an independent survey to identify the extent of the problem since they could not rely on official statistics. They discovered that, as residents returned after the Hurricane, so too had the crime problems. In that year, there were eight murders and 28 shootings, slightly lower than pre-Katrina levels but still catastrophic for a community of fewer than 6,000 residents (Tudor, 2018, p. 122).

\section{Site observations}

As the residents became involved in Livability Academy and SafeGrowth training, they were tasked with taking ownership over observing the neighborhood

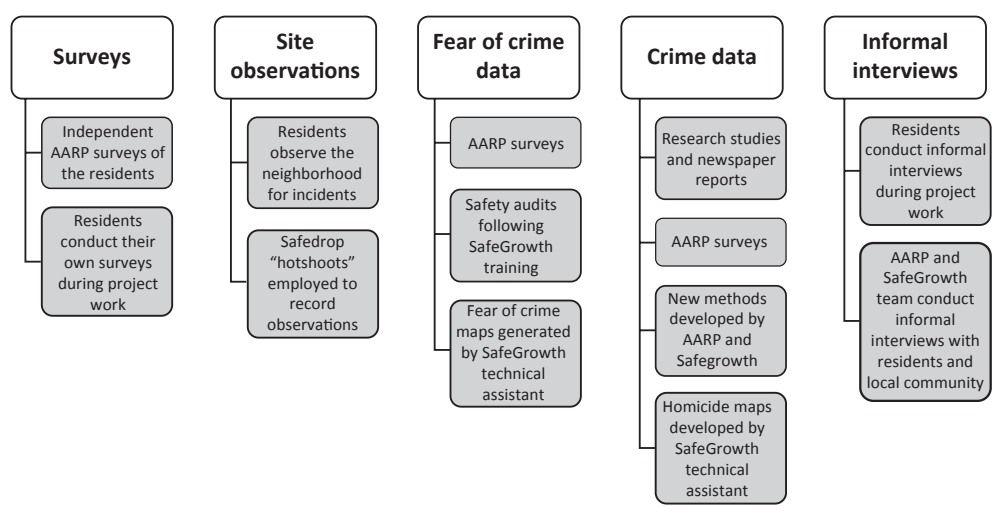

Figure 20.3 Data and methods used in Hollygrove.

Source: Authors. 
for safety concerns so they could better understand and tackle the problems. They also developed safe drop hotsheets described above.

\section{Fear of crime data}

AARP collected fear-of-crime data during their initial surveys of the residents. This approach was then expanded through the use of safety audits and that allowed collection of micro-spatial information. A SafeGrowth research assistant was able to help analyze this information that culminated in a number of crime fear maps such as the one in Figure 20.4.

\section{Crime data}

Area-specific homicide data were very difficult to obtain for the Hollygrove neighborhood. There were serious problems with under-reporting (Tudor, 2018), and the New Orleans police did not use geocoding prior to Hurricane Katrina.

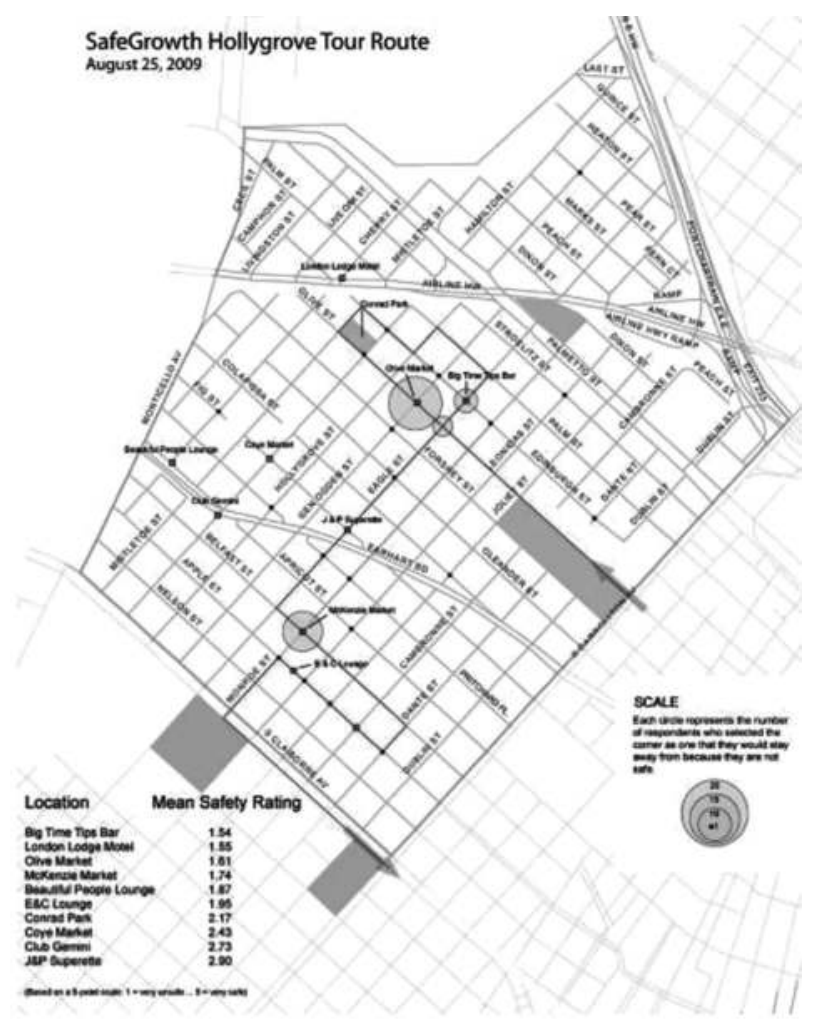

Figure 20.4 Map showing locations of high fear levels.

Source: Authors. 
However, one research study (Childs, 2009) did offer some insight regarding homicides in the years immediately preceding the hurricane. From that study we extracted partial homicide data for both New Orleans and Hollygrove for the three-year period prior to the hurricane, from 2002-2004. For 2015-2017 (the three most recent years following the majority of the capacity building work) we referred to the New Orleans Police Department's public data (City of New Orleans, 2019). With such a limited dataset of small sample sizes we cannot use parametric methods with any confidence to assess the shape of data distribution.

Prior to the hurricane, Hollygrove suffered high crime and it seemed to be getting worse. This is reflected in Table 20.1, showing a 15 percent increase in homicides in Hollygrove compared with a 2 percent increase in the rest of the city. It also suggests that Hollygrove generated a significant homicide hotspot ( 5 percent of all city homicides), when Hollygrove's population was only 1.4 percent of the whole city (Plyer, 2016).

We also examined crime and homicide statistics available on the City of New Orleans' website to observe for homicide trends in the years 2015-2017. We report these finds in the results section in Table 20.1.

Other crime data specific to Hollygrove were also collected through the initial AARP surveys and later through implementation of hotsheets and through the assistance of a SafeGrowth technical expert who also analyzed and graphically represented the data (Figure 20.5).

\section{Informal interviews}

Informal interviews with the residents revealed they were fearful of going outside their house for everyday tasks such as walking to complete errands or to use public transport. One of the training participants following the hurricane said, "you can't be healthy if you're afraid to go outdoors", revealing that fear of crime has much wider implications for quality of life. This realization later culminated in one of the first projects-Soul Steppers-a senior's outdoor walking club.

Informal interviews were also a suitable method for gathering information about the success stories following the completion of SafeGrowth programming. By hearing from the residents either directly or through AARP

Table 20.1 Reported homicides for New Orleans and Hollygrove neighborhood 2002-2004

\begin{tabular}{lrrrc}
\hline Reported homicides & 2002 & 2003 & 2004 & \% change \\
\hline New Orleans (City) & 258 & 274 & 264 & +2 \\
Hollygrove & 13 & 11 & 15 & +15 \\
\hline
\end{tabular}

Note

Data extracted from "A New Orleans state of crime: spatio-temporal analysis of shifting homicide patterns in post-hurricane Katrina New Orleans, LA” by L. Childs (2009). 


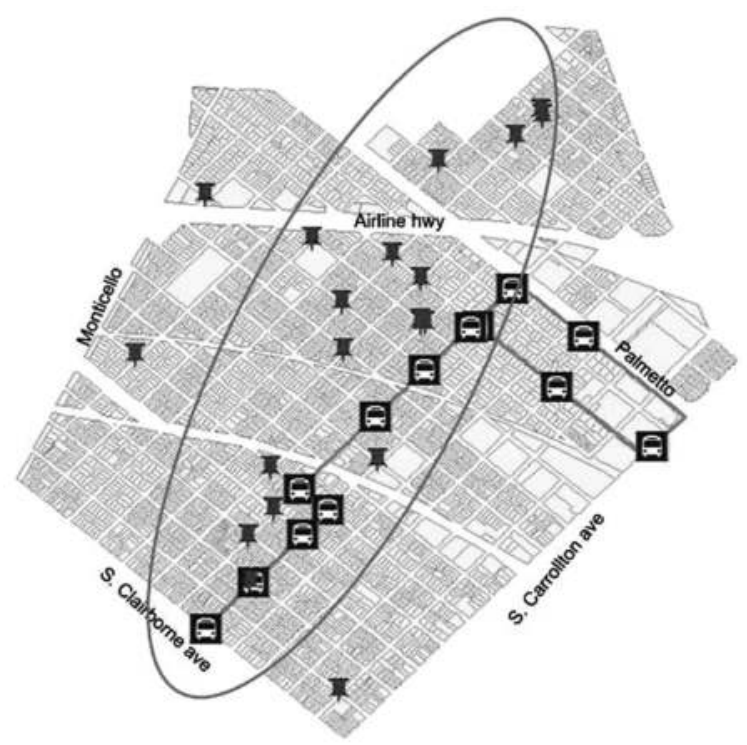

Figure 20.5 A map showing bus stop-homicide correlates.

Source: Authors.

we were, for example, able to obtain information about the residents' resistance to the city's proposed rail development, described below in the results section.

\subsection{Results}

\section{Project work to address crime and fear}

\section{Soul Steppers}

One of the first and most impactful strategies included an often-forgotten population-seniors. A group of Hollygrove Seniors on the Health Committee realized the importance of walking to ensure physical activity and also for reclaiming their streets. They formed a senior's walking group called "Soul Steppers" and they started with the Walks Against Crime program as a way of addressing open-air, street drug dealing. The residents quickly realized there was an association between health and safety. They observed that the walkers dissuaded drug dealers from selling drugs at street corners and therefore took back ownership over the streets (Edmondson, 2010).

The initiative began in 2009 with fewer than a half-dozen participants, but then quickly grew in size and scope to over 100 people, not only in Hollygrove, but across the entire city. By 2012 there were 14 Soul Stepper groups throughout New Orleans (Sisco, 2012). 


\section{Clean-ups and abandoned buildings}

Abandoned buildings were a significant blight on the neighborhood, especially following the hurricane when owners were unable to afford home repairs. As a result, properties fell into further disrepair, grass and weeds were overgrown in their yards, and dealers would use such properties to sell illicit drugs. There were two different strategies residents used to address clean-ups and abandoned buildings.

First, residents simply began sharing resources such as lawn mowers, and began mowing the overgrown lawns on abandoned properties. They collected litter on these properties until owners eventually managed to make repairs or the city tore down the building. This helped clean up unsightly landscaping on their streets and contributed to a stronger sense of territorial control.

The second strategy concerns abandoned buildings used for illicit drug dealing. The Crime and Safety team located one derelict drug house and decided to have it demolished. They were able to launch a process to have the building officially demolished. Three months later, when that finally occurred, one resident commented:

We've been trying for years to get the house demolished next to me, and AARP came in and we went down to City Hall in groups ... cause it was a big crack house and I lived next to it. And I thank God and AARP for helping to get it [torn] down.

(The Policy Research Group, 2010, p. 16)

Today, residents use the property to host block parties and picnics.

\section{Local crime hotspot}

For many years a local bar known as "Big Tips" had been a drug dealing location and a violence generator. In 2009 there were three shootings and one murder (Tudor, 2018, p. 123). The neighborhood made several unsuccessful attempts to get the city to repair a streetlight across from the bar where street fights from the bar would occur. The Trinity Community Center, including a local church Pastor who participated in the CPTED trainings, obtained funds and then installed their own sodium light pointing at the offending location.

Violence and fights significantly declined at that location. However, when another shooting occurred in the following months, residents followed up and collaborated with the Federal District Attorney and the Louisiana Alcohol and Tobacco Department, and a police raid led to the revocation of the bar license (Eggler, 2012). When the bar finally closed permanently, shootings and violence around that corner were eliminated (Tudor, 2018).

\section{Other projects for long-term redevelopment}

All the early project work triggered dozens of other short and long-term initiatives in the years following the first team projects. In one case, the Economic 
team obtained temporary use of an independently owned, community farm, turning it into a learning and money-generating center named Hollygrove Market and Farm for a Hollygrove weekly vegetable market that was sought out by patrons from across New Orleans (Kato, Passidomo, \& Harvey, 2014). The farm lasted a decade and created numerous economic and learning opportunities for families and children in Hollygrove (McNulty, 2018). Eventually, the land was sold for other purposes by the land owner, however, by that point there were dozens of initiatives and programs underway and, as yet, there seems to be no negative impact on crime.

One of the most dramatic projects was the residents' effort to save an historic seniors' center. In the years immediately following the hurricane, there were few facilities or amenities open for residents. This was especially acute for seniors who once had access to a seniors' center that was now derelict and slated for demolition. The Hollygrove Livability teams, as well as groups throughout the neighborhood, chose to petition the municipal government to save the center and allocate funds for repairs. While there was initial resistance, as the capacity of local groups expanded into a more sophisticated influence on municipal politics, it became clear that ignoring Hollygrove yet again was not going to happen. As a result, municipal politicians rallied behind the initiative and, in 2015, a new \$3.4 million dollar, Carrollton Hollygrove Senior Center opened with 11,600 square feet of space with dining rooms, library, computer room, classrooms, arts and crafts, and medical facilities (Webster, 2015).

\section{Rebuilding for long-term resilience}

The cumulative effect of these various Second Generation CPTED projects was to gradually transform a high-crime neighborhood into a more livable community for residents. There has been a marked improvement in fear and violence, as indicated in Table 20.2.

A decade following the hurricane there is a significant decrease in crime in Hollygrove, which is partially reflected in Table 20.2 showing a 66 percent decrease in homicides for Hollygrove versus a 4 percent decrease in the rest of the city. Hollygrove no longer generates a homicide hotspot for New Orleans as it is currently less than 1 percent of all city homicides. Hollygrove residents also report in local forums dramatic declines in crime and violence (Morris, 2012).

Table 20.2 Reported homicides for New Orleans and Hollygrove neighborhood 2015-2017

\begin{tabular}{lrrrr}
\hline Reported homicides & 2015 & 2016 & 2017 & $\%$ change \\
\hline New Orleans (City) & 164 & 174 & 157 & -4 \\
Hollygrove & 3 & 4 & 1 & -66 \\
\hline
\end{tabular}

Note

Data extracted from "New Orleans police department: Data and dashboards" by City of New Orleans (2019). 
Because this action-based practice employed a more holistic focus, there were lasting impacts on other types of neighborhood development that negatively impact their quality of life. For example, when a rail company proposed plans to government officials to significantly expand rail traffic through the Hollygrove neighborhood, residents took action (Mock, 2014). This rail expansion would have detracted from the quality of life in Hollygrove due to health issues from air and noise pollution, reduced property values and risks of derailments of hazardous materials. Hollygrove residents, already familiar with how to organize and develop action plans, were able to mobilize a campaign and stop the development.

Although the rail expansion initiative seems unrelated to crime and fear issues, it is notable for two reasons: first, prior to the capacity building work there were few such efforts by Hollygrove to mobilize for their own political health and safety. But once the residents presented a common voice to City Hall, the Council passed a resolution and stopped the new rail development (City of New Orleans, 2015b). Second, community crime prevention programs often stall when programmers fail to activate residents or when local groups lose interest. In Hollygrove, program work continued for years.

\subsection{Discussion of the results}

The case study here tracks changes in Hollygrove, New Orleans, following the devastation of Hurricane Katrina in 2005. It describes the journey of neighborhood residents as they aimed to repair their neighborhood, reduce crime and fear, and build their own capacity to solve future problems-a process of neighborhood activation.

This case study shows how community capacity building helped transform Hollygrove into a more resilient neighborhood due to a few determined Hollygrove leaders, the work of an engaged non-profit organization-the Louisiana chapter of AARP - and training in Second Generation CPTED and SafeGrowth by crime prevention specialists.

\section{Lessons from Hollygrove}

There are three essential lessons emerging from the Hollygrove study.

First, engaging residents and activating neighborhoods for crime prevention is not a straightforward process. When residents are fearful of their own streets and shootings are regular events, program development can stall and fail. In such an environment, simplistic strategies are at risk of failure, such as expanding police patrols without community engagement, or implementing simple and isolated CPTED tactics such as lights and access controls.

Social infrastructure is important, especially considering the critical role of social capital and social networks in driving resilience (Aldrich \& Meyer, 2015). Social infrastructure does not just happen; it requires social programming that provides ample opportunities for residents to work together and reduce opportunities and 
motives for crime (Cleveland \& Saville, 1997). In Hollygrove this became evident when crime continued to increase until the involvement of AARP and specialists in SafeGrowth and Second Generation CPTED who offered a systematic approach to problem solving and capacity building. Ohmer and Beck (2006) describe how neighborhood organizations can establish wide-reaching positive social relationships to building collective efficacy and establish informal social controls. In the case of Hollygrove, participants established a core for relationship-building that rebuilt social infrastructure for sustained success.

Second, Hollygrove's resilience and capacity for action emerged from an AR methodology. This proved crucial for understanding the crime and fear problems and for stimulating change in the neighborhood. Action-based practice relies on residents themselves and their native intelligence (Hodgkinson \& Saville, 2018; Stringer, 2014). This is especially important in communities such as Hollygrove that struggle with inequality, socioeconomic and racial disadvantage, conditions that negatively influence collective efficacy and increase violence (Sampson, 2004; Sampson \& Raudenbush, 2001; Steenbeek \& Hipp, 2011).

The most effective way of addressing crime problems in a neighborhood such as Hollygrove is by directly engaging the residents and providing them with resources, such as funds and police support, and training in crime prevention. However, as the research literature and this case study demonstrate, those traditional practices are, in themselves, insufficient to produce sustainable results. The AR methodology ensures that the residents themselves, in partnership with researchers and practitioners, are the principal stakeholders in both research and action. For neighborhood programming to have an effect, the solutions need to address the problems identified by those affected by them (Mihinjac, 2018).

Disadvantaged communities are especially faced with challenges such as fear of crime, poor citizen participation and a lack of community organizing skills. For such places, participation in activities that build strong interpersonal relationships is crucial; only then can a group effectively work together on an ongoing basis (Speer \& Hughey, 1995). Addressing specific problems is important; however, concurrently the teams also develop relationships to sustain their work. As the Hollygrove teams developed their projects they directly and indirectly addressed crime and fear problems while they concurrently built ownership, ongoing capacity and relationships.

Third, neighborhood activation occurred when small-scale projects served as a catalyst for long-term action, which is especially important in places of concentrated disadvantage. Hollygrove residents started with small projects, which amounted to big changes over time.

It became apparent that, following the hurricane, poverty and racial inequality in the city influenced recovery and the amount of resources invested in individual neighborhoods. Hollygrove was one of the neighborhoods that originally received little government support (Hobor, 2015), illustrating how concentrated disadvantage was a major factor contributing to increases in 
violent crime in the first few years following the hurricane (Weil et al., 2019). The fact that disadvantaged communities cannot rely on local governments for assistance increases the impotence of neighborhood activation through empowerment and partnership strategies.

Despite official polices for empowering communities, this is poorly realized in practice (Head, 2007; Mowbray, 2005). Many authorities seem to fear transferring power to the community and are instead driven by higher level politics. As a result, citizen empowerment suffers, especially since governments usually rely on programs that do not focus on social relationships between the residents (Speer \& Hughey, 1995) and fail to establish skills that lead to community capacity building (Lowndes, Pratchett, \& Stoker, 2001).

This is why community capacity building for resilient neighborhoods must focus on small-scale action-based projects based on residents' own neighborhood conditions. When authorities rely on actions from those outside the community, they create dependency relationships in which residents of disadvantaged communities repeatedly seek outsiders for action (Cuthill \& Fien, 2005; Kretzmann \& McKnight, 1993). The Hollygrove case study illustrates how neighborhood activation happens when residents and prevention practitioners participate in intense levels of collaborative problem-solving (Mihinjac, 2018).

Our findings are echoed by both Brown's (2016) work on homicide in Hollygrove and by Sampson's (2012) collective efficacy research in Chicago:

Sampson (2012) recommended that effective violence interventions, instead of being targeted toward individual offenders, should instead address efforts to restore at-risk communities by improving both the physical and social infrastructure... These findings are similar to some of the homicide solutions proposed by Hollygrove residents.

(Brown, 2016, p. 241)

\section{Displacement and costs}

There was no independent measure of crime displacement in this study, primarily because crime data early on were not in a form that allowed a pre-test/ post-test examination. Consequently, the possibility of displacement does exist; however, in the larger municipality of New Orleans, city-wide crime rates for a majority of crimes in the past decade have either plateaued or experienced slight drops (Asher, 2016). Unfortunately, this is difficult to assess since recent research suggests that statistical methods of displacement analysis have been far from accurate and may even produce spurious results that distract from other crime prevention effects (Hodgkinson, Saville, \& Andresen, 2020).

Regarding costs for the various Hollygrove capacity building initiatives over a decade, it is difficult to parse a specific figure for crime prevention strategies versus community development. However, some initial funding 
during the launch of livability and SafeGrowth planning in the first few years included grants of $\$ 410,000$ from AARP and a private, non-profit foundation (Tudor, 2018). Following that initial funding, resources flowed into the neighborhood from a wide variety of municipal agencies and community-based initiatives, from local economic strategies such as the Hollygrove Farm (that accrued over $\$ 1,000,000$ in gross yearly revenue for use within the neighborhood), to municipal and education agencies that funded the reopening of an elementary school and community center (Tudor, 2018).

\subsection{Conclusions and recommendations}

This study has some important practical and theoretical contributions related to the use of capacity building to enhance collective efficacy. Hollygrove demonstrates the importance of methods such as SafeGrowth and SecondGeneration CPTED for expanding social infrastructure and building collective efficacy. The test of such methods rests in Hollygrove where improved physical infrastructure, new and enhanced social programs, local economic development, and reduced crime and fear, remain part of the Hollygrove experience today.

\section{Limitations}

A SafeGrowth planning system was utilized in Hollygrove in the form of Second-Generation CPTED, the community training embodied in the Livability Academy, and other capacity building tactics employed through AR. However, adopting AR as a research methodology, or SafeGrowth as a way to implement neighborhood planning, presented some limitations worth considering in future studies:

- One limitation of the AR approach is that it has a much longer time-frame than many social science case studies. In the Hollygrove example here the project extended almost a decade.

- Another limitation was that existing police-based quantitative data were either non-existent for the New Orleans police department (which only after this study commenced collecting more comprehensive crime data), or problems with under-reporting due to poor community-police relations.

- A third limitation is that AR projects require specialized knowledge to establish an AR methodology in which residents and researchers collaborate to co-design the research and co-plan response strategies. Collaborative data collection, research, and planning with residents is not an easy process and in SafeGrowth a considerable amount of attention is spent on establishing effective action-based practice (Hodgkinson \& Saville, 2018) and activating resident participation (Mihinjac, 2018). 


\subsection{Recommendations for future research and practice}

The AR methods applied in Hollygrove, within the framework of the SafeGrowth planning system, offer the prospect of expanding existing theory while at the same time developing practical strategies for local neighborhood residents to improve conditions in their neighborhood.

The second recommendation, is that quantitative data analysis, while critical for evaluative and cross-sectional studies, remains an important, but not a necessary, pre-requisite within AR. There is no doubt quantitative data will greatly enhance the examination of ex post facto case study results, especially for measuring crime displacement. However, even without a rigorous quantitative data collection and analysis methodology, AR still provides researchers with the opportunity to collect different forms of data, assess theory, and implement real-world strategies to reduce crime.

A third recommendation is that funding for high demand, poor neighborhoods such as Hollygrove, rarely exists to collect independent quantitative data. This is the case in all kinds of research but the difference in AR is that a lack of quantitative data does not handicap researchers from working with residents on other forms of data, such as informal interviews and observations. Because the AR methodology is based on building networks from both those who reside in troubled neighborhoods and those agencies that service them, alternative resources for funding often emerge within the neighborhood and within the larger community.

\section{Note}

Maps in Figure 20.1 were created using $\operatorname{ArcGIS}^{\circledR}$ software by Esri. ArcGIS ${ }^{\circledast}$ and $\operatorname{ArcMap}^{\mathrm{TM}}$ are the intellectual property of Esri and are used herein under license. Copyright (C) Esri. All rights reserved. For more information about Esri ${ }^{\circledR}$ software, please visit www.esri.com.

\section{References}

AARP (2018). AARP Livability Index, June. http://livabilityindex.aarp.org/categories/ neighborhood (accessed 13 January 2019).

Abramovic, F., \& Van Dusen, R. (2004). Second Generation CPTED: The Case of North Central, Breaking Down the Barriers. Presented at the 9th Annual Conference of the International CPTED Association, held 13-16 September 2004, Brisbane, QLD.

Aldrich, D. P., \& Meyer, M. A. (2015). Social capital and community resilience. American Behavioral Scientist, 59, 254-269.

Asher, J. (2016). NOLA crime News-Historical Statistics. https://nolacrimenews.com/ statistics/historical-statistics (accessed 13 January 2019).

Brown, K. J. (2016). You could get killed any day in Hollygrove: A qualitative study of neighborhood level homicide. [Doctoral Dissertation]. New Orleans, LA: University of New Orleans.

Burgess, E. W., Lohman, J. D., \& Shaw, C. R. (1937). The Chicago Area Project: Coping with Crime. New York: National Probation Association.

Carr, W., \& Kemmis, S. (1983). Becoming Critical: Knowing through Action Research. Waurn Ponds, VIC: Deakin University Press. 
Center for Education Innovation, The Hong Kong University of Science and Technology. Action Research (n.d.). http://cei.ust.hk/teaching-resources/action-research (accessed 29 January 2020).

Chicago School of Sociology (n.d.). http://sociology.iresearchnet.com/urban-sociology/ chicago-school-of-sociology (accessed 13 January 2019).

Childs, L. (2009). A New Orleans state of crime: spatio-temporal analysis of shifting homicide patterns in post-hurricane Katrina New Orleans, LA. [Master's thesis]. New Orleans, LA: University of New Orleans. http://scholarworks.uno.edu/td/974 (accessed 17 January 2019).

City-Data.com (2016). Hollygrove neighborhood in New Orleans, Louisiana (LA), 70118 detailed profile. www.city-data.com/neighborhood/Hollygrove-New-OrleansLA.html (accessed 10 January 2019).

City of New Orleans (2015a). Comprehensive Annual Financial Report. New Orleans, LA: Finance Department of the City of New Orleans. www.govwiki.info/pdfs/General\%20 Purpose/LA\%20New\%20Orleans\%202015.pdf (accessed 10 January 2019).

City of New Orleans (2015b). Resolution No. R-15-323. https://cityofno.granicus.com/ MetaViewer.php?view_id=3\&event_id=518\&meta_id=292564 (accessed 10 January 2019).

City of New Orleans (2019). New Orleans Police Department: Data and Dashboards. www.nola.gov/nopd/data/ (accessed 10 January 2019).

Cleveland, G., \& Saville, G. (1997). Second Generation CPTED and School Safety. Presented at the 2nd International CPTED Association Conference, 2 December, Orlando, FL.

Cozens, P. (2007). Planning, crime and urban sustainability. Sustainable Development and Planning III, II, 187-196.

Cuthill, M., \& Fien, J. (2005). Capacity building: facilitating citizen participation in local governance. Australian Journal of Public Administration, 64, 63-80.

DeKeseredy, W. S., Donnermeyer, J. F., \& Schwartz, M. D. (2009). Toward a gendered second generation CPTED for preventing woman abuse in rural communities. Security Journal, 22, 178-189.

Edmondson, B. (2010). A Comeback Story in New Orleans. www.aarp.org/homegarden/livable-communities/info-08-2010/a_comeback_story_in_new_orleans.html (accessed 20 January 2019).

Eggler, B. (2012). City revokes license of problem Hollygrove bar Big Time Tips. The Times-Picayune. www.nola.com/politics/2012/05/city_revokes_license_of_proble. html (accessed 13 January 2019).

Federal Bureau of Investigation (FBI) (2015). Crime in the United States, 2014. http:// ucr.fbi.gov/crime-in-the-u.s/2014/crime-in-the-u.s.-2014/cius-home (accessed 17 January 2019).

Flyvbjerg, B. (2011). Case study. In N. K. Denzin \& Y. S. Lincoln (Eds.), The SAGE Handbook of Qualitative Research (pp. 301-316). Thousand Oaks, CA: SAGE.

Head, B. W. (2007). Community engagement: participation on whose terms? Australian Journal of Political Science, 42, 441-454.

Hobor, G. (2015). New Orleans' remarkably (un)predictable recovery: developing a theory of urban resilience. American Behavioral Scientist, 59, 1214-1230.

Hodgkinson, T., \& Saville, G. (2018). Principle 1: action-based practice. In G. Saville (Ed.), SafeGrowth: Building Neighborhoods of Safety \& Livability (pp. 131-140). Scotts Valley, CA: CreateSpace.

Hodgkinson, T., Saville, G., \& Andresen, M. A. (2020). The diffusion of detriment: tracking displacement using a city-wide mixed methods approach. The British Journal of Criminology, 60(1), 198-218. 
Hughes, E. C. (1943). French Canada in Transition. Chicago, IL: University of Chicago Press.

Kato, Y., Passidomo, C., \& Harvey, D. (2014). Political gardening in a post-disaster city: lessons from New Orleans. Urban Studies, 51, 1833-1849.

Kohfeld, C. W., Salert, B. S., \& Schoenberg, S. (1981). Neighborhood associations and urban crime. Journal of Community Action, 1, 37-44.

Kretzmann, J. P., \& McKnight, J. L. (1993). Building Communities from the Inside Out: A Path Toward Finding and Mobilizing a Community's Assets. Chicago, IL: ACTA Publications.

Lavrakas, P. J., \& Herz, E. J. (1982). Citizen participation in neighborhood crime prevention. Criminology, 20, 479-498.

Letch, J., McGlinn, E., Bell, J. F., Downing, E., \& Cook, D. M. (2011). An Exploration of the 1st and 2nd Generation CPTED for End of Year School Leavers at Rottnest Island. Presented at the 4th Australian Security and Intelligence Conference. http://ro.ecu. edu.au/cgi/viewcontent.cgi article $=1012 \&$ context $=$ asi $($ accessed 18 January 2019.

Lewin, K. (1946). Action research and minority problems. Journal of Social Issues, 2, 34- 46.

Lewis, D., Grant, J., \& Rosenbaum, D. (1988). The Social Construction of Reform: Crime Prevention and Community Organizations. New Brunswick, NJ: Transaction Books.

Lowndes, V., Pratchett, L., \& Stoker, G. (2001). Trends in public participation: Part 2Citizens' perspectives. Public Administration, 79, 445-455.

McCann, A. (2018). 2018's Best- \& Worst-run Cities in America. Wallet Hub News. http://wallethub.com/edu/best-run-cities/22869/\#main-findings (accessed 13 January 2019).

McNulty, I. (2018). Hollygrove Market is closing; future of the New Orleans hub for urban farming uncertain. The New Orleans Advocate. www.theadvocate.com/new orleans/entertainment_life/food_restaurants/article_c915ed70-1b31-11e8-be7fc74f9827634e.html (accessed 18 January 2019).

Mihinjac, M. (2018). Principle 3: neighborhood activation. In G. Saville (Ed.), SafeGrowth: Building Neighborhoods of Safety \& Livability (pp. 151-166). Scotts Valley, CA: CreateSpace.

Mock, B. (2014). Train of thoughtlessness: proposed rail line puts NOLA neighborhood on the wrong track. Grist. http://grist.org/cities/train-of-thoughtlessness-proposedrail-line-puts-nola-neighborhood-on-the-wrong-track/ (accessed 18 January 2019).

Morris, R. (2012). Hollygrove activists tout neighborhood's reduction in crime at Tulane forum. Uptown Messenger. http://uptownmessenger.com/2012/02/reducing-crimein-hollygrove-community-panel-at-tulane/ (accessed 21 January 2019).

Mowbray, M. (2005). Community capacity building or state opportunism? Community Development Journal, 40, 255-264.

Ohmer, M., \& Beck, E. (2006). Citizen participation in neighborhood organizations in poor communities and its relationship to neighborhood and organizational collective efficacy. Journal of Sociology and Social Welfare, 33, 179-202.

Olajide, S. E., Lizam, M., \& Adewole, A. (2015). Towards a crime-free housing: CPTED versus CPSD. Journal of Environment and Earth Science, 5, 53-63.

Plyer, A. (2016). Facts for Features: Katrina Impact. www.datacenterresearch.org/dataresources/katrina/facts-for-impact/ (accessed 12 January 2019).

Ramsey, D. X. (2015). How Katrina sparked reform in a troubled police department. The Atlantic. www.theatlantic.com/politics/archive/2015/08/katrina-blew-the-lid-off-thenopd/402814 (accessed 13 January 2019).

Sampson, R. (2004). Neighbourhood and community. New Economy, 11, 106-113.

Sampson, R. (2012). Great American City: Chicago and the Enduring Neighborhood Effect. Chicago, IL: The University of Chicago Press. 
Sampson, R. J., \& Raudenbush, S. W. (2001). Disorder in Urban Neighborhoods-Does it Lead to Crime? (Research in Brief). Washington, DC: National Institute of Justice. www.ncjrs.gov/pdffiles1/nij/186049.pdf (accessed 16 January 2019).

Sampson, R. J., Morenoff, J. D., \& Gannon-Rowley, T. (2002). Assessing "neighborhood effects": social processes and new directions in research. Annual Review of Sociology, 28, 443-478.

Saville, G. (2009). SafeGrowth: moving forward in neighbourhood development. Built Environment, 31, 386-403.

Saville, G., \& Cleveland, G. (2013). Second-generation CPTED: rise and fall of opportunity theory. In R. Atlas (Ed.), 21st Century Security and CPTED: Designing for Critical Infrastructure Protection and Crime Prevention (pp. 91-106). Boca Raton, FL: CRC Press.

Sisco, A. (2012). "Soul Steppers" walking clubs making big strides in New Orleans. The Times-Picayune, 4 March. www.nola.com/health/2012/03/soul_steppers_walking_ clubs_ma.html (accessed 13 January 2019).

Skogan, W. G. (1988). Community organizations and crime. Crime and Justice, 10, 39-78.

Speer, P. W., \& Hughey, J. (1995). Community organizing: an ecological route to empowerment and power. American Journal of Community Psychology, 23, 729-748.

Stake, R. E. (1978). The case study method in social inquiry. Educational Researcher, 7, 5-8.

Steenbeek, W., \& Hipp, J. R. (2011). A longitudinal test of social disorganization theory: feedback effects among cohesion, social control, and disorder. Criminology, $49,833-871$.

Stringer, E. T. (2014). Action Research. Thousand Oaks, CA: SAGE.

The Data Center (2018). Hollygrove Statistical Area. www.datacenterresearch.org/dataresources/neighborhood-data/district-3/Hollygrove/ (accessed 17 January 2019).

The Policy Research Group (2010). AARP/Hollygrove Livable Communities Project Focus Group Report-Project Year Two. New Orleans, LA: The Policy \& Research Group.

Tudor, J. (2018). Hollygrove-back from the brink. In G. Saville (Ed.), SafeGrowth: Building Neighborhoods of Safety \& Livability (pp. 117-128). Scotts Valley, CA: CreateSpace.

Walker, S., Alpert, G. P., \& Kenney, D. J. (2001). Early Warning Systems: Responding to the Problem Police Officer (Research in Brief, July). Washington, DC: National Institute of Justice. www.ncjrs.gov/pdffilesl/nij/188565.pdf (accessed 13 January 2019).

Webster, R. A. (2015). \$3.4M Hollygrove senior center opens. The Times-Picayune, 16 October. www.nola.com/politics/2015/10/34m_hollygrove_senior_center_o.html (accessed 19 January 2019).

Weil, F. D., Barton, M., Rackin, H., Valasik, M., \& Maddox, D. (2019). Collective resources and violent crime reconsidered: New Orleans before and after hurricane Katrina. Journal of Interpersonal Violence. https://doi.org/10.1177/0886260518822345

Whyte, W. F. (1943). Street Corner Society: The Social Structure of an Italian Slum. Chicago, IL: University of Chicago Press.

Yin, R. K. (2012). Applications of Case Study Research. Thousand Oaks, CA: SAGE Publications.

Zimmermann, K. A. (2015). Hurricane Katrina: facts, damage \& aftermath. Live Science, 27 August. www.livescience.com/22522-hurricane-katrina-facts.html (accessed 16 January 2019). 


\section{Safety in the making

An assessment of urban planners'
practices in municipalities in Sweden

Vania Ceccato

\subsection{Introduction}

Shootings, explosions and riots in public places (see Magnusson's chapter in this book and BRÅ, 2015; Ceccato, Li, \& Haining, 2018; Sturup, Rostami, Gerell, \& Sandholm, 2018) in recent years have changed the perception of public areas in Sweden as a safe realm; such events have also affected the image of the country's largest cities, such as Stockholm, Gothenburg and Malmö (Savage, 2019; Watson \& Said-Moorhouse, 2017). Smaller municipalities where low crime rates are often taken as a sign that crime is not a major problem (Ceccato, 2018) also show an impact on safety perceptions. Similar to other municipalities in Europe and the United States, these changes are often dictated by forces far beyond their local reality (Barclay, Scott, \& Donnermeyer, 2011; Barton, Storey, \& Palmer, 2011; Ceccato \& Ceccato, 2017; Woods, 2011). This development is imposing a number of challenges on the professionals in charge of safety issues in these municipalities. The primary pressure is on the police and emergency services, but is also on safety experts and planners who work with places that attract crime or are perceived as unsafe. Yet, there is a lack of knowledge about how municipalities work with safety issues on a daily basis in Nordic countries (but see Ceccato \& Dolmen, 2013; Ceccato \& Pettersson, 2019; Mäkeläinen et al., 2019). Although there is a great deal of international research showing links between the urban environment and safety (e.g., Armitage, 2013; Colquhoun, 2004; Cozens \& Love, 2015), most new property developments in Sweden seems to disregard crime and safety aspects in the construction process. In practice, safety seems to be more often associated with planning of fire hazards and traffic safety than with crime and safety perceptions (Ceccato et al. 2019).

This chapter makes a contribution to this knowledge base by reporting the answers from surveys from 85 percent of municipalities in Sweden collected in Spring 2019. The focus of the study is on the incorporation of situational crime prevention principles into planning practices, and in particular the use of crime prevention through environmental design (CPTED) when designing new areas. Using statistical analysis, this chapter assesses differences in answers from planners in urban and rural municipalities. 
The overall aim with this chapter is to provide an overview of the status of urban planning practices in Sweden with a particular focus on safety issues, by answering the following questions.

1. Is safety incorporated into the planning process by municipalities when it refers to the physical and social environment of public places, and if so how?

2. Which are the most common aspects of situational crime prevention applied by these municipalities? How do the municipalities vary in their safety work? If they cooperate, what type of cooperation do they have and with whom?

3. What are the expectations of planners about the future use of situational crime prevention principles in planning practices, in particular the use of CPTED?

"Crime prevention" refers to any measure designed to reduce the actual level of crime and/or perceived fear of crime. The focus of this chapter is on measures aimed at reducing crime opportunities in a particular location, either during the planning stage of a residential area or when the area already exists. Safety perceptions also depend on the design of the physical and social environments of particular places.

Note that although neighborhood watch schemes, safety walks and other safety participatory initiatives make important contributions to overall safety, they are not the focus of this chapter.

In the next section, we review some of the most relevant theories that link the urban environment with crime and safety perceptions. Then, we present the study area, data and methods, followed by results and conclusions.

\subsection{Theoretical background}

Safety is one of the main concerns regarding public places (Costamagna, Lind, \& Stjernström, 2019) and highly affects their use and accessibility. Therefore, how a public place is designed and managed has a major impact on an individual's safety (Ceccato, 2016). Planning public places is an important municipal responsibility. It is unclear whether and how safety principles are incorporated in new housing developments and plans. Equally important is to deal with public places that already exist and are unsafe or perceived to be so.

Internationally, safety has not been high on the agenda in urban planning. Previous literature has assessed crime prevention initiatives in rural areas as a whole (Ceccato \& Dolmen, 2013; Woods, 2011; Yarwood \& Edwards, 1995), but not with a situational crime perspective. Indeed, in Sweden, it is not well known whether and how the quality of public places is incorporated in crime prevention practices and/or safety improving measures. In the next section, we discuss the theoretical reasons for focusing on situational conditions of crime and fear. 


\section{Situational theories of crime and fear}

The basic argument is that people commit crimes when they perceive a crime as an acceptable course of action in a given circumstance. Interventions that specifically target environmental characteristics will only be effective in preventing crime if they promote changes in how people perceive crime as an alternative in the specific environment (Wikström \& Treiber, 2017). Therefore, the environment has an important role to play in crime occurrence, according to Situational Action Theory (Wikström, 2006). Below we discuss how urban environments can be planned or changed to make crime a less likely alternative for motivated offenders.

Situational crime prevention is about preventing or obstructing crime from being committed by changing the actual situation where crime can occur (Clarke, 1983). Urban design principles can be used to identify criminogenic or unsafe places, map and analyze their dynamics, tackle the problem, assess it and then attempt to solve it. This process is often carried out by police and safety experts, but local actors and members of civil society who live and work in these areas have started to get involved.

One can "think situationally" and "build in" safety from the outset when planning new areas, for example by planning the design of facades, the location of buildings, streets and shops-everything that can affect people's mobility and their ability to act for everyone's safety. The type, function and architectural design of a building influences what happens in the building and in surrounding places. This means that environments can be planned, constructed and modified according to certain design principles that can reduce the opportunities of crime and/or can maximize safety perceptions. This may, for example, involve planning in advance clear boundaries between public and semi-private places and strengthening social control capacities, for example by designing buildings with windows that have an overview of outdoor areas. Crime Prevention Through Environmental Design, or CPTED, (Crowe, 2000, 46) is defined as "the corrected design and the efficient use of the built environment that can lead to a reduction in fear of crime and crime incidents and to an improvement in quality of life". The classic CPTED model is based on a set of principles that provide indications of the quality of the environment from a safety perspective.

CPTED is built around core principles that focus on the physical environment (Figure 21.1), all of which cover a certain part of the situational work against crime. Natural surveillance and access control limit the opportunities for crime. Increased territoriality incorporates higher social control in an area. Proper maintenance, which gives a good image of an area, and activity support assures individuals that the situation is under control and provide them with "tools" to combat crime themselves. Target hardening complements all of these principles by making it even more difficult to commit crimes. CPTED has been extended in recent decades to incorporate other aspects of the social environment and public participation as well as issues of technology and users' perspectives on safety (for details, see Iqbal \& Ceccato, 2016). Safety walks and other 


\begin{abstract}
Natural surveillance is achieved by the use of design to promote guardianship and therefore less crime. Formal surveillance is carried out by local stakeholders, including security guards and shopkeepers (users of the space), whereas informal surveillance is performed by residents and/or transients of a place (Hilborn 2009).

Territoriality refers to how the physical design can develop a sense of ownership in specific areas (Reynald 2015).

In second-generation CPTED, Saville and Cleveland (2008) stated that sense of ownership can help to create the idea of shared standards among different user groups, while in third-generation CPTED, territoriality can be promoted by sharing real-time information about what is happening in the place and in the immediate surroundings. Urban-scale green, sustainable and technologically enhanced design strategies are used to foster the perception of safety in cities (UNICRI 2012).

Access control refers to property control by barriers, enclosures and entry portals. Access control in third-generation CPTED can be related to pedestrian-friendly urban streetscapes (UNICRI, 2012) in smart cities by installation of safety information signs through wireless network transmissions (audio/video).

Target hardening is about how the design of a space can make it difficult for people to steal or damage private and/or public property (e.g. by installing padlocks). Cozens, Saville and Hillier (2005 p.338) warned that overuse of target hardening measures can lead to the development of a "fortress mentality"

Image of the place/Maintenance informs how the esthetic pleasantness of the environment can enhance the perceived safety of the area and keep potential criminals away because well-kept environments show that people are in control of the area.
\end{abstract}

Figure 21.1 CPTED core principles.

techniques under the umbrella "place making" are used to identify and address safety problems, together with residents and other relevant stakeholders.

This chapter reports on results by exploring aspects of diffusion of safety principles by municipalities through the planning practices of urban planners. In particular,

1. whether and how safety is incorporated into the planning process,

2. what planners use as a reference when working with safety issues,

3. how municipalities vary in their work based on whether they are urban or rural, and whether they cooperate with other actors, and finally,

4. their future expectations about the use of situational crime prevention principles in planning practices, in particular the use of CPTED.

\title{
21.3 Framing the case study
}

Of Sweden's 10 million inhabitants, a few more than 2 million live in the countryside, according to the National Rural Development Agency. Sweden has a relatively low population density of 21 inhabitants per square kilometer (the corresponding figure for Denmark is 125), with the highest concentration of inhabitants in the southern half of the country (OECD, 2017). Some of the 
differences in crime rates are related to the economic character of different municipalities. For instance, rural touristic municipalities tend to experience seasonal variations in crime rates, often dependent on visitor inflows, demanding special care in terms of crime prevention. In Sweden, police records over 15 years show that urban and accessible rural areas are at higher risk of crime than the most remote ones but that increases of risk of crime converge toward the year 2014. Although the trends diverge somewhat in urban and rural areas, in the short term they seem to track one another quite closely up to 2014, when rates dropped to levels similar to those found in 2002. The biggest increases are in violent crimes, criminal damage and some types of property crime (Ceccato, 2016). Crime victim surveys in Sweden show a more stable picture but indicate an increasing trend in crime since 2016 (BRA, 2019).

The country has 290 municipalities with a long tradition of comprehensive planning, embodying a rich experience of various methods and techniques. The current planning system was developed in the 1960s and 1970s, when the era of planning based on the master plan concept ended. Municipal planning guidelines became the new planning instrument that in practice replaced the former master plan for cities and towns from the 1970s to the 1990s. Over time, planning systems continue to change, subject to new requirements. New planning methods have started to be used, for example the "municipal planning monopoly", which in practice means that the system is designed by the municipalities (Ptichnikova, 2012). All municipalities are required to have a comprehensive plan that covers the entire municipality (översiktsplan) and shows the main ways in which land and water should be used and how development should take place. The comprehensive plan is not binding on authorities or individuals. There is yet another comprehensive plan (fordjupad översiktsplan) that has the same status as a comprehensive plan but only covers a part of a municipality. Land use and development within a municipality is controlled through the detailed development plan (detaljplan), which is the implementation instrument of the municipality and is legally binding. The detailed development plan has to show areas designated for public places, such as streets, roads, squares and parks. The municipality can also set requirements for the execution of the buildings (Ptichnikova, 2012). Thus, there are two planning instruments that the municipalities use as a basis for their tasks - the comprehensive plan and the detailed development plan-and, based on these, planners can incorporate safety aspects in new developments, often in close collaboration with external stakeholders, such as the police or safety experts. The planning process is regulated by the Planning and Building Act and the Environmental Code, which form the legal basis for urban planning in Sweden.

For existing areas (not new or redevelopment), the municipalities together with the Police Authority form the core of the local crime prevention work, and it is important that this work is carried out long-term, efficiently and is knowledge-based (Ministry of Justice, 2019). However, the majority of these local councils have concentrated their work on social crime prevention, such as prevention of alcohol and drug addiction among youth. Lack of resources, poor involvement of certain members working with crime prevention and limited 
knowledge have been highlighted as barriers for crime prevention work (BRA, 2005). The model of crime prevention often concentrates on problems that are more relevant to large cities than to rural areas. For a review of local crime prevention practices in Sweden, see Ceccato \& Dolmen (2013). This lack of attention to crimes in rural areas is not unique. At the European level, the rural dimension has been omitted in the evaluation of safety and crime prevention policies (Robert, 2010). Therefore, this chapter looks at potential differences in answers by planners from urban and rural municipalities.

\section{Data and methods}

The survey consisted of questions about situational crime prevention, safety perspectives and measures in relation to the built environment as well as the processes for planning, design, construction and management of the built environment. There were also questions about cooperation, standardization and expectations about the future in this area. The survey was sent via email on 25 April 2019, followed by four reminders on 29 April, 6 May, 16 May and 23 May. We received the addresses of the persons responsible in each municipality from the Swedish National Board of Housing, Building and Planning (Boverket). As many as 185 municipalities answered at least one survey completely (69 percent); if we include the incomplete answers, 214 municipalities answered at least one ( 80 percent). Those who did not answer all the questions were often living in sparsely populated municipalities (some did not think that all questions suited their context).

As for the profile of the respondents, as many as 33 percent of planners are 40-49 years old. Planners who answered the survey were most often community planners or physical planners (4l percent), followed by "other option" (20 percent), such as architects, 20 percent having a technical education while the remainder have a community- or security-related education. The sample that answered the questions turned out to be fairly gender balanced ( 50 percent men to 48 percent women, 2 percent not stating gender or gender status).

For the analysis, assuming that the planning context differs across the country in terms of the safety challenges planners face (high crime areas/ demand or not) and resources they have available (such as police force supply), municipalities were divided into urban and rural. Rural municipalities combine accessible rural and remote rural municipalities into one category, since only 7 percent of municipalities in Sweden are remote rural. As defined by the Swedish National Rural Development Agency (2005), remote rural municipalities cannot be reached within 45 minutes by car from the nearest urban neighborhood with more than 3,000 inhabitants; accessible rural municipalities can be reached within 5-45 minutes by car from urban locations with more than 3,000 inhabitants. Municipalities with more than 3,000 inhabitants that can be reached within five minutes by car are regarded as urban municipalities.

Descriptive statistics were used to characterize the data and to test for differences between two independent groups of answers by type of municipality 
(rural and urban); the chi-square test was utilized or, in the case of small expected frequencies, Fisher's exact test.

\subsection{Results and discussion}

\section{General trends}

Issues of crime and safety have increasingly become a part of urban planning in most municipalities in Sweden, but there are major differences in how these aspects are applied in practice. Planners declare that safety is an important part of the planning process, but in most municipalities the way in which the safety issues are dealt with varies greatly. Below, we discuss this in more detail.

Half of planners have knowledge about the concept of CPTED, but not many of them say that they apply it in practice: only 27 percent of planners consider safety in the design of new buildings in a way that strengthens natural surveillance. The same applies to situational crime prevention principles. Note that some answers came from experts working in the emergency services, who consequently may be unfamiliar with these terms. Almost 25 percent of them say that their municipalities do not work at all with safety in terms of crime and fear of crime in planning but with other types of security, such as fire hazards or traffic safety. A few examples of the answers from planners are illustrated below.

We do not work with that. We do not have much crime in our municipality.

We do not have any clear planning documentation or checklists yet, but we have a collaboration with public health strategists during the planning process.

It is part of our profession to consider safety and security issues in the planning process without special guiding policy documents.

Yes, safety issues are taken into account in all our detailed plans.

Other municipalities employ consultants or choose other routes that show a combination of solutions as listed below.

We work with physical planning in terms of safety and inclusion with e.g., open meeting places. Safe walkways with free visibility and good lighting.

... changes in the green areas, clearing for increased natural surveillance, better maintenance.

Yes, to some extent in the center of the village, where the goal is to create a safer center environment with the help of redesign such as lighting, planning, etc.

In response to the question "Which policy, governance document or similar is most widely used for crime prevention in your municipality?" 67 percent of 


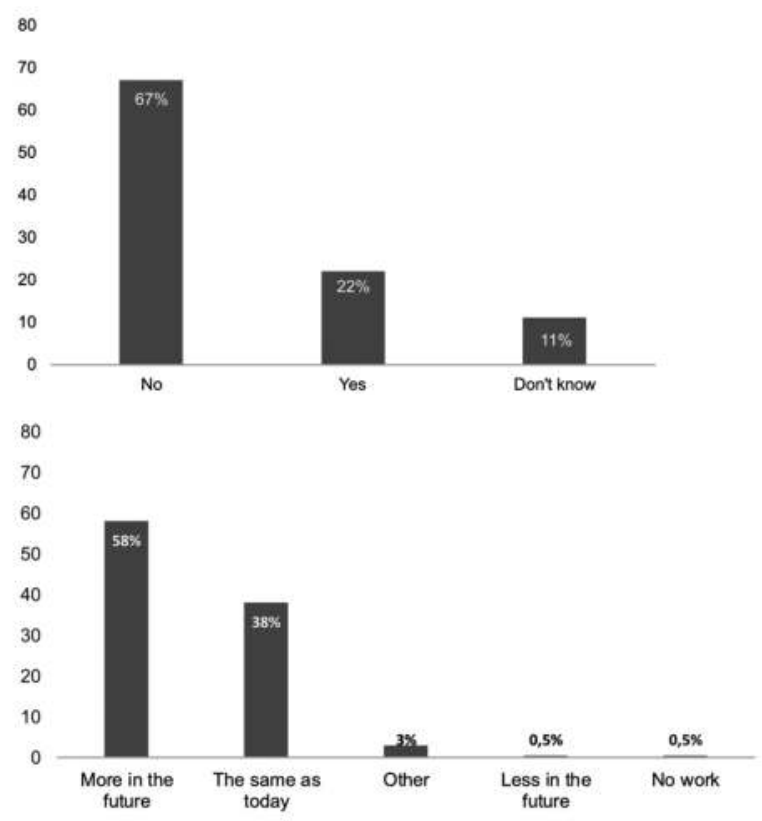

(a)

(b)

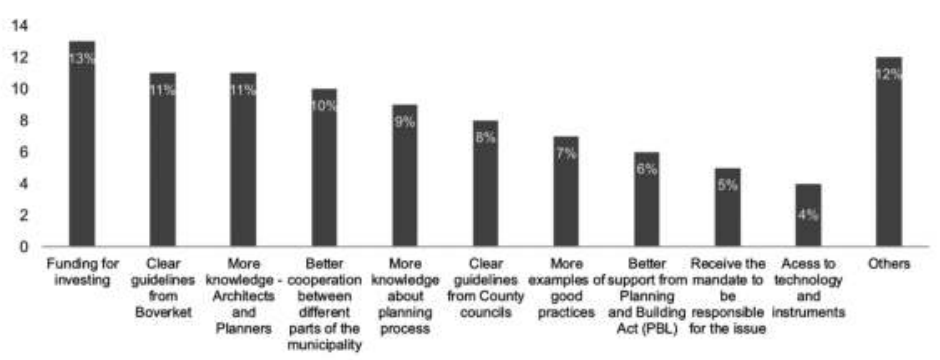

(c)

Figure 21.2 (a) Do you use any policies, governance documents or the like that deal with forms of crime prevention and security-creating physical measures, $N=137$ ( 55 percent). (b) Will you in your municipality work more with the physical environment and safety in planning? $N=137$ (55 percent). (c) What would planners want in the municipality to better work preventively with the incorporation of physical environment principles and situational crime prevention? $N=138$ (56 percent, respondents were encouraged to select multiple alternatives).

planners stated that they lack guiding policy, governance or similar documents that deal with crime prevention through environmental design (Figure 21.2(a)). Only 22 percent of the municipalities declare having government documents or similar that deal with forms of crime prevention and security-creating physical measures. 
If we consider existing areas (not new housing areas or redevelopment), municipalities invest in safety in slightly different ways. Some of them involve changes in the physical environment, others require the involvement of several actors, including civil society, or a combination of these. On the positive side, almost 70 percent of planners respond that they have a safety coordinator in the municipality with whom they cooperate, to some extent or to a large extent. Here are some examples of their own words.

We work continuously with safety walks together with the local crime prevention council and the police.

We have a continuous dialogue between the police, the municipality's prevention unit and the municipality's security coordinator.

BID (Business improvement districts) is a model that was started in a district. Too early to say anything about the results yet.

For example, the survey shows that according to 61 percent of planners, social aspects (including safety in a children's perspective, gender focus, etc.) are taken into account in some form in physical planning. Sixty-two percent of municipalities agree that the safety should be attained by all and everywhereregardless of gender, age, background or abilities. In the next section, the diffusion of the CPTED core principles in planning practices is discussed in more detail.

\section{Incorporation of CPTED core principles}

Findings show that planners in urban municipalities are more often aware of the effect of the physical environment on people's capacity to exercise natural surveillance than are those in rural municipalities. However, in reference to maintenance of public spaces (in particular playgrounds and parks), no difference was found between answers from urban and rural municipalities; two thirds of all municipalities find maintenance of public spaces very important for safety. Below, we describe differences and similarities concerning the application of CPTED principles in new housing production and existing residential areas by type of municipality. The physical environment and design affect the following.

- Natural surveillance-This is promoted by features that maximize the visibility of people, parking areas and entrances and foster positive social interaction and guardianship. Having windows on the most important sides of the facade (and at the "right height") is highlighted as important regardless of type of municipality ( 66 percent among urban, and 55 percent among rural, $p=0.165$ ), indicating that planners value highly visibility as a safety measure. Cutting down trees and maintaining vegetation in parks and streets 
are actions that ensure visibility. As many as 83 percent of urban municipalities consider maintenance of vegetation as important to facilitating natural surveillance; the figure is a much smaller 64 percent among rural municipalities $(p=0.017)$. Findings are similar for a number of other aspects, such as the importance of the height of the buildings to ensuring the capacity of surveillance on streets and in parks and surroundings (72 percent in urban municipalities, and 48 percent in rural, $p=0.005$ ) and location of the houses in relation to each other and in the residential area (79 percent in urban municipalities, and 54 percent in rural, $p=0.002)$. However, planners in urban municipalities more often do not see that buildings and other physical elements of the urban landscape are in themselves barriers to visibility and natural surveillance, while in rural municipalities they do (76 percent in rural against 56 percent in urban areas, $p=0.027$ ).

- Territoriality and access control-This is about how spaces are designed and built to communicate ownership or occupancy of areas and possessions. For instance, 74 percent of urban municipalities consider the separation between private and public spaces an important feature at the entrances of houses and apartments to make a statement of change of ownership; only 55 percent of the rural municipalities do $(p=0.028)$, indicating that these features may not be as important in rural communities for safety as they are for bigger cities, where the degree of anonymity is greater than in rural areas. Regardless of municipality size, about half of those who answered the questionnaire wished to have signs stating who owns or administrates a property as a safety measure.

- Maintenance-This refers to maintenance of public spaces (in particular playgrounds and parks), and no difference in the answers of planners in urban and rural municipalities was found. Two thirds of all municipalities find maintenance very important $(80$ percent in urban municipalities, 72 percent in rural municipalities, $p=0.339)$. Illumination is an important factor for all types of municipality: more than half of the sample describe the importance of having it well functioning at the entrances of houses and apartments and well planned in the area, regardless of municipality type.

- Target hardening-Planners have little knowledge about the types of doors suggested in new housing developments (9 percent in urban areas, and 14 percent in rural municipalities, $p=0.338$ ), and this level of detail (doors) does not seem to be part of their work in ensuring safety. Most planners (65 per cent) do not see gated communities as an alternative for housing developments in Sweden. When asked if they thought, "safety could be ensured by building areas that are surrounded by physical barriers, such as gates, fences and the similar", their answer was most commonly, "no", regardless of municipality type (65 percent among urban municipalities, and 64 percent among rural ones, $p=825)$.

- Activity support-This includes both passive and active efforts to promote the presence of place users in an area, thus increasing legitimate use and discouraging criminal activities or unsafe spots. Mixed land use in central areas (with 
offices, services and residential areas) is suggested as an essential component when planners build new residential areas. No significant differences between urban and rural municipalities were found: 87 percent and 79 percent, respectively $(p=0.225)$. Similar results were found with regard to investing in places that attract multiple users, such as squares and playgrounds.

- Image/Identity - Nearly all municipalities believe that architecture and landscape architecture (gardens/parks) can be used to create a positive identity for the area, but much more so in urban municipalities than in rural ones, $p=0.051$. Half of them also agree about creating activities to ensure "place ownership" (ägarskap av en plats) by supporting local cooperation between actors (46 percent of urban areas, 40 percent of rural ones). Similar results were found for creation of places for common social activities of local associations (70 percent of urban municipalities, 63 percent of rural municipalities, $p=0.925$ ).

\section{Consultation and cooperation}

Urban safe environments require well-coordinated actions of architects, planners, safety experts and police-to name but a few. Findings show that the police still play a central role in this constellation of actors. To the question, "If you think about the last occasion when you collaborated on crime and/or security issues in your municipality, what stakeholders and actors were involved?" planners first indicated police, followed by safety coordinators. The third most common partner for planners was property owners, accompanied by schools or planning architects, civil society, emergency services followed by others and those who have not yet engaged in any cooperation.

Planners and safety experts have important roles to play in the process, so cooperation between them is essential to make sure safety principles become an integral part of the planning and building process as described below.

Tiny municipality, simple communication paths.

Through the planning process, emails.

We try to participate in safety walks.

Social aspects are discussed to a certain extent in various cases (building permits/detailed plan).

According to planners, most of the cooperation takes place at three levels: comprehensive plan (översiktsplan, always), detailed plan (detaljplan, sometimes) or in connection with any policy document. This finding reflects how the municipalities function nowadays in Sweden; namely they now have a single unit for planning with subdivisions, in which building permits and planning (översiktsplan, detaljplan) are normally in separate departments. Safety issues affect both levels. Findings show that there is a desire among planners for increased contact between these levels of local government. 


\section{Vania Ceccato}

There are differences in cooperation by municipality type. Planners were asked, "Do you cooperate with a safety and security coordinator?" Exactly 75 percent of planners in urban municipalities cooperate with safety experts; this figure is slightly lower in rural municipalities, but note that the differences between groups are not statistically significant. Rural municipalities say more often than urban ones that they interact with the planning department and the building permits department in security and safety matters $(71$ percent of municipalities in rural areas, 57 percent in urban ones, $p=0.073)$. Below, some of the municipalities explain the nature of their cooperation or lack of it.

We have different agendas ... there is lack of knowledge about the needs of each party, which is why in the action plan for security against crime we set a goal to inventory the plan and the need for knowledge of the land use office to be able to work effectively with security.

There are no goals or incentives to work with the issues to make it effective.

Creating a program/policy document together with the community and development sector would make a big difference in the future.

There are opportunities for improvement regarding cooperation between planning and building permits departments, with 27 percent declaring that there is no collaboration at present. Because safety needs to be taken into account in most units within a municipality, collaboration becomes important-even crucial-unless a uniform process or guidelines for the work exist. A similar proportion of respondents say they cooperate on these issues with the county administrative board. More than half of the planners are aware of cooperation between the municipality and the police on these issues and are generally positive about the local cooperation. A clear set of goals or "vision" for the municipality is a recurrent aspect mentioned in their answers.

\section{Future expectation of planners and planning practices}

The majority of planners who answered the questionnaire believe that in the future they will work more with safety issues in planning ( 58 percent) than they do today (Figure 21.1(b)). To make this possible, they primarily believe that better funding is necessary. Other aspects, such as more knowledge among planners and architects, better coordination and clearer guidelines from national bodies, are also highlighted (Figure 21.1(c)).

In answer to the question, "Do you perceive that increased standardization of the process to incorporate safety in planning practices could have positive effects?" 70 percent of those planners who answered this question agree that it would be easier to take these aspects into account if clearer safety guidelines were in place. Many of those who answered this question highlighted the following, to consider the specificities of contexts. 
It depends on whether the standardization facilitates the creation of good environments based on specific place conditions.

Different solutions are required for cities and for us in the smaller municipalities. Difficult then with general solutions. A framework or standard, on the other hand, should be clear.

More interestingly, in the future, only 7 percent of planners would consider physical barriers as an alternative to ensuring security and safety; more precisely, 65 percent of planners in urban municipalities agree that security cannot be created by building areas that are bounded by physical barriers such as gates or fences.

\subsection{Conclusions and recommendations}

Natural surveillance and maintenance are the most common aspects considered by planners in their planning safety practices. This is true to a greater extent in urban than in rural municipalities. Illumination is an important maintenance factor for all types of municipality: more than half of the sample describe the importance of having well-functioning illumination regardless of municipality type. However, implementing physical barriers as a safety solution was not considered an alternative for most planners. The police are still indicated as central actors with reference to safety in municipalities; they are also pointed out by planners as their main partners with regards to issues of crime and safety. Yet, more than half of planners express a lack of guidance on safety issues. About two-thirds of them wish for an increased standardization of the process to make possible the incorporation of safety in planning practices. They believe that some guidance could have positive effects for all parts involved. This rather gloomy development has major implications for current urban quality of life and, most importantly, it challenges the ideals of a safe society in the frame of reference embodied by the UN 2030 Sustainable Development Goals.

Based on the responses from urban and rural municipalities, it would be beneficial to create safety guidelines to support the work done by urban planners, a model anchored in research evidence and sensitive to the needs of all individuals. These guidelines could be linked to the Planning and Building Act and evaluated over time with information on, and support for, practices involving different stakeholders. In particular, it would be beneficial to identify and work against current barriers to cooperation between the municipality and the police as well as other stakeholders, such as building companies. Knowledge paths, from the local level to the national, that involve smaller municipalities in influencing the creation and implementation of safety guidelines could be created. Equally important is to create educational opportunities for learning about safety guidelines, recommended for experts working on construction and crime prevention at the municipal and regional levels, this could take shape as a "safety monitoring lab". 


\section{Vania Ceccato}

This chapter is not free from limitations. The focus here has been on planners' perspectives, disregarding the views and experiences of other stakeholders, such as safety experts and other external stakeholders. Another limitation is that it does not report on safety initiatives that are associated more with second-and third-generation CPTED or experiences with neighborhood watch schemes, safety walks, night patrols and the like. Finally, despite the fact that rural municipalities were part of the sample, some of the questions were not completely appropriate for their contexts. Despite these limitations, this analysis provides one of the first overviews of the status of urban planning practices in Sweden with regards to the implementation of situational crime prevention and CPTED principles.

\section{Acknowledgements}

My deep gratitude goes to those who made this study possible by participating in the surveys in Sweden and participating in interviews for this research project. Thanks also to Linda Langefors and Robin Petersson who supported the survey in April 2019 as well as for the valuable comments and discussions with colleagues from the Swedish National Board of Housing, Building and Planning (Boverket). Finally, thanks go to FORMAS, the Research Council for the Environment, Area of Business and Community Building, for partially funding this study.

\section{References}

Armitage, R. (2013). Crime Prevention through Housing Design: Policy and Practice. Basingstoke: Palgrave Macmillan

Barclay, E., Scott, J., \& Donnermeyer, J. (2011). Policing the outback: impacts on integration in an Australian context. In R. Mawby \& R. Yarwood (Eds.), Rural Policing and Policing the Rural: A Constable Countryside? (pp. 33-44). Farnham: Ashgate.

Barton, A., Storey, D., \& Palmer, C. (2011). A trip in the country? Policing drug use in rural settings. In R. Mawby \& R. Yarwood (Eds.), Rural Policing and Policing the Rural: A Constable Countryside? (pp. 147-167). Farnham: Ashgate.

BRÅ, Brottsförebygganderådet (2005). Ett steg på väg. Kartläggning av de lokala brottsförebyggande råden. Stockholm: BRÅ. www.bra.se/publikationer/arkiv/publikationer/ 2005-11-10-ett-steg-pa-vag.html (accessed 10 December 2019).

BRÅ, Brottsförebygganderådet (2015). Skjutningar 2006 och 2014-omfattning, spridning och skador. Stockholm: BRÅ. www.bra.se/publikationer/arkiv/publikationer/2015-1118-skjutningar-2006-och-2014.html (accessed 15 January 2020).

BRÅ-Brottsförebyggande rådet (2019) Den nationella Trygghets undersökning: Om utsatthet, otrygghet och förtroende. Stockholm: BRÅ.

Ceccato, V. (2016). Public space and the situational conditions of crime and fear. International Criminal Justice Review, 26, 69-79.

Ceccato, V. (2018). Fear of crime and overall anxieties in rural areas: the case of Sweden. In G. M. Murray Lee (Ed.), The Routledge International Handbook on Fear of Crime (1 ed., pp. 354-368), Abingdon: Routledge.

Ceccato, V., \& Ceccato, H. (2017). Violence in the rural global south: trends, patterns, and tales from the Brazilian countryside. Criminal Justice Review, 42, 270-290. 
Ceccato, V., \& Dolmen, L. (2013). Crime prevention in rural Sweden. European Journal of Criminology, 10, 89-112.

Ceccato, V., Li, G., \& Haining, R. (2018). The ecology of outdoor rape: the case of Stockholm, Sweden. European Journal of Criminology, 16, 210-236.

Ceccato, V., \& Pettersson, R. (2019). Tryggstadsmiljön i praktiken: Visioner, exempel och tips. Retrieved from Stockholm: www.kth.se/files/view/vace/5dc3a43c38cal004b7abb8el/ trygg-stadsmiljoe-i-praktiken_v.pdf (accessed 18 January 2020).

Ceccato, V., Vasquez, L., Langefors, L., Cannabarro, A., \& Petersson, R. (2019). Trygg stadsmiljö: Teori och praktik för brottsförebyggande \& trygghetsskapande àtgärder. Retrieved from Stockholm: www.boverket.se/globalassets/publikationer/dokument/ 2019/trygg-stadsmiljo.pdf (accessed 2 April 2020).

Clarke, R. V. (Ed.) (1983). Situational Crime Prevention: Its Theoretical Basis and Practical Scope. Chicago: University of Chicago Press.

Colquhoun, I. (2004). Design out crime: creating safe and sustainable communities. Crime Prevention and Community Safety, 6(4), 57-70, doi:10.1057/palgrave. cpcs.8140201.

Costamagna, F., Lind, R., \& Stjernström, O. (2019). Livability of urban public spaces in northern Swedish cities: the case of Umeå. Planning Practice \& Research, 34, 131-148.

Cozens, P., \& Love, T. (2015). A review and current status of Crime Prevention Through Environmental Design (CPTED). Journal of Planning Literature, 30(4), 393-412.

Cozens, P. M., Saville, G., \& Hillier, D. (2005). Crime prevention through environmental design (CPTED): a review and modern bibliography. Property Management, 23(5), 328-356, doi:10.1108/02637470510631483.

Crowe, T. (2000). Crime Prevention Through Environmental Design: Applications of Architectural Design and Space Management Concepts. Oxford: Butterworth-Heinemann.

Hilborn, J. (2009). Dealing with Crime and Disorder in Urban Parks. Retrieved from www.cops.usdoj.gov (accessed 20 April 2020).

Iqbal, A., \& Ceccato, V. (2016). Is CPTED useful to guide the inventory of safety in parks? A study case in Stockholm, Sweden. International Criminal Justice Review, 26, 150-168.

Ministry of Justice (2019). Kommunernas ansvar för brottsförebyggande arbete. Direktiv, Stockholm:Regeringen,www.regeringen.se/4ad703/contentassets/e3f3333d8f7e4l6fae6ac75457ba57d4/kommunernas-ansvar-for-brottsforebyggande-arbete-dir.-201 994 (accessed 18 January 2020).

Mäkeläinen, T., Häkkinen, T., Federley, M., Poutanen, O., Kyttä, M., Staffans, A., Välimäki, S., Ratvio, R., Kekki, T., \& Nikkanen, M. (2019). Turvalliseksi koetun lähiympäristön ohjauksen ja suunnittelun nykytila ja suosituksia. http://urn.fi/URN: ISBN:978-952-287-734-5 (accessed 3 May 2020).

OECD (2017). Improving Rural Policy Development in Sweden. Paris: OECD.

Ptichnikova, G. (2012). Current trends in planning system in Sweden. Paper presented at the 48th ISOCARP Congress 2012-Knowledge for Better Cities. www.isocarp.net/ Data/case_studies/2251.pdf (accessed 6 January 2020).

Reynald, D. M. (2015). Environmental design and crime events. Journal of Contemporary Criminal Justice, 31(1), 71-89, doi:10.1177/1043986214552618.

Robert, P. (2010). Assessing evaluation of safety and crime prevention policies in Europe. In: Assessing Deviance, Crime and Prevention in Europe, https://pdfs.semanticscholar. org/fd5f/dd2b6b97f9b50bb33704al3aae49a6c7c79e.pdf (accessed 6 January 2020).

Savage, M. (2019). Sweden's 100 explosions this year: what's going on? BBC news. Retrieved from www.bbc.com/news/world-europe-50339977 (accessed 16 December 2019).

Saville, G., \& Cleveland, G. (2008). Second-generation CPTED: the rise and fall of opportunity theory. In R. Atlas (Ed.), 21st Century Security and CPTED: Designing for Critical Infrastructure Protection and Crime Prevention. Boca Raton: CRC Press. 


\section{Vania Ceccato}

Sturup, J., Rostami, A., Gerell, M., \& Sandholm, A. (2018). Near-repeat shootings in contemporary Sweden 2011 to 2015. Security Journal, 31, 73-92.

Swedish National Rural Development Agency (2005). Sveriges gles-och landsbygder 2005. Västerås: Edita Västra Aros.

UNICRI, The United Nations Interregional Crime and Justice Research Institute (2012). Improving urban security through green environmental design new energy for urban security. Retrieved from www.unicri.it/topics/urban_security/archive/urban_ design (accessed 20 April 2020).

Watson, I., \& Said-Moorhouse, L. (2017). Sweden: riots erupt in Stockholm neighborhood. CNN. Retrieved from https://edition.cnn.com/2017/02/21/europe/sweden-stockholmriots/index.html (accessed 16 December 2019).

Wikström, P. O. (2006). Individuals, settings and acts of crime: situational mechanisms and the explanation of crime. In P. O. W. R. J. Sampson (Ed.), Individuals, Settings and Acts of Crime: Situational Mechanisms and the Explanation of Crime (pp. 61-107). Cambridge: Cambridge University Press.

Wikström, P. O., \& Treiber, K. (2017). Beyond risk factors: an analytical approach to crime prevention. In B. Teasdale \& M. S. Bradley (Eds), Preventing Crime and Violence. Advances in Prevention Science (pp. 73-87). Cham: Springer.

Woods, M. (2011). Policing rural protest. In R. Mawby \& R. Yarwood (Eds), Rural Policing and Policing the Rural: A Constable Countryside? (pp. 109-122). Farnham: Ashgate.

Yarwood, R., \& Edwards, B. (1995). Voluntary action in rural areas: the case of Neighbourhood Watch. Journal of Rural Studies, 11, 447-459. 


\section{Part VII}

\section{Crime and fear in public places}

Conclusions and recommendations

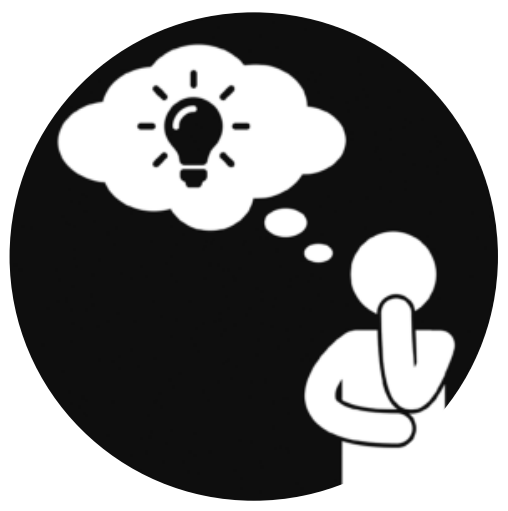




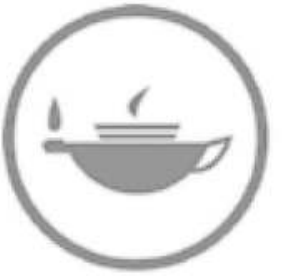

Taylor \& Francis Taylor \& Francis Group http://taylorandfrancis.com 


\title{
22 Crime and fear in public places
}

\author{
A global look
}

\author{
Mabesh K. Nalla and \\ Vania Ceccato
}

\subsection{Introduction}

This volume brings together a collection of original research that addresses the fear of crime and safety with a focus on public places such as parks, green spaces and public transit, from scholars from around the world. These original contributions highlight and demonstrate fear of crime and safety concerns intersecting with spatial and geographic locations. This volume adds to the growing literature on underscoring the significance of fear of crime as an integral part of social and geographic concerns centered on environmental planning and urban affairs. Scholars from both developed and emerging democracies have contributed to this volume, covering a wide range of countries from the global North and the global South. They include Brazil, India, Japan, Mexico, Nigeria, Pakistan, Poland, Sweden, the United Kingdom and the United States. The comparative research presented in this edited volume has focused both on theoretical and methodological issues, with practical and pragmatic recommendations for policy. In this chapter, we synthesize and critically review some of the key findings based on each chapter and subsequently on the five crosssectional themes. We identify relevant lessons and challenges that emerge from a variety of research fields and country contexts.

This book is divided into seven parts. The first part consists of three chapters that lay the theoretical and conceptual frameworks for the various original research papers selected for inclusion in this volume. The first chapter introduces crime and fear in public places and defines the scope and theoretical framework of the book. In Chapter 2, Ceccato provides an overview of the theories surrounding the circumstances of crime and fear of crime in public spaces. She begins with the description of the concept of public places in relation to the dynamics of urban crime and fear and identifies competing theories that identify the mechanisms that link crime and fear with the built environment, and finally analyzes the role of architects, planners and safety experts in the implementation of safety interventions in planning practices.

In the final article in this section (Chapter 3), Ceccato provides a comprehensive literature review on the architecture of crime and fear of crime drawing evidence in the international literature on the relationship between various 
crime prevention strategies such as surveillance cameras, lighting, and other guardianship attributes and their impact on individual' perceptions of safety and fear of crime. In this chapter, Ceccato reviews a massive amount of literature published between 1968 and 2018, drawn from various databases including Scopus, Web of Science, and JSTOR. More specifically, the literature review covers three issues: the impact of urban design on crime and fear of crime; the effect of lighting and/or surveillance on crime and perceptions of safety; and, by focusing on the creation of barriers and gated communities, the author discusses the impact of the "side effects" of prioritizing this type of "safety solution" on the overall city sustainability. The author concludes by answering the following question: what makes a public place safe? Lighting and maintenance are for sure important components of a safe public place but these characteristics, she concludes, often do not come alone. An environment that promotes guardianship also makes it safe, and seems to be a recurrent aspect of these studies. People's involvement in local (crime preventive) initiatives may also help curb crime and improve safety. A note of caution is necessary because although the sample covers more than 4,000 articles, it is biased towards expected positive results. This means it is impossible to know how many studies that have produced negative or "unexpected" results were never published. The author recommends caution with these results also because not all technical solutions that positively affect crime, can produce sustainable outcomes (for instance, gated communities).

\subsection{The environment}

The second section, entitled The environment, highlights crime and perceptions of the safety of urban spaces with specific reference to parks and designated green spaces, which are the landscapes of urban planning. Two articles focus on open urban spaces, more specifically parks and green areas located in urban settings, which while designed for residents and visitors to relax and spend quality time with families and friends are also contested spaces and that perceptions of safety and crime are strongly tied to residents' decision to use these spaces. The third article in this section focuses on public spaces such as school premises as avenues for specific forms of victimization, particularly disability hate crimes. In the first article of the section (Chapter 4), Ceccato and her colleagues conduct a comprehensive review of the literature on the relationship between green spaces in cities and their impact on citizens' perceptions of crime and safety. Drawing from existing research on the subject matter and placing it in the context of research from other parts of the world, authors reviewed nearly 5,000 research articles from the past five decades to systematize scholarly knowledge on the topic. A majority of the articles ( 60 percent) of the studies were based in the US, 23 percent from Europe, and 23 percent from Asia. More specifically, they summarize findings from prior research that addresses the common types of green areas (i.e., parks, green areas in neighborhoods, and woodlands) associated with risk of crime and perceived safety, if green spaces 
are related to the incidence of crime and disorder, and, finally, the ways in which green spaces shape perceptions of safety and fear of crime among the citizens. Based on this extensive review the authors cautiously conclude that there appears to be evidence for green areas in cities having a positive impact on decreasing crime. The authors' cautionary tale stems from a lack of fairly extensive literature that covers a wide range and variety of green areas in cities. Second, given a wide range of methods employed to examine these issues, drawing comparisons from these the results can be complicated. Finally, the authors also caution the applicability of findings from mostly North American and the United Kingdom to emerging democracies and the areas in the global south.

The findings of a positive relationship between green areas and perceived safety have implications for policy. Given that green spaces are often contested spaces in a city, the authors highlight that plans to create green areas is essentially a plan for safer cities and inclusivity for all groups of residents in the community. This process requires multifaceted approaches and continued commitment from multiple authors.

The next article (Chapter 5 ) focuses on safety within urban parks and the fear of crime in general in parks. Bogacka, drawing from a case study in Cytadela Park in Poznań, Poland, examines the specific characteristics of a park that makes users feel safe and the extent to which perceptions of safety are impacted by the physical and social environments of the park. The park includes playgrounds, fortifications, museums, cemeteries, monuments, sculptures, an amphitheater, two restaurants, and two open-air gyms. Drawing from the conceptual framework of Crime Prevention Through Environmental Design (CPTED) and a survey of over 500 users about crime risk, Bogacka measures the quality of the environment of the park and how that relates to its safety. More specifically, employing the six CPTED concepts of territoriality, surveillance, access control, target hardening, the image of the place/maintenance and activity support this research evaluates the safety within urban parks as well. Considering the size of the park and its location in the city and situated in the residential area, the park receives a lot of human traffic from both domestic visitors and tourists. Findings from this study reveal that most of the users walk alone in the park or engage in physical exercise activities. Park users feel safer during the day in contrast to at night. Additionally, regardless of the time of day, older visitors to the park felt less safe. Park users identified adequate lighting, the presence of another person or people, video surveillance, and the presence of the police as factors associated with the feeling of safety. Findings also suggest that alcohol consumption, the presence of homeless people and vandalism were among the key factors resulting in park users' sense of perceived fear of park usage. Drawing from these findings, the author suggests some pragmatic recommendations for improving a sense of safety and reducing fear of victimization that include the organization of more social events, renovating the amphitheater, adding benches, placing garbage bins and improved lighting. 
The third article in this section (Chapter 6) is a comprehensive literature review that focuses on disability hate crimes (DHCs). More specifically, the goals of Girolimetto and Iudici were to ascertain where such crimes are more likely to occur, how different locations facilitate this form of crime and to offer suggestions of how public places may limit violence and DHCs, a form of crime that is under-reported relative to other types of crime. Drawing from a large number of studies on the subject and identified in databases of Scopus and PubMed, the authors identify the role of public places' in aiding the occurrence of DHCs. They limited their research to printed articles, reviews, notes, and editorials and searched using the main keyword 'disability hate crime' and present their findings in three categories: locations where DHCs were most likely to occur; public places as an active factor in aiding DHC events; and, public places as an active factor in preventing DHC events.

School environments, public spaces along with streets, and government buildings are primary locations of DHC incidents. They identify disabled children as most vulnerable to DHC violence which occurs in institutions and communities and state that many disabled people live in isolation in vulnerable conditions. For the second category that relates to how specific locations facilitate DHC events, the authors found three factors contribute to DHC occurrences: poverty and deprivation and spaces that often have limited guardianship, such as public institutions and virtual spaces. Lastly, the authors find from prior research that suggests that changes in the structural conditions of public places may help to limit violence, harassment, abuse, and crime. While this literature review focused on education and virtual environments, the authors find that addressing negative attitudes towards disabled people can help to make an educational environment a safe place. This literature review also revealed support for virtual forms of communication as a medium to implement diagnostic prevention systems to identify forms of hate.

\subsection{The movement}

The focus of this section is on perceptions of safety and victimization in public transit. Contributions for this section come mostly from the global South. The essence of these contributions is that public transit, as part of the urban space that facilitates movement for urban residents, can be prime sources of crime, sexual violence and victimization, which degrade the quality of urban life for its residents. Despite the diversity of geographic locations that served as the research settings, common threads among the findings are evident. Gender, time and frequency of commuting are all associated with a higher degree of sexual victimization and sexual harassment. Additionally, these research articles highlight the issues regarding the safety of public transportation and ways to reduce these problems with a focus on increasing guardianship through both physical and electronic monitoring systems, mechanisms identified in the literature on situational crime prevention (SCP) and CPTED. The underlying theme is that understanding the logistics of sexual victimization in public transportation 
would help generate ideas to make it easier to solve the specific issues in particular locations.

The first of the four studies (Chapter 7) by Romero-Torres and Ceccato address the issue of sexual harassment and safety perceptions of public transportation users in the eastern part of Mexico City, Mexico. The authors surveyed 381 university students from the CU Nezahualcóyotl campus to assess their perceptions of safety and victimization from three forms of sexual offenses, which were nonverbal sexual violence/abuse, verbal sexual violence/abuse, and physical sexual violence/abuse. The findings suggest that compared with men, more women reported sexual victimization of one form or another. The likelihood of victimization occurs most often in buses followed by Metros. The findings also reveal that both frequency and duration, as well as the time of the day, are strongly linked to victimization. That is, the longer the duration of travel and the greater the frequency of commuting, the higher the likelihood of victimization occurring. Among the forms of sexual victimization, more victims experienced verbal victimization in buses and non-verbal victimization was more common in the Metros.

Other interesting observations from the victims reveal that the offender's anonymity at times in these areas makes it easier for these types of crimes to occur. In particular, in the absence of a capable guardian-that is, if offenders do not believe they are being watched by either other people or technologythey are more likely to commit a crime. The study also highlights four main categories of behavioral responses to the fear of crime: avoidance behavior, protective behavior, behavioral and lifestyle adjustments, and participation in relevant collective activities. Findings from this study prompt the authors to recommend constant monitoring of areas surrounding public transportation, including public transit while on board.

The second study in this section (Chapter 8 ) focuses on public safety perceptions among college students in Tokyo/Kanagawa public transit systems in Japan. In this study, Shibata examines women's perceptions of how safe they feel commuting in these railway cars. The main concern the women experience in this study is sexual offenses focused on groping while traveling by trains, and other forms of sexual violence in transit environments. Findings from a survey of 400 college students comprising both males and females reveal gender differences in sexual victimization, that is, females are the predominant victims of various forms of sexual harassment. Among the various forms of sexual harassment, groping was the most common form of violence experienced by women commuters. The researchers also discuss two countermeasures against groping: women-only cars and CCTV cameras as security measures on trains and platforms.

The next article (Chapter 9) centers on university students' perceptions of safety and experiences of gender violence and crime in public transit, which included bus stations and on-board buses in the Brazilian city of Rio Claro. Three forms of violence were included in this study: sexual assault or harassment; other forms of violent crime (aggravated assault, robbery, rape); and, 


\section{4}

property crime (theft/pickpocket, jewelry snatching or robbery). The data collected from 569 students included nearly 18 percent who identified themselves as Lesbian, Gay, bisexual, and transgender (LGBT). As in the previous research findings from Mexico and Japan highlighted in this section, women in Rio Claro, Brazil, were more likely to be victims of all forms of crime including sexual violence and harassment. Perhaps, a more interesting finding from this study was that female LGBTs were five times or more likely than male LGBTs to be victims of sexual assault and harassment. Apart from the high degree of victimization of crime and sexual violence, 95 percent of all those surveyed feared using the bus service at night-time and 70 percent during daytime, with nearly two-thirds of all respondents identifying sexual assault or harassment as the main form of fear.

Drawing from these results, the researchers identified five measures that best contribute to improving safety in public transportation. These include better lighting, police patrol, surveillance cameras on board the bus and at bus stops, and digital timetables at bus stops. The authors also suggest that improving public knowledge through campaigns and educational programs, though a long-range goal, will help sensitize and bring and raise awareness among users of public transportation. The authors also acknowledge that some of these changes are easier or more attainable than others, such as better lighting and cameras, while police patrol and educational programs are more difficult. Additionally, having more patrols around bus stops and relocating bus stops to safer places requires more organizing and planning than may seem.

Common themes and findings also emerge from research (Chapter 10) from Lagos, Nigeria. Otu and Agugua examined perceptions of fear and actual crime in public transport systems (PTS) and networks. While PTS constitutes the most common forms available for transportation in the high-density population of Lagos, the limited availability of PTS relative to the demand results in overcrowding of these stations and, consequently, crime. Similar to the research reported earlier in this section, compared with men, women report in greater numbers both the fear of crime and criminal victimization in PTS, the most common forms being pickpocketing, robbery and sexual harassment. This study identifies several recommendations for safety improvements, including surveillance cameras, digital timetables, direct police lines and more police officers, improved lighting, and women-only modes of transportation. As with many public transport safety issues, while recommendations such as additional lighting, use of cameras and digital timetables are more attainable solutions, calls for more police officers and womenonly modes of transportation are harder to attain.

\subsection{The users' perspective}

The articles in this section, The user's perspective, address both conceptual arguments relating to contested spaces, both in terms of individual and spatial dimensions as well as perspectives from the victims, and one article in particular 
from the offenders' perspectives. In the first article in this section (Chapter 11) Vera-Gray and Kelly discuss the issues regarding women's safety in public spaces. The feminist movement has been seen throughout history and is constantly changing, along with the safety issues that females face in public spaces. The issue with studying this area of crime is understanding the right to public spaces and trying to gender the fear of crime. It is hard to understand why women report significantly higher levels of fear of crime than men, but women have a lower rate of victimization and Vera-Grey and Kelly explain why gendering fear of crime is complex. According to the authors, studies of gender and work have brought about two forms of invisible work for women: violence work and safety work. Violence work is the work women must do to undo the harms and make their lives livable, which takes time and energy that could have been spent on more meaningful projects. On the other hand, safety work is work that women do to avoid violence in public space. What we draw from this research is an understanding of, and an increase in our knowledge of, the strategies women and girls adopt and adapt to avoid potential threats. These strategies include altering routes going to and from home, and making strategic choices of seating on public transport, physically minimizing their presence in public, with headphones and sunglasses usage to make themselves more invisible, all to avoid sexual harassment and other forms of sexual violence. The authors propose that future research should investigate public places where women feel they must practice the most safety work. Understanding these public situations and places will help to better understand how to make them safer for not only women but all who come into contact with these spaces. It is also important to understand why these public spaces are contested gender spaces. There may be an issue that is not as apparent as researchers may think that could be causing women to feel like they need to practice either type of invisible work.

A slight departure from the research reported here, which predominantly focuses on victims, can be found in the next article (Chapter 12) by Nalla, which captures sexual harassment and sexual violence experiences from the perspectives of both the victims and the offenders. Drawing data from a large sample of nearly 1,400 male and female respondents, using multistage cluster and quota sampling, who travel by public transport in New Delhi, India, Nalla examined the incidence of victimization and the age distributions of both victims and offenders on a range of sexual harassment $(\mathrm{SH})$ experiences. In addition, he also examined male offenders' self-reported offending patterns, male offenders' friends offending, as well as the awareness of the existence of laws relating to sexual harassment and their effectiveness. Compared with other research in this section, which focused exclusively on the college-going population, this study included the general population. Findings suggest that victims and perpetrators of sexual harassment ranged across all age categories. A higher concentration of victimization rates was found in the age groups of 18 to 40 years, although there was a considerable concentration of victims in the age group of 41 and 80 years. A similar distribution of offending patterns among 
males was also observed, with nearly a third under the age of 30 years and about 16 percent of all offenders in the age group of 51 years and stretching into their 70s. Perhaps, an important result from this study is the finding of a high congruence between self-reported offenders and knowing a male friend who has engaged in similar sexual harassment behaviors, suggesting the perpetration of these behaviors occurs in the company of friends. Additionally, although less than half of the offenders (42.2 percent) knew there were punishments associated with $\mathrm{SH}$ offending, less than a third believed that the SH laws (29.2 percent) or SH enforcement of laws (33.8 percent) were effective. These perceptions may have some impact on their behavior and willingness to engage in $\mathrm{SH}$.

Similar to findings from the study in Lagos, Nigeria, the author raises issues relating to the infrastructure deficiency in relation to public transportation in New Delhi. Given the overcrowding of transport areas, such as bus and metro stations, as well as the public transport system, guardianship and surveillance concerns become paramount. Furthermore, citizens' trust in the legal system or law enforcement is far from positive, giving rise to cynicism as well as the absence of legitimacy in the governance of crime. However, the author suggests the utilization of the sports and entertainment industry idols, who have a large fan following in India, to provide public service messages on this form of social problem.

Unlike the papers summarized earlier, the next paper (Chapter 13), by Stjernborg and Bamzar, focuses on older adults' perceptions of crime. The setting for this study is two neighborhoods, Hässelby Gård and Seved, which are located in the two major cities of Sweden, Stockholm and Malmö, respectively. Approximately 15 percent of Hässelby Gård's and 8 percent of Seved's population are in the age group of 65 and 93 years. These people have unique characteristics that are important to examine when trying to understand how crime and fear of crime affect older adults. Fear of crime in older adults is influenced by many factors, such as marital status and health as well as the significance of loneliness and low levels of life satisfaction. News and media also play a role in the perception of safety. The article explains mental maps being used to express a person's perceptions of different places, including views on where they want to go and places they want to avoid. It is important to look at how the news and media may affect people's perceptions of certain areas, especially those perceptions of older people. The lack of social participation that can come with aging may also lead to a low perception of safety. The study shows that daily life may be affected by the fear of crime. People change their daily activities and schedules because of their perception of crime in the areas they populate. The role of the context of daily life should be further researched to better understand and meet the needs of older adults. Understanding their daily lives will also help to develop age-friendly neighborhoods that allow older people to stick to their daily routines and not have those routines affected by the fear of crime. Additionally, more research should be done regarding social participation and how that plays a significant role in the fear of crime. This area of interest would also benefit from research regarding the roles that municipalities and other actors play in supporting the older generation and "healthy aging". 
The location of the following chapter (Chapter 14) by Yates and Ceccato is also set in Sweden's capital city of Stockholm. This chapter focuses on women's fear of crime, but specifically on how this fear of crime varies. Findings from three large surveys administered in 2008, 2011 and 2018 reveal that women's fear of crime is not homogeneous and is individual. Further, relationship status, ethnic background and gender status also play a major role in fear of crime. A strong relationship between fear of crime and the neighborhood's social and physical characteristics is also established in this research. Women would express more fear in public space than in private space, even though most attacks against women occur in the private space (domestic environment) by people that they know. It is a paradox because women experience more fear in public spaces, which in turn makes them change and adapt to how they move in these spaces. However, they do not change or adapt their behaviors in more domestic spaces because they feel safer, even though they are at greater risk of victimization in these private spaces. As with previous research, reported fear of crime is higher for women than men. A strong factor in high fear of crime among women is poor social connections. Further research in this area would help to better understand women's views on their personal social connections and how to better these so they feel safer in public spaces. The study also shows that young women have a high fear of crime, and research looking at the intersections between age, family structure, and socio-economic status could help to better understand how fear operates in the lives of young women. Additionally, looking at individual and environmental characteristics of where women live and how that relates to crime will help to better understand the fear of crime they may have.

\subsection{The metrics}

This section consists of three research papers that address the measurement of fear of crime using novel methodologies. The first of these papers (Chapter 15), by Irvin-Jackson and Kamiran, considers the factors shaping fear of crime in public transit in Lahore, Pakistan. This chapter employs Ecological Momentary Assessments (EMAs) to collect real-time and near real-time data on an individual's fear of crime among users of public transit. Deploying EMAs through a mobile survey app in Lahore, Pakistan, the authors gathered real-time and near realtime context-specific data on fear of crime. Fear of crime can be dependent on many factors, including different times of transit, different modes of transit, and different stages of travel. Additionally, the perceived level of incivilities and experiences of crowdedness in and around public transit can play into the fear of crime. This study would gain empirical support if it were to have a larger sample group; however, future research may benefit from using EMAs as a way to collect data. Future research would also benefit from looking at these data from the individual level. As other research has shown, the fear of crime is not homogeneous and may change per person. Examining the relationship between the fear of crime and characteristics among individuals can be beneficial in 
understanding how to combat the fear of crime. This research also has relevance to fields that fall outside the realm of criminology. It is important to take the data that have been collected and use them to better understand this area of research. The data can be taken into further research or used to implement policy. Lastly, examining the relationship between fear of crime and transit times, transit modes and stages of travel will help to better understand how the fear of crime may change based on the variations dealing with transit.

The next article (Chapter 16) by Magnusson examines open drug scenes (ODS), which are public places where drug use and distribution are common. These areas are typically located close to transportation hubs and central business districts and are the scene of various types of crime. These drug scenes gain attention and make people fearful of these areas and affect living environments, cause safety issues and create problems for the surrounding neighborhoods and communities. ODS has a negative impact on the communities and causes a perceived fear of crime in those areas. Drug scenes also have a perceived disruption that comes with them. It is important to understand where these drug scenes are most likely to occur to better implement strategies to combat them. The use of police-recorded data and Geographical Information Systems underlie the methodology used in this study. Open drug scenes are most common in areas of transport because drug use and distribution rely on populated areas where they can be hidden. There needs to be additional research in these areas to see the impact of cameras and lighting and understand if those types of strategies are working. Additionally, hot spot policing may also be a method to combat these open drug scenes. There are various studies that use hot spot policing, but hot spot policing in transit areas may need more empirical support and research.

In the last article of this section (Chapter 17), Castro-Toledo and his colleagues examine fear of crime in the realm of cyberspace. They specifically look at the fear of cyberspace through social media and how fear of attacks is spread through the medium of language. Although the fear of crime is difficult to define and measure, the researchers are attempting to encode authors' emotions through Twitter so they can track fear across different "places" and time in cyberspace. They are also specifically looking at tweets regarding terrorism and the emotive profile or response or emotional response that comes from them. The researchers show that the experience of fear through Twitter users is not something that can be documented immediately. They show that this fear in cyberspace can be analyzed and accounted for as if it were measured at the time of their experience. Furthering this type of research would include more realtime data research. This would help to understand the immediate feelings or fear of crime associated with the tweet. Someone may feel fearful after seeing a tweet during a certain time and space and then they could see it again and not feel fearful. It would also be important to understand what it is about the tweet that caused fear of crime, or fear of terrorism more specifically. Additionally, more research regarding criminology and linguistics would be beneficial. Understanding how crime and fear of crime work through different social 
media outlets is helpful in understanding how to combat it through those social media outlets as well.

\subsection{The intervention}

Three articles included in this volume address the assessment of interventions to reduce perceptions of fear of crime and crime itself. The first article, a literature review by Struyf (Chapter 18) addresses the question of the impact of reduced street lighting on crime and fear of crime. As city managers around the world have increasingly focused on reducing street lighting with an eye to minimize pollution and deal with diminishing revenues, the consequences emanating from such bureaucratic decisions have not gone unnoticed. One of the fallouts from such decisions is fear of crime, which Pia Struyf addresses in her research. She examines the effect of reduced street lighting on fear of crime, drawing from quantitative and qualitative scholarly publications in the English language between 1960 and 2019 which examined the impact of street lighting on crime and fear of crime. In this literature review, Struyf also examines the concerns relating to measurement issues and the generalizability of the findings of reduced street lighting on crime. She concludes that the findings from the limited scholarship available on the subject suggest that at best the impact of street lighting on crime has been largely inconclusive, leading her to conclude that reducing or switching off street lighting does not necessarily result in increases in crime, in the way that is mostly presumed. However, the available research is inconclusive and limited, with both studies showing certain limitations in terms of generalizability (but see also the review on lighting reported in Chapter 3). Similar findings were noted on the impact of reduced street lighting on fear of crime; however, reduced street lighting was found to have an effect on fear of physical injuries from tripping, traffic accidents, and the general ability to see the night sky. Based in this review Struyf suggests "the right amount of light", based on a careful assessment of the cost-benefits emanating from the energy savings goal and citizens' physical safety, whether it is crimerelated or from physical injuries. In conclusion, she calls for more analysis with greater attention to specific social and physical environments to advise and guide local governments regarding street lighting regimes.

The focus of Garius, Ward, Teague, and Tseloni in the next article (Chapter 19), which is centered on the United Kingdom, examines if outdoor spaces licensed for holding large gatherings such as music festivals, and other forms of recreational activities in the night-time economy (NTE), create opportunities for crime and sexual victimization. The key driver for many of these behaviors is alcohol. In their study, drawing from data routinely collected by police and environmental criminological theories, Garius and her colleagues evaluate the "Drinkaware Crew" harm-reduction initiative developed by Drinkaware's "Drunken Nights Out" campaign, and examine its relevance and applicability to a music festival, another form of NTE. From their evaluation, the authors conclude that the impact of the "Drinkaware Crew" initiative in NTEs was that in 
one city there was an increase in crime, while the results were inconclusive on recorded crime in the test venue in the second city. They suggest that the finding was rather unexpected and inconsistent with existing literature, which shows that increased guardianship reduces alcohol-related harm, while at the same time it is consistent with literature that crime rate changes may be part of police recording and citizen reporting practices as well as changes in public attitudes. Interestingly, however, they find that "Drinkaware Crew" initiatives can be successfully implemented as harm-reduction services at music festivals, with a perceptible drop in alcohol-related harm for both themselves and others. The lessons we can draw from this work are that social media's presence can enhance visibility, and the effectiveness of the program can be improved by increasing the Festival Crew-topatron ratio. Another lesson that can be drawn from this study is creating a welldefined Drinkaware space at festivals to facilitate on-site training and improving the $\log$ accuracy, validity, and reliability for procedures for data collection.

The chapter on Hollygrove neighborhood in New Orleans by Mihinjac and Saville (Chapter 20) offers an uplifting account of achieved neighborhood improvements from high crime, violence, and fear of crime, after the devastation that Hurricane Katrina brought to this region in 2005. The success of community efforts is related to the empowerment of local neighborhoods to achieve lasting improvements. The case study maps out the journey of neighborhood residents as they "aimed to repair their neighborhood, reduce crime and fear, and build their own capacity to solve future problems-a process of neighborhood activation". The authors draw and offer three key lessons from this case study. First, engaging residents in neighborhood crime prevention activities is predicated on social programming of activities for residents to participate and work together in crime reduction efforts. In Hollygrove, the success of this program came from the core relationships that served as the foundation that rebuilt the social capital and social infrastructure. Second, it is required to support residents' efforts with resources such as funds, police support, and training in crime prevention. These resources were critical in providing muchneeded assurance and confidence building for the residents to actively engage in crime prevention activities. Third, small-scale projects served as a catalyst for long-term action projects yielding big changes over time in Hollygrove, an area that has seen extreme inequality and neighborhood disadvantage.

Chapter 21 focuses on safety and urban planning from a Nordic perspective. Despite increasing safety challenges in many Swedish cities, there is a lack of knowledge about how municipalities work with issues of safety in daily planning practices. Using answers from surveys with planners, Ceccato suggests that municipalities vary greatly in their readiness to deal with issues of crime and safety. Natural surveillance, illumination, and maintenance of the city environments are often considered as important for safety, more so in urban municipalities than in those that are rural. Yet, more than half of planners express a lack of guidance on safety issues. The author concludes that it would be beneficial for the creation of safety guidelines to support the work done by urban planners-a model anchored in research evidence and sensitive to the needs of all individuals. 


\subsection{Concluding remarks}

No matter the size or location of a city, urban crime does not happen randomly in space or time. Even within inner-city areas, the degree of criminality varies as a function of people's routine activity and the types of land use that attract and pull people over the day. Part II of this book shows the role of the city structure (green areas in particular) on victimization and safety perceptions. Parks and other green areas appear to have a positive impact on decreasing crime but there is also evidence that perceptions of users differentiate aspects in these green areas that can be linked to the feeling of safety or lack of it. Lighting and maintenance are also highlighted in this book as important components of a safe public place. Studies show that lighting has a reductive effect on a variety of types of crime, from public disorder to homicides, and on fear of crime. In addition, "an environment that promotes guardianship" seems to be a recurrent aspect associated with less crime and fear. A key component in these studies seems to be the individual's capacity to exercise social control in these environments. Some vulnerable groups are more at risk. Places such as school environments, public spaces along streets, and government buildings are, according to the research reported in this book, the primary locations of incidents against individuals declaring a disability. Poor areas with less social control are also associated with these particular crimes.

Cities are dynamic places. Mobility enables individuals to overcome distance, access spaces and perform activities. However, if people feel unsafe, their mobility is limited. Part III of this book focuses on sexual harassment in transit environments and how these incidents affect the lives of many people, in particular women, causing them to experience stress or even fear in everyday life. Place and time avoidance are recurrent phenomena, no matter whether they travel in Brazil, Nigeria or Japan. Some ways of dealing with the problem must change how individuals are educated and require long-term policies. In the short term, taking the physical environment into consideration can be helpful, such as changing the design of transit vehicles, stops, and systems. Adopting 'a whole journey approach' to safety has also been highlighted as a way to improve safety for travelers from door-to-door. The authors in this book agree that there is not a single initiative that completely addresses unwanted sexual behavior and sexual crimes in transit environments, but more focus on the differences in the safety needs of individuals is desirable. Recognizing the intersectionality of safety (e.g., age, gender, disability) is expected to become more central than it is today in the assessment of the mobility needs of travelers. Changes in the perception of transport operators and other stakeholders towards those who are more targets (of victimization) while in transit is an important long-term goal. A more progressive safety agenda, non-gender neutral and tailored to affect the lives of those who have their mobility impaired is also fundamental. A similar message is also suggested in Part IV of the book, focused on users' perspective of safety. Gender, age, sexual status, disability as well as socio-economic conditions are co-identified as contributing to poor safety. The intersections of 


\section{Mahesh K. Nalla and Vania Ceccato}

these dimensions affect the risk of an individual becoming a victim of crime. The situational conditions are shown also to be relevant for explaining patterns of offending and safety perceptions. Local initiatives that focus on changing the physical and social environment to tackle risks and perceptions are also desirable but may not be enough. In in particular, we echo Vera-Gray and Kelly (Chapter 11): we need to return to earlier feminist efforts to create a right for women to occupy public space on the same terms as men. In many parts of the world, women are still smaller, less visible and yet highly targeted by sexual victimization in public spaces. Women should feel they have a right to the city, that they can belong in public spaces on their terms, rather than "gendered business as usual".

These initiatives (or interventions) require further development of groundbreaking methodologies to best assess safety conditions in public places and later tackle them, which has also been well illustrated in Parts V and VI of this book. These chapters provided examples of new types of real-time data sources (tweets) and technologies, as well as new advances in transportation and ICT that are bound to affect people's safety. The challenges in using geographical information and spatially-related techniques to support research and (safety) planning are not merely linked to the data, theory or tools themselves, but to the way in which they are incorporated in the process of decision-making. One of the key conclusions is that it is more beneficial to establish a ground on which to "build-in" safety in an inclusive way at the beginning of the process of construction of an area, than to try "to fix" safety problems after a public area has become a risky, unsafe place. Not only the police but planners, architects and safety experts have a crucial role to play in the process of making safety. Evidence from this book indicates that there is an urgent need to move from a gender-neutral agenda to policies that adopt a perspective that regards the intersection of gender, age and other individual factors that affect one's safety.

In the next chapter, we draw from all contributions to this volume to propose recommendations on how to respond to crime and fear of crime in public places. Finally, we set out an agenda for research and practice aligned to the UN-Habitat Safer Cities program. 


\title{
23 Responding to crime and fear in public places
}

\section{Towards an agenda for research and practice}

\author{
Vania Ceccato and Juma Assiago
}

\subsection{Introduction}

Make cities and human settlements inclusive, safe, resilient and sustainable.

(United Nations, 2019)

Safety and security are an important part of social sustainability. A safe environment enables the most basic human needs: safe housing and a safe urban environment that allows free movement for everyone. This is clear from the objectives of the UN 2030 Agenda for Sustainable Development, which was adopted by all United Nations Member States in 2015.

\subsection{Responding to crime and fear in public places}

The discussion that follows is not meant to be a summary of the suggestions deriving from the chapters but rather a critical reflection of the recommendations they present. Some suggest minor changes and adjustments to public environments, while others demand long-term investment or changes in people's attitudes, changes traditions within organizations and society as a whole.

\section{Research}

Crime Prevention Through Environmental Design (CPTED) strategies can provide useful guidelines for interventions, as illustrated in Chapter 2. However, further research is needed to evaluate whether and how individuals' characteristics interact with various environments, be it a park or a bus stop.

Sometimes the context and scale of a particular problem/case play a role in affecting outcomes. It is no surprise when an intervention that worked in big cities does not produce the same results in a rural community. In addition, the vast majority of studies are developed in North America and Europe, so there is a need for further research that can check to what extent current theories and practices of interventions fit public places in Global South contexts. Equally 


\section{Vania Ceccato and Juma Assiago}

important is to illustrate how Global South contexts can be informative and help interpret the safety dynamics found elsewhere.

One of the future research areas is the need to better understand why certain types of public places become a crime magnet and others do not; namely, why they become risky places that concentrate crime. The temporal and spatial contexts of these public places are important aspects to be further considered using real-time data and new ways of depicting public places using real-time streaming and other records, as illustrated in Chapter 17.

Another area that remains open for further research is the relationship between the use of spaces by different users and the well-known mismatches between the design of places and safety perceptions in multifunctional public places. In particular, the possibility of tailoring safety interventions that tackle fear of particular groups of users is an important task in urban planning. More research should be carried out on the importance of social interaction and its effect as a mediator of crime.

"The whole journey approach" to safety is fundamental in the context of the United Nation's 2030 Agenda and its goals for sustainable development. Women and other riders with special safety needs feel less safe than other riders while in public transit. The elderly report feeling more fear than the rest of the population. LGBTQI status and disability also affect safety. Only when we focus on safety patterns over time and space will we be able to tackle safe travel from door to door. In particular, sexual crimes against women in transit environments represent a rather invisible problem and demand more attention both in research and practice. In addition, it is also important to investigate the role of municipalities and other local actors in supporting people's mobility and safety needs, for instance, in old age.

More knowledge is needed about the nature of crime and safety in public places that are privately owned, such as shopping malls or stadiums. Issues of public conduct (what is allowed or isn't in terms of behavior in public places) is at the core when safety is assessed. Surveillance and questions of integrity are also relevant in semi-public places such as shopping centers. This raises questions about who is accountable for or responsible in case "something happens". If safety is commodified, for whom is it intended in these semi-public places? Knowledge is lacking in the international discourse about safety in semi-public places, such as retail environments. There is a lack of evidence-based research on crime and its prevention in these semipublic places, especially knowledge about environments and the situational conditions of these crimes. We first need to understand what safety conditions look like, define interventions and assess what works and what does not work. The debate must also involve issues of accountability among relevant actors.

Future research should also focus on the "unexpected results" (for instance, lighting is related to both increases and decreases in crime in one place) and how training of staff affects the outcome of safety interventions. 
Digitalization, "big data" and new technologies have the potential to change the way a public place is managed and to improve our safety. Yet, policies and practices are slow to respond to these developments. Safety challenges vary across the city and affect different groups of people in different ways. Despite a fairly good knowledge of factors that affect safety, there is often a gap between the knowledge gained in research and what is applied to practical use, due to various obstacles to this knowledge being put into practice. We need to further develop groundbreaking methodologies to best translate and transfer scientific knowledge to practical action (Laub, 2011) and, at the same time, help academics learn from other experts. Until now, the knowledge that is needed in this area has been limited to universities and research institutes. This requires a process that engages and is well informed by academics, safety experts, people in the private sector (e.g., in housing companies) and practitioners in different fields in knowledge creation, exchange and diffusion-that reflect different realities, from large metropolitan areas to rural communities. Technology-based and inclusive safety solutions are at the core of this research that welcomes experimental frameworks for inclusive and safe public places.

In summary, the novelty of this future set of research ideas is to consider that risks are unequally distributed in society and, as such, interventions must be tailored to the needs of different groups, to explore innovative methods in empirical research, especially spatial analytical tools in safety research. Reality demands more integrated, holistic and cross-disciplinary theories and methods that are capable of guiding (and dealing with) an ever-increasing volume of space and time data, to develop ways to improve the transfer of knowledge from researchers to practice, and vice versa. The suggestions put forward focus on the topics that were presented in the book but may not be limited to them.

\section{Design}

Lighting and maintenance are often highlighted as important components of a safe public place, but these characteristics do not come alone. In all studies, guardianship is another important component of a place's safety, no matter if it is a park, a station or a musical festival, regardless of crime type. A safe public place also demands people's involvement in local crime-prevention initiatives, which may also help curb crime and improve safety. A word of caution is necessary, because the evidence is based on studies using different methods and a variety of approaches. In addition, although our sample of articles covers several decades of research, it is biased towards "expected positive results", in other words, articles that show effects of decreasing crime tend to be published, and those that show no effects or unexpected results are not published.

In addition, improving safety conditions in specific locations by using one strategy only might be ineffective because the urban environment does not affect all individuals equally. It is important to consider the mixture, or intersection, of activities, the social interactions (and their contexts and accompanying characteristics) at a certain point in time that lead a motivated criminal to act 


\section{6}

(or that lead us to become a crime victim). From the urban planning perspective, there is vast evidence of a number of factors that can affect both crime and fear of crime that are linked to a particular area, but policies should also be sensitive to the dynamics of temporal patterns of human activity and city contexts.

Crimes are linked to specific environmental conditions, at a particular location and at a specific time, which can be tackled because they are not random events. Different characteristics of the physical environment are important, but their effects vary. This insight has important consequences not only for understanding why crimes occur, where or when, but also how they can be prevented. Therefore, safety intervention needs to adopt a holistic perspective taking into account the interaction between individuals and environments. As suggested by Wikström and Treiber (2017), this can be difficult for crime prevention agencies to influence locally. Therefore, it is important that politicians and policymakers at national levels focus on improving social conditions and change social rules, to the greatest extent possible, to prevent people's exposure to criminogenic conditions, with a certain emphasis on criminally motivated people. As suggested by these authors, interventions that specifically target environmental characteristics will only be effective in preventing crime if they promote changes in how people perceive crime as an alternative in their specific environment.

The implementation of physical barriers (e.g., gates, fences and walls) must be evaluated beyond their technical effects. The literature overview may indicate some evidence that gated communities reduce crime in unequal societies, but what are the costs for the whole society when buses must take longer trips to accommodate spatially fragmented spaces? What is the impact on the safety of those who are "transit captives"? What is the impact of CCTV cameras on people's privacy and integrity? What is the overall environmental impact when more lights are put on the streets for the sake of reducing crime? How can we prioritize investments by types of sustainability goal? We argue that safety solutions that conflict with overall sustainability goals of equality and inclusiveness need to be assessed more strictly in relation to who is the recipient of a particular solution and the overall impact on society. This applies to major housing solutions such as gated communities or other minor technical features of public places such as lighting or surveillance technologies.

\section{Policy}

Architects, planners and safety specialists should expect to have their actions directed towards a safe and sustainable environment supported by the national rules and regulations of construction and planning of their respective countries. In an attempt to direct actions to achieve the UN 2030 Sustainable Development Goals, we should strive for implementation of a system of ongoing, self-evaluating safety guidelines. Equally important is to balance safety principles with other sustainable principles. Breaking down principles for planning and projects for carbon dioxide emissions and other sustainability dimensions should be the next step. 
If it is voluntary, as it is now in many countries around the world, safety as an integral part of sustainability is unlikely to be incorporated into practice in the near future. In order to ensure that safety guidelines are put in practice, there is a need to provide a mandate for municipalities and regional bodies to implement safety guidelines with support from the county administrative boards or similar authorities.

These guidelines are intended to be used as a plan to stimulate new knowledge, change processes and promote new ways of implementing planning practices. The importance of the urban environment and people's daily routine activity would be central when creating written guidelines for architects and planners to incorporate safety as part of their daily work. The focus can be on planning and building permits, detailed plans and outline plans for new housing developments, but also on actions that can tackle existing problematic environments in cities. Safety guidelines should be anchored by national building acts and be implemented with the participation of public stakeholders (e.g., universities), from national to local planning levels in a standardized set of processes.

Equally important is to establish evaluation mechanisms for knowledge and methods used when implementing safety guidelines in practice. This should be a self-evaluating process that demands establishment of good cooperation among sectors (e.g., housing, transportation, social care, health) as well as from national to local levels throughout the planning process. In many countries, including countries with a long planning tradition, such as the Nordic countries, the hierarchy in planning systems prevents the introduction of guidelines. In these countries, a municipal planning monopoly means that legally binding physical plans must be approved by the municipalities before being ratified, which means municipalities are key to ensuring that new developments follow these safety guidelines. However, the system is composed of many steps and moved by diverse interests. The perception is that there are major gaps between urban planning, detailed planning, environmental planning and neighborhood planning and the process for building permits and permits for land use. We argue that these gaps and barriers that limit the implementation of safety guidelines must be identified and tackled, taking into account the particularities of each country.

A plan of action for implementing safety guidelines based on the 2030 Goals could include the following standards of practice:

1. Create clear written guidelines for architects, planners and safety experts by embedding safety as part of their daily work. Focus on planning and building permits, detailed plans but also current crime prevention processes and practices.

2. Strengthen the existing interface between academia, governmental authorities, public and private enterprises, police, municipalities, data production agencies, non-governmental organizations.

3. Identify and work against current barriers to cooperation between the municipality and the police and other stakeholders, such as building companies. 
4. Improve processes and methods in design alongside target-hardening methods (other than walls, cameras, gates, etc.), taking into account users' perspectives of safety.

5. Create arenas locally and regionally for discussions on current methods, theory and practices in crime prevention practices- "what works" and "what does not work". Which way is desirable? Take the "good examples" in perspective and embrace learning lessons from "failed" initiatives show proven methods and examples for municipalities on how to achieve minimum expected standard levels on these aspects.

6. Facilitate changes in the perceptions and attitudes of stakeholders towards those who are more targeted (potential victims). Apply an inclusive safety agenda, non-gender-neutral and tailored to affect the lives of those who have their mobility impaired because of the safety challenges they face. The intersectionality of safety (e.g., age, gender, disability, sexual status) is expected to become more central than today in the assessment of individuals safety needs.

7. Identify barriers and obstacles regarding implementation of actions that improve users' safety as well as barriers to the use of digitally based mobility products and services that can be suitable for particular groups of travelers with safety needs.

8. Implement methods so the individual (regardless of gender, age, etc.) is involved and can influence the design of public places. It is important to ensure that channels are created so that the "unheard voices" in the planning process are included. Tackling ethnic, socio-economic and geographical segregation through housing and employment policies is a pre-condition for ensuring safety for all.

9. Create educational opportunities where learning about crime and safety guidelines is offered to experts working on crime prevention and safetyenabling measures at municipal and regional levels.

10. Consider issues of crime and safety as public health issues, combine solutions to deal with challenging and unjust environments where people live and spend time. As previously suggested in this chapter, it is important that politicians and policymakers at national levels focus on improving social conditions and change social rules, to the greatest extent possible, to prevent people's exposure to criminogenic conditions.

In conclusion, it is important to make crime and safety a mandatory aspect of national building, land use and construction statutes by defining safety guidelines around the world. "Building in" safety at the beginning of a process of construction is more beneficial than trying to fix safety problems after a public place has become a risky place. Yet, interventions that specifically target environmental characteristics will only be effective in preventing crime if they promote changes in how people perceive crime as an alternative in the specific environment. This process would benefit from training mechanisms for experts and cooperation at local to national levels to realize that 
issues of crime and safety are a result of complex interactions between individuals and their environment. It is also necessary to promote training for planners and designers to maximize design options that enable urban safe environments in an inclusive way, considering other perhaps conflicting sustainability goals. More empirical evidence from research to guide planning practice and education is needed. It is vital to strengthen collaboration between stakeholders at local levels, in particular between safety experts and urban planners.

Public places can be made safer for various types of users through some of the following recommendations.

1. Foster urban safety through inclusive policies and practices by: (a) prioritizing the voices of the most marginalized to articulate their own needs; (b) building their own capacities to create safe and secure places, both independently and through collective action; and (c) placing these at the core of a roadmap towards fostering urban safety for all. This also involves supporting community champions, local thought leaders and social workers to continue to innovate local solutions to prevent and reduce crime and fear in public places.

2. Use innovative measures to accurately understand people's pulnerabilities to crime and fear. Field test methodologies that provide a workable set of principles to guide efforts to understand the vulnerabilities to crime and fear at street, neighborhood and city levels and how these vary by gender, age and identity.

3. Prioritize safety for all, not securitizing, public places. A strong and articulate stand against militaristic and hard targeted responses to urban crime and violence, which have limited success and often create long-term instability, is required. Policies and programs that are more likely to be successful in the long-run promote a sense of shared ownership over public places. Increasing the visibility, validity and voice of, for example, street traders, to inform legal, design and planning frameworks to co-produce safe and secure places in the city can revitalize neighborhoods "lost" to crime and fear. It is essential to think "inclusive" when it comes to public places. Public places should be envisioned, designed and built considering the everyday lives, needs and desires of users, children, young people and their families.

\subsection{Conclusions}

In summary, cities can address crime and fear in public places as issues of good urban governance with citizens as the key agents of change. Successful experiences that have reduced urban crime and fear have been shown to improve governance and at the same time benefit greatly from the improved framework for interaction among urban development actors. Participatory governance through urban planning and management approaches towards sustainable urban development are critical to addressing crime and fear in public spaces and are basic to 
the strategy for reducing urban insecurities. It is essential to keep in mind that safety is a human right- to feel free from risk and fear of danger is crucial for all people and a prerequisite for modern society. Safety guarantees, in a sustainable city, every person has the right to a place to live free of danger and free of fear. Safety also promotes and encourages mobility, which is fundamental to an individual's quality of life. Indeed, successful, thriving and prosperous communities are characterized by spaces that are safe and attractive- "livable" places of which local people are proud and to which they feel a sense of belonging and ownership.

If a city is to be called sustainable, "all" places may not be planned for everyone, but everyone should have a place in it. Not in a segregated city, but in an environment where safety is a guaranteed human right.

\section{References}

Laub, J. (2011). Translational criminology and the science of community. US Justice Department. www.youtube.com/watch?v=oETawAfN3Kw (accessed 22 January 2020).

Wikström, P. O., \& Treiber, K. (2017). Beyond risk factors: an analytical approach to crime prevention. In B. M. E. Teasdale, B. (Ed.), Preventing Crime and Violence. Advances in Prevention Science. Cham: Springer.

United Nations (2019) UN 2030 Agenda for Sustainable Development. www.un.org/ sustainabledevelopment/ (accessed 7 May 2020). 


\section{Index}

Page numbers in bold denote tables, those in italics denote figures.

abandoned buildings $25,386,391$

access control 110, 113, 404

action research $379,383-385,387$, 396-397

action research: aligns with the early ecological traditions in crime theorizing 383; approach 396; case study in one neighborhood of New Orleans 380; characterized as a systematic way to investigate and solve local problems 383 ; collaborative team process is inherently participatory and democratic 383 ; cycle 379,384 ; projects 396 active factors 131-132, 134, 136-137, 422 activities $48,52,78,257$; criminal 119-120, 307, 410; cultural 198; disorderly 292; gang 382 ; miscreant 209 ; programmed 99, 253, 256; sexual 146

Acts and Regulations: Hate Crime

Statistics Act 1990 126; Swedish Planning and Building Act 2010 405, 413; UN-Habitat, Safer Cities Program 1996 432; UN Sustainable Development Goals 2030 436; Violent Crime Control and Law Enforcement Act 1994126

Africa 7, 160, 195

African-American women 221, 268

African Americans 201

age groups 145, 147, 150, 160, 189, 191, 204, 234, 239-240, 245, 271, 312, 425-426

aggressions in relation to gender and transportation mode $\mathbf{1 5 4}$

alcohol consumption 117, 120, 362-365, $372,374-375,421,430$

Alexander, Christopher 19

algorithms 330, 340 alleys $17,58,61,120$

'altruistic fear' 267, 279

American Association of Retired Persons 379, 382, 384-389, 391, 393-394, 396

analysis $190,275,333,373$; bibliometric 40-41, 78-79, 82; exploratory 274, 279, 365; intersectional 268, 279; linguistic 328; methodology 397; psycholinguistic 340 ; qualitative 41 , 43; of the relationship of green areas and crime and fear/perceived safety 84 ; spatio-temporal 389; thematic 367-368

Analysis of Variance (ANOVA) 333-334

ANOVA (Analysis of Variance) 333-334

anti-social behaviors 134, 363-364

Aoeteroa (New Zealand) 227

apartments 92, 254-256, 318, 410; empty 259; general 253; rental 254; studio 255; two-room 255

APIs see Application Programming Interface

app-based studies 327

Appendix references 43, 78, 81, 84-87, 202, 210,272, 283, 333

Application Programming Interface 328, 330-331

AR see action research

Asia 7, 43, 83, 86, 160, 195, 420

assaults $56-57,59,79,84,90-93$, 102-103, 147, 156, 195, 197, 200, 209, 227, 309, 315; aggravated 57, 184-185, 208, 423; gun 85-86, 93, 102 ; indecent 162 ; physical 296

Atkins, S. 45, 349-350, 352-353, 356

Atlas, R. 108, 120, 178 
attacks 12, 188, 268, 326, 330-331, $333-335,337,427-428$; analyzed terror 338; escaping criminal 190; racial 95; sarin gas 163; sexual 95; terrorist 163, 204-205, 208-209, 326-327, $329-331,333,335,337-340$

Australia 8, 50, 83, 93, 225, 294, 320; CCTV schemes 48; universities 292 avoidance 24, 147, 197, 208, 222, 227, $253,258,260,269,272-273$, 277-278, 281-282, 423, 431; behavior $147,222,253,258,260,273,278$, 281,423 ; rape 227,310 ; time 260 , 269,431 ; time and place 260,273 , 277-278, 281-282

awareness space 21,77 ; of an individual 21 ; offender's 77 ; restricted 21

background 4, 128, 256; educational 237; ethnic 10, 39, 265, 267, 269, 273, 277, 281, 283, 427; immigrant 267, 279; social 127; socioeconomic 78 ; of Tokyo's transportation 160

Barcelona 12, 326, 330-331, 338

Barrett, L. F. 328-329, 332

barriers 27, 29, 40, 51, 53, 109-110, 127, 223, 251, 404, 406, 410, 420, 437-438; current 413, 437; installing 110; linguistic 135; organizational 58; physical 17, 30, 410, 413, 436; social 134; symbolic 110

basic action research cycle 384

basic emotions 328-329; see also emotions

Bazalgette, L. 250-252

Beck, E. 25, 394

Beeler, J. N. 108, 110

behavioral responses 147, 251, 253, 257-259, 261; expressing 260; four categories of 253 ; main categories of 147,423

behaviors 205, 219-221, 225, 235-238, 241, 243, 245-246, 260, 269-270, 273-275, 303, 306, 352-353, 355-356, 426-427; aggressive 320; antisocial 134, 194, 204-205, 209, 211, 349, 363-364; criminal 319; delinquent 208; deviant 197-198, 208, 313; disorderly 292; human 18, 109,301 ; offensive 236; physical 242; pro-active 273 ; self-protective 222; self-reported 232; sexual 10 , 145-146, 199, 209, 431; women's $225,272,275,281$

Beller, A. 11, 147
Berlin 111-112

Bertoli, L. 24, 128

Beyer, K. M. 75, 91

Bhattacharyya, R. 234, 236

bias 302, 358; gender 179; potential 302,353

bibliometric analysis 40-41, 78-79, 82

BIDs see building improvement districts BIM see building information modeling binary logistic regression 273, 275-278, 280 bisexuals 424

Bogotá 96, 198

Borhan, M. 196-197, 209

Bowers, K. J. 23, 49, 77

Boyce, P. R. 347, 349-350, 352-353, 357

Branas, C. C. 10, 28, 49, 75, 102, 85-87

Brantingham, P. J. 17, 23, 77, 196, 199

Brantingham, P. L. 17, 23, 77, 196, 199

Brazil 11, 162, 176-179, 182, 191, 318, $419,424,431$; and the concentration of sexual violence at central stations 50 ; situational factors explaining homicide within the favela 50; society 182, 191; victimization of women in 179,190

British cities 45, 47

British studies 350-351

building improvement districts 20,30, 409

building information modeling 25-26

buildings $17,19,26-27,29,31,77,254$, 258-259, 391, 394, 396, 403, 405-406, 410-412, 437; abandoned $25,386,391$; apartment 29, 92 , 254-256, 318, 410; designing 27, 403; fortification 117; government 132, 422, 431; high-rise 259; low-rise 259; public 218; vandalized 292

bullying 133,135

burglaries 46, 55, 56-57, 59-60, 79, 84, $86,90-93,354$; re-offending 57 ; residential 55, 57-58, 61

burglars 79, 356

bus drivers 197, 235

Bus Rapid Transit 148, 294-295, 302

bus stations, modern LAMA and LAMTA bus station and Molue bus station in Lagos, Nigeria 199, 200

bus stops $8,10,23,50,146,152$, 155-157, 180, 182-185, 189-191, 198, 205-207, 246, 424, 433; avoiding particular 189; conditions 184; perceived safety in stations and 50 ; public 246; relocating 424; and transit stations 49 ; vulnerable 191; walking to/from 155 
buses $10,145,147-158,161,180$, 182-185, 188-191, 194-195, 197-198, 201-202, 204-205, 207, 234-235, 246, 423-424; crowded 246; overcrowding 180, 247; public 199, 234-235, 246; and reports of sexual harassment on 6

cameras 47, 163, 172, 189, 206, 250, $424,428,438$; body-worn 12; positioning of surveillance 163; serving to reduce criminal activity 119

campaigns 177, 189-191, 226, 362, 393, 424, 429; digital 201; educational 189; fiu-fiu 177; massive educational antiharassment 191; well-meaning 225 cannabis $305,312,317,320$ carbon emissions 347, 355, 357-358, 436 carbon footprint 46 Carrollton Hollygrove Senior Center 392 cars 58, 162-164, 169-173, 318, 423; abandoned 292; passenger 163; private 145, 199; see also motor vehicles case studies 11, 251, 255-256, 383, 396; Lagos, Nigeria 9, 11, 194-201, 203-207, 209, 211, 424, 426; Mexico City 11, 145, 148-149, 155-156, 158, 162; Rio Claro, Brazil 11, 176, 179-180, 191, 423-424; Tokyo/

Kanagawa 11, 160-161, 164, 172, 423 categorization of green areas adapted from Goode and Collins (2014) 82

CCTV see closed circuit television cemeteries 76, 112, 121, 421 central stations 16, 50, 179

characteristics of the participants in the two case studies $\mathbf{2 5 6}$

characteristics of the two neighborhoods 254

Chicago 18, 20, 49, 90-92, 95, 97, 102, $86,379,395$

Chicago Area Project 380

Chicago School of Human Ecology 379

children 19, 29, 112, 114, 255-256, 267, 273-274, 276, 278-280, 283, 293, $373,375,382,392$; disabled 132, 422; lost 373 ; and women 19

cities 3-4, 6-7, 9-13, 52-53, 85-86, 88, 102, 178-180, 207-208, 366, 368-370, 374, 389-392, 420-421, 430-435; British 45, 47; Bulgarian 271; divided 250; global 82, 84; large 31, 45, 47, 52, 91, 401, 406; liberal 109; metro 234; populous 236; safe 3, 24, 272,
421; segregated 440 ; sustainable 3-4, 9 , $24,75,440$; transit 6 ; unsafe 236 citizens $3,75,135,190,247,347-348$, 351-355, 357-358, 420-421, 426, 429-430, 439; active 261; attitudes of 164; feeling safer 356 ; senior 240, 254; surveys $308,317,321$

city $109,112,114,116,210,254,258$, 260; environments $3-4,7,11,16,430$; homicides 389,392 ; managers 429 ; planners 13, 291; structures 77,88 , 431; sustainability 420

City of New Orleans see New Orleans civil rights movement 218

closed circuit television $11,17,29,38-41$, $43,47-48,50,52,56,61,189,206$; cameras 19, 38, 47, 49, 163, 196, 211 , 423,436 ; for control and surveillance 29, 48; effect of 43, 47-48, 56; and security personnel 363 ; usage 56,48 cocaine $305,312,317,320$

Cohen, Lawrence 21, 165-166, 169 collective efficacy $21,59,318-319$, 379-380, 386, 394, 396; differences 319; research 380,395

Collective Transportation System 148 college students 11, 158, 160-161, 164, $170,172-173,179,194,209,235,423$ communities 19-20, 26-27, 45, 59, 61, 97, 132, 305-307, 310-312, 315, 317-318, 321-322, 382, 394-395, 421-422, 428; disadvantaged 383, 394-395; gated 20, 50-53, 269, 410, 420, 436; livable 384,392 ; low-income 96, 380; marginalized 134; poor 396; prosperous 440 ; public health 363 ; rural $24,59,45,47-48,52-53,268$, 401-402, 405-406, 409-414, 434-435; sustainable 19

community capacity building (concept) 380, 384, 393, 395

community planners 406

commuters 160, 164, 171, 194, 199, 201, $207,422-423$

comparison of percentage of self-reported offending and offending by their male friends $\mathbf{2 4 4}$

comparison of percentage of victimization $(N=467)$ and self-reported offending ( $N=317)$ of $\mathrm{SH}$ behaviors 242 contested gendered space 217-228 control areas 31, 350-352, 354-355 control venues 365-366, 368, 370, 373-374 
countries 4, 7, 160-162, 179-180, 182, 186, 194-195, 197, 201, 219, 232-233, 236, 353-354, 404-406, 437; crime-ridden 20; developing 198 , 232-233

CPS see Crown Prosecution Service

CPTED see Crime Prevention Through Environmental Design

crime 6-8, 20-32, 38-61, 75-79, 81-87, 100, 194-200, 250-255, 265-275, 281-284, 291-303, 326-331, 347-358, 401-408, 419-436; addressing 394, 439; alcohol-related 376,386 ; architecture of 38-61, 419; combatting 347,403 ; concentrations 24, 306, 309, 314, 318, 321 ; cyber hate $128,134,136$; decreasing 85,421 , 431, 435; and disorder 85, 91, 195-196, 199, 310; displacement 56, $356,395,397$; drug 306, 320-321; dynamics of 23-24; effect of street lighting on $45,347-348,354$, 356-357, 429; generators 6, 23, 77, 86, $91,196,200$; governance 426 ; high 51 , $236,379,382,385,389,430$; incidents $18,93,211,403$; increasing 41,85 , 374 ; indoor 55,46 ; knife and weapon 309,315 ; methodologies 327; nighttime 350, 386; occurrences $21,38,45$, $85,191,196,347,403$; opportunities for $4,16-18,22-23,29,40,45,49$, $77,146,363,403,429$; organized 28 , 217; paradox 220, 225; perception of $56,48,160,426$; prevalence of 349 , 351,358 ; preventing $21,27,403,436$, 438; recorded 236, 372, 374, 430; reducing $41,52,108,211,374,384$, 396,436 ; reported $24,46,126,321$, 350 ; research 301,340 ; risks $7,40,52$, $113,373,405,421$; sexual transit 158 ; statistics 10, 126, 220, 308-309, 321; surveys 296, 309-310, 365, 372; underreported 186; vehicle 56-57, 350, 354; victims of 3, 6-7, 10-11, 21, 24, 114, 267, 273-278, 283, 432, 436; violent and property 54,351 ; white paper on 162-163

crime absorber 23,77

crime and fear 4, 6-7, 11-12, 16-17, $48-49,87,393,421,423,425,427$, $429-431,435,437,439$; of crime 27 , $38-41,43,45,46,47,49,51,53,55$, $58,60,354,356-357,419-420,426$; in Hollygrove 379-397; and the impact of reduced street lighting on 347-358; metrics of 16; in public places $1,3-4,5$, 7, 11-13, 16, 176, 179, 419, 433, 439; in public spaces $4,12,439$; situational conditions of 402 ; situational theories of 403-404

Crime and Fear in Public Places Conference 2018179

crime and safety $3,39,75,77,79,81$, $82-83,85,87,89,401,407,413,430$, $438-439$; fear of 419 ; project team 385,391

crime attractors $6,23,77,196,199$

crime concentration in Open Drug Scene $\mathbf{3 1 5}$

crime data $26,309,366,383,388-389$, 395; comprehensive 396; geocoded 26; police-recorded $310,350,352,365,372$ crime levels 40, 109, 350-351, 355, 402; changing 281; high 28; recorded 362

Crime Pattern Theory 196, 318 crime places 21-22, 130, 310

crime prevention 18-19, 27, 29, 301, 321, $380,385,393-394,401-403$, 405-406, 408-409, 413, 430, 433, 438 ; activities 430 ; agencies 436 ; effective informal 17; effectiveness 347 , $351,380,395$; experts 29 ; initiatives 20, 357-358, 435; literature 380; local 406; measures 357; place-based 3 ; policies 406; practices 402, 437-438; programs 19; social 405 ; specialists 393 ; strategies 301, 349, 352, 395, 420; tools 52; work 406

Crime Prevention Service 126

Crime Prevention Through Environmental Design 11, 18, 38, 40-41, 43, 48-50, 58-60, 108-111, 210, 380, 385-386, $401,403,407-408,421-422$; assessed 49 ; and the concept of territoriality 421 ; core principles 404; effect of 58 ; effectiveness of 51 ; features on reducing crime and maximizing safety perceptions $38,40,44,52$; ideas 18-19; importance of 50; interventions 60,210 ; in planning practices 409 ; principles 20, 43, 48, 108-111, 113, 120-121, 409, 414; principles and used methods 113; programming 379; qualities 50; and the safety of public places 48,110 ; second generation of 19; studies 52; third-generation of 404 , 414; training 385-386, 391; use of 402,404 
crime radiators 23,77 ; see also crime absorber

crime rates $45,49,60,109,197,210$, $291,350,352,354,356,366,368$, 405 ; changes 430 ; city-wide 395 ; high $49,60,198,351,354$; increasing 347 , 349 , 356; low 51, 374, 401; property 94; recorded 354

crime reduction 45-46, 49, 92; efforts 430 ; significant 47 ; strategies 380

Crime Survey for England and Wales 127, $365,372-373$

crime types $41,87,184,186,309,315$, $350,352,372,374,435$

criminal justice system 18, 126, 191, 306

criminal networks $310,312,316-317$, 319,322

criminals $21,23,133,188$; motivated 21 , 435 ; potential 404

criminogenic places $22-23,49,146$

criminological theories 319-320, 429

criminologists $18,21,220,251,380$

criminology 3-4, 13, 198, 291, 296, 301, $303,338,340,383,428$

cross-tables between the experiences and perceptions of groping on trains among female participants 167

cross-tables between the experiences of groping and the perceptions of survey cameras and women-only cars among female participants 169

crowdedness (binary variable) 292, 296-297, 300, 303, 427

Crown Prosecution Service 126

cyber hate crimes 128, 134, 136

cybersecurity 330

cyberspace 12, 326-327, 329-331, 333, $335,337-340,428$

Cytadela Park, Pozna冈 108-109, 111, $112-117,120-121,421$

data $26,47,52,327-328,427,434$; cross-sectional 272; and methods used in Hollygrove 387; police-recorded 358, 428; venue-acquired 374-375

data collection 79-80, 113, 125, 130-131, 237, 293-296, 302, 362, 374-376, 386, 396, 430; method 25, 291; quantitative 90, 397; and selection in Scopus and Google Scholar 1968-2018 80; tool 303

databases $41,78,80-81,91,96,130$, $135,138,164,328,331,348,420$, 422 ; JSTOR $38,40,42,420$; major 75 ;
PubMed 130; Scopus 38, 40, 42, 79-81, 83, 125, 130, 138, 420, 422; Web of Science 38, 40, 42, 176, 348,420

datasets $41,160,164,272,283-284,331$, 366,368 ; large 272, 338; limited 389; safety survey 272

daytime $102,157,167-168,182$, 189-191, 195, 202, 206-207, 209, 241, 424; control 350; hours 302; waiting on the station platform during the 165

"defensible space" 18, 58, 109

descriptive statistics for the observations included in the OLS model 298

descriptive statistics of victims $(N=467$, $60.7 \%)$ and offenders ( $N=317) 238$

design 11-13, 17-19, 26, 30, 49, 59, 82, $88,103,300-301,402-404,406-407$, 409, 431, 434-435, 438-439;

experimental 94; features 16-17; internal 209; landscape 99;

methodological 339; open 196; physical 259,404 ; poor 16; strategies 404

development 19-20, 25, 76, 98, 109, 250, 318-319, 328, 333-334, 337, 393, 401, 404-405, 432, 435; local economic 396; modern 20; negative social 319 ; new property $401,405,437$; technological 7; and the use of tweets' during the first 24 hours after each attack and groped by hashtags 334 deviant behaviors 197-198, 208, 313 DHCs see disability hate crimes diagnostic prevention systems 136, 422 Dickenson, Cary 131 digital timetables 189, 191, 206, 424 disabilities 11, 24, 125-138, 147, 177, 194, 251, 431, 434, 438; intellectual 135; learning 131; multiple 131; perceived 125-126; victim's 126 disability hate crimes $6,125-138,420$, 422; addressing 128; carried out by a perpetrator's hostility towards the victim's disability 126 ; facilitating 132 ; incidents 127, 422; limiting 125, 128, 134, 137-138; literature 138; occurrences 125, 130-133, 136, 422; perpetration of 131,134 ; in public places 125; studies 128; violence 422 disabled people 125-129, 131-137, 422 disciplines $3-4,13,16,218$ disorder 10, 20-21, 23, 76, 79, 85-86, 91, 103, 195-196, 199, 269, 292, 310, 
disorder continued

316, 375-376; and crime 54; eating

177; environmental 100; public 50, 52,

$57,103,431$; social 25, 116, 292

disruption in the area associated with the Open Drug Scene $\mathbf{3 1 3}$

distribution 120, 180-181, 237, 272, 305, 311, 319-320, 331, 335-337, 425, 428; balanced 186; criminal network 316; of emotive values (valence and arousal) across different hashtags 336; geographic 236; national 181

Drinkaware "Festival Crew" 362-368, 370-375, 429-430; activity log data 367, 370-371, 375; harm reduction initiatives $364,373,375$; in operation 367, 370-371; training 367, 370 drugs 57, 76, 100, 120, 305-306, 310, 316, 320-321, 382, 391; distribution 116-117, 120, 319; illicit 382, 391; markets 77, 305, 307, 310, 318-319; offences 112; problems 321 ; sales 314 , 318-319, 321; scenes 308, 312, 314, 320-321, 428; trade 315, 318; users $116,120,293,305-307,311,314$, 320,428

drunkenness 92

East Japan Railway 162-163

Ecological Momentary Assessment 12, 25, 291-292, 294-296, 298, 300-303, 427

education 235, 238, 251, 270, 406, 422, 433,439

effect of CCTV on crime and/or fear (publications mentioning CCTV in the title, keywords, abstracts) 56, 57

effect of CPTED on crime and/or fear (publications mentioning CPTED in the title, keywords, abstracts) 58, 59, 60, 61 effect of lighting, CCTV and CPTED features on crime and fear of crime according to the international literature 1968-201844

effect of lighting on crime and/or fear 54,55

EHRC see Equality and Human Rights Commission

EMAs see Ecological Momentary Assessment

emotional responses 330, 337-338, 428 emotions 24-25, 221, 291, 301, 303, 326-329, 332-335, 340, 353, 358, 428; basic 328-329; discrete 328; encoded 327; measuring 353; people's 222,353

emotive responses 327, 329-330, 335, 337,340

emotive values 332-336, 338; by hashtag 334; by speech act classes of hashtag 333; of tweets across different classes of hashtags (descriptive, solidary, opposed) 335

End Violence Against Women Coalition 224

environment 4, 6, 17-19, 21-24, 40-41, 51-52, 77-78, 96, 108-109, 198-199, 291-294, 363-364, 403-404, 419-421, 436-440; educational 135, 137, 422; fictional 25; high-rise 268; improved lighting 54; natural 97, 300-303; physical 11, 18-19, 26, 29-30, 43, 51, $110,210,292-293,357,403$, 408-409, 429, 431, 436; public 16, 29, $128,145,178,433$; retail 48, 268, 434; social 19-20, 32, 77, 108, 113, 115, 282, 291-292, 402-403, 421, 432; socio-cultural 186; sustainable 13, 75, 436; transit 16, 47, 49-50, 146-147, 153, 157-158, 160, 203-204, 423, 431,434 ; virtual $134-135,422$

environmental 3-4, 9, 16-18, 27, 38, 49-50, 75-76, 100-101, 108-109, 115-116, 172-173, 196, 356-358, 403, 436-438; changes 357; characteristics $4,27,284,403,427$, 436, 438; conditions 371, 436; constraints 97 ; criminology theories 3 , 13, 16-17, 89, 196, 362; design 27, $108,120,356,380,403,421$; factors $11,49,365$; features $38,256,274$; planning 419, 437; protection 357 ; social features 115-116

Equality and Human Rights Commission 127-129, 134

ethnic minorities 267-268

ethnicity 78, 95, 126, 134, 136, 181, 186, $198,251,256,265$; groups 150; nonwhite 181; perceived 125

evaluation $19,31,46,47,53,81,110$, 226-227, 320, 326, 365, 367-368, 370, 374, 429; criteria 7; mechanisms 437; of police efforts 307 ; process 7 ; short-term 48

EVAW see End Violence Against Women Coalition

evidence 6-7, 38, 40-41, 45, 82, 85, 87-88, 347-348, 350-351, 372, 
374-375, 419, 421, 431-432, 435-436; based planning 13, 53; demonstrating significant crime reduction 47; empirical 49, 321, 439; gathering 284; mixed 47; positive 46; recent 47,352 ; reported 160 ; strong 75,253

FBI see Federal Bureau of Investigation fear levels 17, 277, 279, 388

fear of crime 41-44, 59-61, 86-88, 100-101, 250-253, 260-261, 265-270, 281, 291-303, 326-331, 337-340, 347-349, 352-358, 419-421, 423-431; contextual determinants of 12,291 ; correlates of 292-293, 300; experienced 251; high 427; increased 100, 210, 292; individual's 269, 427; levels of 24, 220, 251, 253, 257, 267-269, 273-274, $279,292,340,425$; measurement of 296, 300-301, 427; nature of 12, 266; negative consequences of 291; perceived 402, 428; previous research on 147 , 270 ; in public transit $293,295,297$, $299,301,303$; in relation to everyday mobility, mental maps, and social participation 251; spatial dimensions of women's 265,282

fearful women 265-266, 272-282

fears 39-40, 50, 78, 204, 220, 223, 265, 267-269, 282, 284, 357, 383-384; functional 24, 273, 277, 279-282; generators 196; important 204; incidents 295; individual's 39, 78

Federal Bureau of Investigation 382 Federal Government Revitalizing Rail Project 199

Felson, Marcus 21

female 176-177, 187, 197, 201-202, 205, 207, 209, 211, 232, 234, 237-240, 256, 267-268, 423, 425; flight attendants 221; LGBTs 424; participants 166-167, 169, 171; partners 224; patrons 373; population 187; targets 364; victimization 187 , 234,236

Ferraro, K. F. 267, 348

festivals 364-365, 367-368, 370-372, $375-376,430$

focus groups 31

forests $6,75,79,90,112$

fortification ruins and mixed types of path surfaces 117,118 ; lit paths by night 117,118 ; amphitheater 117,118 fortifications $112,117,120-121,421$

framework 16, 19, 233, 397, 413; analytical 284; common spatial 26 ; conceptual 16, 419, 421; convenient sampling 236; experimental 435; improved 439; interdisciplinary 326 ; intersectional 270; social 129 ;

theoretical 11, 125, 128-130, 138, 196, $327,380,419$

frequency $61,113,133,153,156$, 164-165, 169, 183, 205-207, 210, $235,327,367,370,422-423$; and age distribution of victims and offenders 240 ; of crime $56,86,93,352$; and the Fisher's Exact Test 273; levels of safety 156; small expected 273

functional fear 24, 273, 277, 279-282

gated communities 20,51-53, 269, 410, 420,436

gay men $6,284,424$

gay sexualities 224

gender 6, 125-126, 146-147, 152, 154-155, 167-168, 181, 184, 186, 201-203, 267-268, 282-283, 425, 431-432, 438-439; differences 98, 164, 166-167, 202, 220, 236, 241, 244, 423; disparities 265; equality 191 ; inequalities 208; roles 220, 233; segregation 217-218; status 267, 406, 427; studies 4, 425; violence 176, 233, 423

Gender Equality Bureau Cabinet Office (Japan) 161, 170

geographic information systems 26 , 309-310, 314

girls 132, 178-179, 195, 201, 208, 217-219, 222-227, 235, 425; learning bodily strategies to prevent or minimize the possibility of men's intrusion 223; modifying their behavior to reduce their risk of harassment 195, 208; schoolaged 227; and women 179, 195, 201, 208, 217-219, 222-223, 226-227

GIS see geographic information systems green areas 9, 75-79, 81-87, 89, 98-99, 101-103, 408, 419-421, 431; categorization of 76,82 ; common types of 76-77, 420; controlled 76; and crime and safety perceptions/fear of crime 76 , $85,102,103$; effects of $81,87,91$; parks, forests, neighborhood parks, green vacant land, interstitial spaces and crime $90,91,92,93,94$; and safety 
green areas continued

perceptions/fear of crime surrounding the use of public parks in the city 78 , $86,95,96,97,98,99,100,101$; tended 76,82 ; theory and definitions of 76; un-tended 76; urban 82, 87, 91, 100; well-lit 54, 91

groping 156, 160-163, 166-167, 169-173, 205-206, 234-235, 364, 423; cases 172 ; deterring 172 ; experience of 162, 166-167, 170-171, 173; facilitating 173; prevalence 163 ; reported incidents 162-163; sexual 162, 243 ; victims of 161

groups 11, 26, 28-30, 88-89, 114, 183-189, 238-239, 245-246, 250-251, 253, 258-259, 277, 311-313, 379-380, 390-392; ethnic minority 24; generic 190; heterogeneous 251; homogeneous 265 , 273; impairment 133; independent 406; large 114, 132, 136; male 183; nonLGBTI 186, 188; non-white 186, 189; of people $30,95,362,435$; of residents 379,421 ; social 4, 27, 183; of students 183, 189; victimized 185-186, 190; vulnerable 176, 179, 186, 306, 313, 431; white 186; women's 182; extremist 329

guardians 23, 25, 223; capable 21-23, 196, 318, 423; effective 200; formal 23 guardianship 17-18, 77, 89, 149, 318, $363,372,404,409,420,426,431$, 435; attributes 420; capable 363 ; diminished 233; increased venue-level $372,422,430$; personal 363; poor 25 gun assaults $85-86,93,102$ gun violence $305,307,319-320$; data 309; lethal 319; recurrent 319; and shootings 315

Hall, E. 127, 131

harassment 125-128, 133-136, 153-154, $157,164-167,170,176-177$, 180-181, 184-186, 190, 195, 198, 220, 223-225, 422-424; crimes 187; cyber 134, 136; experienced 165-166; experiences 166; physical 157, 179; preventing 135, 137; risk of 195, 208

harm in night-time economy venues, alcohol-related 363-364

harm-reduction initiatives 362-363, 365, $367,369,371,373,375$

harm-reduction strategies 305 hashtags 328-340; ordering by mean valence 338; popular 329; relevance of 337-338; and tweets 331; usage 337

Hässelby Gård (Stockholm) 253-255, 257-261, 426

hate crimes $11,125-126,128-129,132$, 284; discourses 127; focus on "minority-victimology" 126; incidents 132; posters 135

hate speech $134,136,340$

HC see hate crimes

health $24,43,75,78,92,133-134,251$, $261,270,354-355,390,426,437$; conditions 10, 253; human 9, 51; outcomes 75; political 393; public 19, 177, 301; status 86, 257; women's 177

healthcare 306-307, 311, 322

Hebdo, Charlie 12, 326, 330-331, 337

high crime $51,236,379,382,385$, 389,430

Hollygrove 379-387, 389-397, 430; neighborhood 379-381, 388-389, 392-393; neighborhood boundaries 381; neighborhood in relation to New Orleans CBD and the Hollygrove neighborhood boundaries 381 ; population 380-381, 389; reported homicides 389, 392; residents 382-383, 392-395; resilience and capacity for action 394; Seniors 390; teams 386, 394

Hollygrove Farm 396

homeless people $117,120,421$

homicides $45-46,50,52,54-55,59,86$, $92,109,198,386,389-390,392,395$, 431 ; see also murders

homosexuals 201

housing $18,27,29,49,58,90,102,110$, $134,148,389,391,406,410$, 437-438; age-segregated 261-262; developments 95, 255, 410; poor 133, 135, 137; senior 253, 255-256, 258,260

housing developments 51, 351, 402, 410,437

Hurricane Katrina 379, 382-383, 387-389, 391-395, 430

illicit drugs 382,391

incidents $6,126,133,161,163,166,232$, 309, 366, 373, 375, 431; disorderly 350; groping-related 162; and interactions 373; low-level 374 
incivilities 99-100, 293, 298-299, 303, 427; perceived 293, 297-298, 300; perception of 293-294; physical 269, 274, 292, 294, 296; social 279, 292-293

inclusion and exclusion criteria 81

India $8,11,162,219,232-237,239$, 241, 243-247, 419, 425-426; cities 246; northeastern 234

Indian Penal Code 237

individual characteristics $6,39,150$, 265-267, 273, 275, 279, 282, 433; multiple 279; particular 270

information 23, 25, 29, 204-205, 291-292, 300, 302, 308, 310, 339-340, $364,384,386-388,390,397$; boards 120; demographic 293; detailed 120; emotive 329; false 134; gathering 327 , 389; general 113; micro-spatial 388; non-contextual linguistic 328 ; pertinent evaluation-related 349 ; sharing 176 , 385 ; systems 26,310 ; visual 353

infrastructure 92, 117, 161, 246-247, 270, 382; public transportation service 189; social 393-395, 430

initiatives $25,176,255,257,262$, 349-350, 354, 362, 365-366, 368, 370, 373-376, 390, 392, 420; community-based 396; crime prevention 20,357-358, 435; evaluating behavior change 375 ; failed 438 ; harm-reduction 12, 362, 364, 374; long-term 391; night-time economy venue 371 ; partnership 20; public participation 26; rail expansion 393; safety 414 ; safety participatory 402; sexual 233; street lighting 348

injuries, physical 227, 355, 429

insecurity 10, 29, 31, 156, 177-178, 182, $232,250,319,340$; imagined 250; reducing urban 3,440 ; sense of 178

International Centre for CrimePrevention 197

internet 134, 137, 190, 219

intersectionality 10, 181, 184-185, 190, $224,265,267-268,282$; approach 10 ; of safety 431, 438; of students' concerns about public transportation $\mathbf{1 8 5}$; theories of 265,268 ; of victims regarding sexual assault or harassment crime 187; of victims regarding three types of crime analyzed $\mathbf{1 8 5}$

interventions $4,6-8,13,25-28,30-31$, 50, 52-53, 84-85, 99, 101, 306-307,
320-321, 368, 429, 432-436; early 319 ; effective 307 ; radical 227 ; repressive 321

interviews $31,48,95,97,110-111$, 113-114, 137, 223, 234, 256-257, 350, $355,367,375,383$; face-to-face 255 ; group 355 ; in-depth 48,355 ; informal $383,389,397$; motivational 305; semistructured $362,367,370-371$

Islam 329-330, 337

Islamic terror 331

Islamophobic tendencies 338

isolation 110, 132-134, 177, 218, 252, 265, 348, 422; disability-related 227 ; social 134,136

Jacobs, Jane 18, 109

Japan 8, 11, 160-163, 165, 167, 169, 171-173, 194, 419, 423-424, 431; property crime in 45 ; transit safety and students in 161, 163, 165, 167, 169, 171,173

Japan Ministry of Land, Infrastructure and Transport 161

Jeffery, Ray 18, 109

JeSuisCharlie (hashtag) 331, 333, 338

jewelry snatching $184,204,424$

JR East see East Japan Railway

JSTOR (database) $38,40,42,420$

justice 10, 18, 218, 373, 405; criminal 18, 126, 191, 306; informal 219

justice officials 386

Kanagawa Prefecture 160-161, 170

Kansas City 349

Keio Electric Railway 162

keywords 43, 56, 58, 79-81, 82-83, 125, 330 ; and the creation of biblio-metric maps 41 ; and their relatedness in terms of co-citation links 43; and the use of CPTED in the 43

kidnappings 197

knife crime 315

knowledge 20, 26, 28, 30, 32, 136, 292, 296, 320-321, 406-407, 410, 412, 430, 434-435, 437; improving 27, 176, 424; scholarly 40, 76, 348, 420; scientific 348, 358, 435; specialized 396

labor 221-222

Lagos 9, 11, 194-201, 203-207, 209, 211, 424, 426; metropolitan city of 196, 198-199, 201; population 198; undergraduates 201 
Lagos State Government 198

Lagos State Transport Authority 210

language 9, 129, 243, 326, 328-329, 428; abusive 241, 243; obscene 153, 204, 208, 243; pattern 19

laws $9,22,39-40,177,218,235,240$, 245, 247, 306, 425-426; criminal 162, 247; effective 247; enforcement 4, 13, $18,191,426$

lesbians 224, 424

LGBT 187, 424

LGBTI 181, 186, 189-190; female victims $179,188,190$; groups 181, 183, 186, 188 , 190; non-white 182; people 178; students 179; women reporting feeling unsafe while waiting at the bus stop 182; youths 176-177, 179, 181, 183, $185,187,189,191$

lifestyle adjustments 147, 253, 258, 260,423

lighting 38-41, 43-44, 45-46, 52, 60, $116,119,121,349-350,353$, 420-421, 428-429, 431, 433, 435-436; appropriate $115,117,120$, 121; bus stop 190; conditions 158, 356; effect of 41, 43, 44, 46-47, 420; electric systems 347 ; improved 206, 210, 386, 421, 424; interventions 351 ; poor 268; public 347, 352-354; regimes 354 , 429 ; research evidence on 38 ; sensors 48; street 45-46, 350-351; systems 354 ; urban 353

literature $38-41,48,50,52,75-76,78$, $80,87-88,125,128-133,252$, 301-302, 356, 358, 420-422; contemporary 284 ; criminological 126 ; existing 7, 129, 132, 294, 301, 372-374, 430; mainstream 279; national 365 ; reviews $125,129,198$, $348,358,419-420,422,429$

literature search 40-41, 78, 82; based on 4 , 730 articles 41 ; covers 59 years from 1968 to 2018 40; for the keyword: "greenspace" in publications that relate to crime and fear of crime 1968-2018 83

local governments 3, 348-349, 354, $356-358,395,411,429$

local police 112, 135, 137, 312, 385-386; see also police

Louisiana State University 385

LSU see Louisiana State University

main impediments for students using bus service more frequently. 184 males 98, 202, 207, 209, 232, 234-239, $241,307,423,426$; elderly 268 ; offenders 425 ; white 268

maps $12,38,79-80,308-309,385,388$, 390, 397, 403, 430; crime fear 388;

informative network 41, 80; mental 24 , 251-252, 260, 426; network

visualization 42,83 ; showing bus stophomicide correlates 390; showing locations of high fear levels 388 measurement 296, 300-302, 327, 340, $349,427,429$; of context-specific fear and perceived risk of crime 302 ; from EMAs 301; of fear of crime and perceived risk of victimization 296 measures 296, 301-302, 340; of fear of crime and perceived risk of crime 301

media 232, 240, 245, 247, 259, 261, 269, $305,307,426$

medications 305

mental health system 132

Metro 147-157, 180, 234, 274, 317, 423; bus stops 158; lines 148; riders 156 ; stations $23,60,153,156-157,235$, 246, 254-255, 259, 283, 426; system 145,158 ; trip frequency 151 ; users 158 Mexico 8, 11, 145-146, 148-149, $157-158,162,197,353,419,423-424$

Mexico City 11, 145, 148-149, 155-156, 158,162 ; considered the second most dangerous in the world 145; eastern 145, 148, 157, 423; metropolitan area of 145-146; shows the highest sexual victimization rate on buses 149; student precautions while travelling on public transit 149, 157

mobility $247,252,256-257,260,262$, 266, 270, 274-275, 348, 353, 355, $358,431,438,440$; human 51; impairment 265; patterns 146; policies 282; restrictions 51 ; strategies 253 ; urban 176-177, 180; women's 6 mobility policies 282 model 18-20, 25, 32, 90, 128, 273, 275, 277, 281, 298-299, 332-335, 337-339, 406, 409, 413; conceptual 196 ; implementing planning safety 19 ; linear 332-335; multilevel 284; regression $85,90,266,296,298,300$; social 128 ; tests 273

motor vehicles 56, 59, 61, 91-92, 110, 153, 198, 209, 291, 294-295, 297-299; crimes 56-57, 350, 354; safety 349 
motorcycles 148, 180, 194, 202, 204-207

municipalities 12, 24, 27, 30, 109, 111, $148,255,257,270,401-402$, 404-413, 426, 434, 437-438; larger 395 ; populated 406; rural 401, 405-406, 409-414; Stockholm 270, 284, 309, 316; surrounding 148; urban $406,409-412,430$

murders 79, 91, 131, 178, 208, 225, 309, $315,317,382,387,391$

music festivals $362,364-365,367,375$, 429-430; attendances at 362; considered crime generating locations 363; evaluating harm-reduction initiatives in the UK 12; patrons vulnerable to risks of alcohol-related harm and victimization 365; UK-based 362,365

National Capital Territory 236

National Crime Record Bureau 236

National Police Agency 162-163

National Rural Development Agency 404 natural surveillance $18,27,40,49,110$, $121,256,259,356-357,380$, 403-404, 408-410, 430

NCRB see National Crime Record Bureau

NCT see National Capital Territory neighborhoods 19-20, 45, 61, 92-99, 101-106, 250-251, 253-262, 268-283, 310-312, 318-319, 356-357, 379-380, 382, 384-387, 391-394, 396-397; cooperation 48; crime prevention activities 430 ; disorganized 20; environments 250 , 269; high-crime 392 ; integrated 269 ; low-income $84,101,259$; murderous 379 ; organizations 394 ; parks 75,87 , 90; planning process $380,396,437$; planning systems 380,385 ; resilient 393,395 ; revitalizing 439 ; run-down 269; selected 51 ; surrounding 428 ; Swedish 250; troubled 397; urban 101, 406; vulnerable $307,310,316$, 319-320

neighbors 29, 58, 273-282, 379, 385 network visualization map with focus on "crime" and "fear of crime." 42 networks (criminal) 310, 312, 316-317, 319,322

New Orleans 12, 379-382, 388-390, 392-393, 395-396, 430; and Hollygrove 381, 389; state of crime 389 New Orleans Police Department 385, 389
Newman, Oscar 18, 109, 268

Nigeria 11, 194-195, 198-200, 203-209, $419,424,426,431$; citizens 201 ; public transport users in 205; roads 195 ; undergraduate females 209

night-time 114, 165, 167-168, 170, 182, 202, 358, 424; and alcohol-related harm in economy venues $363-365,372$; crime 350, 386; economy 12, 362-366, 373-376, 429; index crimes 351 ; safety 167 ; users 114,119

NTE see night-time economy

ODS see Open Drug Scenes

offences 4, 21, 79, 153, 198, 351, 363, 372-374; criminal 125-126, 160, 163; drug 112; minor 162; sexual 10, 366, $369,372-373$; violent $160,366,372$ offenders 7, 11, 27, 77, 126-127, 153, 196, 199, 232, 234, 236-246, 356, $363,366,423-426$; age groups 245 ; majority of 238,244 ; male 425 ; motivated 6, 21-22, 196, 200, 233, $318,363,403$; potential 22, 45, 49, $247,318,353,356,364$; self-reported 241-242, 426

offending patterns $11,232,243-244$, 246,425

online $12,128,136,180,326-327$; blog space 219; discursive contents 328; research methods 137; surveys 136,180

Open Drug Scenes 8, 18-20, 53-61, 84-88, 90-93, 250-255, 268-269, 274, 305-322, 327-330, 356-358, 387, 393-397, 428, 437-439; areas 314; combatting 306-307; inventory of 308,310 ; mapping 315 ; nascent 319 ; in the northern part of Stockholm 2017 313 ; shootings and perceived safety measures in the northern part of Stockholm municipality 316; and shootings in Stockholm county 2017 $311,314,321$; typology of 311,317 ; users 312 ; and vulnerable neighborhoods 316 ; in vulnerable neighborhoods 320

ordinal logistic regression results of fear of crime $(n=216) 299$

ordinal logistic regression results of perceived risk of victimization $(n=216) 299$

outdoor violence 309,311

overdoses 321 
Pain, Rachel 220, 251

park users $6,99,110,113,115-117$,

119-121, 421; declared safety perceptions by 109; and the physical and social environments of a park 108; safety of 108-109, 111, 113, 115, 117, 119-121; urban 100, 108-111, 113, $115,117,119-121,421$

parks 3-4, 6, 8-9, 11-12, 16-18, 46-47, 75-77, 79, 83-89, 90-92, 97-94, 108-117, 119-121, 409-410, 419-421; clustered 198; desolated 77; inner-city 111; multi-functional 88; neighborhood 75, 87, 90; public 95, 225; safety in 98, 110; and streets 12 , 101, 409; unsafe 78; urban 100, $108-110,421$

passengers 50, 161, 163, 174, 194, 196-198, 211, 246; daily 199; drunk 167; railway 172

people 9-11, 22-23, 38-40, 95, 98, 108-112, 114-116, 119-121, 126-127, 131-138, 206-209, 250-257, 259-261, 291-293, 372, 435-438; begging 292; drinking 165 , 204, 208, 297; homeless 117, 120, 421; involved in voluntary activities 48,52 , 420; LGBTI 178; local 293, 440; older $96,254,257,426$; vulnerability of 439 perceived risk of crime 292, 296-297, 300-301, 303

perceived risk of victimization 294, 296-300, 303

perceived safety $7,10-11,25-26,40-41$, $43-45,45-53,58,75-78,86-88$, 95-102, 108, 119-121, 202, 266, 283; assessed 111; in communities 97 ; by day 102; by frequent users 97 ; by gender, transportation mode, settings and time of day 155 ; increasing 41 ; in stations and bus stops 50

percentage comparisons of the imagery of $\mathrm{SH}$ for females $(\mathrm{N}=766)$ and males $(N=621) 239$

percentage of victims ( $N=467)$ and offenders $(N=317)$ awareness of $\mathrm{SH}$ laws and their effectiveness 241

percentages of students in each group who take some precautions in public transportation 188

perceptions 45-46, 48, 146, 148, 165-167, 169-171, 204-205, 236, 245, 292-294, 301, 420, 426, $431-432,437-438$; of incivilities and social cohesion 293-294; individual's 6, 252, 268; measuring 167; people's 48, 92,426 ; public 10 ; safety $38,43-44$, 45-46, 86-88, 99-101, 103, 108-109, 113-117, 145, 147, 155-157, 167-168, 255-256, 401-402, 420-423; subjective 173; women's 169 , $279,352,423$

perspectives $4,6-7,13,16,19,24$, 128-129, 135-136, 245-246, 252, 320-321, 414, 424-425, 432, 438; children's 409; historical 17; interdisciplinary 13 ; intersectional 221 , 224; long-term 32; operational 173 ; situational crime 402 ; socio-cultural 233; structural 128; sustainable 51; women's 164

physical barriers $17,30,410,413,436$

physical environment 11, 18-19, 26, 29-30, 43, 51, 110, 210, 292-293, 357, 403, 408-409, 429, 431, 436; principles 408

physical incivilities 269, 274, 292, 294, 296 physical injuries $227,355,429$

physical sexual violence $146,153,423$ pickpockets $8,156,183,195,198-200$, 204, 208, 296, 424

place attachment $3,75,261$

place managers $18,23,25,40$

planners 7, 17-18, 20, 26-28, 32, 401, 405-414, 419, 430, 432, 436-437, 439; city 13, 291; community 406; expectations of 402, 412; physical 406; safety challenges 406 ; and safety experts $17,26,32,411,419,437$; urban $7,12,29,401,404,413,430$, 439; value of 409

planning process $27,30,380,402$, 404-405, 407-408, 411, 437-438 plans $3,153,163,260,393,402,412$, 421, 437; comprehensive 405, 411; detailed development 405, 408, 411, 437; outline 437

Poland 7, 108-109, 111-112, 119, 120, 419,421

police 8, 25-27, 102, 126-127, 134-135, 165-166, 171, 305, 308-309, 319-321, 354-355, 365-366, 372-374, 409, 411-413; data 102, $321,350,354-355$; departments 307-308, 310-311, 315, 354, 382; employees 308-309, 320; enforcement 307 ; hotlines 206; officers 20, 23, 26, $169,305,352,424$; patrols 115, 189 , 
$211,235,393,424$; raids 391; responses $307-308$; services 54 , 382 ; statistics 109, 321; support 394, 430; surveillance 8,158 ; surveys $315-316$ policies 12, 136-138, 178, 194, 199, 279, 408, 419, 421, 428, 432, 435-436, 439; crime prevention 406; employment 438; and governance documents 407 , 408 ; international 217; land development 384; neighborhood 282; public 7, 158; public transport 189, 211; recommendations 146, 321

policing 20, 211, 310; effective 135; harm-focused strategies 320 ; hot spot 320, 428; increased local 190; on-street 119

policymakers 13, 20, 26, 246, 301, $347-348,438$

politicians 436,438

politics 384, 392, 395

POP see Problem Oriented Policing population 10-11, 29-30, 161, 179, 182, 186, 188-190, 199, 201, 232-233, 250, 253-254, 270-272, 380, 382; density 97, 321, 404, 424; female 190, 266, 277; general 11, 24, 425; growth 198; male 188; residential 161, 259 poverty $20,97,99,132-134,177,318$, $356,381,394,422$

Poznań 108-109, 112, 120, 421

precautionary measures 147,158 , 205-207, 265, 279; taken by users of bus/tricycle/motorcycle stops 207; taken to avoid sexual crime victimization while using public transportation 194; variation in women's 281 prescribed medications 305 prevention initiatives 227, 358, 402 Problem Oriented Policing 306 problems 28-32, 48-49, 117, 120, 161-163, 172-174, 176-177, 182-184, 292-293, 305, 309-310, 379-380, 382-383, 387-388, 393-394; common 166, 305; complex 307; drug-related 305, 321; fear 386, 394; major 113, 120, 189, 401; methodological 329; neighborhood 380; safety 20, 25-26, 28-30, 32, 39, 52, 89, 111, 117, 204, $260,404,432,438$; security 89 ; of sexual harassment to respondents encountered at the bus/tricycle/motorcycle stops within the past 3 years in Lagos, Nigeria 206; social 176, 178, 236, 247, 426; traffic 97; transit 184; urban 28 profiles $86,180-181,202,406$; emotional $333-335$; emotive $330,334,428$; of respondents 210; of survey participants 181; of victims and offenders 239 ; women's 273

programs 12, 92-93, 97, 147, 191, 227, 379-380, 384, 392, 395, 430, 439; community crime prevention 393; educational 191, 424; generic 385; recreational 386; school intervention 135; social 284, 380, 396; work 393

projects 25-27, 222, 295, 302, 349, 380, 391-392, 394, 396, 425, 436; largescale social housing 19; new building 27; small-scale 394-395, 430; street lighting 349

property crime $45,54,57,61,86,90,92$, $94,351,405,424$; and the effect of demolition in the United Kingdom 48; in Japan 45; rates of 94

PT see public transportation PTS see public transport systems public health strategists 408 public housing 18, 133 public lighting 347, 352-354 public places 3-9, 11-13, 16-17, 22-27, 30-32, 38-41, 128-132, 134-138, 178-179, 353-354, 401-402, 419-420, 422, 432-436, 438-439; circumstances of crime and fear in 16 ; design of 26,438 ; desolated 8 ; and disability hate crimes 125-138; drug use and distribution in 305 ; environmental factors in 25 ; in inner city areas 17 ; safety of $4,16,48,52$; use of 38,40 , 348 ; virtual 12

public policies 7,158

public spaces 8-9, 11-12, 23-25, 39, 217-220, 222, 227-228, 232-234, 236, 246-247, 268-270, 274, 419-420, 425, 431-432; fear in 427; harassment 219; inclusive 9; maintenance of 409-410; management of 291, 300-301; particular 8; re-designing 210; reported 234; sexual harassment in 177-178, 232, 237; suffragists occupied 218; urban 9, 47; virtual $13,134,136,219$

public transit 10, 59, 157, 291, 293-295, 297, 299-301, 303, 419, 422-423, 427,434 ; availability 3 ; improving 301 ; infrastructure 247; journeys 300,303 ; options 301; spaces 232 
public transport 131-132, 176-177, 194-195, 197-201, 204, 206-209, $211,217,219,221,223,232$, 234-235, 253-255, 425; buses 234; facilities 208, 246; infrastructure 191; lines 209; nodes 268, 283; operations 196; policies 189, 211; providers 194, 211 ; routes 211 ; spaces 200,232 ; stations 196, 199; stops 207; systems 194-200, 207-210, 424; systems in Lagos metropolitan city 201; users 195, 197, 200-201, 207, 209, 211

public transportation 10-11, 51, 145-149, 151-153, 155, 157-158, 179-180, 182-183, 188-189, 197, 199-200, 208-209, 237, 300-301, 422; agenda 145 ; in the evenings 147; frequency of use of 146, 190; modes of 148, 153; and monitoring of areas surrounding 423 ; safety of $180,182-183,422$; and transit environments 147,158 ; urban 190; users 146, 189, 423-424

PubMed (database) 130

quantitative data 201, 396-397

questionnaires 164-166, 180, 255, 308, 410, 412; personal 154, 206, 242-243; retrieved 201; situation-response 353 quota sampling 234,425

railway 160-161, 163-165, 167-169, 171-173; cars 423; companies 161-163, 165, 171, 173; disused lines 76; improving 171; operators 163; platforms 167-168; services 160, 163, 170; stations 50; transport 166, 170, 172; use of $161,164-165,167-168,171$

rape $6,10,76,86,91,93,171,177-178$, $184-185,220,225,227,235-236$, $238,244-245$

recorded crime $236,372,374,430$ recordings 372,375 ; improved police practices 372 ; surveillance camera 172 ; of violent and sexual assaults 373 reduced street lighting 12, 347-349, 351, 353-358, 429; impact of 349, 351, $353,355,357$; policies surrounding 348; potential impact on crime and fear of crime 347-349, 356-358; and scientific research 348

relationships 75-77, 82, 84-85, 87-88, 90-91, 96, 127-128, 261-262, 267-270, 281-282, 291-293, 297-298, 394, 419-420, 427-428; between green areas and crime 76; between green areas and fear or poor perceived safety 76 ; between green areas and safety 75 ; between lighting and crime and/or fear of crime 41 ; between the urban environment and safety 12 ; interpersonal 394; social 394-395; status 238, 267, 273, 277, 283, 427; strong 427

reported homicides for New Orleans and Hollygrove neighborhood 2002-2004 389

reported homicides for New Orleans and Hollygrove neighborhood 2015-2017 392

research $25-27,51-53,128-130$, 222-224, 235-236, 245-247, 265-270, 284, 301-302, 318-322, 352-354, 396-397, 419-422, 424-429, 431-435; academic 354; agenda $12,39,76,219$; areas 88,434 ; assistants 201, 386; change-focused 383 ; contributions 327; designs 75,85 , 383 ; evidence $11,413,430$; evidencebased 434; feminist 218, 268; findings 129, 424; focus 126, 217; institutes 435 ; international $3,52,401$; papers 419, 427; participants 327, 339; previous $45,78,146,191,261,267$, 270, 279, 282, 284, 427; procedure 384 ; projects 164, 190, 195; quantitative 265; questions 291, 307, 348; scientific 348, 357; strategy 129 , 138; studies 82,292

residence (as an anchor point) 21, 132, 237-238, 256, 273, 277, 279-280, 282 residential areas 19-22, 27, 29-30, 46-47, 99, 210, 271-272, 274, 283, 309, 311, $317,402,409-411,421$

residents 19-20, 98-99, 101-102, 254, 259, 261, 270-271, 281, 321, 352-353, 379-382, 384-397, 404, 420,430 ; groups of 379,421 ; of Hollygrove 382-383, 392-395; innercity 95 ; local 379,385 ; neighborhood $393,397,430$; older 255, 259; urban $11,195,422$

respondents 113-117, 120, 183, 189, 201-202, 204-206, 208-209, 234-235, 237-240, 274-275, 283-284, 293, 295-298, 300-302, 353 ; concerns about using buses, tricycle or motorcycles in Lagos, Nigeria 205; fear of crime 296; female 162, 
202, 208, 273-275, 425; male 202, 207-208, 273; measured 296; pilot 295; potential 164, 201; profile of 210 ; sampled 207; sexual harassment 206; who identified measures that would make railway travel safer 169 responses 115-116, 162, 165, 167-168, 170, 180-184, 205-207, 225-226, 243, 250-251, 268-269, 295, 297, 308-309, 338-339; behavioral 147 , 251, 253, 257-259, 261; emotional $330,337-338,428$; emotive 327 , 329-330, 335, 337, 340; encoded emotive 330 ; inconsistent 126; openended 243; police 307-308; survey 310 , $315,320-321$; valid 200; women's 223 results of binary logistic regression 276 , 278, 280

results of participants' safety perceptions (\%) concerning their railway usage during daytime and night-time 168

Rio Claro, Brazil 11, 176, 179-180, 191, 423-424

risk $6-7,23-25,30-31,51-52,56$, 77-78, 133-134, 157, 194, 224, 234-235, 260, 268, 301-302, 431-432; factors 197; increased 133, 156, 227, 362; perception 24; possible 358; potential 269; situational 127

robberies $6,8,45,54,56-59,61,76,79$, $84,86,90-91,93,183-186,195,309$, 423-424

Rollins, Judith 221

Romero-Torres, Javier 423

Rosarium in Cytadela Park 112

rural communities $24,45,47-48,52-53$, 59, 268, 401-402, 405-406, 409-414, $434-435$

SafeGrowth 379-380, 384-386, 389, 396; by crime prevention specialists 393 ; planning system 380,396 ; training 387 ; workshops 385

safety 10-13, 16-21, 25-32, 38-41, 48-53, 75-79, 95-103, 113-117, 119-120, 156-158, 167-173, 401-405, 407-414, 419-423, 430-440; audits 386,388 ; challenges 435,438 ; child 373 ; citizen 315 ; equipment 60,210 ; evaluation of 406 ; experts 17, 26-28, 32, 39, 401, 403, $411-412,414,419,432,435,437$, 439; feelings of $136,202,208-209$, 352, 357, 421, 431; improvements 7 ,
$113,147,206,253,424$; individual's 4, $13,24,402$; intersectionality of 431 , 438; measures 164-165, 169, 171, 173, 282, 316, 409-410; pedestrian 101, 349; perceived 7, 10-11, 25-26, 40-41, $43-45,45-46,58,75-78,86-88$, 95-102, 108, 119-121, 202, 266, 283; personal 6, 98, 102, 355; physical 194, 429; problems 20, 25-26, 28-30, 32, $39,52,89,111,117,204,260,404$, 432, 438; public 146, 198, 291, 301, 375 ; and public places 16 ; road 355 ; sense of 108, 110, 114-116, 119, 182, 190, 207, 281, 421; solutions 20, 51, 413, 420, 435-436; strategies 158; urban 4, 13, 40, 439; of women 19, $162,219,282,284$

safety guidelines $17,27,412-413,430$, 437-438; defining 438; delivering 20; implementing 437; self-evaluating 436

safety interventions $30,32,48,51-52,85$, 419, 434, 436; defining 29; executing 433 ; reporting 31 ; steps 28

safety perceptions $38,43-44,45-46$, 99-101, 103, 86-88, 108-109, 113-117, 145, 147, 155-157, 167-168, 255-256, 401-402, $420-423$; by age groups in transit environments in Lagos 204; and behavior responses 147; defining 147; by gender in transit environments in Lagos 203; lower 109; maximizing 52, 403; of neighborhood environments 250; poor 315; public 423; reducing 41; of users 121; women's 160, 171 safety perspectives $119,121,403,406,431$ safety training 302

safety work 218, 221-226, 402, 425; embodied 222, 224; gendered 225; practices 425; women's 11, 217, 220, 222-223, 225-226, 228, 425

schools 21, 23, 48, 131-133, 135, 137, 174, 189, 191, 209, 219, 232-233, $237-238,247,311$

scientific research 348,357

Scopus (database) 38, 40, 42, 79-81, 83, $125,130,138,420,422$

SCP see situational crime prevention security $4,10,19,29,160,164-165,169$, 194, 197, 200, 211, 365, 371-372, 407, 412-413; alarm systems 110 ; cameras 52, 172; devices 19, 120; enhancing 173; guards 23, 211, 404; guidelines 19; measures 48, 52, 163, 
security continued

423; perceived 29; perceptions

164-165; private 200; public 180; staff

196, 364, 371; systems 52, 200;

technologies 11,38

self-isolation 223

services $45,134,148,162-163,173,194$, 204-205, 227, 254, 364, 367, 371, 375 , 382, 397; delivering security 89 ; emergency 401, 407, 411; existing festival 371; public mass transit 180 sets of keywords, number of results and documents selected from Google Scholar and Scopus 79

sex 153-154, 238, 244-245, 309, 315

sexual abuse 133, 198, 211

sexual aggression 210, 363-364

sexual assault $10,57,59,145,149,153$, $156-157,162,180,184-186,190$, $220,310,373,423-424$; identifying 424 ; and the perception of transit safety among students and their victimization regarding 176, 180, 187; shadow of 267; victimization 190

sexual comments 146, 154, 205-206, 242,244

sexual crimes 11, 145-147, 198, 238, 365, 374, 431, 434; lower-level 374; particular 11; physical 153

sexual favors 243

sexual groping 162,243

sexual harassment 10-11, 145, 147,

157-158, 166-168, 171-172,

$177-179,183-185,195-198$, 204-205, 217, 219-220, 224, 232-247, 422-426; addressing public 224; and assault 147; behaviors 235-237, 241-243, 245-246, 426; common verbal 152; experiences 239 ; fear of $6,170,195,205,208,234,265$; identifying 167; imagery of 238-239, 244; in India 232-247; laws 236, 240-241, 245, 247, 426; lower-level 364; non-verbal 152; physical 156; prevalence of 225,247 ; prevention education campaigns 191; prevention efforts 245; public 217, 219, 224; in public spaces 233-234, 244, 246; reducing 158; reported 235; and sexual violence 145-146, 425; verbal 157; victims of $6,11,147,166,179,186$, 232-235, 241; of women 217, 234 sexual offences 10, 366, 369, 372-373 sexual relations 177,238 sexual victimization $11,145,149-150$, $152-153,157,179,183,186,362$, $422-423,429,432$; by duration 152 ; by duration of the tripand frequency of use of PT with those found in buses and bus stops 152, 153; by individual characteristics and transportation mode 150; reporting of 423

sexual violence $10,50,133,145-146$, $177,179,217,219,225-227,234$, 245, 247, 266-267, 284, 422-425; physical 146, 153, 423; preventing 225-227; and sexual harassment 145-146, 425; systemic 217

SH see sexual harassment shootings 56, 307, 309-311, 314-322, 382, 387, 391, 393, 401; gang-affiliated 321 ; reporting of 309

shopping malls $8,16,23,26-27,41$, 51,434

situational crime prevention 28, 89, 301, 356, 402-403, 406, 408, 414, 422; principles 363, 401-402, 404, 407; theories 356

smartphones 12, 25, 295, 300; see also Android smartphones

social 29, 61, 127, 247, 257, 355, 381, 411; media 12; networks 125, 136-137, 253, 319, 326-327, 340, 393; participation 250-253, 255, 257-258, 261-262, 426; problems 176, 178, 236, 247, 426; programs 284, 380, 396; relations 9, 136, 256; relationships 394-395

social bonds 269, 281

social cohesion 43, 51-52, 58-60, 110, $253,269,274,279,293-294,356$; in the neighborhood 283; perceived 293 social control 10, 20, 23, 25, 27, 29, 403, 431 ; capacities 403; informal 356; natural 353; reduced 292; weak 20 social environment 19-20, 32, 77, 108, $113,115,282,291-292,402-403$, 421,432

social interactions $38,40,78,95,121$, 257, 259, 279, 434-435; poor 281; positive 409 ; quality of 281,284 society $4,9,12,20,125,128,137$, 177-178, 182, 228, 233, 250, 253, 433, 435-436; capitalistic 133; civil 26, 330, 403, 409, 411; integrative 9; modern 25, 440; patriarchal 177; safe 413; unequal 436

stakeholders 19-20, 26-27, 384, 394, $411,413-414,431,437-439$ 
stalking 153, 166, 195, 206, 208, 239, 241,243

stations $21,23,26,49-50,60,157-158$, 165-167, 170, 173, 198-199, 202, 204, 208, 211, 294; central 16, 50, 179; petrol 258-259; public transport 196,199 ; rail 58 ; subway 21,50 ; train/ bus 109 ; transit $23,49,52$; tricycle 202 ; see also train stations; see also railway stations

STC see Collective Transportation System stereotypes 137, 245, 250-251, 260-261; gender 220; implicit 10

Stockholm 7, 176, 179, 250, 253-255, 259, 266, 270-271, 305-308, 310, 314, $317,319,321,426-427$; city center 254; municipalities 270, 284, 309, 316; police departments 308-309; region 308, 310, 315-316; residents 271; by respondents who declare feeling fearful in the neighborhood (percent) 271

Stockholm City 24, 254-255

Stockholm County 306-307, 309-311, 314,321

strategies 129, 135, 137, 188, 190, 222-223, 226, 384-386, 390, 393, $425,428,433,435,440$; co-plan response 396; community development 19; current modelling 281; deterrence 307; effective 302-303; evidence-based 322; government 374; holistic response 301; integrated planning 19; lighting reduction 354; local economic 396; organizational 308 ; preventive 125 , 127-128; problem-solving 384; quota sampling 237; women and public places 222,425

street lighting $12,45-46,61,347-358$, 429 ; crime prevention effect of 352 , 356 ; data 354 ; effects of improved $45-46,119,350,352$; implementation of 349,353 ; improving 119 ; initiatives 348 ; installation of $347-348,352,356$; new 349 ; projects 349 ; provision of 351 ; reduction of $347-348,355$, $357-358,429$; regime 357

streets 8-10, 12, 16-18, 24, 26-27, 39, 47-48, 78, 109, 131-132, 257-258, 260, 293, 390-391, 409-410; commercial 258, 260; crowded 31; deserted 61; desolate 259; poor 235; public 232; shared 217; tree-lined 76 students 131, 133, 135, 137, 146, 148-149, 152-153, 155-158, 161,
$163,165,176,180-190,201,209$; college 11, 158, 160-161, 164, 170, 172-173, 179, 194, 209, 235, 423; female 149, 155, 161, 170-171, 207, 235; groups of 183,189 ; main impediments for 183-184; male 155, 161, 181, 184; non-white 183; perception of public transportation safety after dark 183 ; perception of public transportation safety during daytime 182; tertiary 200, 209

studies, app-based 327

substances 312, 317, 320; amphetamine 305,312 ; buprenorphine 305 ; cannabis $305,312,317,320$; cocaine 305,312 , 317,320

subways 10, 161, 270, 314

summary of the participants' frequency of railway use and commuting time 165 summary of the results of the two cases $\mathbf{2 5 8}$ surveillance 17-18, 21, 40, 56-58, 51, 57, 60, 77, 91, 109-110, 113, 119, 121, 420-421, 426; community 60; formal $56,110,404$; natural $18,27,40,49$, $110,121,256,259,356-357,380$, 403-404, 408-410, 430; police 8, 158; video $115-116,119,120,421$

surveillance cameras 160, 163-164, 168-173, 420, 424; installing 163; perceptions of $170,172,258$ survey 98-101, 145-147, 158, 160-165, 171-173, 176-184, 190, 200-201, 238-239, 255, 271-272, 294-295, 308-310, 353, 406; citizen 308, 317 , 321 ; field 85, 91; participants 164, 181; questionnaires 95,237 ; responses 310 , $315,320-321$; results $113,115,116$,

172, 190; self-reported delinquency 350 survey cameras $163,169,171-172$ survey companies 164-165

sustainability goals $30,38,51,53,436,439$ Sweden 7, 12, 46, 176, 250, 266, 268, 271, 273-274, 305-308, 310, 319-321, 401-407, 409-411, 413; capital of 270; crime victim surveys in 405; general trends on issues of crime and safety 407-409; and the impact of the \#MeToo movement 266; major cities of 253; major cities of Stockholm and Malmö 253, 308, 427; police 305, 310; safety in urban planning in 403 , 405, 407, 409, 411, 413; safety perceptions in 251, 253, 255, 257, 259, 261; status of urban planning practices 
Sweden continued

in 402, 414; and the study of the

Stockholm municipality 270

Swedish National Board of Housing, Building and Planning 406

Swedish National Rural Development Agency 406

Swedish Planning and Building Act 2010 405,413

table of standard mean difference tests $\mathbf{3 7 0}$ taxis 195, 197, 199, 201, 207, 232, 297,355

terrorism 26, 428

terrorist attacks 163, 204-205, 208-209, 326-327, 329-331, 333, 335, 337-340

test venues 365-366, 368, 370, 372, 374,430

tests $46,48,102,296,330,332$, 366-367, 373-374, 396, 406

theft 54, 56, 58-61, 79, 90-92, 109, 112 , $156,200,321$; of cars 58; of household properties 59; personal 59; petty 120 ; by pickpockets 184-185, 424; see also burglaries

threats $119,128,136,170,228,267$, 275, 309-310; physical 204, 208; potential 268, 425; verbal 204, 208

time and place avoidance 260, 273, 277-278, 281-282

time avoidance $260,269,431$

Tokyo 160-164, 170, 173; railway services 161; transportation 160

Tokyo Metro 173-174

Tokyo Metropolitan Police Department 160-161, 170, 172

traffic safety 27, 401, 407

train cars 162-163, 168-173

train stations $10,146,210,232,274$, 314,317

training 50, 53, 113, 134, 227, 295, 302, 370, 375, 385-386, 393-394, 430, 433, 439; community leadership 385, 396 ; content 365,367 ; on-site 365 , $370,375,430$; participants 389 ; safety 302; sessions 114

trains $6,10,132,145,153,161-167$, 169-171, 173, 180, 232, 254, 423; commuter 173,270 ; frequent 58 ; suburban 198; and surveillance cameras in 173

transients 88,404

transit 21, 24-25, 145-146, 148-149, $153,160,162,194,198,202$,
204-207, 291, 295, 427-428, 431; crime 166; environments 16, 47, 49-50, 146-147, 153, 157-158, 160, 203-204, 423, 431, 434; settings 158, 291, 300-301; stations 23, 49, 50, 52; stops 157, 197-198, 294, 297-298; systems 10, 147, 209, 423; users 201, 291, 301, 427; vehicles 157, 295, 297-298, 300, 431

transit safety 4, 11, 160, 168, 173, 176, 180, 194, 196; investigating 170; perception of 176, 180-181; and students in Japan 161, 163, 165, 167, 169, 171, 173; and students in Lagos 195, 197, 199, 201, 203, 205, 207, 209,211 ; studies on 196; women's 160,164

transmissions (wireless network) 404 transport 10, 133, 148, 161, 165, 428; networks 210; operators 431 ; planning 252 ; practices 197,208

transportation 4, 6, 13, 21, 145-146, 157 , $160,163,234-235,291,301,318$, 424, 432, 437; companies 322; hubs $305,317,428$; infrastructure 158 ; modes 146-148, 150, 152-155, 157-158; nodes 4, 27, 314, 317-318; stations 321

tweets 12, 326, 328-337, 339-340, 428, 432; classifying single 338 ; emotive values of 333-335; non-Spanish 331; Spanish 338; stored relevant 331; unique 331

Twitter 26, 136, 326, 328-329, $337-340,428$

types of sexual harassments in transit and by transportation mode. Access means on the way to/from bus stops and or Metro station 153

the typology of ODS in Stockholm 2017317

UN-Habitat, Safer Cities Program 1996432

UN Sustainable Development Goals 2030436

United Kingdom 7, 12, 18-19, 45-46, $48,86,88,95,99,210,224,349,354$, 419,421

United Nations $145,250,433-434$

United States 8, 18-20, 23, 43, 45-48, 51, $75,86,88,91,305,318,349,401,419$

University of Lagos 194, 201, 207

university students $11,145,147-149$, 155-156, 158, 176, 178, 180, 423; see also students 
unsafety $223,268,309,317,321-322$, 353 ; citizens 315 ; measures 315,317 ; places of $7,24,180,403,432$; of women $223,273,275-278,280$

urban crime 3, 16, 32, 419, 431, 439 urban design 18-19, 38-41, 49, 52, 60, 420 ; effects of 38,40 ; and safety 17,39 urban development 13, 439

urban environment 12, 17, 21, 24, 27, 45, $52,78,82,109,210,401-403,433$, 435,437

urban municipalities 406, 409-412, 430 urban parks 100, 108-111, 113, 115, 117, 119-121, 421

urban planning 3-4, 9, 13, 43, 402-403, 405, 407, 409, 411, 413, 420, 430, $434,436-437,439$

urban spaces 17, 19, 43, 61, 93, 108, 219, $232,420,422$

values $20,79,114,128-129,137,185$, $188,297,312-313,326,337,353$, 357; emotive 332-336, 338; exploratory 130 ; high street 321 ; missing 272

vandalism $39,57-58,60,85,87,90,92$, 102, 116-117, 120, 209, 274, 421; graffiti 293; increased 259; littering 183, 204, 208; victims of 274

vehicles see motor vehicles victim surveys $48,220,350,352,358,372$ victimization 11 , 24, 145-146, 148-153, 157-158, 160, 179-180, 232-234, 236, 239-243, 245-246, 291-294, 296-297, 299-301, 420-423; assessed 244;

burglary 59,61 ; criminal 424 ; experiences 352, 423; female 187, 234, 236; incidents 301 ; non-verbal 423; perceived risk of 294, 296-300, 303; potential 158, 268; previous 146-147, 265, 281; proportions of 149,158 ; and safety perceptions 10 , 160,431 ; sexual crime 194; variables 296 , 298; women's 178, 281, 284

"victimology" 126-127

victims 6-8, 24, 114, 126-127, 134, 136-138, 152-153, 171, 177, 185-188, 190, 234-242, 244-246, $372-373,423-425$; of crime $3,6-7$, 10-11, 21, 24, 114, 267, 273-278, 283, 432, 436; disabled 136; distribution of 184,186 ; female 186 , 188, 235; of groping 161; LGBTI 188, 190 ; male 186; non-crime 277 ; nonLGBTI 188; and offenders 11, 125,
127, 236-237, 239, 245, 425; potential $29,247,438$; of rape 171; of sexual harassment $6,11,147,166,179,186$, 232-235, 241

video surveillance 115-116, 119, 120, 421

violence $3,59-60,91-92,102-104$,

125-128, 131-132, 134-136, 176-179, 222, 224-225, 306-307, 314, 318-322, 391-392, 422-423; decreasing 91; deterring 163; domestic 131 ; encountering 219 ; family 59 ; gender-based 176, 183, 222; gun 305, 307, 319-320; homophobic 224; interventions 395 ; lethal 319 ; outdoor 309,311 ; perpetration 49,61 ; recorded 372; school-related 133; urban 186 violent 45, 48, 49, 61, 90-94, 125-126, $132,134-135,309,314-315$, 317-318, 320, 351, 365-366, 369, 372-373; acts 125, 128, 132, 135, 137; offences 160, 366, 372; and sexual offences occurring in City A. 369; and sexual offences occurring in City B 369

Violent Crime Control and Law Enforcement Act 1994126

violent crimes $45,49,57,61,85-86,90$, 92-94, 208, 244, 309, 314-315, 317, $351,395,405,423$; outdoor 309, 314, 318 ; reducing 94

virtual reality 25,58

VR see virtual reality vulnerable neighborhoods 307, 310, 316, 319-320

wallets 156-157, 189, 206-207

war cemeteries 112

Ward, Bethany 429

weapons 57, 156-158, 206-207, 209, 309,315 ; and knife crimes 315 ; the need to carry 156, 158, 206-207, 209

Web of Science (database) 38, 40, 42, $176,348,420$

WHO see World Health Organization wireless network transmissions 404 women 149, 152-153, 155-158, 160-173, 176-179, 186, 188-191, 197-198, 207-208, 217-228, 232-237, 242-244, 265-277, 279, 423-425; abuse in rural areas 59; adult 178, 227; African-American 221, 268; and children 19; commuters 233, 423; disabled 133; fearful 265-266, 272-282; groups of 272,275 ; harassing of 235,238 ; heterosexual 224; LGBTI 179, 186, 
women continued

190; and LGBTI youth 176-177, 181, $183,185,187,189,191$; most fearful group of respondents are those born abroad. 275, 277, 281; non-LGBTI 186; non-LGBTQI 149; non-white 182, 186; perceptions of $169,279,352,423$; perspectives 164; reporting higher levels of fear of crime than men 220,267 , 424-425; safety of 173, 233-234, 425; students 171; victimization of 178, 281, 284; white 186, 221, 223; young 145, 160-162, 172, 178-179, 224, 227, 235-236, 245, 282, 427

women's fear 11, 218, 236, 265-267, 269, 271-275, 277, 279, 281-284; of crime $162,221,223,225,227,265-267$, 269, 271, 273-275, 277, 279, 281-284, 427; and intersectional research investigating 281; modelling 273, 284 Women's Liberation Movement 219

Women's Self Defence Network Wāhine Toa 227
Wood, Elizabeth 18

work 29-30, 50, 53, 220-228, 232-234, 237-238, 376, 379-380, 382-383, 386-387, 393-395, 403-405, 407-410, 412-413, 430; feminist 219; invisible 218, 221-222, 425; programs 393; scholarly 177; by women in the aftermath of violence 222 , 225-226, 425

workers 310, 320, 439

workplaces 8, 46, 132, 176, 217, 224

workshops 135, 137, 385

World Health Organization 250-251, 260,262

young women 145, 160-162, 172, 178-179, 224, 227, 235-236, 245, 282,427

youth 95, 188, 258, 306, 380, 405; centers 311 ; drug crimes 321 ; LGBTI 176-177, 179, 181, 183, 185, 187, 189, 191; safety 145, 147, 149, 151, $153,155,157,179$; unemployed 196 